\title{
Uncommon Diterpenoids from the South China Sea Soft Coral Sinularia humilis and Their Stereochemistry
}

Li-Li Sun $n^{\dagger, \downarrow}$, Wang-Sheng $\mathrm{Li}^{\dagger, \S}$, Jie Li ${ }^{\dagger, \perp}$, Hai-Yan Zhang ${ }^{\dagger, \#, ~ L i-G o n g ~ Y a o ~}{ }^{\dagger}$, Hui Luo ${ }^{\S}$, Yue-Wei Guo $\dagger,+, *$ and $\mathrm{Xu}-\mathrm{Wen} \mathrm{Li}^{\dagger+\ldots, *}$

${ }^{\dagger}$ State Key Laboratory of Drug Research, Shanghai Institute of Materia Medica, Chinese Academy of Sciences, 555 Zu Chong Zhi Road, Zhangjiang Hi-Tech Park, Shanghai 201203, China

$\$$ University of Chinese Academy of Sciences, No. 19A Yuquan Road, Beijing 100049, China

$\S$ The Key Lab of Zhanjiang for R\&D Marine Microbial Resources in the Beibu GulfRim, the Marine Biomedical Research Institute, Guangdong Medical University, Zhanjiang 524023, China

\#CAS Key Laboratory of Receptor Research, Shanghai Institute of Materia Medica, Chinese Academy of Sciences, 555 Zu Chong Zhi Road, Zhangjiang Hi-Tech Park, Shanghai 201203, China

${ }^{\perp}$ Nano Science and Technology Institute, University of Science and Technology of China, 166 Ren Ai Road, Suzhou 215123, China

* Authors for correspondence: ywguo@simm.ac.cn (Y.-W. Guo); xwli@ simm.ac.cn (X.-W.

$\mathrm{Li})$ 


\section{Contents}

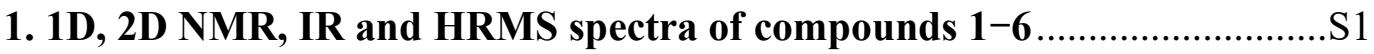

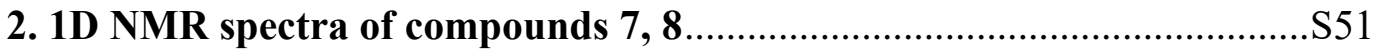

3. The ${ }^{13} C\left\{{ }^{1} \mathbf{H}\right\}$ NMR and DEPT spectra of known compounds $9-14 \ldots \ldots . . . S 55$

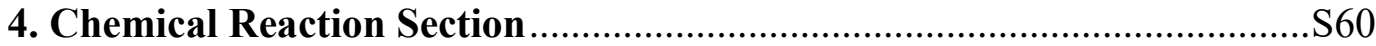

4.1 Absolute configuration determination of compound 2 …....................S60

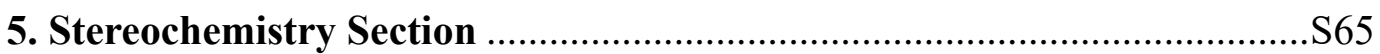

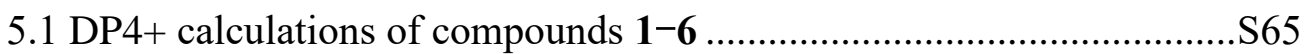

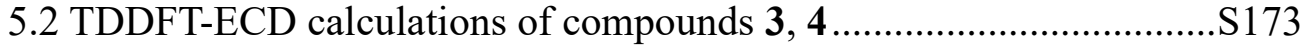

5.3 Optical Rotatory Dispersion (ORD) Experiments of compound 1......S227

5.4 Optical Rotatory calculations of compounds 4-6, 8........................S228

6. Anti-inflammatory activity assay

S229 
1. 1D, 2D NMR, IR and HRMS spectra of compounds 1-6

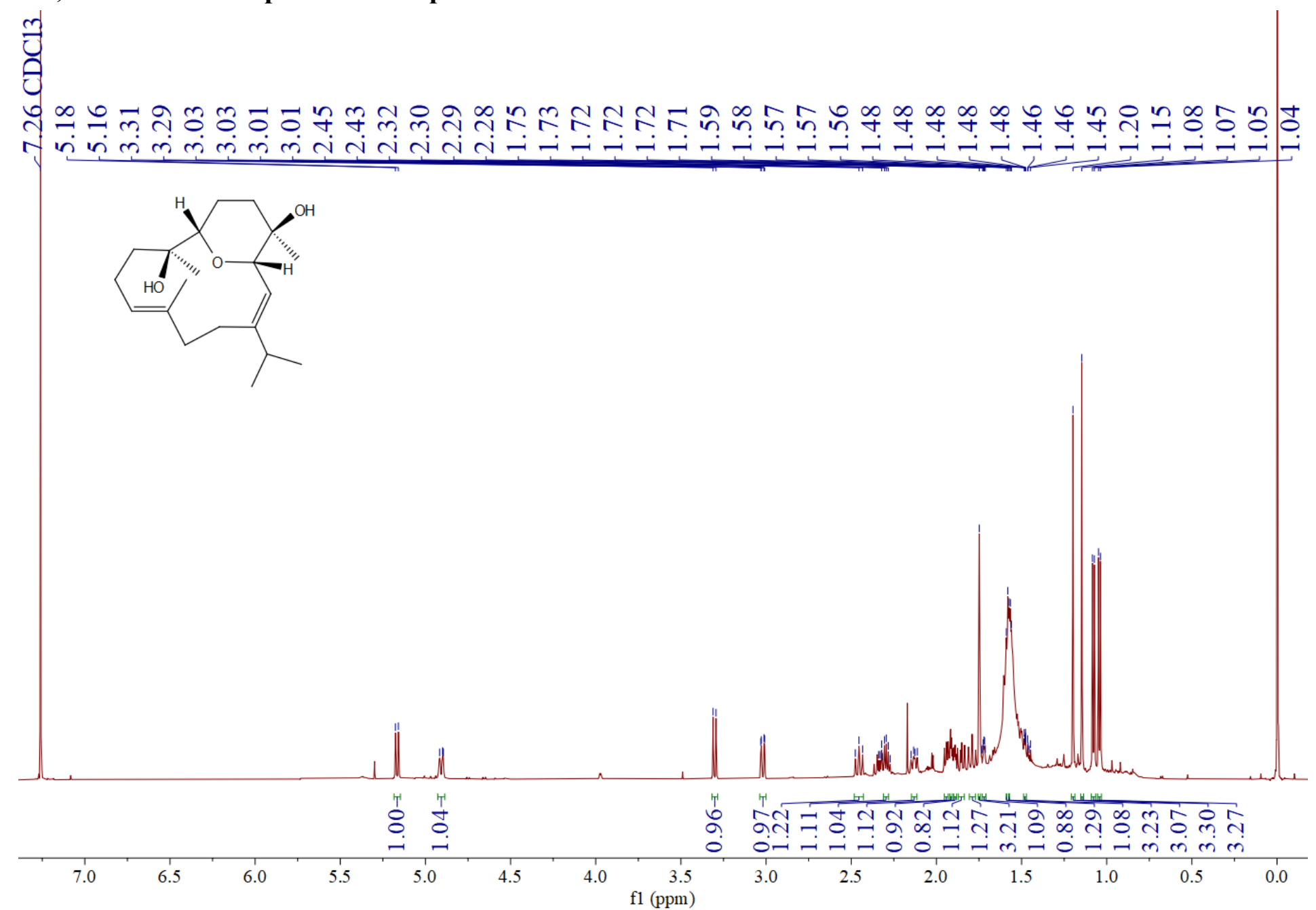

Figure S1. ${ }^{1} \mathrm{H}$ NMR spectrum $(600 \mathrm{MHz})$ of compound 1 in $\mathrm{CDCl}_{3}$ 


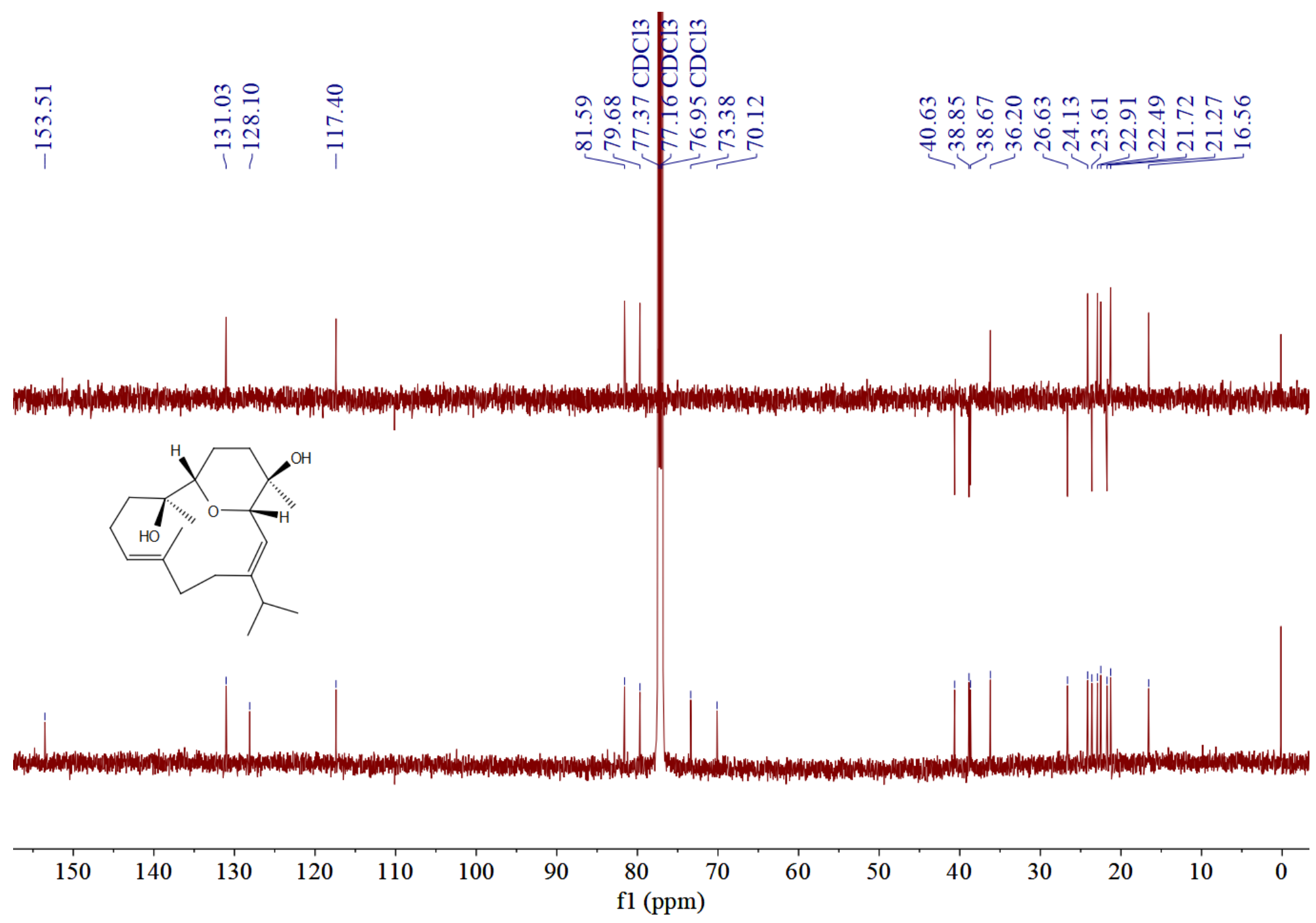

Figure S2. ${ }^{13} \mathrm{C}\left\{{ }^{1} \mathrm{H}\right\}$ NMR and DEPT spectrum $(150 \mathrm{MHz})$ of compound $\mathbf{1}$ in $\mathrm{CDCl}_{3}$ 


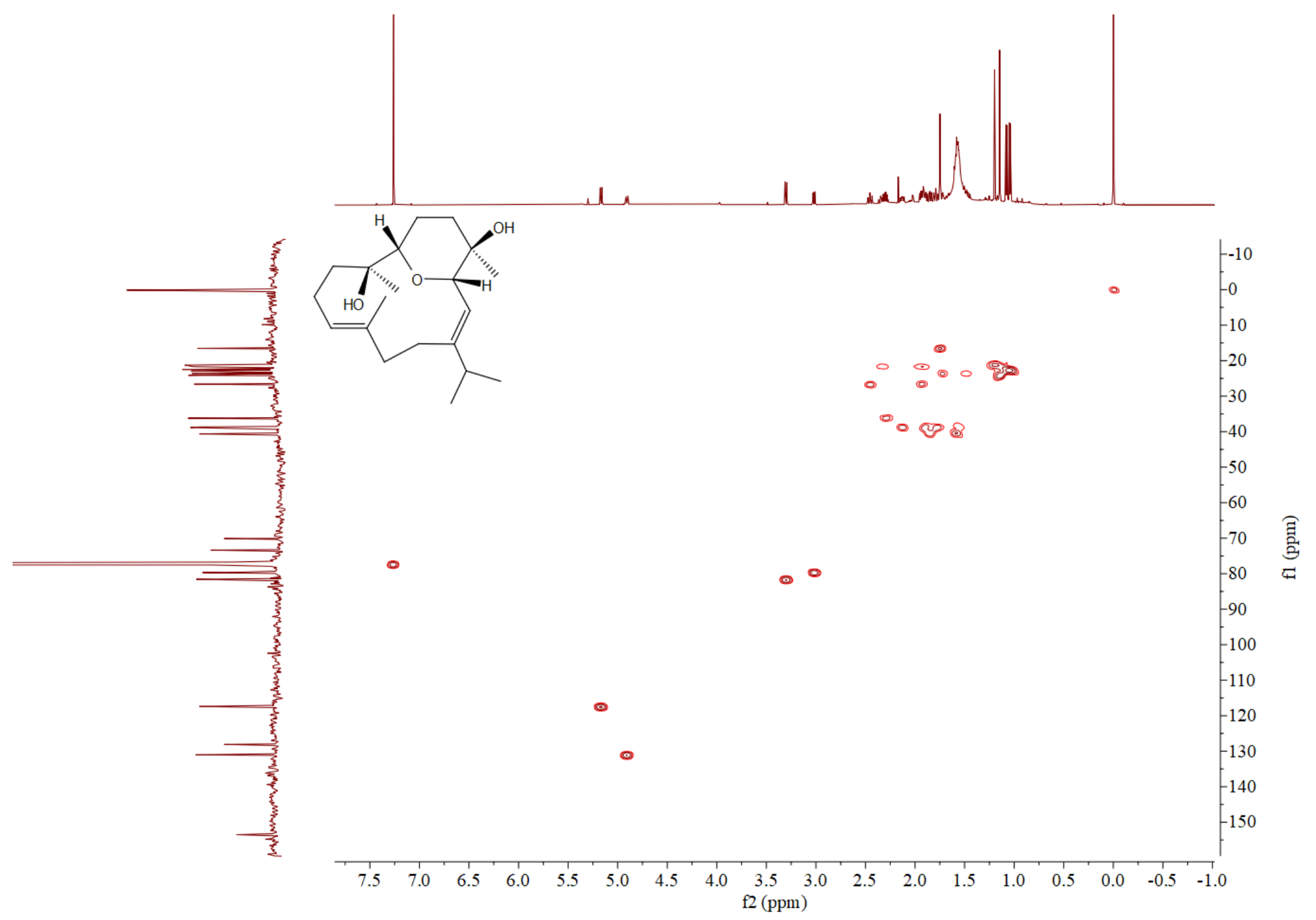

Figure S3. HSQC spectrum (500 MHz) of compound $\mathbf{1}$ in $\mathrm{CDCl}_{3}$ 


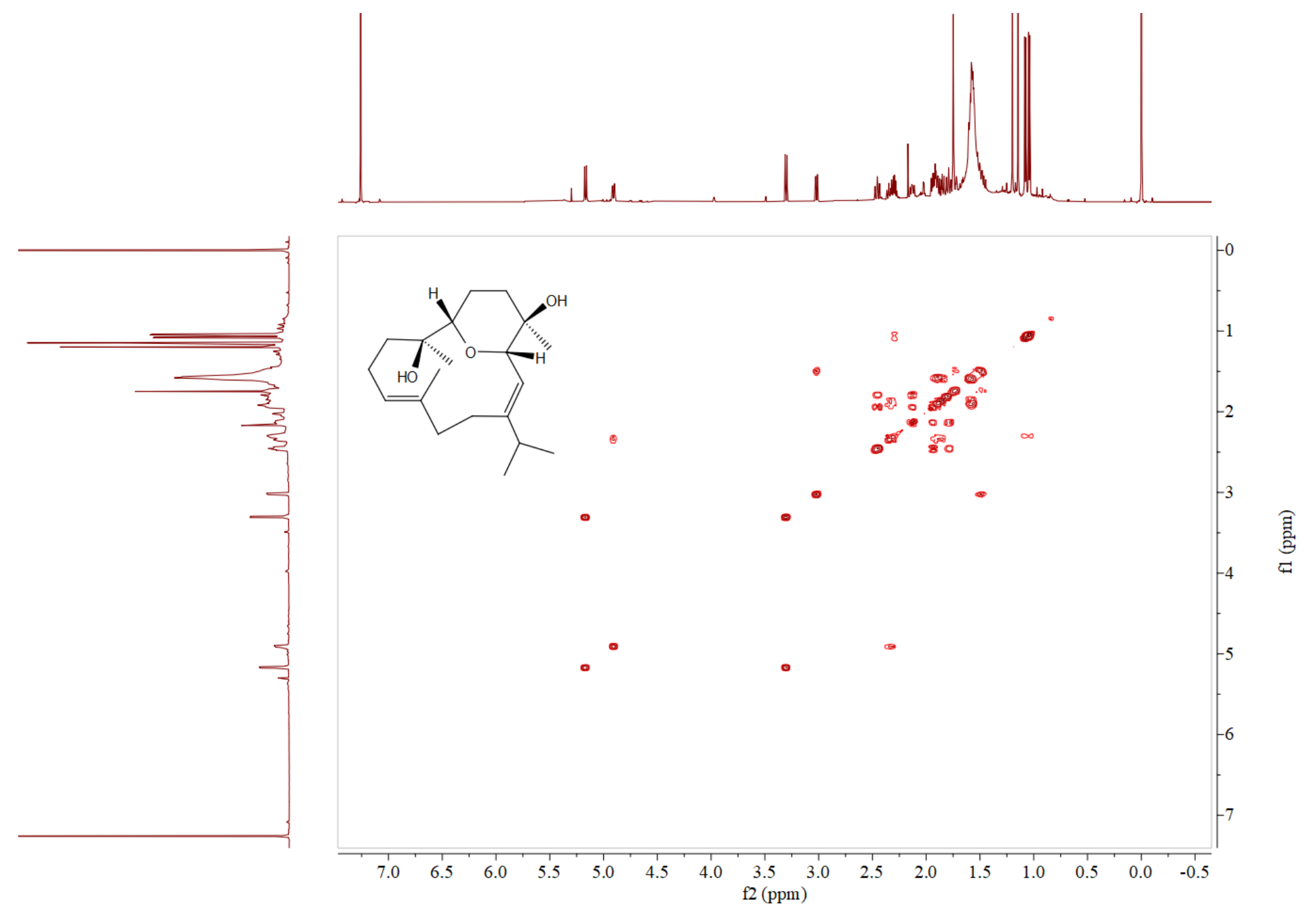

Figure S4. ${ }^{1} \mathrm{H}-{ }^{1} \mathrm{H}$ COSY spectrum $(500 \mathrm{MHz})$ of compound 1 in $\mathrm{CDCl}_{3}$ 


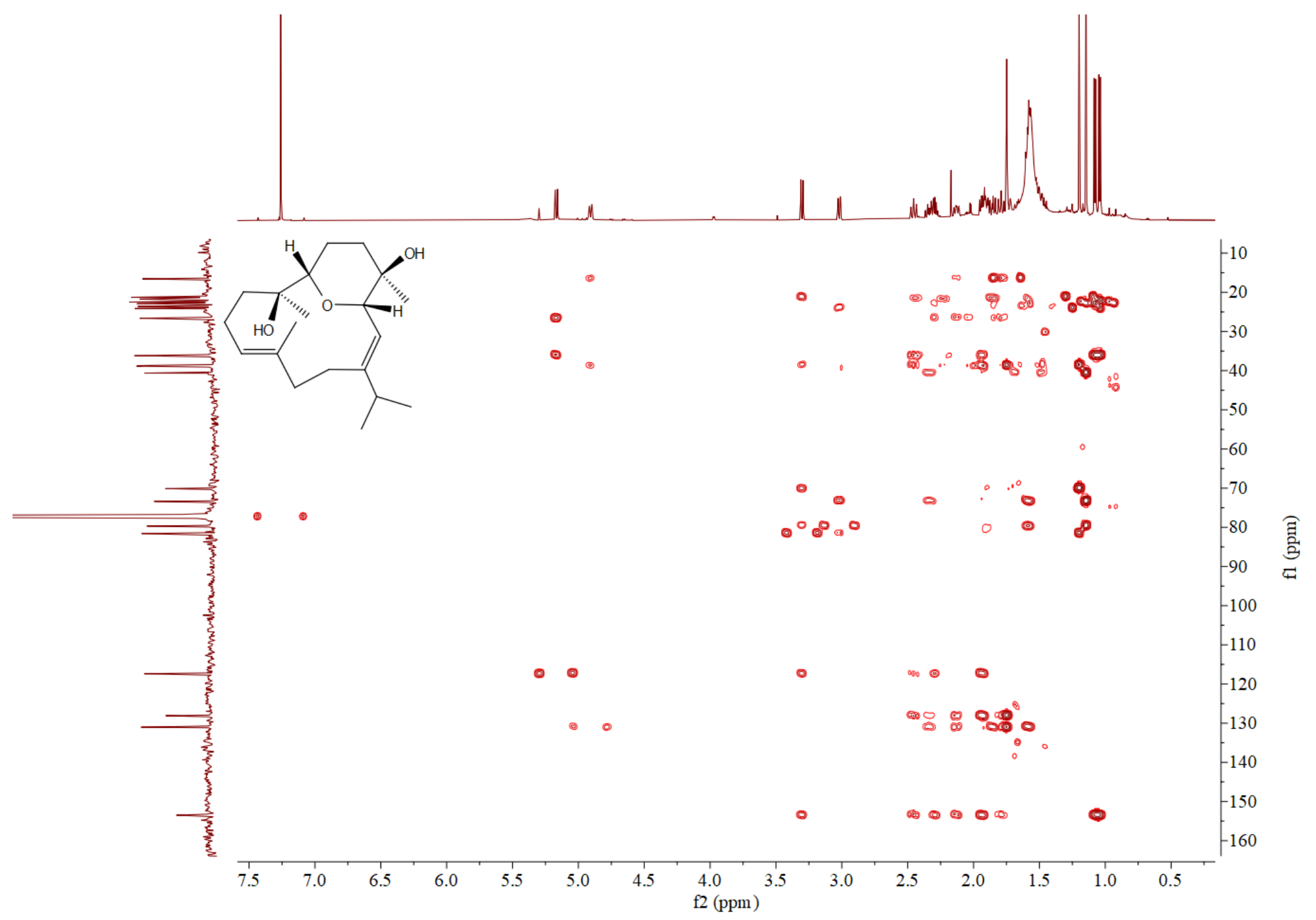

Figure S5. HMBC spectrum (500 MHz) of compound 1 in $\mathrm{CDCl}_{3}$ 


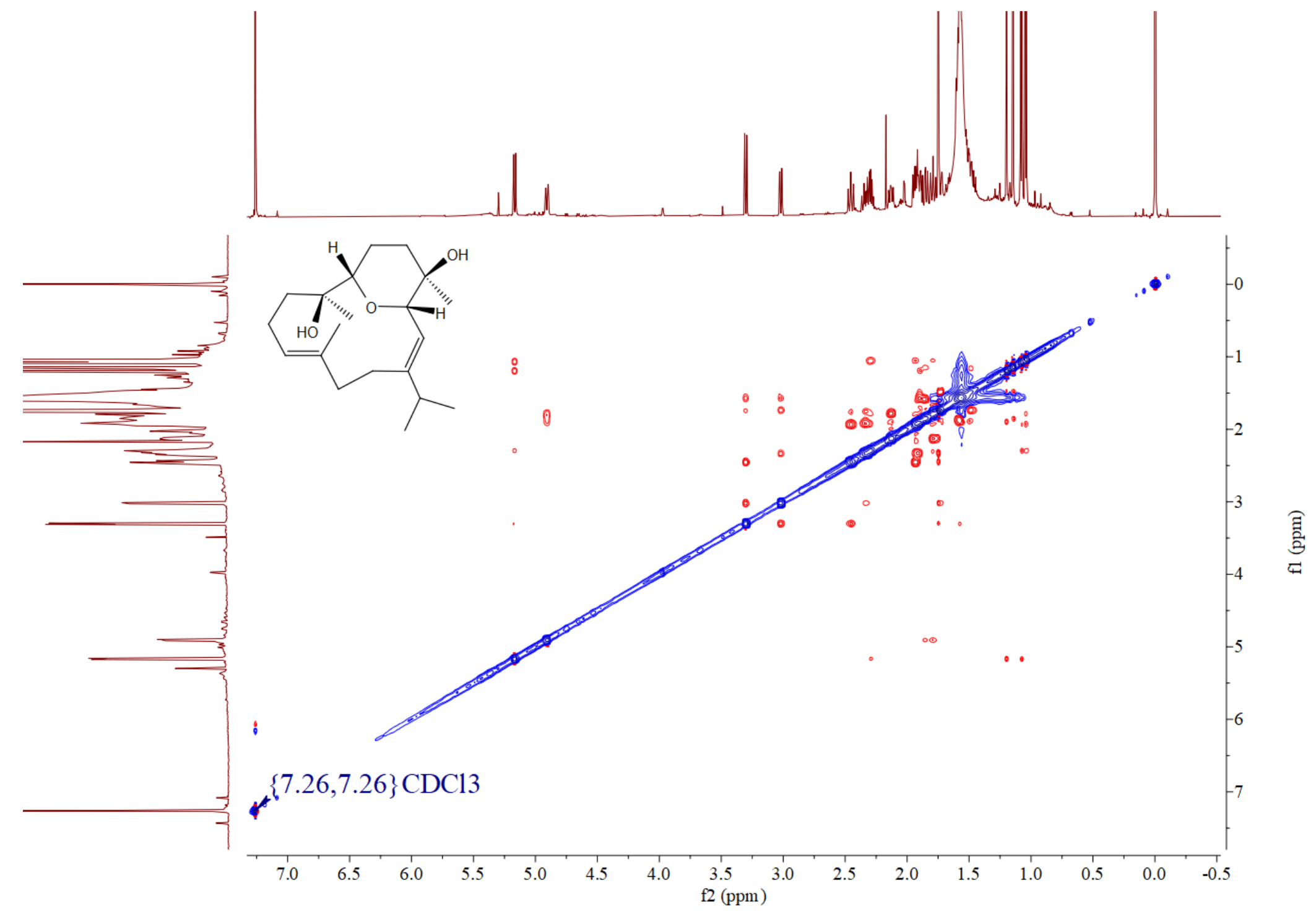

Figure S6. NOESY spectrum $(500 \mathrm{MHz})$ of compound $\mathbf{1}$ in $\mathrm{CDCl}_{3}$ 


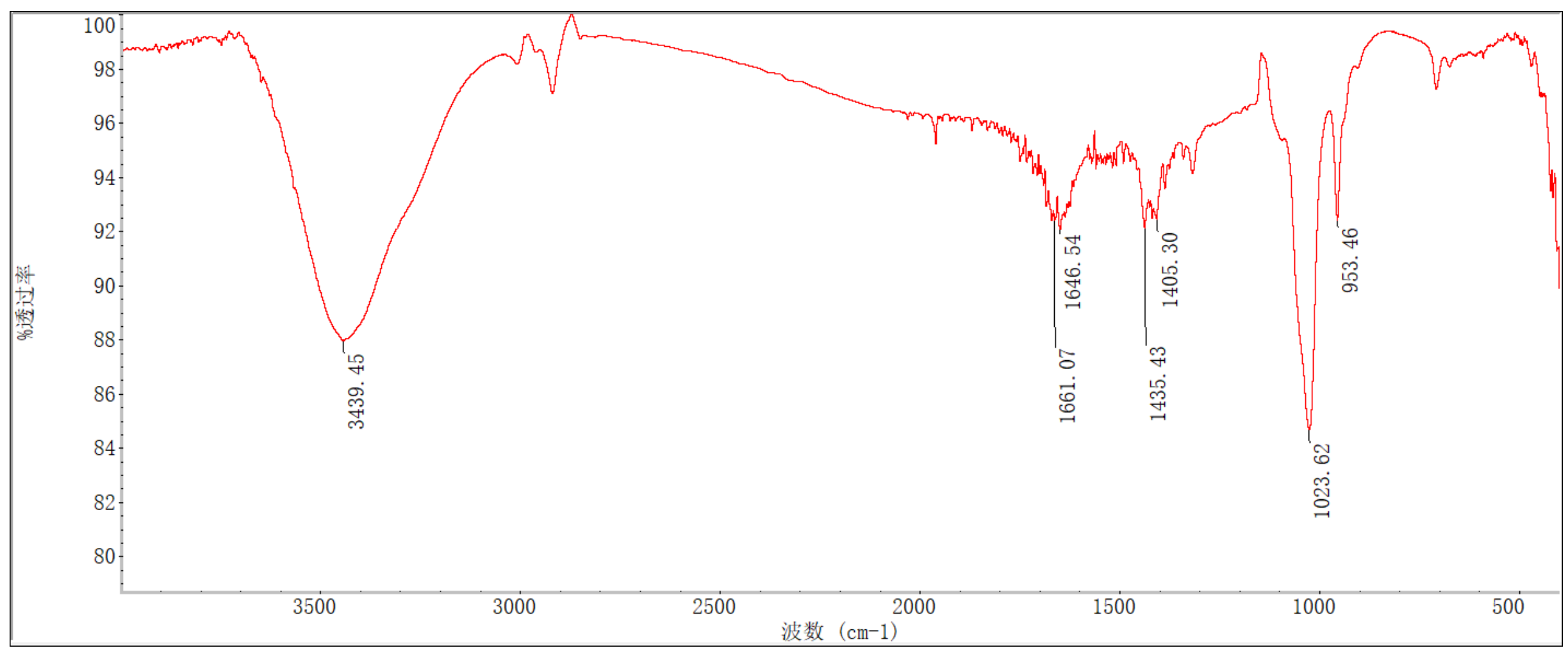

Figure S7. IR spectrum of compound 1 


\begin{tabular}{|c|c|c|c|c|c|c|}
\hline \multirow{2}{*}{\multicolumn{7}{|c|}{ 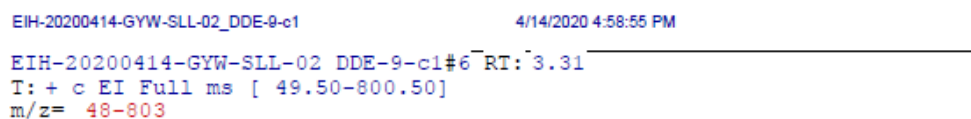 }} \\
\hline & & & & & & \\
\hline $\mathrm{m} / \mathrm{z}$ & Intensity & Relative & $\begin{array}{l}\text { Theo. } \\
\text { Mass }\end{array}$ & $\begin{array}{r}\text { Delta } \\
\text { (mmu) }\end{array}$ & $\begin{array}{l}\text { RDB } \\
\text { equiv. }\end{array}$ & Composition \\
\hline 123.1165 & 1677863.0 & 1.60 & 123.1168 & -0.28 & 2.5 & $\mathrm{C}_{9} \mathrm{H}_{15}$ \\
\hline 124.0878 & 246414.0 & 0.23 & 124.0883 & -0.45 & 3.0 & $\mathrm{C}_{8} \mathrm{H}_{12} \mathrm{O}_{1}$ \\
\hline 124.1230 & 330486.0 & 0.31 & 124.1247 & -1.65 & 2.0 & $\mathrm{C}_{9} \mathrm{H}_{16}$ \\
\hline 125.0958 & 1133405.0 & 1.08 & 125.0961 & -0.28 & 2.5 & $\mathrm{C}_{8} \mathrm{H}_{13} \mathrm{O}_{1}$ \\
\hline 125.1321 & 624992.0 & 0.60 & 125.1325 & -0.39 & 1.5 & $\mathrm{C}_{9} \mathrm{H}_{17}$ \\
\hline 127.0745 & 505449.0 & 0.48 & 127.0754 & -0.81 & 2.5 & $\mathrm{C}_{7} \mathrm{H}_{11} \mathrm{O}_{2}$ \\
\hline 127.1480 & 306902.0 & 0.29 & 127.1481 & -0.16 & 0.5 & $\mathrm{C}_{9} \mathrm{H}_{19}$ \\
\hline 129.0693 & 228663.0 & 0.22 & 129.0699 & -0.59 & 6.5 & $\mathrm{C}_{10} \mathrm{Hg}$ \\
\hline 131.0705 & 975779.0 & 0.93 & 131.0703 & 0.26 & 1.5 & $\mathrm{C}_{6} \mathrm{H}_{11} \mathrm{O}_{3}$ \\
\hline 131.0857 & 524061.0 & 0.50 & 131.0855 & 0.16 & 5.5 & $\mathrm{C}_{10} \mathrm{H}_{11}$ \\
\hline 133.1013 & 1183568.0 & 1.13 & 133.1012 & 0.14 & 4.5 & $\mathrm{C}_{10} \mathrm{H}_{13}$ \\
\hline 134.1083 & 661833.0 & 0.63 & 134.1090 & -0.65 & 4.0 & $\mathrm{C}_{10} \mathrm{H}_{14}$ \\
\hline 135.0807 & 516508.0 & 0.49 & 135.0804 & 0.24 & 4.5 & $\mathrm{C}_{9} \mathrm{H}_{11} \mathrm{O}_{1}$ \\
\hline 135.1169 & 2108993.0 & 2.01 & 135.1168 & 0.10 & 3.5 & $\mathrm{C}_{10} \mathrm{H}_{15}$ \\
\hline 136.1243 & 1119669.0 & 1.07 & 136.1247 & -0.34 & 3.0 & $\mathrm{C}_{10} \mathrm{H}_{16}$ \\
\hline 137.0967 & 357352.0 & 0.34 & 137.0961 & 0.66 & 3.5 & $\mathrm{C}_{9} \mathrm{H}_{13} \mathrm{O}_{1}$ \\
\hline 137.1327 & 901842.0 & 0.86 & 137.1325 & 0.25 & 2.5 & $\mathrm{C}_{10} \mathrm{H}_{17}$ \\
\hline 138.1038 & 219548.0 & 0.21 & 138.1039 & -0.11 & 3.0 & $\mathrm{C}_{9} \mathrm{H}_{14} \mathrm{O}_{1}$ \\
\hline 139.1129 & 384951.0 & 0.37 & 139.1117 & 1.20 & 2.5 & $\mathrm{C}_{9} \mathrm{H}_{15} \mathrm{O}_{1}$ \\
\hline 139.1487 & 263369.0 & 0.25 & 139.1481 & 0.56 & 1.5 & $\mathrm{C}_{10} \mathrm{H}_{19}$ \\
\hline 143.0863 & 254796.0 & 0.24 & 143.0855 & 0.73 & 6.5 & $\mathrm{C}_{11} \mathrm{H}_{11}$ \\
\hline 164.1570 & 257855.0 & 0.25 & 164.1560 & 1.02 & 3.0 & $\mathrm{C}_{12} \mathrm{H}_{20}$ \\
\hline 165.1668 & 326215.0 & 0.31 & 165.1638 & 2.98 & 2.5 & $\mathrm{C}_{12} \mathrm{H}_{21}$ \\
\hline 173.1322 & 336955.0 & 0.32 & 173.1325 & -0.31 & 5.5 & $\mathrm{C}_{13} \mathrm{H}_{17}$ \\
\hline 175.1473 & 627318.0 & 0.60 & 175.1481 & -0.84 & 4.5 & $\mathrm{C}_{13} \mathrm{H}_{19}$ \\
\hline 177.1627 & 418382.0 & 0.40 & 177.1638 & -1.03 & 3.5 & $\mathrm{C}_{13} \mathrm{H}_{21}$ \\
\hline 179.1782 & 247243.0 & 0.24 & 179.1794 & -1.19 & 2.5 & $\mathrm{C}_{13} \mathrm{H}_{23}$ \\
\hline 185.1347 & 249474.0 & 0.24 & 185.1325 & 2.27 & 6.5 & $\mathrm{C}_{14} \mathrm{H}_{17}$ \\
\hline 205.1972 & 262158.0 & 0.25 & 205.1951 & 2.13 & 3.5 & $\mathrm{C}_{15} \mathrm{H}_{25}$ \\
\hline 210.0314 & 280514.0 & 0.27 & 210.0311 & 0.21 & 11.0 & $\mathrm{C}_{13} \mathrm{H}_{6} \mathrm{O}_{3}$ \\
\hline 219.1045 & 229077.0 & 0.22 & 219.1016 & 2.97 & 6.5 & $\mathrm{C}_{13} \mathrm{H}_{15} \mathrm{O}_{3}$ \\
\hline 224.0823 & 788546.0 & 0.75 & 224.0832 & -0.84 & 10.0 & $\mathrm{C}_{15} \mathrm{H}_{12} \mathrm{O}_{2}$ \\
\hline 322.2512 & 231053.0 & 0.22 & 322.2502 & 0.92 & 4.0 & $\mathrm{C}_{20} \mathrm{H}_{34} \mathrm{O}_{3}$ \\
\hline
\end{tabular}

Figure S8. HREIMS spectrum of compound 1 
ยู่

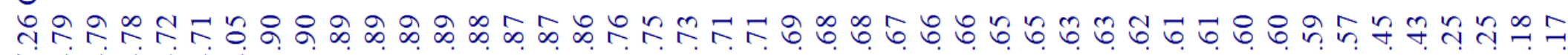

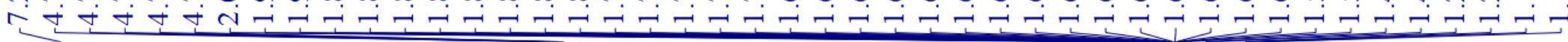
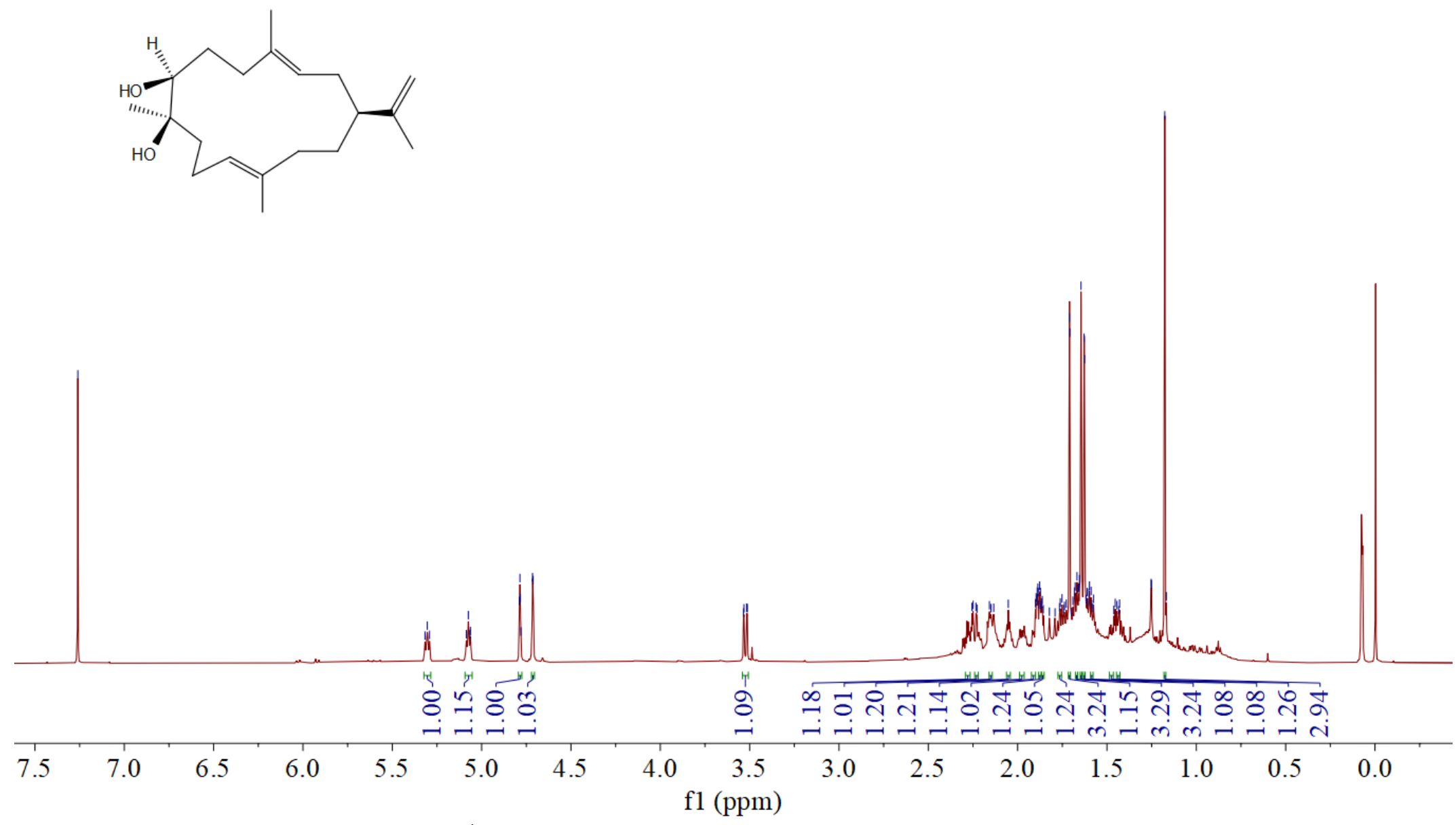

Figure S9. ${ }^{1} \mathrm{H}$ NMR spectrum $(600 \mathrm{MHz})$ of compound 2 in $\mathrm{CDCl}_{3}$ 


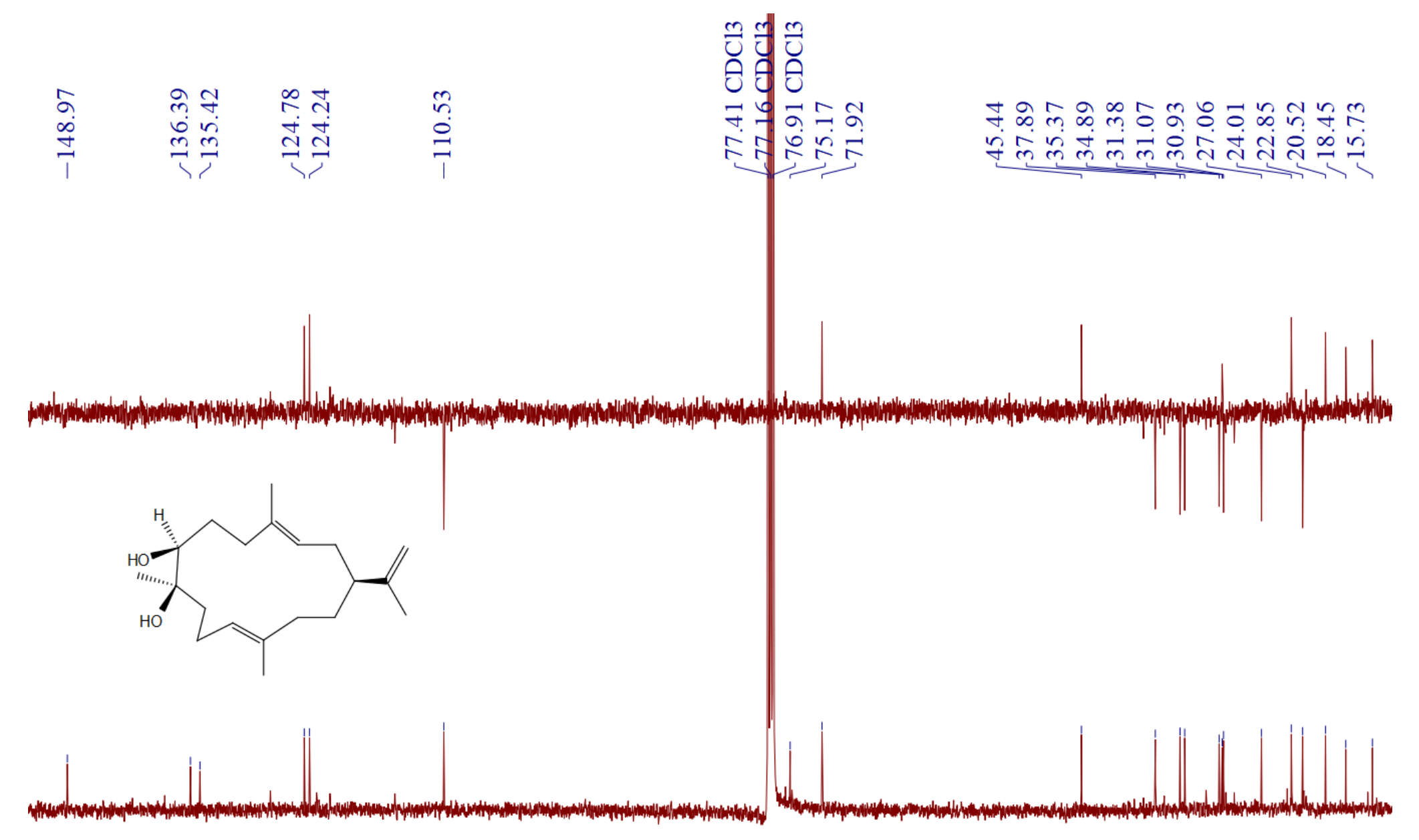

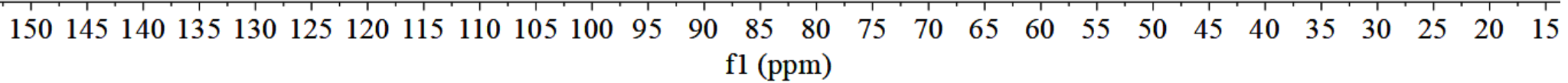

Figure S10. ${ }^{13} \mathrm{C}\left\{{ }^{1} \mathrm{H}\right\}$ NMR and DEPT spectrum (125 MHz) of compound 2 in $\mathrm{CDCl}_{3}$ 


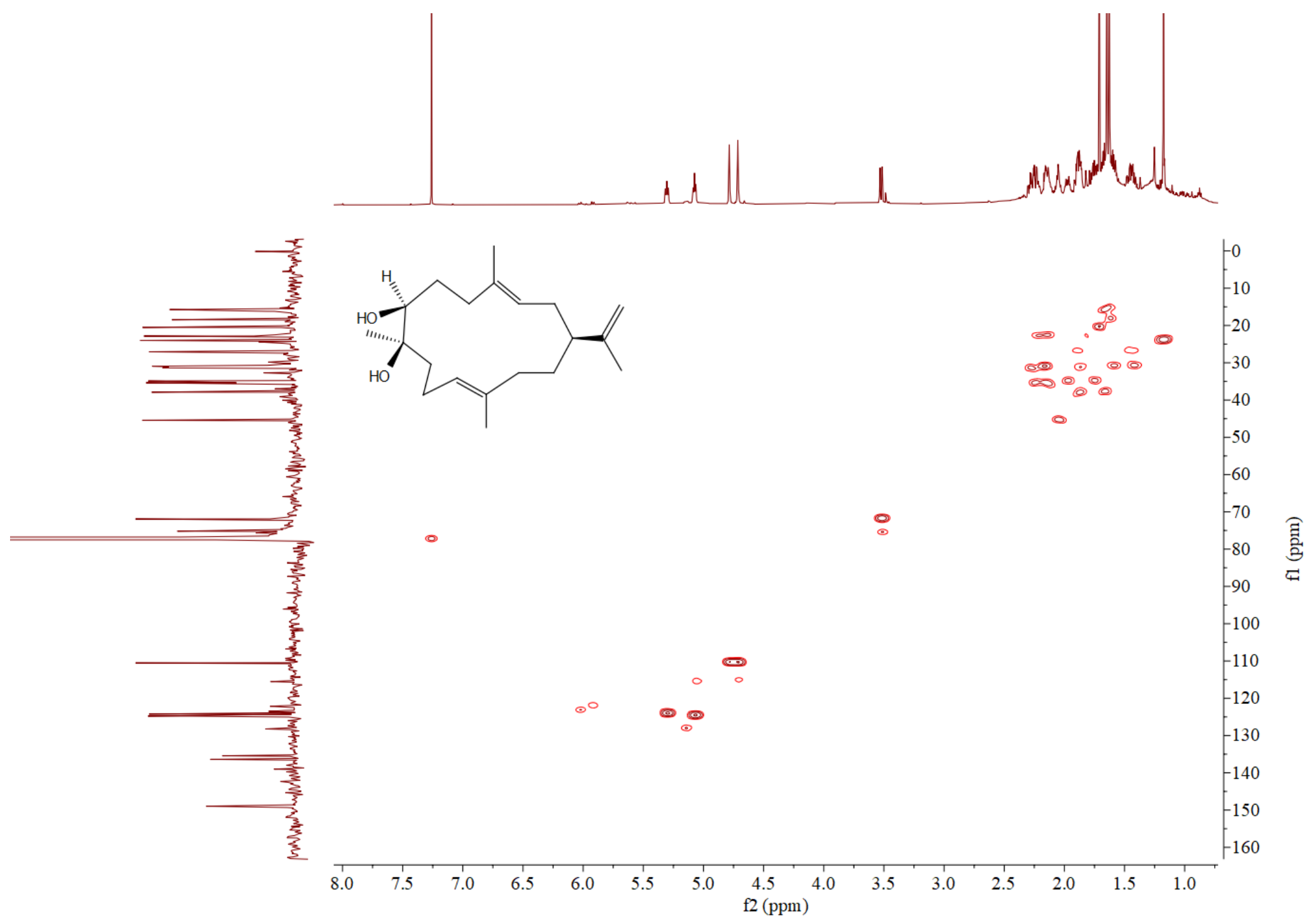

Figure S11. HSQC spectrum (500 MHz) of compound 2 in $\mathrm{CDCl}_{3}$ 


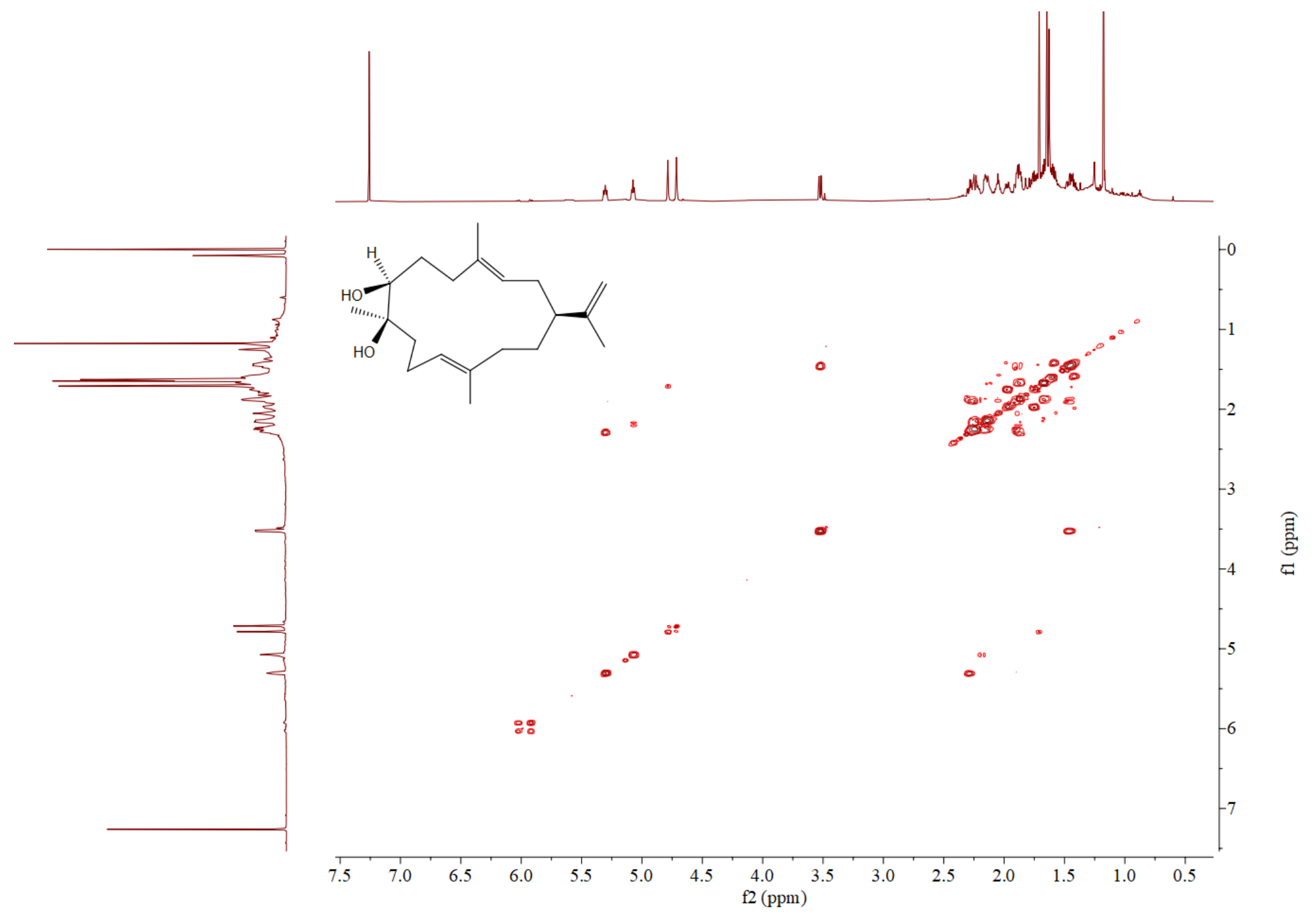

Figure S12. ${ }^{1} \mathrm{H}^{1} \mathrm{H}$ COSY spectrum $(500 \mathrm{MHz})$ of compound 2 in $\mathrm{CDCl}_{3}$ 


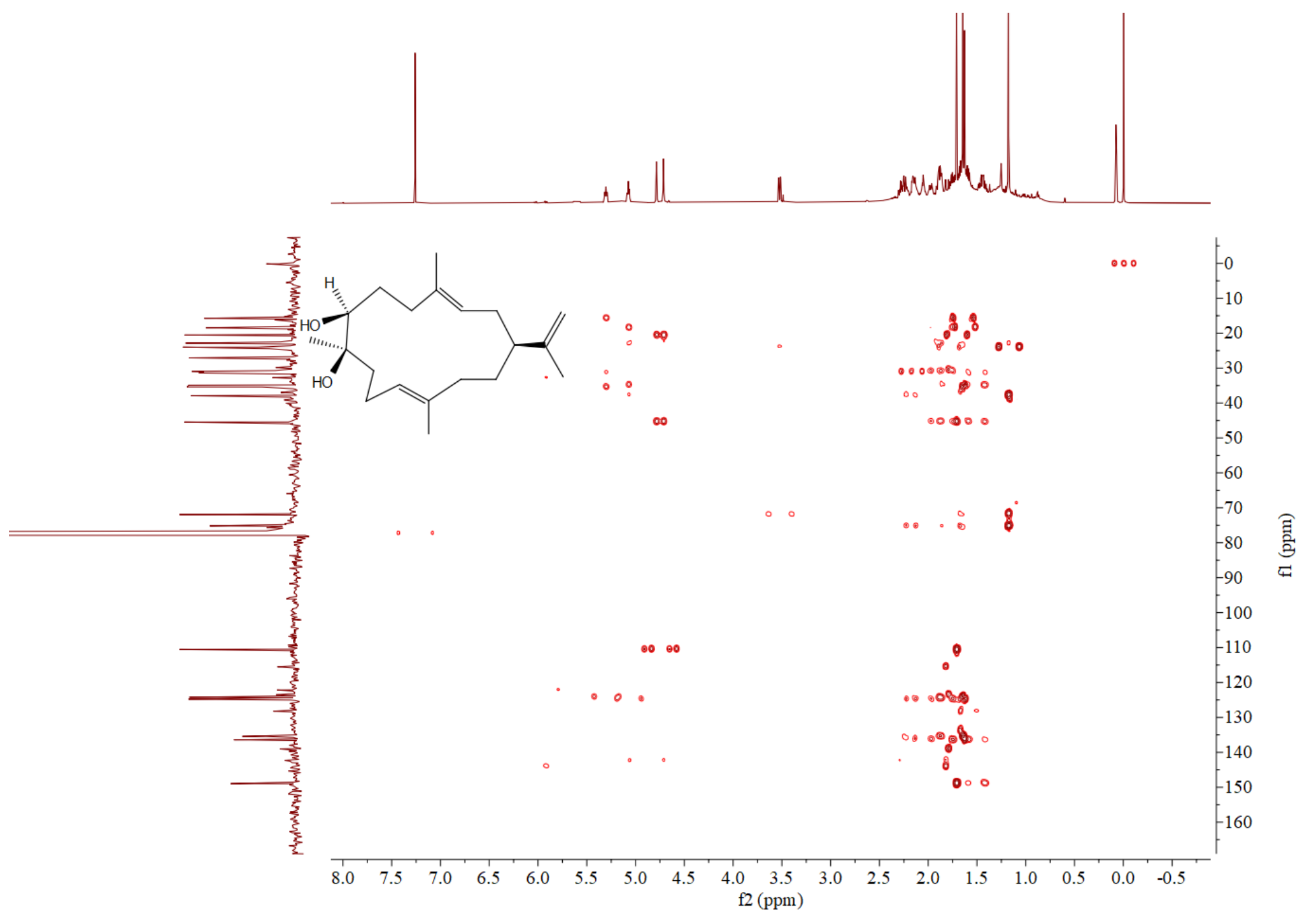

Figure S13. HMBC spectrum (500 MHz) of compound 2 in $\mathrm{CDCl}_{3}$ 


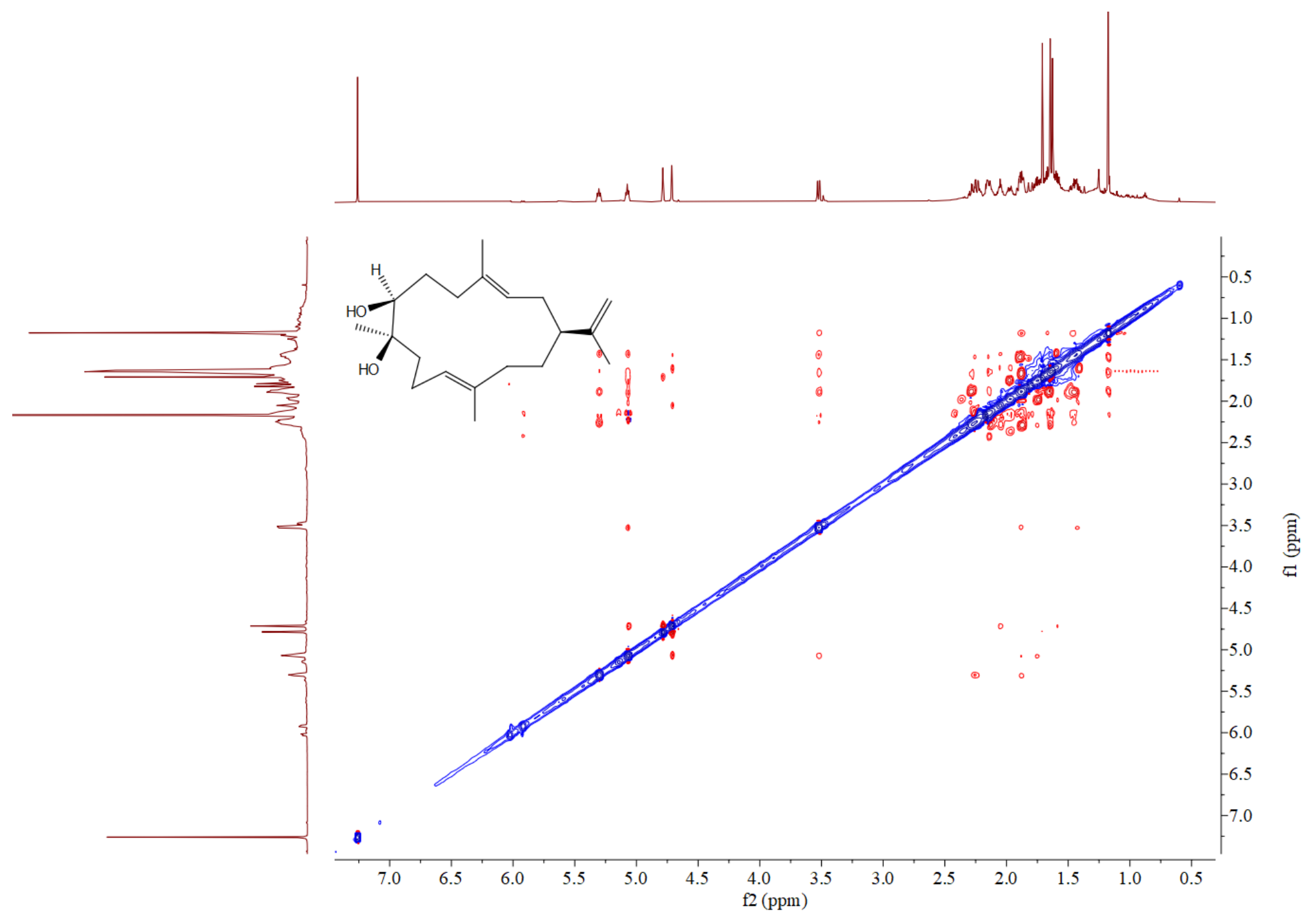

Figure S14. NOESY spectrum $(500 \mathrm{MHz})$ of compound 2 in $\mathrm{CDCl}_{3}$ 


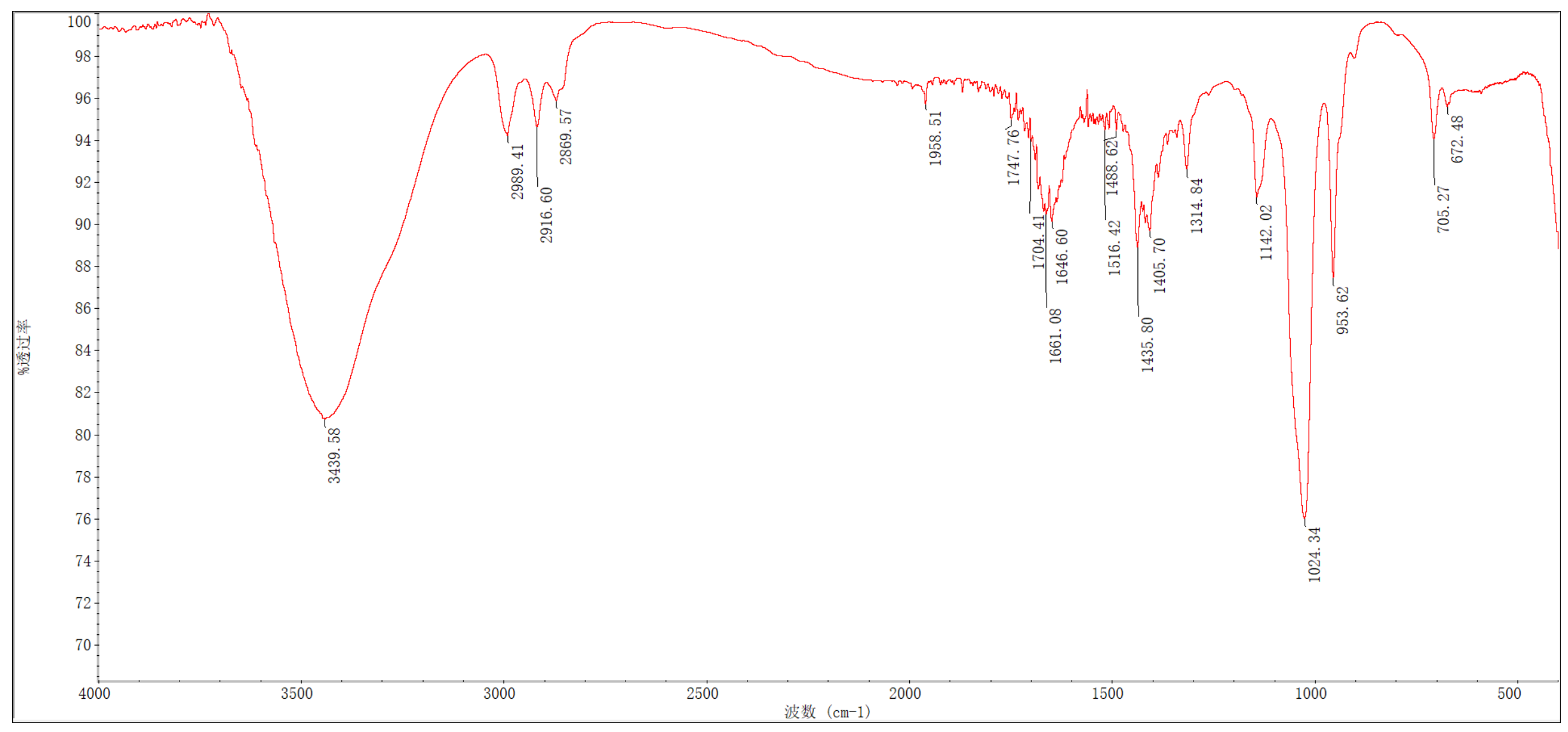

Figure S15. IR spectrum of compound 2 
Qualitative Analysis Report

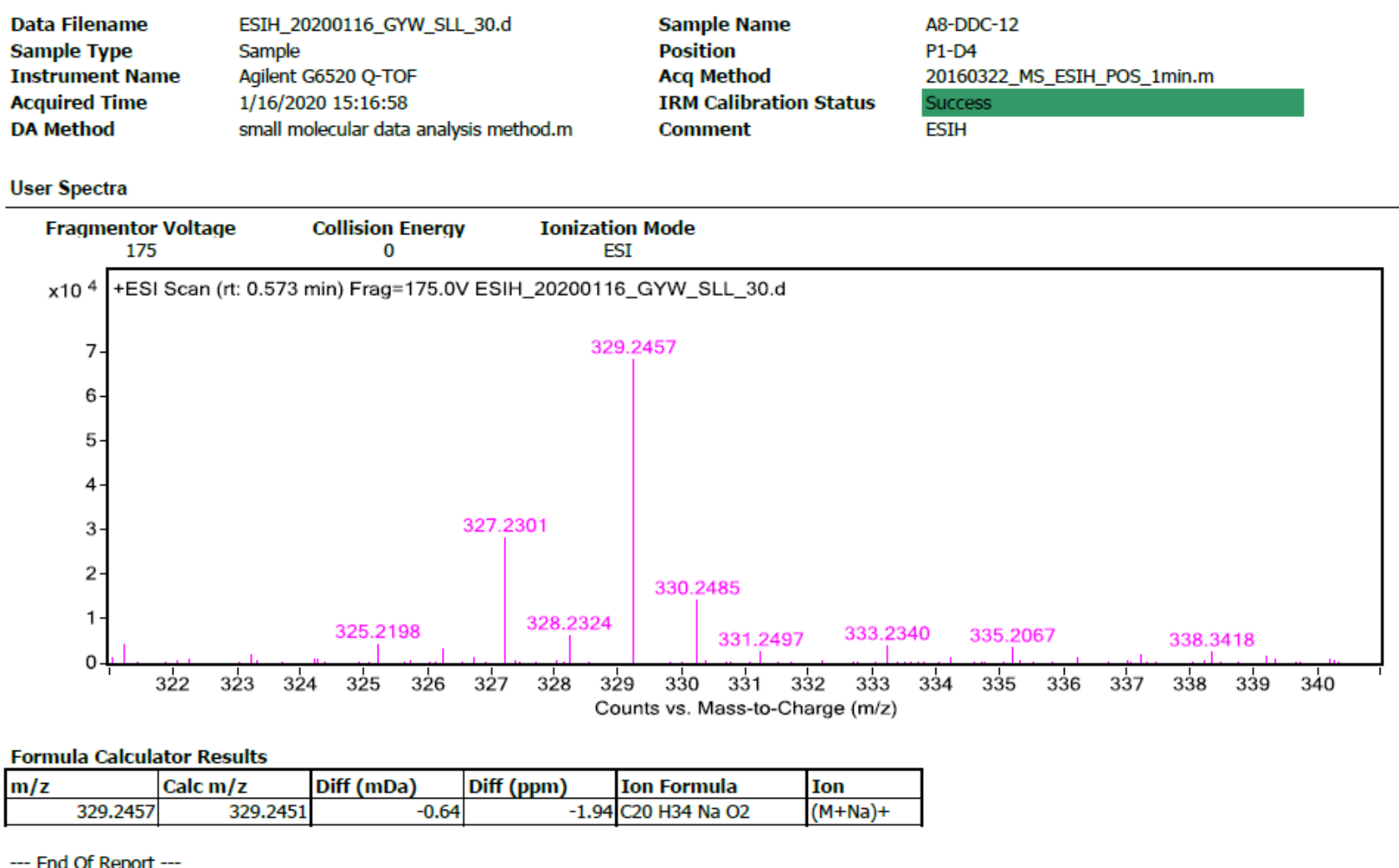

--- End Of Report --

Figure S16. HRESIMS spectrum of compound 2 


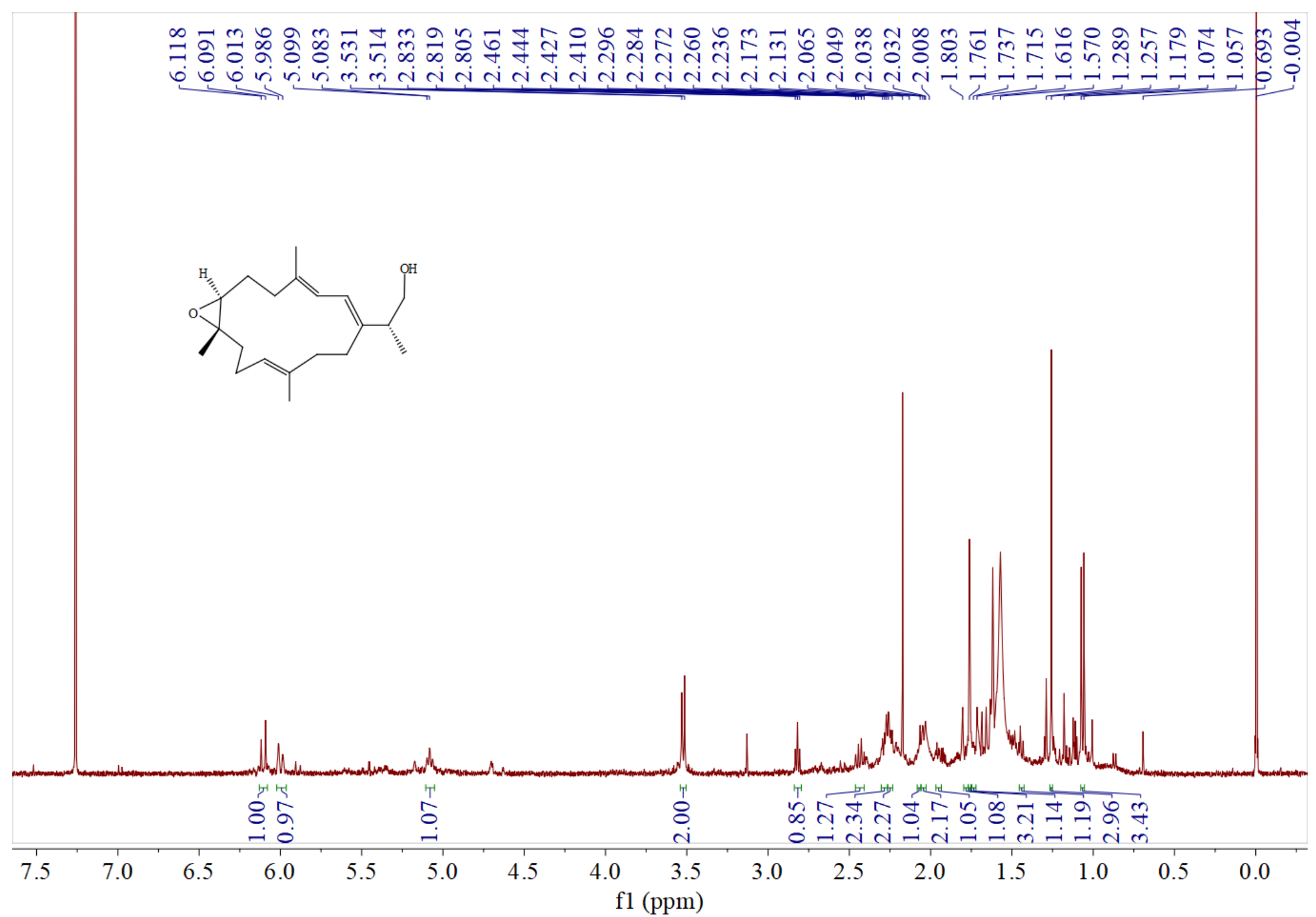

Figure S17. ${ }^{1} \mathrm{H}$ NMR spectrum $(400 \mathrm{MHz})$ of compound 3 in $\mathrm{CDCl}_{3}$ 


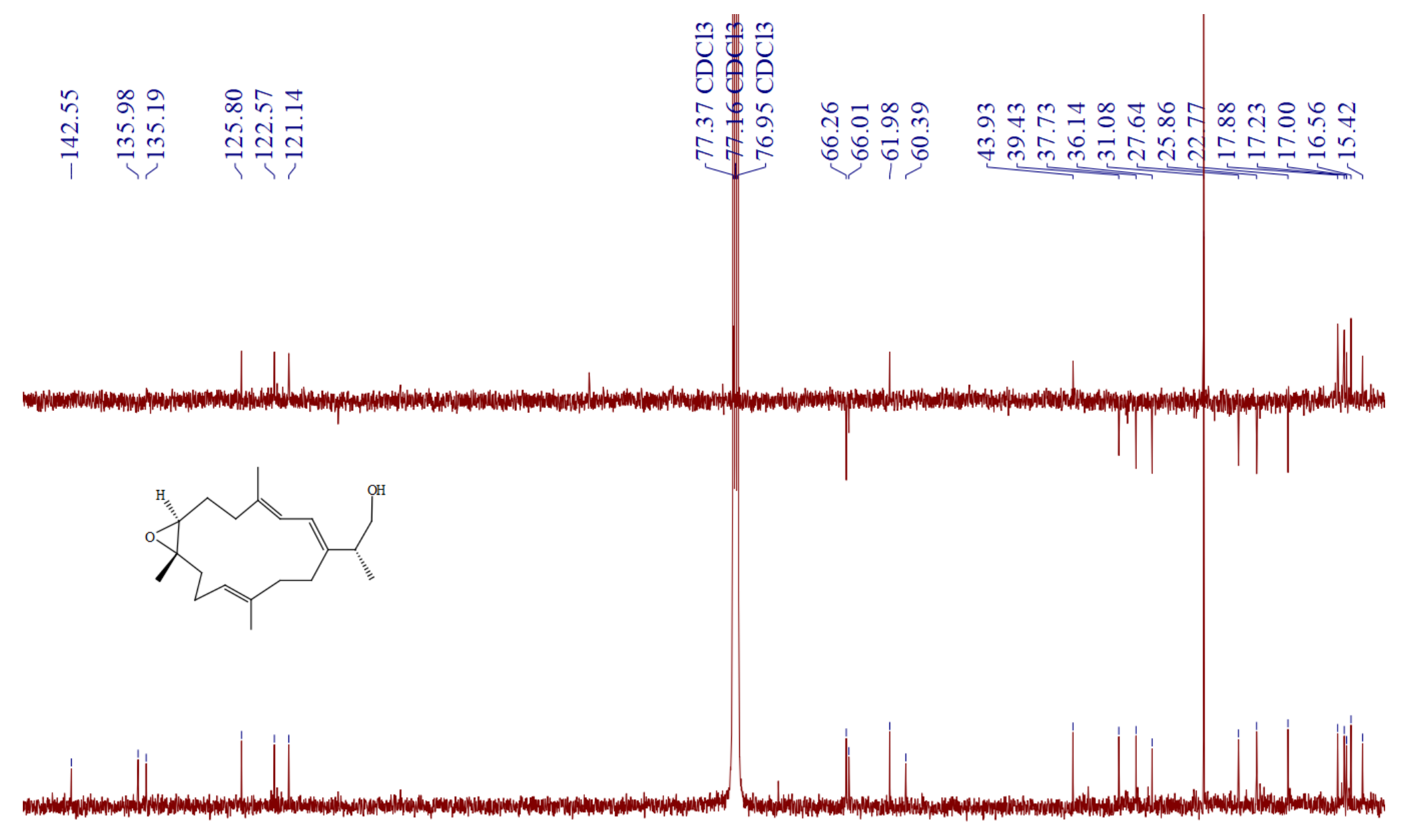

$\begin{array}{lllllllllllllllllllllllllllll}145 & 140 & 135 & 130 & 125 & 120 & 115 & 110 & 105 & 100 & 95 & 90 & 85 & 80 & 75 & 70 & 65 & 60 & 55 & 50 & 45 & 40 & 35 & 30 & 25 & 20 & 15\end{array}$ f1 (ppm)

Figure S18. ${ }^{13} \mathrm{C}\left\{{ }^{1} \mathrm{H}\right\}$ NMR and DEPT spectrum $(150 \mathrm{MHz})$ of compound $\mathbf{3}$ in $\mathrm{CDCl}_{3}$ 


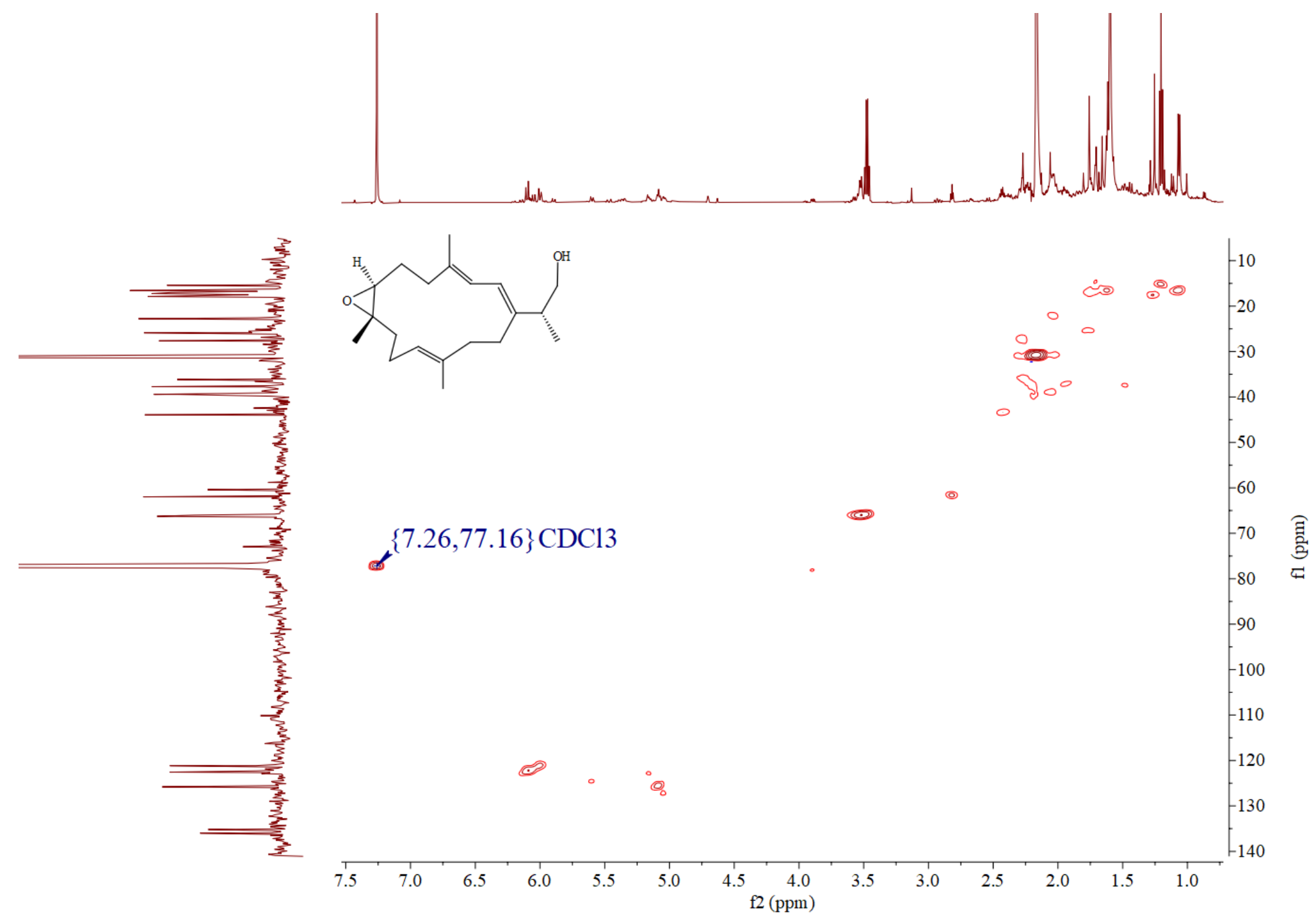

Figure S19. HSQC spectrum (500 MHz) of compound 3 in $\mathrm{CDCl}_{3}$ 


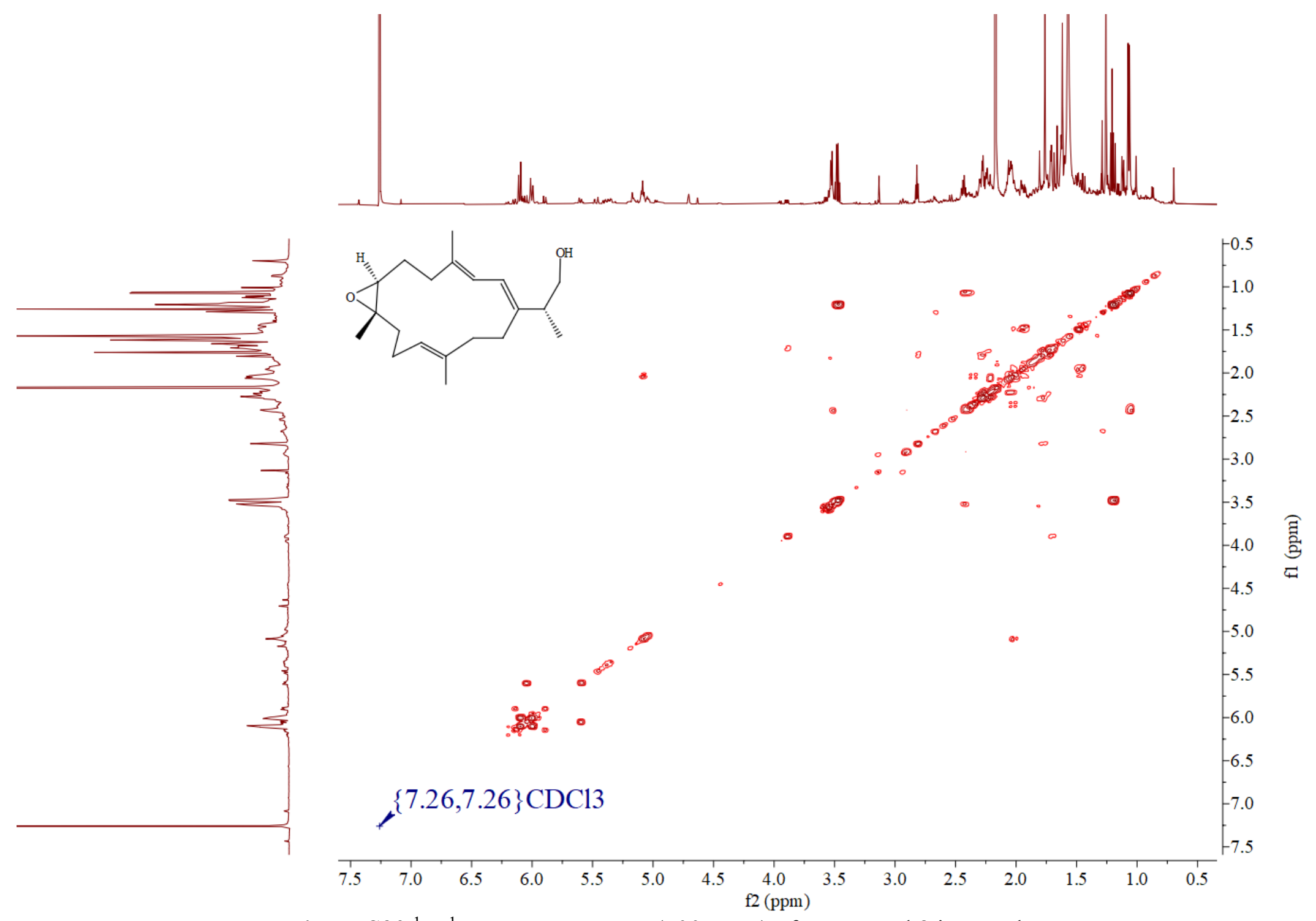

Figure S20. ${ }^{1} \mathrm{H}_{-}{ }^{1} \mathrm{H}$ COSY spectrum $(500 \mathrm{MHz})$ of compound 3 in $\mathrm{CDCl}_{3}$ 


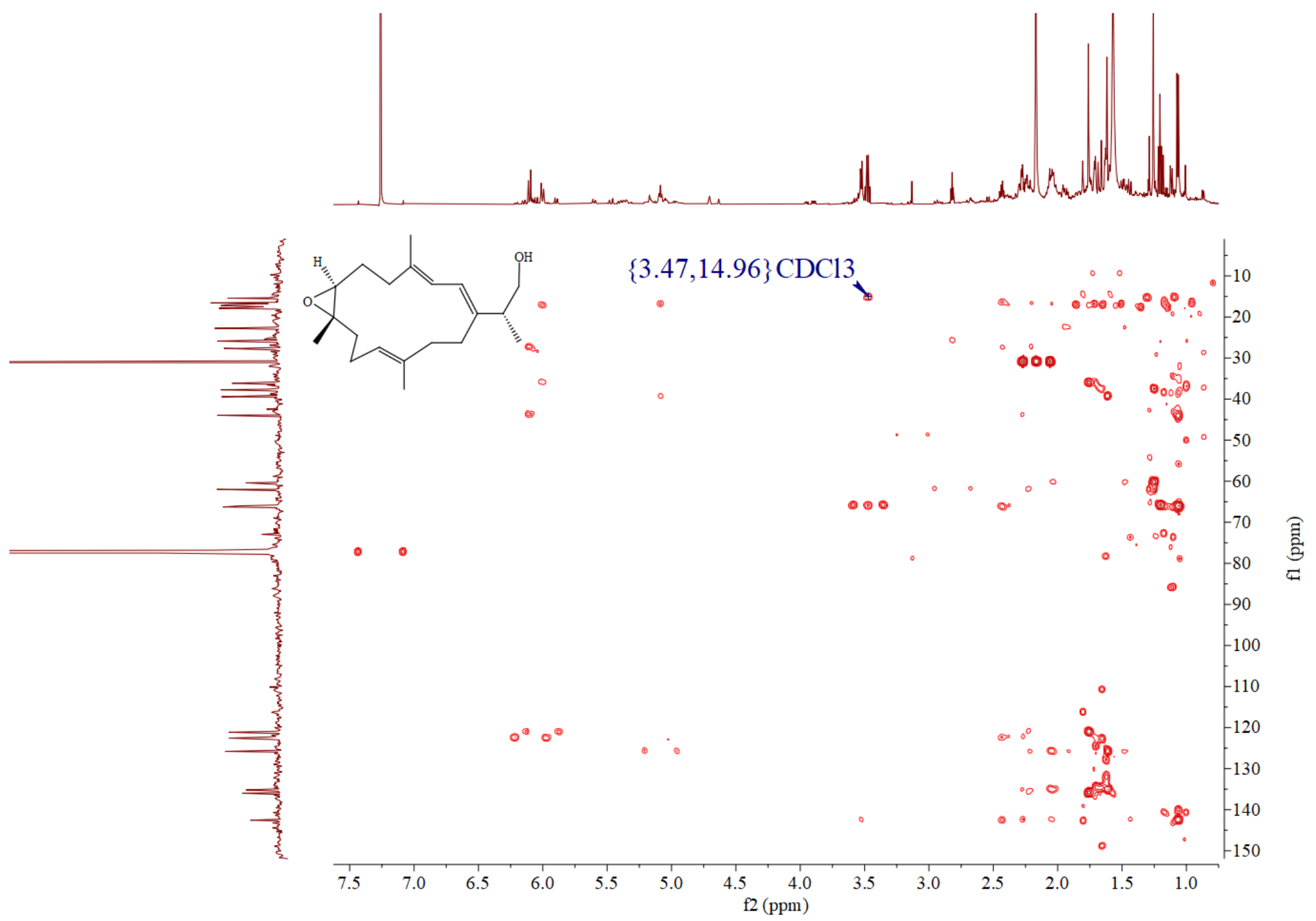

Figure S21. HMBC spectrum (500 MHz) of compound 3 in $\mathrm{CDCl}_{3}$ 


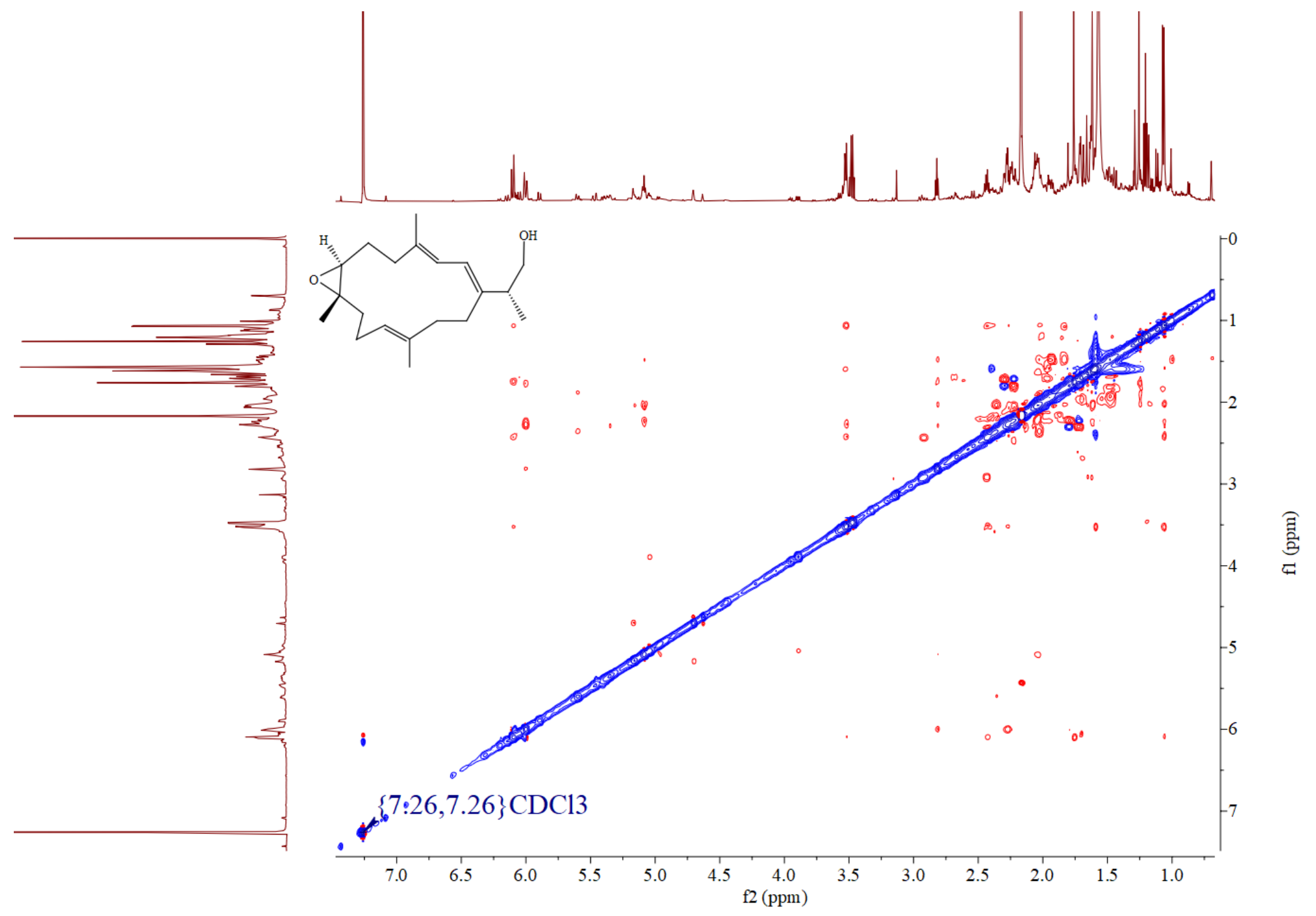

Figure S22. NOESY spectrum (500 MHz) of compound 3 in $\mathrm{CDCl}_{3}$ 


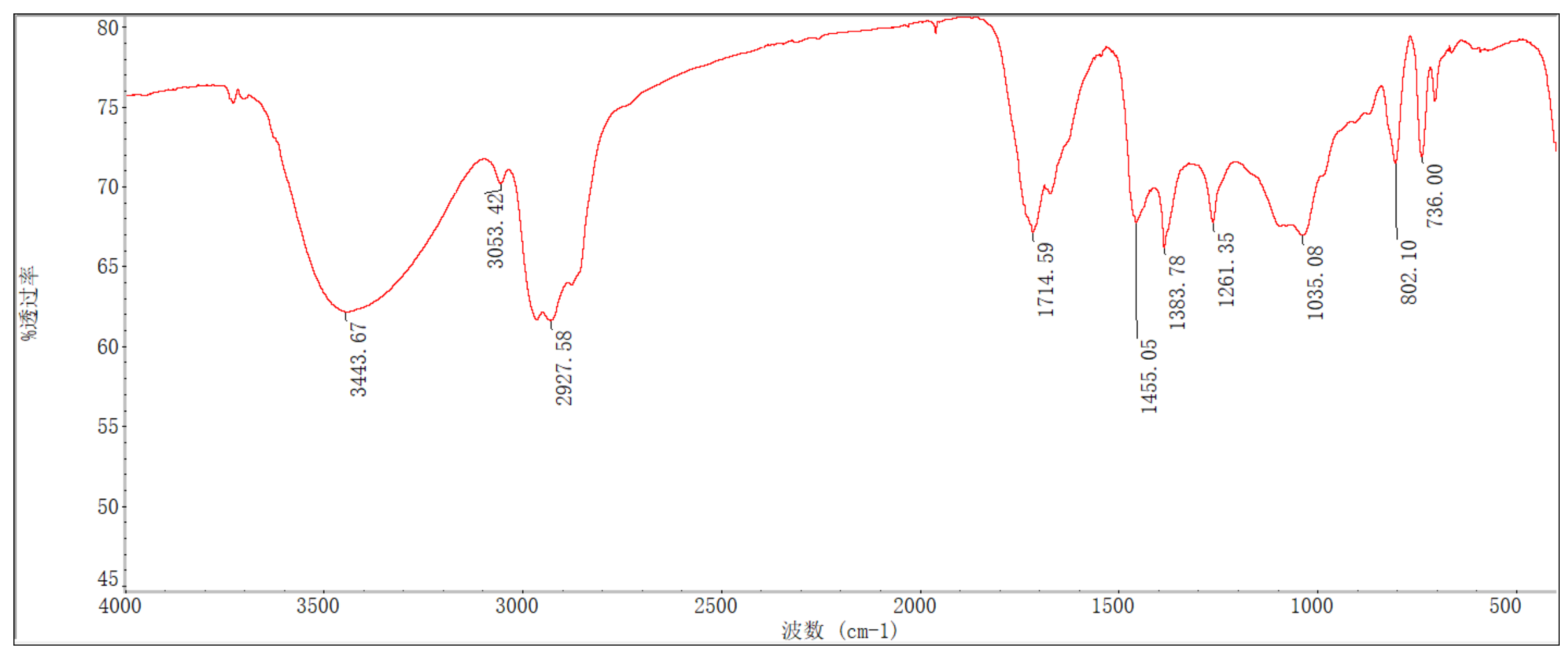

Figure S23. IR spectrum of compound 3 


\section{Qualitative Analysis Report}

$\begin{array}{llll}\text { Data Filename } & \text { ESIH_20191025_GYW_SLL_09.d } & \text { Sample Name } & \text { A8-EDAG-11 } \\ \text { Sample Type } & \text { Sample } & \text { Position } & \text { P1-B1 } \\ \text { Instrument Name } & \text { Agilent G6520 Q-TOF } & \text { Acq Method } & \text { 20160322_MS_ESIH_POS_1min.m } \\ \text { Acquired Time } & 10 / 25 / 2019 \text { 14:55:27 } & \text { IRM Calibration Status } & \text { Success } \\ \text { DA Method } & \text { small molecular data analysis method.m } & \text { Comment } & \text { ESIH by ZZY }\end{array}$

Method

small molecular data analysis method.m

Comment

User Spectra

Fragmentor Voltage Collision Energy Ionization Mode

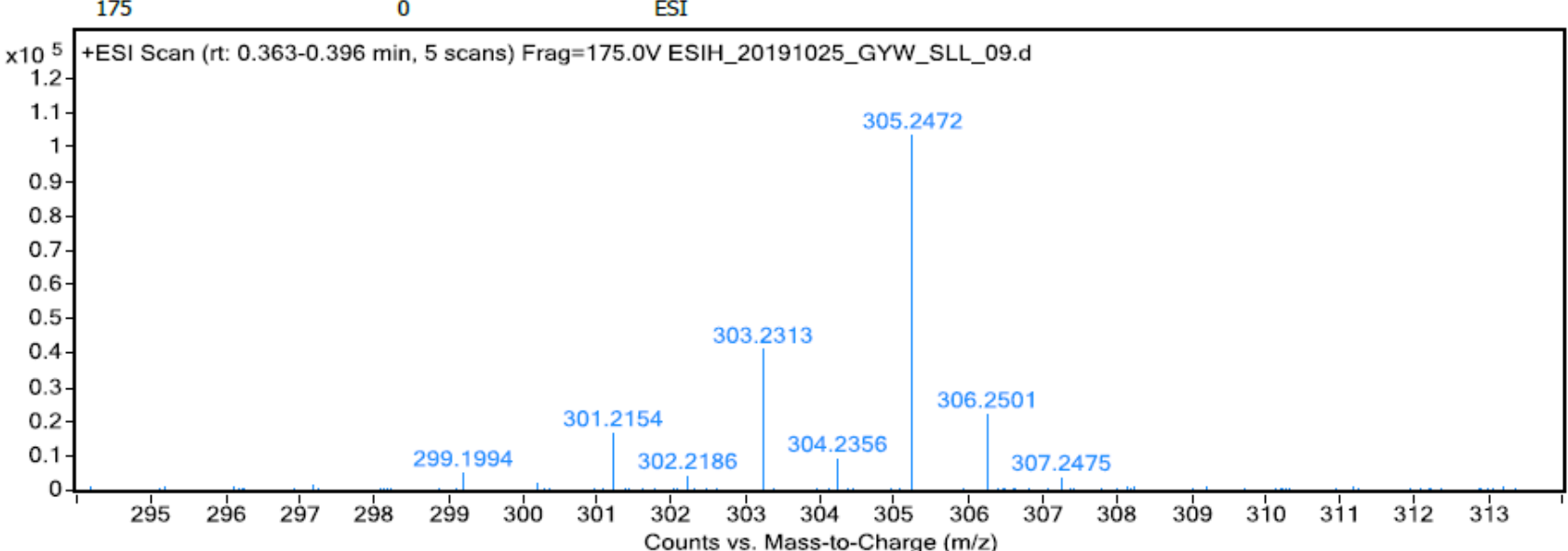

Formula Calculator Result

\begin{tabular}{|l|r|r|r|l|l|}
\hline $\mathrm{m} / \mathrm{z}$ & Calc $\mathrm{m} / \mathrm{z}$ & Diff (mDa) & Diff (ppm) & Ion Formula & Ion \\
\hline 305.2472 & 305.2475 & 0.3 & 0.98 & $\mathrm{C} 20 \mathrm{H} 33 \mathrm{O} 2$ & $(\mathrm{M}+\mathrm{H})+$ \\
\hline
\end{tabular}

--- End Of Report ---

Figure S24. HRESIMS spectrum of compound 3 


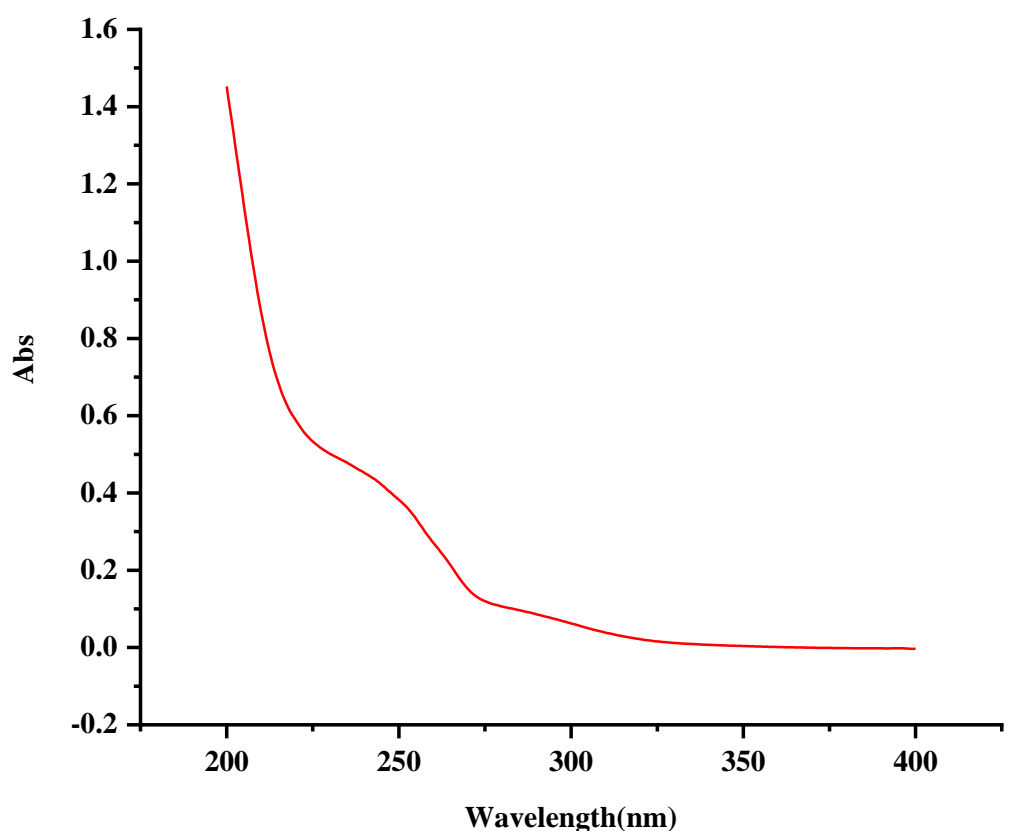

Figure S25. UV spectrum of compound 3 


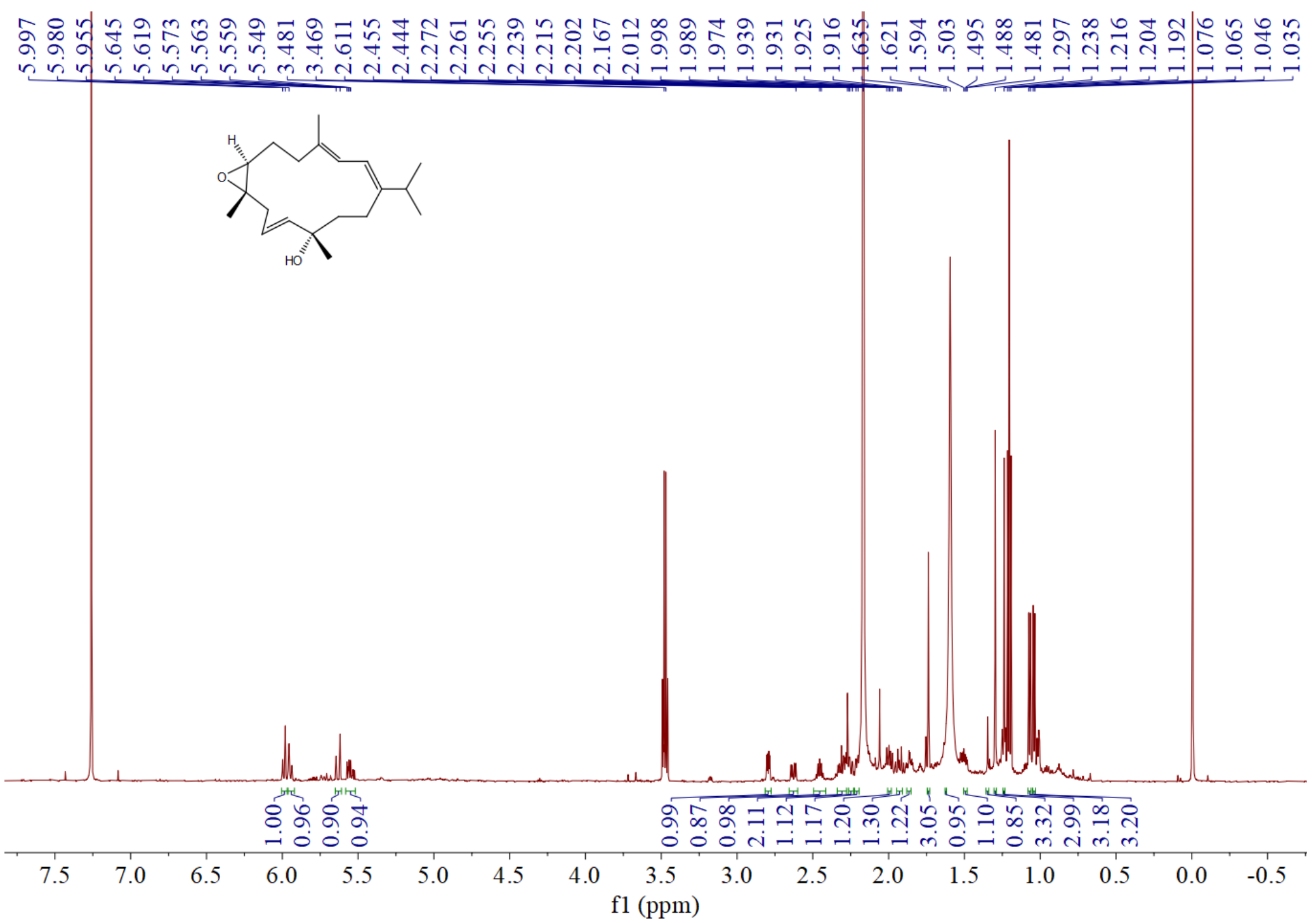

Figure S26. ${ }^{1} \mathrm{H}$ NMR spectrum $(600 \mathrm{MHz})$ of compound 4 in $\mathrm{CDCl}_{3}$ 


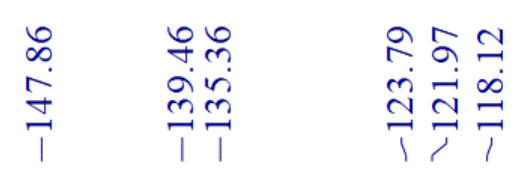
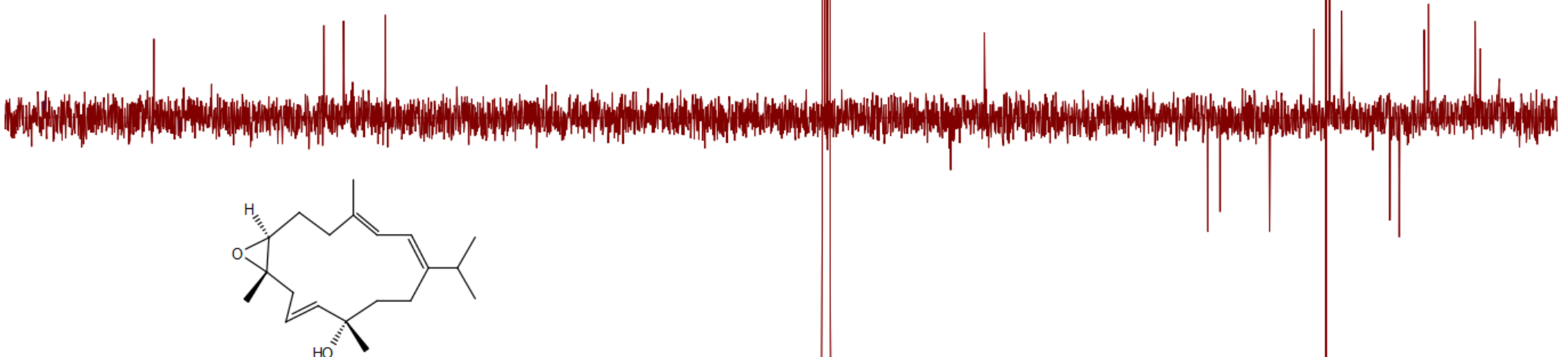



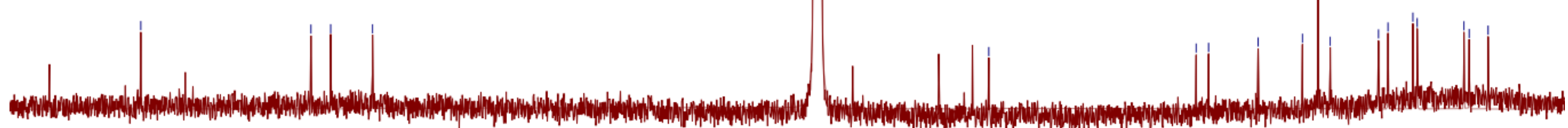

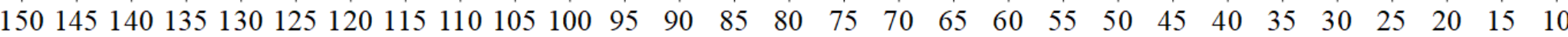
fl (ppm)

Figure S27. ${ }^{13} \mathrm{C}\left\{{ }^{1} \mathrm{H}\right\}$ NMR and DEPT spectrum $(125 \mathrm{MHz})$ of compound 4 in $\mathrm{CDCl}_{3}$ 


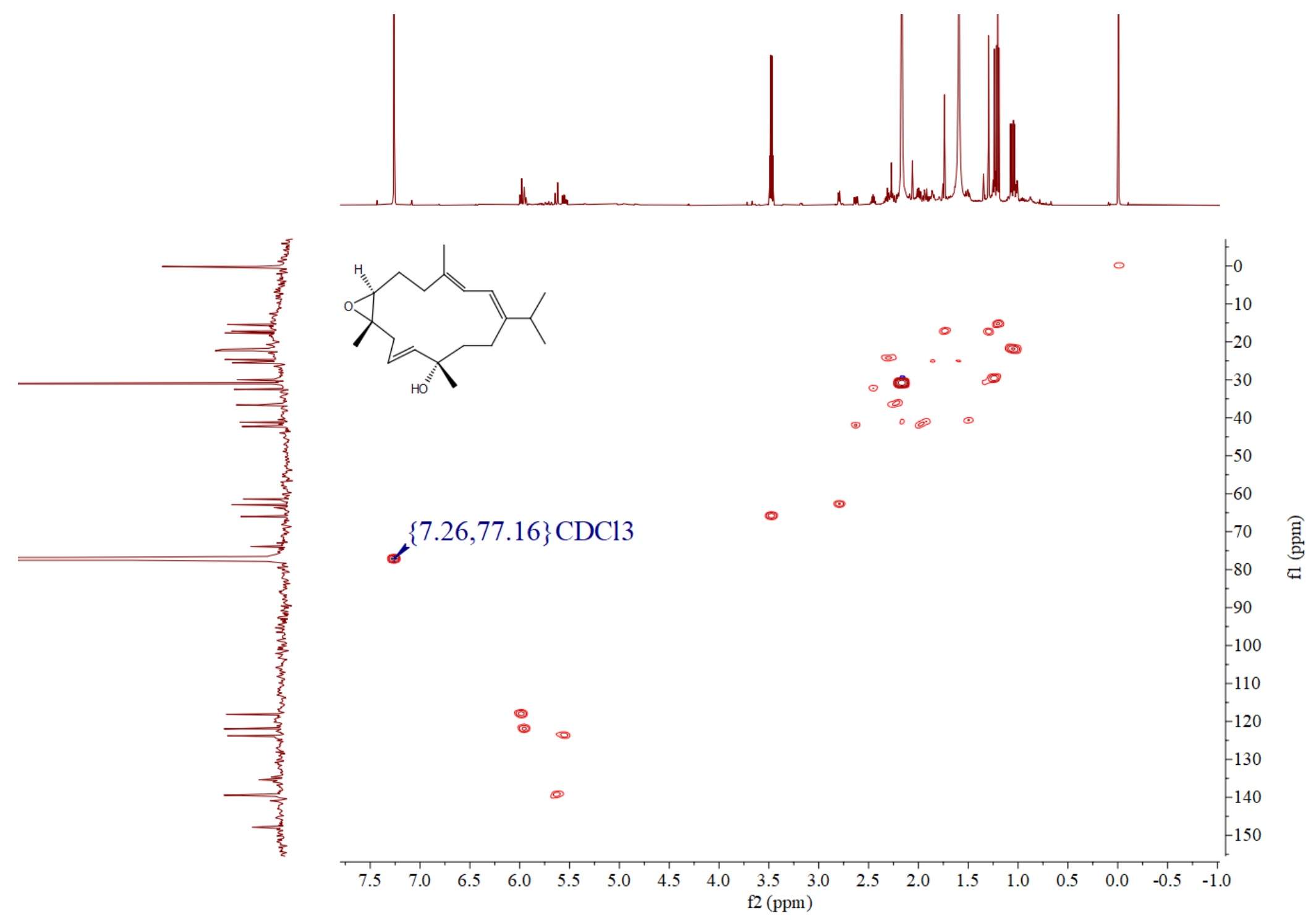

Figure S28. HSQC spectrum (500 MHz) of compound 4 in $\mathrm{CDCl}_{3}$ 


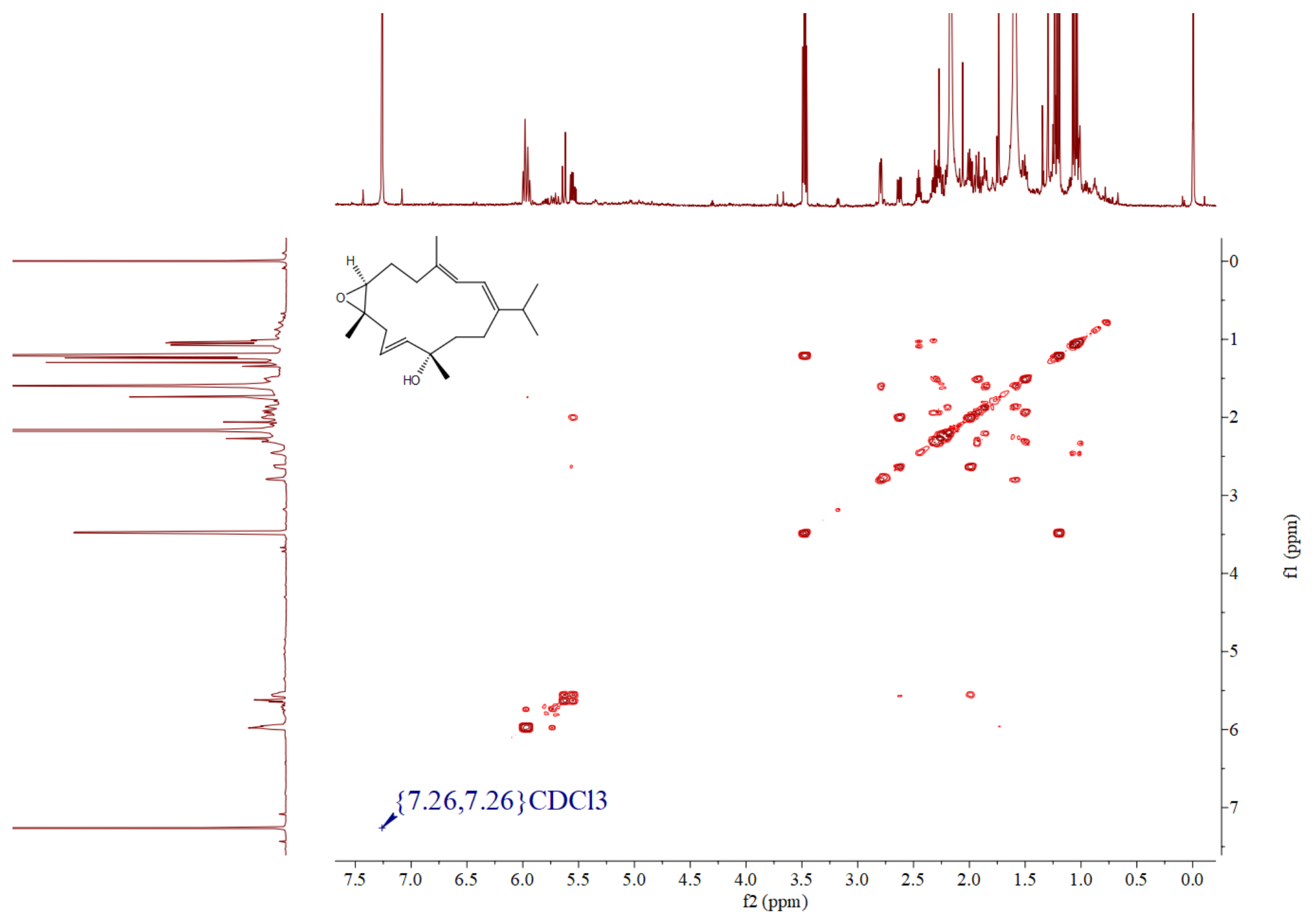

Figure S29. ${ }^{1} \mathrm{H}^{1}{ }^{1} \mathrm{H}$ COSY spectrum $\left(500 \mathrm{MHz}\right.$ ) of compound 4 in $\mathrm{CDCl}_{3}$ 


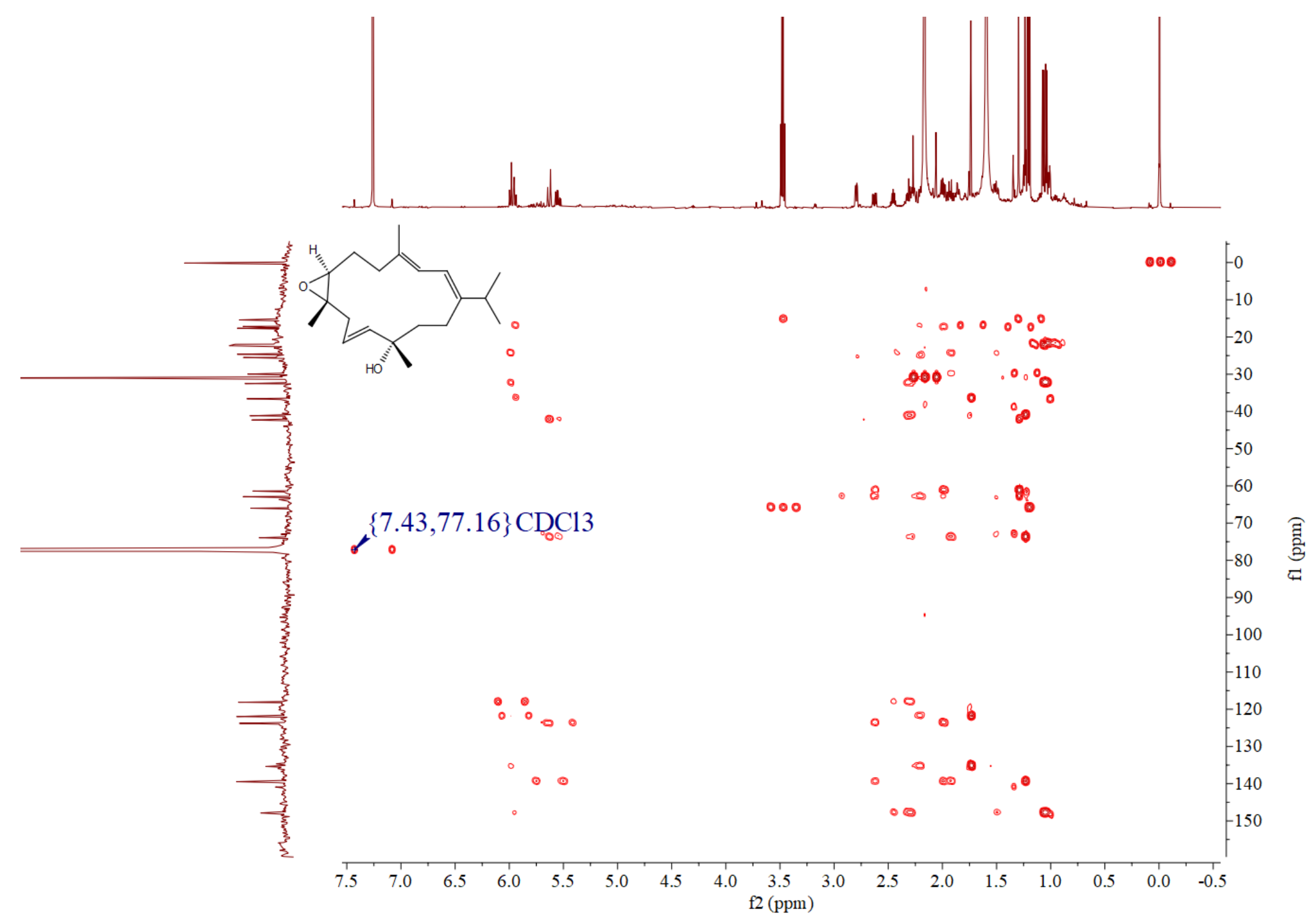

Figure S30. HMBC spectrum (500 MHz) of compound 4 in $\mathrm{CDCl}_{3}$ 


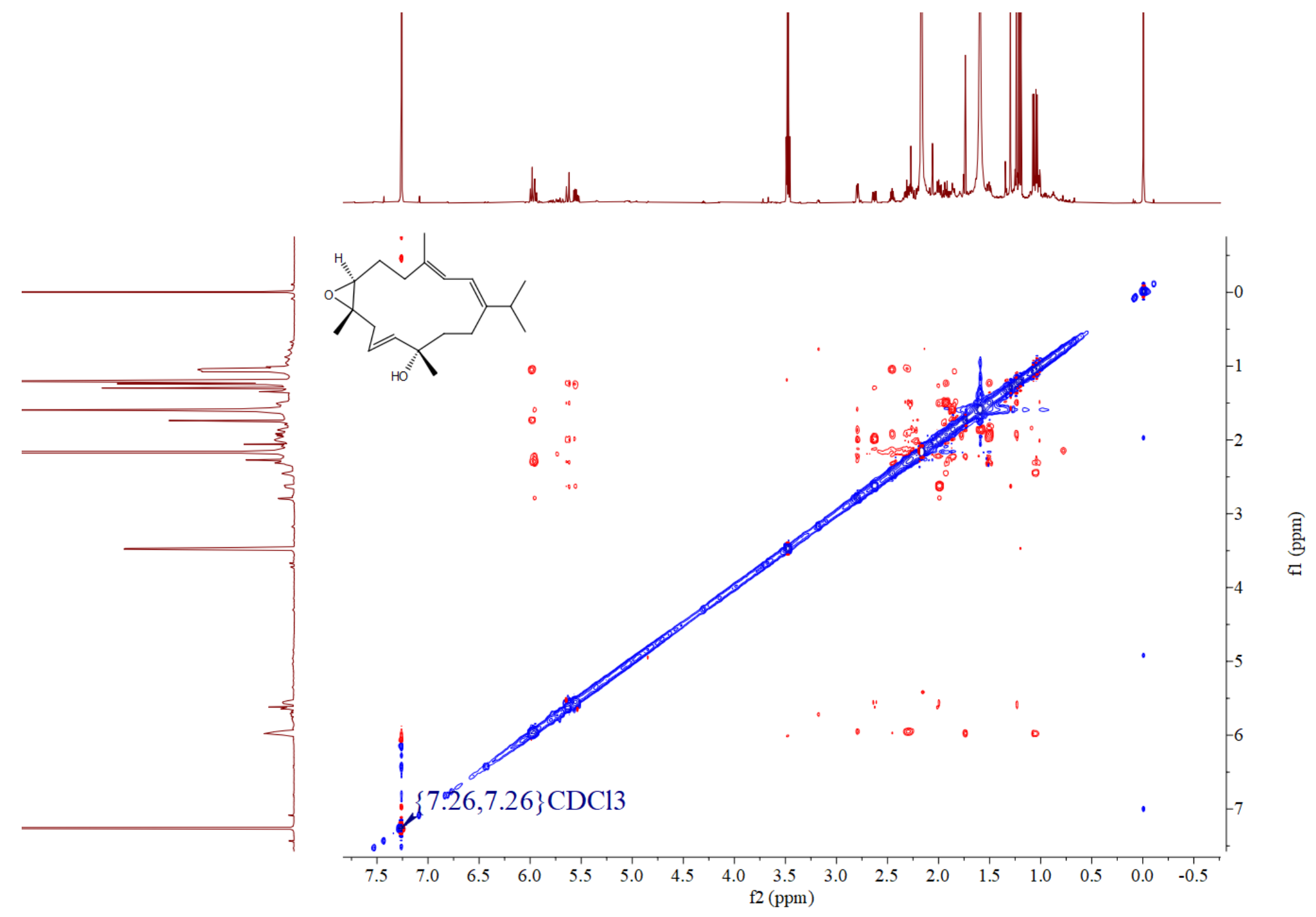

Figure S31. NOESY spectrum (500 MHz) of compound 4 in $\mathrm{CDCl}_{3}$ 


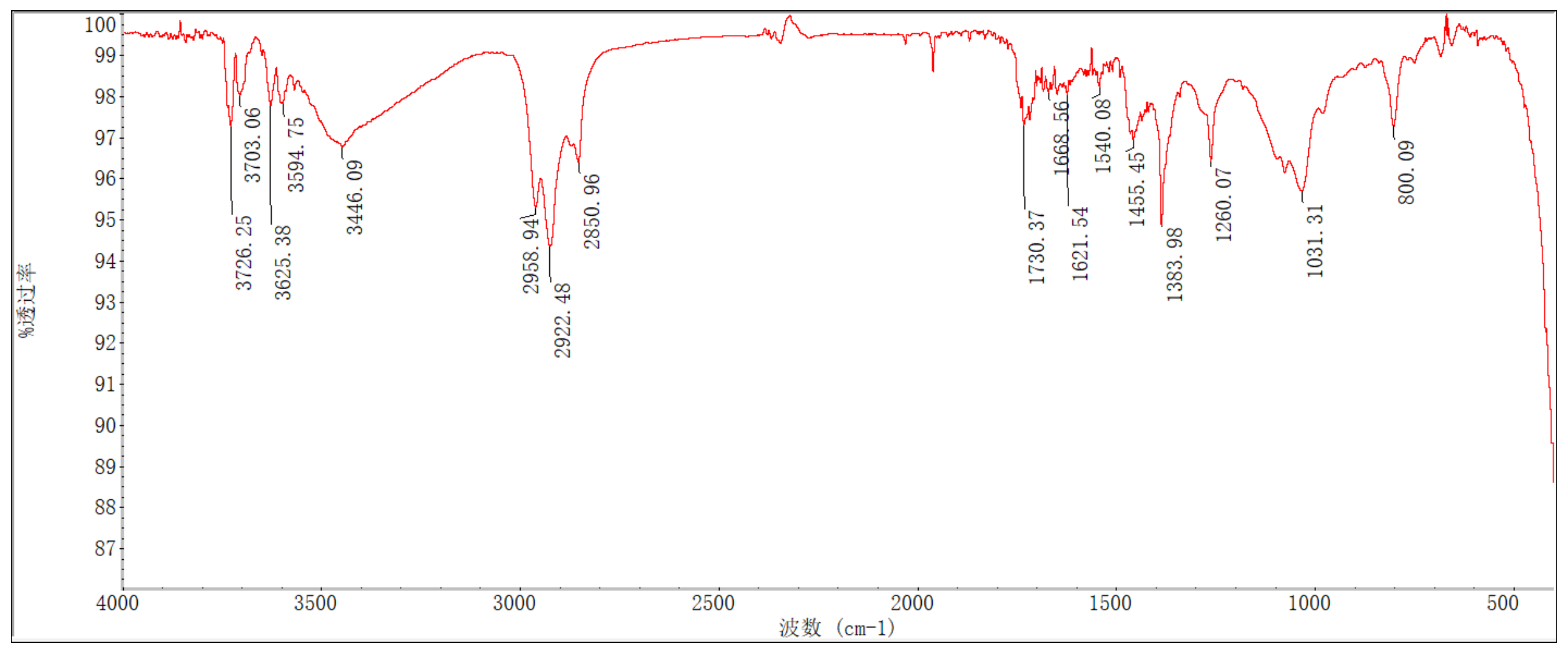

Figure S32. IR spectrum of compound 4 
Qualitative Analysis Report

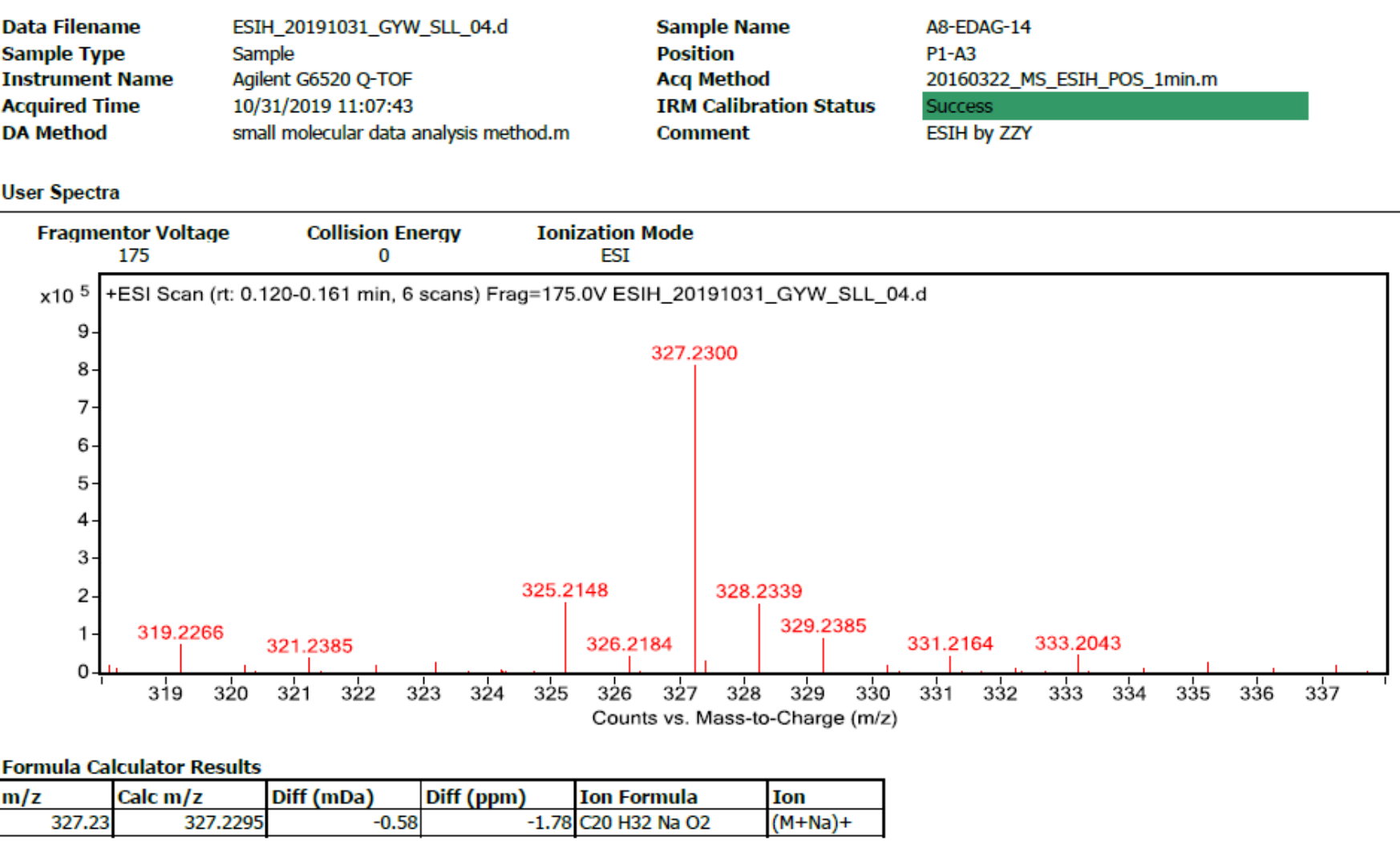

--- End Of Report --

Figure S33. HRESIMS spectrum of compound 4 


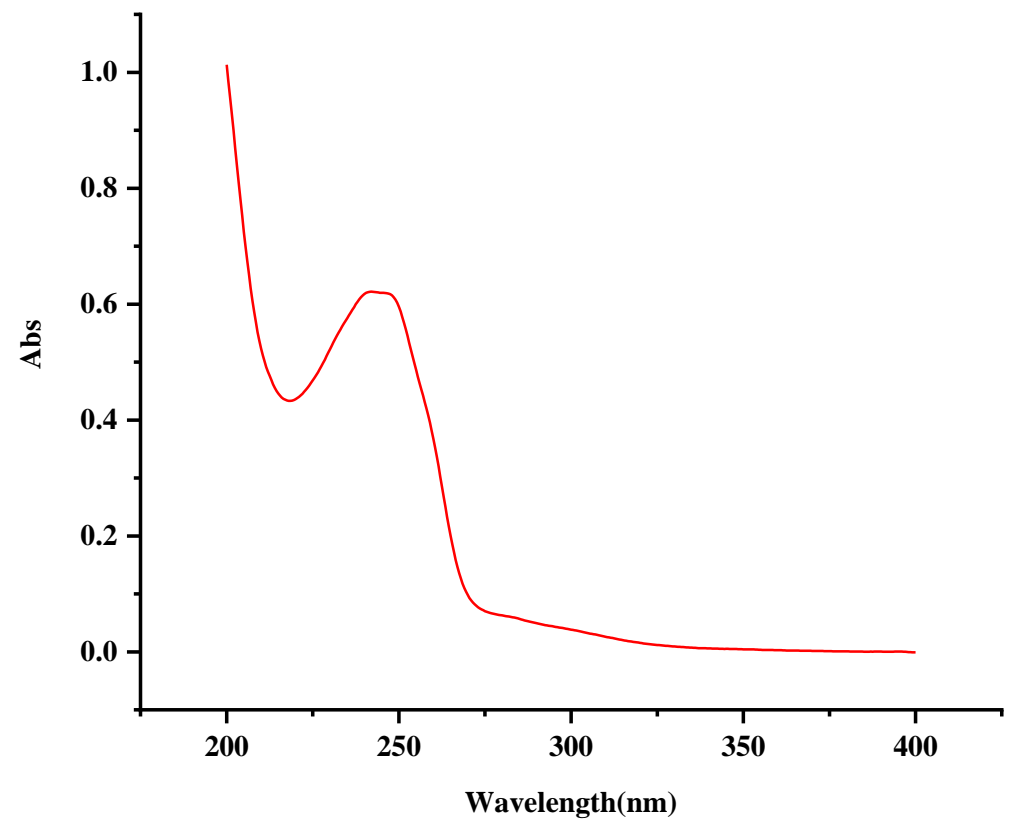

Figure S34. UV spectrum of compound 4 


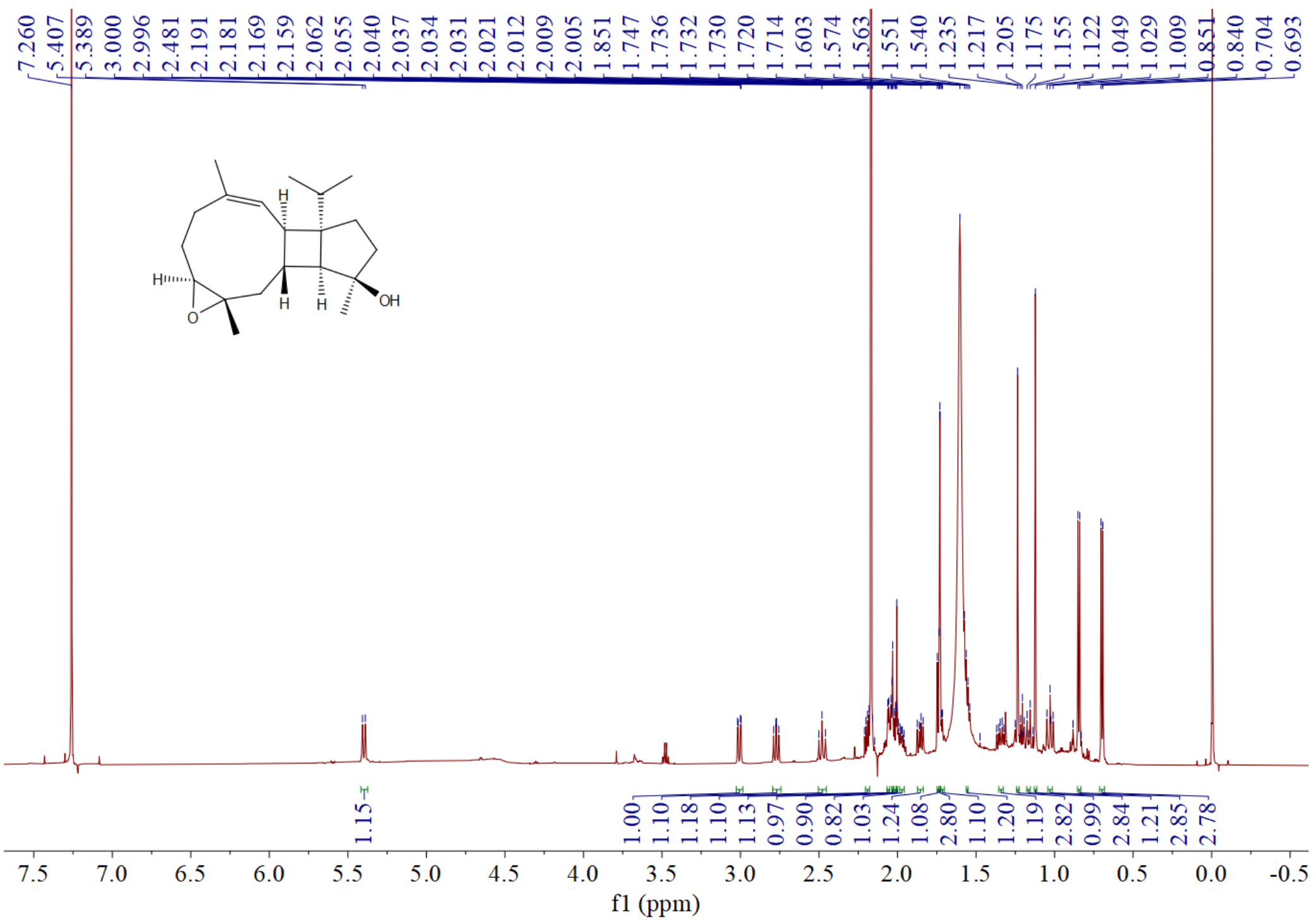

Figure S35. ${ }^{1} \mathrm{H}$ NMR spectrum $(600 \mathrm{MHz})$ of compound 5 in $\mathrm{CDCl}_{3}$ 


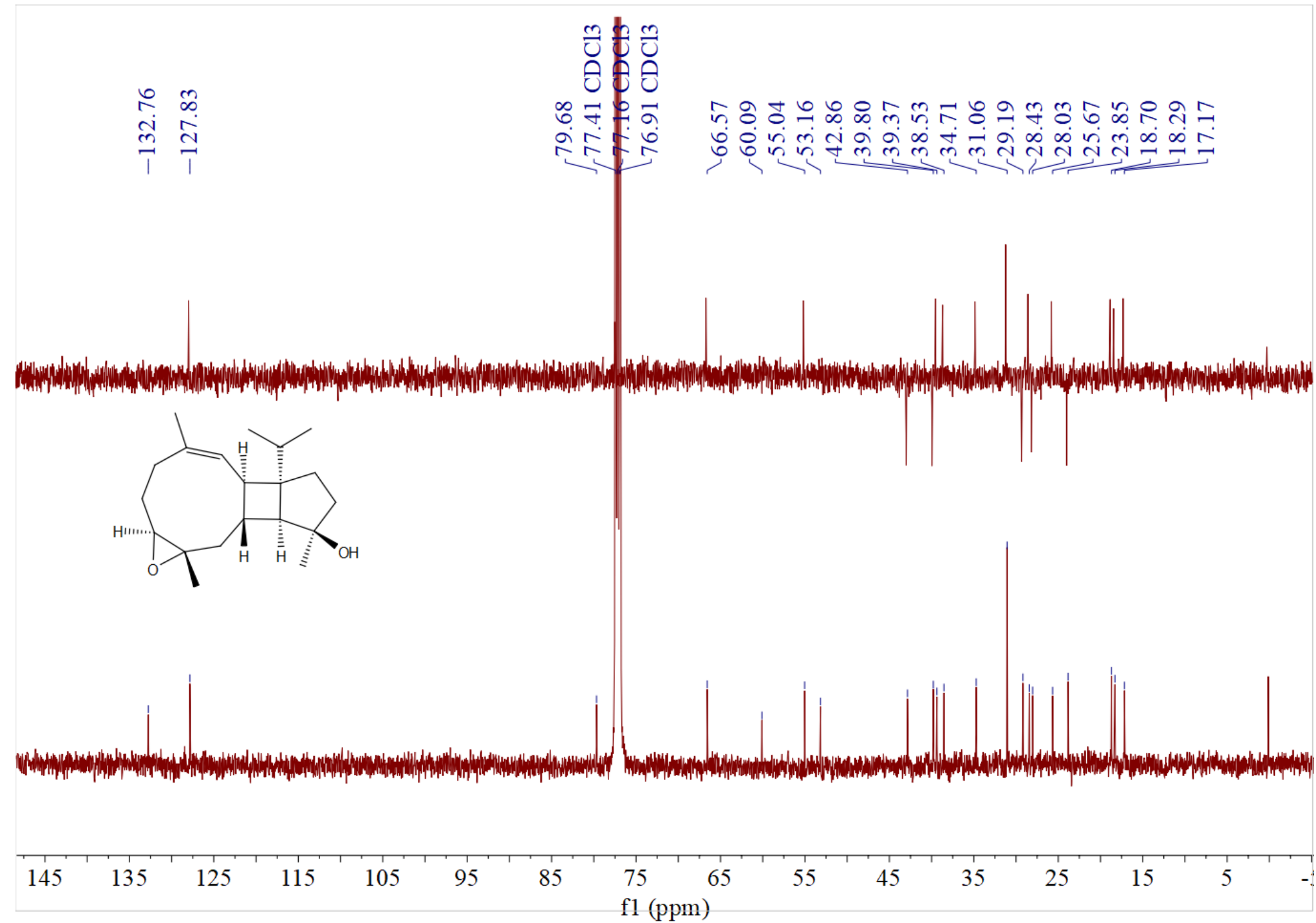

Figure S36. ${ }^{13} \mathrm{C}\left\{{ }^{1} \mathrm{H}\right\}$ NMR and DEPT spectrum $(125 \mathrm{MHz})$ of compound $\mathbf{5}$ in $\mathrm{CDCl}_{3}$ 


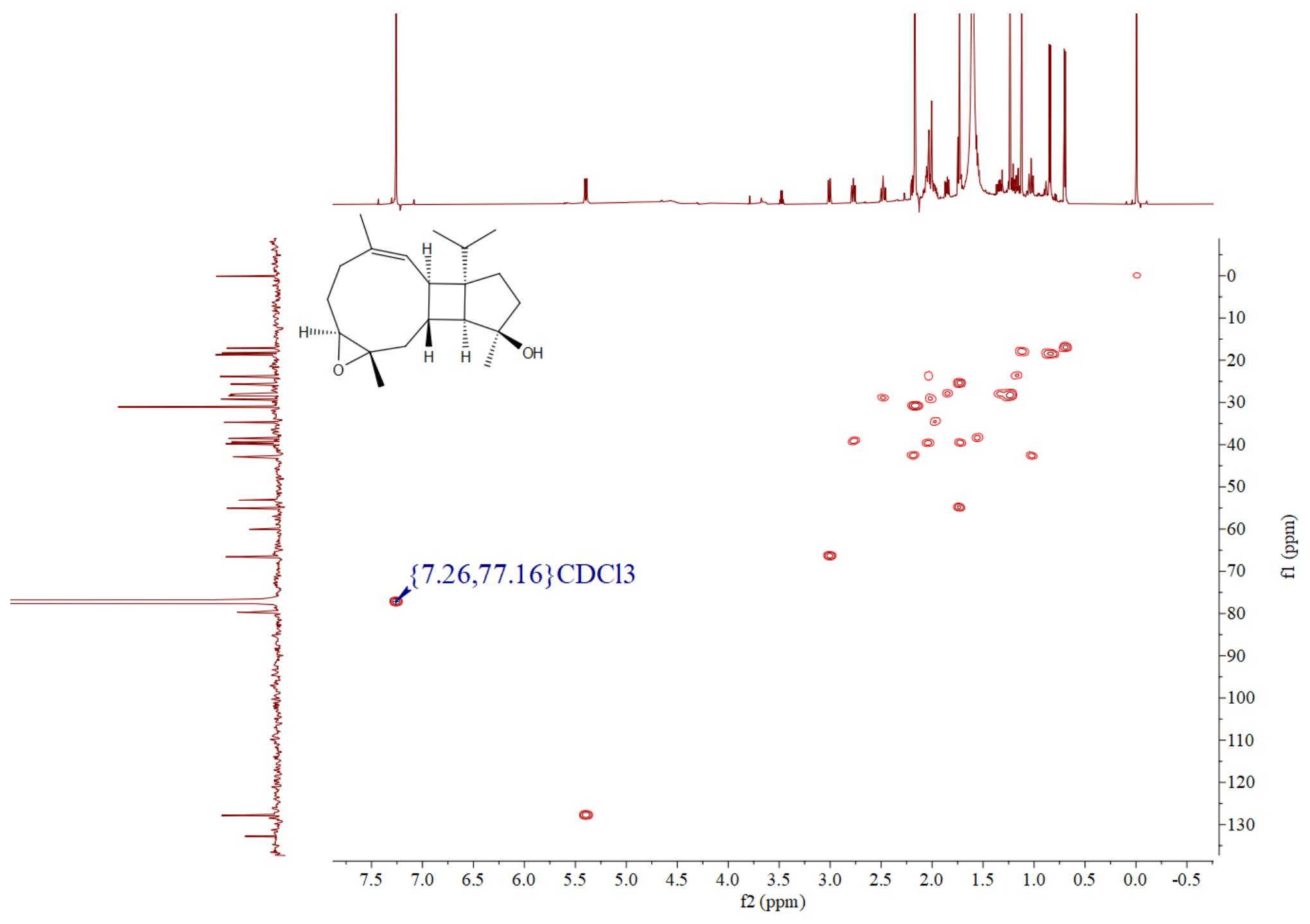

Figure S37. HSQC spectrum (500 MHz) of compound 5 in $\mathrm{CDCl}_{3}$ 

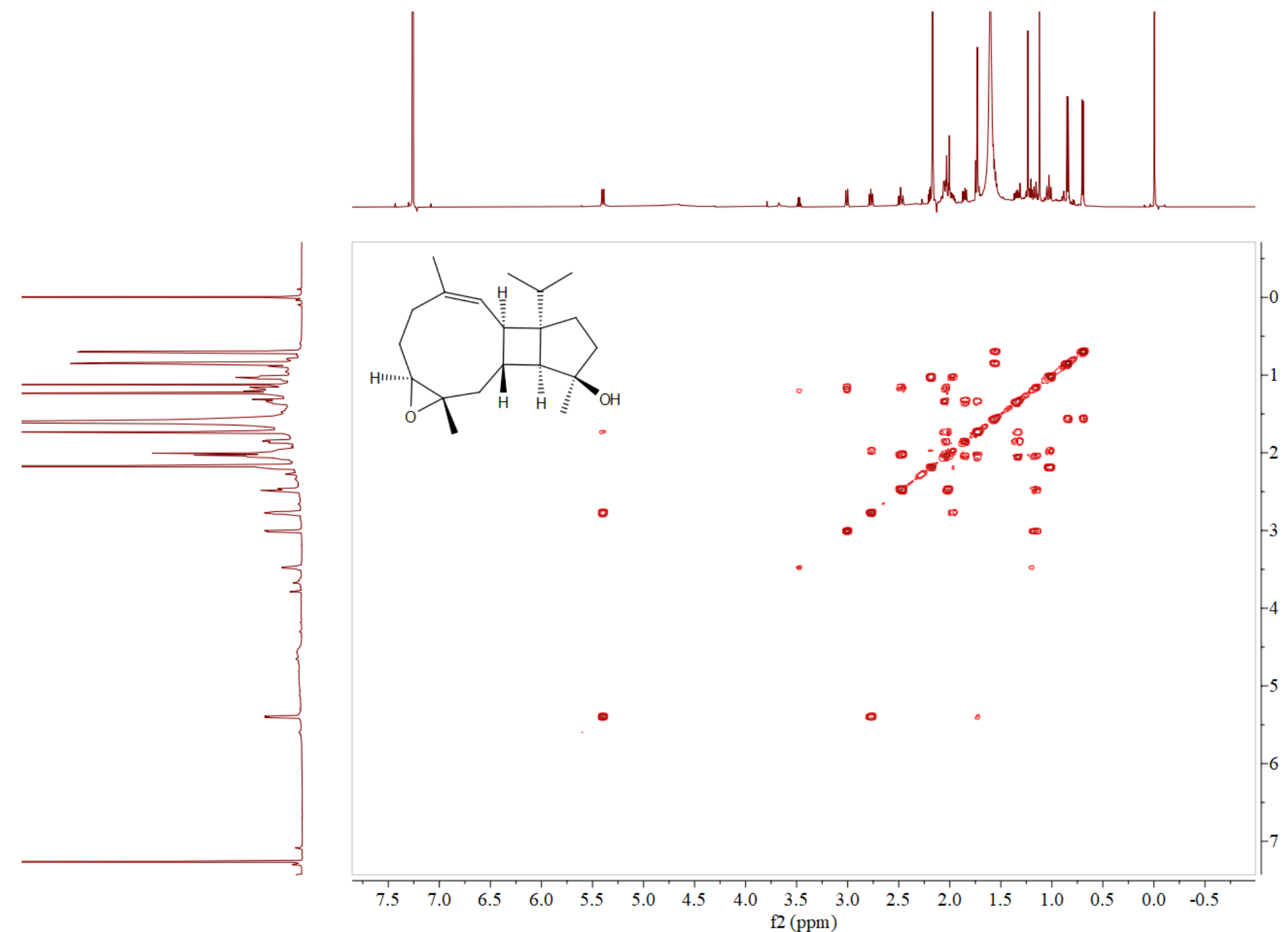

产

Figure S38. ${ }^{1} \mathrm{H}-{ }^{1} \mathrm{H}$ COSY spectrum $(500 \mathrm{MHz})$ of compound 5 in $\mathrm{CDCl}_{3}$ 


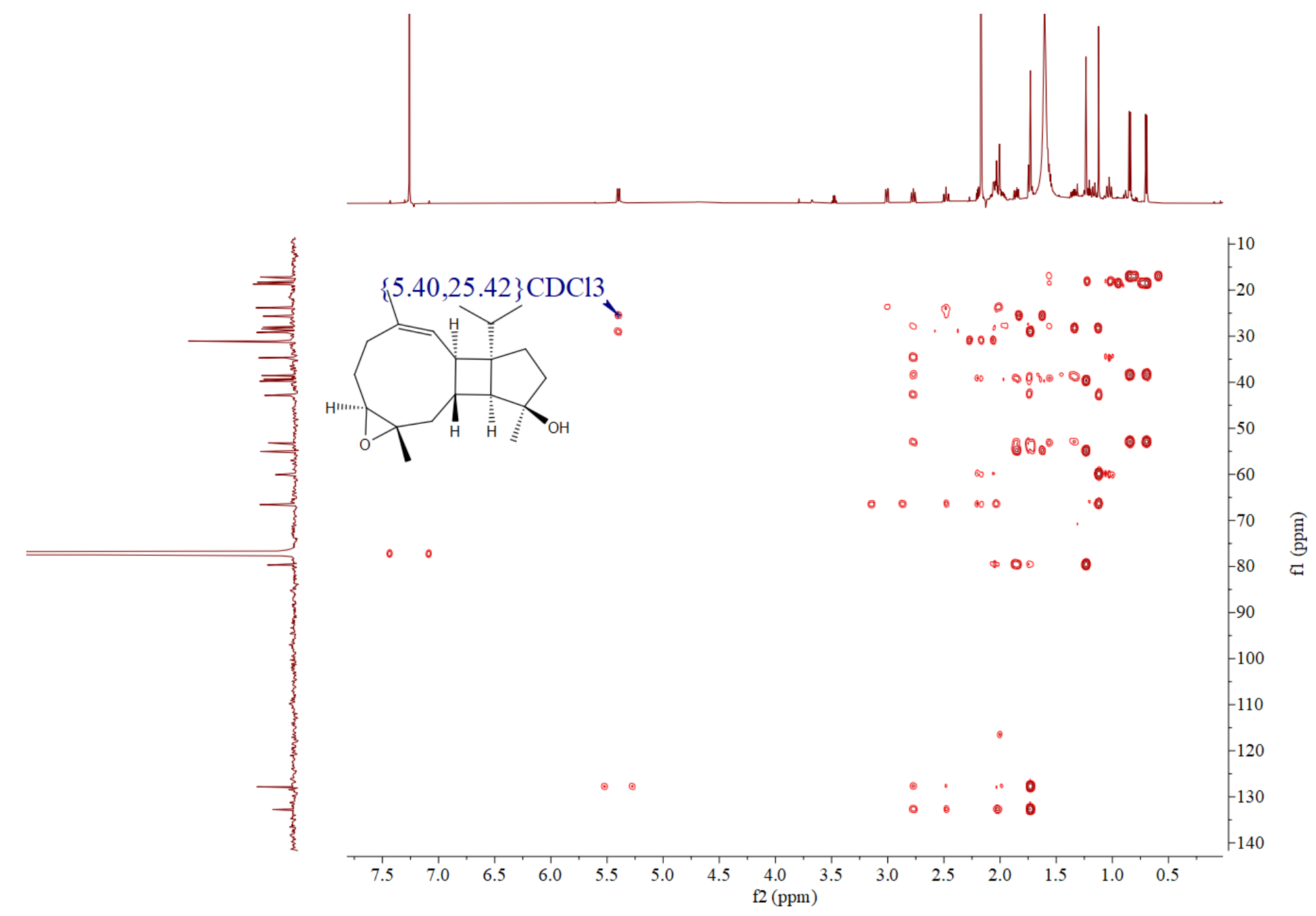

Figure S39. HMBC spectrum (500 MHz) of compound 5 in $\mathrm{CDCl}_{3}$ 


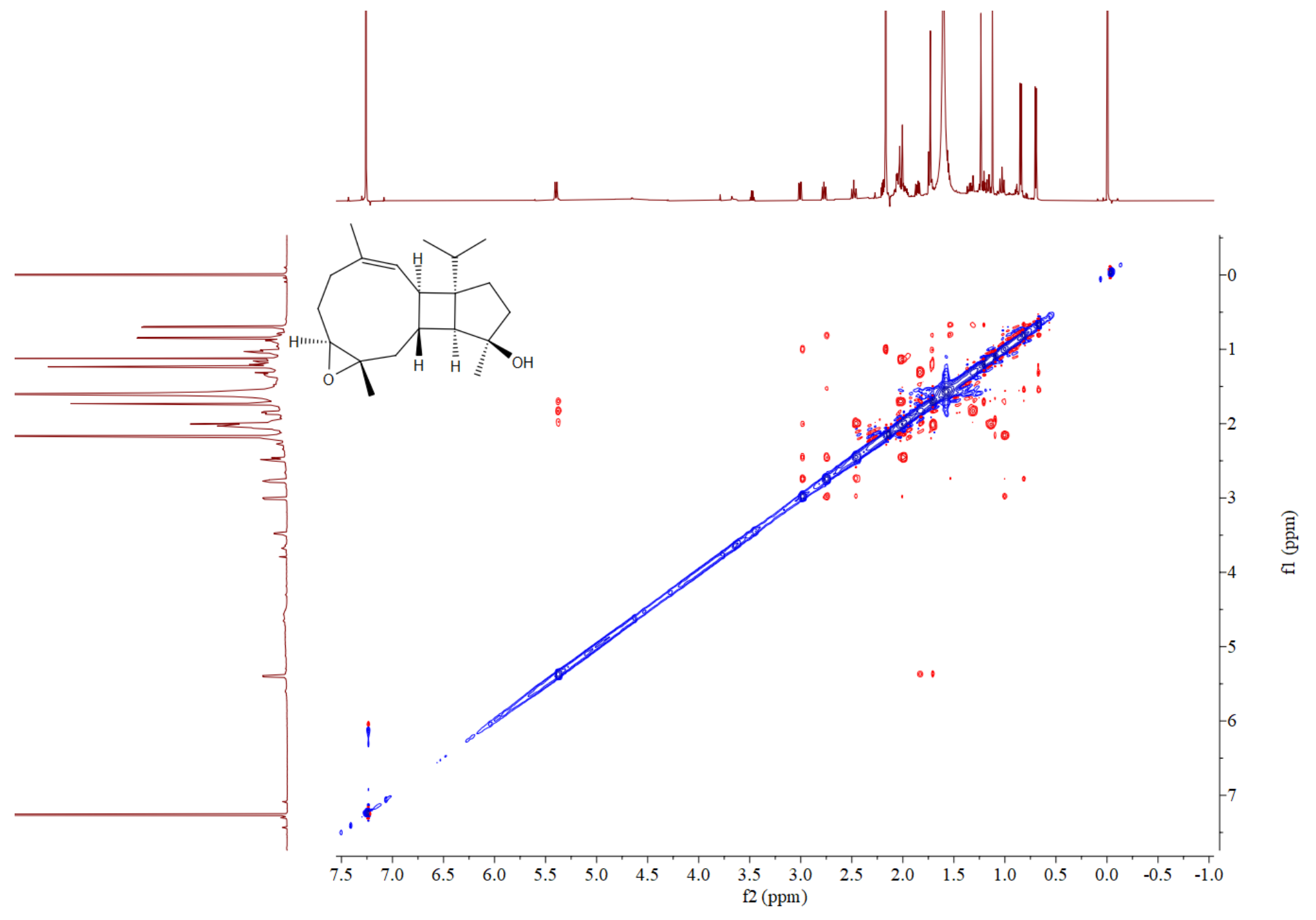

Figure S40. NOESY spectrum $(500 \mathrm{MHz})$ of compound 5 in $\mathrm{CDCl}_{3}$ 


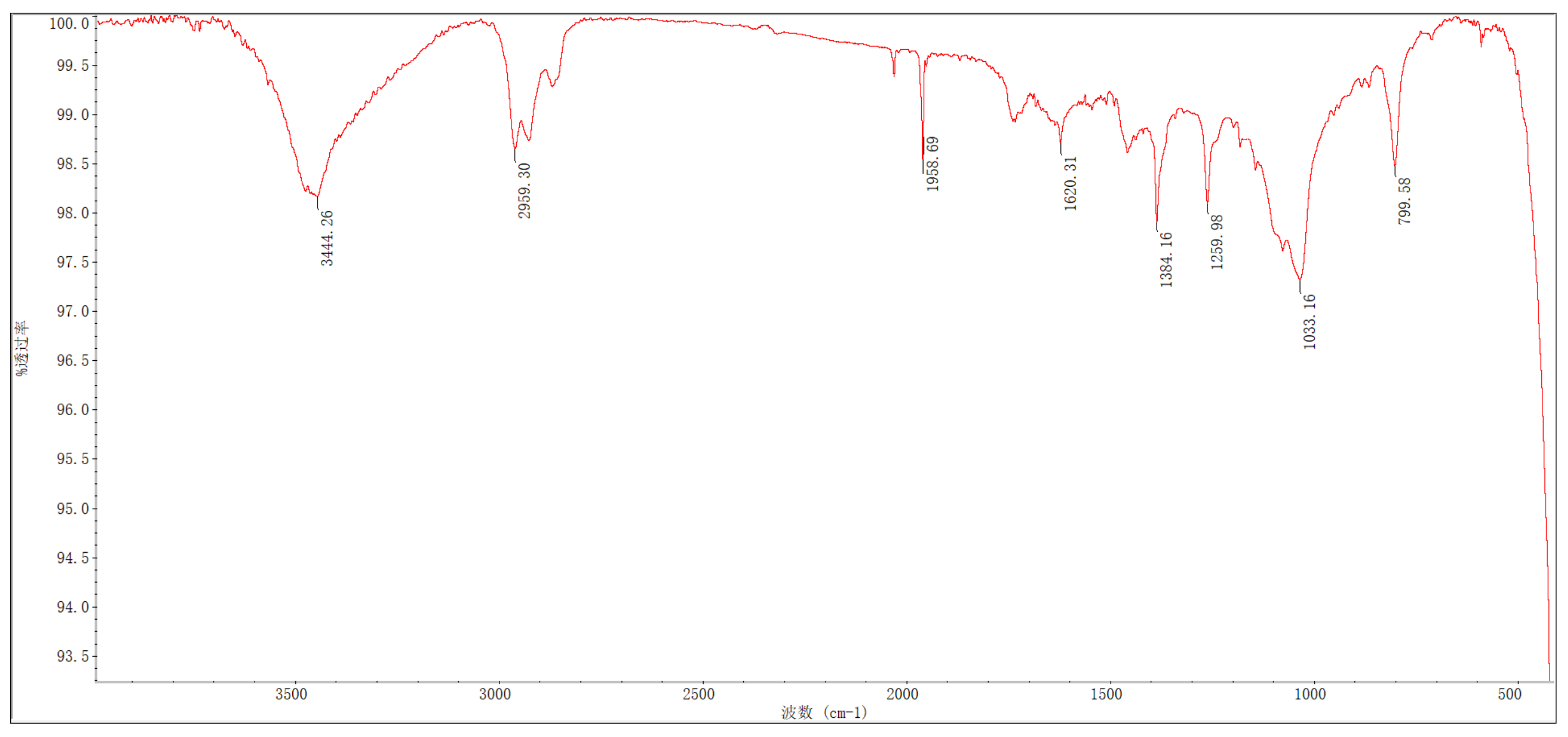

Figure S41. IR spectrum of compound 5 
EIH-20191227-GYW-SLL-02_AB-DEAK-8-01

12/27/2018 2:51:41 PM

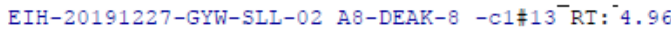

I: + CEI Full ms [ 49.50-800.50]

$\mathrm{m} / \mathrm{z}=48-803$

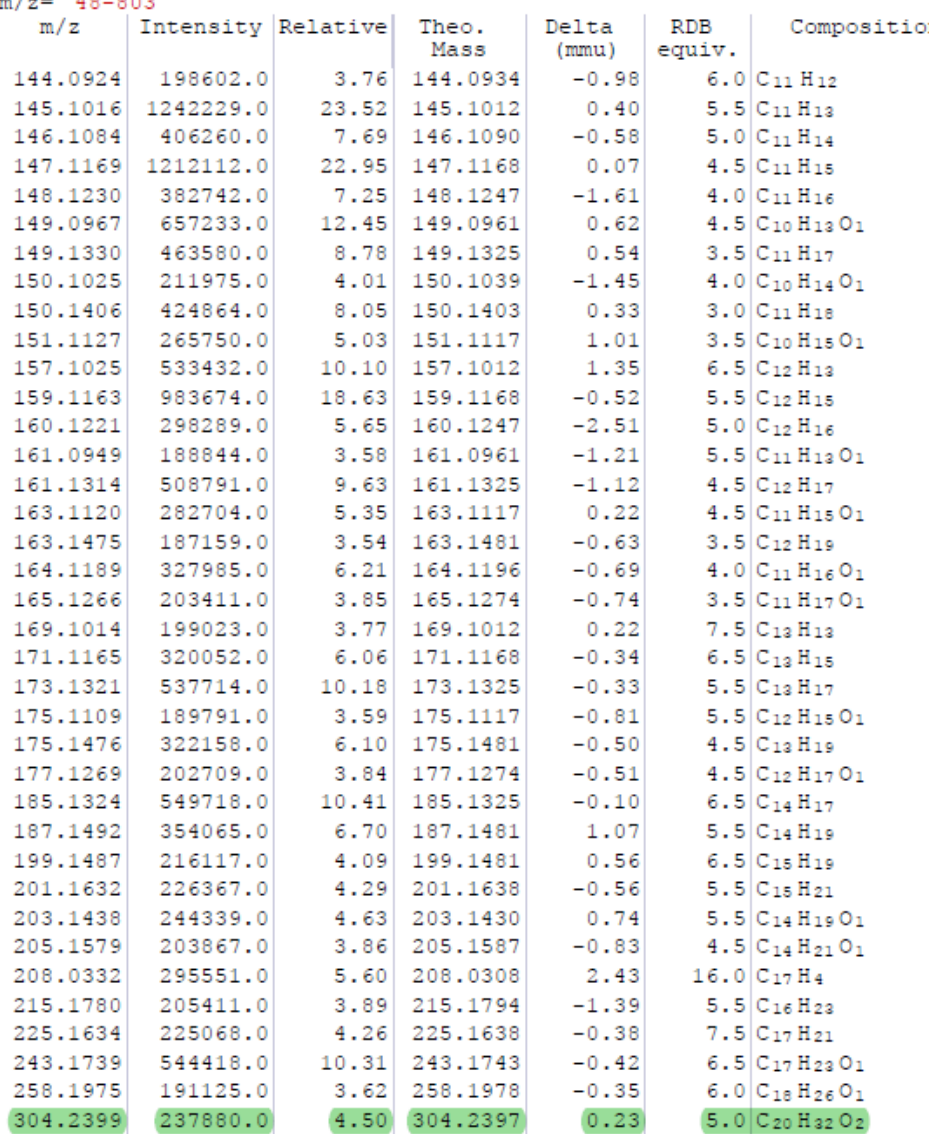

Figure S42. HREIMS spectrum of compound 5 


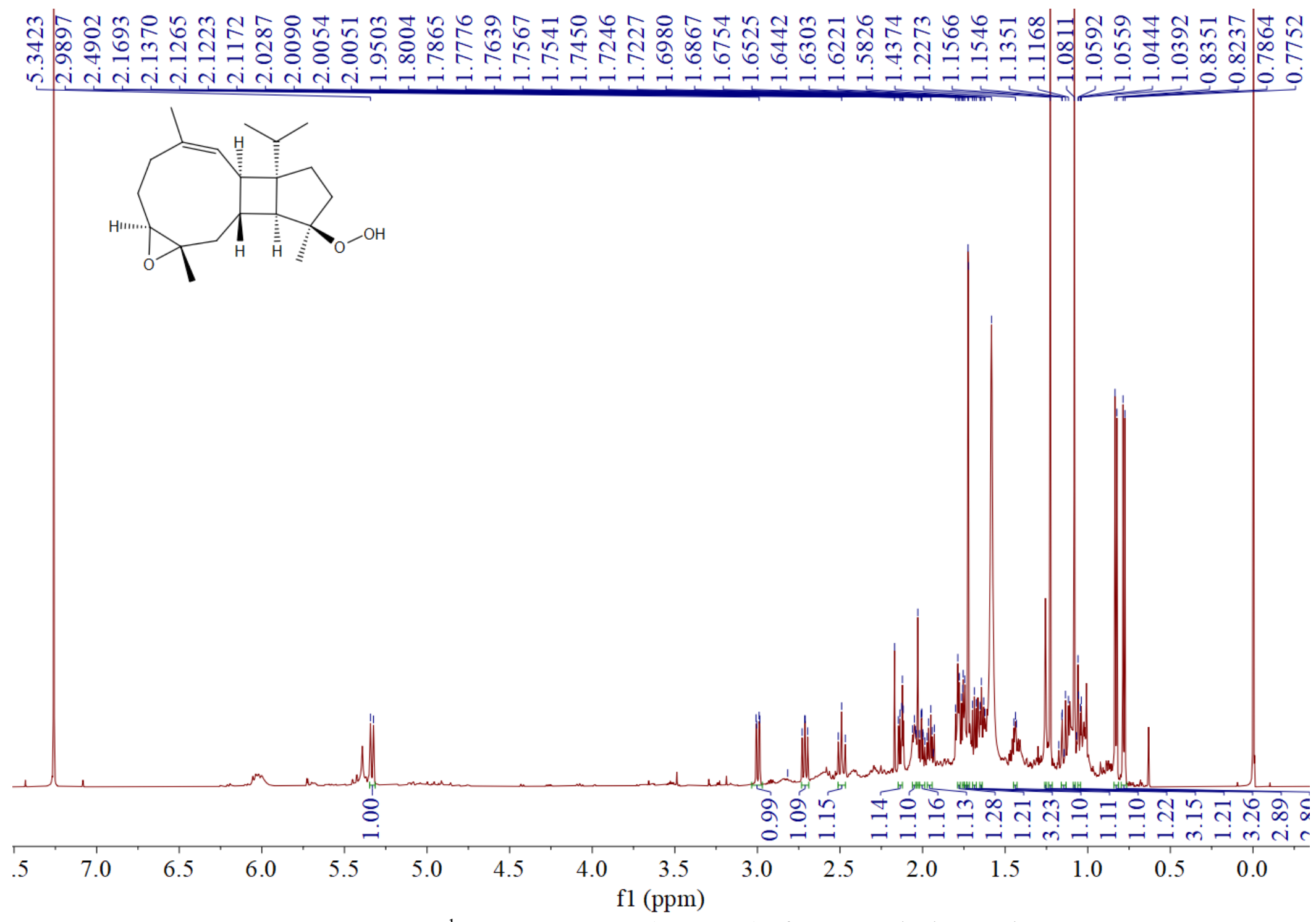

Figure S43. ${ }^{1} \mathrm{H}$ NMR spectrum $(600 \mathrm{MHz})$ of compound 6 in $\mathrm{CDCl}_{3}$ 

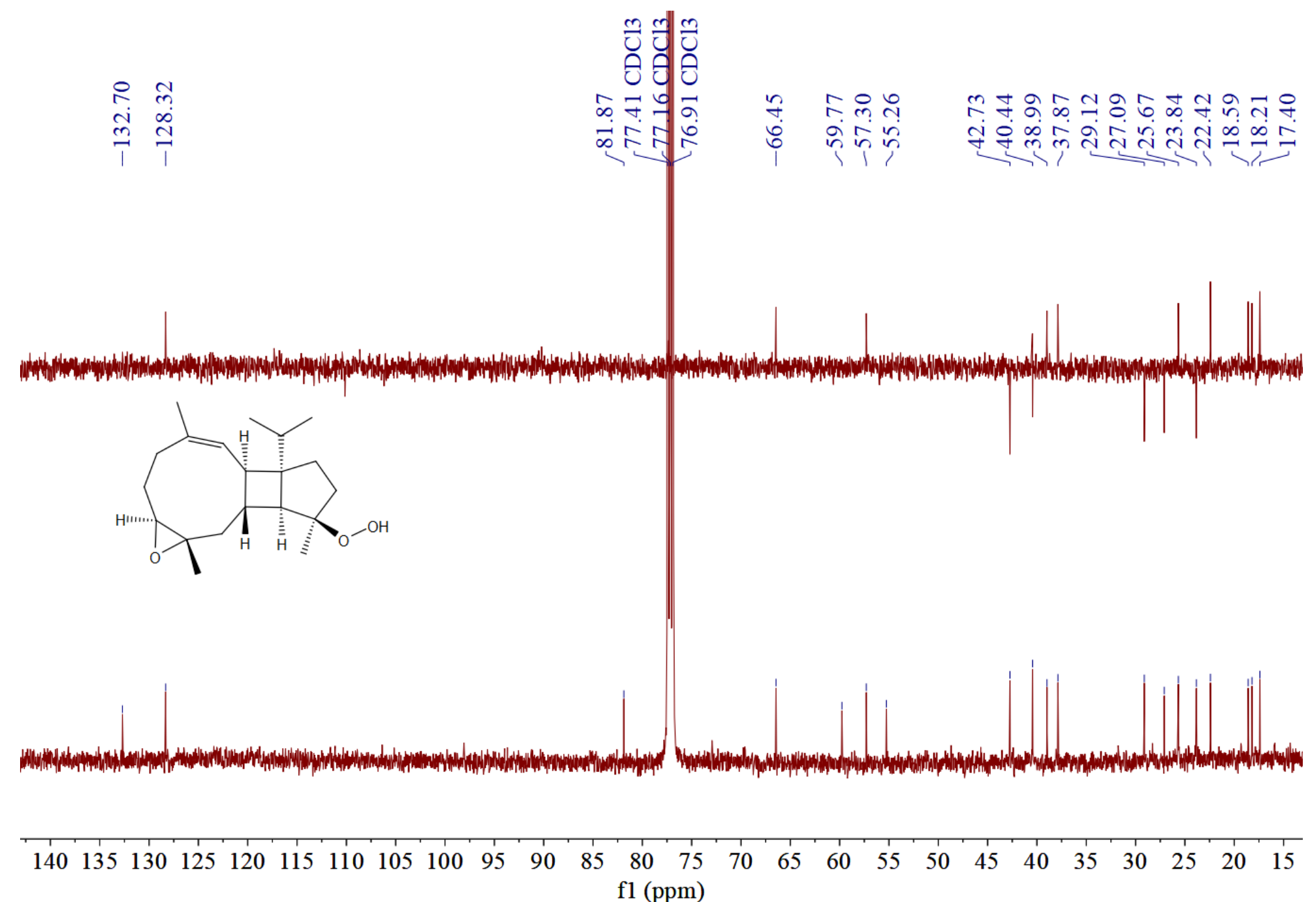

Figure S44. ${ }^{13} \mathrm{C}\left\{{ }^{1} \mathrm{H}\right\}$ NMR and DEPT spectrum $(125 \mathrm{MHz})$ of compound $\mathbf{6}$ in $\mathrm{CDCl}_{3}$ 


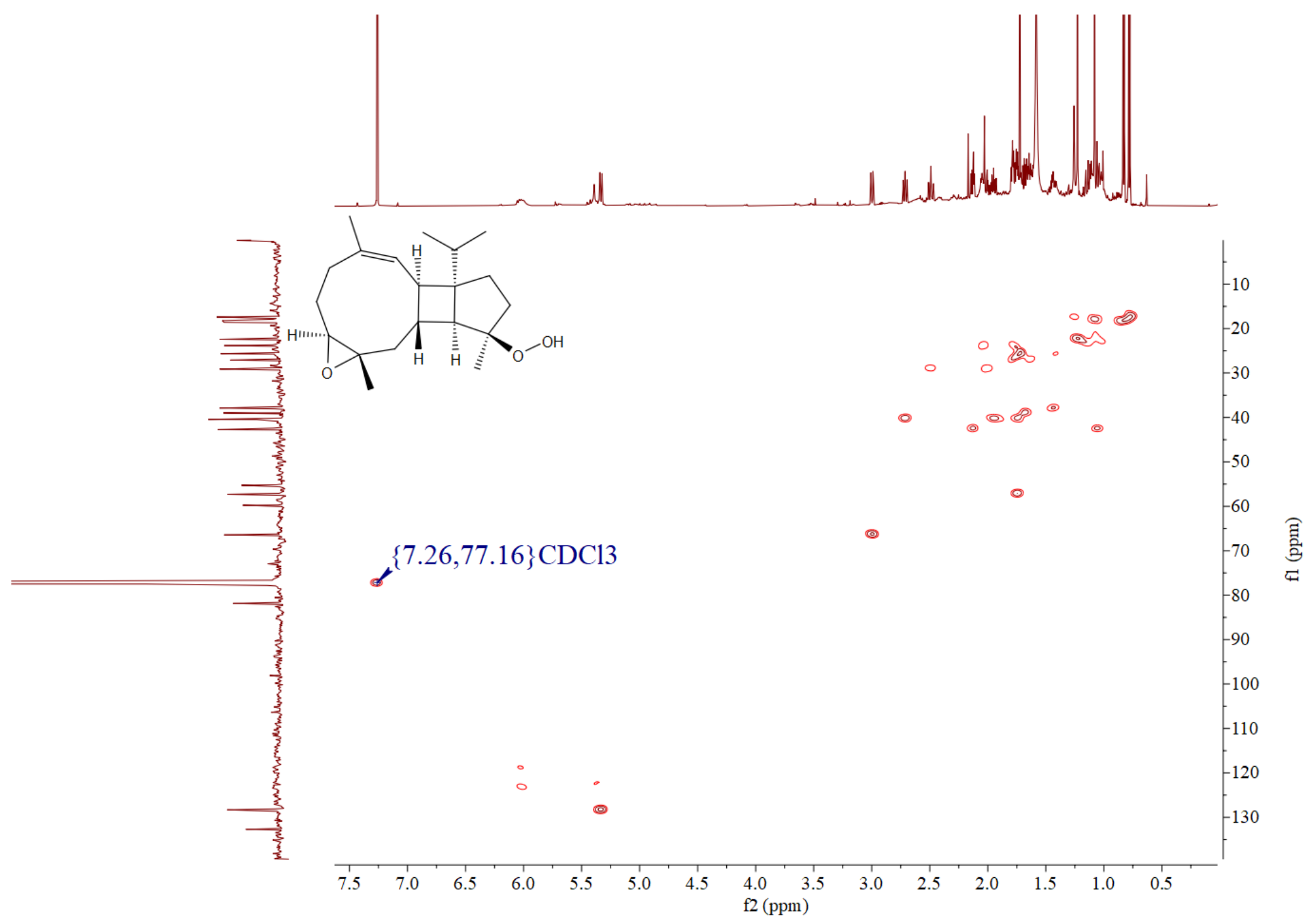

Figure S45. HSQC spectrum (500 MHz) of compound 6 in $\mathrm{CDCl}_{3}$ 


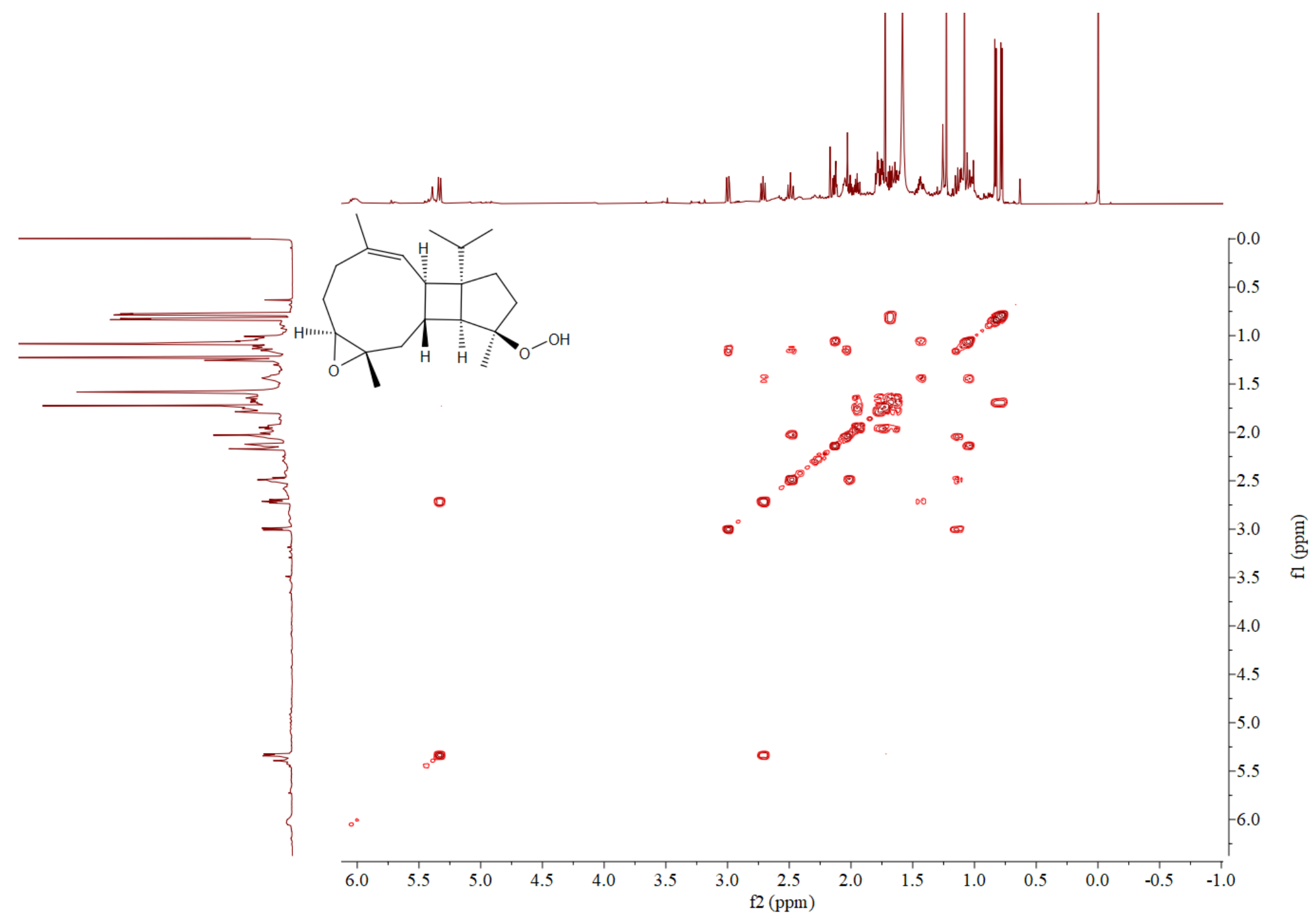

Figure S46. ${ }^{1} \mathrm{H}^{1}{ }^{1} \mathrm{H}$ COSY spectrum $(500 \mathrm{MHz})$ of compound 6 in $\mathrm{CDCl}_{3}$ 


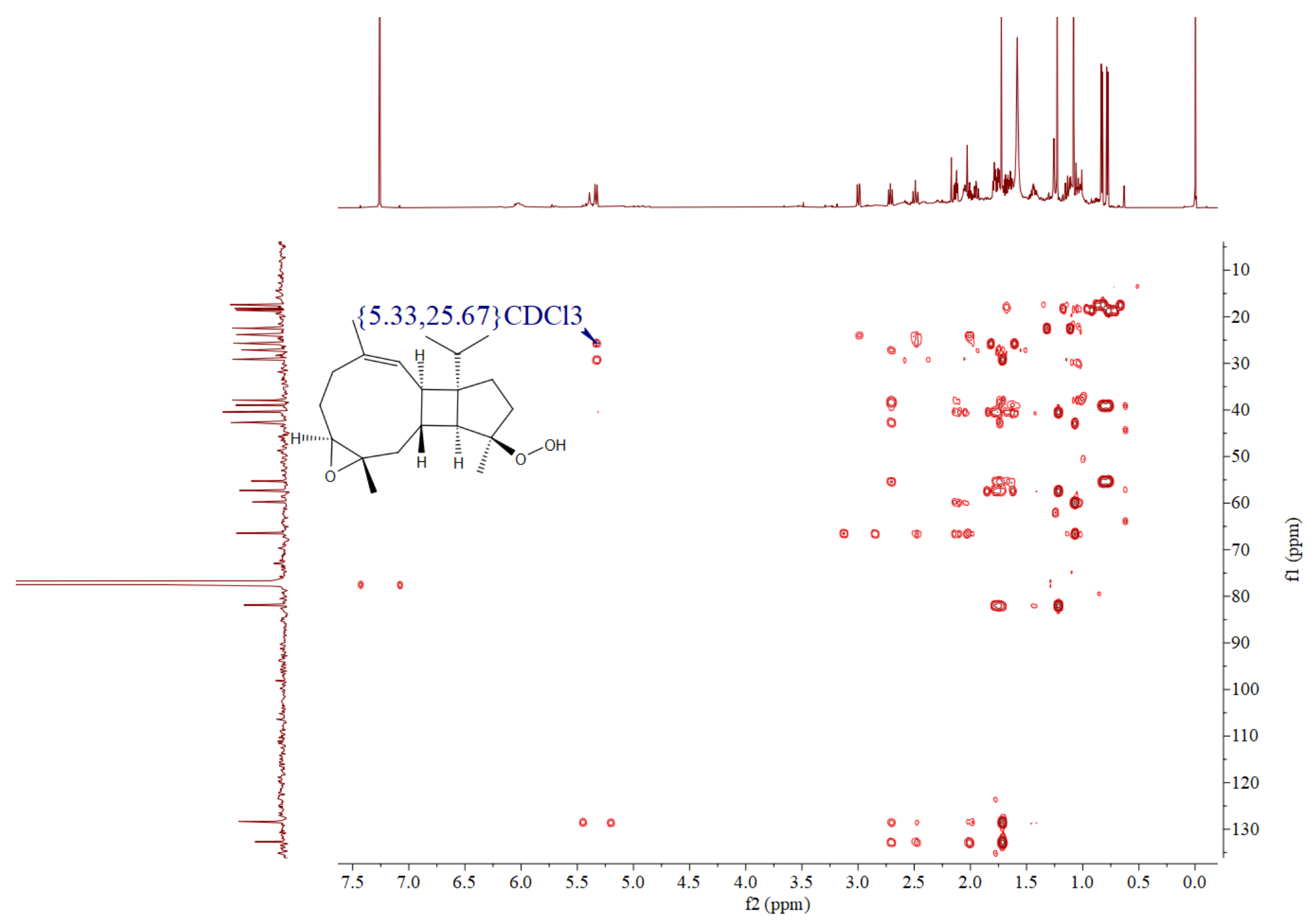

Figure S47. HMBC spectrum (500 MHz) of compound 6 in $\mathrm{CDCl}_{3}$ 


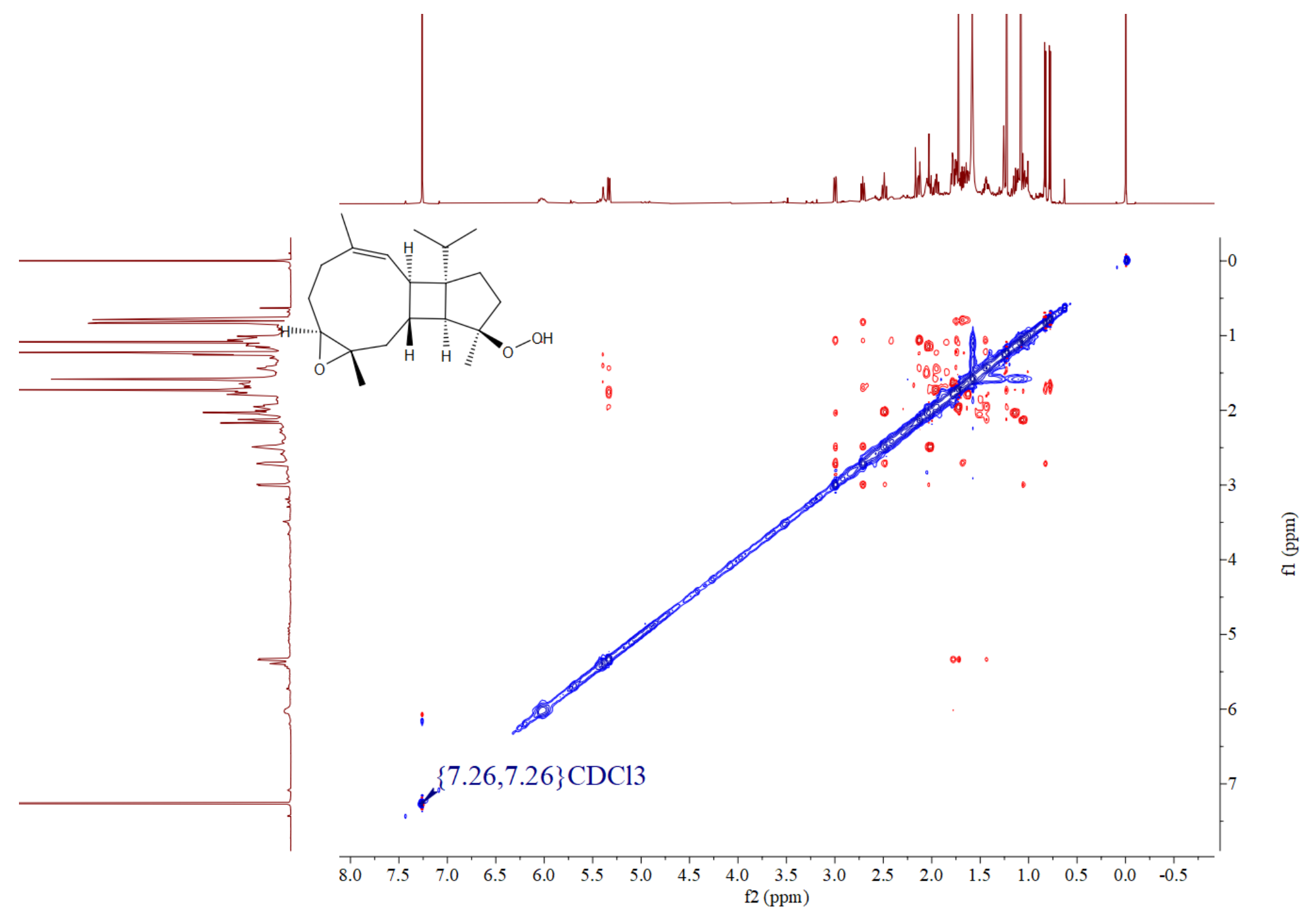

Figure S48. NOESY spectrum $(500 \mathrm{MHz})$ of compound 6 in $\mathrm{CDCl}_{3}$ 


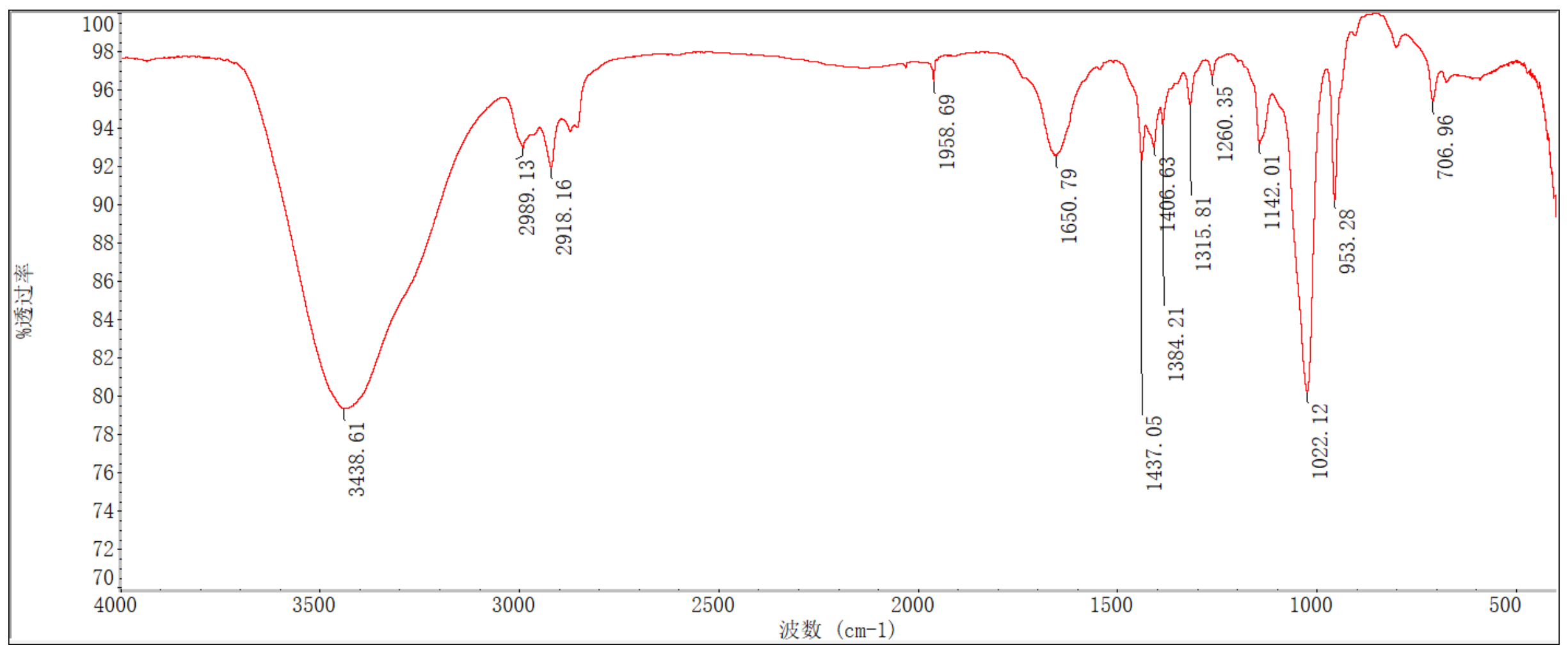

Figure S49. IR spectrum of compound 6 
Qualitative Analysis Report

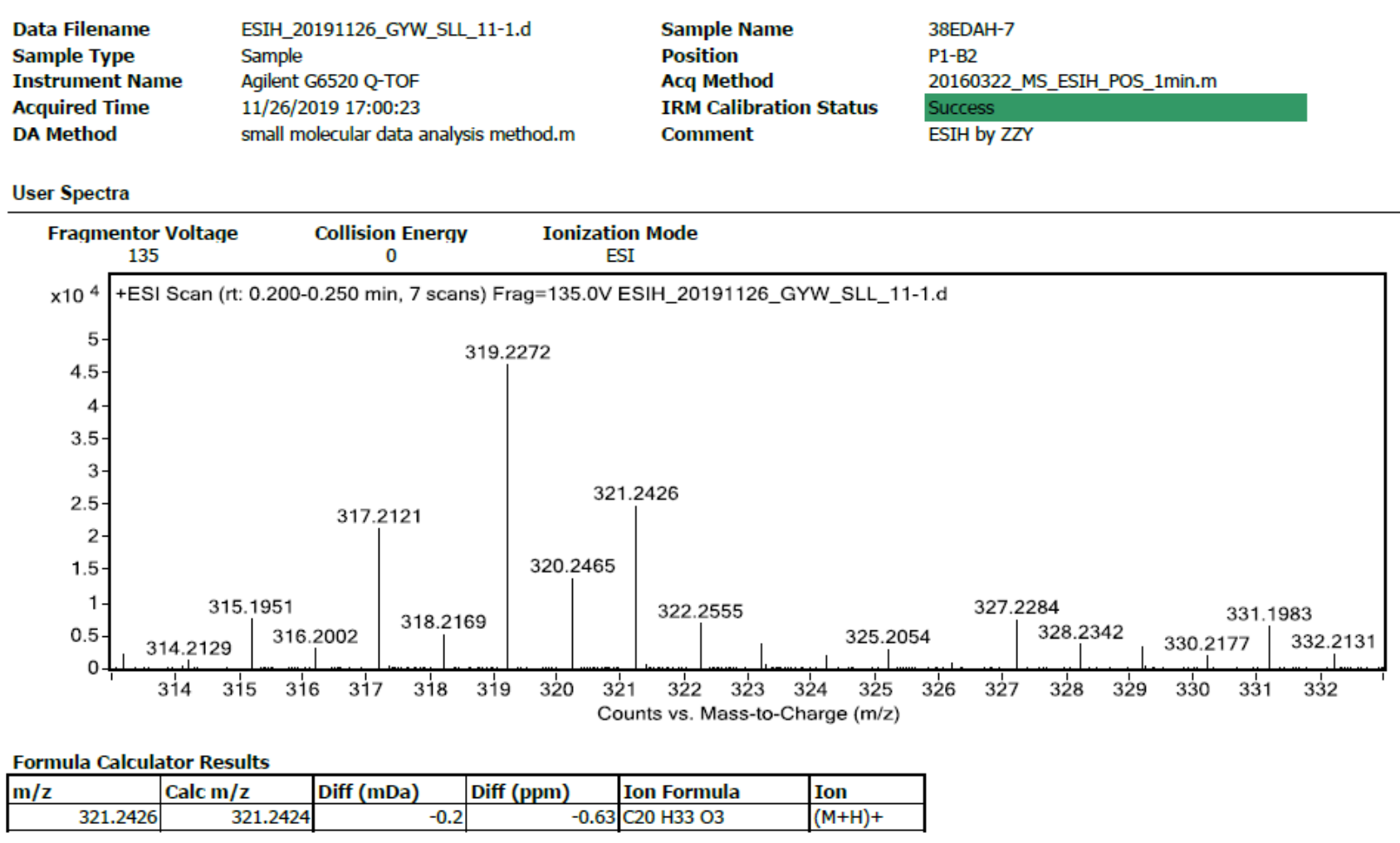

--- End Of Report ---

Figure S50. HRESIMS spectrum of compound $\mathbf{6}$ 
2. 1D NMR spectra of compounds 7,8

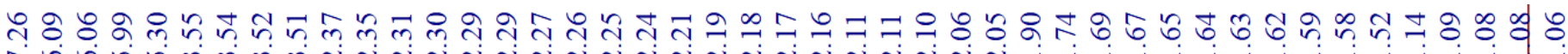
ली
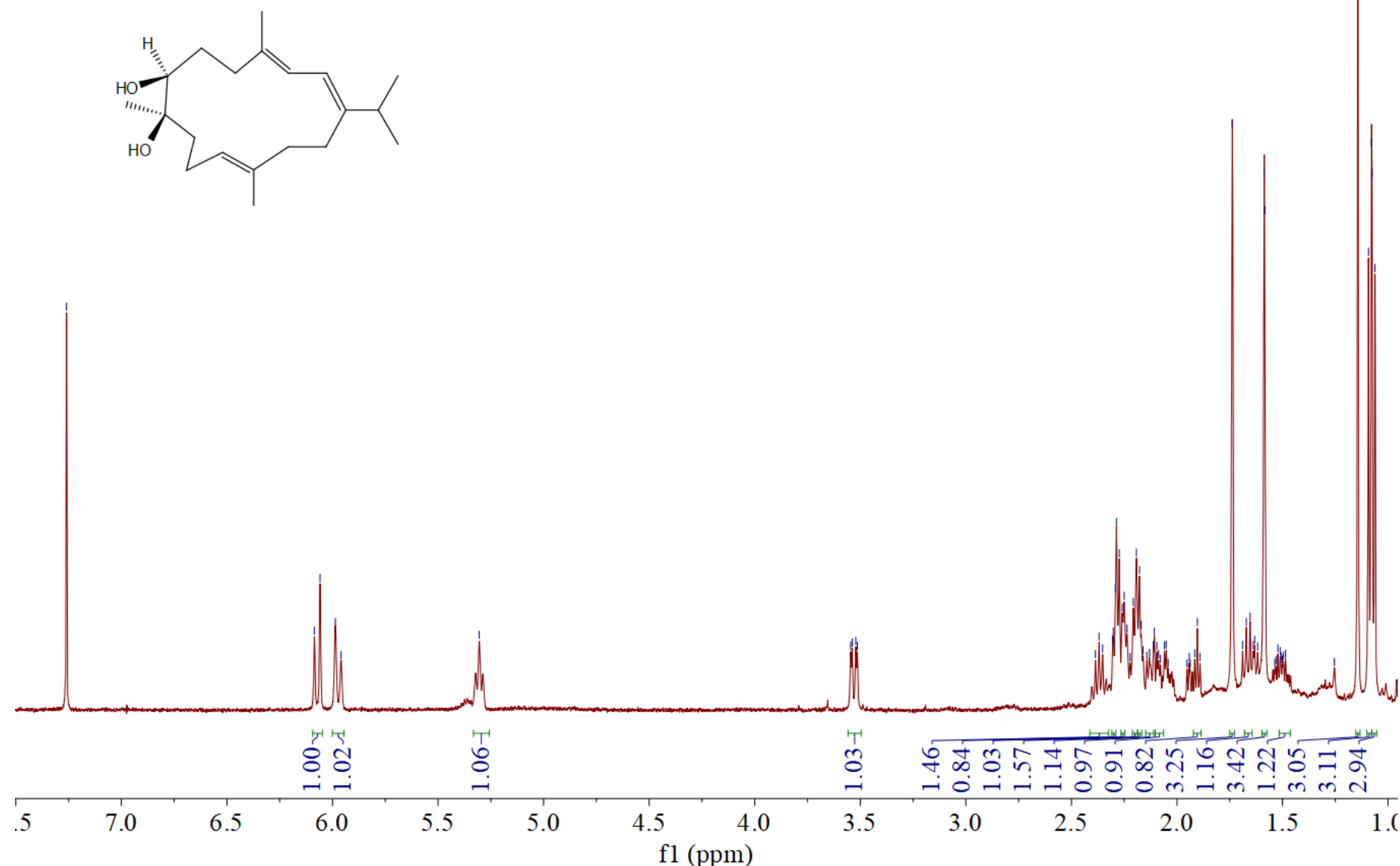

Figure S51. ${ }^{1} \mathrm{H}$ NMR spectrum (400 MHz) of compound 7 in $\mathrm{CDCl}_{3}$ 


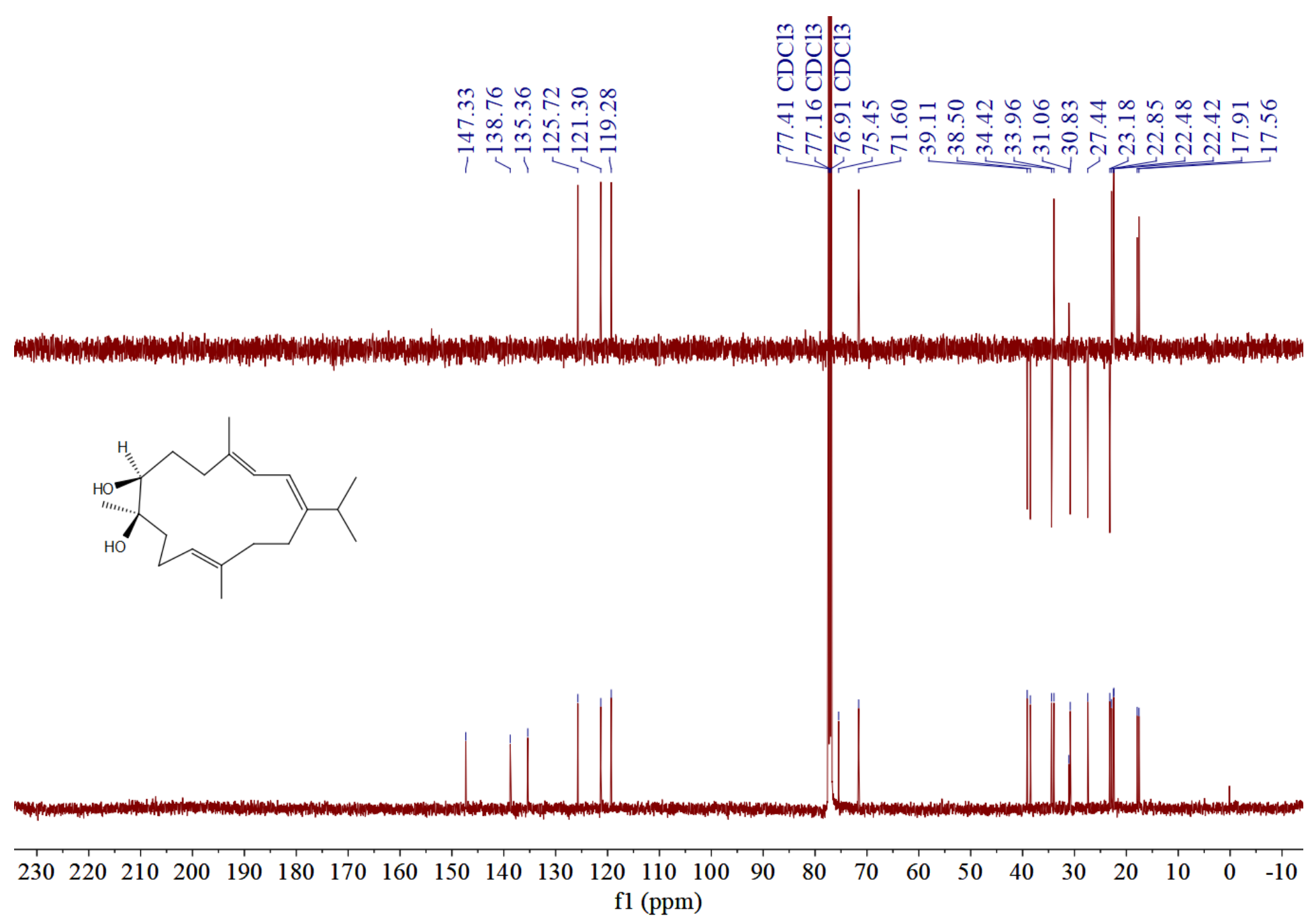

Figure S52. ${ }^{13} \mathrm{C}\left\{{ }^{1} \mathrm{H}\right\}$ NMR and DEPT spectrum $(125 \mathrm{MHz})$ of compound 7 in $\mathrm{CDCl}_{3}$ 


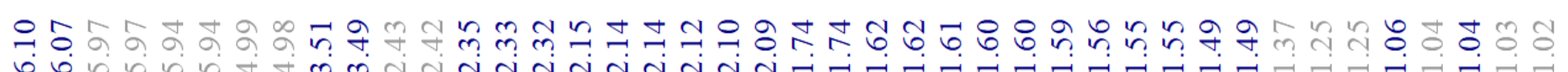
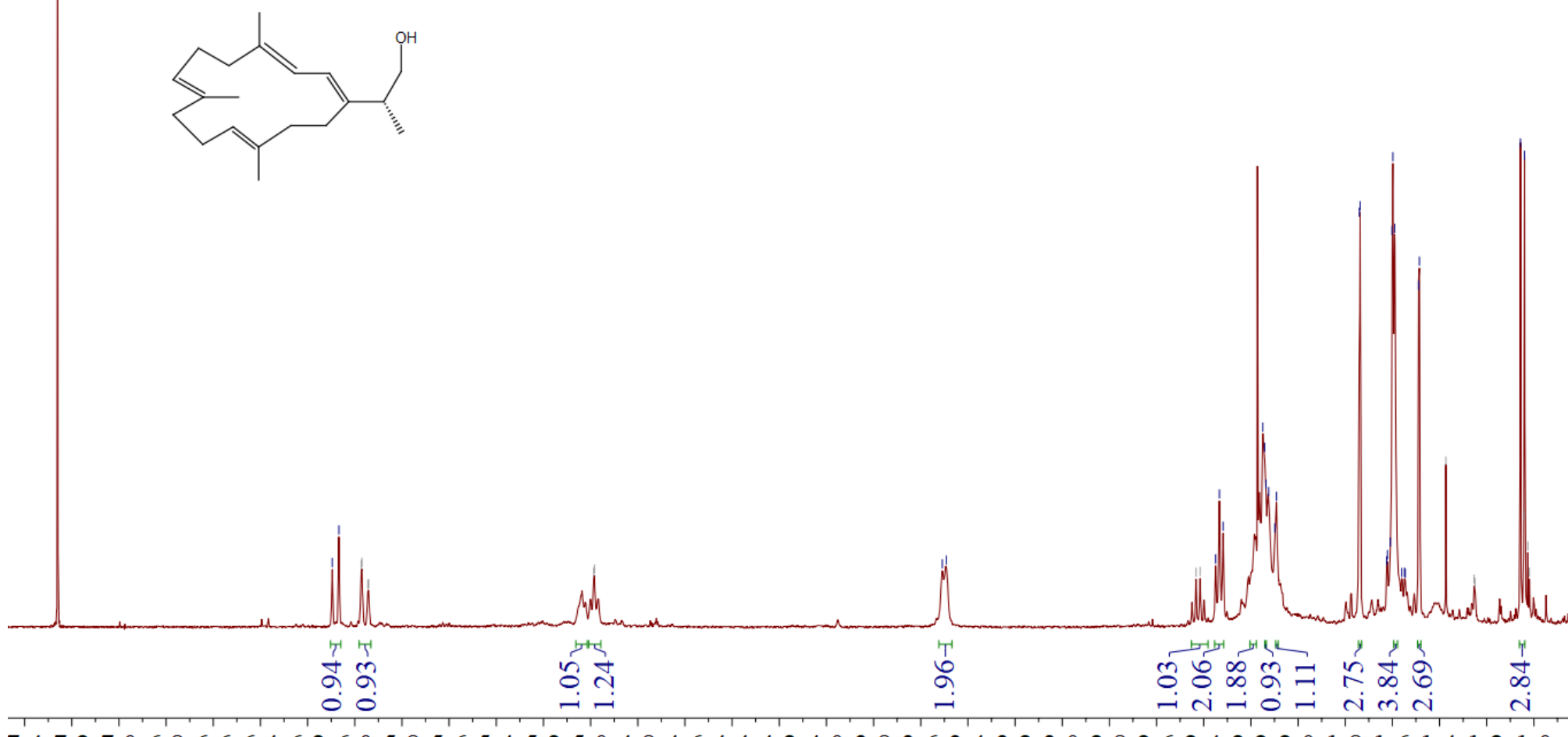

7.4 7.2 7.0 6.8 6.6 6.4 6.2 6.0 5.8 5.6 5.4 5.2 5.0 4.8 4.6 4.4 4.2 4.0 3.8 3.6 3.4 3.2 3.0 2.8 2.6 2.4 2.2 2.01 .81 .61 .41 .21 .0 f1 (ppm)

Figure S53. ${ }^{1} \mathrm{H}$ NMR spectrum $(400 \mathrm{MHz})$ of compound 8 in $\mathrm{CDCl}_{3}$ 

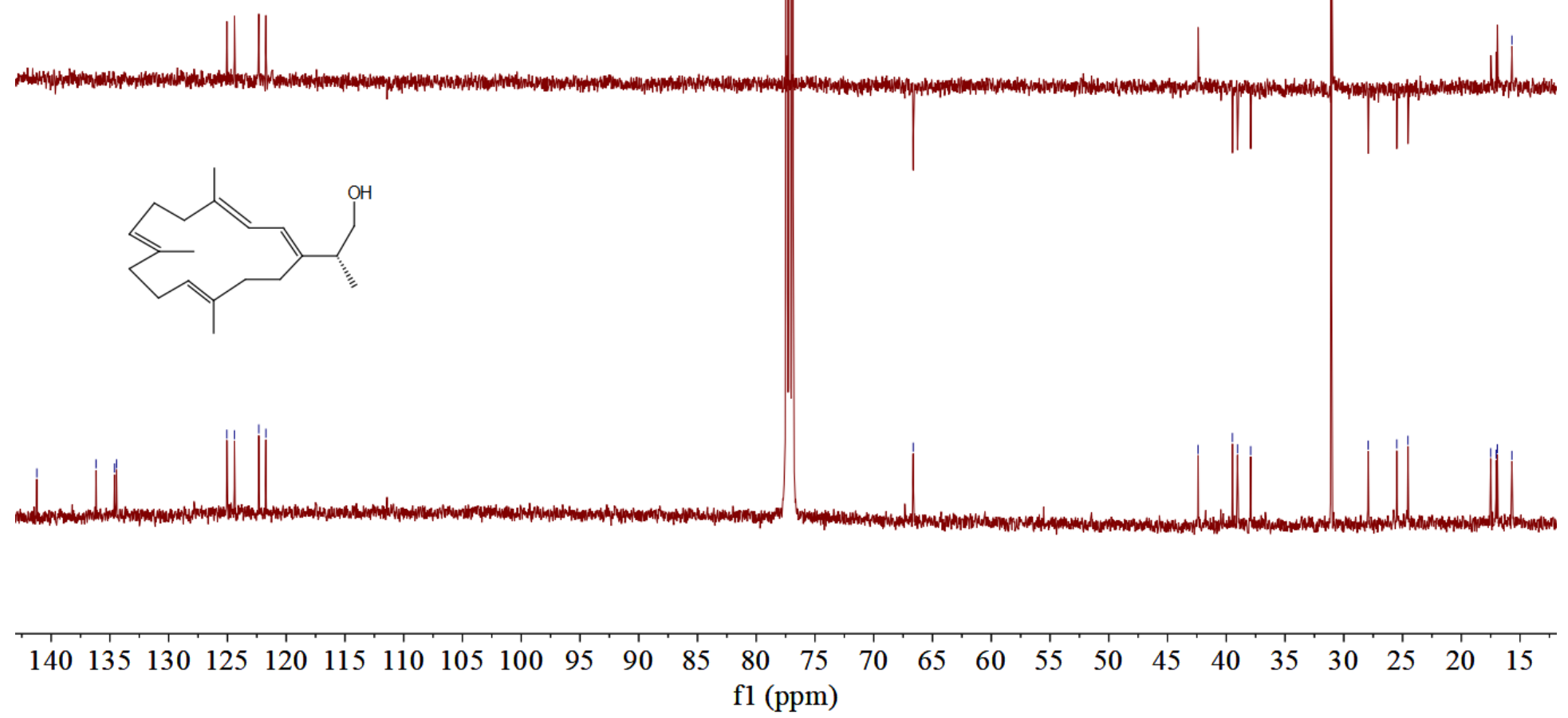

Figure S54. ${ }^{13} \mathrm{C}\left\{{ }^{1} \mathrm{H}\right\}$ NMR and DEPT spectrum $(150 \mathrm{MHz})$ of compound 8 in $\mathrm{CDCl}_{3}$ 
3. The ${ }^{13} \mathrm{C}\left\{{ }^{1} \mathrm{H}\right\}$ NMR and DEPT spectra of known compounds 9-14

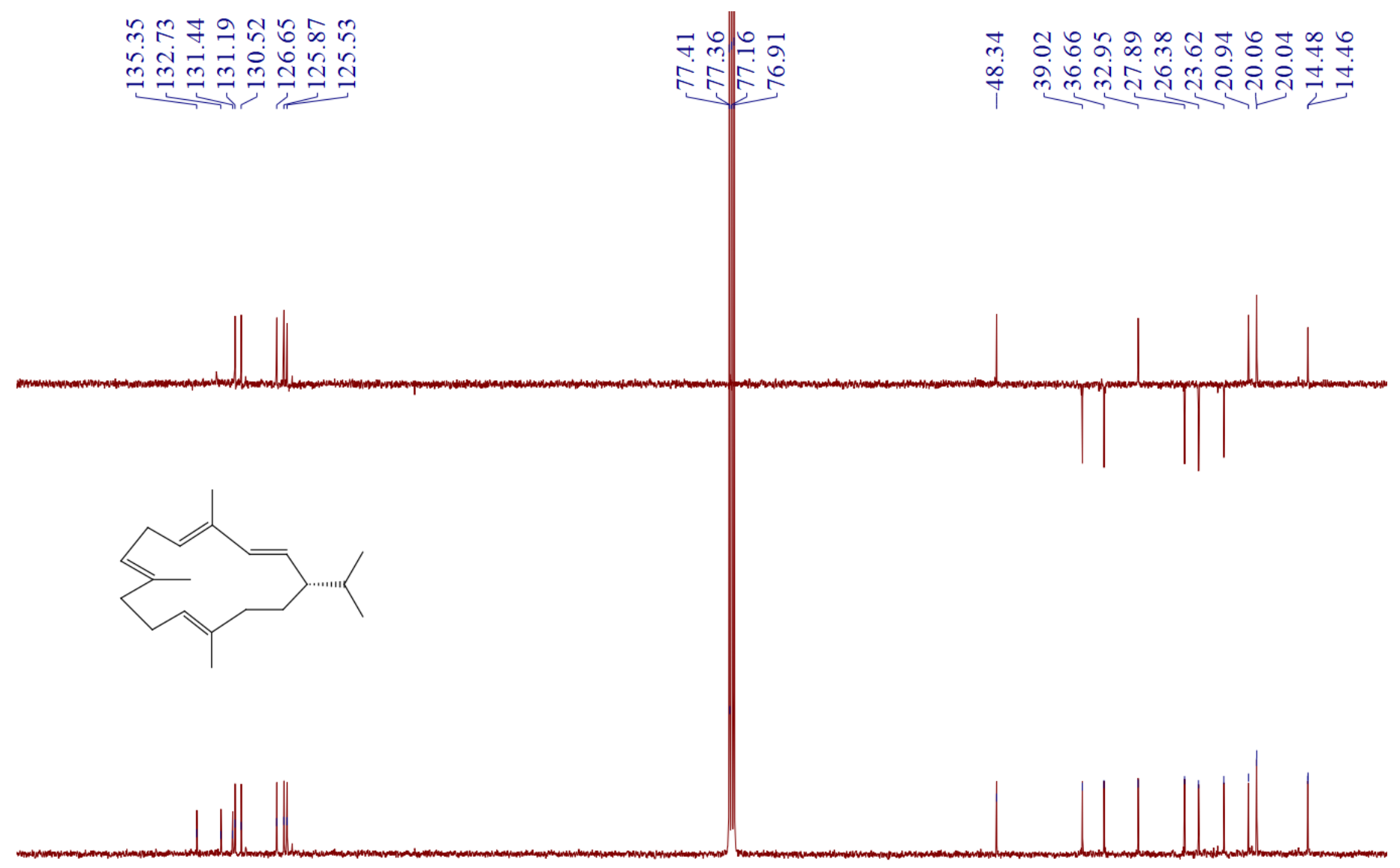

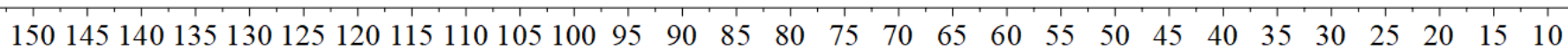
fl (ppm)

Figure S55. ${ }^{13} \mathrm{C}\left\{{ }^{1} \mathrm{H}\right\}$ NMR and DEPT spectrum $(125 \mathrm{MHz})$ of compound 9 in $\mathrm{CDCl}_{3}$ 


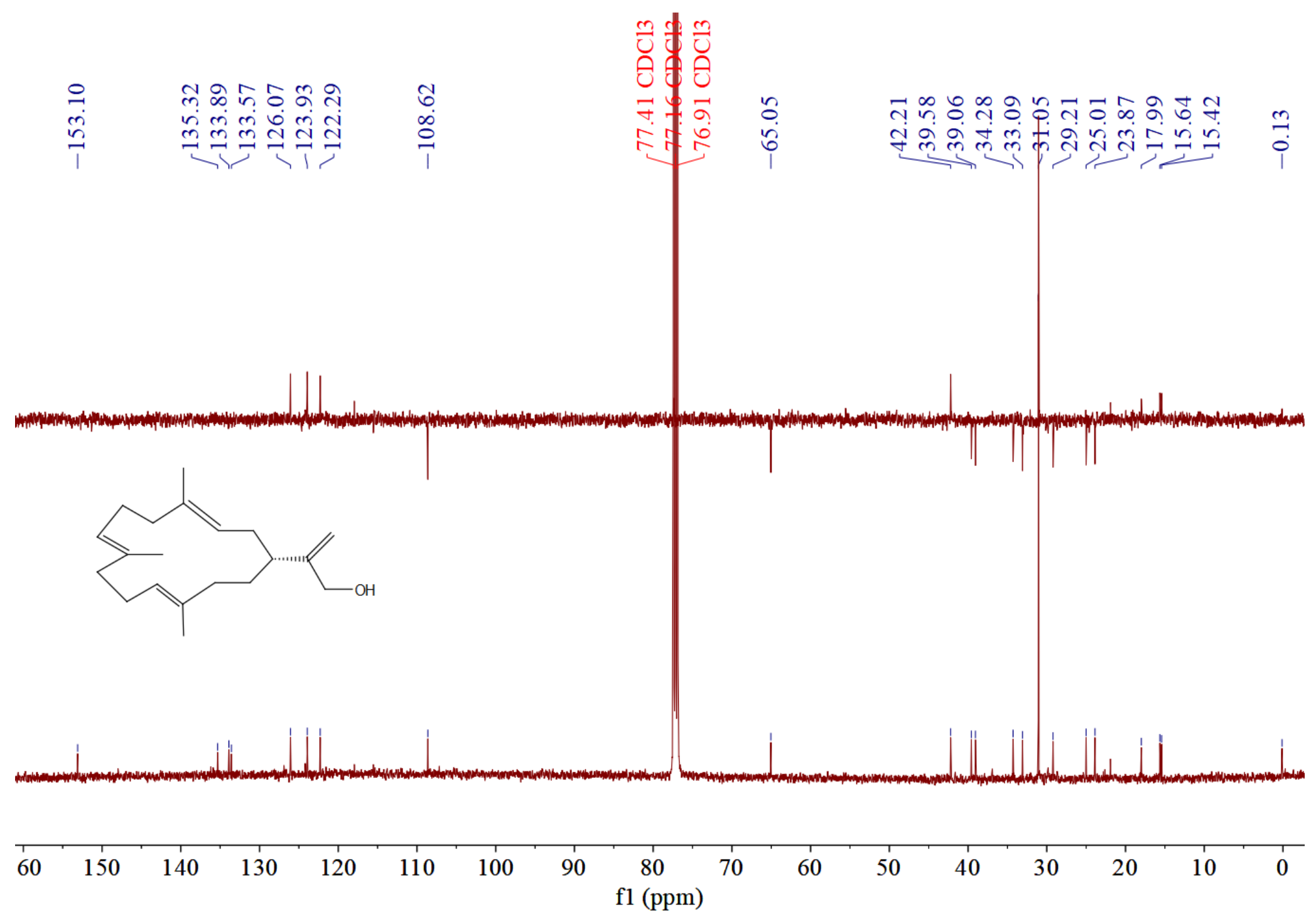

Figure S56. ${ }^{13} \mathrm{C}\left\{{ }^{1} \mathrm{H}\right\}$ NMR and DEPT spectrum $(125 \mathrm{MHz})$ of compound $\mathbf{1 0}$ in $\mathrm{CDCl}_{3}$ 


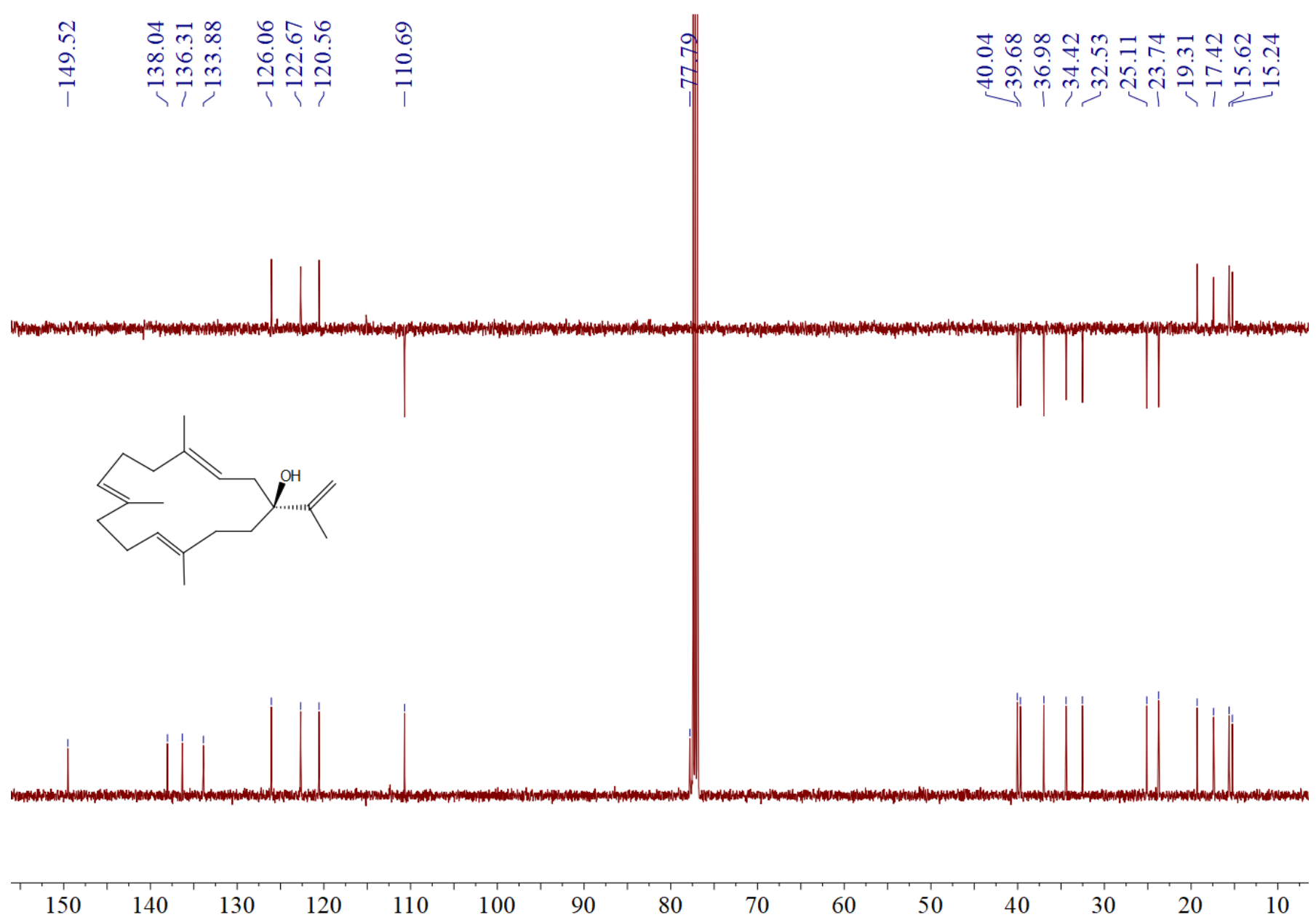

Figure S57. ${ }^{13} \mathrm{C}\left\{{ }^{1} \mathrm{H}\right\}$ NMR and DEPT spectrum $(125 \mathrm{MHz})$ of compound 11 in $\mathrm{CDCl}_{3}$ 


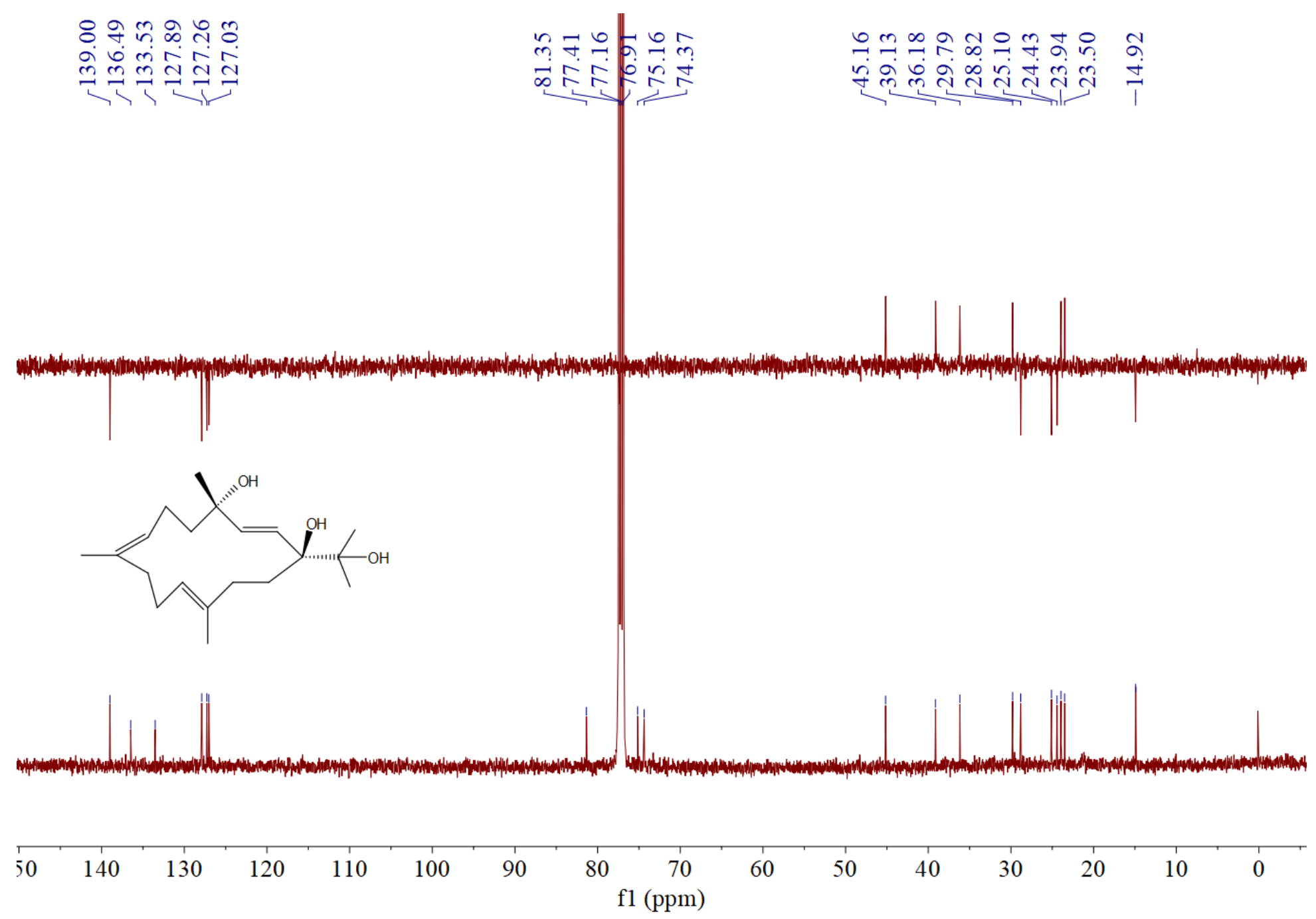

Figure S58. ${ }^{13} \mathrm{C}\left\{{ }^{1} \mathrm{H}\right\}$ NMR and DEPT spectrum (125 MHz) of compound $\mathbf{1 3}$ in $\mathrm{CDCl}_{3}$ 


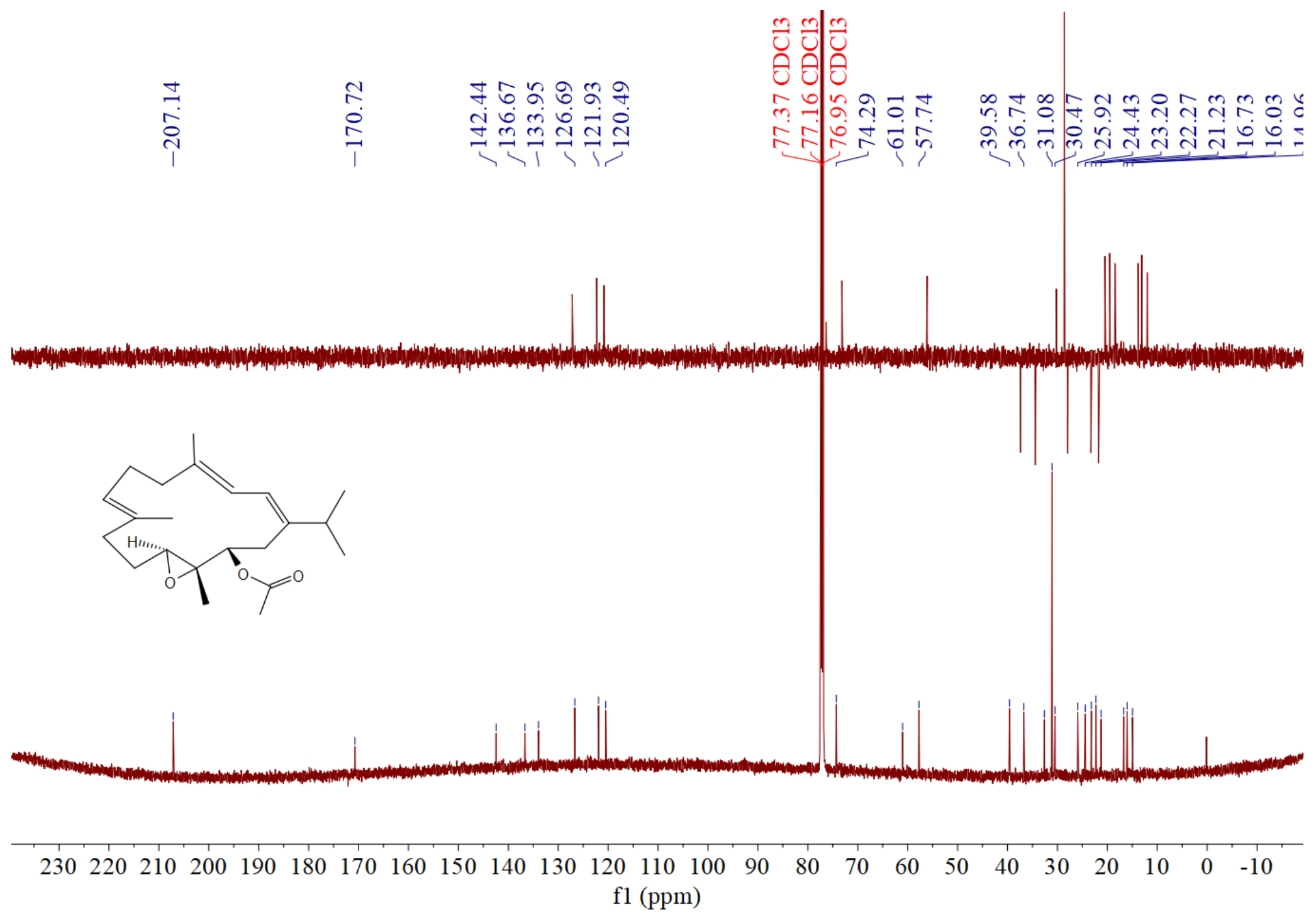

Figure S59. ${ }^{13} \mathrm{C}\left\{{ }^{1} \mathrm{H}\right\}$ NMR and DEPT spectrum $(150 \mathrm{MHz})$ of compound 14 in $\mathrm{CDCl}_{3}$ 


\section{Chemical Reaction Section}

\subsection{Absolute configuration determination of compound 2}

The determination of the absolute stereochemistry of $\mathbf{2}$ is worth discussing. To confirm it, following chemical reactions were carried out. Compound 2 was reacted with 2methoxypropene in the presence of pyridinium 4-toluenesulfonate (PPTS) in $\mathrm{CH}_{2} \mathrm{Cl}_{2}$ to afford the dioxolane 2a. The NOESY experiment could then be conducted to determine the $\mathrm{RC}$ of $\mathrm{C}-7$ and $\mathrm{C}-8$ due to the rigid nature of the five-membered ring in $2 \mathbf{a}$. The clear NOE correlations between $\mathrm{H}-7\left(\delta_{\mathrm{H}} 3.82\right)$ and $\mathrm{H}_{3}-19\left(\delta_{\mathrm{H}} 1.32\right)$ in $\mathbf{2 a}$, confirmed that the RC of two hydroxyls is cis, the same as that in 7, which not only further indicated the possible biogenetic relationship between 2 and 7, but also allowed the application of Snatzke's method to confirm the absolute configuration of the vicinal diol in 2.

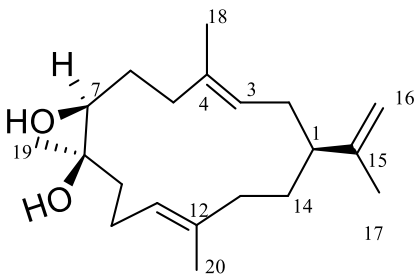

2

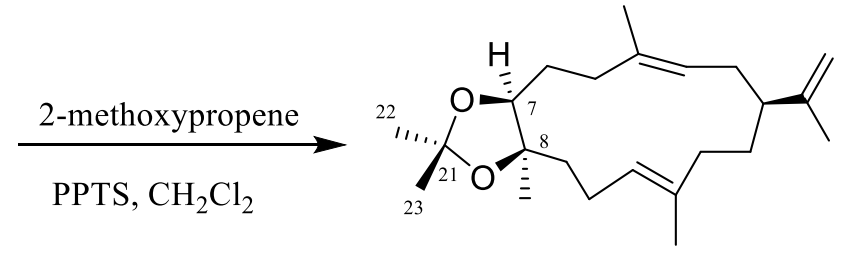

2a

Snatzke's method: $0.5 \mathrm{mg}$ compound 2 was added into anhydrous $1 \mathrm{ml}$ DMSO (c=0.5mg/ml). ECD spectrum of compound 2 in DMSO was measured. Another $0.5 \mathrm{mg}$ compound 2 was added into dry $1 \mathrm{ml} \mathrm{DMSO}(\mathrm{c}=0.5 \mathrm{mg} / \mathrm{ml}) .0 .5 \mathrm{mg} \mathrm{Mo}(\mathrm{AcO})_{4}$ was added into the solvent. The first ICD spectrum is recorded immediately after the mixing, and its time evolution is controlled with a rate of about one spectrum every 10 minutes, until a stationary ICD is reached. The absolute configuration of the 7,8-diol moiety in 2 was verified by $\mathrm{Mo}_{2}(\mathrm{OAc})_{4}$ induced circular dichroism (ICD) experiment developed by Snatzke and Frelek. The ICD spectrum of the Mo-complex for $\mathbf{2}$ showed an obvious sign of negative Cotton effect (CE) at 320-400 nm (bands II - IV), which originated solely from the chirality of the vicinal diol moiety by comparing the ICD with the CD spectrum of 2. Thus C-7 and C-8 were assigned as $7 R, 8 S$ configuration based on the empirical rule. 
Compound 2a: colorless oil; ${ }^{1} \mathrm{H},{ }^{13} \mathrm{C}\left\{{ }^{1} \mathrm{H}\right\}$ NMR and DEPT spectroscopic data, see Table S1; HR-EI-MS m/z 346.2866 [M]+ (calcd for $\mathrm{C}_{23} \mathrm{H}_{38} \mathrm{O}_{2}, 346.2866$ ).

Table S1. ${ }^{1} \mathrm{H},{ }^{13} \mathrm{C}\left\{{ }^{1} \mathrm{H}\right\}$ NMR and DEPT spectroscopic data of compounds $\mathbf{2 a}$ in $\mathrm{CDCl}_{3}{ }^{\mathrm{a}}$

\begin{tabular}{ccc}
\hline Position & \multicolumn{2}{c}{ 2a } \\
\cline { 2 - 3 } & $\delta_{\mathrm{H}}(\mathrm{J}$ in Hz$)$ & $\delta_{\mathrm{C}, \mathrm{type}}$ \\
\hline 1 & $1.93, \mathrm{~m}$ & $47.0, \mathrm{~d}$ \\
2 & $2.10, \mathrm{~m}$ & $31.4, \mathrm{t}$ \\
3 & $5.24, \mathrm{t}(7.22)$ & $124.3, \mathrm{~d}$ \\
4 & & $136.6, \mathrm{~s}$ \\
$5 \mathrm{a}$ & $2.18, \mathrm{~m}$ & $34.9, \mathrm{t}$ \\
$5 \mathrm{~b}$ & $1.90, \mathrm{~m}$ & \\
$6 \mathrm{a}$ & $1.88, \mathrm{~m}$ & $30.7, \mathrm{t}$ \\
$6 \mathrm{~b}$ & $1.58, \mathrm{~m}$ & \\
7 & $3.82, \mathrm{dd}(7.63,6.38)$ & $83.4, \mathrm{~d}$ \\
8 & & $83.3, \mathrm{~s}$ \\
$9 \mathrm{a}$ & $1.74, \mathrm{~m}$ & $36.7, \mathrm{t}$ \\
$9 \mathrm{~b}$ & $1.60, \mathrm{~m}$ & \\
10 & $2.14, \mathrm{~m}$ & $22.7, \mathrm{t}$ \\
11 & $5.14, \mathrm{t}(7.33)$ & $126.0, \mathrm{~d}$ \\
12 & & $135.8, \mathrm{~s}$ \\
13 & $2.02, \mathrm{~m}$ & $36.6, \mathrm{t}$ \\
14 & $2.08, \mathrm{~m}$ & $32.2, \mathrm{t}$ \\
15 & & $149.6, \mathrm{~s}$ \\
16 & & $109.9, \mathrm{t}$ \\
17 & $1.71, \mathrm{~s}$ & $20.0, \mathrm{q}$ \\
18 & $1.65, \mathrm{~s}$ & $16.7, \mathrm{q}$ \\
19 & $1.32, \mathrm{~s}$ & $26.9, \mathrm{q}$ \\
20 & $1.62, \mathrm{~s}$ & $17.9, \mathrm{q}$ \\
21 & & $106.8, \mathrm{~s}$ \\
22 & $1.40, \mathrm{~s}$ & $27.6, \mathrm{q}$ \\
23 & $1.44, \mathrm{~s}$ & $28.7, \mathrm{q}$ \\
\hline
\end{tabular}

${ }^{\text {aRecorded at }} 600$ and $125 \mathrm{MHz}$ for ${ }^{1} \mathrm{H},{ }^{13} \mathrm{C}\left\{{ }^{1} \mathrm{H}\right\}$ NMR and DEPT spectrum, respectively. Assignments were deduced by analysis of $1 \mathrm{D}$ and 2D NMR spectra. 


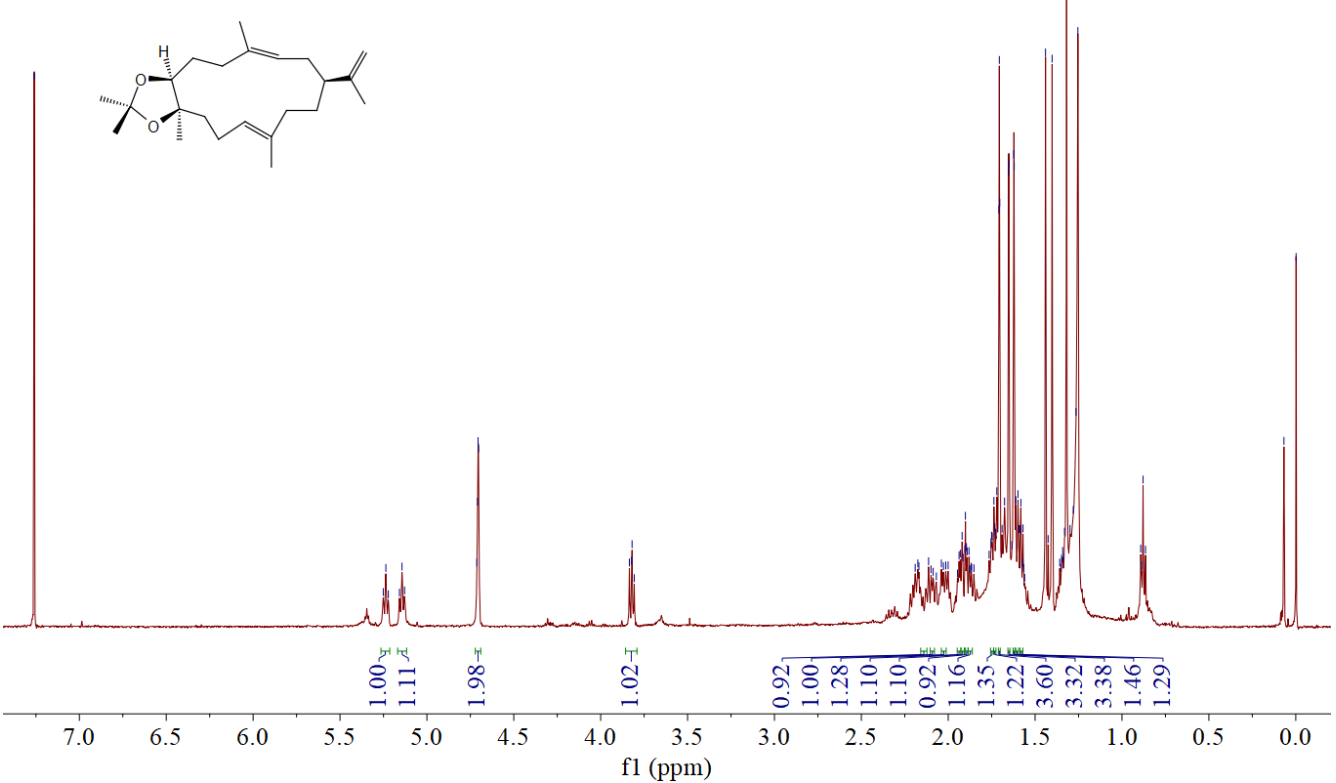

Figure S60. ${ }^{1} \mathrm{H}$ NMR spectrum $(600 \mathrm{MHz})$ of compound 2a in $\mathrm{CDCl}_{3}$
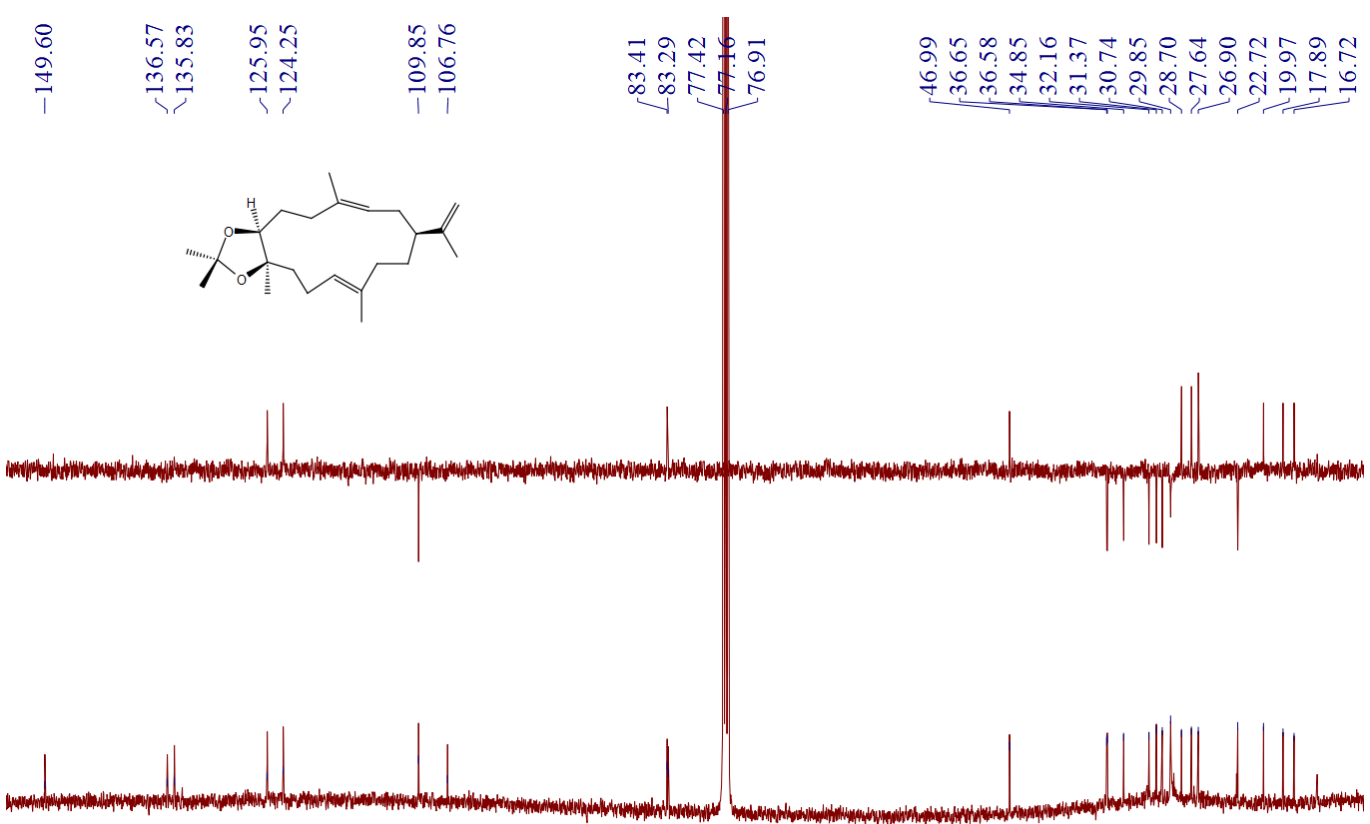

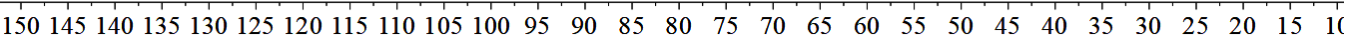
f1 (ppm)

Figure S61. ${ }^{13} \mathrm{C}\left\{{ }^{1} \mathrm{H}\right\}$ NMR and DEPT spectrum (125 MHz) of compound 2a in $\mathrm{CDCl}_{3}$ 


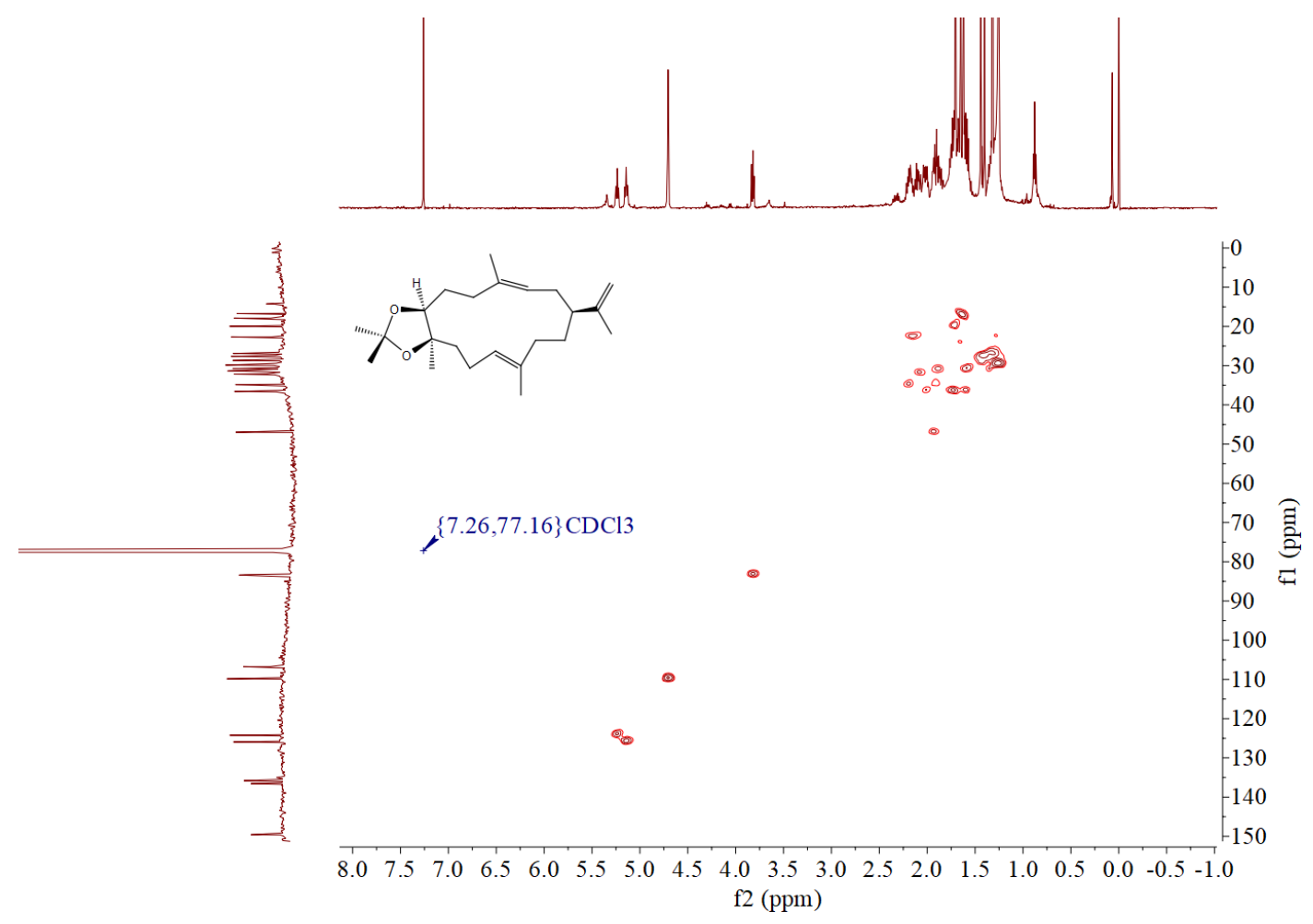

Figure S62. HSQC spectrum (500 MHz) of compound 2a in $\mathrm{CDCl}_{3}$

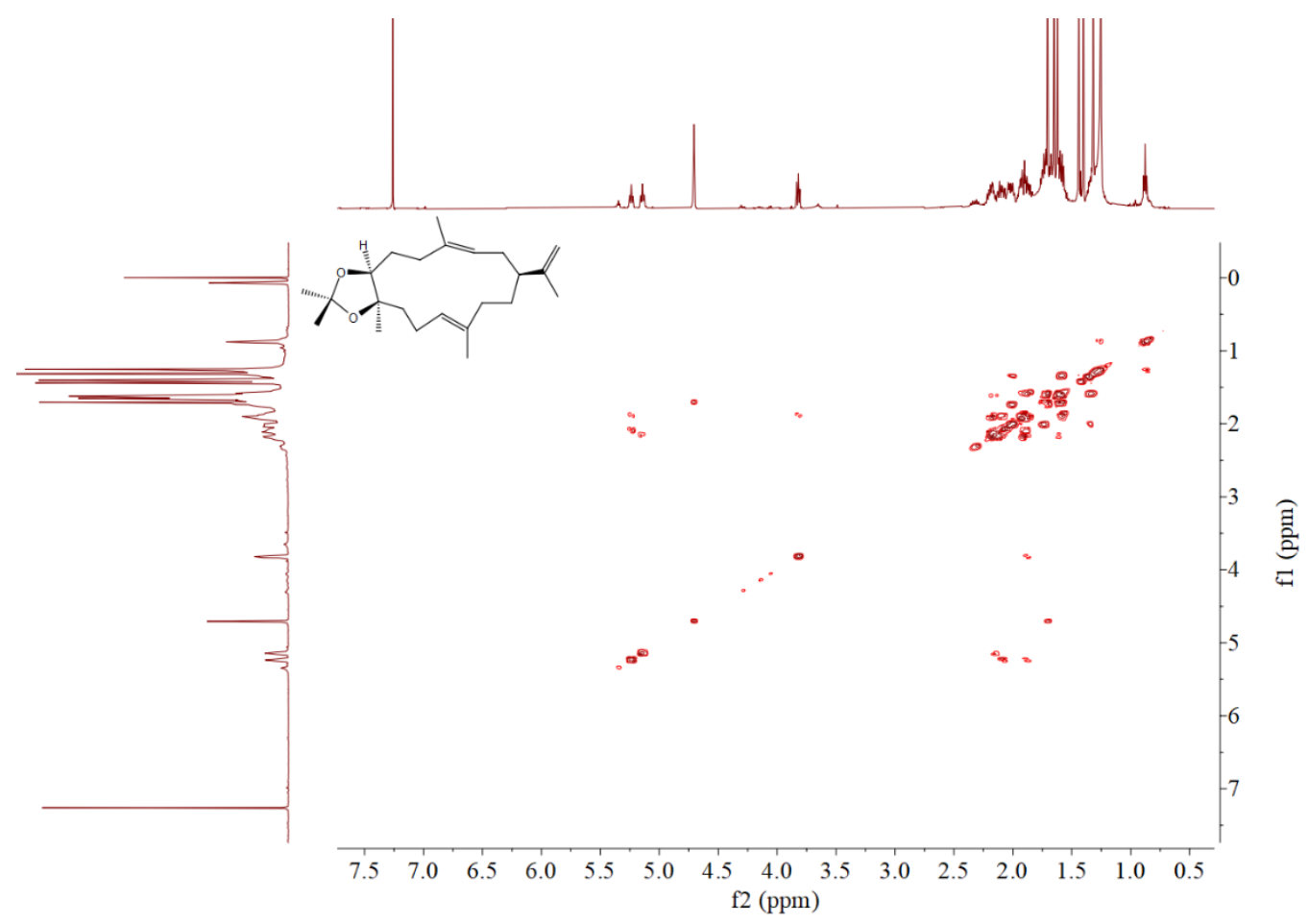

Figure S63. ${ }^{1} \mathrm{H}-{ }^{1} \mathrm{H}$ COSY spectrum $(500 \mathrm{MHz})$ of compound 2a in $\mathrm{CDCl}_{3}$ 


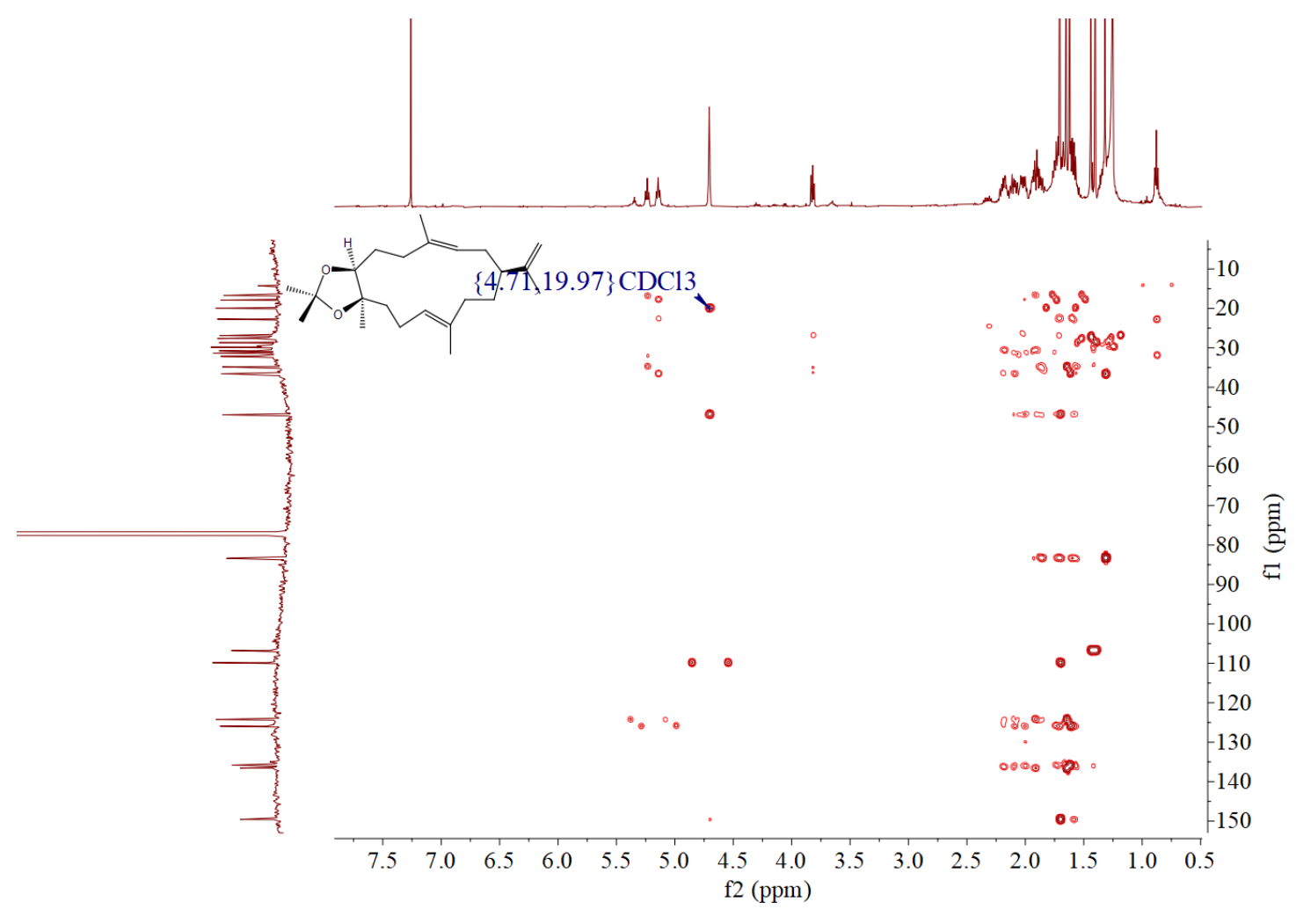

Figure S64. HMBC spectrum (500 MHz) of compound 2a in $\mathrm{CDCl}_{3}$

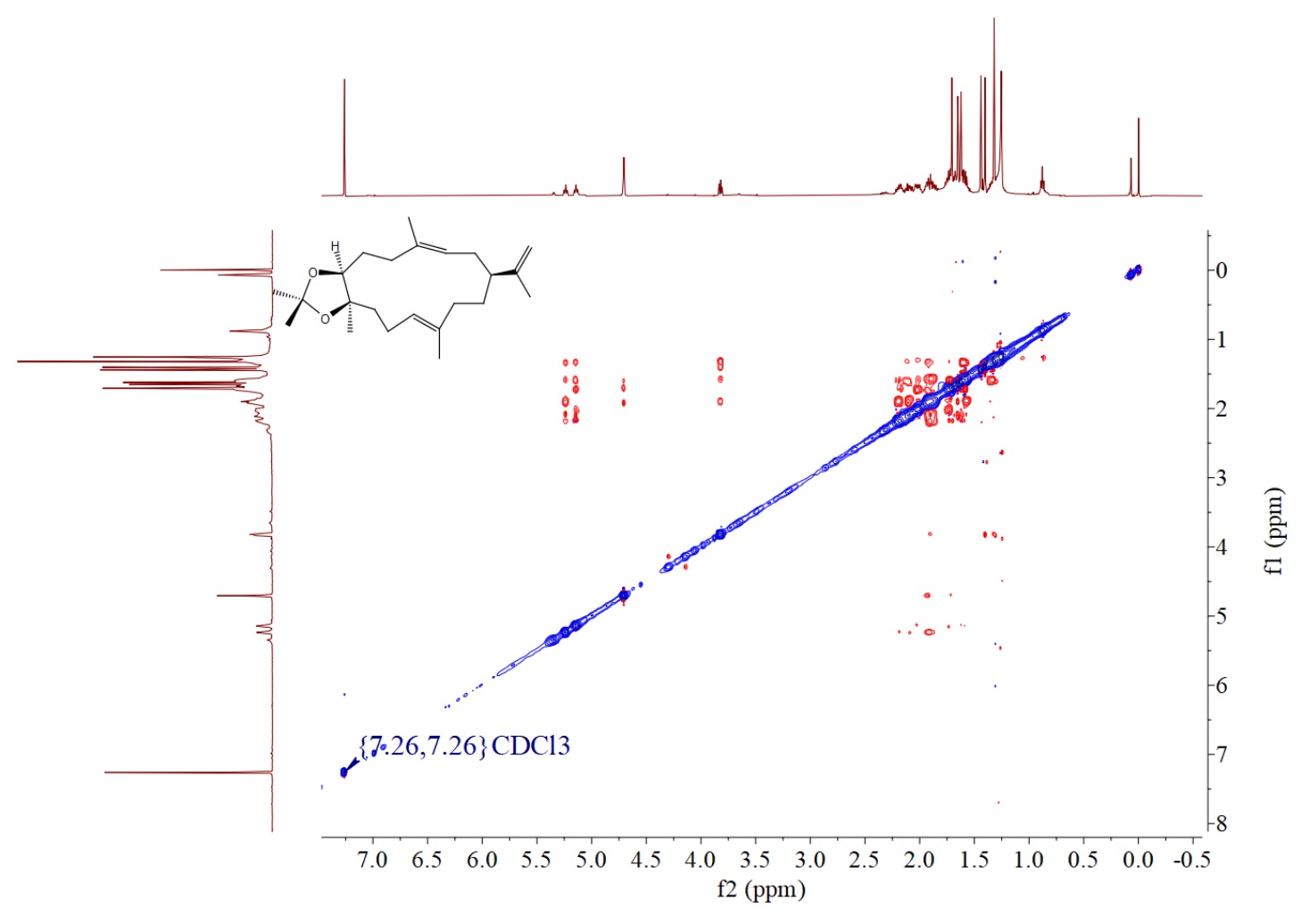

Figure S65. NOESY spectrum (500 MHz) of compound 2a in $\mathrm{CDCl}_{3}$ 


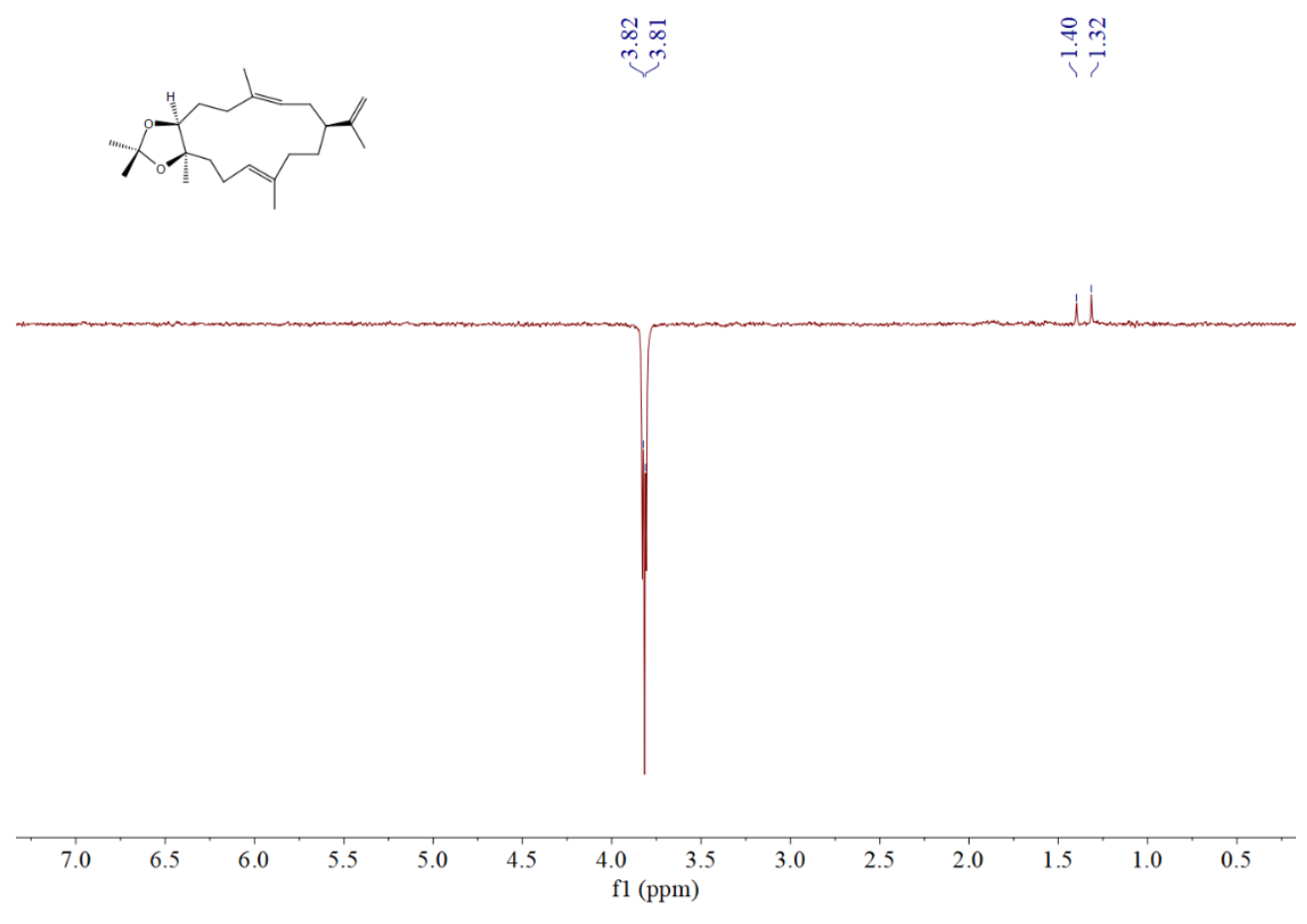

Figure S66. 1D-NOE spectrum $(500 \mathrm{MHz})$ of compound 2a in $\mathrm{CDCl}_{3}$

\section{Stereochemistry Section}

\subsection{DP4+ calculations of compounds 1-6}

\subsubsection{Computational details}

All calculations were done following the general protocols previously described for DP4+. Conformational searches were done using de Macrocycle Conformational Sampling protocol in gas phase using the torsional sampling (MCMM) method and OPLS_2005 force field (as implemented in Macromodel). The constrained calculations were done by keeping only the suitable conformations (that is, those conformations showing dihedral angles in agreement with the experimental ${ }^{3} J_{\mathrm{HH}}$ values). All conformers within $21 \mathrm{~kJ} / \mathrm{mol}$ of the lowest energy conformer were subjected to NMR calculations. DFT calculations were performed using Gaussian 09. Structure optimizations were done at the B3LYP/6-31G(d,p) level of theory. Magnetic shielding constants $(\sigma)$ were calculated by means of the gauge including atomic orbitals (GIAO) method, currently the most widely used to solve the gauge origin problem, at the mPW1PW91/6-31+G(d) level of theory as recommended for DP4+. Finally, shielding constants were averaged over the Boltzmann distribution obtained for each stereoisomer and correlated with the experimental data. 


\subsubsection{Experimental NMR data of compounds 1-6}

Table S2. ${ }^{1} \mathrm{H},{ }^{13} \mathrm{C}\left\{{ }^{1} \mathrm{H}\right\}$ NMR and DEPT spectroscopic data of compounds 1-6

\begin{tabular}{|c|c|c|c|c|c|c|c|c|c|c|c|c|}
\hline \multirow{2}{*}{ No. } & \multicolumn{2}{|c|}{ Compound $\mathbf{1}^{\mathrm{b}}$} & \multicolumn{2}{|c|}{ Compound $\mathbf{2}^{a}$} & \multicolumn{2}{|c|}{ Compound $3^{\mathrm{b}}$} & \multicolumn{2}{|c|}{ Compound $\mathbf{4}^{a}$} & \multicolumn{2}{|c|}{ Compound $\mathbf{5}^{a}$} & \multicolumn{2}{|c|}{ Compound $6^{a}$} \\
\hline & $\delta_{\mathrm{H}}($ mult., $J$ in $\mathrm{Hz})$ & $\delta_{\mathrm{C}}$ mult. & $\delta_{\mathrm{H}}($ mult., $J$ in Hz) & $\delta_{\mathrm{C}}$ mult. & $\delta_{\mathrm{H}}($ mult., $J$ in $\mathrm{Hz}$ ) & $\delta_{\mathrm{C}}$ mult. & $\delta_{\mathrm{H}}($ mult., $J$ in Hz) & $\delta_{\mathrm{C}}$ mult. & $\delta_{\mathrm{H}}($ mult., $J$ in Hz) & $\delta_{\mathrm{C}}$ mult. & $\delta_{\mathrm{H}}$ (mult., $J$ in $\mathrm{Hz}$ ) & $\delta_{\mathrm{c}}$ mult. \\
\hline 1 & & $153.5, \mathrm{~s}$ & $2.05, \mathrm{~m}$ & $45.4, \mathrm{~d}$ & & $142.6, \mathrm{~s}$ & & $147.9, \mathrm{~s}$ & & $53.2, \mathrm{~s}$ & & $55.3, \mathrm{~s}$ \\
\hline $2 \mathrm{a}$ & $5.17, \mathrm{~d}(10.4)$ & $117.4, \mathrm{~d}$ & $2.28, \mathrm{~m}$ & $31.4, \mathrm{t}$ & $6.10, \mathrm{~d}(10.9)$ & $122.6, \mathrm{~d}$ & $5.99, \mathrm{~d}(11.0)$ & $118.1, \mathrm{~d}$ & $2.71, \mathrm{dd}(10.9,9.1)$ & $39.4, \mathrm{~d}$ & $2.71, \mathrm{dd}(10.9,9.1)$ & $40.5, \mathrm{~d}$ \\
\hline $2 \mathrm{~b}$ & & & 1.87 , ov. & & & & & & & & & \\
\hline 3 & $3.30, \mathrm{~d}(10.4)$ & $81.6, \mathrm{~d}$ & $5.30, \mathrm{t}(7.4)$ & $124.2, \mathrm{~d}$ & $6.00, \mathrm{~d}(10.9)$ & $121.1, \mathrm{~d}$ & $5.95, \mathrm{~d}(11.0)$ & $122.0, \mathrm{~d}$ & $5.33, \mathrm{~d}(10.9)$ & $127.8, \mathrm{~d}$ & $5.33, \mathrm{~d}(10.9)$ & $128.3, \mathrm{~d}$ \\
\hline 4 & & $70.1, \mathrm{~s}$ & & $135.4, \mathrm{~s}$ & & $136.0, \mathrm{~s}$ & & $135.4, \mathrm{~s}$ & & $132.8, \mathrm{~s}$ & & $132.7, \mathrm{~s}$ \\
\hline $5 \mathrm{a}$ & $1.89, \mathrm{~m}$ & $38.7, \mathrm{t}$ & $2.23, \mathrm{ov}$ & $35.4, \mathrm{t}$ & 2.25, ov. & $36.1, \mathrm{t}$ & $2.25, \mathrm{dd}(10.6,3.6)$ & $36.6, \mathrm{t}$ & $2.49, \mathrm{t}(12.8)$ & $29.2, \mathrm{t}$ & $2.49, \mathrm{t}(12.8)$ & $29.1, \mathrm{t}$ \\
\hline $5 \mathrm{~b}$ & 1.57 , ov. & & 2.14, ov. & & & & $2.21, \mathrm{~m}$ & & $2.00, \mathrm{~m}$ & & $2.00, \mathrm{dd}(12.8,6.9)$ & \\
\hline $6 a$ & $1.72, \mathrm{~m}$ & $23.6, \mathrm{t}$ & $1.91, \mathrm{~m}$ & $27.1, \mathrm{t}$ & 1.78 , ov. & $25.9, \mathrm{t}$ & $1.59, \mathrm{~m}$ & $25.5, \mathrm{t}$ & $2.03, \mathrm{~m}$ & $23.9, \mathrm{t}$ & $2.03, \mathrm{~m}$ & $23.8, \mathrm{t}$ \\
\hline $6 \mathrm{~b}$ & $1.48, \mathrm{~m}$ & & $1.46, \mathrm{~m}$ & & 1.75 , ov. & & $1.86, \mathrm{~m}$ & & $1.13, \mathrm{~m}$ & & $1.15, \operatorname{dd}(11.8,11.0)$ & \\
\hline 7 & $3.02, \mathrm{dd}(11.3,2.0)$ & $79.7, \mathrm{~d}$ & $3.52, \mathrm{dd}(11.2,1.9)$ & $71.9, \mathrm{~d}$ & $2.82, \mathrm{t}(5.4)$ & $62.0, \mathrm{~d}$ & $2.79, \mathrm{dd}(8.1,3.5)$ & $62.9, \mathrm{~d}$ & $3.00, \mathrm{dd}(11.2,2.4)$ & $66.6, \mathrm{~d}$ & $3.00, \mathrm{dd}(11.8,2.4)$ & $66.5, \mathrm{~d}$ \\
\hline 8 & & $73.4, \mathrm{~s}$ & & $75.2, \mathrm{~s}$ & & $60.4, \mathrm{~s}$ & & $61.9, \mathrm{~s}$ & & $60.1, \mathrm{~s}$ & & $59.8, \mathrm{~s}$ \\
\hline $9 \mathrm{a}$ & $1.86, \mathrm{dd}(14.4,4.2)$ & $40.6, \mathrm{t}$ & 1.87 , ov. & $37.9, \mathrm{t}$ & $1.93, \mathrm{~m}$ & $37.7, \mathrm{t}$ & $2.63, \mathrm{dd}(14.1,5.6)$ & $42.3, \mathrm{t}$ & $2.14, \mathrm{dd}(11.9,5.6)$ & $42.9, \mathrm{t}$ & $2.14, \mathrm{dd}(11.9,5.6)$ & $42.7, \mathrm{t}$ \\
\hline $9 \mathrm{~b}$ & 1.58 , ov. & & $1.67, \mathrm{~m}$ & & $1.44, \mathrm{~d}(10.8)$ & & $1.99, \mathrm{dd}(14.1,8.6)$ & & $1.05, \mathrm{~d}(11.9,3.1)$ & & $1.05, \operatorname{dd}(11.9,10.0)$ & \\
\hline 10a & $2.33, \mathrm{~m}$ & $21.7, \mathrm{t}$ & 2.22 , ov. & $22.9, \mathrm{t}$ & 2.05 , ov. & $22.8, \mathrm{t}$ & $5.55, \mathrm{~m}$ & $123.8, \mathrm{~d}$ & $1.43, \mathrm{~m}$ & $34.7, \mathrm{~d}$ & $1.43, \mathrm{~m}$ & $37.9, \mathrm{~d}$ \\
\hline $10 \mathrm{~b}$ & $1.91, \mathrm{~m}$ & & 2.15 , ov. & & & & & & & & & \\
\hline 11 & $4.91, \mathrm{~d}(10.4)$ & $131.0, \mathrm{~d}$ & $5.07, \mathrm{t}(6.9)$ & $124.8, \mathrm{~d}$ & $5.08, \mathrm{t}(6.4)$ & $125.8, \mathrm{~d}$ & $5.63, \mathrm{~d}(15.6)$ & $139.5, \mathrm{~d}$ & $1.74, \mathrm{~m}$ & $55.0, \mathrm{~d}$ & 1.75 , ov & $57.3, \mathrm{~d}$ \\
\hline 12 & & $128.1, \mathrm{~s}$ & & $136.4, \mathrm{~s}$ & & $135.2, \mathrm{~s}$ & & $73.8, \mathrm{~s}$ & & $79.7, \mathrm{~s}$ & & $81.9, \mathrm{~s}$ \\
\hline 13a & $2.13, \mathrm{dd}(12.6,8.5)$ & $38,9, \mathrm{t}$ & $1.97, \mathrm{~m}$ & $34.9, \mathrm{t}$ & $2.20, \mathrm{~m}$ & $39.4, \mathrm{t}$ & $1.93, \mathrm{dd}(8.8,5.1)$ & $41.2, \mathrm{t}$ & $1.95, \mathrm{~m}$ & $39.8, \mathrm{t}$ & $1.96, \mathrm{~m}$ & $40.4, \mathrm{t}$ \\
\hline $13 \mathrm{~b}$ & $1.79, \mathrm{t}(12.6)$ & & $1.76, \mathrm{~m}$ & & 2.06 , ov. & & $1.49, \mathrm{dd}(8.8,4.6)$ & & $1.73, \mathrm{~m}$ & & 1.74, ov & \\
\hline $14 \mathrm{a}$ & $2.45, \mathrm{t}(12.6)$ & $26.6, \mathrm{t}$ & $1.59, \mathrm{~m}$ & $30.9, \mathrm{t}$ & $2.28, \mathrm{~m}$ & $27.6, \mathrm{t}$ & $2.30, \mathrm{~m}$ & $24.6, \mathrm{t}$ & $1.78, \mathrm{~m}$ & $28.0, \mathrm{t}$ & $1.78, \mathrm{dd}(13.3,8.1)$ & $27.1, \mathrm{t}$ \\
\hline $14 \mathrm{~b}$ & $1.94, \mathrm{dd}(12.6,8.5)$ & & $1.43, \mathrm{~m}$ & & & & & & $1.64, \mathrm{~m}$ & & $1.64, \mathrm{dd}(13.3,4.9)$ & \\
\hline 15 & 2.29 , sept (6.8) & $36.2, \mathrm{~d}$ & & $149.0, \mathrm{~s}$ & $2.43, \mathrm{~m}$ & $43.9, \mathrm{~d}$ & 2.46, sept (6.8) & $32.5, \mathrm{~d}$ & $1.68, \mathrm{~m}$ & $38.5, \mathrm{~d}$ & $1.69, \mathrm{ov}$ & $39.0, \mathrm{~d}$ \\
\hline 16a & $1.08, \mathrm{~d}(6.8)$ & $22.5, \mathrm{q}$ & $4.79, \mathrm{~s}$ & $110.5, \mathrm{t}$ & $3.52, \mathrm{~d}(6.9)$ & $66.8, \mathrm{t}$ & $1.07, \mathrm{~d}(6.8)$ & $22.0, \mathrm{q}$ & $0.83, \mathrm{~d}(6.8)$ & $18.7, \mathrm{q}$ & $0.83, \mathrm{~d}(6.8)$ & $18.6, \mathrm{q}$ \\
\hline $16 \mathrm{~b}$ & & & $4.71, \mathrm{~s}$ & & & & & & & & & \\
\hline 17 & $1.04, \mathrm{~d}(6.8)$ & $22.9, \mathrm{q}$ & $1.71, \mathrm{~s}$ & $20.5, \mathrm{q}$ & $1.07, \mathrm{~d}(6.9)$ & $16.6, \mathrm{q}$ & $1.04, \mathrm{~d}(6.8)$ & $22.3, \mathrm{q}$ & $0.78, \mathrm{~d}(6.8)$ & $17.2, \mathrm{q}$ & $0.78, \mathrm{~d}(6.8)$ & $17.4, \mathrm{q}$ \\
\hline 18 & $1.20, \mathrm{~s}$ & $21.3, \mathrm{q}$ & $1.64, \mathrm{~s}$ & $15.7, \mathrm{q}$ & $1.76, \mathrm{~s}$ & $17.2, \mathrm{q}$ & $1.74, \mathrm{~s}$ & $17.2, \mathrm{q}$ & $1.72, \mathrm{~d}(1.2)$ & $25.7, \mathrm{q}$ & $1.72, \mathrm{~d}(1.2)$ & $25.7, \mathrm{q}$ \\
\hline 19 & $1.12, \mathrm{~s}$ & $24.1, \mathrm{q}$ & $1.18, \mathrm{~s}$ & $24.0, \mathrm{q}$ & $1.26, \mathrm{~s}$ & $17.9, \mathrm{q}$ & $1.30, \mathrm{~s}$ & $17.7, \mathrm{q}$ & $1.08, \mathrm{~s}$ & $18.3, \mathrm{q}$ & $1.08, \mathrm{~s}$ & $18.2, \mathrm{q}$ \\
\hline 20 & $1.75, \mathrm{~s}$ & $16.7, \mathrm{q}$ & $1.63, \mathrm{~s}$ & $18.5, \mathrm{q}$ & $1.61, \mathrm{~s}$ & $17.0, \mathrm{q}$ & $1.24, \mathrm{~s}$ & $30.0, \mathrm{q}$ & $1.23, \mathrm{~s}$ & $28.4, \mathrm{q}$ & $1.23, \mathrm{~s}$ & 22.4, q \\
\hline
\end{tabular}

${ }^{1} \mathrm{H}$ NMR $600 \mathrm{MHz}$ date of compounds1-2,4-6 in $\mathrm{CDCl}_{3} .{ }^{1} \mathrm{H}$ NMR $400 \mathrm{MHz}$ date of compound 3 in $\mathrm{CDCl}_{3}$.

${ }^{a}$ Recorded at $125 \mathrm{MHz}$ in $\mathrm{CDCl}_{3}$ for ${ }^{13} \mathrm{C}\left\{{ }^{1} \mathrm{H}\right\}$ NMR and DEPT spectrum. ${ }^{b}$ Recorded at $150 \mathrm{MHz}$. for ${ }^{1} \mathrm{H},{ }^{13} \mathrm{C}\left\{{ }^{1} \mathrm{H}\right\}$

NMR and DEPT spectrum. Assignments were deduced by analysis of 1D and 2D NMR spectra. 


\subsubsection{Structure of studied isomers of compounds 1-6}

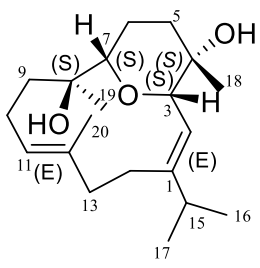

$1 \mathbf{a}$

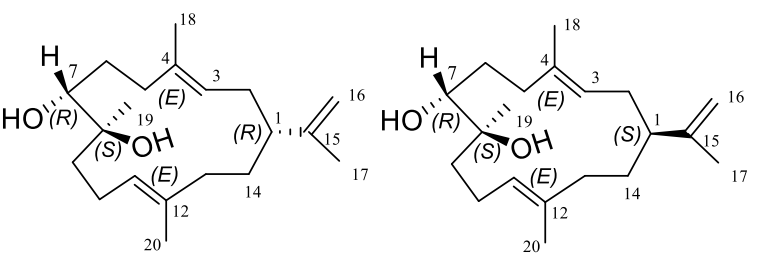

2

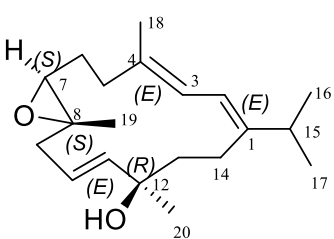

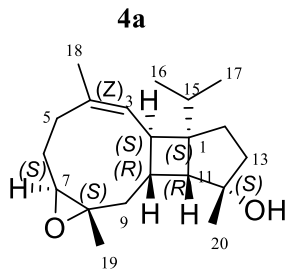

$5 a$

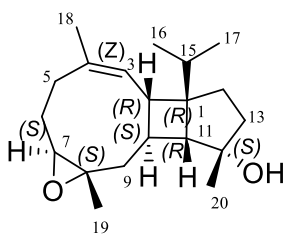

$5 e$

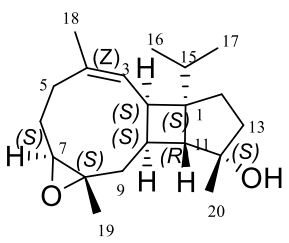

5

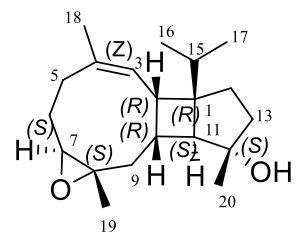

$5 \mathrm{~m}$

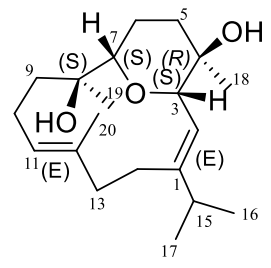

$1 b$

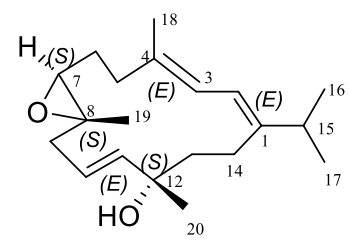

$4 b$

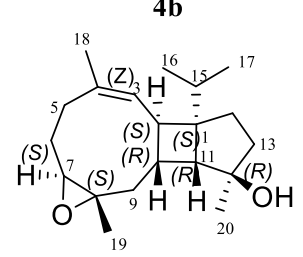

5
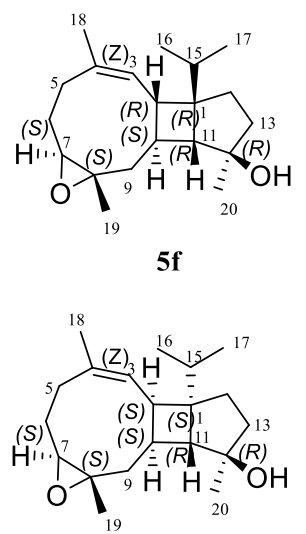

5j

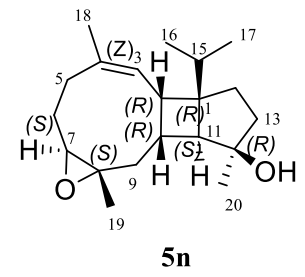

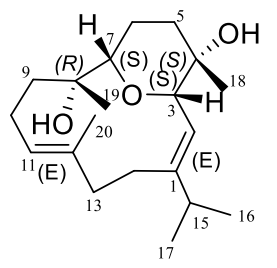

$1 \mathrm{c}$

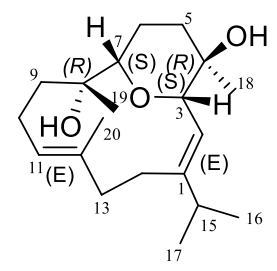

$1 d$

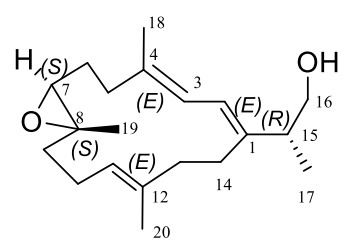

3a

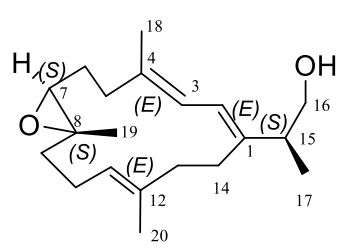

3b

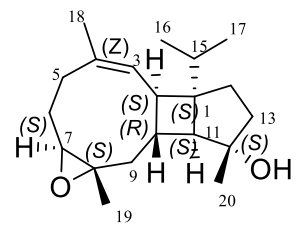

$5 c$
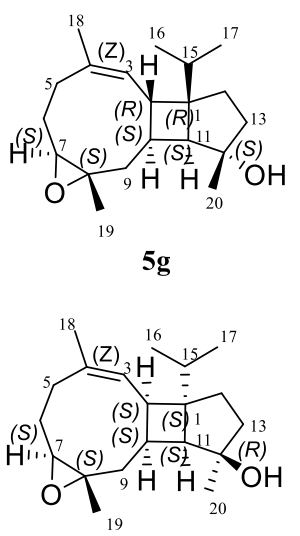

$5 \mathbf{k}$

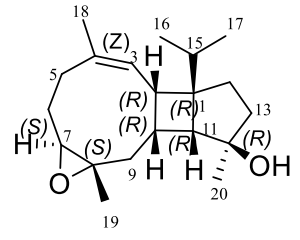

50

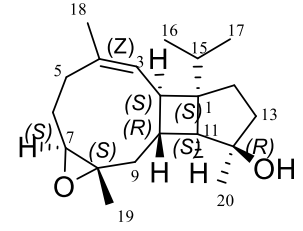

$5 d$

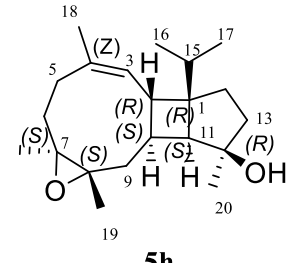

51

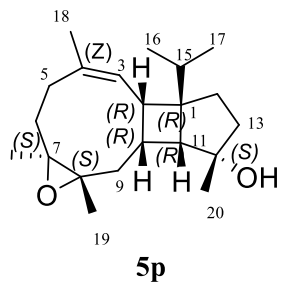




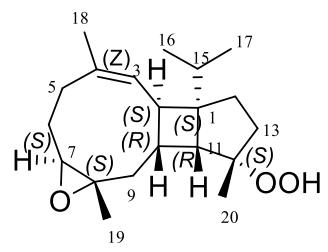

$6 a$

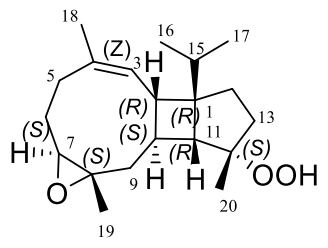

$6 e$

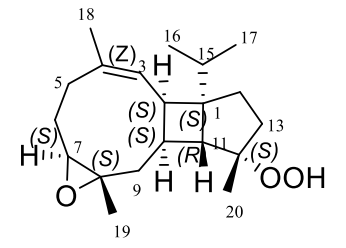

$6 \mathbf{i}$

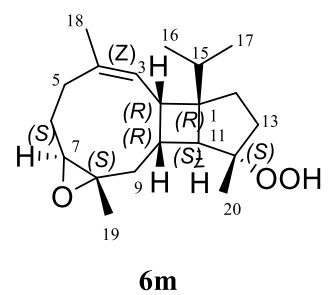

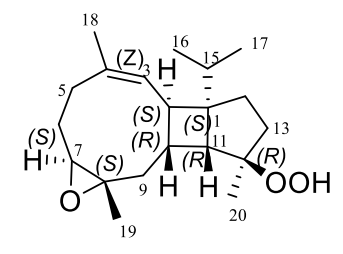

$6 b$

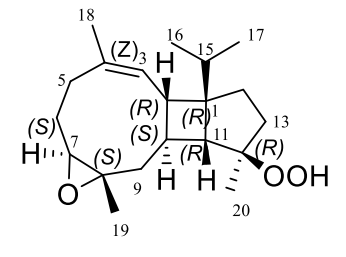

$6 f$

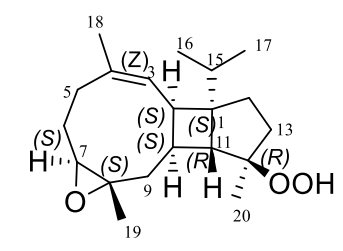

6j

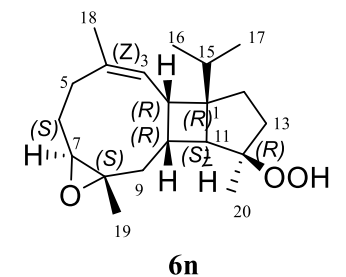

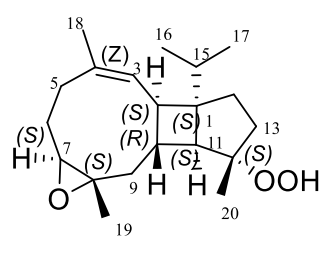

$6 c$

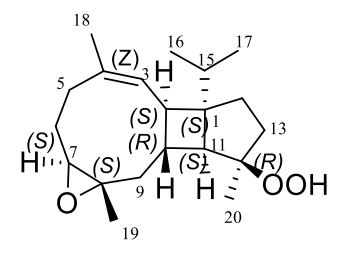

$6 d$

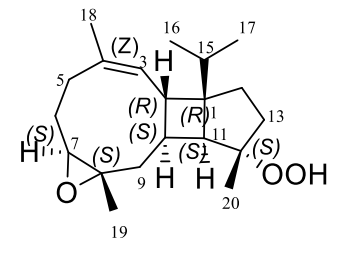

$6 \mathrm{~g}$

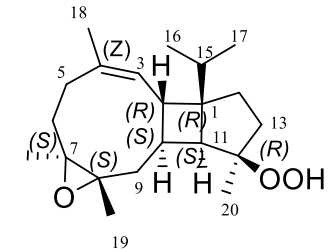

$6 h$

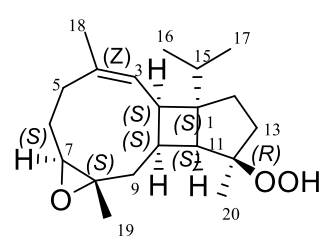

$6 k$

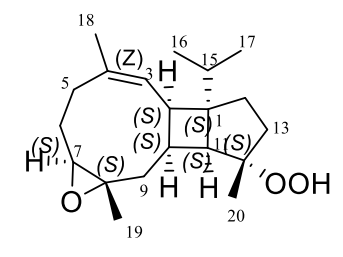

61
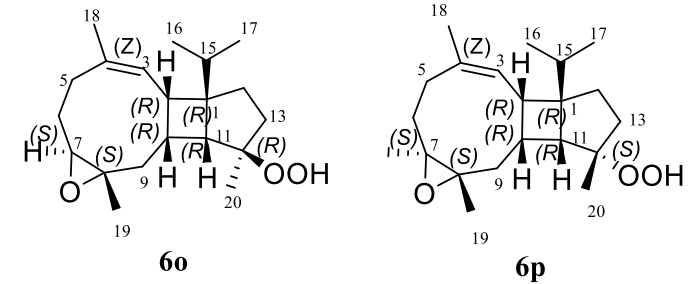

Figure S67. Structures of isomers of compounds 1-6 
5.1.4 Cartesian coordinates and SCF energies of all conformers of studied isomers

Table S3. Cartesian coordinates of DFT-optimized conformers for further use in DP4+ calculations
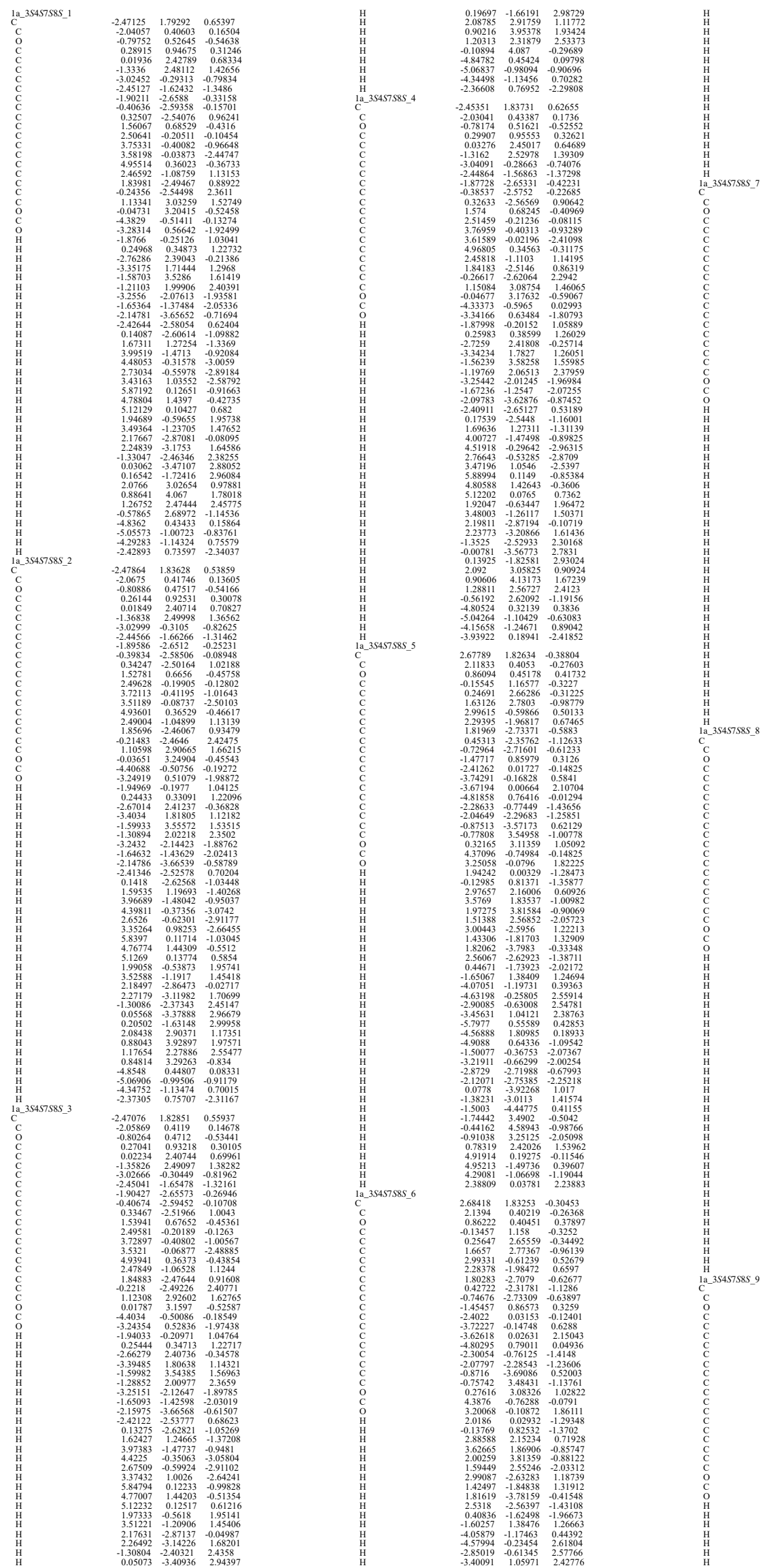

$\begin{array}{lll}-5.7759 & 0.58715 & 0.50686 \\ -4.54472 & 1.84655 \\ -4.24727\end{array}$

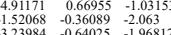

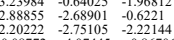

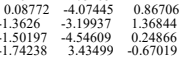

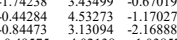

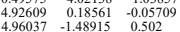
$\begin{array}{lll}4.96037 & -1.48915 & 0.502 \\ 4.33955 & -1.11073 \\ 2.32509 & -1.11159 \\ 2.1229 & -1.19761\end{array}$

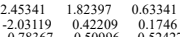

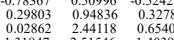

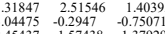

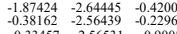
$\begin{array}{llll}1.57316 & 0.68243 & -0.4101 \\ 2.51854 & -0.20792 & -0.08337\end{array}$

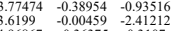

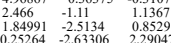

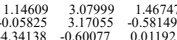

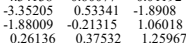

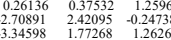

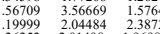

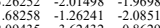

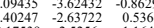

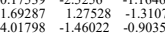

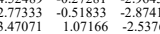

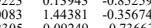

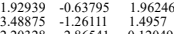

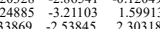

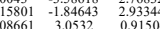

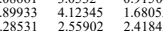

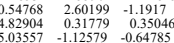

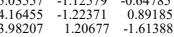

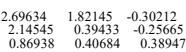

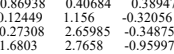

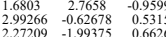
$\begin{aligned} & .78759 \\ & .4184\end{aligned}-2.71327-0.062460$

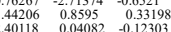

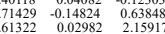
$\begin{array}{llll}2.30902 & -0.7344 & -1.42506 \\ -2.08553 & -2.26077 & -1.26431\end{array}$ $0.73301 \quad 3.48593-1.1 .15276$

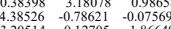

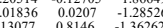

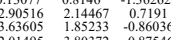

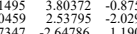

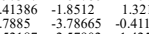

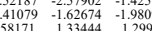

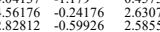

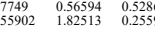

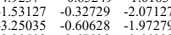

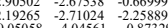

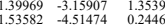

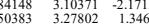

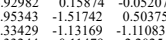

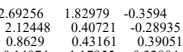

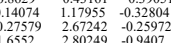

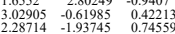

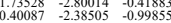

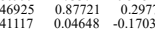

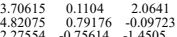

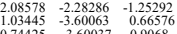
3.3749
3.005799
3

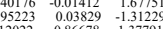

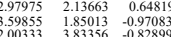



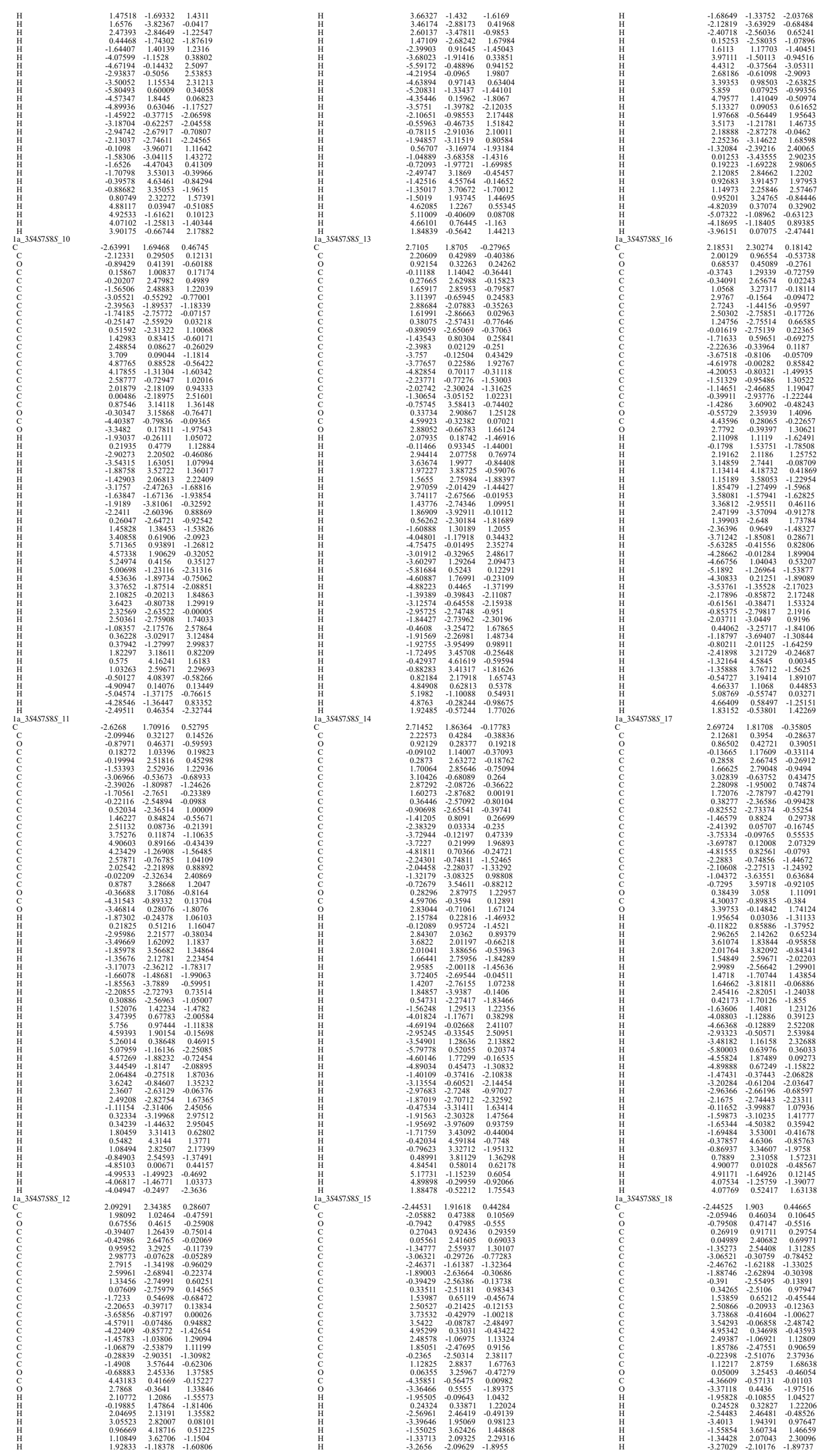

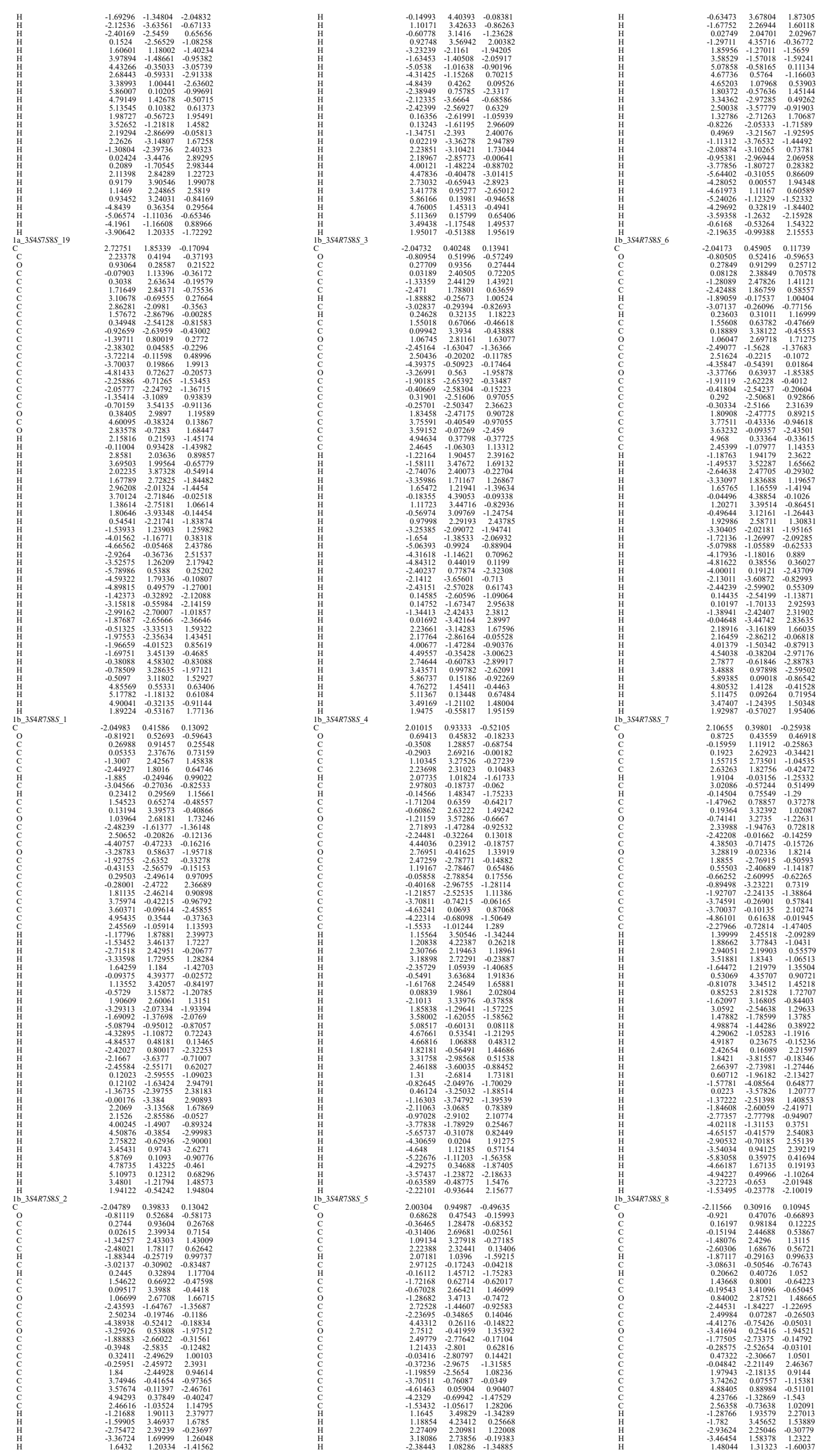

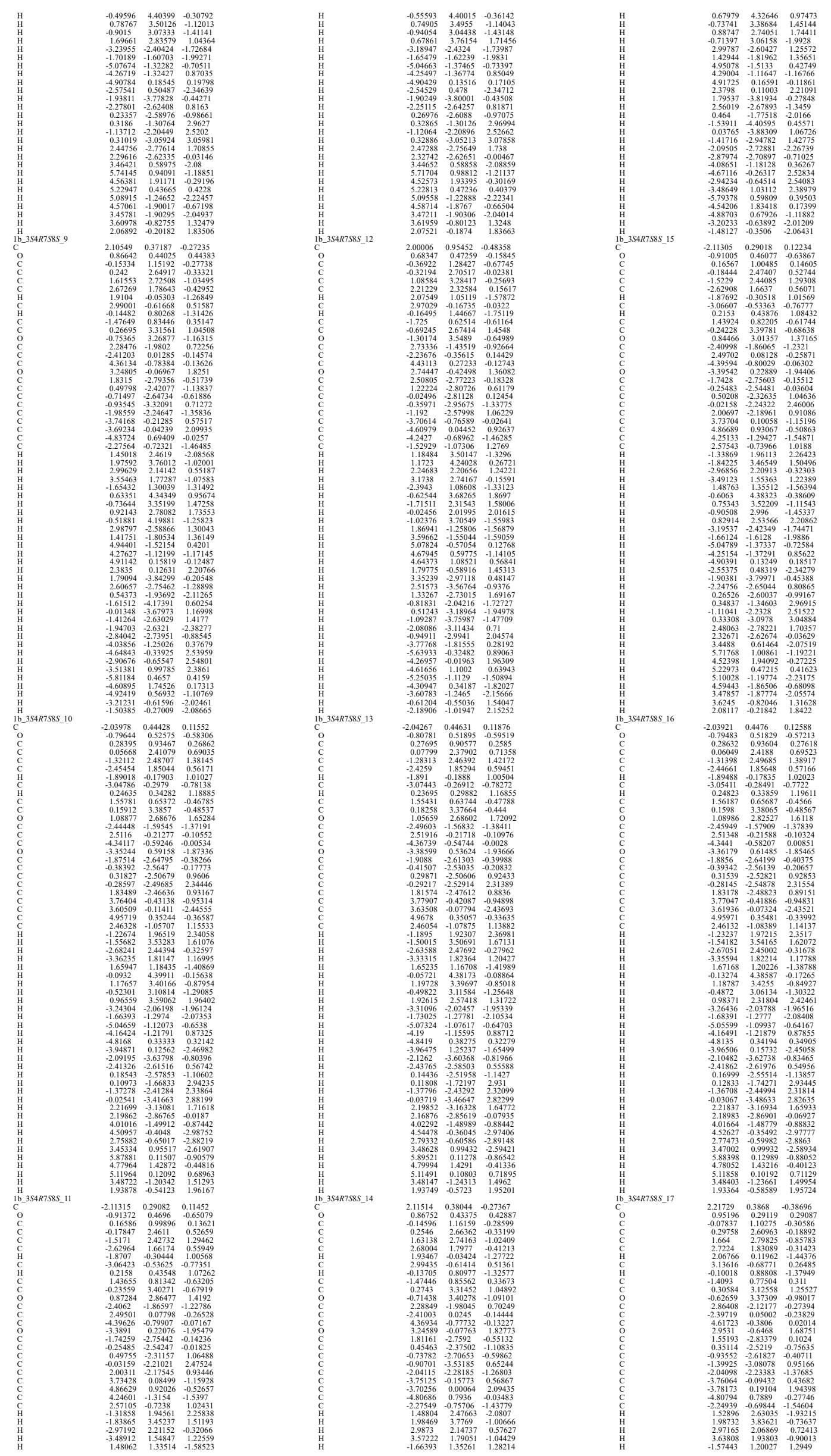

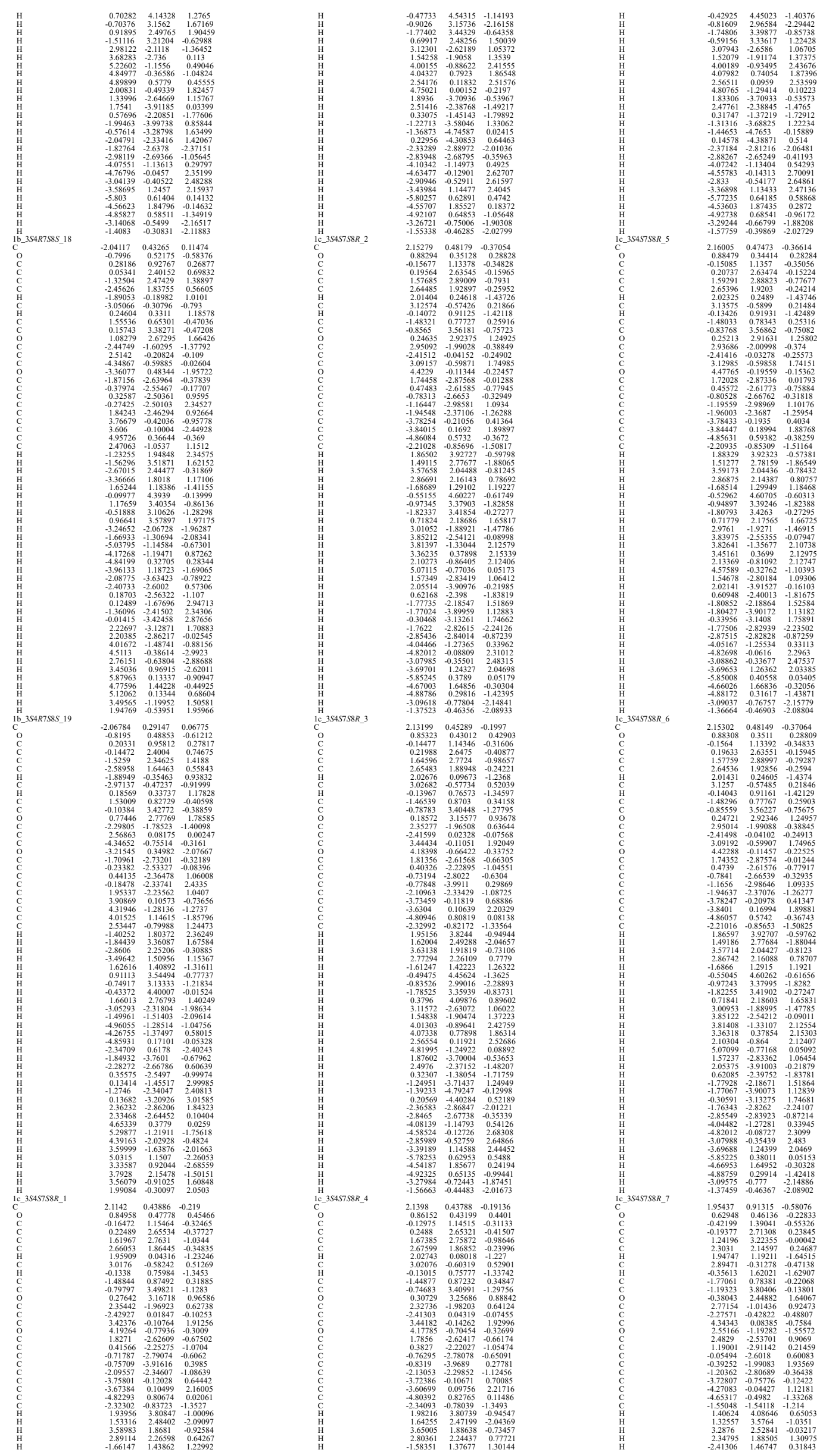

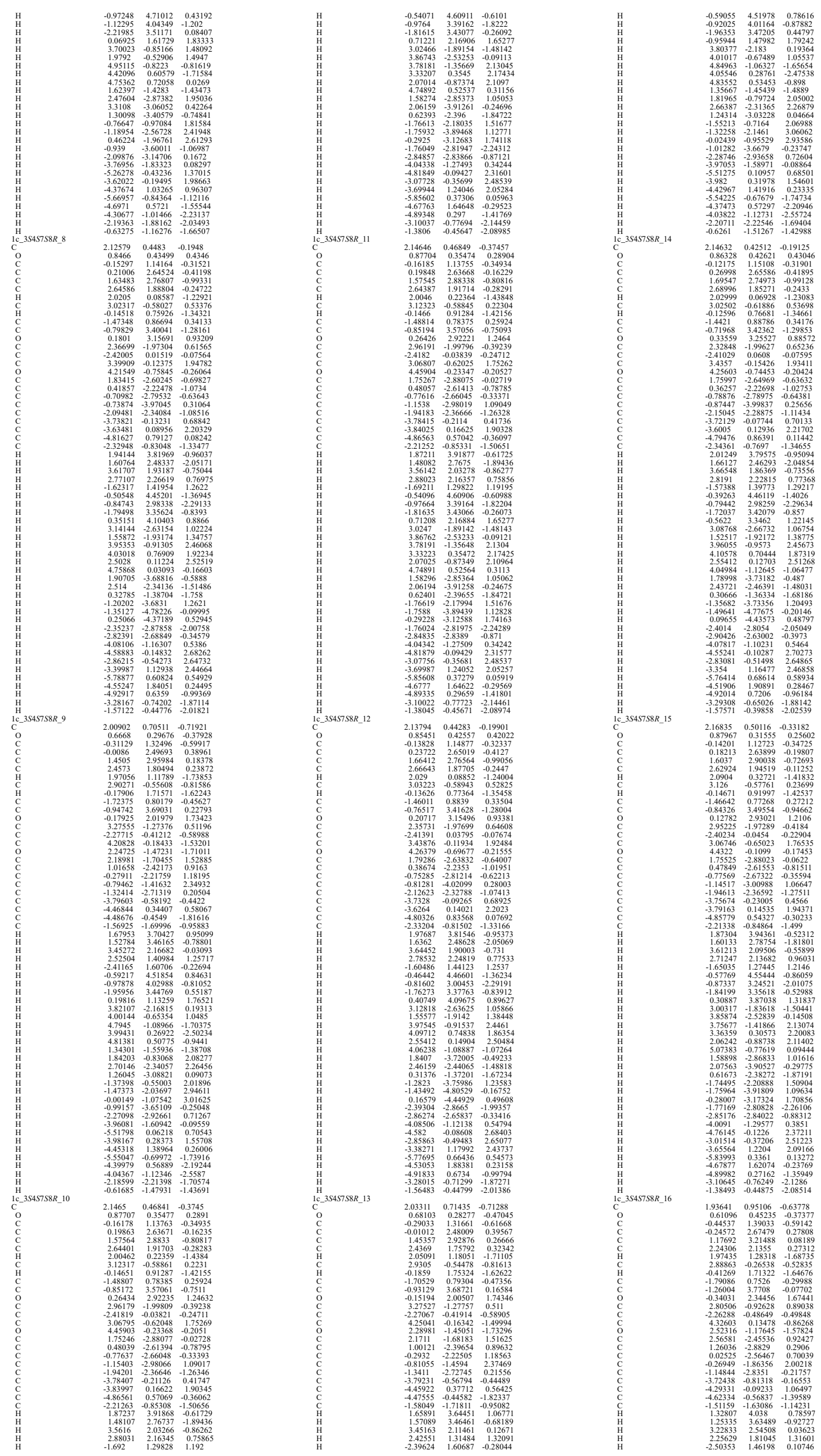

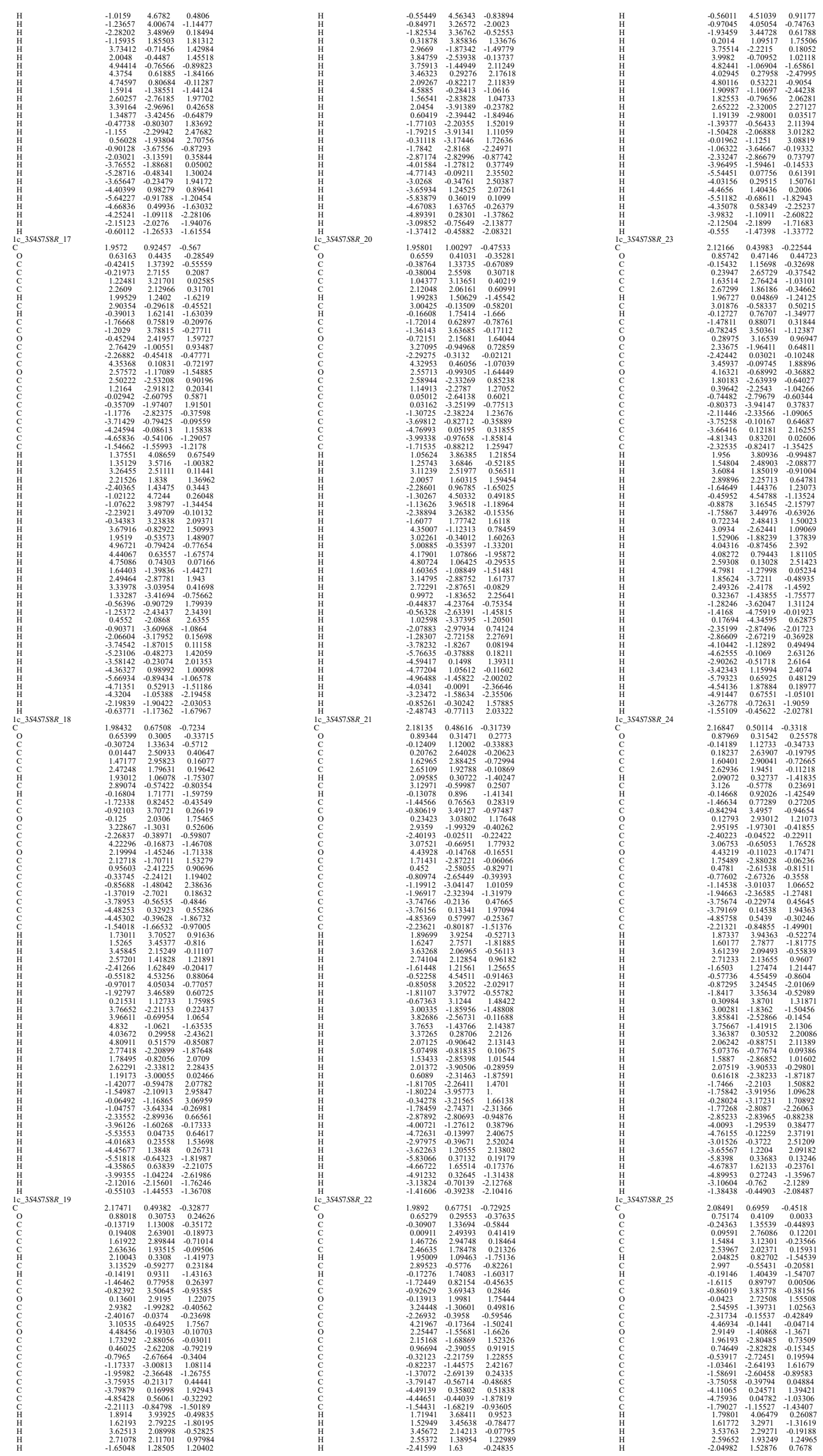

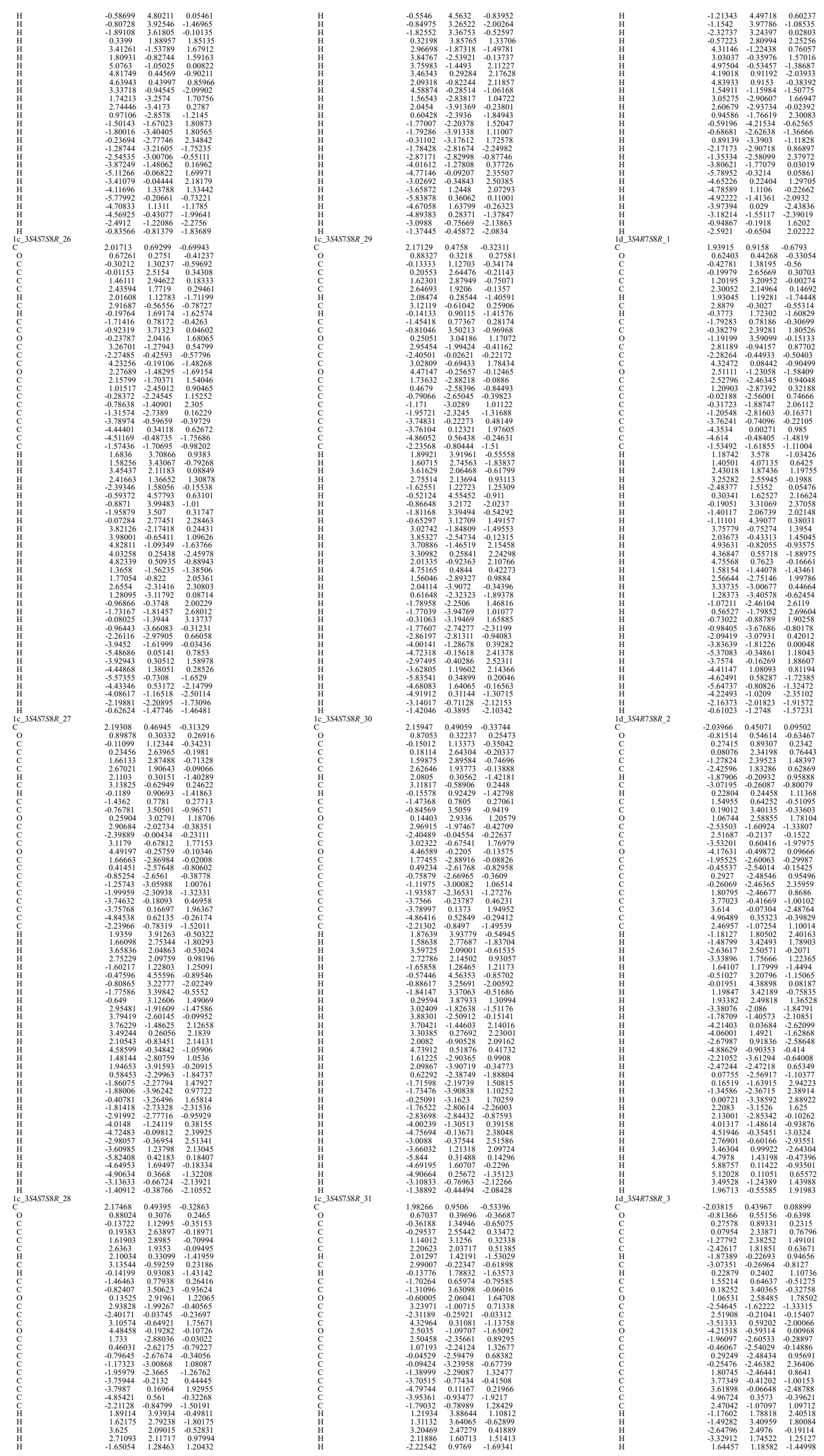

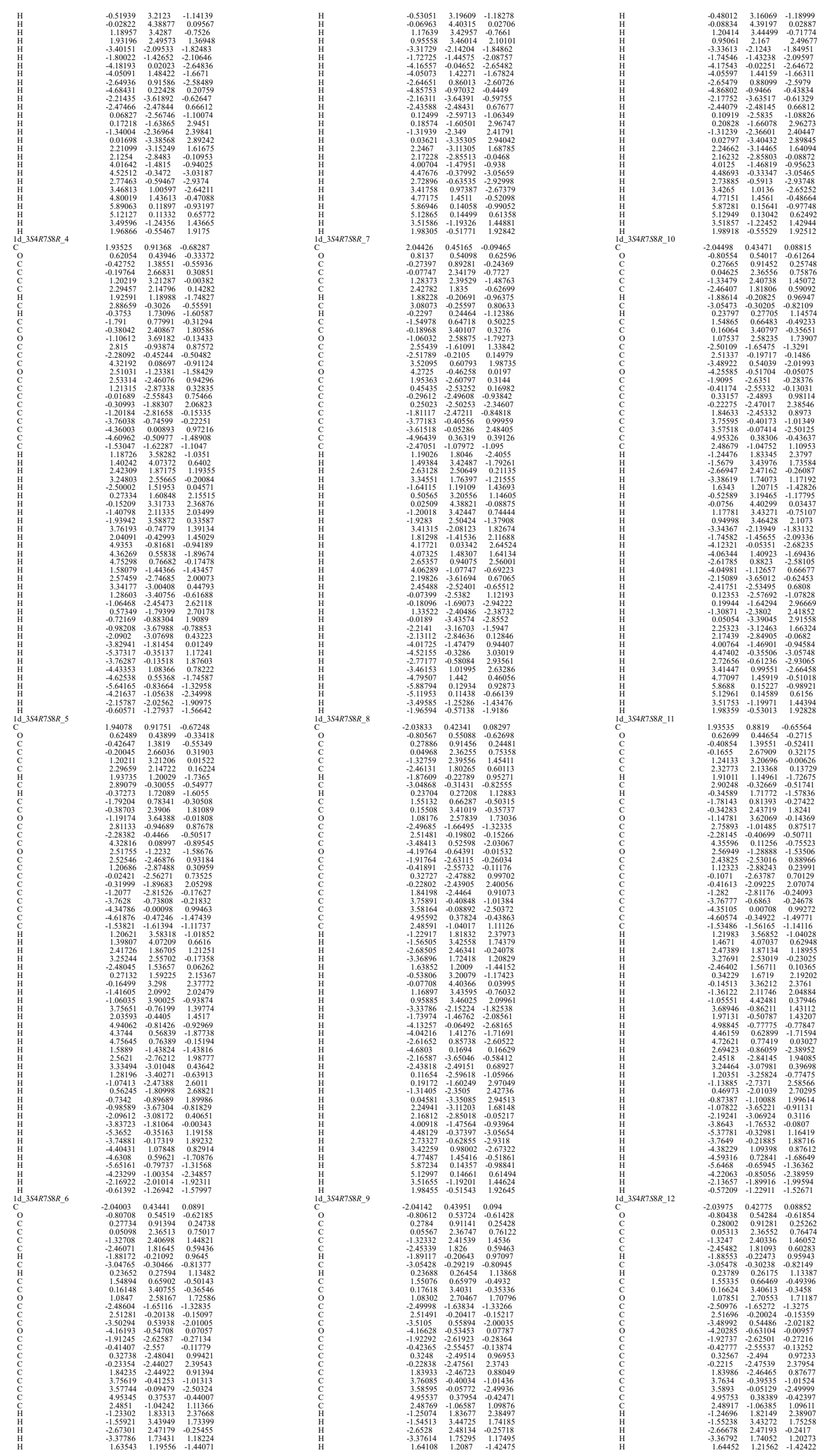

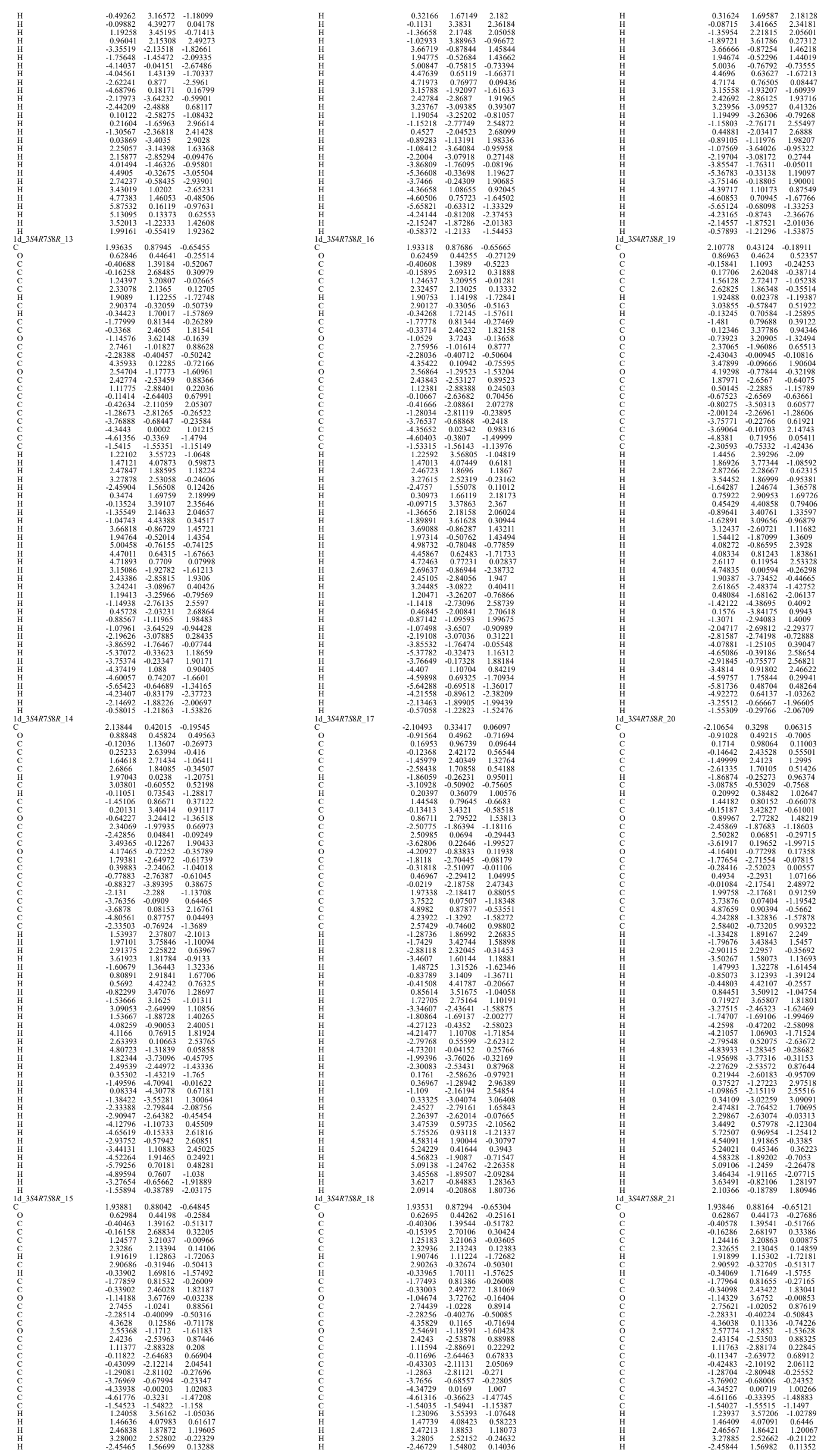

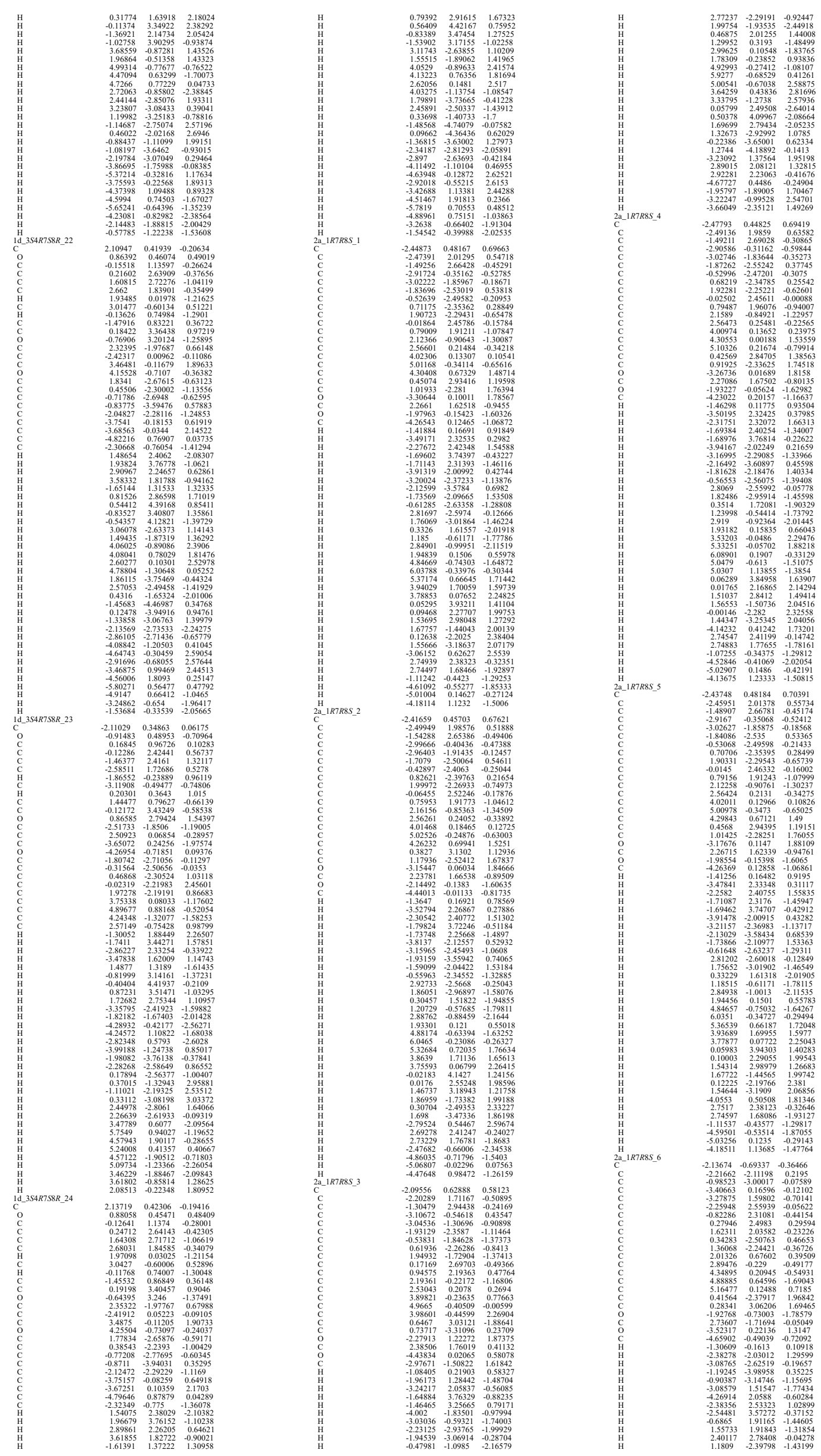

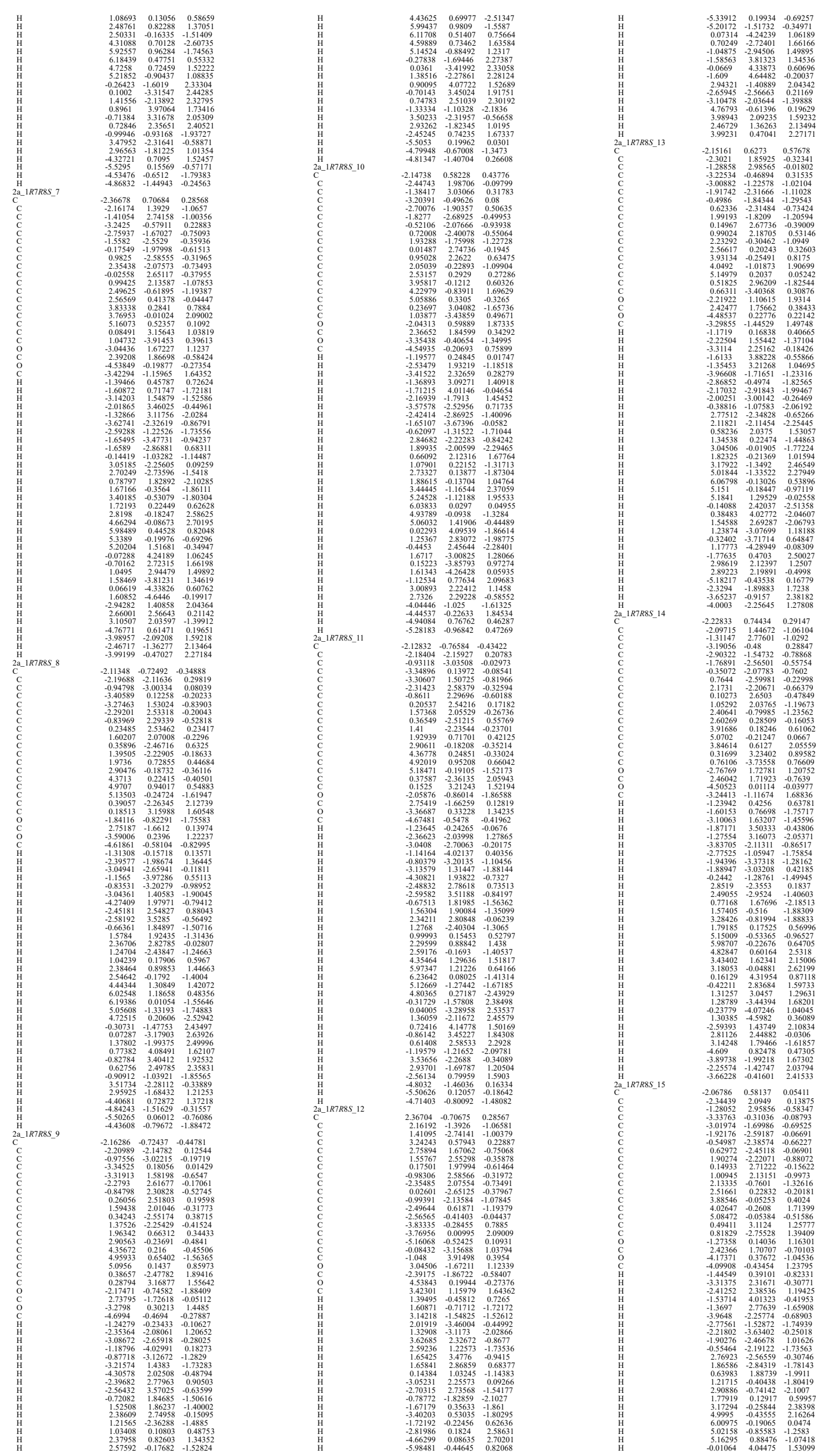

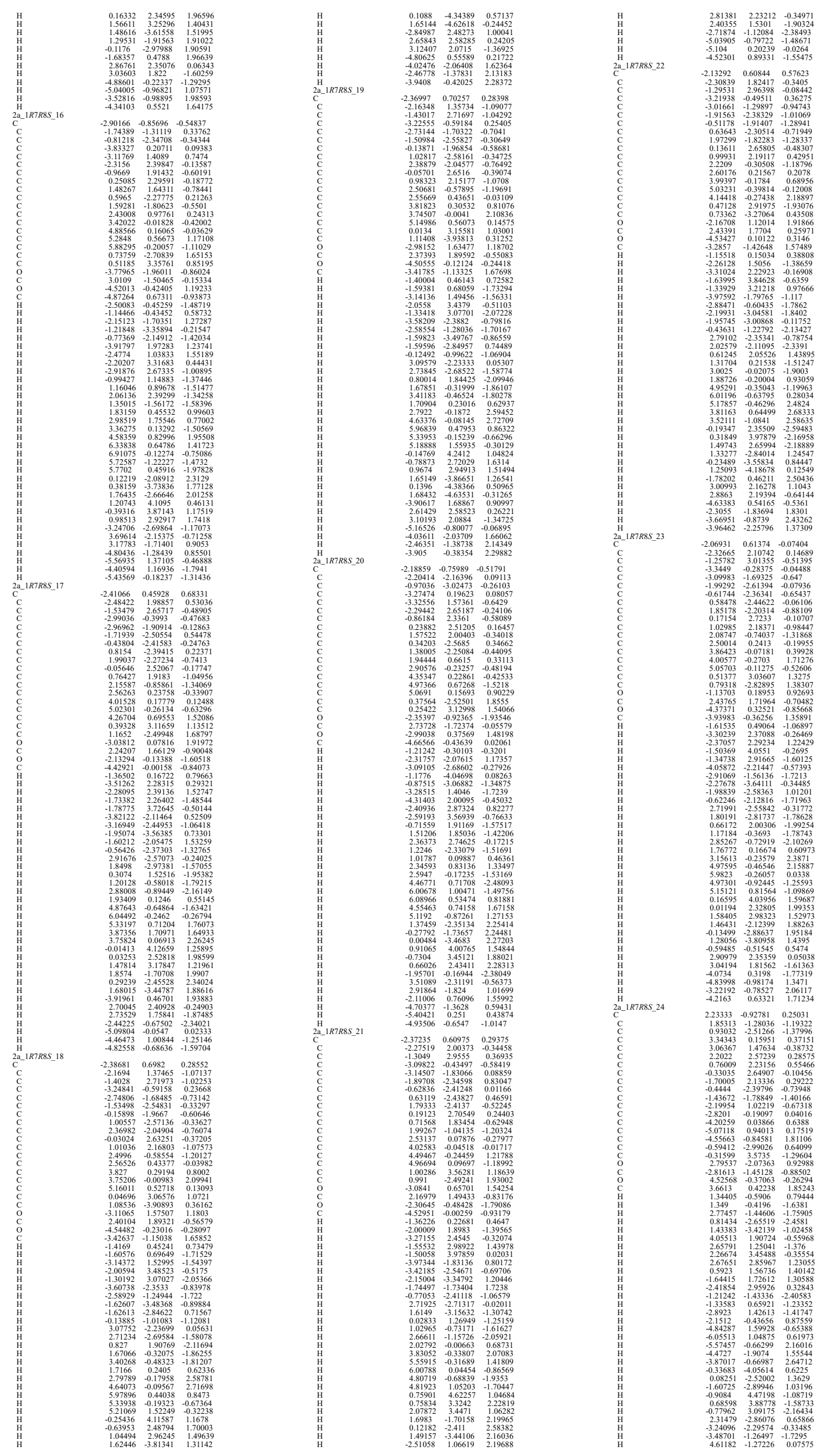

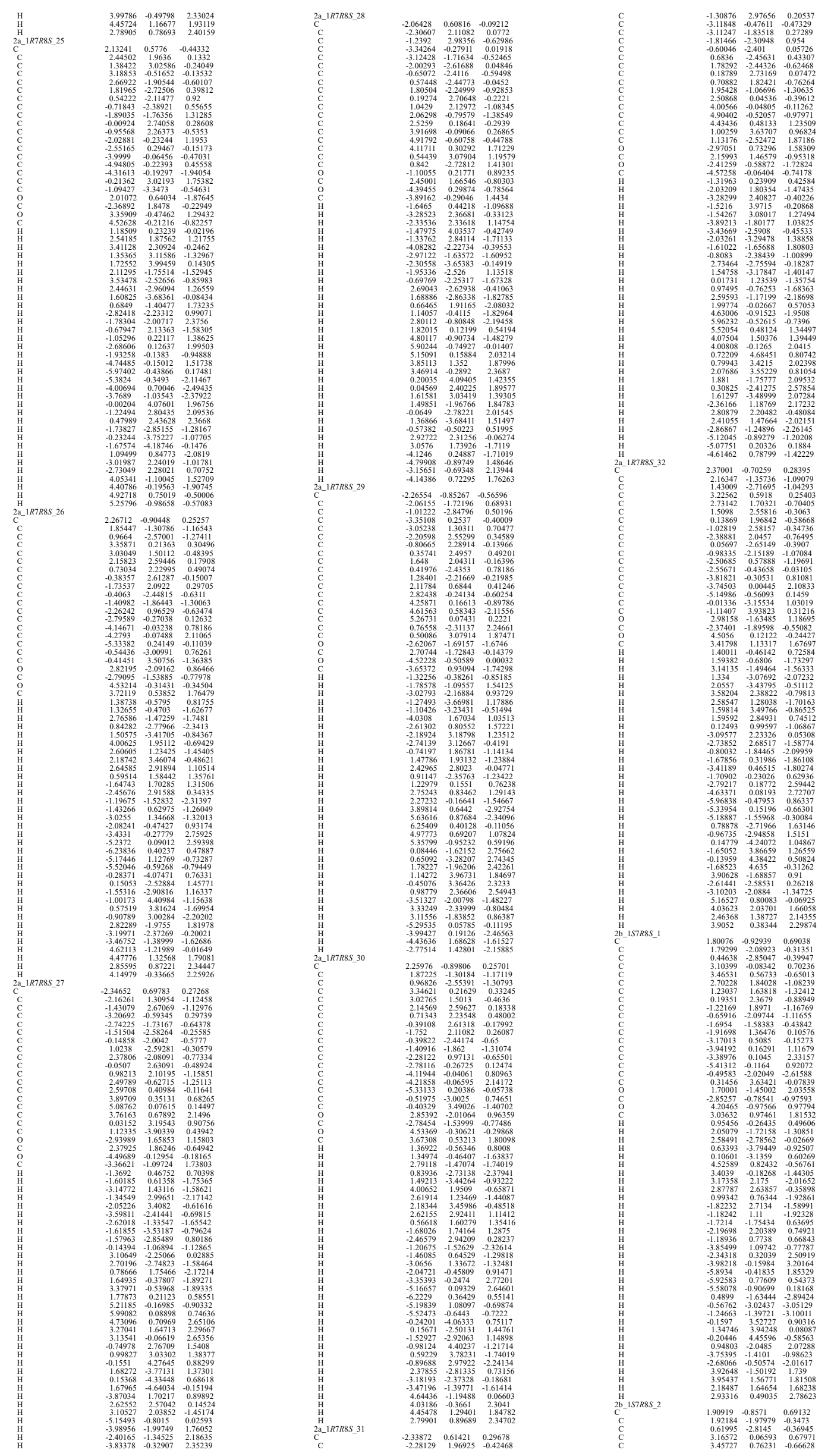

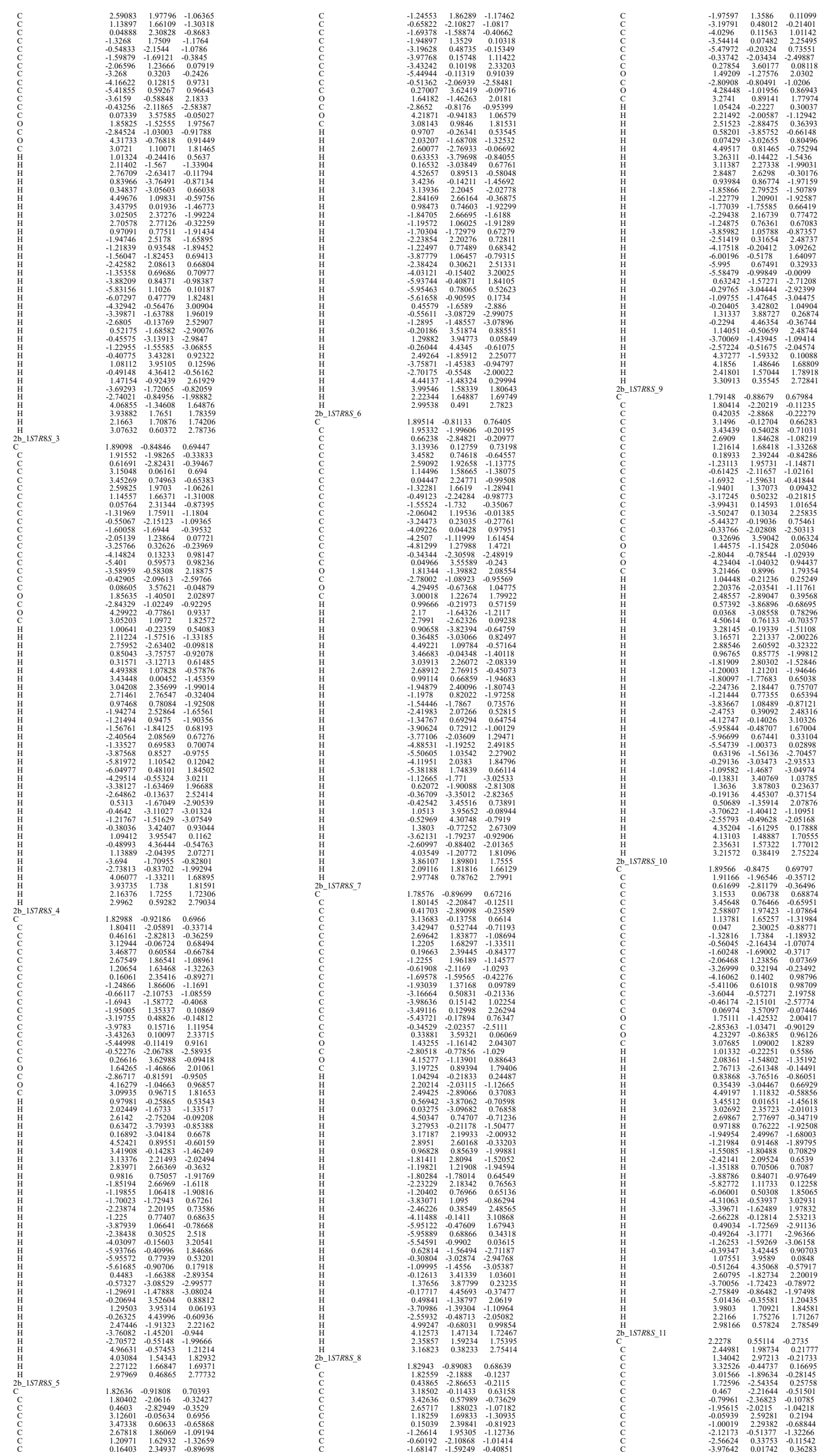

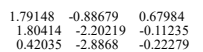

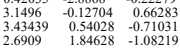

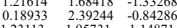

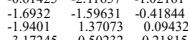

$\begin{array}{lll}-3.99431 & 0.14593 & 1.01654 \\ -3.50277 & 0.13034 & 2.25835 \\ -3 & -2535\end{array}$

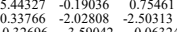

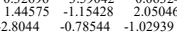

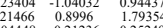

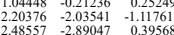

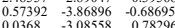

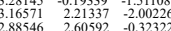

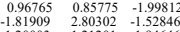

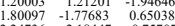

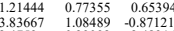

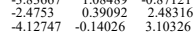

$\begin{array}{lll}-595844 & -0.48707 & 1.67004 \\ -5.566999 & 0.677411 & 0.33100\end{array}$

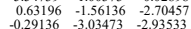

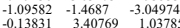

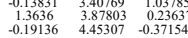

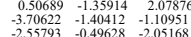

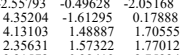

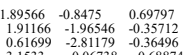

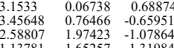

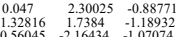

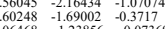

$\begin{array}{llll}-3.26999 & 0.32194 & -0.23492 \\ -4.116062 & 0.1402 & 0.98796\end{array}$

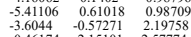

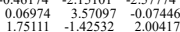

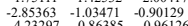

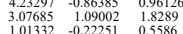

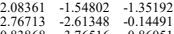

$\begin{array}{llll}0.838688 & -3.756516 & -0.86651 \\ 0.35349 & -3.046767 & 0.66929\end{array}$

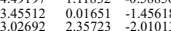

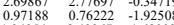

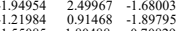

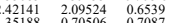

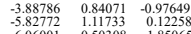

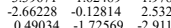

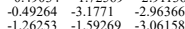

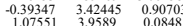

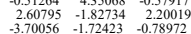

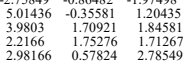

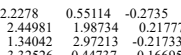

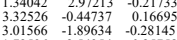

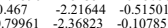

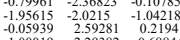

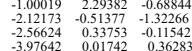



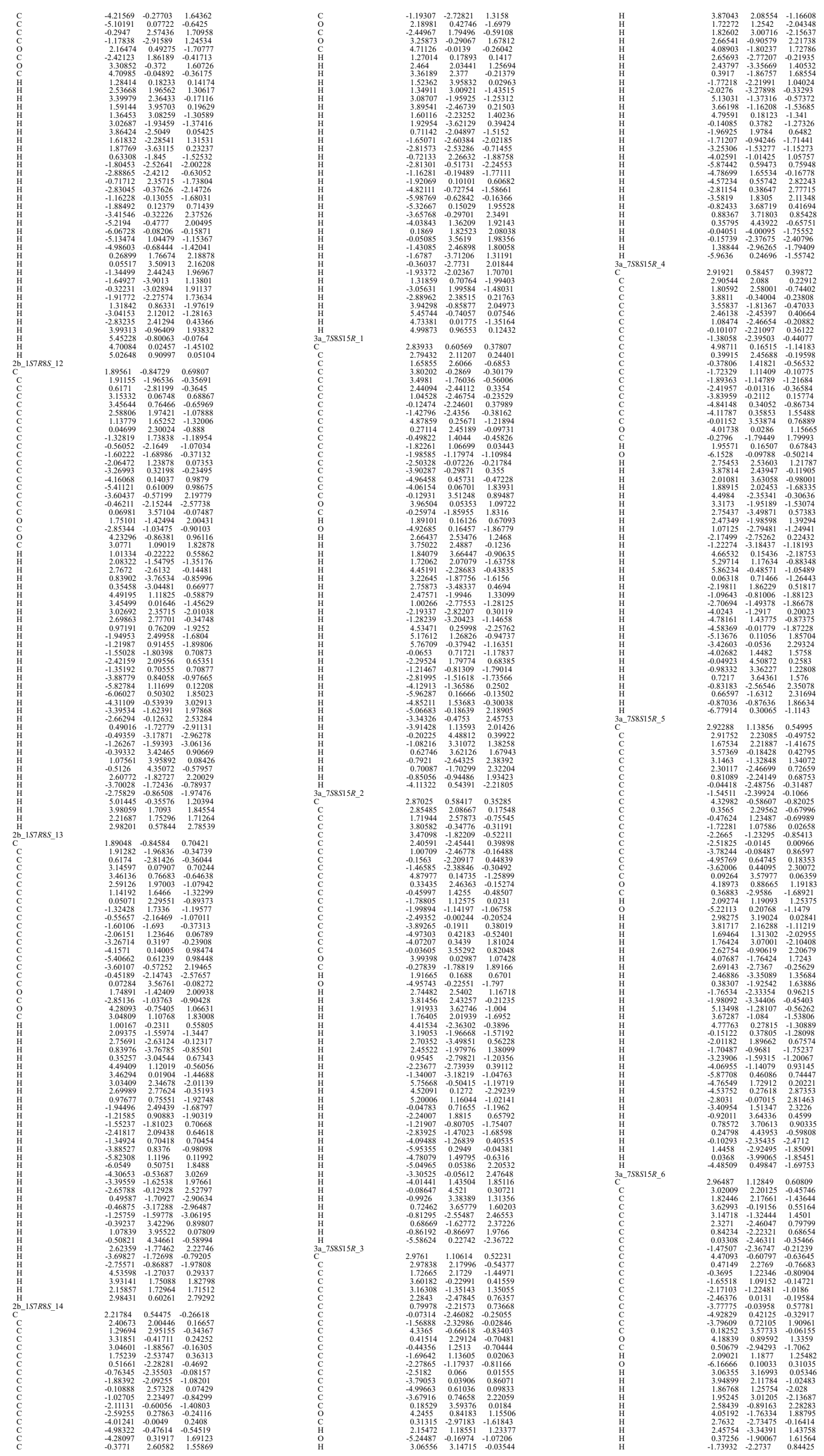

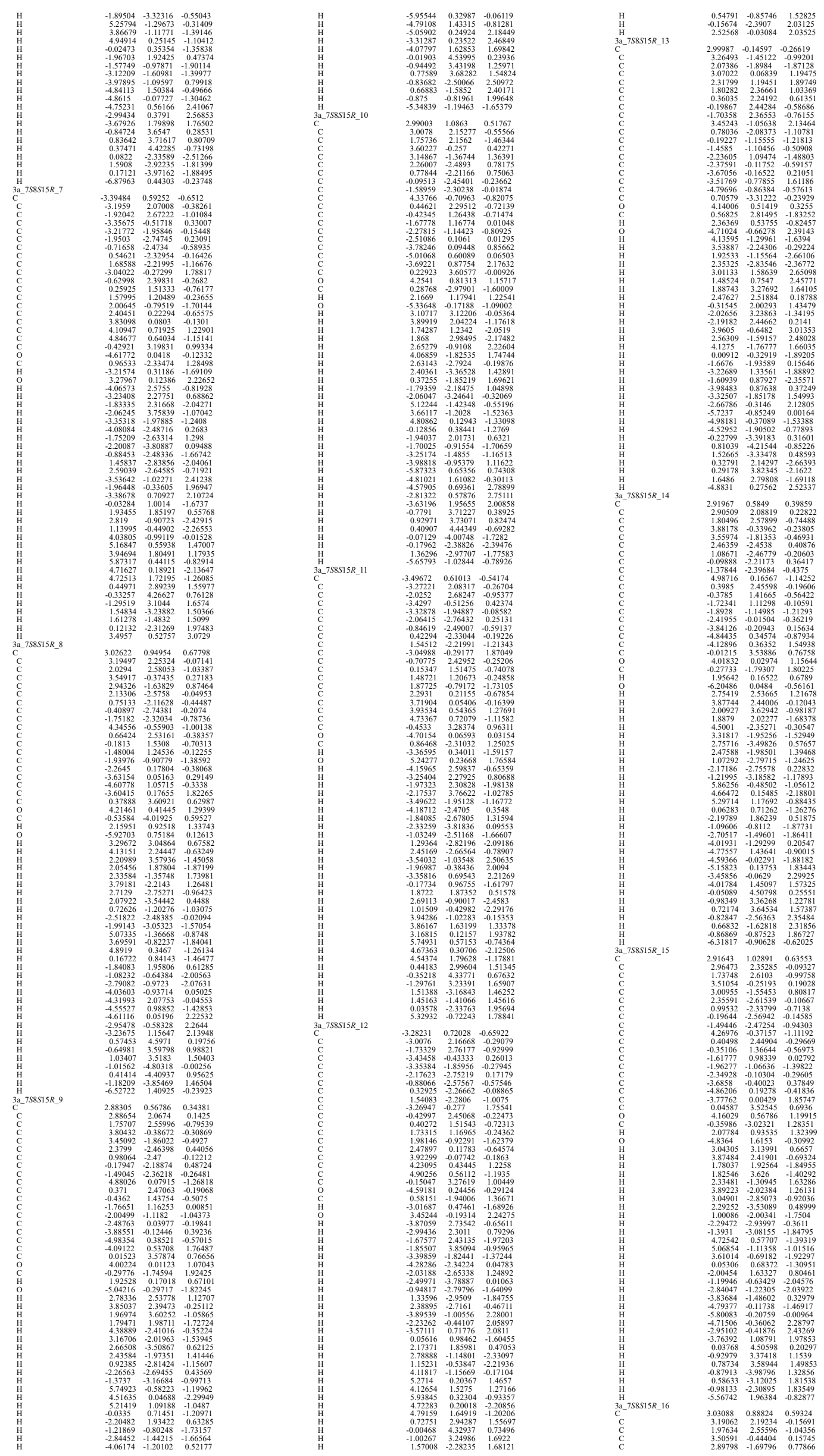

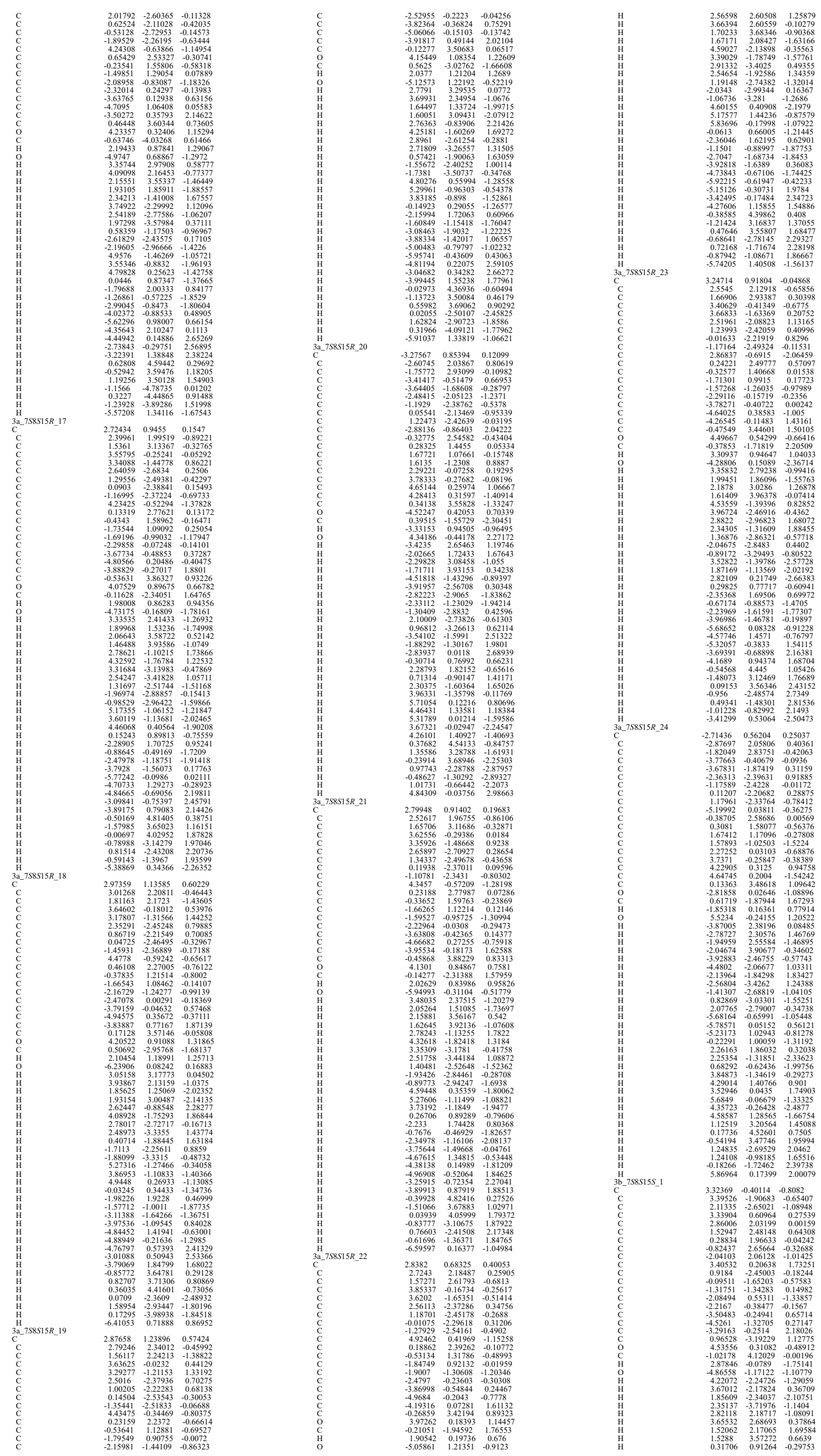

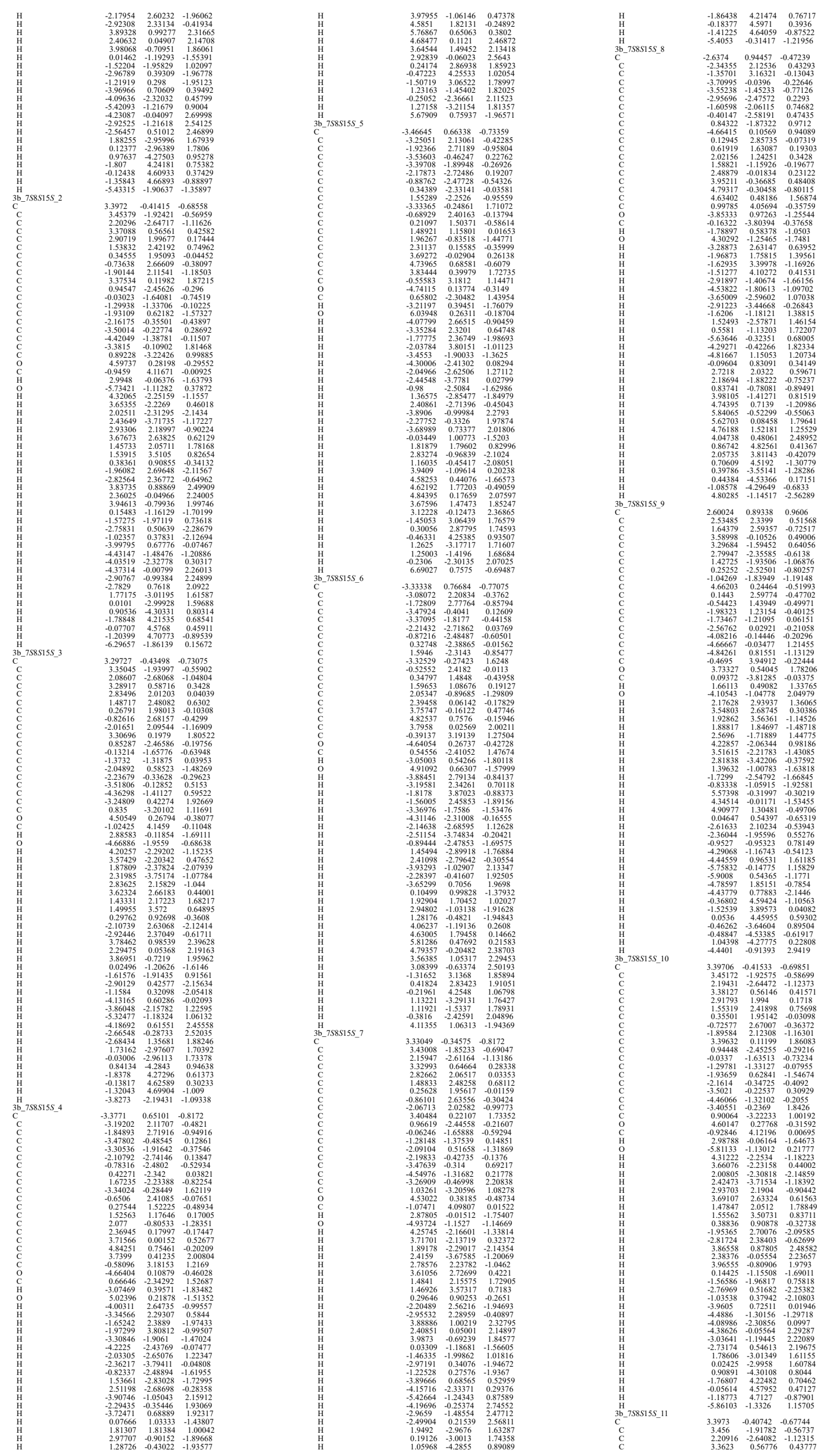

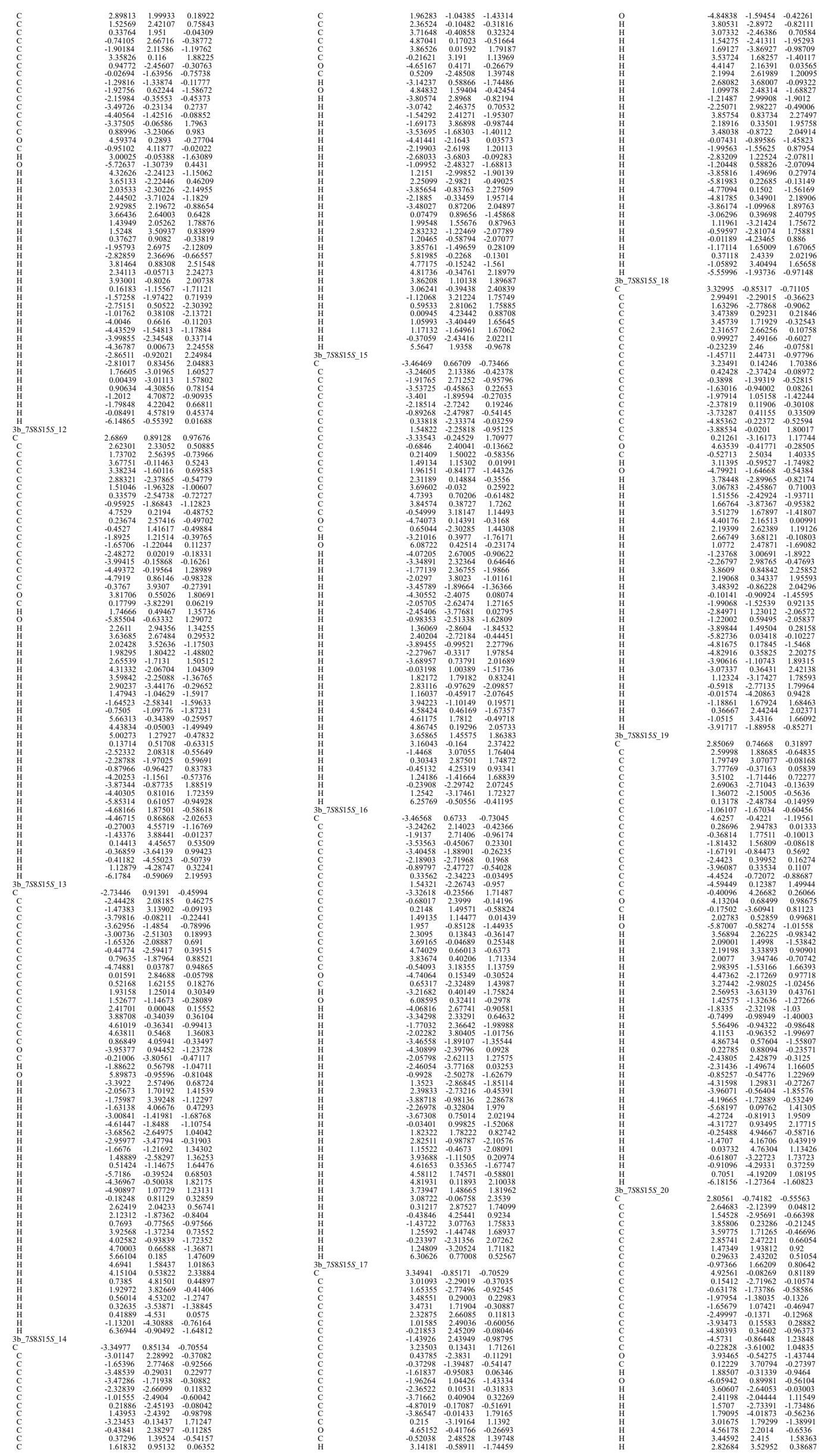

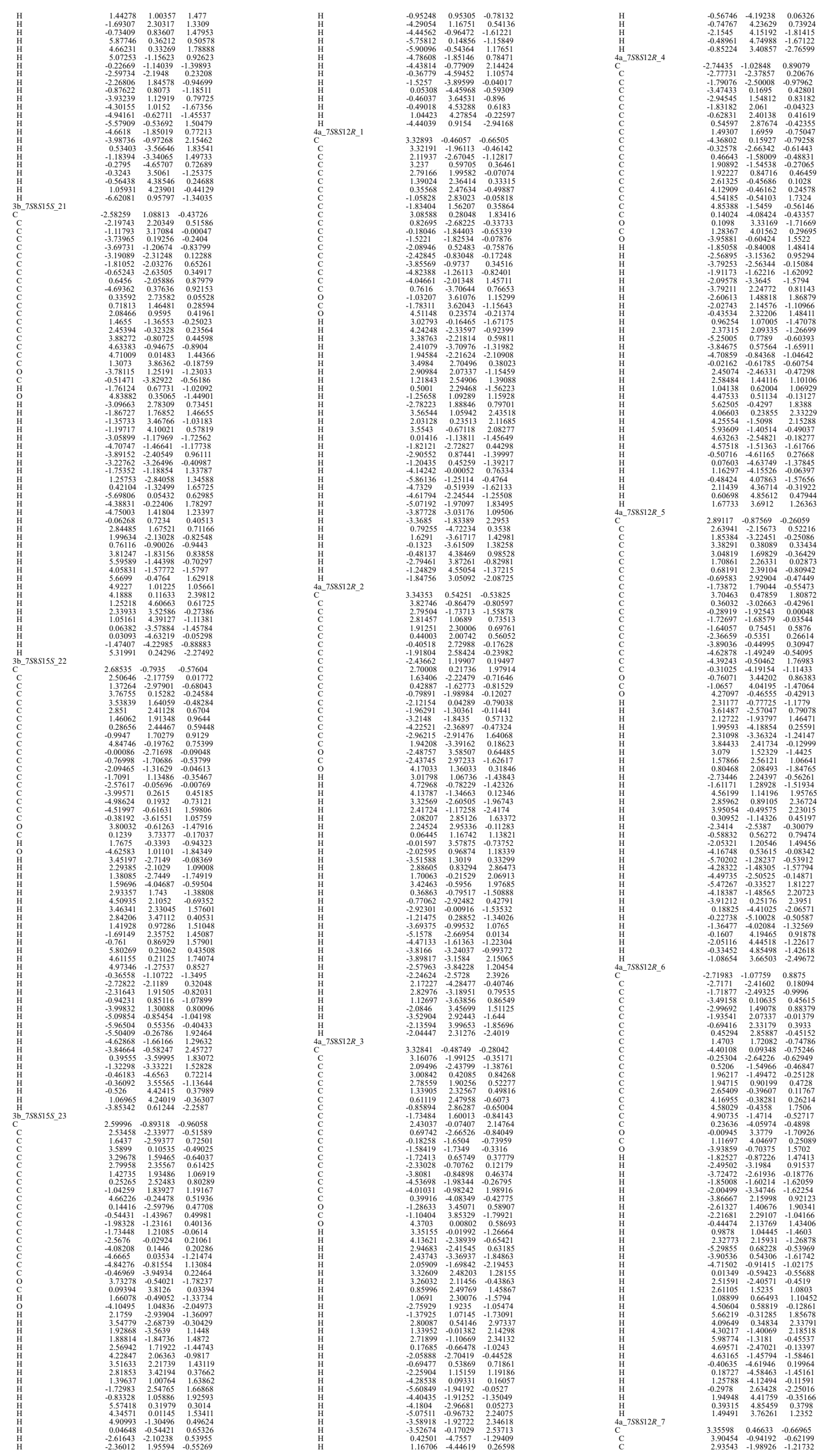

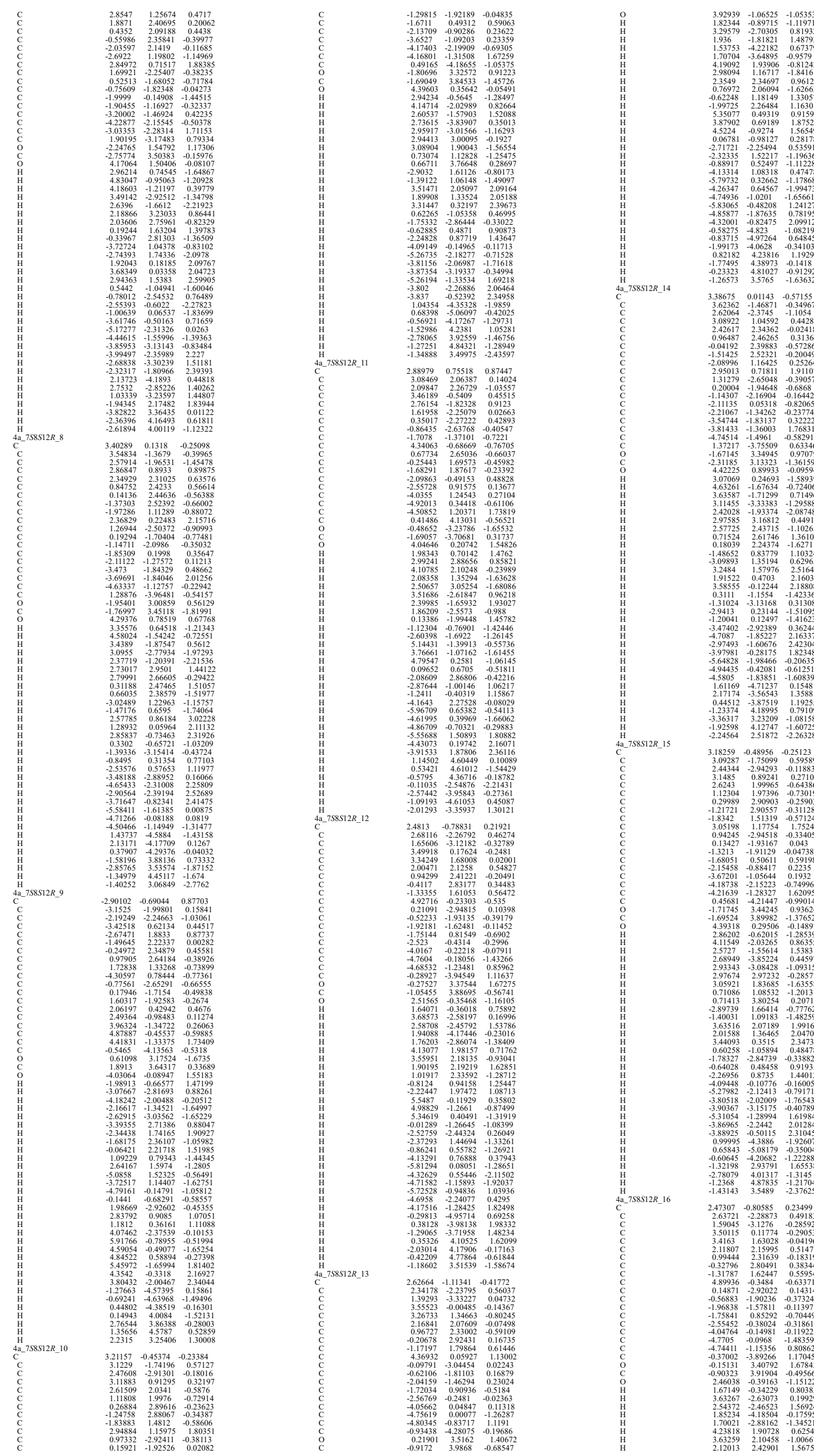

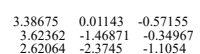

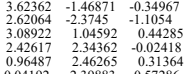

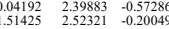

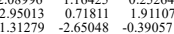

$\begin{array}{ccc}0.20004 & -1.94648 & -0.6868 \\ -1.14307 & -2.16904 & -0.1645\end{array}$

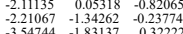

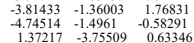

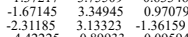

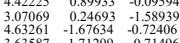

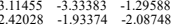

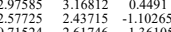

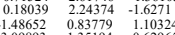

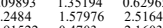

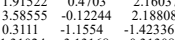

$\begin{array}{llll}-31024 & -3.13168 & 0.31308 \\ -94413 & 0.23144 & -1.51095 \\ -.5\end{array}$

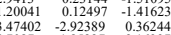

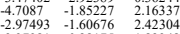

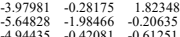

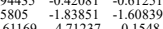

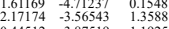

$\begin{array}{lll}-1.23374 & 4.18995 & 0.79109 \\ -.336317 & .32209 & -1.08158 \\ -1.22354 & 2382 & -2238\end{array}$

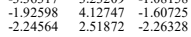

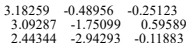

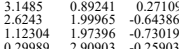

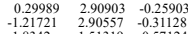

$\begin{array}{lll}3.05198 & 1.17754 & 1.7524\end{array}$

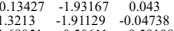

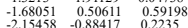

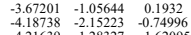

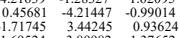

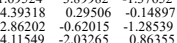

$\begin{array}{lll}2.5727 & -1.55614 & 1.5383 \\ 2.68849 & -3.855224 & 0.44597\end{array}$

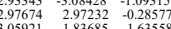

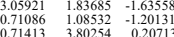

\begin{tabular}{llll}
-2.89739 & 1.66414 & -0.77762 \\
-1.40031 & 1.099183 & -1.48259 \\
\hline
\end{tabular}

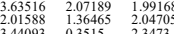

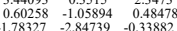

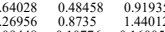

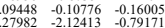

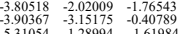

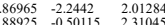

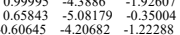

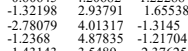

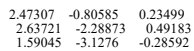

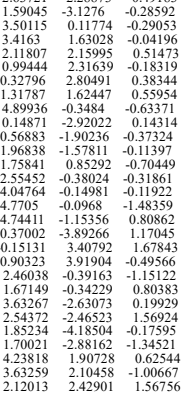



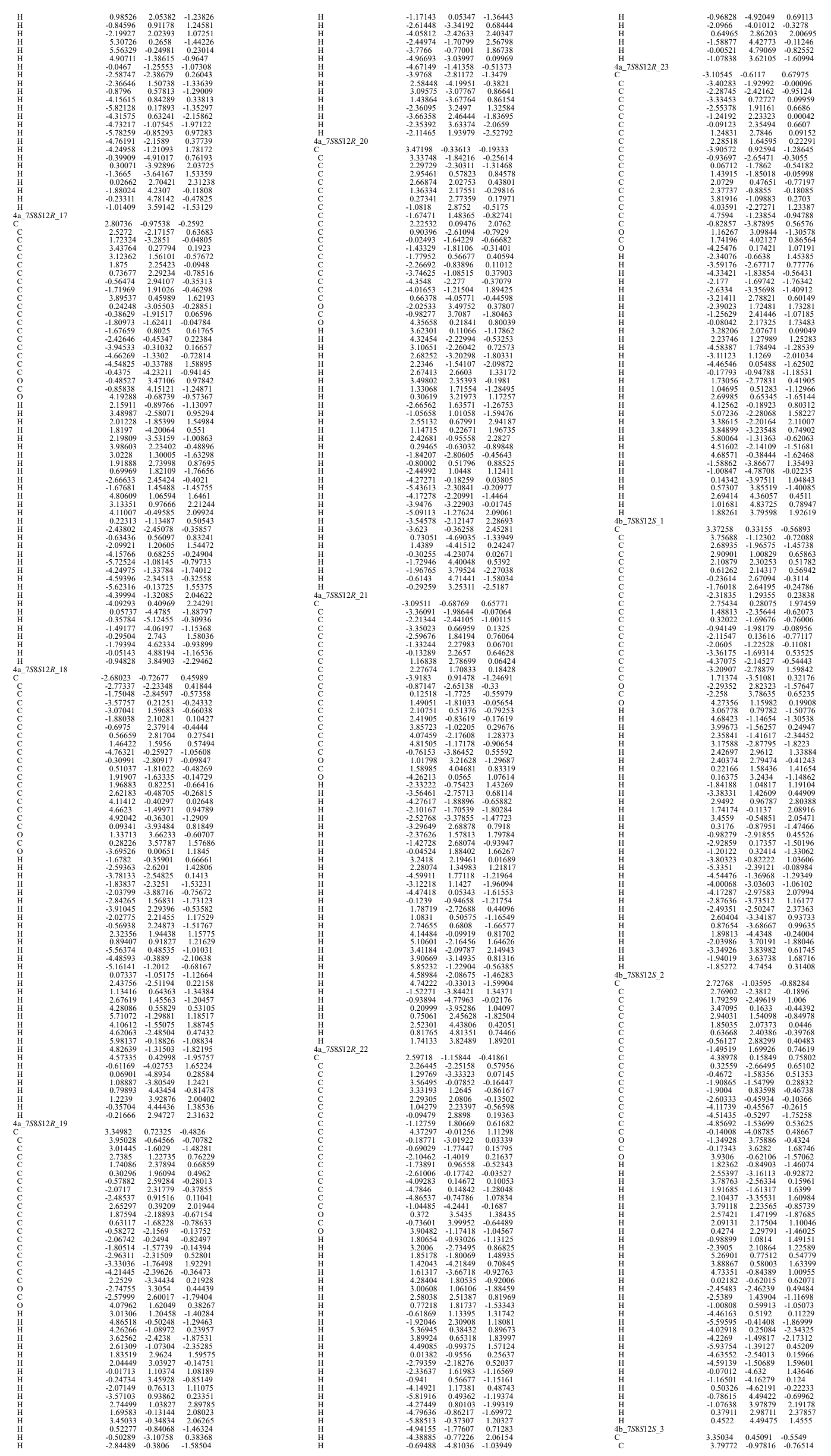

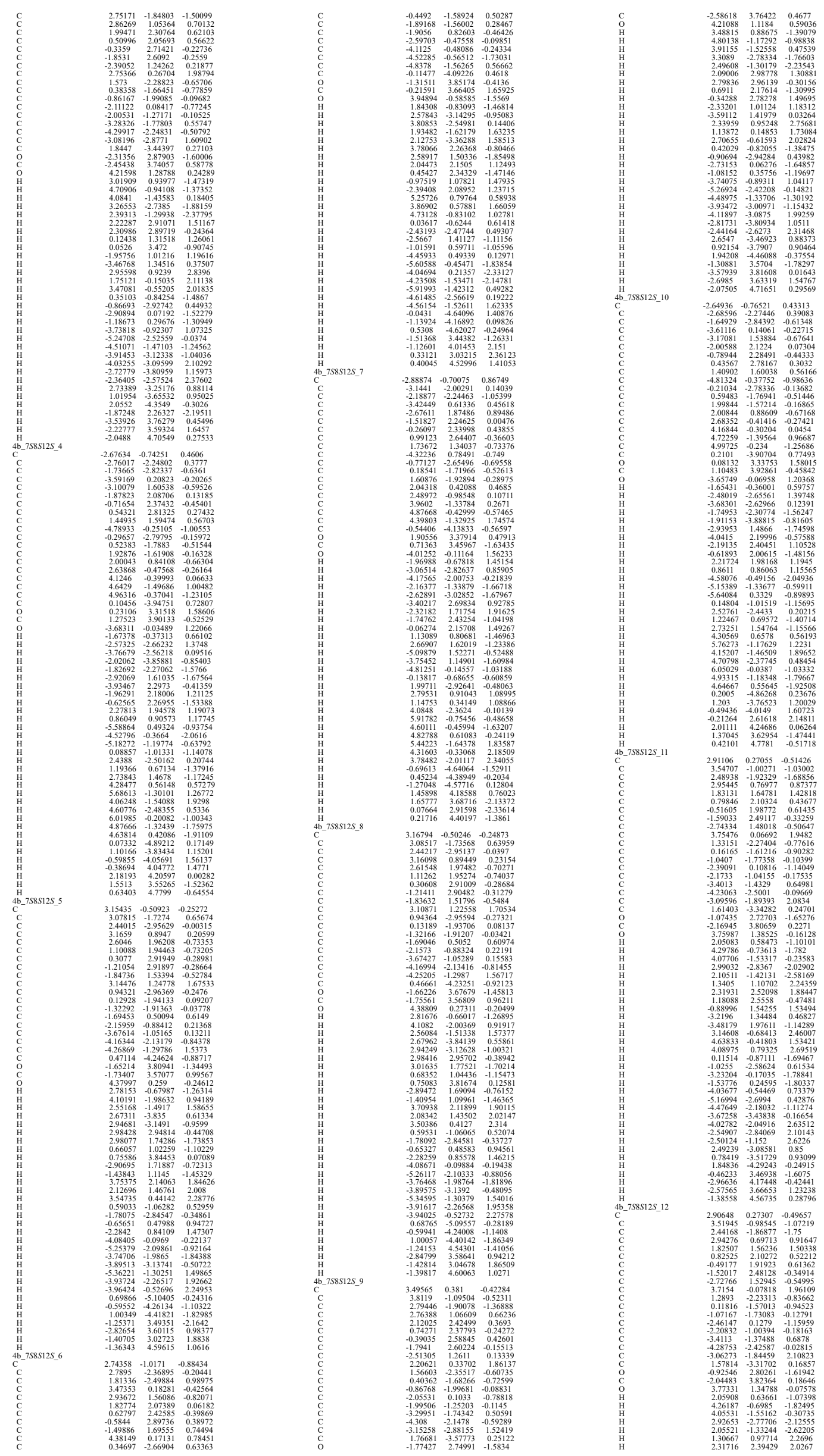

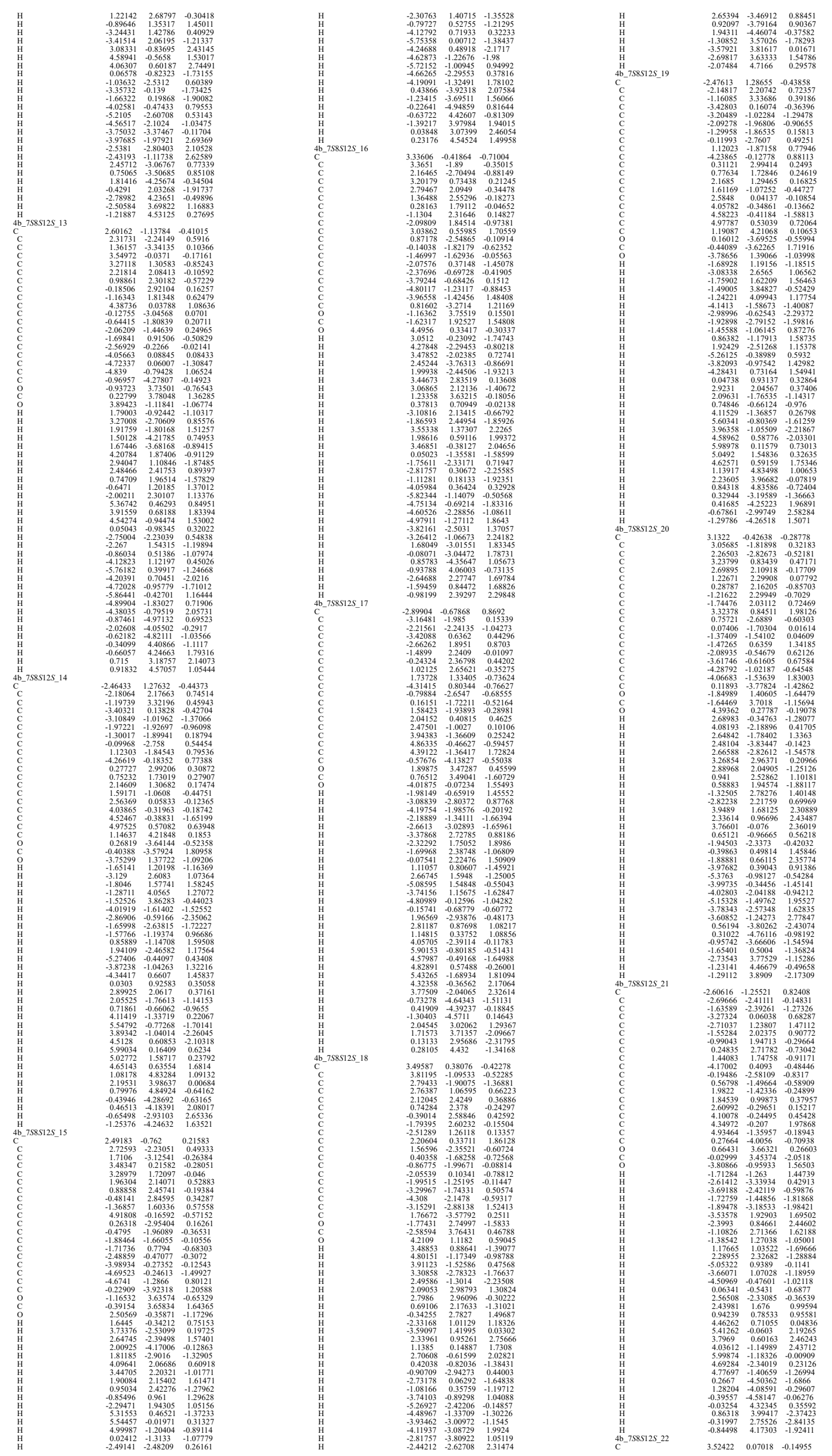

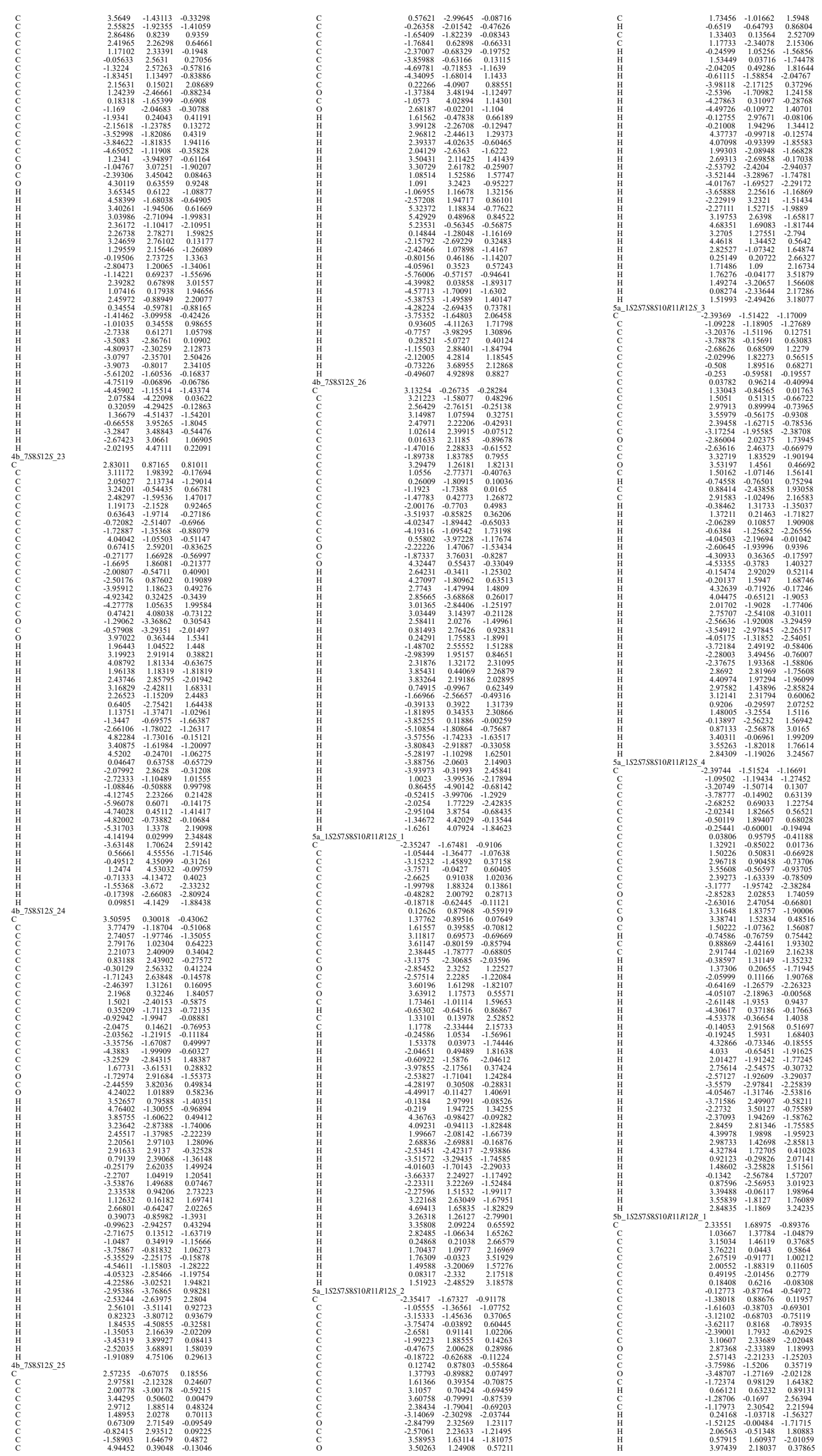

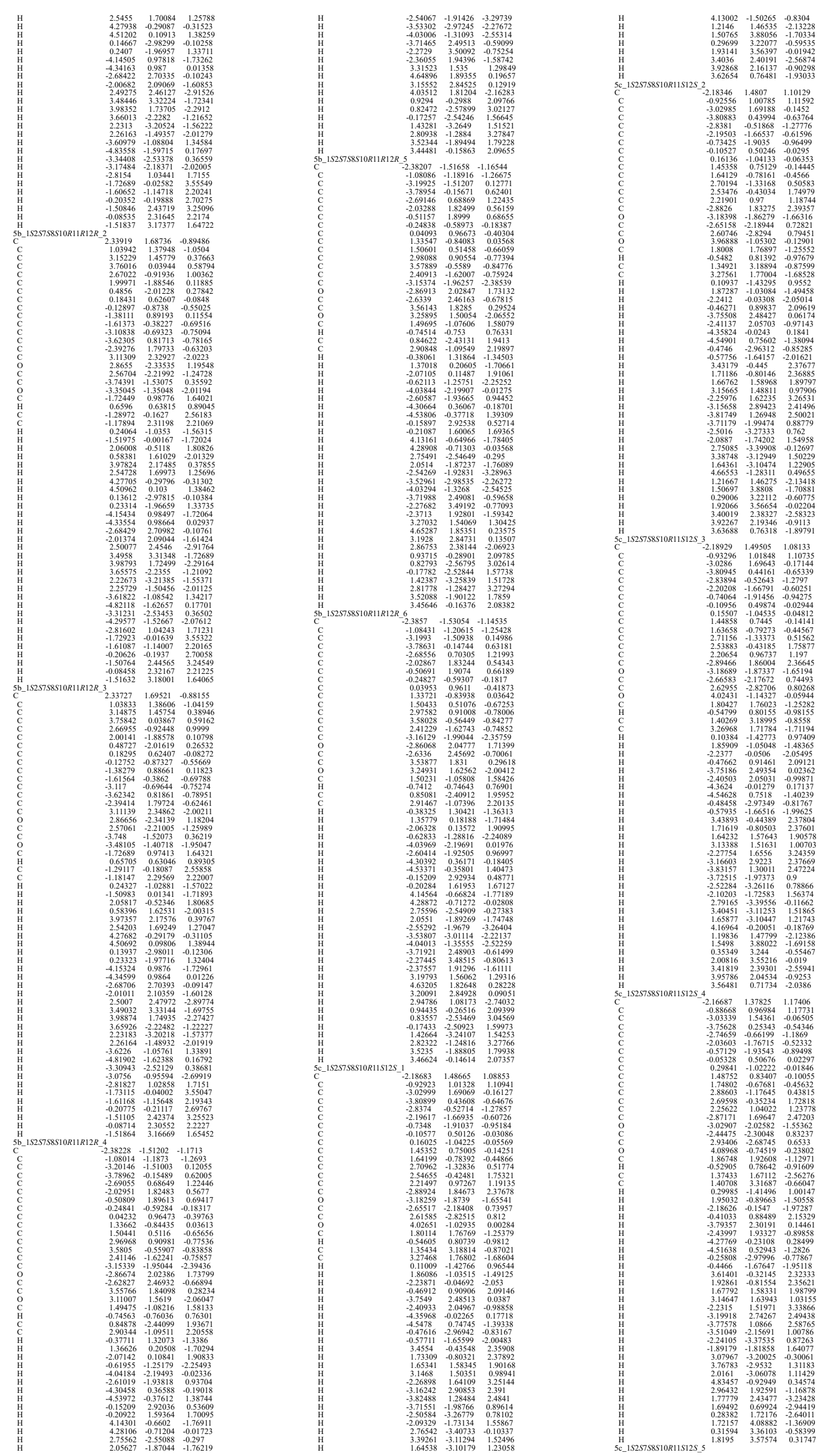

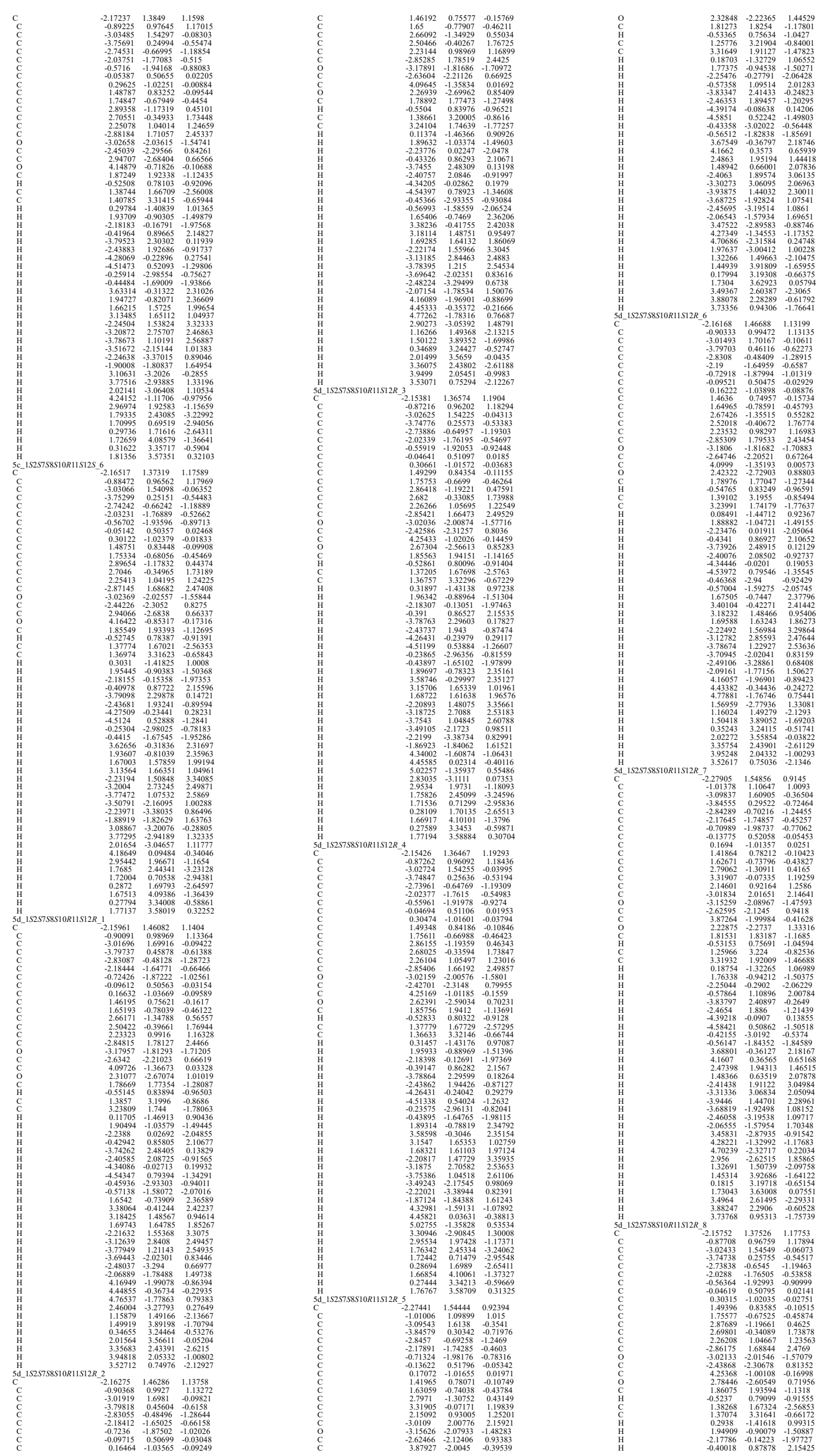

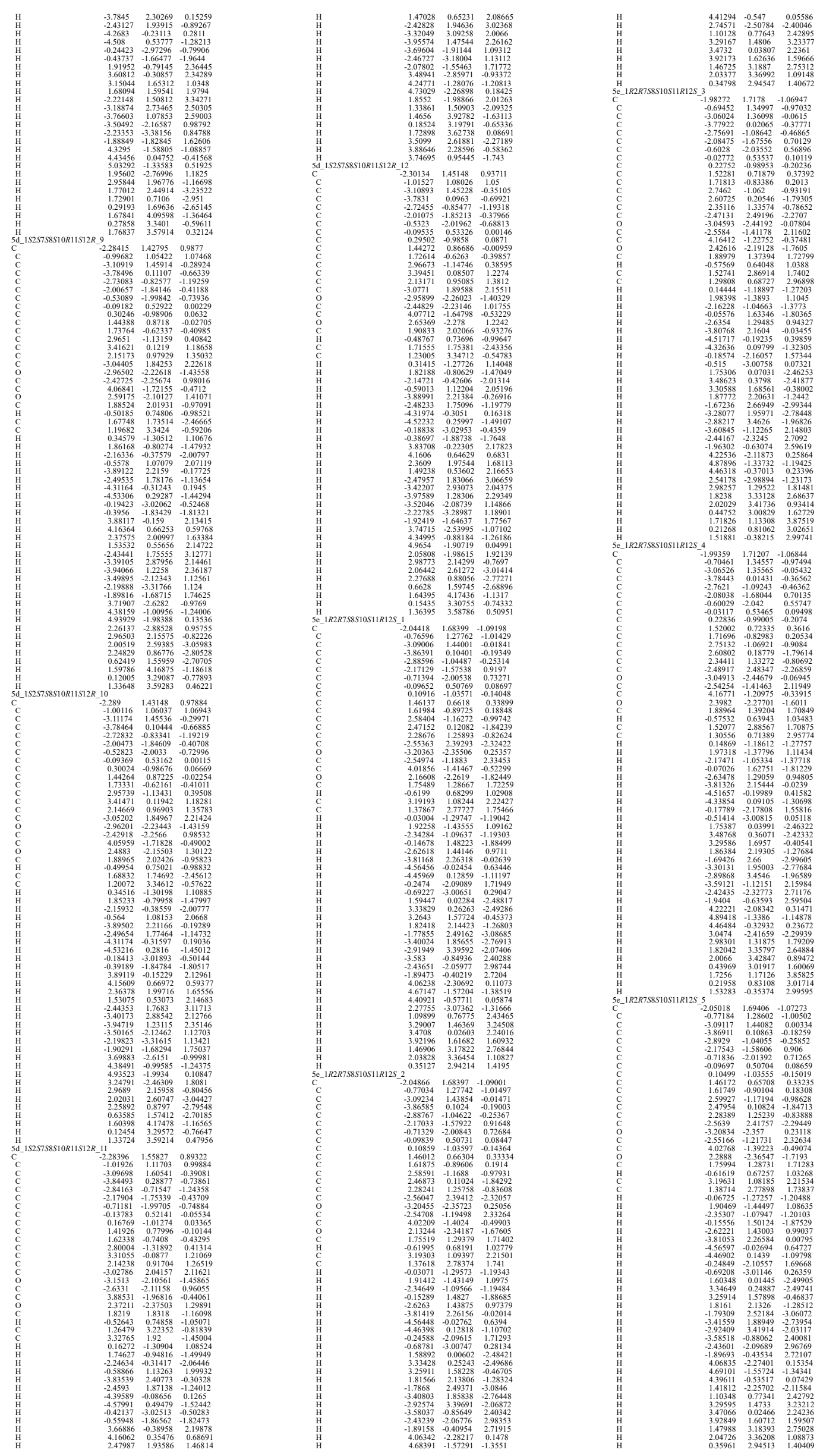

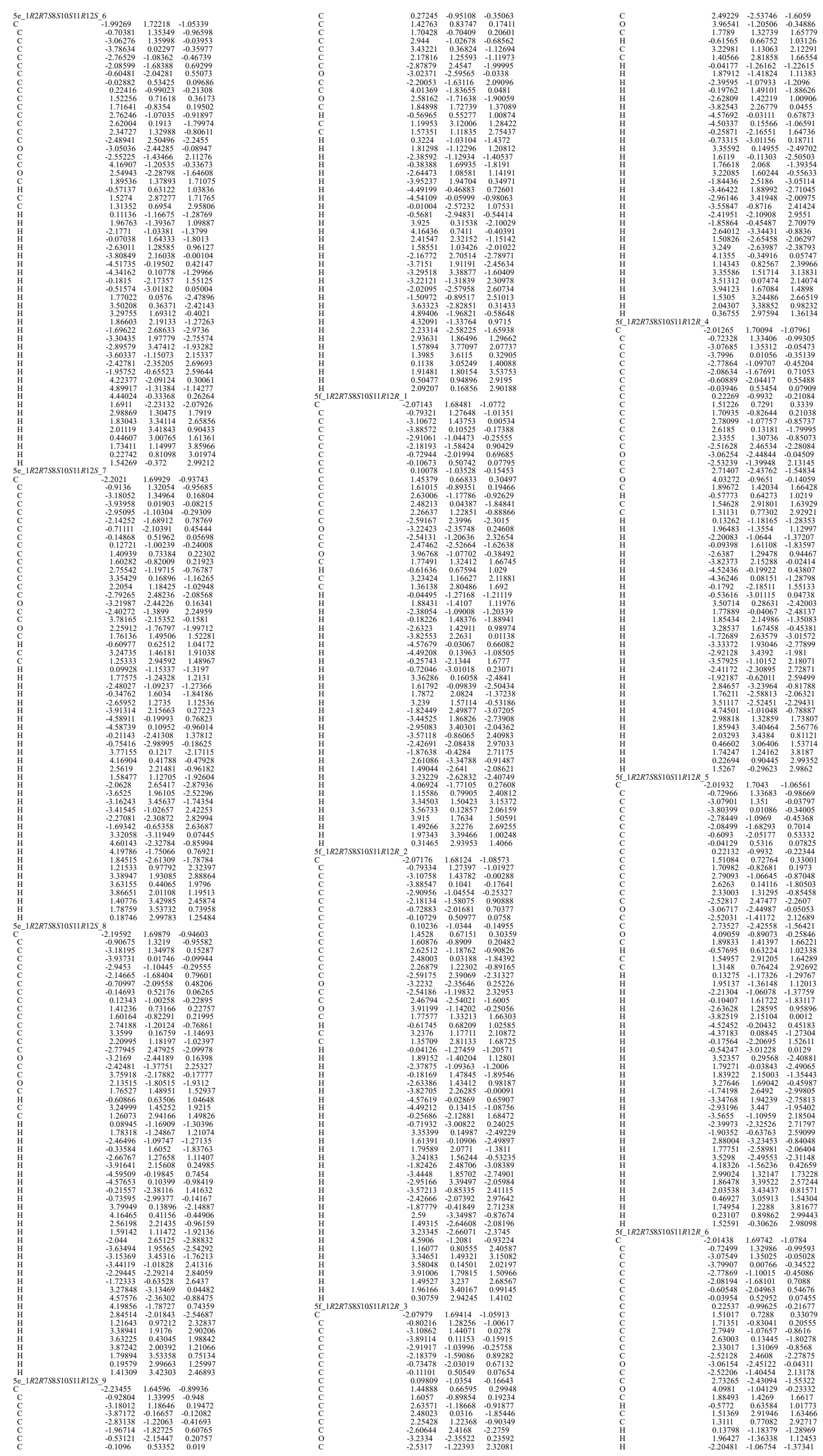

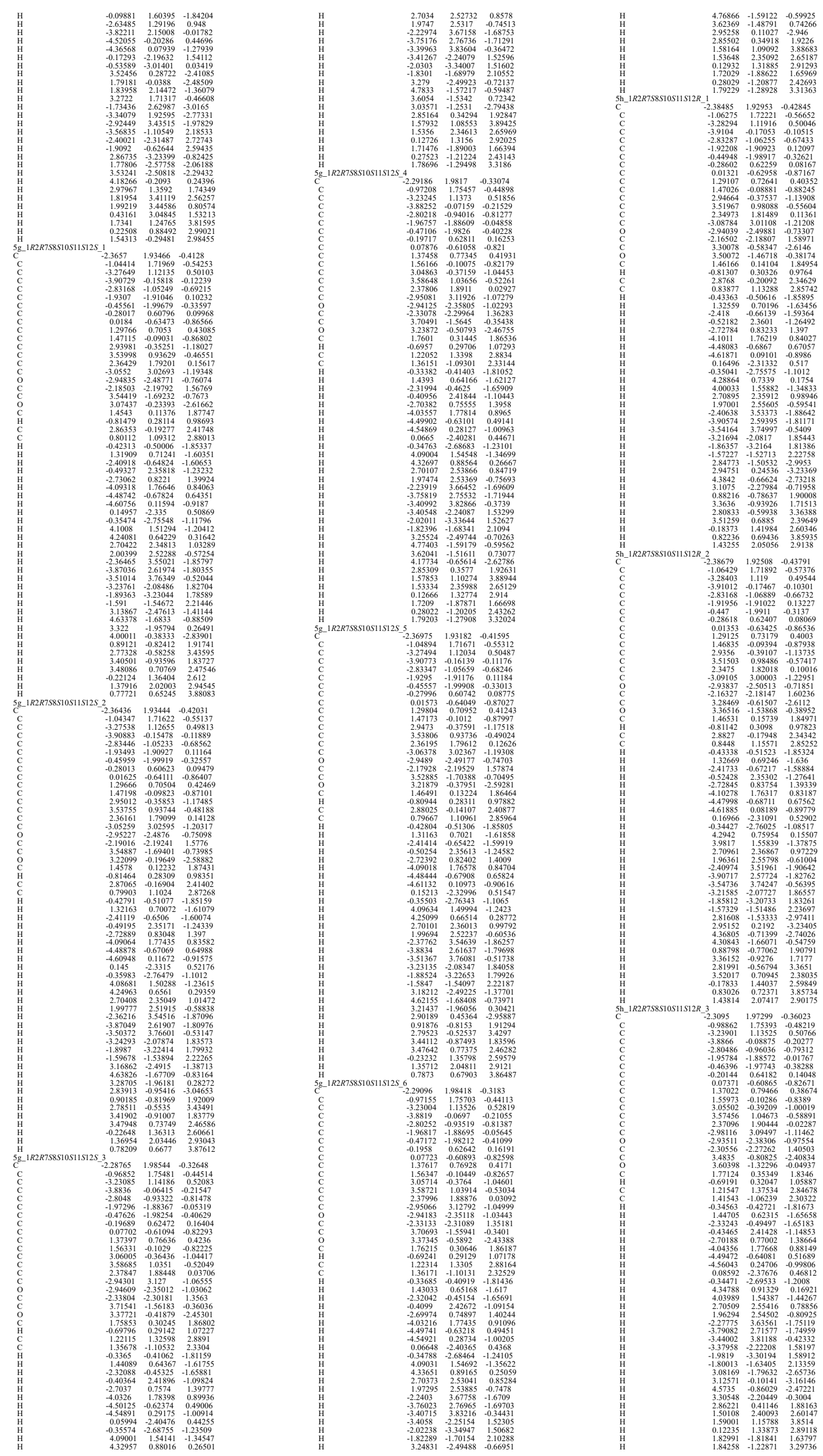

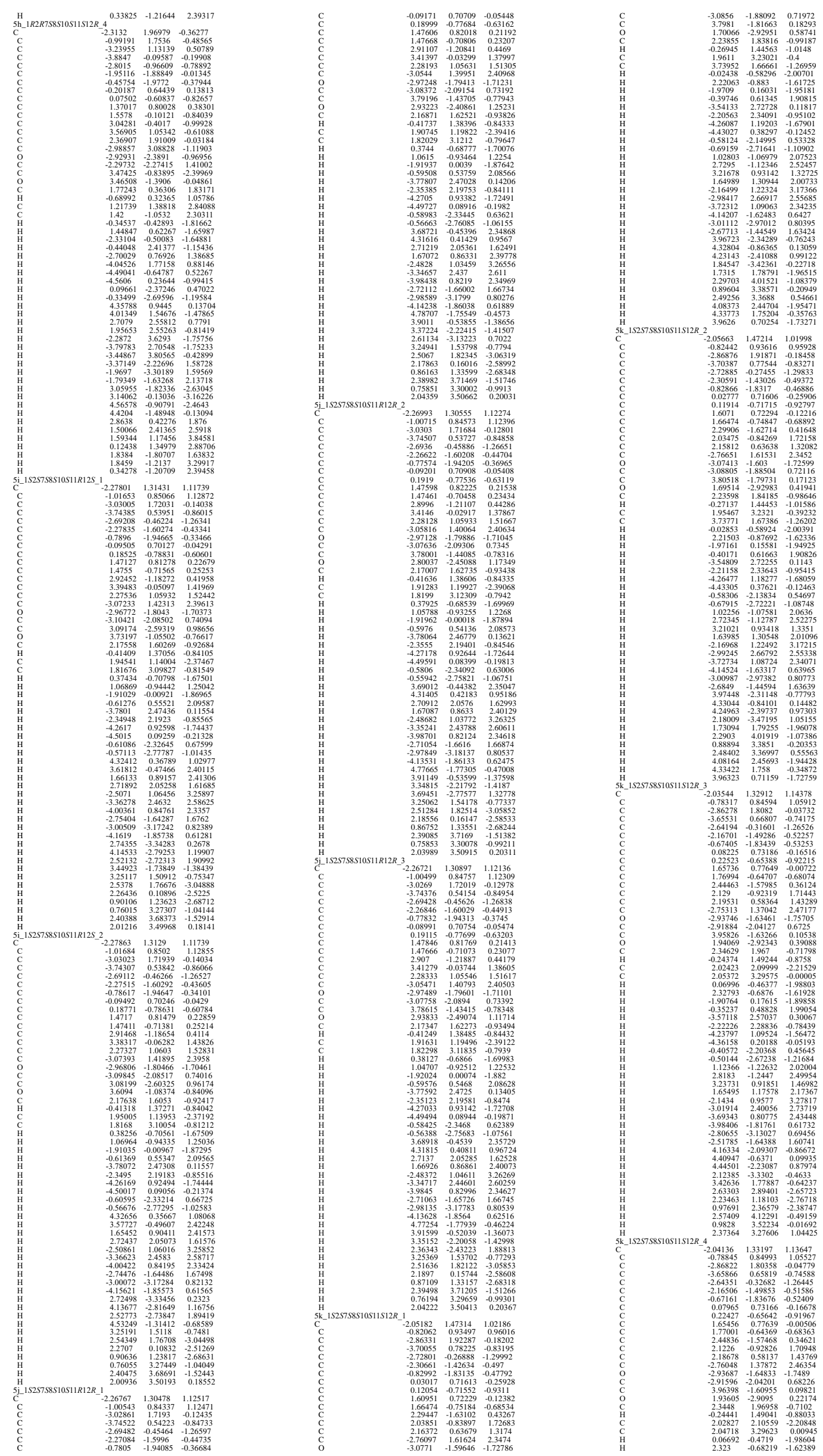

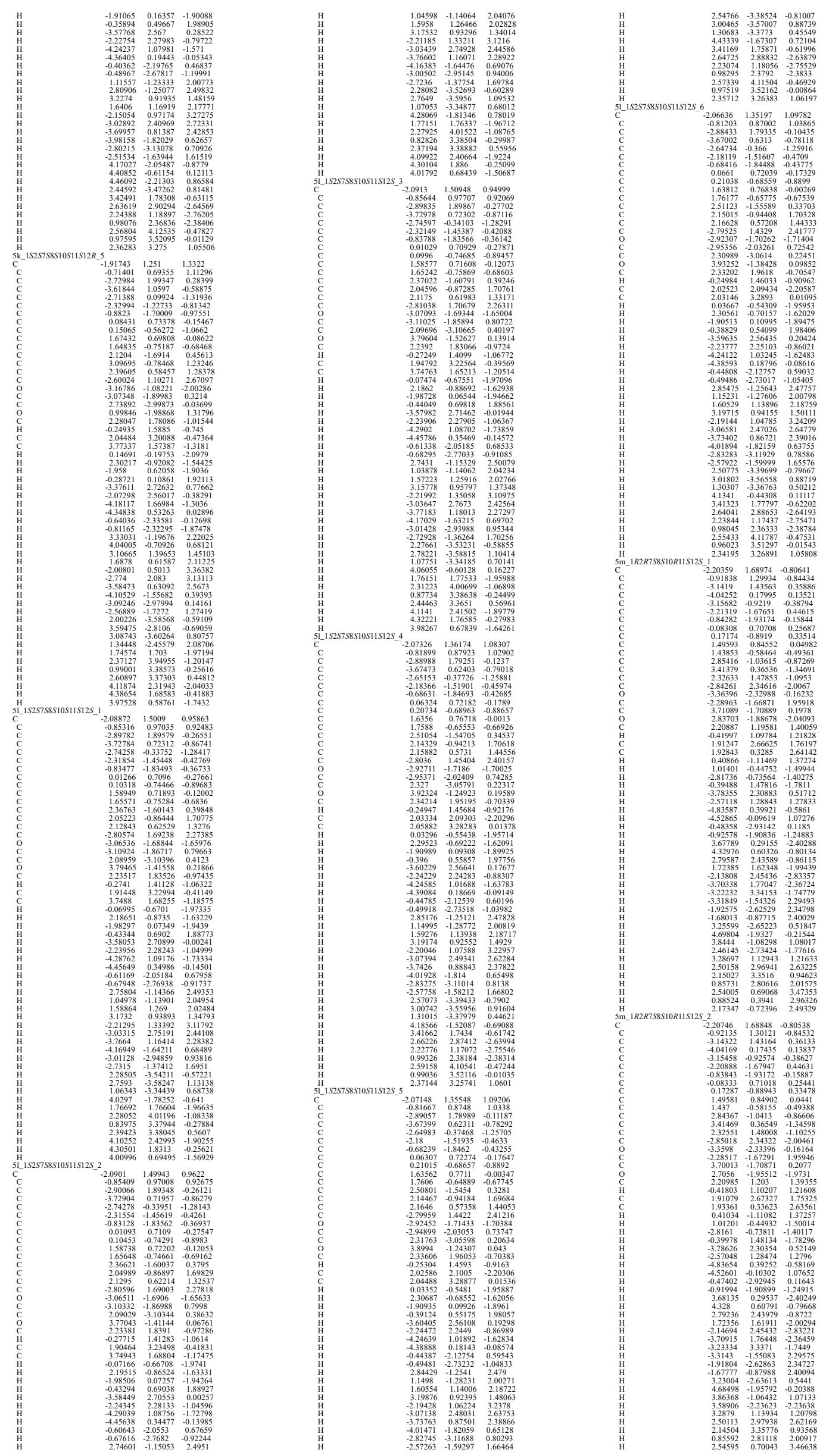

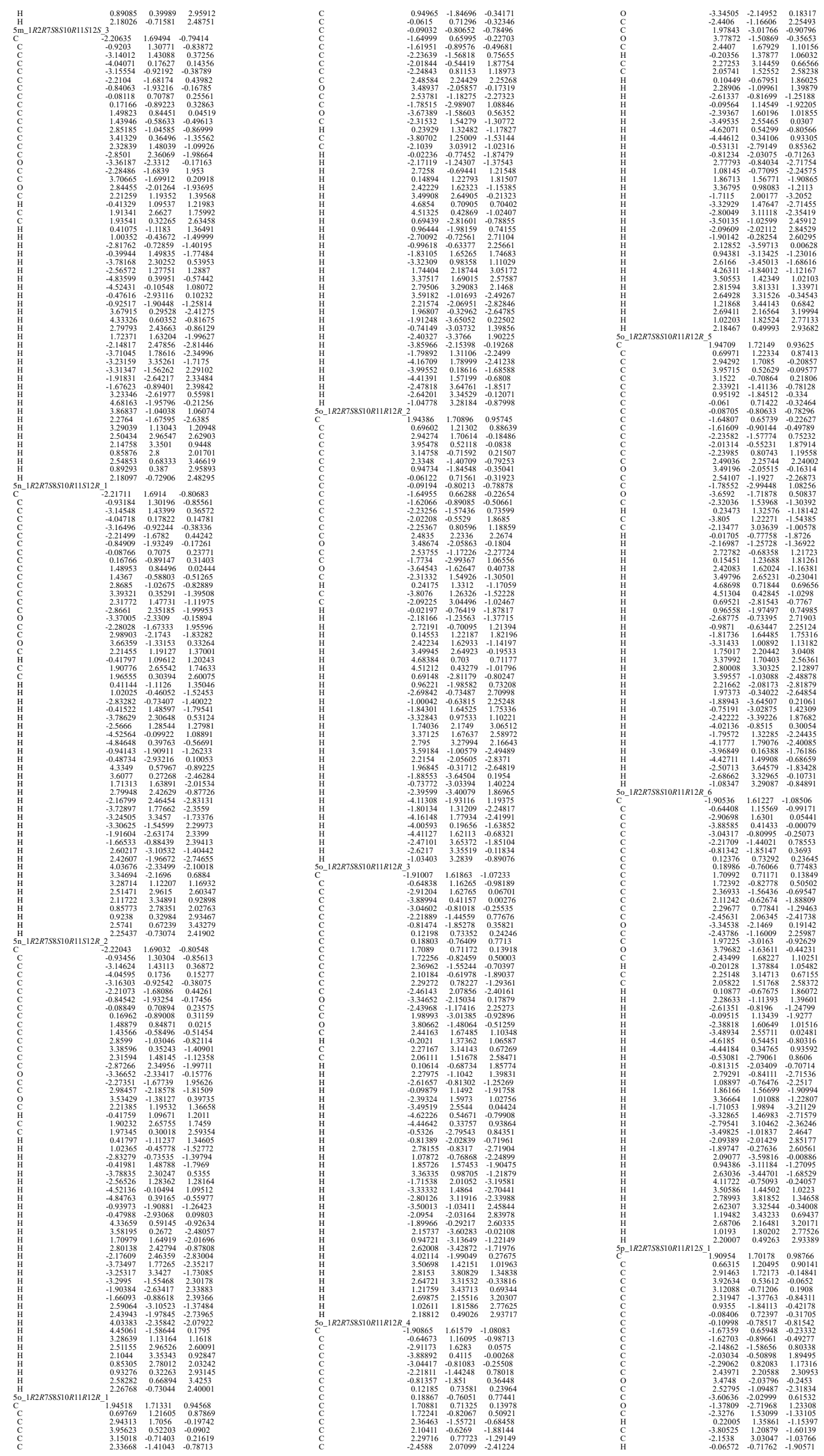

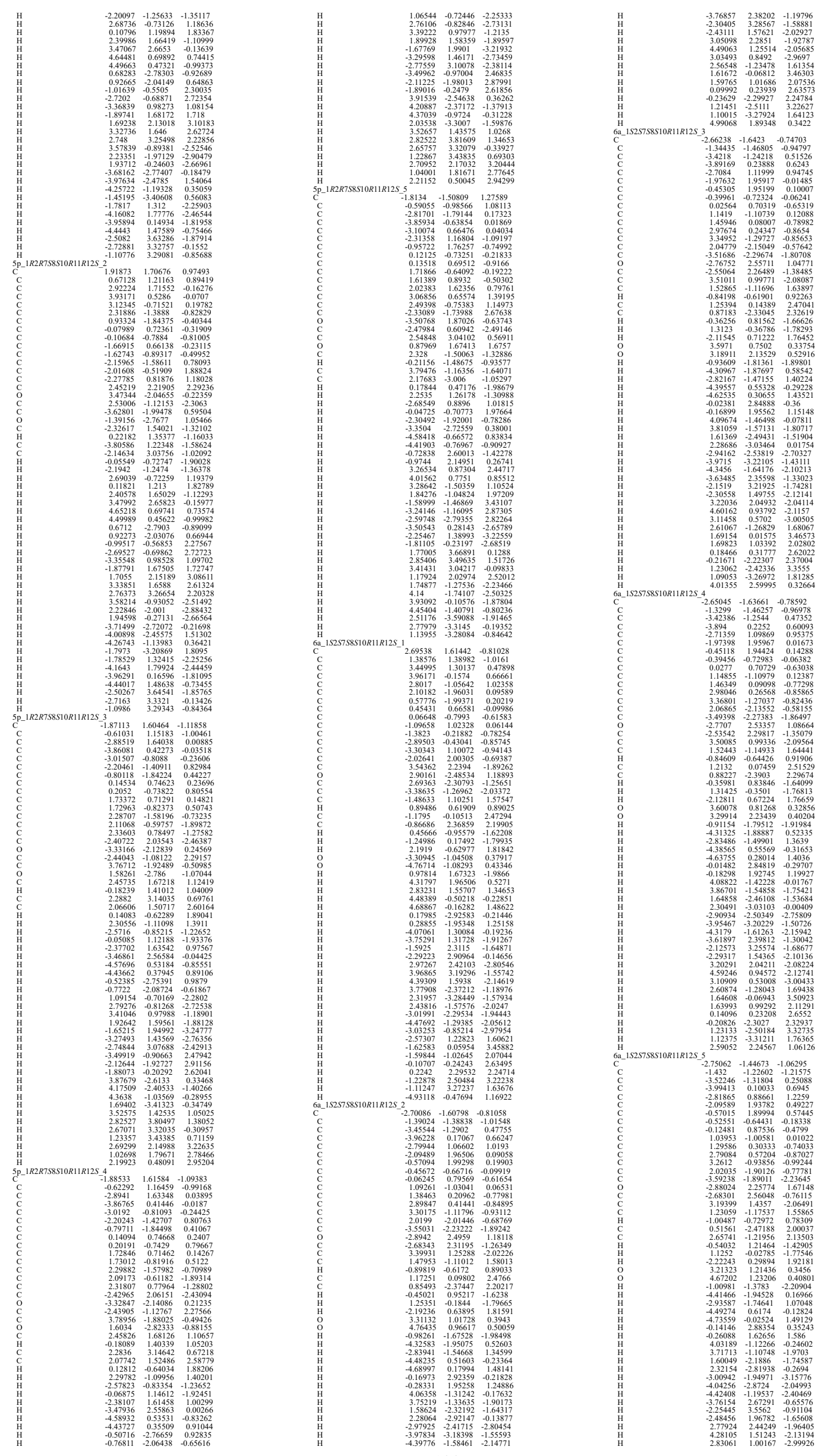

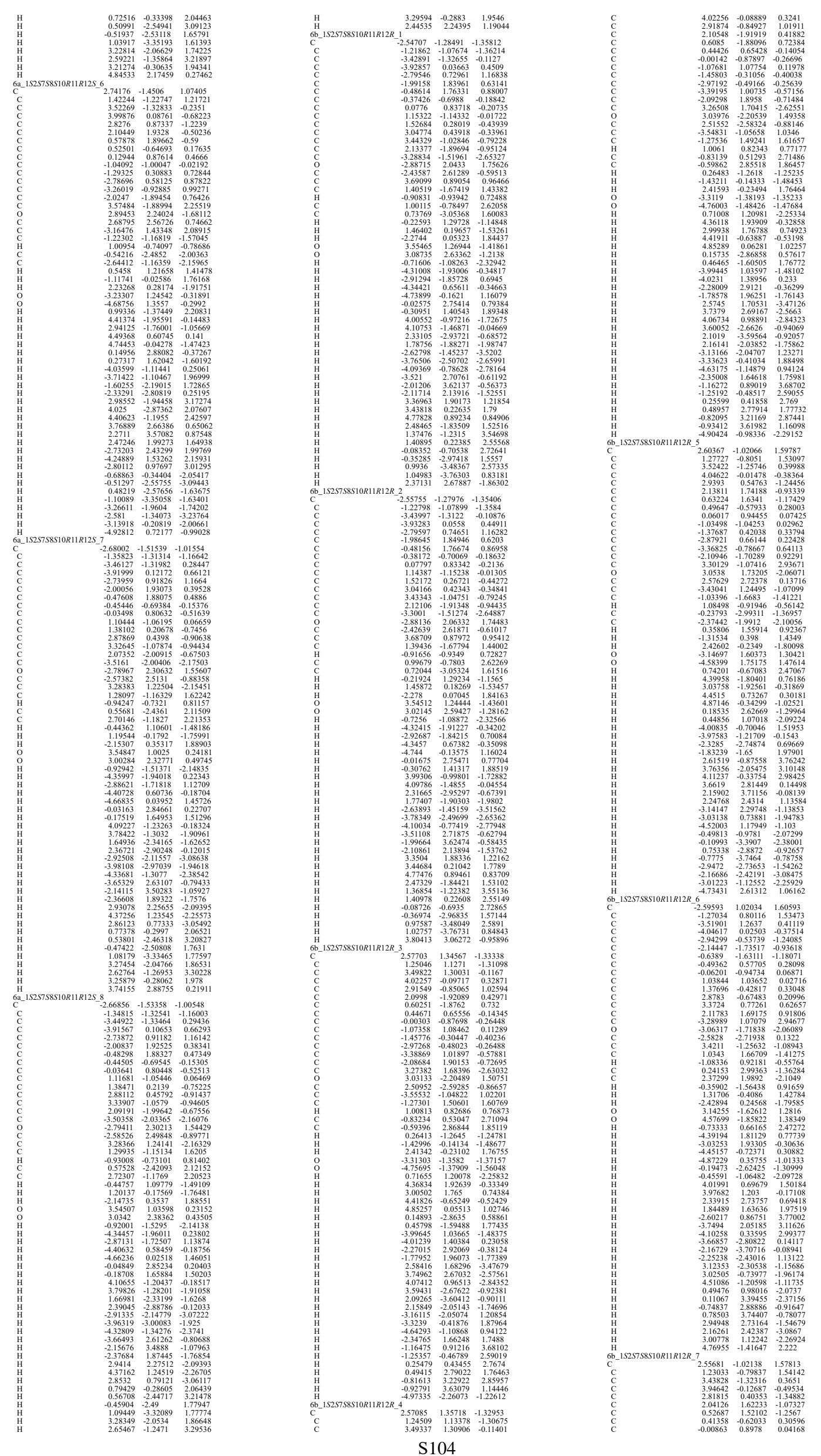

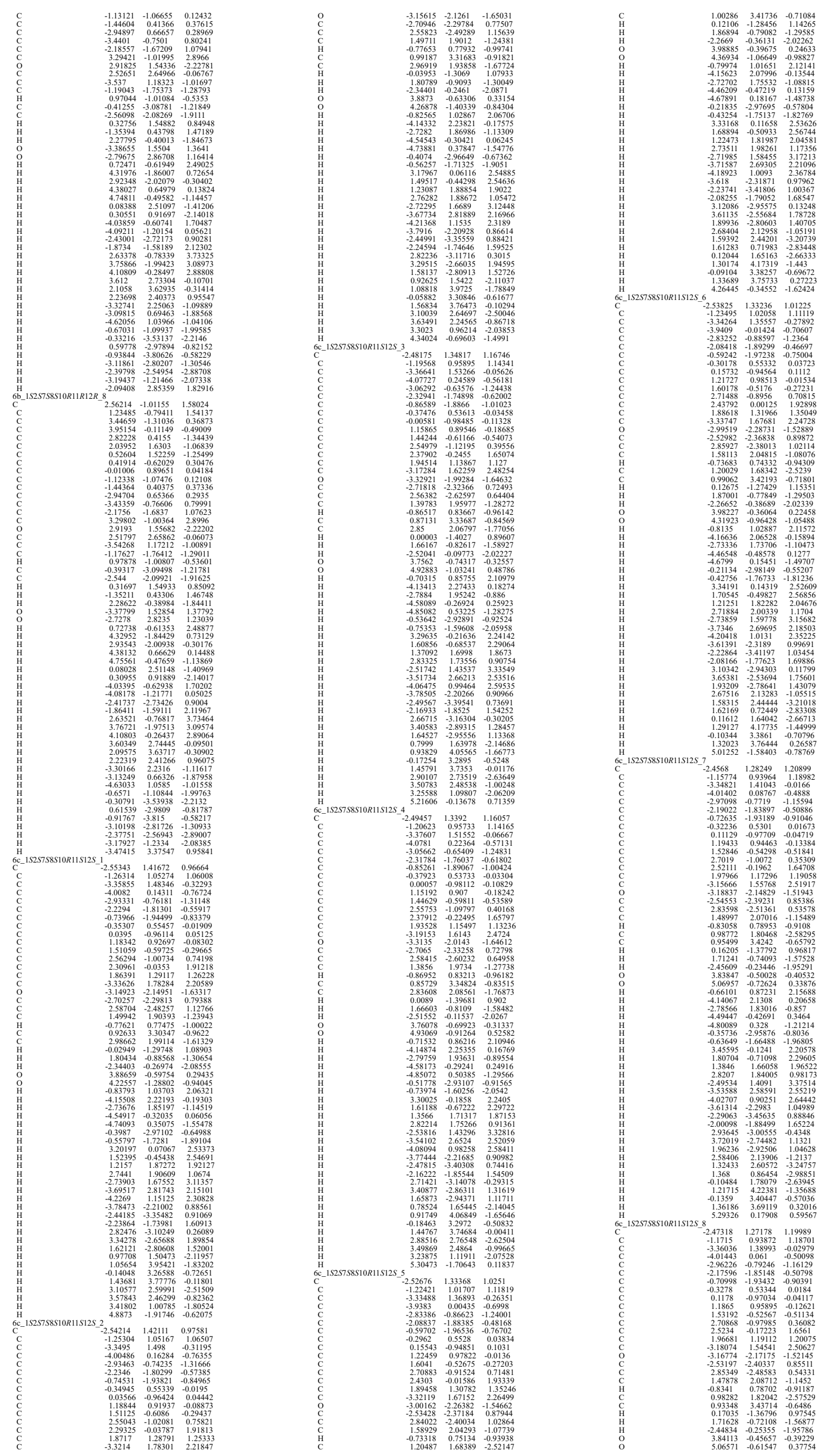

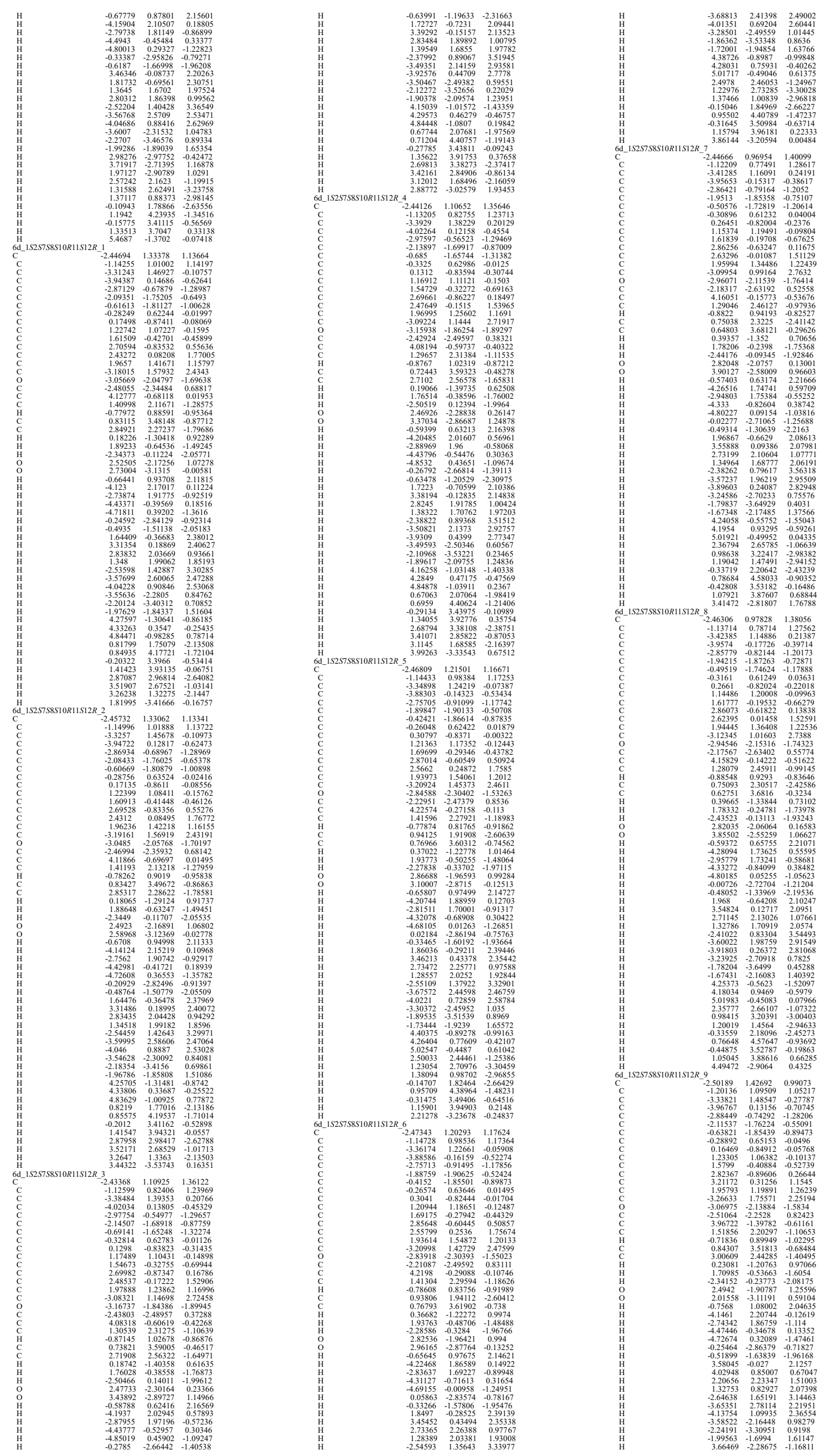

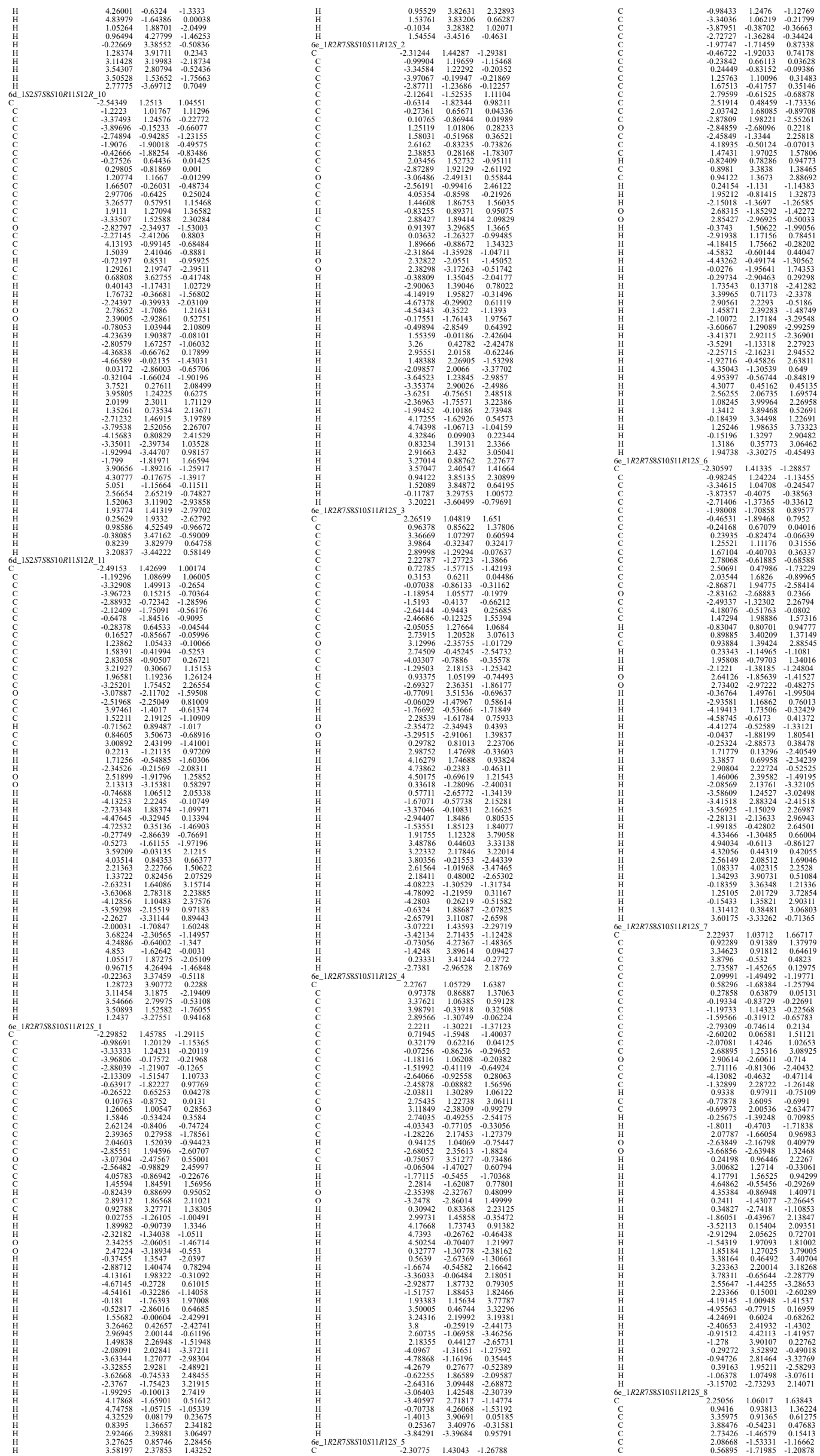

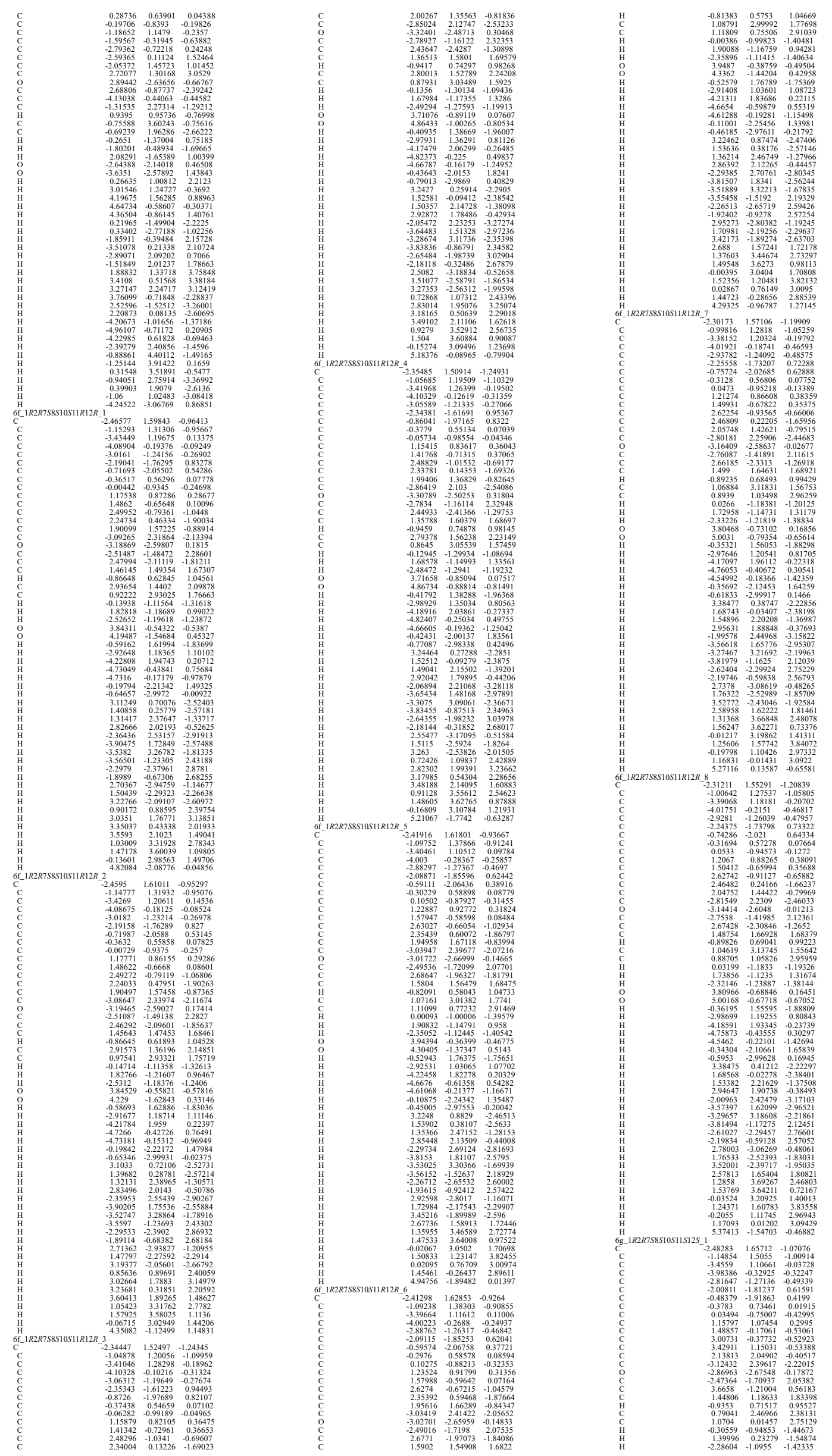

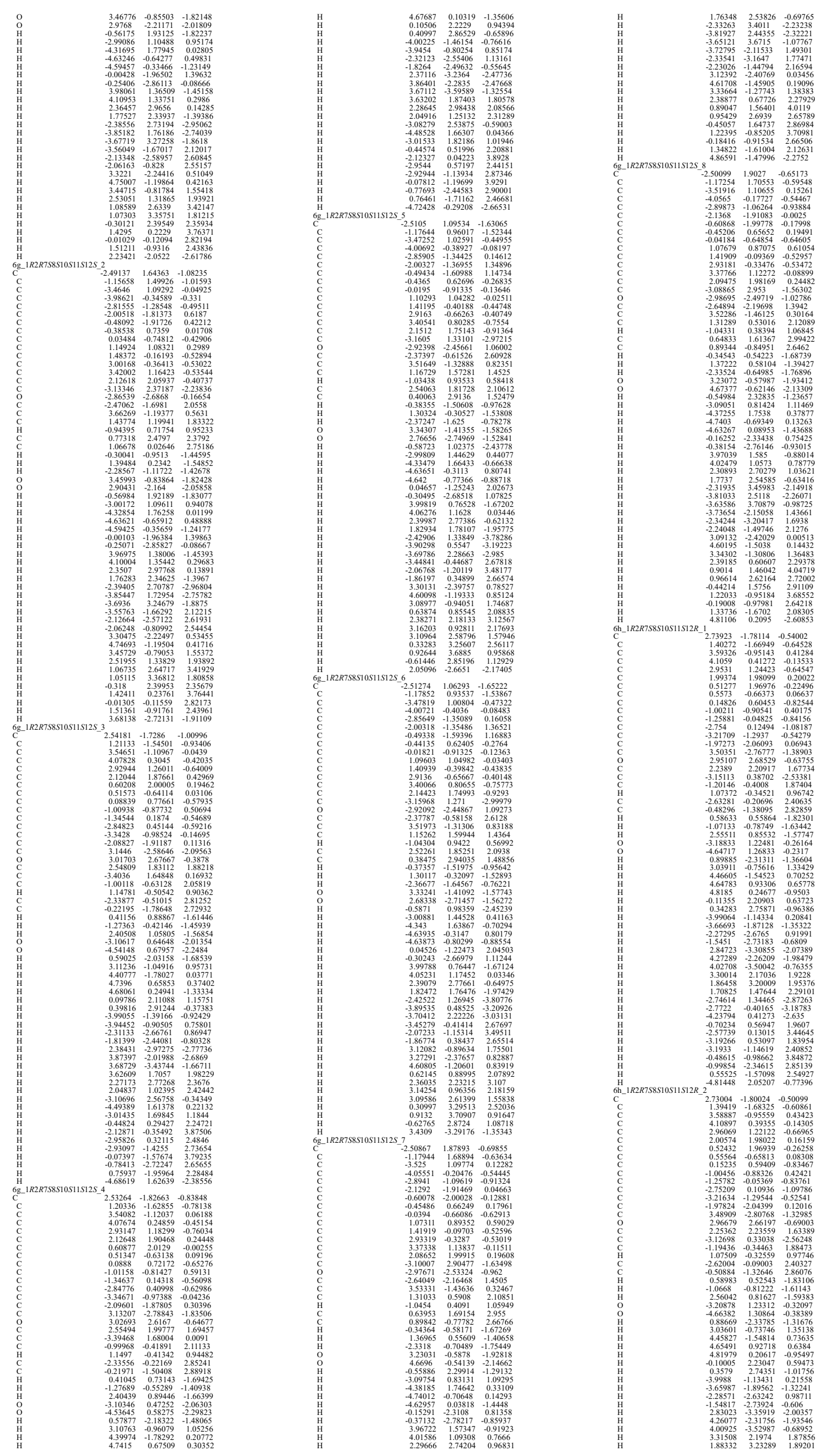

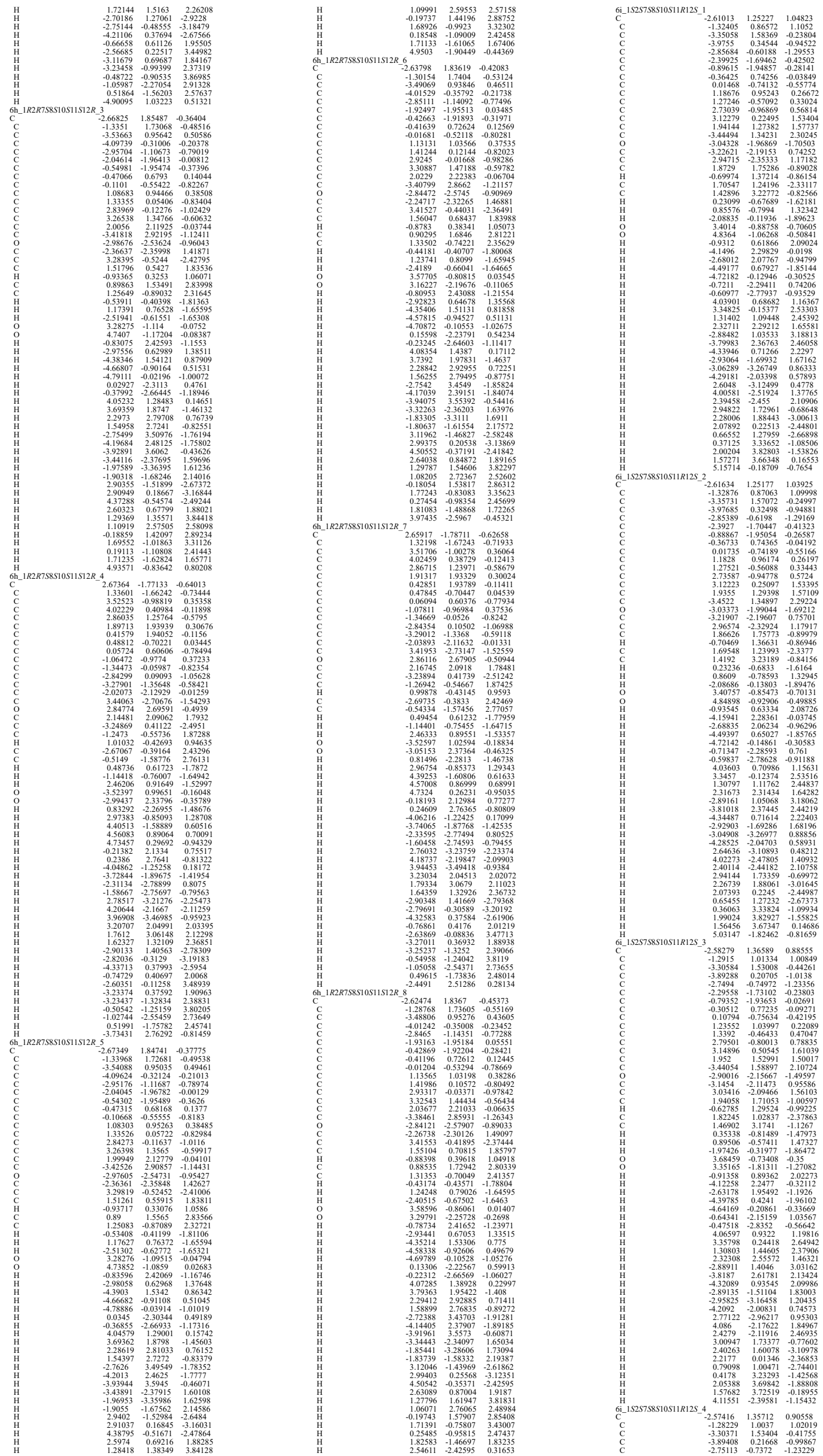

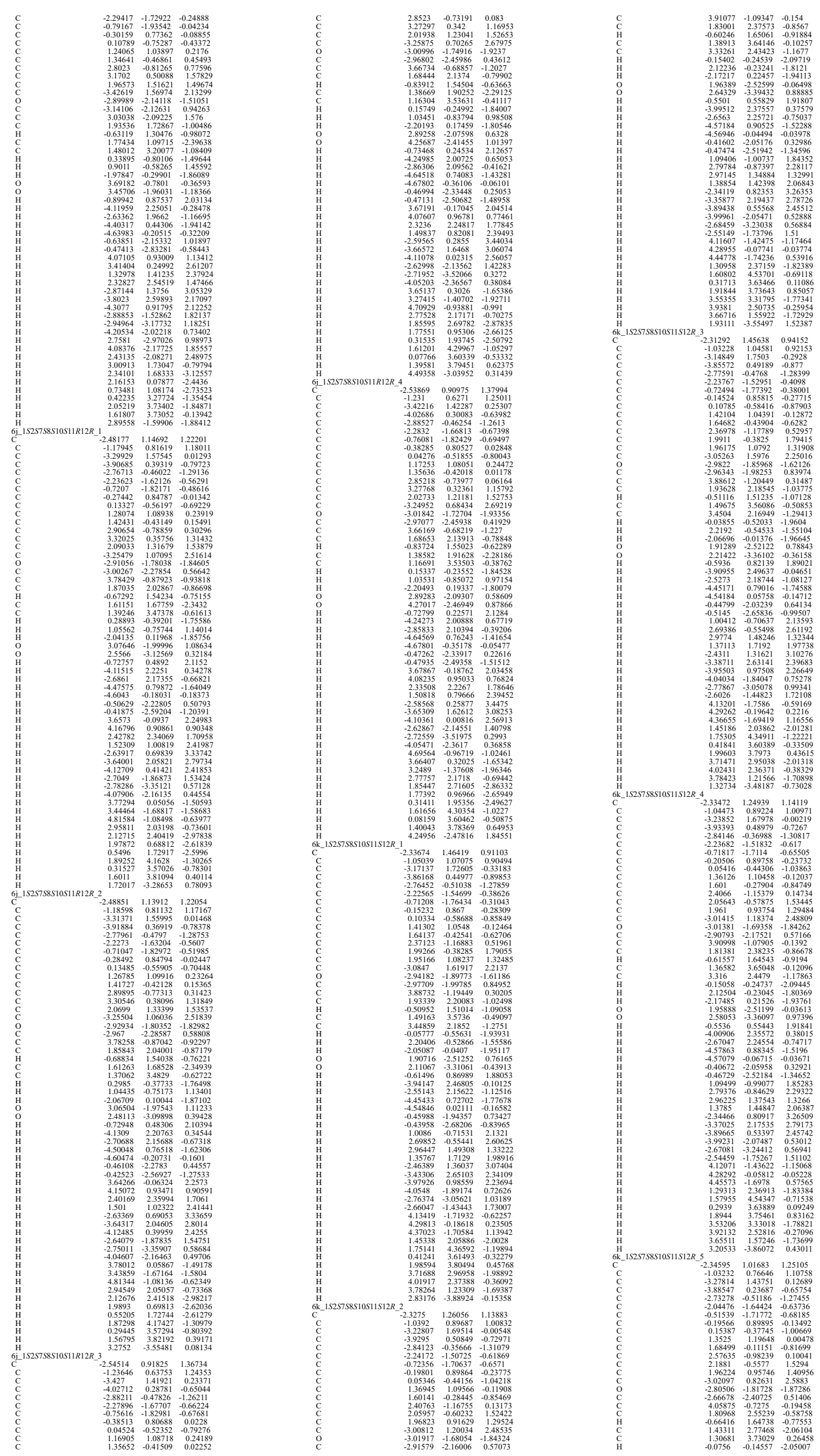

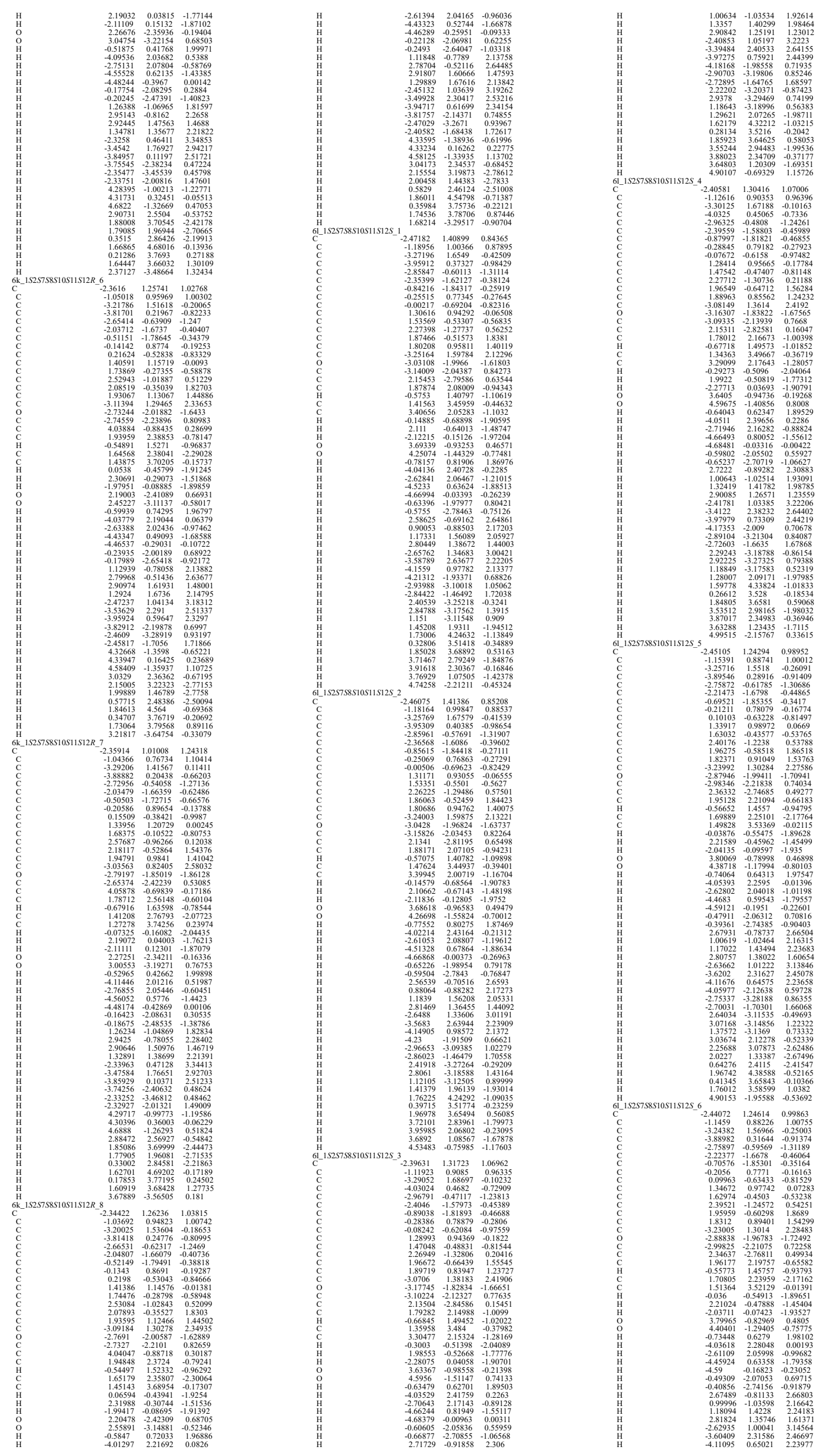

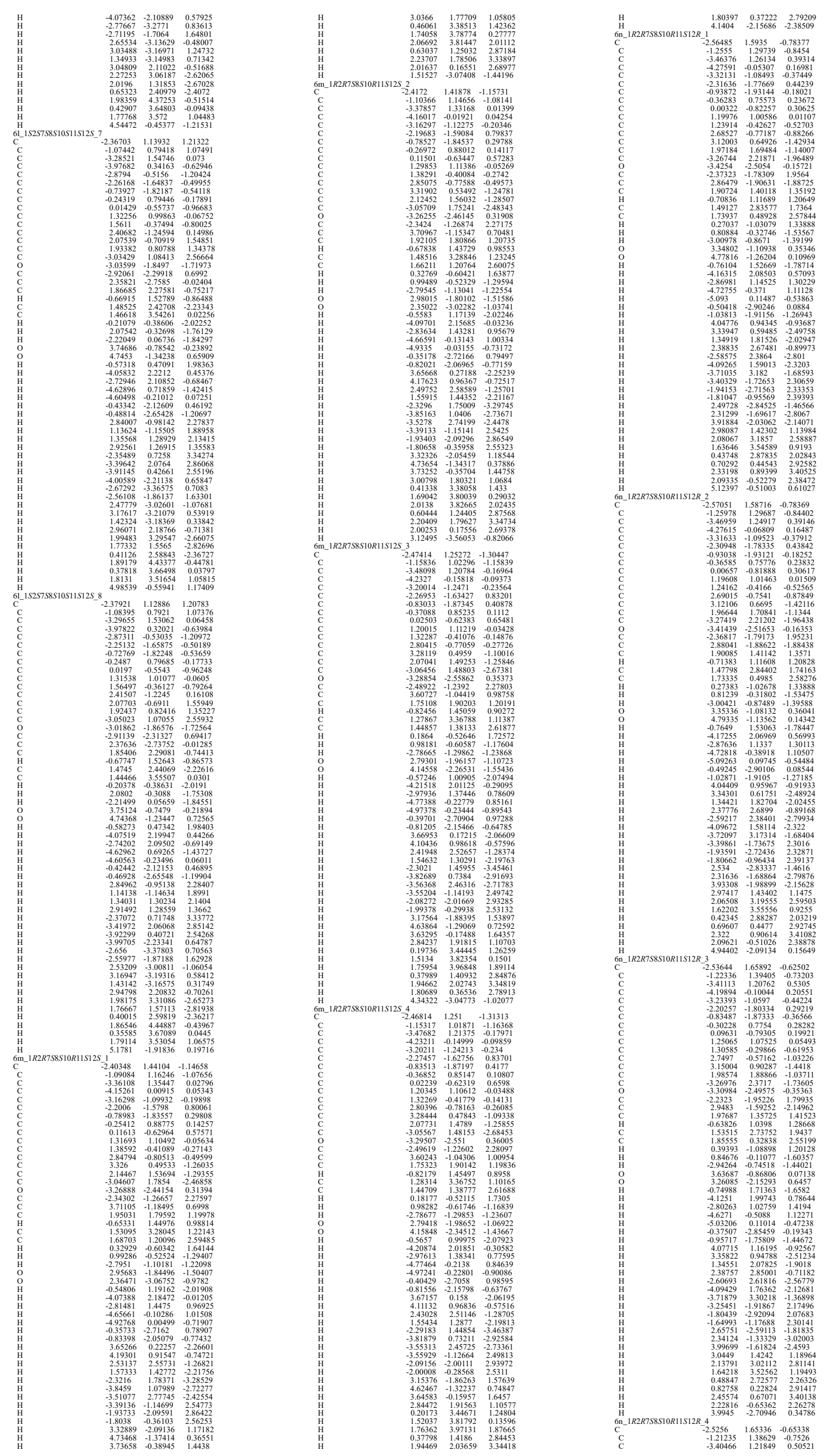

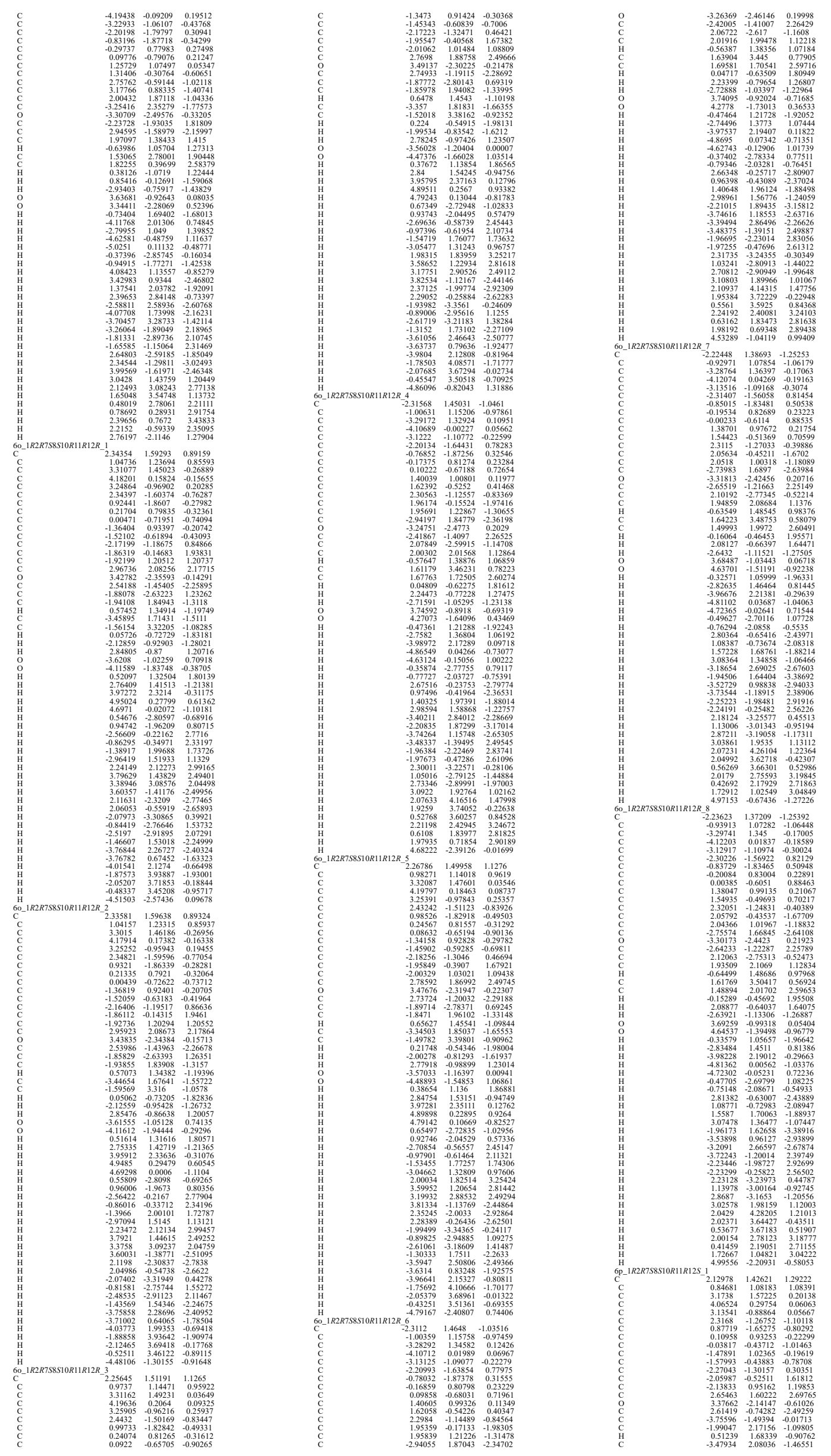

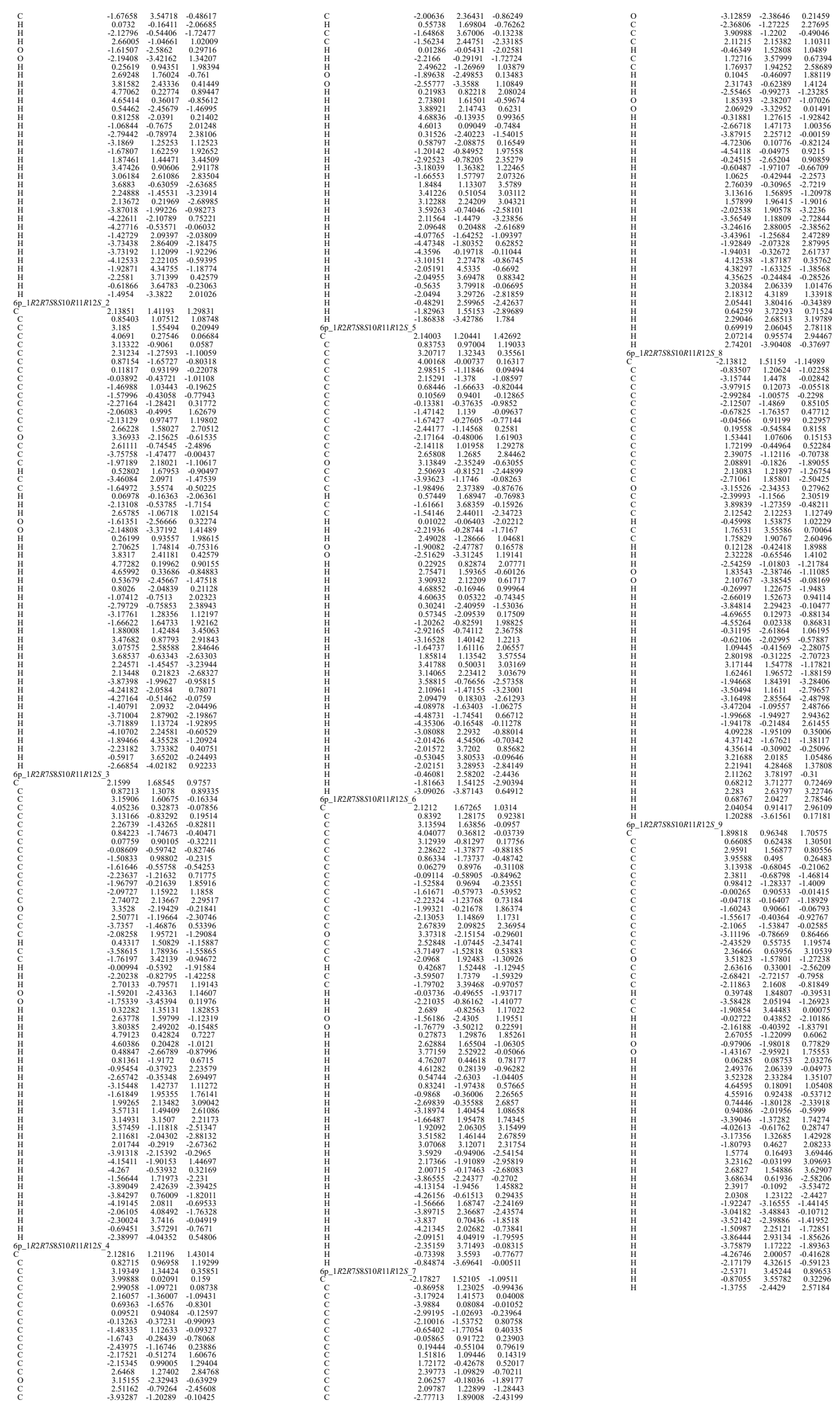
Table S4. SCF energies (Hartree) computed at the PCM/ mPW1PW91/6-31+G* level of theory using coordinate files incorporated in table S5

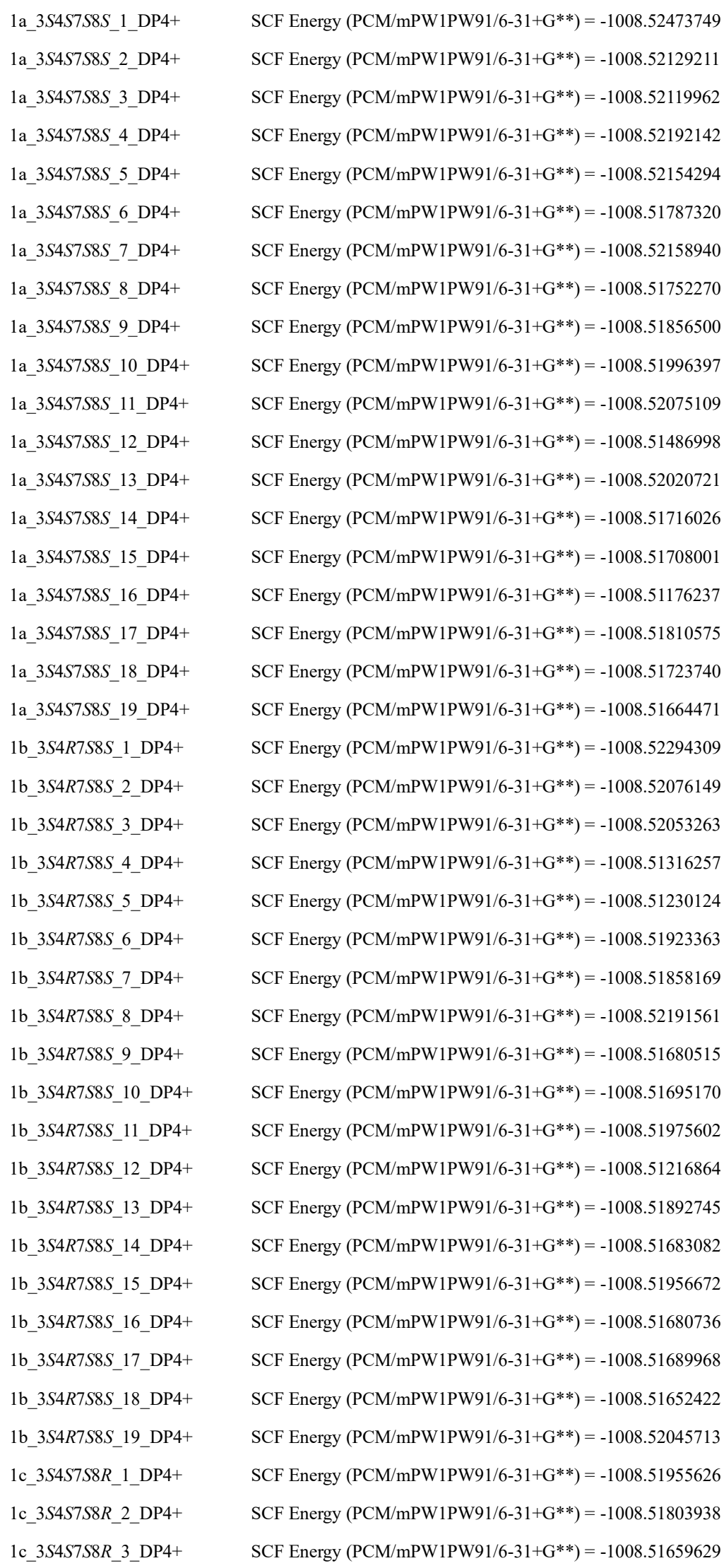




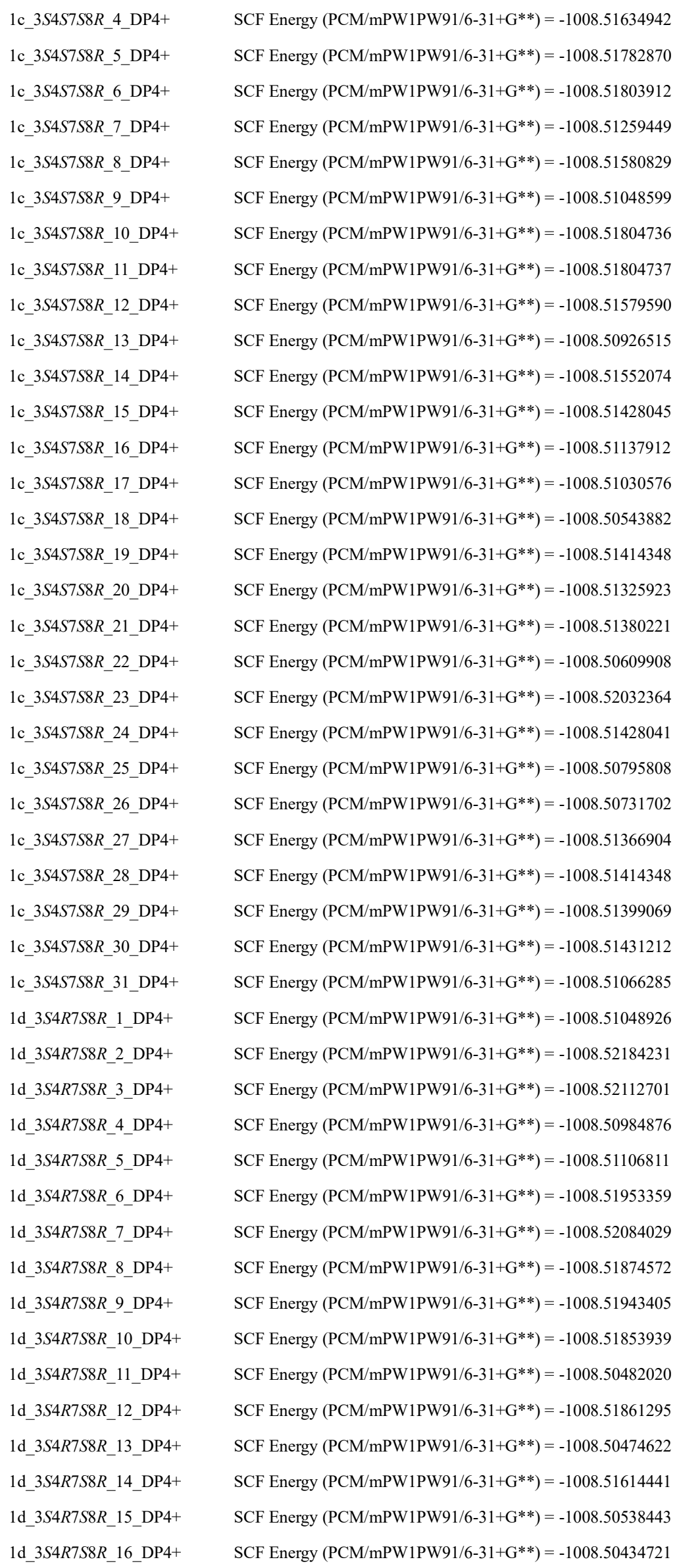

SCF Energy $\left(\mathrm{PCM} / \mathrm{mPW} 1 \mathrm{PW} 91 / 6-31+\mathrm{G}^{* *}\right)=-1008.51634942$ SCF Energy (PCM/mPW1PW91/6-31+G**) = -1008.51782870 SCF Energy (PCM/mPW1PW91/6-31+G**) = -1008.51803912 SCF Energy (PCM/mPW1PW91/6-31+G**) = -1008.51259449 SCF Energy (PCM/mPW1PW91/6-31+G**) = -1008.51580829 SCF Energy (PCM/mPW1PW91/6-31+G**) = -1008.51048599 SCF Energy $\left(\mathrm{PCM} / \mathrm{mPW} 1 \mathrm{PW} 91 / 6-31+\mathrm{G}^{* *}\right)=-1008.51804736$ SCF Energy (PCM/mPW1PW91/6-31+G**) = -1008.51804737 SCF Energy (PCM/mPW1PW91/6-31+G**) = -1008.51579590 SCF Energy (PCM/mPW1PW91/6-31+G**) = -1008.50926515 SCF Energy (PCM/mPW1PW91/6-31+G**) = -1008.51552074 SCF Energy $\left(\mathrm{PCM} / \mathrm{mPW} 1 \mathrm{PW} 91 / 6-31+\mathrm{G}^{* *}\right)=-1008.51428045$ SCF Energy (PCM/mPW1PW91/6-31+G**) = -1008.51137912 SCF Energy (PCM/mPW1PW91/6-31+G**) = -1008.51030576 SCF Energy (PCM/mPW1PW91/6-31+G**) = -1008.50543882 SCF Energy (PCM/mPW1PW91/6-31+G**) = -1008.51414348 SCF Energy (PCM/mPW1PW91/6-31+G**) = -1008.51325923 SCF Energy $\left(\mathrm{PCM} / \mathrm{mPW} 1 \mathrm{PW} 91 / 6-31+\mathrm{G}^{* *}\right)=-1008.51380221$ SCF Energy (PCM/mPW1PW91/6-31+G**) = -1008.50609908 SCF Energy $\left(\mathrm{PCM} / \mathrm{mPW} 1 \mathrm{PW} 91 / 6-31+\mathrm{G}^{* *}\right)=-1008.52032364$ SCF Energy (PCM/mPW1PW91/6-31+G**) = -1008.51428041 SCF Energy (PCM/mPW1PW91/6-31+G**) = -1008.50795808 SCF Energy (PCM/mPW1PW91/6-31+G**) = -1008.50731702 SCF Energy (PCM/mPW1PW91/6-31+G**) = -1008.51366904 SCF Energy $\left(\mathrm{PCM} / \mathrm{mPW} 1 \mathrm{PW} 91 / 6-31+\mathrm{G}^{* *}\right)=-1008.51414348$ SCF Energy (PCM/mPW1PW91/6-31+G**) = -1008.51399069 SCF Energy (PCM/mPW1PW91/6-31+G**) = -1008.51431212 SCF Energy $\left(\mathrm{PCM} / \mathrm{mPW} 1 \mathrm{PW} 91 / 6-31+\mathrm{G}^{* *}\right)=-1008.51066285$ SCF Energy $\left(\mathrm{PCM} / \mathrm{mPW} 1 \mathrm{PW} 91 / 6-31+\mathrm{G}^{* *}\right)=-1008.51048926$ SCF Energy (PCM/mPW1PW91/6-31+G**) = -1008.52184231 SCF Energy (PCM/mPW1PW91/6-31+G**) = -1008.52112701 SCF Energy (PCM/mPW1PW91/6-31+G**) = -1008.50984876 SCF Energy $\left(\mathrm{PCM} / \mathrm{mPW} 1 \mathrm{PW} 91 / 6-31+\mathrm{G}^{* *}\right)=-1008.51106811$ SCF Energy (PCM/mPW1PW91/6-31+G**) = -1008.51953359 SCF Energy (PCM/mPW1PW91/6-31+G**) = -1008.52084029 SCF Energy $\left(\mathrm{PCM} / \mathrm{mPW} 1 \mathrm{PW} 91 / 6-31+\mathrm{G}^{* *}\right)=-1008.51874572$ SCF Energy (PCM/mPW1PW91/6-31+G**) = -1008.51943405 SCF Energy $\left(\mathrm{PCM} / \mathrm{mPW} 1 \mathrm{PW} 91 / 6-31+\mathrm{G}^{* *}\right)=-1008.51853939$ SCF Energy (PCM/mPW1PW91/6-31+G**) = -1008.50482020 SCF Energy (PCM/mPW1PW91/6-31+G**) = -1008.51861295 SCF Energy $\left(\mathrm{PCM} / \mathrm{mPW} 1 \mathrm{PW} 91 / 6-31+\mathrm{G}^{* *}\right)=-1008.50474622$ SCF Energy $\left(\mathrm{PCM} / \mathrm{mPW} 1 \mathrm{PW} 91 / 6-31+\mathrm{G}^{* *}\right)=-1008.51614441$ SCF Energy (PCM/mPW1PW91/6-31+G**) = -1008.50538443 SCF Energy $\left(\mathrm{PCM} / \mathrm{mPW} 1 \mathrm{PW} 91 / 6-31+\mathrm{G}^{* *}\right)=-1008.50434721$ 


$$
\begin{aligned}
& \text { 1d_3S4R7S8R_17_DP4+ } \\
& \text { SCF Energy }\left(\mathrm{PCM} / \mathrm{mPW} 1 \mathrm{PW} 91 / 6-31+\mathrm{G}^{* *}\right)=-1008.52032321 \\
& \text { 1d_3S4R7S8R_18_DP4+ } \\
& \text { 1d_3S4R7S8R_19_DP4+ } \\
& \text { 1d_3S4R7S8R_20_DP4+ } \\
& \text { 1d_3S4R7S8R_21_DP4+ } \\
& \text { 1d_3S4R7S8R_22_DP4+ } \\
& \text { 1d_3S4R7S8R_23_DP4+ } \\
& \text { 1d_3S4R7S8R_24_DP4+ } \\
& \text { 2a_1R7R8S_1_DP4+ } \\
& \text { 2a_1R7R8S_2_DP4+ } \\
& \text { 2a_1R7R8S_3_DP4+ } \\
& \text { 2a_1R7R8S_4_DP4+ } \\
& \text { 2a_1R7R8S_5_DP4+ } \\
& \text { 2a_1R7R8S_6_DP4+ } \\
& \text { 2a_1R7R8S_7_DP4+ } \\
& \text { 2a_1R7R8S_8_DP4+ } \\
& \text { 2a_1R7R8S_9_DP4+ } \\
& \text { 2a_1R7R8S_10_DP4+ } \\
& \text { 2a_1R7R8S_11_DP4+ } \\
& \text { 2a_1R7R8S_12_DP4+ } \\
& \text { 2a_1R7R8S_13_DP4+ } \\
& \text { 2a_1R7R8S_14_DP4+ } \\
& \text { 2a_1R7R8S_15_DP4+ } \\
& \text { 2a_1R7R8S_16_DP4+ } \\
& \text { 2a_1R7R8S_17_DP4+ } \\
& \text { 2a_1R7R8S_18_DP4+ } \\
& \text { 2a_1R7R8S_19_DP4+ } \\
& \text { 2a_1R7R8S_20_DP4+ } \\
& \text { 2a_1R7R8S_21_DP4+ } \\
& \text { 2a_1R7R8S_22_DP4+ } \\
& \text { 2a_1R7R8S_23_DP4+ } \\
& \text { 2a_1R7R8S_24_DP4+ } \\
& \text { 2a_1R7R8S_25_DP4+ } \\
& \text { 2a_1R7R8S_26_DP4+ } \\
& \text { 2a_1R7R8S_27_DP4+ } \\
& \text { 2a_1R7R8S_28_DP4+ } \\
& \text { 2a_1R7R8S_29_DP4+ } \\
& \text { 2a_1R7R8S_30_DP4+ } \\
& \text { 2a_1R7R8S_31_DP4+ } \\
& \text { 2a_1R7R8S_32_DP4+ } \\
& \text { 2b_1S7R8S_1_DP4+ } \\
& \text { 2b_1S7R8S_2_DP4+ } \\
& \text { 2b_1S7R8S_3_DP4+ } \\
& \text { 2b_1S7R8S_4_DP4+ }
\end{aligned}
$$




$$
\begin{aligned}
& \text { 2b_1S7R8S_5_DP4+ } \\
& \text { 2b_1S7R8S_6_DP4+ } \\
& \text { 2b_1S7R8S_7_DP4+ } \\
& \text { 2b_1S7R8S_8_DP4+ } \\
& \text { 2b_1S7R8S_9_DP4+ } \\
& \text { 2b_1S7R8S_10_DP4+ } \\
& \text { 2b_1S7R8S_11_DP4+ } \\
& \text { 2b_1S7R8S_12_DP4+ } \\
& \text { 2b_1S7R8S_13_DP4+ } \\
& \text { 2b_1S7R8S_14_DP4+ } \\
& \text { 3a_7S8S15R_1_DP4+ } \\
& \text { 3a_7S8S15R_2_DP4+ } \\
& \text { 3a_7S8S15R_3_DP4+ } \\
& \text { 3a_7S8S15R_4_DP4+ } \\
& \text { 3a_7S8S15R_5_DP4+ } \\
& \text { 3a_7S8S15R_6_DP4+ } \\
& \text { 3a_7S8S15R_7_DP4+ } \\
& \text { 3a_7S8S15R_8_DP4+ } \\
& \text { 3a_7S8S15R_9_DP4+ } \\
& \text { 3a_7S8S15R_10_DP4+ } \\
& \text { 3a_7S8S15R_11_DP4+ } \\
& \text { 3a_7S } 8 S 15 R \_12 \_D P 4+ \\
& \text { 3a_7S8S15R_13_DP4+ } \\
& \text { 3a_7S8S15R_14_DP4+ } \\
& \text { 3a_7S } 8 S 15 R \_15 \_D P 4+ \\
& \text { 3a_7S8S15R_16_DP4+ } \\
& \text { 3a_7S8S15R_17_DP4+ } \\
& \text { 3a_7S8S15R_18_DP4+ } \\
& \text { 3a_7S } 8 S 15 R \_19 \_D P 4+ \\
& \text { 3a_7S8S15R_20_DP4+ } \\
& \text { 3a_7S8S15R_21_DP4+ } \\
& \text { 3a_7S } 8 S 15 R \_22 \_D P 4+ \\
& \text { 3a_7S } 8 S 15 R \_23 \_D P 4+ \\
& \text { 3a_7S8S15R_24_DP4+ } \\
& \text { 3b_7S8S15S_1_DP4+ } \\
& \text { 3b_7S8S15S_2_DP4+ } \\
& \text { 3b_7S8S15S_3_DP4+ } \\
& \text { 3b_7S8S15S_4_DP4+ } \\
& \text { 3b_7S8S15S_5_DP4+ } \\
& \text { 3b_7S8S15S_6_DP4+ } \\
& \text { 3b_7S8S15S_7_DP4+ } \\
& \text { 3b_7S8S15S_8_DP4+ } \\
& \text { 3b_7S8S15S_9_DP4+ } \\
& \text { 3b_7S8S15S_10_DP4+ }
\end{aligned}
$$




$$
\begin{aligned}
& \text { 3b_7S8S15S_11_DP4+ } \\
& \text { 3b_7S8S15S_12_DP4+ } \\
& \text { 3b_7S8S15S_13_DP4+ } \\
& \text { 3b_7S8S15S_14_DP4+ } \\
& \text { 3b_7S8S15S_15_DP4+ } \\
& \text { 3b_7S8S15S_16_DP4+ } \\
& \text { 3b_7S8S15S_17_DP4+ } \\
& \text { 3b_7S8S15S_18_DP4+ } \\
& \text { 3b_7S8S15S_19_DP4+ } \\
& \text { 3b_7S8S15S_20_DP4+ } \\
& \text { 3b_7S8S15S_21_DP4+ } \\
& \text { 3b_7S8S15S_22_DP4+ } \\
& \text { 3b_7S8S15S_23_DP4+ } \\
& \text { 4a_7S8S12R_1_DP4+ } \\
& 4 a \_7 S 8 S 12 R \_2 \text { DP44+ } \\
& \text { 4a_7S8S12R_3_DP4+ } \\
& \text { 4a_7S8S12R_4_DP4+ } \\
& \text { 4a_7S8S12R_5_DP4+ } \\
& \text { 4a_7S8S12R_6_DP4+ } \\
& \text { 4a_7S8S12R_7_DP4+ } \\
& \text { 4a_7S8S12R_8_DP4+ } \\
& \text { 4a_7S8S12R_9_DP4+ } \\
& \text { 4a_7S8S12R_10_DP4+ } \\
& \text { 4a_7S8S12R_11_DP4+ } \\
& \text { 4a_7S8S12R_12_DP4+ } \\
& \text { 4a_7S8S12R_13_DP4+ } \\
& \text { 4a_7S8S12R_14_DP4+ } \\
& \text { 4a_7S8S12R_15_DP4+ } \\
& \text { 4a_7S8S12R_16_DP4+ } \\
& \text { 4a_7S8S12R_17_DP4+ } \\
& \text { 4a_7S8S12R_18_DP4+ } \\
& \text { 4a_7S8S12R_19_DP4+ } \\
& \text { 4a_7S8S12R_20_DP4+ } \\
& \text { 4a_7S8S12R_21_DP4+ } \\
& \text { 4a_7S8S12R_22_DP4+ } \\
& \text { 4a_7S8S12R_23_DP4+ } \\
& \text { 4b_7S8S12S_1_DP4+ } \\
& \text { 4b_7S8S12S_2_DP4+ } \\
& \text { 4b_7S8S12S_3_DP4+ } \\
& \text { 4b_7S8S12S_4_DP4+ } \\
& \text { 4b_7S8S12S_5_DP4+ } \\
& \text { 4b_7S8S12S_6_DP4+ } \\
& \text { 4b_7S8S12S_7_DP4+ } \\
& \text { 4b_7S8S12S_8_DP4+ }
\end{aligned}
$$




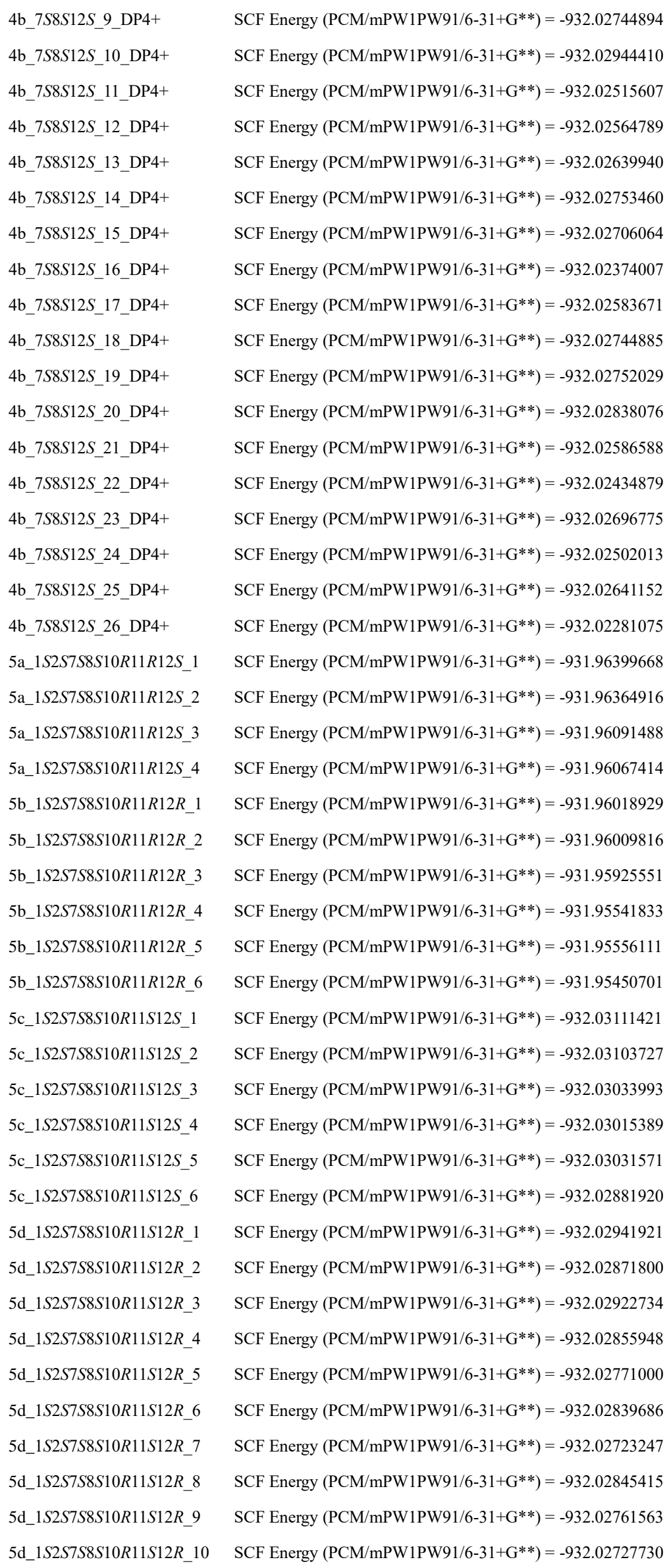

SCF Energy $\left(\mathrm{PCM} / \mathrm{mPW} 1 \mathrm{PW} 91 / 6-31+\mathrm{G}^{* *}\right)=-932.02744894$ SCF Energy $\left(\mathrm{PCM} / \mathrm{mPW} 1 \mathrm{PW} 91 / 6-31+\mathrm{G}^{* *}\right)=-932.02944410$ SCF Energy $\left(\mathrm{PCM} / \mathrm{mPW} 1 \mathrm{PW} 91 / 6-31+\mathrm{G}^{* *}\right)=-932.02515607$ SCF Energy (PCM/mPW1PW91/6-31+G**) = -932.02564789 SCF Energy $\left(\mathrm{PCM} / \mathrm{mPW} 1 \mathrm{PW} 91 / 6-31+\mathrm{G}^{* *}\right)=-932.02639940$ SCF Energy $\left(\mathrm{PCM} / \mathrm{mPW} 1 \mathrm{PW} 91 / 6-31+\mathrm{G}^{* *}\right)=-932.02753460$ SCF Energy (PCM/mPW1PW91/6-31+G**) = -932.02706064 SCF Energy $\left(\mathrm{PCM} / \mathrm{mPW} 1 \mathrm{PW} 91 / 6-31+\mathrm{G}^{* *}\right)=-932.02374007$ SCF Energy $(\mathrm{PCM} / \mathrm{mPW}$ 1PW91/6-31+G**) = -932.02583671 SCF Energy $(\mathrm{PCM} / \mathrm{mPW}$ PW91/6-31+G**) = -932.02744885 SCF Energy $\left(\mathrm{PCM} / \mathrm{mPW} 1 \mathrm{PW} 91 / 6-31+\mathrm{G}^{* *}\right)=-932.02752029$ SCF Energy (PCM/mPW1PW91/6-31+G**) = -932.02838076 SCF Energy $\left(\mathrm{PCM} / \mathrm{mPW} 1 \mathrm{PW} 91 / 6-31+\mathrm{G}^{* *}\right)=-932.02586588$ SCF Energy $\left(\mathrm{PCM} / \mathrm{mPW} 1 \mathrm{PW} 91 / 6-31+\mathrm{G}^{* *}\right)=-932.02434879$ SCF Energy (PCM/mPW1PW91/6-31+G**) = -932.02696775 SCF Energy $\left(\mathrm{PCM} / \mathrm{mPW} 1 \mathrm{PW} 91 / 6-31+\mathrm{G}^{* *}\right)=-932.02502013$ SCF Energy $(\mathrm{PCM} / \mathrm{mPW}$ 1PW91/6-31+G**) = -932.02641152 SCF Energy $\left(\mathrm{PCM} / \mathrm{mPW} 1 \mathrm{PW} 91 / 6-31+\mathrm{G}^{* *}\right)=-932.02281075$ SCF Energy $\left(\mathrm{PCM} / \mathrm{mPW} 1 \mathrm{PW} 91 / 6-31+\mathrm{G}^{* *}\right)=-931.96399668$ SCF Energy $\left(\mathrm{PCM} / \mathrm{mPW} 1 \mathrm{PW} 91 / 6-31+\mathrm{G}^{* *}\right)=-931.96364916$ SCF Energy $\left(\mathrm{PCM} / \mathrm{mPW} 1 \mathrm{PW} 91 / 6-31+\mathrm{G}^{* *}\right)=-931.96091488$ SCF Energy $\left(\mathrm{PCM} / \mathrm{mPW} 1 \mathrm{PW} 91 / 6-31+\mathrm{G}^{* *}\right)=-931.96067414$ SCF Energy $\left(\mathrm{PCM} / \mathrm{mPW} 1 \mathrm{PW} 91 / 6-31+\mathrm{G}^{* *}\right)=-931.96018929$ SCF Energy $\left(\mathrm{PCM} / \mathrm{mPW} 1 \mathrm{PW} 91 / 6-31+\mathrm{G}^{* *}\right)=-931.96009816$ SCF Energy $\left(\mathrm{PCM} / \mathrm{mPW} 1 \mathrm{PW} 91 / 6-31+\mathrm{G}^{* *}\right)=-931.95925551$ SCF Energy $\left(\mathrm{PCM} / \mathrm{mPW} 1 \mathrm{PW} 91 / 6-31+\mathrm{G}^{* *}\right)=-931.95541833$ SCF Energy $\left(\mathrm{PCM} / \mathrm{mPW} 1 \mathrm{PW} 91 / 6-31+\mathrm{G}^{* *}\right)=-931.95556111$ SCF Energy $\left(\mathrm{PCM} / \mathrm{mPW} 1 \mathrm{PW} 91 / 6-31+\mathrm{G}^{* *}\right)=-931.95450701$ SCF Energy $\left(\mathrm{PCM} / \mathrm{mPW} 1 \mathrm{PW} 91 / 6-31+\mathrm{G}^{* *}\right)=-932.03111421$ SCF Energy $\left(\mathrm{PCM} / \mathrm{mPW} 1 \mathrm{PW} 91 / 6-31+\mathrm{G}^{* *}\right)=-932.03103727$ SCF Energy $\left(\mathrm{PCM} / \mathrm{mPW} 1 \mathrm{PW} 91 / 6-31+\mathrm{G}^{* *}\right)=-932.03033993$ SCF Energy $\left(\mathrm{PCM} / \mathrm{mPW} 1 \mathrm{PW} 91 / 6-31+\mathrm{G}^{* *}\right)=-932.03015389$ SCF Energy $\left(\mathrm{PCM} / \mathrm{mPW} 1 \mathrm{PW} 91 / 6-31+\mathrm{G}^{* *}\right)=-932.03031571$ SCF Energy $\left(\mathrm{PCM} / \mathrm{mPW} 1 \mathrm{PW} 91 / 6-31+\mathrm{G}^{* *}\right)=-932.02881920$ SCF Energy $\left(\mathrm{PCM} / \mathrm{mPW} 1 \mathrm{PW} 91 / 6-31+\mathrm{G}^{* *}\right)=-932.02941921$ SCF Energy $(\mathrm{PCM} / \mathrm{mPW}$ 1PW91/6-31+G**) = -932.02871800 SCF Energy $\left(\mathrm{PCM} / \mathrm{mPW} 1 \mathrm{PW} 91 / 6-31+\mathrm{G}^{* *}\right)=-932.02922734$ SCF Energy $\left(\mathrm{PCM} / \mathrm{mPW} 1 \mathrm{PW} 91 / 6-31+\mathrm{G}^{* *}\right)=-932.02855948$ SCF Energy $(\mathrm{PCM} / \mathrm{mPW}$ 1PW91/6-31+G**) = -932.02771000 SCF Energy $\left(\mathrm{PCM} / \mathrm{mPW} 1 \mathrm{PW} 91 / 6-31+\mathrm{G}^{* *}\right)=-932.02839686$ SCF Energy $\left(\mathrm{PCM} / \mathrm{mPW} 1 \mathrm{PW} 91 / 6-31+\mathrm{G}^{* *}\right)=-932.02723247$ SCF Energy $\left(\mathrm{PCM} / \mathrm{mPW} 1 \mathrm{PW} 91 / 6-31+\mathrm{G}^{* *}\right)=-932.02845415$ SCF Energy $\left(\mathrm{PCM} / \mathrm{mPW} 1 \mathrm{PW} 91 / 6-31+\mathrm{G}^{* *}\right)=-932.02761563$ SCF Energy $\left(\mathrm{PCM} / \mathrm{mPW} 1 \mathrm{PW} 91 / 6-31+\mathrm{G}^{* *}\right)=-932.02727730$ 


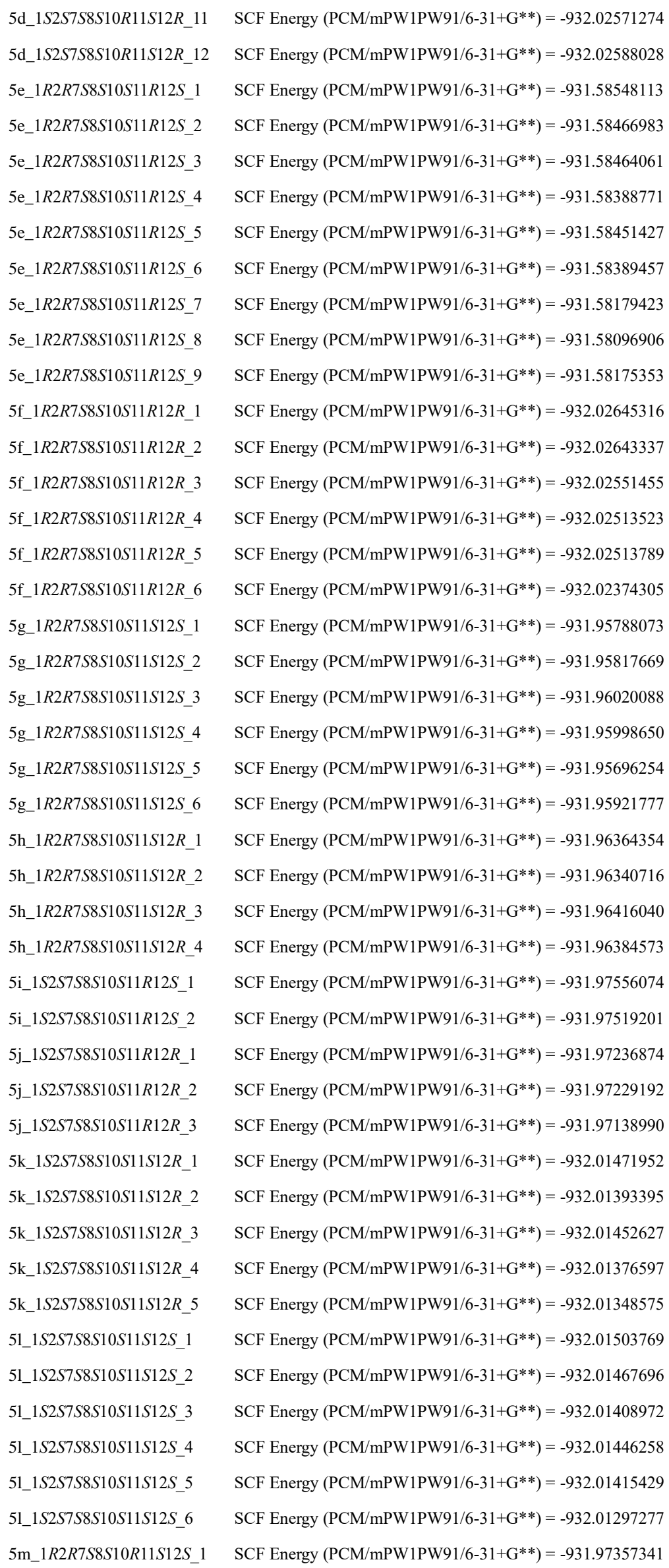

SCF Energy $\left(\mathrm{PCM} / \mathrm{mPW} 1 \mathrm{PW} 91 / 6-31+\mathrm{G}^{* *}\right)=-932.02571274$

SCF Energy $\left(\mathrm{PCM} / \mathrm{mPW} 1 \mathrm{PW} 91 / 6-31+\mathrm{G}^{* *}\right)=-932.02588028$

SCF Energy $\left(\mathrm{PCM} / \mathrm{mPW} 1 \mathrm{PW} 91 / 6-31+\mathrm{G}^{* *}\right)=-931.58548113$

SCF Energy $\left(\mathrm{PCM} / \mathrm{mPW} 1 \mathrm{PW} 91 / 6-31+\mathrm{G}^{* *}\right)=-931.58466983$

SCF Energy $\left(\mathrm{PCM} / \mathrm{mPW} 1 \mathrm{PW} 91 / 6-31+\mathrm{G}^{* *}\right)=-931.58464061$

SCF Energy $\left(\mathrm{PCM} / \mathrm{mPW} 1 \mathrm{PW} 91 / 6-31+\mathrm{G}^{* *}\right)=-931.58388771$

SCF Energy $\left(\mathrm{PCM} / \mathrm{mPW} 1 \mathrm{PW} 91 / 6-31+\mathrm{G}^{* *}\right)=-931.58451427$

SCF Energy $\left(\mathrm{PCM} / \mathrm{mPW} 1 \mathrm{PW} 91 / 6-31+\mathrm{G}^{* *}\right)=-931.58389457$

SCF Energy $(\mathrm{PCM} / \mathrm{mPW}$ 1PW91/6-31+G**) = -931.58179423

SCF Energy $\left(\mathrm{PCM} / \mathrm{mPW} 1 \mathrm{PW} 91 / 6-31+\mathrm{G}^{* *}\right)=-931.58096906$

SCF Energy $\left(\mathrm{PCM} / \mathrm{mPW} 1 \mathrm{PW} 91 / 6-31+\mathrm{G}^{* *}\right)=-931.58175353$

SCF Energy $(\mathrm{PCM} / \mathrm{mPW}$ 1PW91/6-31+G**) = -932.02645316

SCF Energy $\left(\mathrm{PCM} / \mathrm{mPW} 1 \mathrm{PW} 91 / 6-31+\mathrm{G}^{* *}\right)=-932.02643337$

SCF Energy $\left(\mathrm{PCM} / \mathrm{mPW} 1 \mathrm{PW} 91 / 6-31+\mathrm{G}^{* *}\right)=-932.02551455$

SCF Energy $\left(\mathrm{PCM} / \mathrm{mPW} 1 \mathrm{PW} 91 / 6-31+\mathrm{G}^{* *}\right)=-932.02513523$

SCF Energy $\left(\mathrm{PCM} / \mathrm{mPW} 1 \mathrm{PW} 91 / 6-31+\mathrm{G}^{* *}\right)=-932.02513789$

SCF Energy $(\mathrm{PCM} / \mathrm{mPW}$ 1PW91/6-31+G**) = -932.02374305

SCF Energy $\left(\mathrm{PCM} / \mathrm{mPW} 1 \mathrm{PW} 91 / 6-31+\mathrm{G}^{* *}\right)=-931.95788073$

SCF Energy $\left(\mathrm{PCM} / \mathrm{mPW} 1 \mathrm{PW} 91 / 6-31+\mathrm{G}^{* *}\right)=-931.95817669$

SCF Energy $\left(\mathrm{PCM} / \mathrm{mPW} 1 \mathrm{PW} 91 / 6-31+\mathrm{G}^{* *}\right)=-931.96020088$

SCF Energy $\left(\mathrm{PCM} / \mathrm{mPW} 1 \mathrm{PW} 91 / 6-31+\mathrm{G}^{* *}\right)=-931.95998650$

SCF Energy $\left(\mathrm{PCM} / \mathrm{mPW} 1 \mathrm{PW} 91 / 6-31+\mathrm{G}^{* *}\right)=-931.95696254$

SCF Energy $\left(\mathrm{PCM} / \mathrm{mPW} 1 \mathrm{PW} 91 / 6-31+\mathrm{G}^{* *}\right)=-931.95921777$

SCF Energy $\left(\mathrm{PCM} / \mathrm{mPW} 1 \mathrm{PW} 91 / 6-31+\mathrm{G}^{* *}\right)=-931.96364354$

SCF Energy $\left(\mathrm{PCM} / \mathrm{mPW} 1 \mathrm{PW} 91 / 6-31+\mathrm{G}^{* *}\right)=-931.96340716$

SCF Energy $\left(\mathrm{PCM} / \mathrm{mPW} 1 \mathrm{PW} 91 / 6-31+\mathrm{G}^{* *}\right)=-931.96416040$

SCF Energy $\left(\mathrm{PCM} / \mathrm{mPW} 1 \mathrm{PW} 91 / 6-31+\mathrm{G}^{* *}\right)=-931.96384573$

SCF Energy $\left(\mathrm{PCM} / \mathrm{mPW} 1 \mathrm{PW} 91 / 6-31+\mathrm{G}^{* *}\right)=-931.97556074$

SCF Energy $\left(\mathrm{PCM} / \mathrm{mPW} 1 \mathrm{PW} 91 / 6-31+\mathrm{G}^{* *}\right)=-931.97519201$

SCF Energy $\left(\mathrm{PCM} / \mathrm{mPW} 1 \mathrm{PW} 91 / 6-31+\mathrm{G}^{* *}\right)=-931.97236874$

SCF Energy $(\mathrm{PCM} / \mathrm{mPW}$ 1PW91/6-31+G**) = -931.97229192

SCF Energy $\left(\mathrm{PCM} / \mathrm{mPW} 1 \mathrm{PW} 91 / 6-31+\mathrm{G}^{* *}\right)=-931.97138990$

SCF Energy $(\mathrm{PCM} / \mathrm{mPW}$ 1PW91/6-31+G**) = -932.01471952

SCF Energy $\left(\mathrm{PCM} / \mathrm{mPW} 1 \mathrm{PW} 91 / 6-31+\mathrm{G}^{* *}\right)=-932.01393395$

SCF Energy $\left(\mathrm{PCM} / \mathrm{mPW} 1 \mathrm{PW} 91 / 6-31+\mathrm{G}^{* *}\right)=-932.01452627$

SCF Energy $\left(\mathrm{PCM} / \mathrm{mPW} 1 \mathrm{PW} 91 / 6-31+\mathrm{G}^{* *}\right)=-932.01376597$

SCF Energy $\left(\mathrm{PCM} / \mathrm{mPW} 1 \mathrm{PW} 91 / 6-31+\mathrm{G}^{* *}\right)=-932.01348575$

SCF Energy $\left(\mathrm{PCM} / \mathrm{mPW} 1 \mathrm{PW} 91 / 6-31+\mathrm{G}^{* *}\right)=-932.01503769$

SCF Energy (PCM/mPW1PW91/6-31+G**) = -932.01467696

SCF Energy $\left(\mathrm{PCM} / \mathrm{mPW} 1 \mathrm{PW} 91 / 6-31+\mathrm{G}^{* *}\right)=-932.01408972$

SCF Energy $(\mathrm{PCM} / \mathrm{mPW}$ 1PW91/6-31+G**) $=-932.01446258$

SCF Energy $\left(\mathrm{PCM} / \mathrm{mPW} 1 \mathrm{PW} 91 / 6-31+\mathrm{G}^{* *}\right)=-932.01415429$

SCF Energy (PCM/mPW1PW91/6-31+G**) = -932.01297277

SCF Energy $(\mathrm{PCM} / \mathrm{mPW}$ 1PW91/6-31+G**) = -931.97357341 


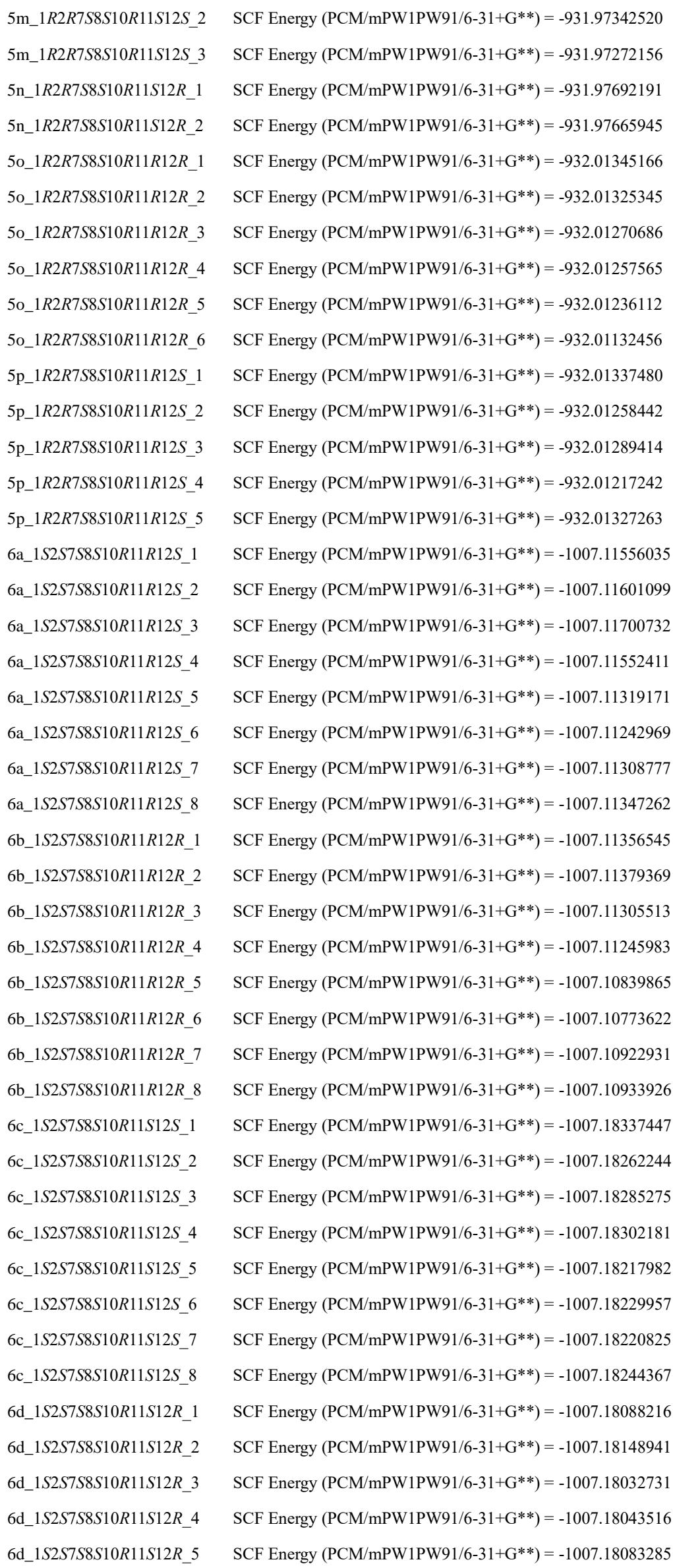

SCF Energy $\left(\mathrm{PCM} / \mathrm{mPW} 1 \mathrm{PW} 91 / 6-31+\mathrm{G}^{* *}\right)=-931.97692191$

SCF Energy $\left(\mathrm{PCM} / \mathrm{mPW} 1 \mathrm{PW} 91 / 6-31+\mathrm{G}^{* *}\right)=-931.97665945$

SCF Energy $\left(\mathrm{PCM} / \mathrm{mPW} 1 \mathrm{PW} 91 / 6-31+\mathrm{G}^{* *}\right)=-932.01345166$

SCF Energy $\left(\mathrm{PCM} / \mathrm{mPW} 1 \mathrm{PW} 91 / 6-31+\mathrm{G}^{* *}\right)=-932.01325345$

SCF Energy $\left(\mathrm{PCM} / \mathrm{mPW} 1 \mathrm{PW} 91 / 6-31+\mathrm{G}^{* *}\right)=-932.01270686$

SCF Energy $\left(\mathrm{PCM} / \mathrm{mPW} 1 \mathrm{PW} 91 / 6-31+\mathrm{G}^{* *}\right)=-932.01257565$

SCF Energy $\left(\mathrm{PCM} / \mathrm{mPW} 1 \mathrm{PW} 91 / 6-31+\mathrm{G}^{* *}\right)=-932.01236112$

SCF Energy $(\mathrm{PCM} / \mathrm{mPW}$ PW91/6-31+G**) = -932.01132456

SCF Energy $(\mathrm{PCM} / \mathrm{mPW}$ PW91/6-31+G**) $=-932.01337480$

SCF Energy $\left(\mathrm{PCM} / \mathrm{mPW} 1 \mathrm{PW} 91 / 6-31+\mathrm{G}^{* *}\right)=-932.01258442$

SCF Energy $\left(\mathrm{PCM} / \mathrm{mPW} 1 \mathrm{PW} 91 / 6-31+\mathrm{G}^{* *}\right)=-932.01289414$

SCF Energy $\left(\mathrm{PCM} / \mathrm{mPW} 1 \mathrm{PW} 91 / 6-31+\mathrm{G}^{* *}\right)=-932.01217242$

SCF Energy $\left(\mathrm{PCM} / \mathrm{mPW} 1 \mathrm{PW} 91 / 6-31+\mathrm{G}^{* *}\right)=-932.01327263$

SCF Energy (PCM/mPW1PW91/6-31+G**) = -1007.11556035

SCF Energy (PCM/mPW1PW91/6-31+G**) = -1007.11601099

SCF Energy $\left(\mathrm{PCM} / \mathrm{mPW} 1 \mathrm{PW} 91 / 6-31+\mathrm{G}^{* *}\right)=-1007.11700732$

SCF Energy (PCM/mPW1PW91/6-31+G**) = -1007.11552411

SCF Energy $\left(\mathrm{PCM} / \mathrm{mPW} 1 \mathrm{PW} 91 / 6-31+\mathrm{G}^{* *}\right)=-1007.11319171$

SCF Energy (PCM/mPW1PW91/6-31+G**) = -1007.11242969

SCF Energy $\left(\mathrm{PCM} / \mathrm{mPW} 1 \mathrm{PW} 91 / 6-31+\mathrm{G}^{* *}\right)=-1007.11308777$

SCF Energy (PCM/mPW1PW91/6-31+G**) = -1007.11347262

SCF Energy (PCM/mPW1PW91/6-31+G**) = -1007.11356545

SCF Energy (PCM/mPW1PW91/6-31+G**) = -1007.11379369

SCF Energy $(\mathrm{PCM} / \mathrm{mPW}$ PW91/6-31+G**) = -1007.11305513

SCF Energy (PCM/mPW1PW91/6-31+G**) = -1007.11245983

SCF Energy $\left(\mathrm{PCM} / \mathrm{mPW} 1 \mathrm{PW} 91 / 6-31+\mathrm{G}^{* *}\right)=-1007.10839865$

SCF Energy (PCM/mPW1PW91/6-31+G**) = -1007.10773622

SCF Energy (PCM/mPW1PW91/6-31+G**) = -1007.10922931

SCF Energy $\left(\mathrm{PCM} / \mathrm{mPW} 1 \mathrm{PW} 91 / 6-31+\mathrm{G}^{* *}\right)=-1007.10933926$

SCF Energy $\left(\mathrm{PCM} / \mathrm{mPW} 1 \mathrm{PW} 91 / 6-31+\mathrm{G}^{* *}\right)=-1007.18337447$

SCF Energy $\left(\mathrm{PCM} / \mathrm{mPW} 1 \mathrm{PW} 91 / 6-31+\mathrm{G}^{* *}\right)=-1007.18262244$

SCF Energy $\left(\mathrm{PCM} / \mathrm{mPW} 1 \mathrm{PW} 91 / 6-31+\mathrm{G}^{* *}\right)=-1007.18285275$

SCF Energy (PCM/mPW1PW91/6-31+G**) = -1007.18302181

SCF Energy $\left(\mathrm{PCM} / \mathrm{mPW} 1 \mathrm{PW} 91 / 6-31+\mathrm{G}^{* *}\right)=-1007.18217982$

SCF Energy (PCM/mPW1PW91/6-31+G**) = -1007.18229957

SCF Energy $\left(\mathrm{PCM} / \mathrm{mPW} 1 \mathrm{PW} 91 / 6-31+\mathrm{G}^{* *}\right)=-1007.18220825$

SCF Energy $\left(\mathrm{PCM} / \mathrm{mPW} 1 \mathrm{PW} 91 / 6-31+\mathrm{G}^{* *}\right)=-1007.18244367$

SCF Energy $\left(\mathrm{PCM} / \mathrm{mPW} 1 \mathrm{PW} 91 / 6-31+\mathrm{G}^{* *}\right)=-1007.18088216$

SCF Energy $\left(\mathrm{PCM} / \mathrm{mPW} 1 \mathrm{PW} 91 / 6-31+\mathrm{G}^{* *}\right)=-1007.18148941$

SCF Energy $\left(\mathrm{PCM} / \mathrm{mPW} 1 \mathrm{PW} 91 / 6-31+\mathrm{G}^{* *}\right)=-1007.18032731$

SCF Energy (PCM/mPW1PW91/6-31+G**) = -1007.18043516

SCF Energy $\left(\mathrm{PCM} / \mathrm{mPW} 1 \mathrm{PW} 91 / 6-31+\mathrm{G}^{* *}\right)=-1007.18083285$ 
6d_1S2S7S8S10R11S12R_6 6d_1S2S7S8S10R11S12R_7 6d_1S2S7S8S10R11S12R_8 6d_1S2S7S8S10R11S12R_9 6d_1S2S7S8S10R11S12R_10 6d_1S2S7S8S10R11S12R_11 6e_1R2R7S8S10S11R12S_1 6e_1R2R7S8S10S11R12S_2 $6 \mathrm{e} \_1 R 2 R 7 S 8 S 10 S 11 R 12 S 3$ 6e_1R2R7S8S10S11R12S 4 6e_1R2R7S8S10S11R12S_5 6e_1R2R7S8S10S11R12S_6 6e_1R2R7S8S10S11R12S_7 6e_1R2R7S8S10S11R12S_8 6f_1R2R7S8S10S11R12R_1 6f_1R2R7S8S10S11R12R_2 6f_1R2R7S8S10S11R12R_3 6f_1R2R7S8S10S11R12R_ 4 6f_1R2R7S8S10S11R12R_5 6f_1R2R7S8S10S11R12R 6 6f_1R2R7S8S10S11R12R_7 6f_1R2R7S8S10S11R12R_8 6g_1R2R7S8S10S11S12S_1 6g_1R2R7S8S10S11S12S_2 6g_1R2R7S8S10S11S12S_3 6g_1R2R7S8S10S11S12S_4 6g_1R2R7S8S10S11S12S_5 6g_1R2R7S8S10S11S12S_6 6g_1R2R7S8S10S11S12S_7 6g_1R2R7S8S10S11S12S_8 $6 \mathrm{~h} \_1 R 2 R 7 S 8 S 10 S 11 S 12 R \_1$ 6h_1R2R7S8S10S11S12R_2 $6 \mathrm{~h} \_1 R 2 R 7 S 8 S 10 S 11 S 12 R \_3$ 6h_1R2R7S8S10S11S12R_4 $6 \mathrm{~h} \_1 R 2 R 7 S 8 S 10 S 11 S 12 R \_5$ $6 \mathrm{~h} \_1 R 2 R 7 S 8 S 10 S 11 S 12 R \_6$ 6h_1R2R7S8S10S11S12R_7 $6 \mathrm{~h} \_1 R 2 R 7 S 8 S 10 S 11 S 12 R \_8$ 6i_1S2S7S8S10S11R12S 1 6i_1S2S7S8S10S11R12S_2 6i_1S2S7S8S10S11R12S_3 6i_1S2S7S8S10S11R12S_4 $6 \mathrm{j} \_1 S 2 S 7 S 8 S 10 S 11 R 12 R \_1$ $6 j \_1 S 2 S 7 S 8 S 10 S 11 R 12 R \_2$
SCF Energy $\left(\mathrm{PCM} / \mathrm{mPW} 1 \mathrm{PW} 91 / 6-31+\mathrm{G}^{* *}\right)=-1007.18132283$ SCF Energy $\left(\mathrm{PCM} / \mathrm{mPW} 1 \mathrm{PW} 91 / 6-31+\mathrm{G}^{* *}\right)=-1007.18025245$ SCF Energy (PCM/mPW1PW91/6-31+G**) = -1007.18033726 SCF Energy (PCM/mPW1PW91/6-31+G**) = -1007.18021675 SCF Energy (PCM/mPW1PW91/6-31+G**) = -1007.18023607 SCF Energy $\left(\mathrm{PCM} / \mathrm{mPW} 1 \mathrm{PW} 91 / 6-31+\mathrm{G}^{* *}\right)=-1007.17934802$ SCF Energy (PCM/mPW1PW91/6-31+G**) = -1007.17700892 SCF Energy (PCM/mPW1PW91/6-31+G**) = -1007.17723730 SCF Energy $\left(\mathrm{PCM} / \mathrm{mPW} 1 \mathrm{PW} 91 / 6-31+\mathrm{G}^{* *}\right)=-1007.17593995$ SCF Energy $\left(\mathrm{PCM} / \mathrm{mPW} 1 \mathrm{PW} 91 / 6-31+\mathrm{G}^{* *}\right)=-1007.17591727$ SCF Energy (PCM/mPW1PW91/6-31+G**) = -1007.17608478 SCF Energy (PCM/mPW1PW91/6-31+G**) = -1007.17624668 SCF Energy (PCM/mPW1PW91/6-31+G**) = -1007.17510518 SCF Energy (PCM/mPW1PW91/6-31+G**) = -1007.17511992 SCF Energy (PCM/mPW1PW91/6-31+G**) = -1007.17890522 SCF Energy (PCM/mPW1PW91/6-31+G**) = -1007.17823556 SCF Energy (PCM/mPW1PW91/6-31+G**) = -1007.17855959 SCF Energy $\left(\mathrm{PCM} / \mathrm{mPW} 1 \mathrm{PW} 91 / 6-31+\mathrm{G}^{* *}\right)=-1007.17872257$ SCF Energy (PCM/mPW1PW91/6-31+G**) = -1007.17747801 SCF Energy $\left(\mathrm{PCM} / \mathrm{mPW} 1 \mathrm{PW} 91 / 6-31+\mathrm{G}^{* *}\right)=-1007.17729935$ SCF Energy (PCM/mPW1PW91/6-31+G**) = -1007.17734672 SCF Energy (PCM/mPW1PW91/6-31+G**) = -1007.17759605 SCF Energy $\left(\mathrm{PCM} / \mathrm{mPW} 1 \mathrm{PW} 91 / 6-31+\mathrm{G}^{* *}\right)=-1007.11342874$ SCF Energy (PCM/mPW1PW91/6-31+G**) = -1007.11345294 SCF Energy $\left(\mathrm{PCM} / \mathrm{mPW} 1 \mathrm{PW} 91 / 6-31+\mathrm{G}^{* *}\right)=-1007.11096034$ SCF Energy $\left(\mathrm{PCM} / \mathrm{mPW} 1 \mathrm{PW} 91 / 6-31+\mathrm{G}^{* *}\right)=-1007.11023406$ SCF Energy (PCM/mPW1PW91/6-31+G**) = -1007.11179133 SCF Energy (PCM/mPW1PW91/6-31+G**) = -1007.11176067 SCF Energy (PCM/mPW1PW91/6-31+G**) = -1007.11273830 SCF Energy (PCM/mPW1PW91/6-31+G**) = -1007.11217733 SCF Energy $\left(\mathrm{PCM} / \mathrm{mPW} 1 \mathrm{PW} 91 / 6-31+\mathrm{G}^{* *}\right)=-1007.11593820$ SCF Energy (PCM/mPW1PW91/6-31+G**) = -1007.11508812 SCF Energy $\left(\mathrm{PCM} / \mathrm{mPW} 1 \mathrm{PW} 91 / 6-31+\mathrm{G}^{* *}\right)=-1007.11564282$ SCF Energy $\left(\mathrm{PCM} / \mathrm{mPW} 1 \mathrm{PW} 91 / 6-31+\mathrm{G}^{* *}\right)=-1007.11584527$ SCF Energy $\left(\mathrm{PCM} / \mathrm{mPW} 1 \mathrm{PW} 91 / 6-31+\mathrm{G}^{* *}\right)=-1007.11612928$ SCF Energy $\left(\mathrm{PCM} / \mathrm{mPW} 1 \mathrm{PW} 91 / 6-31+\mathrm{G}^{* *}\right)=-1007.11704144$ SCF Energy $\left(\mathrm{PCM} / \mathrm{mPW} 1 \mathrm{PW} 91 / 6-31+\mathrm{G}^{* *}\right)=-1007.11576346$ SCF Energy (PCM/mPW1PW91/6-31+G**) = -1007.11530224 SCF Energy $\left(\mathrm{PCM} / \mathrm{mPW} 1 \mathrm{PW} 91 / 6-31+\mathrm{G}^{* *}\right)=-1007.12693004$ SCF Energy (PCM/mPW1PW91/6-31+G**) = -1007.12740062 SCF Energy $\left(\mathrm{PCM} / \mathrm{mPW} 1 \mathrm{PW} 91 / 6-31+\mathrm{G}^{* *}\right)=-1007.12828159$ SCF Energy $\left(\mathrm{PCM} / \mathrm{mPW} 1 \mathrm{PW} 91 / 6-31+\mathrm{G}^{* *}\right)=-1007.12656776$ SCF Energy (PCM/mPW1PW91/6-31+G**) = -1007.12592953 SCF Energy $\left(\mathrm{PCM} / \mathrm{mPW} 1 \mathrm{PW} 91 / 6-31+\mathrm{G}^{* *}\right)=-1007.12590342$ 
6j_1S2S7S8S10S11R12R_3

$6 j_{-} 1 S 2 S 7 S 8 S 10 S 11 R 12 R \_4$

$6 \mathrm{k} \_1 S 2 S 7 S 8 S 10 S 11 S 12 R \_1$

$6 \mathrm{k} \_1 S 2 S 7 S 8 S 10 S 11 S 12 R \_2$

$6 \mathrm{k} \_1 S 2 S 7 S 8 S 10 S 11 S 12 R \_3$

$6 \mathrm{k} \_1 S 2 S 7 S 8 S 10 S 11 S 12 R \_4$

$6 \mathrm{k} \_1 S 2 S 7 S 8 S 10 S 11 S 12 R \_5$

$6 \mathrm{k} \_1 S 2 S 7 S 8 S 10 S 11 S 12 R \_6$

$6 \mathrm{k} \_1 S 2 S 7 S 8 S 10 S 11 S 12 R \_7$

6k_1S2S7S8S10S11S12R_8

61_1S2S7S8S10S11S12S_1

61_1S2S7S8S10S11S12S_2

61_1S2S7S8S10S11S12S_3

61_1S2S7S8S10S11S12S_4

61_1S2S7S8S10S11S12S_5

61_1S2S7S8S10S11S12S_6

61_1S2S7S8S10S11S12S_7

61_1S2S7S8S10S11S12S_8

$6 \mathrm{~m} \_1 R 2 R 7 S 8 S 10 R 11 S 12 S \_1$

$6 \mathrm{~m} \_1 R 2 R 7 S 8 S 10 R 11 S 12 S \_2$

$6 \mathrm{~m} \_1 R 2 R 7 S 8 S 10 R 11 S 12 S \_3$

$6 \mathrm{~m} \_1 R 2 R 7 S 8 S 10 R 11 S 12 S \_4$

6n_1R2R7S8S10R11S12R_1

6n_1R2R7S8S10R11S12R_2

6n_1R2R7S8S10R11S12R_3

$6 \mathrm{n} \_1 R 2 R 7 S 8 S 10 R 11 S 12 R \_4$

6o_1R2R7S8S10R11R12R_1

6o_1R2R7S8S10R11R12R_2

6o_1R2R7S8S10R11R12R_3

6o_1R2R7S8S10R11R12R_4

6o_1R2R7S8S10R11R12R_5

6o_ $1 R 2 R 7 S 8 S 10 R 11 R 12 R \_6$

6o_1R2R7S8S10R11R12R_7

6o_1R2R7S8S10R11R12R_8

6p_1R2R7S8S10R11R12S_1

$6 \mathrm{p} \_1 R 2 R 7 S 8 S 10 R 11 R 12 S \_2$

6p_1R2R7S8S10R11R12S_3

$6 \mathrm{p} \_1 R 2 R 7 S 8 S 10 R 11 R 12 S \_4$

$6 \mathrm{p} \_1 R 2 R 7 S 8 S 10 R 11 R 12 S \_5$

$6 \mathrm{p} \_1 R 2 R 7 S 8 S 10 R 11 R 12 S \_6$

6p_1R2R7S8S10R11R12S_7

6p_1R2R7S8S10R11R12S_8

$6 \mathrm{p}_{-} 1 R 2 R 7 S 8 S 10 R 11 R 12 S \_9$
SCF Energy $\left(\mathrm{PCM} / \mathrm{mPW} 1 \mathrm{PW} 91 / 6-31+\mathrm{G}^{* *}\right)=-1007.12525182$

SCF Energy $\left(\mathrm{PCM} / \mathrm{mPW} 1 \mathrm{PW} 91 / 6-31+\mathrm{G}^{* *}\right)=-1007.12466326$

SCF Energy (PCM/mPW1PW91/6-31+G**) = -1007.16648331

SCF Energy $\left(\mathrm{PCM} / \mathrm{mPW} 1 \mathrm{PW} 91 / 6-31+\mathrm{G}^{* *}\right)=-1007.16529162$

SCF Energy $\left(\mathrm{PCM} / \mathrm{mPW} 1 \mathrm{PW} 91 / 6-31+\mathrm{G}^{* *}\right)=-1007.16622921$

SCF Energy $\left(\mathrm{PCM} / \mathrm{mPW} 1 \mathrm{PW} 91 / 6-31+\mathrm{G}^{* *}\right)=-1007.16546852$

SCF Energy $\left(\mathrm{PCM} / \mathrm{mPW} 1 \mathrm{PW} 91 / 6-31+\mathrm{G}^{* *}\right)=-1007.16525973$

SCF Energy (PCM/mPW1PW91/6-31+G**) = -1007.16642117

SCF Energy $\left(\mathrm{PCM} / \mathrm{mPW} 1 \mathrm{PW} 91 / 6-31+\mathrm{G}^{* *}\right)=-1007.16543713$

SCF Energy $\left(\mathrm{PCM} / \mathrm{mPW} 1 \mathrm{PW} 91 / 6-31+\mathrm{G}^{* *}\right)=-1007.16622350$

SCF Energy $\left(\mathrm{PCM} / \mathrm{mPW} 1 \mathrm{PW} 91 / 6-31+\mathrm{G}^{* *}\right)=-1007.16717677$

SCF Energy $\left(\mathrm{PCM} / \mathrm{mPW} 1 \mathrm{PW} 91 / 6-31+\mathrm{G}^{* *}\right)=-1007.16651317$

SCF Energy $\left(\mathrm{PCM} / \mathrm{mPW} 1 \mathrm{PW} 91 / 6-31+\mathrm{G}^{* *}\right)=-1007.16679869$

SCF Energy $\left(\mathrm{PCM} / \mathrm{mPW} 1 \mathrm{PW} 91 / 6-31+\mathrm{G}^{* *}\right)=-1007.16692426$

SCF Energy $\left(\mathrm{PCM} / \mathrm{mPW} 1 \mathrm{PW} 91 / 6-31+\mathrm{G}^{* *}\right)=-1007.16633439$

SCF Energy $\left(\mathrm{PCM} / \mathrm{mPW} 1 \mathrm{PW} 91 / 6-31+\mathrm{G}^{* *}\right)=-1007.16611624$

SCF Energy $\left(\mathrm{PCM} / \mathrm{mPW} 1 \mathrm{PW} 91 / 6-31+\mathrm{G}^{* *}\right)=-1007.16659483$

SCF Energy $\left(\mathrm{PCM} / \mathrm{mPW} 1 \mathrm{PW} 91 / 6-31+\mathrm{G}^{* *}\right)=-1007.16677238$

SCF Energy $\left(\mathrm{PCM} / \mathrm{mPW} 1 \mathrm{PW} 91 / 6-31+\mathrm{G}^{* *}\right)=-1007.12742748$

SCF Energy $\left(\mathrm{PCM} / \mathrm{mPW} 1 \mathrm{PW} 91 / 6-31+\mathrm{G}^{* *}\right)=-1007.12702028$

SCF Energy $\left(\mathrm{PCM} / \mathrm{mPW} 1 \mathrm{PW} 91 / 6-31+\mathrm{G}^{* *}\right)=-1007.12637228$

SCF Energy $\left(\mathrm{PCM} / \mathrm{mPW} 1 \mathrm{PW} 91 / 6-31+\mathrm{G}^{* *}\right)=-1007.12584207$

SCF Energy $\left(\mathrm{PCM} / \mathrm{mPW} 1 \mathrm{PW} 91 / 6-31+\mathrm{G}^{* *}\right)=-1007.12844485$

SCF Energy $\left(\mathrm{PCM} / \mathrm{mPW} 1 \mathrm{PW} 91 / 6-31+\mathrm{G}^{* *}\right)=-1007.12892458$

SCF Energy $\left(\mathrm{PCM} / \mathrm{mPW} 1 \mathrm{PW} 91 / 6-31+\mathrm{G}^{* *}\right)=-1007.12973227$

SCF Energy $\left(\mathrm{PCM} / \mathrm{mPW} 1 \mathrm{PW} 91 / 6-31+\mathrm{G}^{* *}\right)=-1007.12788084$

SCF Energy (PCM/mPW1PW91/6-31+G**) = -1007.16572462

SCF Energy $\left(\mathrm{PCM} / \mathrm{mPW} 1 \mathrm{PW} 91 / 6-31+\mathrm{G}^{* *}\right)=-1007.16515963$

SCF Energy (PCM/mPW1PW91/6-31+G** $=-1007.16557561$

SCF Energy $\left(\mathrm{PCM} / \mathrm{mPW} 1 \mathrm{PW} 91 / 6-31+\mathrm{G}^{* *}\right)=-1007.16474769$

SCF Energy $\left(\mathrm{PCM} / \mathrm{mPW} 1 \mathrm{PW} 91 / 6-31+\mathrm{G}^{* *}\right)=-1007.16567662$

SCF Energy $\left(\mathrm{PCM} / \mathrm{mPW} 1 \mathrm{PW} 91 / 6-31+\mathrm{G}^{* *}\right)=-1007.16445104$

SCF Energy $\left(\mathrm{PCM} / \mathrm{mPW} 1 \mathrm{PW} 91 / 6-31+\mathrm{G}^{* *}\right)=-1007.16492198$

SCF Energy $\left(\mathrm{PCM} / \mathrm{mPW} 1 \mathrm{PW} 91 / 6-31+\mathrm{G}^{* *}\right)=-1007.16509993$

SCF Energy (PCM/mPW1PW91/6-31+G**) = -1007.16396196

SCF Energy (PCM/mPW1PW91/6-31+G**) = -1007.16387810

SCF Energy (PCM/mPW1PW91/6-31+G**) = -1007.16507462

SCF Energy (PCM/mPW1PW91/6-31+G**) = -1007.16368301

SCF Energy $\left(\mathrm{PCM} / \mathrm{mPW} 1 \mathrm{PW} 91 / 6-31+\mathrm{G}^{* *}\right)=-1007.16359269$

SCF Energy $\left(\mathrm{PCM} / \mathrm{mPW} 1 \mathrm{PW} 91 / 6-31+\mathrm{G}^{* *}\right)=-1007.16477990$

SCF Energy $\left(\mathrm{PCM} / \mathrm{mPW} 1 \mathrm{PW} 91 / 6-31+\mathrm{G}^{* *}\right)=-1007.16458784$

SCF Energy $\left(\mathrm{PCM} / \mathrm{mPW} 1 \mathrm{PW} 91 / 6-31+\mathrm{G}^{* *}\right)=-1007.16429134$

SCF Energy $\left(\mathrm{PCM} / \mathrm{mPW} 1 \mathrm{PW} 91 / 6-31+\mathrm{G}^{* *}\right)=-1007.16405903$ 
Table S5. Imaginary frequencies and absolute energy values of all conformers of compounds 1-6 used after optimization at the B3LYP/6-31G* level of theory as required for DP4+.

\begin{tabular}{|c|c|c|}
\hline \multirow{2}{*}{ 1a_354S7S8S_1_DP4+ } & \multicolumn{2}{|l|}{ Imaginary Freq $=0$} \\
\hline & $\begin{array}{l}\text { Zero-point correction }= \\
\text { Thermal correction to Energy }= \\
\text { Thermal correction to Enthalpy= } \\
\text { Thermal correction to Gibbs Free Energy }= \\
\text { Sum of electronic and zero-point Energies= } \\
\text { Sum of electronic and thermal Energies= } \\
\text { Sum of electronic and thermal Enthalpies= } \\
\text { Sum of electronic and thermal Free Energies= }\end{array}$ & $\begin{array}{l}0.510203 \text { (Hartree/Particle) } \\
0.535061 \\
0.536005 \\
0.458720 \\
-1008.014535 \\
-1007.989676 \\
-1007.988732 \\
-1008.066017\end{array}$ \\
\hline \multirow[t]{2}{*}{ 1a_3S4S7S8S_2_DP4+ } & Imaginary Freq $=0$ & \\
\hline & $\begin{array}{l}\text { Zero-point correction }= \\
\text { Thermal correction to Energy }= \\
\text { Thermal correction to Enthalpy= } \\
\text { Thermal correction to Gibbs Free Energy }= \\
\text { Sum of electronic and zero-point Energies= } \\
\text { Sum of electronic and thermal Energies= } \\
\text { Sum of electronic and thermal Enthalpies }= \\
\text { Sum of electronic and thermal Free Energies= }\end{array}$ & $\begin{array}{l}0.509955 \text { (Hartree/Particle) } \\
0.534914 \\
0.535858 \\
0.458430 \\
-1008.011337 \\
-1007.986378 \\
-1007.985434 \\
-1008.062862\end{array}$ \\
\hline \multirow[t]{2}{*}{ 1a_3S4S7S8S_3_DP4+ } & Imaginary Freq $=0$ & \\
\hline & $\begin{array}{l}\text { Zero-point correction }= \\
\text { Thermal correction to Energy }= \\
\text { Thermal correction to Enthalpy= } \\
\text { Thermal correction to Gibbs Free Energy }= \\
\text { Sum of electronic and zero-point Energies }= \\
\text { Sum of electronic and thermal Energies= } \\
\text { Sum of electronic and thermal Enthalpies }= \\
\text { Sum of electronic and thermal Free Energies= }\end{array}$ & $\begin{array}{l}0.509905 \text { (Hartree/Particle) } \\
0.534885 \\
0.535829 \\
0.458322 \\
-1008.011294 \\
-1007.986315 \\
-1007.985371 \\
-1008.062878\end{array}$ \\
\hline \multirow[t]{2}{*}{ 1a_3S4S7S8S_4_DP4+ } & Imaginary Freq $=0$ & \\
\hline & $\begin{array}{l}\text { Zero-point correction= } \\
\text { Thermal correction to Energy }= \\
\text { Thermal correction to Enthalpy= } \\
\text { Thermal correction to Gibbs Free Energy= } \\
\text { Sum of electronic and zero-point Energies= } \\
\text { Sum of electronic and thermal Energies= } \\
\text { Sum of electronic and thermal Enthalpies= } \\
\text { Sum of electronic and thermal Free Energies= }\end{array}$ & $\begin{array}{l}0.509652 \text { (Hartree/Particle) } \\
0.534709 \\
0.535653 \\
0.457681 \\
-1008.012270 \\
-1007.987213 \\
-1007.986269 \\
-1008.064240\end{array}$ \\
\hline \multirow[t]{2}{*}{ 1a_3S4S7S8S_5_DP4+ } & Imaginary Freq $=0$ & \\
\hline & $\begin{array}{l}\text { Zero-point correction }= \\
\text { Thermal correction to Energy }= \\
\text { Thermal correction to Enthalpy= } \\
\text { Thermal correction to Gibbs Free Energy }= \\
\text { Sum of electronic and zero-point Energies= } \\
\text { Sum of electronic and thermal Energies= } \\
\text { Sum of electronic and thermal Enthalpies }= \\
\text { Sum of electronic and thermal Free Energies= }\end{array}$ & $\begin{array}{l}0.509905 \text { (Hartree/Particle) } \\
0.534948 \\
0.535892 \\
0.457296 \\
-1008.011638 \\
-1007.986595 \\
-1007.985651 \\
-1008.064247\end{array}$ \\
\hline \multirow[t]{2}{*}{ 1a_3S4S7S8S_6_DP4+ } & Imaginary Freq $=0$ & \\
\hline & $\begin{array}{l}\text { Zero-point correction }= \\
\text { Thermal correction to Energy }= \\
\text { Thermal correction to Enthalpy= } \\
\text { Thermal correction to Gibbs Free Energy }= \\
\text { Sum of electronic and zero-point Energies= } \\
\text { Sum of electronic and thermal Energies }= \\
\text { Sum of electronic and thermal Enthalpies }= \\
\text { Sum of electronic and thermal Free Energies= }\end{array}$ & $\begin{array}{l}0.509283 \text { (Hartree/Particle) } \\
0.534573 \\
0.535517 \\
0.456089 \\
-1008.008590 \\
-1007.983300 \\
-1007.982356 \\
-1008.061784\end{array}$ \\
\hline \multirow[t]{2}{*}{ 1a_3S4S7S8S_7_DP4+ } & Imaginary Freq $=0$ & \\
\hline & $\begin{array}{l}\text { Zero-point correction= } \\
\text { Thermal correction to Energy }= \\
\text { Thermal correction to Enthalpy= } \\
\text { Thermal correction to Gibbs Free Energy= } \\
\text { Sum of electronic and zero-point Energies= } \\
\text { Sum of electronic and thermal Energies= } \\
\text { Sum of electronic and thermal Enthalpies= } \\
\text { Sum of electronic and thermal Free Energies= }\end{array}$ & $\begin{array}{l}0.509777 \text { (Hartree/Particle) } \\
0.534763 \\
0.535707 \\
0.457934 \\
-1008.011812 \\
-1007.986826 \\
-1007.985882 \\
-1008.063656\end{array}$ \\
\hline \multirow[t]{2}{*}{ 1a_3S4S7S8S_8_DP4+ } & Imaginary Freq $=0$ & \\
\hline & $\begin{array}{l}\text { Zero-point correction= } \\
\text { Thermal correction to Energy }= \\
\text { Thermal correction to Enthalpy }= \\
\text { Thermal correction to Gibbs Free Energy }= \\
\text { Sum of electronic and zero-point Energies= } \\
\text { Sum of electronic and thermal Energies }= \\
\text { Sum of electronic and thermal Enthalpies }= \\
\text { Sum of electronic and thermal Free Energies= }\end{array}$ & $\begin{array}{l}0.509361 \text { (Hartree/Particle) } \\
0.534634 \\
0.535579 \\
0.456068 \\
-1008.008161 \\
-1007.982888 \\
-1007.981944 \\
-1008.061455\end{array}$ \\
\hline \multirow[t]{2}{*}{ 1a_3S4S7S8S_9_DP4+ } & Imaginary Freq $=0$ & \\
\hline & $\begin{array}{l}\text { Zero-point correction= } \\
\text { Thermal correction to Energy }= \\
\text { Thermal correction to Enthalpy= } \\
\text { Thermal correction to Gibbs Free Energy= } \\
\text { Sum of electronic and zero-point Energies= } \\
\text { Sum of electronic and thermal Energies= } \\
\text { Sum of electronic and thermal Enthalpies= } \\
\text { Sum of electronic and thermal Free Energies= }\end{array}$ & $\begin{array}{l}0.509467 \text { (Hartree/Particle) } \\
0.534675 \\
0.535619 \\
0.455874 \\
-1008.009098 \\
-1007.983890 \\
-1007.982946 \\
-1008.062691\end{array}$ \\
\hline \multirow[t]{2}{*}{ 1a_3S4S7S8S_10_DP4+ } & Imaginary Freq $=0$ & \\
\hline & $\begin{array}{l}\text { Zero-point correction= } \\
\text { Thermal correction to Energy }= \\
\text { Thermal correction to Enthalpy= } \\
\text { Thermal correction to Gibbs Free Energy= } \\
\text { Sum of electronic and zero-point Energies= } \\
\text { Sum of electronic and thermal Energies= } \\
\text { Sum of electronic and thermal Enthalpies= } \\
\text { Sum of electronic and thermal Free Energies= }\end{array}$ & $\begin{array}{l}0.509325 \text { (Hartree/Particle) } \\
0.534546 \\
0.535490 \\
0.457319 \\
-1008.010639 \\
-1007.985418 \\
-1007.984474 \\
-1008.062645\end{array}$ \\
\hline \multirow[t]{2}{*}{ 1a_3S4S7S8S_11_DP4+ } & Imaginary Freq $=0$ & \\
\hline & $\begin{array}{l}\text { Zero-point correction= } \\
\text { Thermal correction to Energy= }\end{array}$ & $\begin{array}{l}0.509890 \text { (Hartree/Particle) } \\
0.534888\end{array}$ \\
\hline
\end{tabular}


1a_3S4S7S8S_12_DP4+

1a_3S4S7S8S_13_DP4+

1a_3S4S7S8S_14_DP4+

1a_3S4S7S8S_15_DP4+

1a_3S4S7S8S_16_DP4+

1a_3S4S7S8S_17_DP4+

1a_3S4S7S8S_18_DP4+

1a_3S4S7S8S_19_DP4+

1b_3S4R7S8S_1_DP4+

1b_3S4R7S8S_2_DP4+

1b_3S4R7S8S_3_DP4+
Thermal correction to Enthalpy=

Thermal correction to Gibbs Free Energy=

Sum of electronic and zero-point Energies

Sum of electronic and thermal Energies=

Sum of electronic and thermal Free Energie

Imaginary Freq $=0$

Thermal correction to Energy=

Thermal correction to Enthalpy=

Thinnal correction to Gibbs Free Energy=

oint Energies=

Sum of electronic and thermal Energies=

Sum of electronic and thermal Free Energies=

Imaginary Freq $=0$

Zero-point correction=

Thermal correction to Energy=

Thermal correction to Enthalpy=

Thermal correction to Gibbs Free Energy=

Sum of electronic and zero-point Energies

Sum of electronic and thermal Energies=

Sum of electronic and thermal Enthalpies=
Sum of electronic and thermal Free Energies

Imaginary Freq $=0$

Zero-point correction

Thermal correction to Energy=

Thermal correction to Gibbs Free Energy

Sum of electric and zero-point Energy =

Sum of electronic and zero-point Energies

Sum of electronic and thermal Enthalpies=

Sum of electronic and thermal Free Energies=

Imaginary Freq $=0$

Zero-point correction $=$

Thermal correction to Energy=

Thermal correction to En

Thermal correction to Gibbs Free Energy=

Sum of electronic and zero-point Energies

Sum of electronic and thermal Energies=

Sum of electronic and thermal Enthalpies=

Imaginary Freq $=0$

Zero-point correction

Thermal correction to Energy=

Sum of electronic and 2 bbs Free Energy=

Sum of electronic and thermal Energes

Sum of electronic and thermal Enthalpies=

Sum of electronic and thermal Free Energies=

Imaginary Freq $=0$

Zero-point correction=

Thermal correction to Energy=

Thermal correction to Gibbs Free Energy=

Sum of electronic and zero-point Energies

Sum of electronic and thermal Energies=

Sum of electronic and hermal Enthalpies-

Imaginary Freq $=0$

Zero-point correction

Thermal correction to Energy=

Thermal correction to Gibbs Free Energy=

Sum of electronic and zero-poi

Sum of electronic and thermal Energies=

Sum of electronic and thermal Free Energies=

Imaginary Freq $=0$

Zero-point correction=

Thermal correction to Energy=

Thermal correction to Gibbs Free Energy=

Sum of electronic and zero-point Energies

Sum of electronic and homal Energies=

Sum of ecctronic and

Imaginary Freq $=0$

Zero-point correctio

cection to Energy=

Thermal correction to Enthalp

Thermal correction to Gibbs Free Energy=

Sum of electronic and zero-point Energies

Sum of electronic and thermal Energies=

Sum of electronic and thermal Enthalpies=
Sum of electronic and thermal Free Energies=

Imaginary Freq $=0$

Zero-point correction=

Thermal correction to Energy=

Thermal correction to Gibbs Free Energy=

Sum of electronic and zero-point Energes

Sum of electronic and thermal Energies=

Sum of electronic and thermal Free Energies=

Imaginary Freq $=0$

Zero-point correction

Thermal correction to Energy=

Thermal correction to Enthalpy=

Thermal correction to Gibbs Free Energy=
0.535832

$-1008.010861$

$-1007.985863$

$-1007.984919$

$-1008.062420$

0.509885 (Hartree/Particle)

0.53468

0.535627

$-1008.00498$

-1008.004985
-1007.980187

$-1007.979243$

$-1008.056554$

0.510140 (Hartree/Particle)

0.534955

0.535900

0.458359

$-1008.010067$

$-1007.985252$

$-1007.984308$

0.509737 (Hartree/Particle)

0.534689

0.457837

-1008.007423
-1007.982472

-1007.98247
-1007.981527

$-1008.059324$

0.509366 (Hartree/Particle)

0.534539
0.535483

0.535483

0.457524

$-1008.007714$

$-1007.982541$

$-1007.981597$

0.509714 (Hartree/Particle)

0.534571

0.535515
0.458115

$-1008.002049$

-1008.002049
-1007.97719

$-1007.976247$

$-1008.053647$

0.509629 (Hartree/Particle)

0.534738

0.535682

0.456666

$-1008.008477$

$-1007.983368$

$-1007.062424$

0.509303 (Hartree/Particle)

0.534501

0.457343

-1008.007935
-.1007 .082736

$-1007.982736$

-1007.982736
-1007.981792

$-1008.059895$

0.509591 (Hartree/Particle)

0.534644

0.535588

457278

$-1008.007054$

$-1007.982000$

$-1008.059367$

0.510043 (Hartree/Particle)

0.534993

0.535937

0.458511

$-1008.012900$

$-1007.98795$

$-1007.987006$

$-1008.064432$

0.509838 (Hartree/Particle)

0.534865

0.535809

$-1008.010923$

$-1008.010923$

-1007.985897
-1007.984952

$-1008.062552$

0.509975 (Hartree/Particle)

0.534975

0.535920
0.458367 
1b 3S4R7S8S_4_DP4+

1b_3S4R7S8S_5_DP4+

1b_3S4R7S8S_6_DP4+

1b_3S4R7S8S_7_DP4

1b_3S4R7S8S_8_DP4+

1b_3S4R7S8S_9_DP4

1b_3S4R7S8S_10_DP4+

1b_3S4R7S8S_11_DP4+

1b_3S4R7S8S_12_DP4+

1b $354 R 758 S \_13$ DP4+

1b_3S4R7S8S_14_DP4+
Sum of electronic and zero-point Energies= Sum of electronic and thermal Energies= Sum of electronic and thermal Free Energie

Imaginary Freq $=0$

Zero-point correction =

Thermal correction to Energy=

Thermal correction to Gibbs Free Energy=

Sum of electronic and zero-point Energies

Sum of electronic and thermal Energies=

Imaginary Freq =

Zero-point

to Energy

Thermal correction to Enthay=

Thermal correction to Gibbs Free Energy=

Sum of electronic and zero-point Ener

Encos

Sum of electronic and thermal Free Energies=

Imaginary Freq $=0$

Zero-point correction

Thermal correction to Energy=

Thermal correction to Gibbs Free Energy=

Sum of electronic and acro-pont Energies

Sum of electronic and thermal Energies

Sum of electronic and thermat Free Energies

Imaginary Freq $=0$

Zero-point co

to Energy=

Thermal correction to Enthalpy

Thermal correction to Gibbs Free Energy=

Sum of electronic and zero-point Energie

Sum of electronic and thermal Energies

Sum of electronic and thermal Free Energies=

Imaginary Freq $=0$

Zero-point correction

Thermal correction to Energy=

Thermal crectice

-point Energies=

Sum of electronic and thermal Energies=

Sum of electronic and thermal Enthalpies=

Sum of electronic and thermal Free Energies=

Imaginary Freq $=0$

Thermal correction to Energy=

Thermal correction to Enthalpy=
Thermal correction to Gibbs Free Energy=

Sum of electronic and zero-point Energies

Sum of electronic and thermal Energies=

Sum of electronic and thermal Free Energies=

Imaginary Freq $=0$

Zero-point correction

Thermal correction to Energy=

Thermal correction to Gibbs Free Energy=

Sum of electronic and zero-point Energies

Sum of ectronic and zero-point Energes

Sum of electronic and thermal Enthalpies=

Sum of electronic and thermal Free Energies=

Imaginary Freq $=0$

Zero-point correction=

Thermal correction to Energy=

Thermal correction to Gibbs Free Energy=

Sum of electronic and zero-point Energies

Sum of electronic and thermal Energies=

Sum of electronic and thermal Enthalpies=

Imaginary Freq $=0$

Zero-point correction

The conection to Energy=

Thermal correction to Gibbs Free Energy=

Sum of electronic and zero-point Energies-

Sum of electronic and thermal Energies-

Sum of electronic and thermal Enthalpies=

Sum of electronic and thermal Free Energies=

Imaginary Freq $=0$

Zero-point correction

Thermal correction to Energy=

ergy=

Thermal correction to Gibbs Free Energy=

Sum of electronic and zero-point Energies-

Sum of electronic and thermal Energies=

Imaginary Freq $=0$

Zero-point correction

Thermal correction to Energy=

Thermal correction to Enthalpy=

Sum of electronic and zero-point Energies=

Sum of electronic and thermal Energies=
$-1008.010558$

$-1007.985557$

$-1008.062166$

0.510256 (Hartree/Particle)

0.535025

0.535969

458771

008.002907
-1007.978138

$-1007.978138$

$-1008.054391$

0.510034 (Hartree/Particle)

0.534880

0.535824
0.458525

$-1008.002267$

007.97742

$-1007.976477$

$-1008.053776$

0.509493 (Hartree/Particle)

0.534649

0.535593

0.457548

$-1007.984585$

$-1007.984585$

$-1008.061685$

0.510005 (Hartree/Particle)

0.535071

0.536015

0.457848

$-1008.008577$

$-1007.983511$

$-1007.982567$

0.510040 (Hartree/Particle)

0.535003

0.535948

$-1008.011876$

-1008.011876
-1007.986912

$-1007.985968$

$-1008.063315$

0.509700 (Hartree/Particle)

0.534870

0.535814

0.457110

$-1008.007106$

$-1007.981935$

$-1007.980991$

0.509283 (Hartree/Particle)

0.534534

0.535478

457217

$-1008.007669$

-1007.982418
-1007.981474

$-1008.059734$

0.509471 (Hartree/Particle)

0.534667

0.535611

.457476

-1008.010285
-1007.985089

$-1007.985089$

$-1007.984145$

0.510000 (Hartree/Particle)

0.534848

0.458487

$-1008.002168$

$-1008.002168$

$-1007.977321$

$-1008.053682$

0.509592 (Hartree/Particle)

0.534700

0.535644

0.457810

$-1008.009336$

$-1007.984228$

$-1008.083284$

0.509636 (Hartree/Particle)

0.534841

0.456596

$-456596$

$-1007.981990$ 
1b_3S4R7S8S_15_DP4+

1b_3S4R7S8S_16_DP4+

1b_3S4R7S8S_17_DP4+

1b_3S4R7S8S_18_DP4+

1b_3S4R7S8S_19_DP4+

1c_3S4S7S8R_1_DP4+

1c_3S4S7S8R_2_DP4+

$1 \mathrm{c} \_3 S 4 S 7 S 8 R \_3$ DPP4+

1c_3S4S7S8R_4_DP4+

1c_3S4S7S8R_5_DP4+

1c $3 S 4 S 7 S 8 R \_6$ DP 4
Imaginary Freq $=0$

Zero-point correction

Thermal correction to Energy=

Thermal correction to Gibbs Free Energy=

Sum of electronic and zero-point Energies

Sum of electronic and thermal Free Energies=

Imaginary Freq $=0$

Zero-point correction

Thermal correction to Energy $=$

Thermal correction to Gibbs Free Energy=

Sum of electronic and zero-point Energies-

Sum of ectronic and

Imaginary Freq $=0$

Zero-po

to

Thermal correction to Enthalpy

Thermal correction to Gibbs Free Energy=

Sum of electronic and zero-point Energies

Sum of electronic and thermal Energies=

Sum of electronic and thermal Free Energies=

Imaginary Freq $=0$

Zero-point correction

Thermal correction to Energy=

(Thermal correction to Enhalpy $=$

Thermal correction to Gibbs Free Energy=

Sun of elcrocic and

Sum of electronic and thermis

Sum of electronic and thermal Free Energies

Imaginary Freq $=0$

Zero-point correction

Thermal correction to Energy=

Thermal correction to Enthalpy=
Thermal correction to Gibbs Free Energy=

Sum of electronic and zero-point Energies

Sum of electronic and thermal Energies

Sum of electronic and thermal Free Energies=

Imaginary Freq $=0$

Zero-point correction

Thermal correction to Energy=

Thermal correction to Gibbs Free Energy=

Sum of electronic and zero-point Energies=

Sum of electronic and thermal Energies=

Sum of electronic and thermal Enthalpies=

Sum of electronic and thermal Free Energies=

Imaginary Freq $=0$

Zero-point correction=

Thermal correction to Energy=

Thermal correction to Enthalpy

Thermal correction to Gibbs Free Energy=

Sum of electronic and zero-point Energies

Sum of electronic and thermal Energies

Imaginary Freq $=$

Zero-point correction

Thermal correction to Energy=

Sum of ectron=

Sum of electronic and thermal Energies=

Sum of electronic and thermal Free Energies=

Imaginary Freq $=0$

Zero-point correction=

Thermal correction to Energy=

Thermal correction to Gibbs Free Energy=

Sum of electronic and zero-point Energies

Sum of electronic and thermal Energies=

Sum of electronic and thermal Enthalpies=

Imaginary Freq $=0$

Zero-point correction

on to Energy=

Thermal correction to Gibbs Free Energy

Sum of electronic and zero-point Energies-

Sum of electronic and therm

Sum of electronic and thermal Enthalpies=

Sum of electronic and thermal Free Energies=

Imaginary Freq $=0$

Zero-point correction-

Thermal correction to Energy=

Thermal correction to Gibbs Free Energy=

Sum of electronic and zero-point Energies

Sum of electronic and themal Energies=
0.509647 (Hartree/Particle)

0.534782

0.535726

0.457765

$-1008.009920$

$-1007.98478$

007.983840

$-1008.061801$

0.509395 (Hartree/Particle)

0.534605

0.535549

457383

$-1007.982202$

$-1007.981258$

1008.059424

0.509712 (Hartree/Particle)

0.534805

0.53574

0.457231

$-1008.007188$

$-1007.982095$

-1007.981151
-1008.059669

0.509320 (Hartree/Particle)

0.534552

0.535496

0.457265

-1008.007204
-1007.981972

$-1007.981972$

$-1008.059260$

0.510561 (Hartree/Particle)

0.535288

0.536233

0.459600

$-1008.009897$

$-1007.98516$

$-1007.984224$

$-1008.060857$

0.509769 (Hartree/Particle)

0.534858

0.457200

0.457200
-1008.009788

$-1007.984698$

$-1007.983754$

$-1008.062356$

0.509712 (Hartree/Particle)

0.53468

0.535628

0.457872

$-1008.008328$

$-1007.983355$

$-1007.982411$

0.509249 (Hartree/Particle)

0.534503

0.535447

$-1008.007348$

-1007.982093
-1007.981149

$-1008.060077$

0.509140 (Hartree/Particle)

0.534463

0.535407

0.456255

$-1008.007210$

$-1007.981886$

$-1007.980942$

0.509531 (Hartree/Particle)

0.534573

0.457394

$-1008.008297$

-1008.008297
-1007.983256

$-1007.98231$

$-1008.060434$

0.509708 (Hartree/Particle)

0.534681

0.535625

$-457867$

$-1008.008331$

-1007.983359
-1007.982414 
1c_3S4S7S8R_7_DP4

1c $3 S 4 S 7 S 8 R \_8$ DP4

1c_3S4S7S8R_9_DP4

1c_3S4S7S8R_10_DP4+

1c_3S4S7S8R_11_DP4+

1c_3S4S7S8R_12_DP4+

1c_3S4S7S8R_13_DP4+

1c_3S4S7S8R_14_DP4+

1c_3S4S7S8R_15_DP4+

1c_3S4S7S8R_16_DP4+

1c_3S4S7S8R_17_DP4+
Imaginary Freq $=0$

Zero-point correction

Therme Energy=

Thermal correction to Gibbs Free Energy=

Sum of electronic and zero-point Energies=

Sum of electronic and thermal Energies=

Sum of electronic and thermal Enthalpies=

Imaginary Freq $=0$

Zero-point correction

Thermal correction to Energy=

Thermal correction to Gibbs Free Energy=

Sum of electronic and zero-point Energies=

Sum of electronic and the pol Energies=

Imaginary Freq $=0$

Zero-point

ection to Energy=

Thermal correction to Enthalpy

Thermal correction to Gibbs Free Energy=

Sum of electronic and zero-point Energic

Sum of electronic and thermal Energ

Sum of electronic and thermal Free Energies=

Imaginary Freq $=0$

Zero-point correction

Thermal correction to Energy=

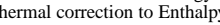

Thermal correction to Gibbs Free Energy=

Sum of ectronic and them Engles

Sum of electronic and thermal Free Energies=

Imaginary Freq $=0$

Zero-point corect

Thermal correction to Energy=

Thermal correction to Enthalpy=
Thermal correction to Gibbs Free Energy=

Sum of electronic and zero-point Energies

Sum of electronic and thermal Energies

Sum of electronic and thermal Free Energies=

Imaginary Freq $=0$

Zero-point correction

Thermal correction to Energy=

Thermal correction to Gibbs Free Energy=

Sum of electronic and zero-point Energies=

Sum of electronic and therment Eneries

Sum of electronic and thermal Enthalpies-

Sum of electronic and thermal Free Energies=

Imaginary Freq $=0$

Zero-point correction=

Thermal correction to Energy=

Thermal correction to Enthalpy

Thermal correction to Gibbs Free Energy=

Sum of electronic and zero-point Energies

Sum of electronic and thermal Energies

Imaginary Freq $=0$

Zero-point correction

Thermal correction to Energy=

Free Energy=

-point Energies=

Sum of electronic and thermal Energies=

Sum of electronic and thermal Free Energies=

Imaginary Freq $=0$

Zero-point correction=

Thermal correction to Energy=

Thermal correction to Gibbs Free Energy=

Sum of electronic and zero-point Energies

Sum of electronic and thermal Energies=

Sum of electronic and thermal Enthalpies=

Imaginary Freq $=0$

Zero-point correction

to Energy=

Enthalpy=

Thermal correction to Gibbs Free Energy=

Sum of electronic and zero-point Energies-

Sum of electronic and therm

Sum of electronic and thermal Enthalpies=

Sum of electronic and thermal Free Energies=

Imaginary Freq $=0$

Zero-point correction=

Thermal correction to Energy=

Thermal correction to Gibbs Free Energy=

Sum of electronic and zero-point Energies

Sum of electronic and themal Energies=
0.510120 (Hartree/Particle)

0.534915

0.458654

$-1008.002474$

$-1007.97768$

$-1007.976735$

$-1008.053941$

0.509437 (Hartree/Particle)

0.534643

0.457041

.457041

-1008.006371

$-1007.980221$

1008.058767

0.509695 (Hartree/Particle)

0.534646

0.535590

0.458122

$-1008.000791$

$-1007.975840$

$-1007.974896$

$-1008.052364$

0.509792 (Hartree/Particle)

0.534708

0.535653

$-1008.008255$

-1008.008255
-1007.983339

$-1007.982395$

$-1008.060043$

0.509793 (Hartree/Particle)

0.534708

0.535653

0.535653
0.458011

$-1008.008254$

$-1007.983339$

$-1007.982395$

$-1008.060037$

0.509285 (Hartree/Particle)

0.53451

0.556643

$-1008.00651$

-1008.006511
-1007.981284

$-1007.980340$

$-1008.059153$

0.509333 (Hartree/Particle)

0.534422

0.535367

0.457730

$-1007.999932$

$-1007.974843$

$-1007.973899$

0.509179 (Hartree/Particle)

0.534472

0.556335

$-1008.006342$

-1007.98104
-1007.980105

$-1008.059186$

0.509185 (Hartree/Particle)

0.534347

0.535291

0.457276

$-1008.005096$

$-1007.97993$

$-1007.978989$

0.510131 (Hartree/Particle)

0.534895

0.535839

$-1008.0012$

$-1008.001249$

$-1007.975540$

$-1008.052427$

0.510213 (Hartree/Particle)

0.534903

0.535847

.459182

$-1008.000093$

$-1007.975403$ 
1c_3S4S7S8R_18_DP4+

1c_3S4S7S8R_19_DP4+

1c_3S4S7S8R_20_DP4+

1c_3S4S7S8R_21_DP4+

1c_354S7S8R_22_DP4+

1c_3S4S7S8R_23_DP4+

1c_3S4S7S8R_24_DP4+

1c_3S4S7S8R_25_DP4+

1c_3S4S7S8R_26_DP4+

1c_3S4S7S8R_27_DP4+

1c_3S4S7S8R_28_DP4+
Imaginary Freq $=0$

Zero-point correction

Them conection to Energy=

Thermal correction to Gibbs Free Energy=

Sum of electronic and zero-point Energies=

Sum of electronic and thermal Free Energies=

Imaginary Freq $=0$

Zero-point correction=

Thermal correction to Energy $=$

Thermal correction to Gibbs Free Energy=

Sum of electronic and zero-point Energies=

Sum of ectronic and thm Engase

Imaginary Freq $=0$

Zero-po

Tero-point correction $=$

Thermal correction to Enthalpy

Thermal correction to Gibbs Free Energy=

Sum of electronic and zero-point Energ

Sum of electronic and thermal Energie

Sum of electronic and thermal Free Energies=

Imaginary Freq $=0$

Zero-point correction

Thermal correction to Energy=

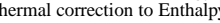

Thermal correction to Gibbs Free Energy=

Sum of electronic and thermes

Sum of electronic and thermal Free Energies=

Imaginary Freq $=0$

Zero-point correc

Thermal correction to Energy=

Thermal correct

Thermal correction to Gibbs Free Energy=

Sum of electronic and zero-point Energies

Sum of electronic and thermal Energies

Sum of electronic and thermal Free Energies=

Imaginary Freq $=0$

Zero-point correctio

Thermal correction to Energy=

Thermal correction to Gibbs Free Energy=

Sum of electronic and zero-point Energies=

Sum of eletronic and thermi Energes

Sum of electronic and thermal Enthalpies=

Sum of electronic and thermal Free Energies=

Imaginary Freq $=0$

Zero-point correction=

Thermal correction to Energy=

Thermal correction to Enthalpy

Thermal correction to Gibbs Free Energy=

Sum of electronic and zero-point Energies

Sum of electronic and thermal Energies

Imaginary Freq $=0$

Zero-point correction

Thermal correction to Energy=

Thermal correction to Gibbs Free Energy

Sum of ectronic and zero-point Energes

Sum of electronic and thermal Energies=

Sum of electronic and thermal Enthalpies=

Sum of electronic and thermal Free Energies=

Imaginary Freq $=0$

Zero-point correction $=$

Thermal correction to Energy=

Thermal correction to Gibbs Free Energy=

Sum of electronic and zero-point Energies

Sum of electronic and thermal Energies=

Sum of electronic and thermal Enthalpies=

Imaginary Freq $=0$

Zero-point correction

ection to Energy=

Thermal correction to Gibbs Free Energy=

Sum of electronic and zero-point Energies-

Sum of electronic and therm

Sum of electronic and thermal Enthalpies=

Sum of electronic and thermal Free Energies=

Imaginary Freq $=0$

Zero-point correction=

Thermal correction to Energy=

Thermal correction to Gibbs Free Energy=

Sum of electronic and zero-point Energies

Sum of electronic and thenmal Energies=
0.509523 (Hartree/Particle)

0.534451

0.535395

$-1007.995915$

$-1007.97098$

- 007.970044

$-1008.047345$

0.509069 (Hartree/Particle)

0.534250

0.535194

456995

008.005075
-1007.979893

$-1007.978949$

$-1008.057148$

0.510435 (Hartree/Particle)

0.535204

0.53614

0.458423

$-1008.002824$

$-1007.97805$

$-1007.977111$

$-1008.054836$

0.509127 (Hartree/Particle)

0.534348

0.535292

$-1008.004675$

-1008.004675
-1007.97945

$-1007.979454$

$-1008.056984$

0.509432 (Hartree/Particle)

0.534458

0.535402

0.457950

$-1007.996667$

$-1007.97164$

$-1007.970697$

$-1008.048149$

0.509634 (Hartree/Particle)

0.534748

0.536966

$-1008.010690$

-1008.010690
-1007.985576

$-1007.984632$

$-1008.063358$

0.509181 (Hartree/Particle)

0.534344

0.535288

0.457272

$-1008.005100$

-1007.979937
-1007.978992

$-1008.057009$

0.509896 (Hartree/Particle)

0.509896
0.534762
0.535707

0.457498

$-1007.998062$

-1007.998062
-1007.973196

-1007.973196
-1007.972252

$-1008.050460$

0.509285 (Hartree/Particle)

0.534358

0.535302

.457554

$-1007.998032$

$-1007.97295$

$-1007.972015$

0.508968 (Hartree/Particle)

0.534244

0.535188

$-1008.004701$

$-1007.97848$

$-1008.057406$

0.509062 (Hartree/Particle)

0.534247

0.535192

0.456976

-1008.005081
-1007.979896

-1007.979896
-1007.978952 
1c_3S4S7S8R_29_DP4+

1c_3S4S7S8R_30_DP4+

1c_3S4S7S8R_31_DP4+

1d_3S4R7S8R_1_DP4+

1d_3S4R7S8R_2_DP4+

1d_3S4R7S8R_3_DP4+

1d_3S4R7S8R_4_DP4+

1d_3S4R7S8R_5_DP4+

1d_3S4R7S8R_6_DP4+

1d_3S4R7S8R_7_DP4+

1d $3 S 4 R 7 S 8 R \quad 8$ DP4+
Imaginary Freq $=0$

Zero-point correction=

Thermal correction to Energy=

Thermal correction to Enthalpy=
Thermal correction to Gibbs Free Energy=

Sum of electronic and zero-point Energies=

Sum of electronic and thermal Energies=

Sum of electronic and thermal Enthalpies=

Imaginary Freq $=0$

Zero-point correction

Thermal correction to Energy=

Thermal correction to Gibbs Free Energy=

Sum of electronic and zero-point Energies

Sum of electronic and thermal Energies=

Imaginary Freq $=0$

Zero-pointc

Tero-point correction=

Thermal correction to Enthalpy

Thermal correction to Gibbs Free Energy=

Sum of electronic and zero-point Energies=

Sum of electronic and thermal Energies=

Sum of electronic and thermal Enthalpies=
Sum of electronic and thermal Free Energies=

Imaginary Freq $=0$

Zero-point correction

Thermal correction to Energy=

Thermal correction to Enthalpy=

Thermal correction to Gibbs Free Energy=

Sum of electronic and zero-point Energie

Sum of electronic and thermal Enthalpies

Sum of electronic and thermal Free Energies

Imaginary Freq $=0$

Zero-point corec

Thermal correction to Energy=

Thermal correction to Enthalpy=
Thermal correction to Gibbs Free Energy=

Sum of electronic and zero-point Energies=

Sum of electronic and thermal Energies=

enthalpies=

Sum of electronic and thermal Free Energies=

Imaginary Freq $=0$

Zero-point correction

Thermal correction to Energy=

Thermal correction to Enthalpy=
Thermal correction to Gibbs Free Energy=

Sum of electronic and zero-point Energies=

Sum of electonic and zero-pont Energies

Sum of electronic and thermal Enthalpies=

Sum of electronic and thermal Free Energies=

Imaginary Freq $=0$

Zero-point correction=

Thermal correction to Energy=

Thermal correction to Enthalpy

Thermal correction to Gibbs Free Energy=

Sum of electronic and zero-point Energies-

Sum of electronic and thermal Energies-

Sum of electronic and thermal Free Energies=

Imaginary Freq $=$

Zero-point correction

Thermal correction to Energy=

Thermal correction to Gibbs Free Energy

Sum of ectronic and zero-point Energy

Sum of electronic and thermal Energes

Sum of electronic and thermal Enthalpies=

Sum of electronic and thermal Free Energies=

Imaginary Freq $=0$

Zero-point correction $=$

Thermal correction to Energy=

Thermal correction to Gibbs Free Energy=

Sum of electronic and zero-point Energies

Sum of electronic and thermal Energies=

Sum of electronic and thermal Enthalpies=

Imaginary Freq $=0$

Zero-point correction

rection to Energy=

Thermal correction to Gibbs Free Energy=

Sum of electronic and zero-point Energies=

Sum of electronic and thermal

Sum of electronic and thermal Enthalpies=

Sum of electronic and thermal Free Energies=

Imaginary Freq $=0$

Zero-point correction=

Thermal correction to Energy=

Thermal correction to Gibbs Free Energy=

Sum of electronic and zero-point Energies

Sum of electronic and thermal Energies=
509328 (Hartree/Particle)

0.534442

0.457212

$-1008.004663$

007.97954

$-1007.978605$

$-1008.056779$

0.509355 (Hartree/Particle)

0.534420

0.535364

$-1008.004957$

$-1007.004957$

$-1007.978948$

1008.056759

0.510018 (Hartree/Particle)

0.510018
0.534918
0.535862

0.535862

0.458088

$-1008.000645$

$-1007.975745$

$-1007.974801$

$-1008.052575$

0.509738 (Hartree/Particle)

0.534664

0.535608

$-1008.00075$

$-1007.975826$

$-1007.975826$

$-1008.052136$

0.509644 (Hartree/Particle)

0.534713

0.53565
0.458077

$-1008.012198$

$-1007.987129$

$-1007.986185$

$-1008.063765$

0.509594 (Hartree/Particle)

0.534702

0.535646

457987

-1008.011533
-1007.98642

-1007.986425
-1007.985481

$-1008.063140$

0.509794 (Hartree/Particle)

0.534714

0.535658
0.458435

$-1008.000054$

$-1007.975135$

$-1007.974190$

0.510039 (Hartree/Particle)

0.510039
0.534830
0.535774

0.458849

$-1008.001029$

-1008.001029
-1007.976239

$-1007.975294$

$-1008.052219$

0.509361 (Hartree/Particle)

0.534545

0.535489

0.457570

-1008.010173
-1007.984989
-1007.984045

$-1007.984045$

0.509330 (Hartree/Particle)

0.534519

0.535463

$-1008.0115$

$-1007.98632$

$-1007.98537$

$-1008.063341$

0.509354 (Hartree/Particle)

0.534557

0.535501

0.457541

$-1008.009392$

-1007.984189
-1007.983245 
1d_3S4R7S8R_9_DP4+

1d_3S4R7S8R_10_DP4+

1d_3S4R7S8R_11_DP4+

1d_3S4R7S8R_12_DP4+

1d_3S4R7S8R_13_DP4+

1d_3S4R7S8R_14_DP4+

1d_3S4R7S8R_15_DP4+

1d_3S4R7S8R_16_DP4+

1d_3S4R7S8R_17_DP4+

1d_3S4R7S8R_18_DP4+

1d_3S4R7S8R_19_DP4+
Imaginary Freq $=0$

Zero-point correction=

Thermal correction to Energy=

Thermal correction to Enthalpy=
Thermal correction to Gibbs Free Energy=

Sum of electronic and zero-point Energies=

Sum of electronic and thermal Energies=

Sum of electronic and thermal Enthalpies=

Imaginary Freq $=0$

Zero-point correction

Thermal correction to Energy=

Thermal correction to Gibbs Free Energy=

Sum of electronic and zero-point Energies

Sum of electronic and thermal Energies=

Imaginary Freq $=0$

Zero-poin

Tero-point correction=

Thermal correction to Entgy=

Thermal correction to Gibbs Free Energy=

Sum of electronic and zero-point Energies

Sum of electronic and thermal Energies

Sum of electronic and thermal Free Energies=

Imaginary Freq $=0$

Zero-point correction

Thermal correction to Energy=

Thermal correction to Enthalpy=

Thermal correction to Gibbs Free Energy=

Sum of electronic and zero-point Energie

Sum of electronic and thermal Energies=

Sum of electronic and thermal Free Energies

Imaginary Freq $=0$

Zero-point correction=

Thermal correction to Energy=

Thermal correction to Enthay

Thermal correction to Gibbs Free Energy=

Sum of electronic and zero-point Energies-

Sum of electronic and thermal Energies=

Sum of electronic and thermal Enthalpies=
Sum of electronic and thermal Free Energies=

Imaginary Freq $=0$

Zero-point correction

Thermal correction to Energy=

Thermal correction to Enthalpy=
Thermal correction to Gibbs Free Energy=

Sum of electronic and zero-point Energies=

Sum of electronic and zero-point Energies-

Sum of electronic and thermal Enthalpies=

Sum of electronic and thermal Free Energies=

Imaginary Freq $=0$

Zero-point correction=

Thermal correction to Energy=

Thermal correction to Enthalpy

Thermal correction to Gibbs Free Energy=

Sum of electronic and zero-point Energies

Sum of electronic and thermal Energies-

Sum of electronic and thermal Free Energies=

Imaginary Freq $=0$

Zero-point correction=

Thermal correction to Energy=

Thermal correction to Enthalpy=
Thermal correction to Gibbs Free Energy=

Sum of electonic and zero-point Energy =

Sum of electronic and thermal Enthalpies=

Sum of electronic and thermal Free Energies=

Imaginary Freq $=0$

Zero-point correction $=$

Thermal correction to Energy=

Thermal correction to Gibbs Free Energy=

Sum of electronic and zero-point Energies

Sum of electronic and thermal Energies=

Sum of electronic and thermal Enthalpies=

Imaginary Freq $=0$

Zero-point correction

To Energy=

Thermal correction to Gibbs Free Energy=

Sum of electronic and zero-point Energies

Sum of electronic and therma

Sum of electronic and thermal Enthalpies=

Sum of electronic and thermal Free Energies=

Imaginary Freq $=0$

Zero-point correction=

Thermal correction to Energy=

Thermal correction to Enthalp

Thermal correction to Gibbs Free Energy=

Sum of electronic and zero-point Energies

Sum of electronic and thermal Energies=
0.509534 (Hartree/Particle)

0.534656

0.457820

$-1008.009900$

$-1007.98477$

$-1007.983833$

$-1008.061614$

0.509241 (Hartree/Particle)

0.534455

0.535399

0.457426

$-1008.009298$

$-1007.983140$

1008.061113

0.509073 (Hartree/Particle)

0.509073
0.534293
0.535237

0.534293

0.456707

$-1007.995747$

$-1007.970527$

$-1007.969583$

$-1008.048114$

0.509508 (Hartree/Particle)

0.534658

0.535602

0.457745

-1008.009105
-1007.983955

-1007.983955
-1007.983011

$-1008.060867$

0.509326 (Hartree/Particle)

0.534408
0.535352

0.535352
0.457399

$-1007.995420$

$-1007.970338$

$-1007.969394$

$-1008.047348$

0.509794 (Hartree/Particle)

0.534714

0.535658

$-1008.00005$

-1008.000054
-1007.975135

-1007.975135
-1007.974190

$-1008.051413$

0.509498 (Hartree/Particle)

0.534512
0.535457

0.457601

$-1007.995887$

$-1007.970872$

$-1007.969928$

0.508990 (Hartree/Particle)

0.534278

0.535222

$-1007.995357$

$-1007.995357$

-1007.970070
-1007.969125

$-1008.047997$

0.509868 (Hartree/Particle)

0.534911

0.535855

0.458541

$-1008.010455$

$-1007.985412$

$-1007.984468$

0.509228 (Hartree/Particle)

0.534367

0.535311

0.457224
-1007.995027

$-1007.969888$

$-1007.968944$

$-1008.047031$

0.509675 (Hartree/Particle)

0.534884

0.535828

0.457127

$-1008.006468$

-1007.981259
-1007.980314 
1d_3S4R7S8R_20_DP4+

1d_3S4R7S8R_21_DP4+

1d_3S4R7S8R_22_DP4+

1d_3S4R7S8R_23_DP4+

1d_3S4R7S8R_24_DP4+

2a_1R7R8S_1_DP4+

2a_1R7R8S_2_DP4+

2a_1R7R8S_3_DP4+

2a_1R7R8S_4_DP4+

2a_1R7R8S_5_DP4+

2a_ $1 R 7 R 8 S$ 6 $6 \mathrm{DP} 4+$
Imaginary Freq $=0$

Zero-point correction=

Thermal correction to Energy=

Thermal correction to Enthalpy=
Thermal correction to Gibbs Free Energy=

Sum of electronic and zero-point Energies=

Sum of electronic and thermal Energies=

Sum of electronic and thermal Enthalpies=

Imaginary Freq $=0$

Zero-point correction

Thermal correction to Energy=

Thermal correction to Gibbs Free Energy=

Sum of electronic and zero-point Energies

Sum of electronic and thermal Energies=

Sum of electronic and thermat Fine

Imaginary Freq $=0$

Zero-pointc

Tero-point correction=

Thermal correction to Entgy =

Thermal correction to Gibbs Free Energy=

Sum of electronic and zero-point Energies

Sum of electronic and thermal Energies

Sum of electronic and thermal Enthalpies=

Imaginary Freq $=0$

Zero-point correction

Thermal correction to Energy=

Thermal correction to Enthalpy=

Thermal correction to Gibbs Free Energy=

Sum of electronic and zero-point Energie

Sum of electronic and thermal Energies=

Sum of electronic and thermal Free Energies

Imaginary Freq $=0$

Zero-point correction=

Thermal correction to Energy=

Thermal correction to Enthal $=$

Thermal correction to Gibbs Free Energy=

Sum of electronic and zero-point Energies

Sum of electronic

thermal Enthalpies

Sum of electronic and thermal Free Energies=

Imaginary Freq $=0$

Zero-point correction

Thermal correction to Energy=

Thermal correction to Gibbs Free Energy=

Sum of ectoctic

Sum of electronic and zero-point Energies-

Sum of electronic and thermal Enthalpies=

Sum of electronic and thermal Free Energies=

Imaginary Freq $=0$

Zero-point correction=

Thermal correction to Energy=

Thermal correction to Enthalpy

Thermal correction to Gibbs Free Energy=

Sum of electronic and zero-point Energies

Sum of electronic and thermal Energies=

Sum of electronic and thermal Free Energies=

Imaginary Freq $=0$

Zero-point correction

Thermal correction to Energy=

Thermal correction to Gibbs Free Energy=

Sum of ectronic and zero-point Energes

Sum of electronic and thermal Energies=

Sum of electronic and thermal Enthalpies=

Sum of electronic and thermal Free Energies=

Imaginary Freq $=0$

Zero-point correction=

Thermal correction to Energy=

Thermal correction to Gibbs Free Energy=

Sum of electronic and zero-point Energies-

Sum of electronic and thermal Energies=

Sum of electronic and thermal Enthalpies=
Sum of electronic and thermal Free Energies=

Imaginary Freq $=0$

Zero-point correction=

Thergy=

Thermal correction to Gibbs Free Energy=

Sum of electronic and zero-point Energies-

Sum of electronic and therm

Sum of electronic and thermal Enthalpies=

Sum of electronic and thermal Free Energies=

Imaginary Freq $=0$

Zero-point correction=

Thermal correction to Energy=

Thermal correction to Gibbs Free Energy=

Sum of electronic and zero-point Energies

Sum of electronic and themal Energies=
0.509199 (Hartree/Particle)

0.534455

0.457508

$-1008.009531$

$-1007.98427$

$-1007.983330$

$-1008.061221$

0.509241 (Hartree/Particle)

0.534388

0.535333

.456891

-007.996061
-1007.970914

$-1007.969969$

$-1008.048411$

0.509245 (Hartree/Particle)

0.509245
0.534562
0.535506

0.535506

0.455960

$-1008.005719$

$-1007.980402$

-1007.979457
-1008.059004

0.509743 (Hartree/Particle)

0.534796

0.535740

0.458378

$-1007.985200$

$-1007.985200$

$-1008.061618$

0.509676 (Hartree/Particle)

0.534824
0.535768

0.535768
0.457202

$-1008.006381$

$-1007.981233$

$-1007.980288$

$-1008.058854$

0.503121 (Hartree/Particle)

0.52834

0.42928

0.449936

-932.754221
-932.728999

$-932.728055$

$-932.807406$

0.502544 (Hartree/Particle)

0.528022

0.528966

0.448573

$-932.752143$

$-932.726666$

$-932.725722$

0.503529 (Hartree/Particle)

0.528602

0.529546

$-932.7541$

-932.754110
-932.729037

$-932.728093$

$-932.807628$

0.502976 (Hartree/Particle)

0.528380

0.529324

0.449000

$-932.755567$

$-932.730163$

-932.729219
-932809543

0.503310 (Hartree/Particle)

0.528499

0.450180

$-932.7541$

-932.754169
-932.72898

$-932.728037$

$-932.807299$

0.502362 (Hartree/Particle)

0.528096

0.529040

0.447040

$-932.758480$

-932.732746
-932.731802 
2a_1R7R8S_7_DP4+

2a_1R7R8S_8_DP4+

2a_1R7R8S_9_DP4+

2a_1R7R8S_10_DP4+

2a_1R7R8S_11_DP4+

2a_1R7R8S_12_DP4+

2a_1R7R8S_13_DP4+

2a_1R7R8S_14_DP4+

2a_1R7R8S_15_DP4+

2a_1R7R8S_16_DP4+

2a_1R7R8S_17_DP4+
Imaginary Freq $=0$

Zero-point conec

Therm correction to Entay=

Thermal correction to Gibbs Free Energy=

Sum of electronic and zero-point Energies=

Sum of electronic and thermal Enthalpies=

Sum of electronic ar

Zero-point correction

Thermal correction to Energy=

Thermal correction to Gibbs Free Energy=

Sum of electronic and zero-point Energies=

Sum of eectric and hermal Energies=

Imaginary Freq $=0$

Zero-point

Thermal correction =

Thermal correction to Enthalpy

Thermal correction to Gibbs Free Energy=

Sum of electronic and zero-point Energies

Sum of electronic and thermal Energies

Sum of electronic and thermal Free Energies=

Imaginary Freq $=0$

Zero-point correction

Thermal correction to Energy=

(Thermal correction to Enthalpy

Thermal correction to Gibbs Free Energy=

Sum of electronic and thermes

Sum of electronic and thermal Free Energies=

Imaginary Freq $=0$

Zero-point co

Thermal correction to Energy=

Thermal co

Thermal correction to Gibbs Free Energy=

Sum of electronic and zero-point Energies

Sum of electronic and thermal Energies

Sum of electronic and thermal Free Energies=

Imaginary Freq $=0$

Zero-point correction

Thermal correction to Energy=

Thermal correction to Gibbs Free Energy=

Sum of electronic and zero-point Energies=

Sum of electronic and therm Ener

Sum of electronic and thermal Enthalpies=

Sum of electronic and thermal Free Energies=

Imaginary Freq $=0$

Zero-point correction=

Thermal correction to Energy=

Thermal correction to Enthalpy

Thermal correction to Gibbs Free Energy=

Sum of electronic and zero-point Energies

Sum of elctronic and thermal Energies-

Imaginary Freq $=0$

Zero-point correction

Thermal correction to Energy=

Thermal correction to Gibbs Free Energy

Sum of electronic and rero-point Enegres

Sum of electronic and thermal Energies=

Sum of electronic and thermal Enthalpies =

Sum of electronic and thermal Free Energies=

Imaginary Freq $=0$

Zero-point correction

Thermal correction to Energy=

Thermal correction to Gibbs Free Energy=

Sum of electronic and zero-point Energies

Sum of electronic and thermal Energies=

Sum of electronic and thermal Enthalpies=
Sum of electronic and thermal Free Energies=

Imaginary Freq $=0$

Zero-point correction

to Energy=

Enthalpy=

Thermal correction to Gibbs Free Energy=

Sum of electronic and zero-point Energies-

Sum of electronic and thermal Energ

Sum of electronic and thermal Enthalpies=

Sum of electronic and thermal Free Energies=

Imaginary Freq $=0$

Zero-point correction=

Thermal correction to Energy=

Thermal correction to Gibbs Free Energy=

Sum of electronic and zero-point Energies

Sum of electronic and themal Energies=
0.503063 (Hartree/Particle)

0.528423

0.448215

$-932.754342$

$-932.728982$

$-932.728038$

$-932.809190$

0.502353 (Hartree/Particle)

0.528026

0.528970

0.54630

$-932.757411$

$-932.731739$

$-932.812134$

0.502169 (Hartree/Particle)

0.528014

0.446493

$-932.758252$

$-932.732407$

$-932.731463$

$-932.813929$

0.502629 (Hartree/Particle)

0.528267

0.529212

$-932.75524$

$-932.755241$

$-932.728658$

$-932.809887$

.502359 (Hartree/Particle)

0.528049

0.447566

$-932.756999$

$-932.731309$

-932.730365
-932.811792

0.503063 (Hartree/Particle)

0.52842

0.529366

$-932.754342$

-932.754342
-932.728983

$-932.728039$

$-932.809186$

0.502377 (Hartree/Particle)

0.528036

0.52898

0.446788

$-932.752181$

$-932.726521$

$-932.725577$

0.503072 (Hartree/Particle)

0.52835

0.448201

$-932.752801$

-932.752801
-932.727516

$-932.726572$

$-932.807672$

0.503121 (Hartree/Particle)

0.528343

0.529287

0.449936

$-932.754221$

$-932.728999$

$-932.728055$

0.502960 (Hartree/Particle)

0.528450

-44900
-932.753209

-932.753209
-932.727719

$-932.726775$

$-932.807168$

0.502642 (Hartree/Particle)

0.528100

0.529044

448637

$-932.751937$

-932.726479
-932.725535 
2a_1R7R8S_18_DP4+

2a_1R7R8S_19_DP4+

2a_1R7R8S_20_DP4-

2a_1R7R8S_21_DP4+

2a_1R7R8S_22_DP4+

2a_1R7R8S_23_DP4+

2a_1R7R8S_24_DP4+

2a_1R7R8S_25_DP4+

2a_ $1 R 7 R 8 S \_26 \_D P 4+$

2a_1R7R8S_27_DP4+

2a_1R7R8S_28_DP4+
Imaginary Freq $=0$

Zero-point corec

Thermal correction to Enthalpy

Thermal correction to Gibbs Free Energy=

Sum of electronic and zero-point Energies=

Sum of electronic and thermal Enthalpies=

maginary Freq $=0$

Zero-point correction

Thermal correction to Energy=

Thermal correction to Gibbs Free Energy=

Sum of electronic and zero-point Energies=

Sum of electronic and the pal Energies=

Imaginary Freq $=0$

Zero-point

Thermal correction $=$

Thermal correction to Enthalpy

Thermal correction to Gibbs Free Energy=

Sum of electronic and zero-point Energies

Sum of electronic and thermal Ener

Sum of electronic and thermal Free Energies=

Imaginary Freq $=0$

Zero-point correction

Thermal correction to Energy=

(T)

Thermal correction to Gibbs Free Energy=

Sum of electronic and them

Sum of electronic and thermal Free Energies

Imaginary Freq $=0$

Zero-point co

Thermal correction to Energy=

Thermal co

Thermal correction to Gibbs Free Energy=

Sum of electronic and zero-point Energies

Sum of electronic and thermal Energies

Sum of electronic and thermal Free Energies=

Imaginary Freq $=0$

Zero-point correction

Thermal correction to Energy=

Thermal correction to Gibbs Free Energy=

Sum of electronic and zero-point Energies=

Sum of electronic and thermi Energer

Sum of electronic and thermal Enthalpies=

Sum of electronic and thermal Free Energies=

Imaginary Freq $=0$

Zero-point correction=

Thermal correction to Energy=

Thermal correction to Enthalpy

Thermal correction to Gibbs Free Energy=

Sum of electronic and zero-point Energies

Sum of electronic and thermal Energies

Imaginary Freq $=0$

Zero-point correctio

Thermal correction to Energy=

Thermal correction to Gibbs Free Energy

Sum of electronic and zero-point Eneres

Sum of electronic and thermal Energies=

Sum of electronic and thermal Enthalpies-

Sum of electronic and thermal Free Energies=

Imaginary Freq $=0$

Zero-point correction $=$

Thermal correction to Energy=

Thermal correction to Gibbs Free Energy=

Sum of electronic and zero-point Energics

Sum of electronic and thermal Energies=

Sum of electronic and thermal Enthalpies=
Sum of electronic and thermal Free Energies=

Imaginary Freq $=0$

Zero-point correction

to Energy=

Enthalpy=

Thermal correction to Gibbs Free Energy=

Sum of electronic and zero-point Energies-

Sum of electronic and therma

Sum of electronic and thermal Enthalpies=

Sum of electronic and thermal Free Energies=

Imaginary Freq $=0$

Zero-point correction=

Thermal correction to Energy=

Thermal correction to Gibbs Free Energy=

Sum of electronic and zero-point Energies

Sum of electronic and thenmal Energies=
0.502887 (Hartree/Particle)

0.528331

0.529275

$-932.753689$

$-932.728245$

$-932.72730$

$-932.808733$

0.502684 (Hartree/Particle)

0.528267

0.529212

. 447210

$-932.755180$

$-932.728652$

$-932.810654$

0.502615 (Hartree/Particle)

0.528253

0.529197

0.447670

$-932.757997$

$-932.732360$

$-932.731416$

$-932.812942$

0.502090 (Hartree/Particle)

0.52795

0.528896

447237

$-932.754214$

$-932.727408$

$-932.809067$

.502991 (Hartree/Particle)

0.528328

0.448933

$-932.750704$

$-932.725368$

$-932.724424$

$-932.804762$

0.502598 (Hartree/Particle)

0.527896

0.528840

$-932.756029$

$-932.756029$

$-932.729787$

$-932.809456$

0.503524 (Hartree/Particle)

0.528732

0.529676

0.449624

$-932.750757$

$-932.725549$

$-932.724605$

0.502723 (Hartree/Particle)

0.528280

0.448445

$-932.753988$

$-932.753988$

$-932.727487$

$-932.808266$

0.503559 (Hartree/Particle)

0.528816

0.529760

0.449234

$-932.752700$

$-932.727443$

$-932.726499$

0.502619 (Hartree/Particle)

0.528129

0.447659

$-932.75384$

$-932.728338$

$-932.727393$

$-932.808808$

0.502910 (Hartree/Particle)

0.528069

0.529013

0.449905

$-932.754636$

-932.729477
-932.728533 
2a_1R7R8S_29_DP4+

2a_1R7R8S_30_DP4+

2a_1R7R8S_31_DP4-

2a_1R7R8S_32_DP4+

2b_1S7R8S_1_DP4+

2b_1S7R8S_2_DP4+

2b_1S7R8S_3_DP4+

2b_1S7R8S_4_DP4+

2b_1S7R8S_5_DP4+

2b_1S7R8S_6_DP4+

2b_1S7R8S 7 DPP4+
Imaginary Freq $=0$

Zero-point correction-

Thermal correction to Energy=

Thermal correction to Gibbs Free Energy=

Sum of electronic and zero-point Energies=

Sum of electronic and thermal Energies-

Sum of electronic and thermal Enthalpies=

Imaginary Freq $=0$

Zero-point correction

Thermal correction to Energy=

Thermal correction to Gibbs Free Energy=

Sum of electronic and zero-point Energies=

Sum of elctric and hermal Energies=

Imaginary Freq $=0$

Zero-point

Tero-point correction=

Thermal correction to Enthalpy

Thermal correction to Gibbs Free Energy=

Sum of electronic and zero-point Energies

Sum of electronic and thermal Ener

Sum of electronic and thermal Free Energies=

Imaginary Freq $=0$

Zero-point correction

Thermal correction to Energy=

(Thermal correction to Enthalpy

Thermal correction to Gibbs Free Energy=

Sum of electronic and thrial Ense

Sum of electronic and thermal Free Energies

Imaginary Freq $=0$

Zero-point correction

Thermal correction to Energy=

Thermal correct

Thermal correction to Gibbs Free Energy=

Sum of electronic and zero-point Energies

Sum of electronic and thermal Energies

Sum of electronic and thermal Free Energies=

Imaginary Freq $=0$

Zero-point correction

Thermal correction to Energy=

Thermal correction to Gibbs Free Energy=

Sum of electronic and zero-point Energies $=$

Sum of electronic and thermi Energie

Sum of electronic and thermal Enthalpies-

Sum of electronic and thermal Free Energies=

Imaginary Freq $=0$

Zero-point correction=

Thermal correction to Energy=

Thermal correction to Enthalpy

Thermal correction to Gibbs Free Energy=

Sum of electronic and zero-point Energies

Sum of elctronic and thermal Energies-

Imaginary Freq $=0$

Zero-point correction

Thermal correction to Energy=

Thermal correction to Gibbs Free Energy

Sum of electronic and zero-point Enegy

Sum of electronic and thermal Energies=

Sum of electronic and thermal Enthalpies =

Sum of electronic and thermal Free Energies=

Imaginary Freq $=0$

Zero-point correction=

Thermal correction to Energy=

Thermal correction to Gibbs Free Energy=

Sum of electronic and zero-point Energies

Sum of electronic and thermal Energies=

Sum of electronic and thermal Enthalpies=
Sum of electronic and thermal Free Energies=

Imaginary Freq $=0$

Zero-point correction

to Energy=

Thermal correction to Gibbs Free Energy=

Sum of electronic and zero-point Energies-

Sum of electronic and therma

Sum of electronic and thermal Enthalpies=

Sum of electronic and thermal Free Energies=

Imaginary Freq $=0$

Zero-point correction=

Thermal correction to Energy=

Thermal correction to Gibbs Free Energy=

Sum of electronic and zero-point Energies-

Sum of electronic and themal Energies=
0.502974 (Hartree/Particle)

0.528428

0.448330

$-932.754767$

$-932.729313$

$-932.728368$

$-932.809410$

0.503687 (Hartree/Particle)

0.528911

0.529856

.449644

$-932.751876$

$-932.726651$

$-932.805919$

0.502296 (Hartree/Particle)

0.527970

0.528915

0.448001

$-932.752829$

$-932.72715$

$-932.72621$

$-932.807124$

0.502685 (Hartree/Particle)

0.528267

0.52921

0.447218

-932.755179
-932.729597

$-932.728653$

$-932810646$

.502901 (Hartree/Particle)

0.528258

.449111

$-932.756336$

$-932.730979$

$-932.810125$

0.503220 (Hartree/Particle)

0.52849

0.529436

. .549480
-932.75582

-932.755821
-932.730549

$-932.729605$

$-932.809560$

0.502808 (Hartree/Particle)

0.528252

0.529196

0.448860

$-932.754831$

$-932.729387$

$-932.728443$

0.502816 (Hartree/Particle)

0.528217

0.448787

$-932.757582$

$-932.757582$

$-932.731236$

$-932.811611$

0.502961 (Hartree/Particle)

0.528318

0.529263

0.448722

$-932.757306$

$-932.73194$

$-932.731004$

0.503231 (Hartree/Particle)

0.528504

0.529448

-932.755477
-

$-932.730205$

$-932.729260$

$-932.809739$

0.502635 (Hartree/Particle)

0.528124

0.529068

0.448749

$-932.753020$

-932.727531
-932.726587 
2b_1S7R8S_8_DP4+

2b_1S7R8S_9_DP4+

2b_1S7R8S_10_DP4+

2b_1S7R8S_11_DP4+

2b_1S7R8S_12_DP4+

2b_1S7R8S_13_DP4+

2b_1S7R8S_14_DP4+

3a_7S8S15R_1_DP4+

3a_7S8S15R_2_DP4+

3a_7S8S15R_3_DP4+

3a_7S8S15R_4_DP4+
Imaginary Freq $=0$

Zero-point correction-

Thermal correction to Energy=

Thermal correction to Gibbs Free Energy=

Sum of electronic and zero-point Energies=

Sum of electronic and thermal Energies=

Sum of electronic and thermal Enthalpies=

Imaginary Freq $=0$

Zero-point correction

Thermal correction to Energy=

Thermal correction to Gibbs Free Energy=

Sum of electronic and zero-point Energies-

Sum of eectric and hermal Energies=

Imaginary Freq $=0$

Zero-pointc

Thermal correction $=$

Thermal correction to Enthalpy

Thermal correction to Gibbs Free Energy=

Sum of electronic and zero-point Energies=

Sum of electronic and thermal Energies=

Sum of electronic and thermal Enthalpies=
Sum of electronic and thermal Free Energies=

Imaginary Freq $=0$

Zero-point correction

Thermal correction to Energy=

Thermal correction to Enthalpy

Thermal correction to Gibbs Free Energy=

Sum of electronic and thermal Enthalpie

Sum of electronic and thermal Free Energies=

Imaginary Freq $=0$

Zero-point correction

Thermal correction to Energy=

Thermal correction to Enthalpy=
Thermal correction to Gibbs Free Energy=

Sum of electronic and zero-point Energies

Sum of electronic and thermal Energies

Sum of electronic and thermal Free Energies=

Imaginary Freq $=0$

Zero-point correction

Thermal correction to Energy=

Thermal correction to Gibbs Free Energy=

Sum of electronic and zero-point Energies $=$

Sum electro

Sum of electronic and thermal Enthalpies=

Sum of electronic and thermal Free Energies=

Imaginary Freq $=0$

Zero-point correction=

Thermal correction to Energy=

Thermal correction to Enthalpy

Thermal correction to Gibbs Free Energy=

Sum of electronic and zero-point Energies

Sum of electronic and thermal Energies =

Imaginary Freq $=0$

Zero-point correction

Thermal correction to Energy=

s. Free Energy=

o-point Energies=

Sum of electronic and thermal Energies=

Sum of electronic and thermal Free Energies=

Imaginary Freq $=0$

Zero-point correction=

Thermal correction to Energy=

Thermal correction to Gibbs Free Energy=

Sum of electronic and zero-point Energies

Sum of electronic and thermal Energies=

Sum of electronic and thermal Enthalpies=
Sum of electronic and thermal Free Energies=

Imaginary Freq $=0$

Zero-point correction

on to Energy $=$

to Enthalpy=

Thermal correction to Gibbs Free Energy=

Sum of electronic and zero-point Energies-

Sum of electronic and thermal Energi

Sum of electronic and thermal Enthalpies=

Sum of electronic and thermal Free Energies=

Imaginary Freq $=0$

Zero-point correction=

Thermal correction to Energy=

Thermal correction to Gibbs Free Energy=

Sum of electronic and zero-point Energies

Sum of electronic and themal Energies=
0.502628 (Hartree/Particle)

0.528135

0.448580

$-932.754119$

$-932.728612$

$-932.727668$

$-932.808168$

0.502729 (Hartree/Particle)

0.528189

0.529133

48866

932.752935

$-932.726530$

$-932.806797$

0.502754 (Hartree/Particle)

0.528212

0.529156

0.448675

$-932.756347$

$-932.730889$

$-932.729944$

$-932.810426$

0.502235 (Hartree/Particle)

0.527935

0.528879

0.447838

-932.758922
-932.733222

$-932.733222$

$-932.813320$

0.502753 (Hartree/Particle)

0.528213

0.52915

0.448669

$-932.756347$

$-932.730887$

$-932.810432$

0.502980 (Hartree/Particle)

0.528350

0.529294

- 932.755991

$-932.755991$

-932.730621
-932.729677

$-932.810088$

0.502130 (Hartree/Particle)

0.527900

0.52884

0.447656

$-932.758007$

$-932.732236$

$-932.731292$

0.480665 (Hartree/Particle)

0.50544

0.50638

$-931.542603$

$-931.517827$

$-931.596376$

0.480195 (Hartree/Particle)

0.50516

0.506108

$-931.541251$

$-931.516283$

$-931.515339$

0.480332 (Hartree/Particle)

0.505238

0.426112

$-931.539902$

$-931.514996$

$-931.514996$

$-931.594123$

0.480240 (Hartree/Particle)

0.505207

0.506151

425831

$-931.542166$

-931.517199
-931.516255 
3a_7S8S15R_5_DP4+

3a_7S8S15R_6_DP4+

3a_7S8S15R_7_DP4+

3a $7 S 8 S 15 R \_8$ DP4+

3a_7S8S15R_9_DP4+

3a_ $7 S 8 S 15 R \_5 \quad 10 \mathrm{DP} 4$

3a_7S8S15R_11_DP4

3a_7S8S15R_12_DP4+

3a_7S8S15R_13_DP4+

3a_7S8S15R_14_DP4+

3a $7 S 8 S 15 R \quad 15 \quad \mathrm{DP} 4+$
Imaginary Freq $=0$

Zero-point corec

Thermal correction to Enthalpy

Thermal correction to Gibbs Free Energy=

Sum of electronic and zero-point Energies=

Sum of electronic and thermal Enthalpies=

Imaginary Freq $=0$

Zero-point correction

Thermal correction to Energy=

Thermal correction to Gibbs Free Energy=

Sum of electronic and zero-point Energies=

Sum of electric and

Imaginary Freq $=0$

Zero-pointc

Tero-point correction=

Thermal correction to Enthalpy

Thermal correction to Gibbs Free Energy=

Sum of electronic and zero-point Energies

Sum of electronic and thermal Energ

Sum of electronic and thermal Enthalpies=

Imaginary Freq $=0$

Zero-point correction=

Thermal correction to Energy=

(Thermal correction to Enthalpy

Thermal correction to Gibbs Free Energy=

Sum of electronic and them Enthas

Sum of electronic and thermal Free Energies=

Imaginary Freq $=0$

Zero-point correction

Thermal correction to Energy=

Thermal correction to Enthalpy=
Thermal correction to Gibbs Free Energy=

Sum of electronic and zero-point Energies

Sum of electronic and thermal Energies-

Sum of electronic and thermal Enthalpies=
Sum of electronic and thermal Free Energies=

Imaginary Freq $=0$

Zero-point correction

Thermal correction to Energy=

Thermal correction to Gibbs Free Energy=

Sum of electronic and zero-point Energies=

Sum of electronic and therment En

Sum of electronic and thermal Enthalpies=

Sum of electronic and thermal Free Energies=

Imaginary Freq $=0$

Zero-point correction=

Thermal correction to Energy=

Thermal correction to Enthalpy

Thermal correction to Gibbs Free Energy=

Sum of electronic and zero-point Energie

Sum of electronic and thermal Energies

Imaginary Freq $=0$

Zero-point correction

Thermal correction to Energy=

Thermal correction to Gibbs Free Energy=

Sum of electronic and zero-point Energe

Sum of electronic and thermal Energies=

Sum of electronic and thermal Enthalpies=

Sum of electronic and thermal Free Energies=

Imaginary Freq $=0$

Zero-point correction=

Thermal correction to Energy=

Thermal correction to Gibbs Free Energy=

Sum of electronic and zero-point Energies

Sum of electronic and thermal Energies=

Sum of electronic and thermal Enthalpies=
Sum of electronic and thermal Free Energies=

Imaginary Freq $=0$

Zero-point correction

to Energy=

Enthalpy=

Thermal correction to Gibbs Free Energy=

Sum of electronic and zero-point Energies-

Sum of electronic and therma

Sum of electronic and thermal Enthalpies=

Sum of electronic and thermal Free Energies=

Imaginary Freq $=0$

Zero-point correction $=$

Thermal correction to Energy=

Thermal correction to Gibbs Free Energy=

Sum of electronic and zero-point Energies

Sum of electronic and thenmal Energies=
0.480578 (Hartree/Particle)

0.505402

0.506346

$-931.541396$

$-931.516572$

$-931.515628$

$-931.596025$

0.480267 (Hartree/Particle)

0.505197

0.506141

(1)

$-931.540948$

$-931.516018$

$-931.595622$

0.479913 (Hartree/Particle)

0.504851

0.50579

$-931.539513$

$-931.514575$

$-931.513631$

$-931.594177$

0.480068 (Hartree/Particle)

0.505176

0.506121

0.424345
-931.5388

$-931.538868$

-931.513759
-931.512815

$-931.594590$

0.480640 (Hartree/Particle)

0.505394

0.506338

0.426826

$-931.541441$

$-931.516687$

$-931.515742$

$-931.595255$

0.480529 (Hartree/Particle)

0.505345

0.506289

0.426003

-931.540259
-931.515443

$-931.514499$

$-931.594784$

0.480409 (Hartree/Particle)

0.505199

0.506143

0.426386

$-931.539693$

$-931.514903$

$-931.513958$

0.480747 (Hartree/Particle)

0.505428

0.506961

$-931.539549$

$-931.51486$

$-931.514868$

$-931.593335$

0.480594 (Hartree/Particle)

0.505366

0.506310

0.426647

$-931.541608$

$-931.516836$

-931.515892
-931.595555

0.480508 (Hartree/Particle)

0.505346

0.426412

0.426412

$-931.51779$

$-931.51685$

$-931.596731$

0.480406 (Hartree/Particle)

0.505337

0.506281

0.425700

$-931.535817$

-931.510886
-931.509942 
3a_7S8S15R_16_DP4

3a_7S8S15R_17_DP4

3a_7S8S15R_18_DP4

3a_7S8S15R_19_DP4+

3a_7S8S15R_5_20_DP4

3a_7S8S15R_21_DP4+

3a_7 $58 S 15 R \_22 \_D P 4+$

3a_7S8S15R_23_DP4+

3a_7S8S15R_24_DP4+

3b_7S8S15S_1_DP4+

3b_7S8S15S_2_DP4+
Imaginary Freq $=0$

Zero-point correction

Them conection to Energy

Thermal correction to Gibbs Free Energy=

Sum of electronic and zero-point Energies=

Sum of electronic and thermal Enthalpies=

Imaginary Freq $=0$

Zero-point correction

Thermal correction to Energy=

Thermal correction to Gibbs Free Energy=

Sum of electronic and zero-point Energies=

Sum of electric and

Imaginary Freq $=0$

Zero-point $c$

Tero-point correction=

Thermal correction to Enthalpy

Thermal correction to Gibbs Free Energy=

Sum of electronic and zero-point E

Sum of electronic and thermal Energies

Sum of electronic and thermal Enthalpies=
Sum of electronic and thermal Free Energies=

Imaginary Freq $=0$

Zero-point correction

Thermal correction to Energy=

.

Thermal correction to Gibbs Free Energy=

Sum of electronic and thries Enthas

Sum of electronic and thermal Free Energies

Imaginary Freq $=0$

Zero-point co

Thermal correction to Energy=

Thermal correction to Gibbs Free Energy=

Sum of electronic and zero-point Energies

Sum of electronic and thermal Energies

Sum of electronic and thermal Free Energies=

Imaginary Freq $=$

Zero-point correction

Thermal correction to Energy=

Thermal correction to Gibbs Free Energy=

Sum of electronic and zero-point Energies=

Sum of electronic and thermiter

Sum of electronic and thermal Enthalpies-

Sum of electronic and thermal Free Energies=

Imaginary Freq $=0$

Zero-point correction=

Thermal correction to Energy=

Thermal correction to Enthalpy

Thermal correction to Gibbs Free Energy=

Sum of electronic and zero-point Energies

Sum of electronic and thermal Energies

Sum of electron anergies

Imaginary Freq $=$

Zero-point correction

Thermal correction to Energy=

Thermal correction to Gibbs Free Energy=

Sum of electronic and zero-point Energe

Sum of electronic and thermal Energies=

Sum of electronic and thermal Enthalpies=

Sum of electronic and thermal Free Energies=

Imaginary Freq $=0$

Zero-point correction

Thermal correction to Energy=

Thermal correction to Gibbs Free Energy=

Sum of electronic and zero-point Energies

Sum of electronic and thermal Energies=

Sum of electronic and thermal Enthalpies=

Imaginary Freq $=0$

Zero-point correction

to Energy=

Enthalpy=

Thermal correction to Gibbs Free Energy=

Sum of electronic and zero-point Energies-

Sum of electronic and thermal

Sum of electronic and thermal Enthalpies=

Sum of electronic and thermal Free Energies=

Imaginary Freq $=0$

Zero-point correction=

Thermal correction to Energy=

Thermal correction to Gibbs Free Energy=

Sum of electronic and zero-point Energies-

Sum of electronic and thent Energies=
0.480311 (Hartree/Particle)

0.505336

0.506280

$-931.537890$

$-931.51286$

$-931.511920$

$-931.592838$

0.480258 (Hartree/Particle)

0.505199

0.506143

0.031 .537625

-931.537625
-931.512684

$-931.511740$

$-931.591907$

. 480519 (Hartree/Particle)

0.505369

0.506313

0.425894

$-931.541277$

$-931.516427$

931.515482

$-931.595901$

0.480336 (Hartree/Particle)

0.505266

0.506210

0.425774

$-931.539373$

-931.514443
-931.513499

$-931.593935$

0.480315 (Hartree/Particle)

0.505169

0.506113

0.426414

$-931.535737$

$-931.510882$

$-931.509938$

$-931.589637$

0.480361 (Hartree/Particle)

0.505280

0.506224

$-931.538333$

$-931.538333$

$-931.513414$

$-931.592539$

0.480203 (Hartree/Particle)

0.505146

0.506090

0.426145

$-931.540594$

$-931.515651$

$-931.514707$

0.480326 (Hartree/Particle)

0.505116

0.426369

$-931.537426$

$-931.537426$

$-931.511692$

$-931.591383$

0.480334 (Hartree/Particle)

0.505177

0.506121

0.426709

$-931.540609$

$-931.51576$

$-931.514821$

0.480316 (Hartree/Particle)

0.505195

$-931.53953$

$-931.51465$

$-931.513710$

$-931.593690$

0.480202 (Hartree/Particle)

0.505175

0.506119

.425678

$-931.540380$

-931.515406
-931.514462 
3b_7S8S15S_3_DP4+

3b_7S8S15S_4_DP4+

3b_7S8S15S_5_DP4+

3b_7S8S15S_6_DP4+

3b_7S8S15S_7_DP4+

3b_7S8S15S_8_DP4+

3b_7S8S15S_9_DP4+

3b_7S8S15S_10_DP4

3b_7S8S15S_11_DP4+

3b_7S8S15S_12_DP4+

3b $7 S 8 S 15 S \_13$ DP4
Imaginary Freq $=0$

Zero-point corec

Thermal correction to Enthalpy

Thermal correction to Gibbs Free Energy=

Sum of electronic and zero-point Energies=

Sum of electronic and thermal Enthalpies=

Imaginary Freq $=0$

Zero-point correction

Thermal correction to Energy=

Thermal correction to Gibbs Free Energy=

Sum of electronic and zero-point Energies=

Sum of electronic and the pal Energies=

Imaginary Freq $=0$

Zero-po

Tero-point correction $=$

Thermal correction to Enthalpy

Thermal correction to Gibbs Free Energy=

Sum of electronic and zero-point Energies=

Sum of electronic and thermal Energies=

Sum of electronic and thermal Enthalpies=
Sum of electronic and thermal Free Energies=

Imaginary Freq $=0$

Zero-point correction

Thermal correction to Energy=

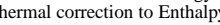

Thermal correction to Gibbs Free Energy=

Sum of electronic and thrial Ens=

Sum of electronic and thermal Free Energies=

Imaginary Freq $=0$

Zero-point correction=

Thermal correction to Energy=

Thermal co

Thermal correction to Gibbs Free Energy=

Sum of electronic and zero-point Energies

Sum of electronic and thermal Energies

Sum of electronic and thermal Free Energies=

Imaginary Freq $=0$

Zero-point correctio

Thermal correction to Energy=

Thermal correction to Gibbs Free Energy=

Sum of electronic and zero-point Energies=

Sum of electronic and therment En

Sum of electronic and thermal Enthalpies-

Sum of electronic and thermal Free Energies=

Imaginary Freq $=0$

Zero-point correction=

Thermal correction to Energy=

Thermal correction to Enthalpy

Thermal correction to Gibbs Free Energy=

Sum of electronic and zero-point Energies

Sum of electronic and thermal Energies

Imaginary Freq $=$

Zero-point correction

Thermal correction to Energy=

Free Energy=

o-point Energies-

Sum of electronic and thermal Energies=

Sum of electronic and thermal Free Energies=

Imaginary Freq $=0$

Zero-point correction=

Thermal correction to Energy=

Thermal correction to Gibbs Free Energy=

Sum of electronic and zero-point Energies

Sum of electronic and thermal Energies=

Sum of electronic and thermal Enthalpies=
Sum of electronic and thermal Free Energies=

Imaginary Freq $=0$

Zero-point correction

to Energy=

Enthalpy=

Thermal correction to Gibbs Free Energy=

Sum of electronic and zero-point Energies-

Sum of electronic and thermal Energies

Sum of electronic and thermal Enthalpies=

Sum of electronic and thermal Free Energies=

Imaginary Freq $=0$

Zero-point correction $=$

Thermal correction to Energy=

Thermal correction to Gibbs Free Energy=

Sum of electronic and zero-point Energies

Sum of electronic and themal Energies=
0.480729 (Hartree/Particle)

0.505419

0.426715

$-931.541464$

$-931.516774$

$-931.515830$

$-931.595478$

0.480353 (Hartree/Particle)

0.505208

0.506152

0.425933

$-931.538603$

$-931.512804$

$-931.593023$

.480145 (Hartree/Particle)

0.50506

0.506005

0.425779

$-931.539820$

$-931.51490$

$-931.513960$

$-931.59418$

0.480778 (Hartree/Particle)

0.505451

0.506395

- -9267.539803

$-931.51513$

$-931.51513$

$-931.593793$

0.480694 (Hartree/Particle)

0.505388

0.506332

0.426655

$-931.539679$

$-931.514985$

$-931.51404$

$-931.593718$

0.480109 (Hartree/Particle)

0.50508

0.50633

. -931.538952

$-931.538952$

$-931.513028$

$-931.593194$

0.480382 (Hartree/Particle)

0.505330

0.506274

0.425910

$-931.536816$

$-931.511868$

$-931.591288$

0.480567 (Hartree/Particle)

0.505387

0.506331

$-931.540522$

$-931.51570$

$-931.514757$

$-931.594678$

0.480400 (Hartree/Particle)

0.505292

0.506237

0.425877

$-931.540900$

$-931.516008$

$-931.515064$

0.480369 (Hartree/Particle)

0.505300

0.425796

$-931.5379$

$-931.537918$

$-931.512043$

$-931.592491$

0.480094 (Hartree/Particle)

0.505107

0.50605

.425698

$-931.539956$

$-931.51494$ 
3b_7S8S15S_14_DP4+

3b_7S8S15S_15_DP4+

3b_7S8S15S_16_DP4

3b_7S8S15S_17_DP4+

3b_7S8S15S_18_DP4

3b_7S8S15S_19_DP4+

3b_7S8S15S_20_DP4+

3b_7S8S15S_21_DP4+

3b_7S8S15S_22_DP4+

3b_7S8S15S_23_DP4

4a_7S8S12R_1_DP4+
Imaginary Freq $=0$

Zero-point core

Thermal correction to Enthalpy

Thermal correction to Gibbs Free Energy=

Sum of electronic and zero-point Energies=

Sum of electronic and thermal Enthalpies=

Imaginary Freq $=0$

Zero-point correction

Thermal correction to Energy=

Thermal correction to Gibbs Free Energy=

Sum of electronic and zero-point Energies=

Sum ofectric and themmal Energies=

Imaginary Freq $=0$

Zero-pointc

Tero-point correction $=$

Thermal correction to Enthalpy

Thermal correction to Gibbs Free Energy=

Sum of electronic and zero-point Energies

Sum of electronic and thermal Energi

Sum of electronic and thermal Enthalpies=

Imaginary Freq $=0$

Zero-point correction=

Thermal correction to Energy=

Thermal correction to Enthalpy

Thermal correction to Gibbs Free Energy=

Sum of electronic and thma Enthas

Sum of electronic and thermal Free Energies

Imaginary Freq $=0$

Zero-point correction=

Thermal correction to Energy=

Thermal correction to Enthalpy=
Thermal correction to Gibbs Free Energy=

Sum of electronic and zero-point Energies

Sum of electronic and thermal Energies-

Sum of electronic and thermal Enthalpie

Sum of electronic and thermal Free Energies=

Imaginary Freq $=0$

Zero-point correctio

Thermal correction to Energy=

Thermal correction to Gibbs Free Energy=

Sum of electronic and zero-point Energies $=$

Sum of electronic and thermal Energie

Sum of electronic and thermal Enthalpies=

Sum of electronic and thermal Free Energies=

Imaginary Freq $=0$

Zero-point correction=

Thermal correction to Energy=

Thermal correction to Enthalpy

Thermal correction to Gibbs Free Energy=

Sum of electronic and zero-point Energies

Sum of electronic and thermal Energies-

Imaginary Freq $=0$

Zero-point correction

Thermal correction to Energy=

Free Energy=

o-point Energies-

Sum of electronic and thermal Energies=

Sum of electronic and thermal Free Energies=

Imaginary Freq $=0$

Zero-point correction=

Thermal correction to Energy=

Thermal correction to Gibbs Free Energy=

Sum of electronic and zero-point Energies

Sum of electronic and thermal Energies=

Sum of electronic and thermal Enthalpies=
Sum of electronic and thermal Free Energies=

Imaginary Freq $=0$

Zero-point correction

to Energy=

Enthalpy=

Thermal correction to Gibbs Free Energy=

Sum of electronic and zero-point Energies-

Sum of electronic and thermal Energi

Sum of electronic and thermal Enthalpies=

Sum of electronic and thermal Free Energies=

Imaginary Freq $=0$

Zero-point correction=

Thermal correction to Energy=

Thermal correction to Gibbs Free Energy=

Sum of electronic and zero-point Energies

Sum of electronic and themal Energies=
0.480443 (Hartree/Particle)

0.505177

0.50612

$-931.537930$

$-931.513196$

$-931.512252$

$-931.591529$

0.480220 (Hartree/Particle)

0.505109

0.506053

0.425460

$-931.540445$

$-931.514612$

$-931.595206$

0.480396 (Hartree/Particle)

0.505215

.506159

0.426102

$-931.540120$

$-931.51530$

-931.514356
-931.594414

0.480450 (Hartree/Particle)

0.505178

0.506122

- -92687953792

-931.537923
-931.513195

-931.513195
-931.512250

$-931.591493$

0.481047 (Hartree/Particle)

0.505464

0.506408

.428130

$-931.541592$

$-931.51717$

$-931.51623$

$-931.594509$

0.479943 (Hartree/Particle)

0.50507

0.425334

- -931.540097

$-931.540097$

-931.514969
-931.514025

$-931.594706$

0.480269 (Hartree/Particle)

0.505159

0.506103

0.425931

$-931.538668$

$-931.513777$

$-931.512833$

0.480074 (Hartree/Particle)

0.50504

0.505907

$-931.538433$

$-931.51346$

$-931.592600$

0.480606 (Hartree/Particle)

0.505369

0.506314

$-931.538949$

$-931.51418$

$-931.513241$

0.480400 (Hartree/Particle)

0.505292

0.425877

$-931.540900$

$-931.516008$

$-931.515064$

$-931.595423$

0.479254 (Hartree/Particle)

0.503994

0.504939

0.425902

$-931.548696$

-931.523956
-931.523012 
4a_7S8S12R_2_DP4+

4a_7S8S12R_3_DP4+

4a_7S8S12R_4_DP4+

4a_7S8S12R_5_DP4+

4a_7S8S12R_6_DP4+

4a $7 S 8 S 12 R 7$ DP4+

4a_7S8S12R_8_DP4+

4a_7S8S12R_9_DP4+

4a_7S8S12R_10_DP4+

4a_7S8S12R_11_DP4+

4a $7 S 8 S 12 R \quad 12 \quad \mathrm{DP} 4+$
Imaginary Freq $=0$

Zero-point correction

Them conection to Energy=

Thermal correction to Gibbs Free Energy=

Sum of electronic and zero-point Energies=

Sum of electronic and thermal Energies=

Sum of electronic and thermal Enthalpies=

Imaginary Freq $=0$

Zero-point correction-

Thermal correction to Energy=

Thermal correction to Gibbs Free Energy=

Sum of electronic and zero-point Energies=

Sum of electric and

Imaginary Freq $=0$

Zero-po

Tero-point correction $=$

Thermal correction to Enthalpy

Thermal correction to Gibbs Free Energy=

Sum of electronic and zero-point Energies

Sum of electronic and thermal Energ

Sum of electronic and thermal Enthalpies=

Imaginary Freq $=0$

Zero-point correction

Thermal correction to Energy=

Thermal correction to Gibbs Free Energy=

Sum of electronic and therme

Sum of electronic and thermal Free Energies-

Imaginary Freq $=0$

Zero-point co

Thermal correction to Energy=

Thermal correction to Gibbs Free Energy=

Sum of electronic and zero-point Energies

Sum of electronic and thermal Energies -

Sum of electronic and thermal Free Energies=

Imaginary Freq $=0$

Zero-point correction

Thermal correction to Energy=

Thermal correction to Gibbs Free Energy=

Sum of electronic and zero-point Energies=

Sum of electronic and therme- Energies

Sum of electronic and thermal Enthalpies=

Sum of electronic and thermal Free Energies=

Imaginary Freq $=0$

Zero-point correction=

Thermal correction to Energy=

Thermal correction to Enthalpy

Thermal correction to Gibbs Free Energy=

Sum of electronic and zero-point Energies

Sum of electronic and thermal Energies -

Imaginary Freq $=0$

Zero-point correction

Thermal correction to Energy=

Free Energy=

-point Energies=

Sum of elect

Sum of electronic and thermal Enthalpies -

Sum of electronic and thermal Free Energies=

Imaginary Freq $=0$

Zero-point correction=

Thermal correction to Energy=

Thermal correction to Gibbs Free Energy=

Sum of electronic and zero-point Energics

Sum of electronic and thermal Energies=

Sum of electronic and thermal Enthalpies=

Imaginary Freq $=0$

Zero-point correction

to Energy=

to Enthalpy=

Thermal correction to Gibbs Free Energy=

Sum of electronic and zero-point Energies-

Sum of electronic and therm

Sum of electronic and thermal Enthalpies=

Sum of electronic and thermal Free Energies=

Imaginary Freq $=0$

Zero-point correction=

Thermal correction to Energy=

Thermal correction to Gibbs Free Energy=

Sum of electronic and zero-point Energies

Sum of electronic and themal Energies=
0.479390 (Hartree/Particle)

0.504214

0.426032

$-931.547251$

$-931.522428$

$-931.521484$

$-931.600609$

0.479128 (Hartree/Particle)

0.503873

0.504817

$-931.548179$

$-931.523435$

$-931.601137$

0.479590 (Hartree/Particle)

0.504222

0.505166

0.426948

$-931.548343$

$-931.523711$

$-931.522766$

$-931.600985$

0.479164 (Hartree/Particle)

0.50395

0.504902

- 42508

$-931.551040$

-931.526245
-931.525301

$-931.604696$

0.479318 (Hartree/Particle)

0.504106

0.505050

0.426189

$-931.546834$

$-931.522046$

$-931.521102$

31.599963

0.479383 (Hartree/Particle)

0.503976

0.426756

0.426756

$-931.549766$

$-931.524229$

$-931.602393$

0.478884 (Hartree/Particle)

0.503782

0.504727
0.425683

$-931.548817$

$-931.523919$

$-931.522975$

0.479493 (Hartree/Particle)

0.504180

0.426866

0.426866

$-931.52438$

$-931.523443$

$-931.601701$

0.478877 (Hartree/Particle)

0.503799

0.504743

0.425173

$-931.548186$

$-931.523264$

$-931.522320$

0.479539 (Hartree/Particle)

0.504280

0.526903

$-931.547444$

$-931.521758$

$-931.600080$

0.479169 (Hartree/Particle)

0.503926

0.504870

0.426059

-931.549447
-931.524690

$-931.524690$ 
4a_7S8S12R_13_DP4

4a_7S8S12R_14_DP4

4a_7S8S12R_15_DP4

4a_7S8S12R_16_DP4+

4a_7S8S12R_17_DP4+

4a_7S8S12R_18_DP4+

4a_7S8S12R_19_DP4+

4a_7S8S12R_20_DP4+

4a_7S8S12R_21_DP4+

4a_7S8S12R_22_DP4+

4a $7 S 8 S 12 R \quad 23 \quad \mathrm{DP} 4+$
Imaginary Freq $=0$

Zero-point correction

Them conection to Energy=

Thermal correction to Gibbs Free Energy=

Sum of electronic and zero-point Energies=

Sum of electronic and thermal Energies=

Sum of electronic and thermal Enthalpies=

Imaginary Freq $=0$

Zero-point correction

Thermal correction to Energy=

Thermal correction to Gibbs Free Energy=

Sum of electronic and zero-point Energies=

Sum of electronic and

Imaginary Freq $=0$

Zero-po

Tero-point correction $=$

Thermal correction to Enthalpy

Thermal correction to Gibbs Free Energy=

Sum of electronic and zero-point Energies

Sum of electronic and thermal Ener

Sum of electronic and thermal Free Energies=

Imaginary Freq $=0$

Zero-point correction

Thermal correction to Energy=

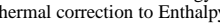

Thermal correction to Gibbs Free Energy=

Sum of electronic and hal Engres=

Sum of electronic and thermal Free Energies

Imaginary Freq $=0$

Zero-point co

Thermal correction to Energy=

Thermal correction to Gibbs Free Energy=

Sum of electronic and zero-point Energies

Sum of electronic and thermal Energies=

Sum of electronic and thermal Free Energies=

Imaginary Freq $=0$

Zero-point correction

Thermal correction to Energy=

Thermal correction to Gibbs Free Energy=

Sum of electronic and zero-point Energies=

Sum of electronic and thermal Energies

Sum of electronic and thermal Enthalpies-

Sum of electronic and thermal Free Energies=

Imaginary Freq $=0$

Zero-point correction=

Thermal correction to Energy=

Thermal correction to Enthalpy

Thermal correction to Gibbs Free Energy=

Sum of electronic and zero-point Energies

Sum of electronic and thermal Energies

Imaginary Freq $=0$

Zero-point correction

Thermal correction to Energy=

Free Energy=

ro-point Energies=

Sum of electronic and thermal Enthalpies=

Sum of electronic and thermal Free Energies=

Imaginary Freq $=0$

Zero-point correction

Thermal correction to Energy=

Thermal correction to Gibbs Free Energy=

Sum of electronic and zero-point Energies

Sum of electronic and thermal Energies=

Sum of electronic and thermal Enthalpies=
Sum of electronic and thermal Free Energies=

Imaginary Freq $=0$

Zero-point correction

to Energy=

orrection to Enthalpy=

Thermal correction to Gibbs Free Energy=

Sum of electronic and zero-point Energies-

Sum of electronic and therma

Sum of electronic and thermal Enthalpies=

Sum of electronic and thermal Free Energies=

Imaginary Freq $=0$

Zero-point correction=

Thermal correction to Energy=

Thermal correction to Gibbs Free Energy=

Sum of electronic and zero-point Energies-

Sum of electronic and thenmal Energies=
0.479022 (Hartree/Particle)

0.503848

0.504792

0.425822

$-931.548289$

$-931.52346$

$-931.522519$

931.601489

0.479590 (Hartree/Particle)

0.504222

0.505166

. 426948

$-931.548343$

$-931.523711$

$-931.600985$

0.479061 (Hartree/Particle)

0.503950

0.504895

0.425195

$-931.548990$

$-931.524100$

$-931.523156$

$-31.602855$

0.479117 (Hartree/Particle)

0.50392

0.504869

0.426045

$-931.547609$

$-931.522801$

$-931.600681$

479211 (Hartree/Particle)

0.504027

425559

$-931.550272$

$-931.52545$

$-931.524512$

$-931.603924$

0.479242 (Hartree/Particle)

0.50399

0.504942

$-931.550552$

$-931.525797$

$-931.524852$

$-931.603465$

.479416 (Hartree/Particle)

0.504239

0.505184

0.426146

$-931.545517$

$-931.520694$

$-931.598787$

0.478836 (Hartree/Particle)

0.503708

0.425552

$-931.544863$

$-931.51999$

$-931.519046$

$-931.598146$

0.479472 (Hartree/Particle)

0.504233

0.505177

0.426113

$-931.549416$

$-931.524656$

$-931.523711$

0.479269 (Hartree/Particle)

0.504037

0.426276

$-.426276$

$-931.546949$

$-931.521237$

$-931.599943$

0.479244 (Hartree/Particle)

0.504059

0.505003

0.425716

$-931.550311$

-931.525495
-931.524551 
4b_7S8S12S_1_DP4+

4b_7S8S12S_2_DP4+

4b_7S8S12S_3_DP4+

4b_7S8S12S_4_DP4+

4b_7S8S12S_5_DP4+

4b_7S8S12S_6_DP4+

4b_7S8S12S_7_DP4+

4b_7S8S12S_8_DP4+

4b_7S8S12S_9_DP4+

4b_7S8S12S_10_DP4+

4b_7S8S12S_11_DP4+
Imaginary Freq $=0$

Zero-point correction

Thermal correction to Energy=

Thermal correction to Gibbs Free Energy=

Sum of electronic and zero-point Energies=

Sum of electronic and thermal Energies=

Sum of electronic and thermal Enthalpies=

Imaginary Freq $=0$

Zero-point correction

Thermal correction to Energy=

Thermal correction to Gibbs Free Energy=

Sum of electronic and zero-point Energies=

Sum of electronic and thermal Energies=

Imaginary Freq $=0$

Zero-point co

Tero-point correction=

Thermal correction to Enthalpy

Thermal correction to Gibbs Free Energy=

Sum of electronic and zero-point Energies=

Sum of electronic and thermal Energies=

Sum of electronic and thermal Enthalpies=
Sum of electronic and thermal Free Energies=

Imaginary Freq $=0$

Zero-point correctio

Thermal correction to Energy=

Thermal correction to Enthalpy=

Thermal correction to Gibbs Free Energy=

Sum of clectronic and zero-point Energie

Sum of electronic and henal Energies-

Sum of electronic and thermal Free Energies

Imaginary Freq $=0$

Zero-point correction=

Thermal correction to Energy=

Thermal correction to Enthalp =

Thermal correction to Gibbs Free Energy=

Sum of electronic and zero-point Energies

Sum of electronic and thermal Energies=

enthe and thermal Enthalpe

Sum of electronic and thermal Free Energies=

Imaginary Freq $=0$

Zero-point correction

Thermal correction to Energy=

Thermal correction to Gibbs Free Energy=

Sum of electronic and zero-point Energies=

Sum of electronic and zero-point Energies

Sum of electronic and thermal Enthalpies=

Sum of electronic and thermal Free Energies=

Imaginary Freq $=0$

Zero-point correction $=$

Thermal correction to Energy=

Thermal correction to Enthalpy

Thermal correction to Gibbs Free Energy=

Sum of electronic and zero-point Energies

Sum of electronic and thermal Energies $=$

Sum of electronic and thermal Free Energies=

Imaginary Freq $=0$

Zero-point correction

Thermal correction to Energy=

Thermal correction to Gibbs Free Energy=

Sum of ectronic and zero-point Enegy=

Sum of electronic and thermal Energies

Sum of electronic and thermal Enthalpies=

Sum of electronic and thermal Free Energies=

Imaginary Freq $=0$

Zero-point correction=

Thermal correction to Energy=

Thermal correction to Gibbs Free Energy=

Sum of electronic and zero-point Energies

Sum of electronic and thermal Energies=

Sum of electronic and thermal Enthalpies=
Sum of electronic and thermal Free Energies=

Imaginary Freq $=0$

Zero-point correction=

Energy=

Thermal correction to Gibbs Free Energy=

Sum of electronic and zero-point Energies-

Sum of electronic and thermal Energies=

Sum of electronic and thermal Enthalpies=

Sum of electronic

Zero-point correction=

Thermal correction to Energy=

Thermal correction to Gibbs Free Energy=

Sum of electronic and zero-point Energies

Sum of electronic and themal Energies=
0.479116 (Hartree/Particle)

0.503929

$-931.547703$

$-931.522890$

$-931.521946$

$-931.600973$

0.479493 (Hartree/Particle)

0.504194

0.505138

0.56730

$-931.547610$

$-931.522909$

$-931.600374$

0.479275 (Hartree/Particle)

0.504100

0.505044
0.425744

$-931.548356$

$-931.523531$

$-931.522587$

$-931.601887$

0.479297 (Hartree/Particle)

0.504010

0.504954

.031 .551310

$-931.551310$

-931.526596
-931.525652

$-931.604194$

0.479119 (Hartree/Particle)

0.504006

0.425536

$-931.547941$

$-931.523055$

$-931.52211$

$-931.601525$

0.479313 (Hartree/Particle)

0.504118

0.505062

0.426373
-931.545894
-931.521090

-931.545894
-931.521090

$-931.520146$

$-931.598835$

0.479343 (Hartree/Particle)

0.504115

0.505060

0.426483

$-931.548395$

$-931.523623$

$-931.522679$

0.478871 (Hartree/Particle)

0.50384

0.424981

.424981
-931.54640

$-931.521437$

$-931.520493$

$-931.600296$

0.479430 (Hartree/Particle)

0.504103

0.505047

$-931.548019$

$-931.523346$

$-931.522401$

0.479493 (Hartree/Particle)

0.504168

0.505112

$-.426815$

$-931.525276$

$-931.524332$

$-931.602629$

0.479094 (Hartree/Particle)

0.503908

0.504852

425180

$-931.546062$

-931.521248
-931.520304 
4b_7S8S12S_12_DP4

4b_7S8S12S_13_DP4+

4b_7S8S12S_14_DP4

4b_7S8S12S_15_DP4+

4b_7S8S12S_16_DP4

4b_7S8S12S_17_DP4

4b_7S8S12S_18_DP4+

4b_7S8S12S_19_DP4

4b_7S8S12S_20_DP4+

4b_7S8S12S_21_DP4

4b $7 S 8 S 12 S \_22$ DP4
Imaginary Freq $=0$

Zero-point correction

Them conection to Energy

Thermal correction to Gibbs Free Energy=

Sum of electronic and zero-point Energies=

Sum of electronic and thermal Energies=

Sum of electronic and thermal Enthalpies=

Imaginary Freq $=0$

Zero-point correction

Thermal correction to Energy=

Thermal correction to Gibbs Free Energy=

Sum of electronic and zero-point Energies=

Sum of electronic and

Imaginary Freq $=0$

Zero-pointc

Tero-point correction=

Thermal correction to Enthalpy

Thermal correction to Gibbs Free Energy=

Sum of electronic and zero-point Energies

Sum of electronic and thermal Energ

Sum of electronic and thermal Enthalpies=

Imaginary Freq $=0$

Zero-point correction=

Thermal correction to Energy=

Thermal correction to Enthalpy

Thermal correction to Gibbs Free Energy=

Sum of electronic and thral Enthas

Sum of electronic and thermal Free Energies=

Imaginary Freq $=0$

Zero-point correction

Thermal correction to Energy=

Thermal correction to Gibbs Free Energy=

Sum of electronic and zero-point Energies

Sum of electronic and thermal Energies

Sum of electronic and thermal Free Energies=

Imaginary Freq $=0$

Zero-point correctio

Thermal correction to Energy=

Thermal correction to Gibbs Free Energy=

Sum of electronic and zero-point Energies $=$

Sum of electronic and therment En

Sum of electronic and thermal Enthalpies-

Sum of electronic and thermal Free Energies=

Imaginary Freq $=0$

Zero-point correction=

Thermal correction to Energy=

Thermal correction to Enthalpy

Thermal correction to Gibbs Free Energy=

Sum of electronic and zero-point Energies

Sum of electronic and thermal Energies

Imaginary Freq $=0$

Zero-point correction

Thermal correction to Energy=

Thermal correction to Gibbs Free Energy=

Sum of electronic and zero-point Enegyes

Sum of electronic and thermal Energies=

Sum of electronic and thermal Enthalpies=

Sum of electronic and thermal Free Energies=

Imaginary Freq $=0$

Zero-point correction=

Thermal correction to Energy=

Thermal correction to Gibbs Free Energy=

Sum of electronic and zero-point Energies

Sum of electronic and thermal Energies=

Sum of electronic and thermal Enthalpies=
Sum of electronic and thermal Free Energies=

Imaginary Freq $=0$

Zero-point correction

to Energy=

Enthalpy=

Thermal correction to Gibbs Free Energy=

Sum of electronic and zero-point Energies-

Sum of electronic and thermal Energi

Sum of electronic and thermal Enthalpies=

Sum of electronic and thermal Free Energies=

Imaginary Freq $=0$

Zero-point correction $=$

Thermal correction to Energy=

Thermal correction to Gibbs Free Energy=

Sum of electronic and zero-point Energies

Sum of electronic and thenmal Energies=
0.479035 (Hartree/Particle)

0.503831

0.425819

$-931.546613$

$-931.521817$

$-931.520873$

$-931.599829$

0.478976 (Hartree/Particle)

0.503865

0.504809

(25647

$-931.547424$

$-931.521590$

$-931.600753$

0.479036 (Hartree/Particle)

0.503807

0.50475

0.426316

$-931.548498$

$-931.523728$

$-931.522784$

$-931.601218$

0.479155 (Hartree/Particle)

0.503951

0.504896

. 425986

$-931.547906$

-931.523109
-931.522165

$-931.601075$

0.479593 (Hartree/Particle)

0.504187

0.50513

0.427109

$-931.544147$

$-931.519553$

$-931.518609$

$-931.596631$

0.479277 (Hartree/Particle)

0.50411

0.426284

0.426284

$-931.52172$

$-931.52172$

$-931.599553$

0.479429 (Hartree/Particle)

0.504103

0.505047

0.426250

$-931.548020$

$-931.523346$

-931.522402
-931.601199

0.479118 (Hartree/Particle

0.503858
0.504802

0.426486

$-931.548402$

$-931.548402$

$-931.523663$

$-931.601034$

0.479659 (Hartree/Particle)

0.504146

0.505091

0.427236

$-931.548722$

$-931.52423$

$-931.523290$

0.479223 (Hartree/Particle)

0.503941

0.426373

$-931.546643$

$-931.52098$

$-931.599493$

0.479131 (Hartree/Particle)

0.503955

0.504900

0.426198

$-931.545217$

-931.520393
-931.519449 
4b_7S8S12S_23_DP4

4b_7S8S12S_24_DP4+

4b_7S8S12S_25_DP4

4b_7S8S12S_26_DP4+

5a_1S2S7S8S10R11R12S_1_DP4

5a_1S2S7S8S10R11R12S_2 DP4+

5a_1S2S7S8S10R11R12S_3_DP4+

5a_1S2S7S8S10R11R12S_4_DP4+

5b_1S2S7S8S10R11R12R_1_DP4

5b_1S2S7S8S10R11R12R_2_DP4+

5b_1S2S7S8S10R11R12R_3_DP4-
Imaginary Freq $=0$

Zero-point correction

Thermal correction to Energy=

Thermal correction to Gibbs Free Energy=

Sum of electronic and zero-point Energies=

Sum of electronic and thermal Energies=

Sum of electronic and thermal Enthalpies=

Imaginary Freq $=0$

Zero-point correction

Thermal correction to Energy=

Thermal correction to Gibbs Free Energy=

Sum of electronic and zero-point Energies=

Sum of electronic and thermal Energies=

Imaginary Freq $=0$

Zero-pointc

Tero-point correction=

Thermal correction to Enthalpy

Thermal correction to Gibbs Free Energy=

Sum of electronic and zero-point Energie

Sum of electronic and thermal Energies

Sum of electronic and thermal Enthalpies=

Imaginary Freq $=0$

Zero-point correction=

Thermal correction to Energy=

Thermal correction to Enthalpy

Thermal correction to Gibbs Free Energy=

Sum of electrente and zero-point Energie

Sum of electronic and henal Energies-

Sum of electronic and thermal Free Energies

Imaginary Freq $=0$

Zero-point correction

Thermal correction to Energy=

Thermal correction to Gibbs Free Energy=

Sum of electronic and zero-point Energies=

Sum of electronic and thermal Energies=

Sum of electronic and thermal Enthalpies=
Sum of electronic and thermal Free Energies=

Imaginary Freq $=0$

Zero-point correction=

Thermal correction to Energy=

Thermal correction to Enthalpy

Thermal correction to Gibbs Free Energy=

Sum of electronic and zero-point Energies

Sum of electronic and hermal Energies =

Imaginary Freq =

Zero-poin

to Energy

Thermal correction to Enthalpy

Thermal correction to Gibbs Free Energy=

Sum of electronic and zero-point Energies=

Sum of electronic and thermal Energies=

Sum of electronic and thermal Enthalpies=
Sum of electronic and thermal Free Energies

Imaginary Freq $=0$

Zero-point correction

Thermal correction to Energy=

Thermal correction to Gibbs Free Energy=

Sthergie

Sum of electronic and hermal Energies=

Sum of electronic and thermat Free Energies

Imaginary Freq $=0$

Zero-point correction

Thermal correction to Energy=

Thermal correction to Gibbs Free Energy=

Sum of electronic and zero-point Energies=

Sum of electronic and thermal Energies

Sum of electronic and thermal Enthalpies=

Sum of electronic and thermal Free Energies=

Imaginary Freq $=0$

Zero-point correction-

Thermal correction to Energy=

Thermal correction to Enthalpy

Thermal correction to Gibbs Free Energy=

Sum of electronic and zero-point Energies

Sum of electronic and thermal Energies=

Imaginary Freq $=0$

Zero-point correction

cction to Energy=

Thermal correction to Energy=

Thermal correction to Gibbs Free Energy=

Sum of electronic and zero-point Energies=

Sum of electronic and thermal Energies=
Sum of electronic and thermal Enthalpies=
0.479564 (Hartree/Particle)

0.504226

0.427362

$-931.547404$

$-931.522742$

$-931.521798$

$-931.599605$

0.479175 (Hartree/Particle)

0.504026

0.504970

0.425362

$-931.545846$

$-931.520994$

$-931.599658$

0.479285 (Hartree/Particle)

0.479285

0.505057

0.425586

$-931.547127$

$-931.522298$

$-931.52135$

$-931.600826$

0.478845 (Hartree/Particle)

0.503689

0.504633

.031 .543966

$-931.543966$

-931.519122
-931.518178

$-931.597293$

0.483303 (Hartree/Particle)

0.505879
0.506823

0.435015

-931.480693
-931.458118

$-931.457174$

$-931.528982$

0.483152 (Hartree/Particle)

0.505788

0.506733

434790

$-931.480497$

$-931.45786$

$-931.528859$

0.483514 (Hartree/Particle)

0.506056

0.507000

0.435208

-931.477401
-931.454859
-931.453915

$-931.453915$

$-931.525707$

0.483431 (Hartree/Particle)

0.505981

0.506926

- 435068

-931.477243
-931.454693

-931.454693
-931.453748

$-931.525606$

0.483538 (Hartree/Particle)

0.506101

0.435231

$-931.476651$

-931.476651
-931.454088

-931.45408
-931.453144

$-931.524958$

0.483467 (Hartree/Particle)

0.506033

0.506977

0.435146

$-931.476631$

$-931.45406$

$-931.524952$

0.483480 (Hartree/Particle)

0.506045

0.506045
0.506989

0.435179

$-931.475776$

-931.453211
-931.452267 
5b_1S2S7S8S10R11R12R_4_DP4+

5b_1S2S7S8S10R11R12R_5_DP4+

5b_1S2S7S8S10R11R12R_6_DP4+

5c_1S2S7S8S10R11S12S_1_DP4+

5c_1S2S7S8S10R11S12S_2_DP4

5c_1S2S7S8S10R11S12S_3_DP4+

5c_1S2S7S8S10R11S12S_4_DP4+

5c_1S2S7S8S10R11S12S_5_DP4+

5c_1S2S7S8S10R11S12S_6_DP4

5d_1S2S7S8S10R11S12R_1_DP4+

5d_1S2S7S8S10R11S12R_2_DP4
Imaginary Freq $=0$

Zero-point correction

Thermal correction to Energy=

Thermal correction to Gibbs Free Energy=

Sum of electronic and zero-point Energies=

Sum of electronic and thermal Energies=

Sum of electronic and thermal Enthalpies=

Imaginary Freq $=0$

Zero-point correction

Thermal correction to Energy=

Thermal correction to Gibbs Free Energy=

Sum of electronic and zero-point Energies=

Sum of electronic and thermal Energies=

Imaginary Freq $=0$

Zero-pointc

Tero-point correction=

Thermal correction to Enthalp

Thermal correction to Gibbs Free Energy=

Sum of electronic and zero-point Energies=

Sum of electronic and thermal Energies=

Sum of electronic and thermal Enthalpies=
Sum of electronic and thermal Free Energies=

Imaginary Freq $=0$

Zero-point correction

Thermal correction to Energ

Thermal correction to Gibbs Free Energy=

Sum of electronic and zero-point Energies=

Sum of electronic and thermal Energies=

Sum of electronic and hermal En halpies=

Imaginary Freq $=0$

Zero-point correction

Thermal correction to Energy=

Thermal correction to Gibbs Free Energy=

Sum of electronic and zero-point Energies

Sum of electronic and thermal Energies=

Sum of electronic and thermal Enthalpies=
Sum of electronic and thermal Free Energies=

Imaginary Freq $=0$

Zero-point correction =

Thermal correction to Energy=

Thermal correction to Enthalpy

Thermal correction to Gibbs Free Energy=

Sum of electronic and zero-point Energies

Sum of electronic and thermal Energies-

Imaginary Freq =

Zero-poin

to Energy

Thermal correction to Enthalpy

Thermal correction to Gibbs Free Energy=

Sum of electronic and zero-point Energies=

Sum of electronic and thermal Energies=

Sum of electronic and thermal Enthalpies=
Sum of electronic and thermal Free Energies

Imaginary Freq $=0$

Zero-point correction

Thermal correction to Energy=

Thermal correction to Gibbs Free Energy=

Sun of electoric and zero-point Energie

Sum of electronic and thermal Energies=

Sum of electronic and thermel Fre Energies

Imaginary Freq $=0$

Zero-poin

The-point correction=

Thermal correction to Enthalpy

Thermal correction to Gibbs Free Energy=

Sum of electronic and zero-point Energie

Sum of electric and thermal Energies=

Sum of electronic and and thermal Free Energies=

Imaginary Freq $=0$

Zero-point correction=

Thermal conection to Energy=

Thermal correction to Gibbs Free Energy=

Sum of electronic and zero-point Energies

Sum of electronic and thermal Energies=

Imaginary Freq $=0$

Zero-point correction=

Thermal correction to Energy=

Thermal correction to Gibbs Free Energy=

Sum of electronic and zero-point Energies=

Sum of electronic and thermal Energies=
Sum of electronic and thermal Enthalpies=
0.483536 (Hartree/Particle)

0.506162

0.434951

$-931.471882$

$-931.449256$

$-931.448312$

$-931.520467$

0.483706 (Hartree/Particle)

0.506268

0.507212

(2)

$-931.471855$

$-931.448349$

$-931.520314$

0.483796 (Hartree/Particle)

0.506311

0.507255
0.435455

$-931.470711$

$-931.448196$

$-931.44725$

$-931.519052$

0.482569 (Hartree/Particle)

0.505346

0.50629

0.433668

$-931.548545$

-931.525768
-931.524824

$-931.524824$

.482745 (Hartree/Particle)

0.482745
0.505430
0.506374

0.434131

$-931.548292$

$-931.525607$

$-931.524663$

$-931.596906$

0.483018 (Hartree/Particle)

0.505600

0.506544

.434648

$-931.547322$

$-931.524740$

$-931.523796$

0.482700 (Hartree/Particle)

0.505414

0.506358

0.433792

-931.547454
-931.524740

-931.524740
-931.523795

-931.523795
-931.596361

0.482683 (Hartree/Particle)

0.505427

0.506372

$-931.547633$

$-931.547633$

$-931.524888$

$-931.596602$

.482608 (Hartree/Particle)

0.505425

0.506370

.433642

$-931.546212$

$-931.546212$

$-931.522450$

$-931.595177$

0.482770 (Hartree/Particle)

0.505430

0.506374

0.434110

931.546649

$-931.523990$

$-931.523045$

0.482706 (Hartree/Particle)

0.505407
0.506352

0.434029

$-931.546012$

$-931.523311$ 
5d_1S2S7S8S10R11S12R_3_DP4-

5d_1S2S7S8S10R11S12R_4_DP4+

5d_1S2S7S8S10R11S12R_5_DP4

5d_1S2S7S8S10R11S12R_6_DP4+

5d_1S2S7S8S10R11S12R_7_DP4+

5d_1S2S7S8S10R11S12R_8_DP4+

5d_1S2S7S8S10R11S12R_9_DP4+

5d_1S2S7S8S10R11S12R_10_DP4+

5d_1S2S7S8S10R11S12R_11_DP4+

5d_1S2S7S8S10R11S12R_12_DP4+

5e_1R2R7S8S10S11R12S_1_DP4+
Imaginary Freq $=0$

Zero-point core

Thermal correction to Enthalpy

Thermal correction to Gibbs Free Energy=

Sum of electronic and zero-point Energies=

Sum of electronic and thermal Enthalpies=

Imaginary Freq $=0$

Zero-point correction

Thermal correction to Energy=

Thermal correction to Gibbs Free Energy=

Sum of electronic and zero-point Energies-

Sum of electric and

Imaginary Freq $=0$

Zero-pointc

Tero-point correction=

Thermal correction to Enthalpy

Thermal correction to Gibbs Free Energy=

Sum of electronic and zero-point Energies

Sum of electronic and thermal Energ

Sum of electronic and thermal Enthalpies=

Imaginary Freq $=0$

Zero-point correction=

Thermal correction to Energy=

(Thermal correction to Enthalpy

Thermal correction to Gibbs Free Energy=

Sum of electronic and thermal Enthalpies

Sum of electronic and thermal Free Energies

Imaginary Freq $=0$

Zero-point correction=

Thermal correction to Energy=

Thermal correction to Enthalpy

Thermal correction to Gibbs Free Energy=

Sum of electronic and zero-point Energies

(1)

Sum of electronic and thermal Free Energies=

Imaginary Freq $=0$

Zero-point correction

Thermal correction to Energy=

Thermal correction to Gibbs Free Energy=

Sum of electronic and zero-point Energies $=$

Sum of eletronic and thermi Energie

Sum of electronic and thermal Enthalpies=

Sum of electronic and thermal Free Energies=

Imaginary Freq $=0$

Zero-point correction=

Thermal correction to Energy=

Thermal correction to Enthalpy

Thermal correction to Gibbs Free Energy=

Sum of electronic and zero-point Energies

Sum of electronic and thermal Energies=

Sum of electronic and thermal Free Energies=

Imaginary Freq $=0$

Zero-point correction

Thermal correction to Energy=

Free Energy=

o-point Energies=

Sum of electronic and thermal Enthalpies=

Sum of electronic and thermal Free Energies=

Imaginary Freq $=0$

Zero-point correction=

Thermal correction to Energy=

Thermal correction to Gibbs Free Energy=

Sum of electronic and zero-point Energies

Sum of electronic and thermal Energies=

Sum of electronic and thermal Enthalpies=
Sum of electronic and thermal Free Energies=

Imaginary Freq $=0$

Zero-point correction

Therm

Thermal correction to Gibbs Free Energy=

Sum of electronic and zero-point Energies-

Sum of electronic and therma

Sum of electronic and thermal Enthalpies=

Sum of electronic and thermal Free Energies=

Imaginary Freq $=0$

Zero-point correction=

Thermal correction to Energy=

Thermal correction

Thermal correction to Gibbs Free Energy=

Sum of electron

c and zero-point Energies=

Sum of electronic and thermal Energies=
Sum of electronic and thermal Enthalpies=
.482839 (Hartree/Particle)

0.505523

0.506467

$-931.546388$

$-931.523704$

$-931.595203$

0.482876 (Hartree/Particle)

0.505553

0.506497

-

$-931.545683$

$-931.523007$

$-931.594386$

0.482918 (Hartree/Particle)

0.505525

0.506470

0.434051

$-931.544792$

$-931.52218$

$-931.521240$

31.593659

0.482783 (Hartree/Particle)

0.505474

0.506418

$-931.545614$

$-931.545614$

$-931.522923$

$-931.594278$

0.482810 (Hartree/Particle)

0.505469

0.506413

433930

$-931.544423$

$-931.521763$

$-931.52081$

$-931.593303$

0.482867 (Hartree/Particle)

0.505563

0.506508

-434115
-931.545587

$-931.545587$

$-931.522897$

$-931.594339$

0.482478 (Hartree/Particle)

0.505271

0.506215

433007

$-931.545138$

$-931.522345$

$-931.521400$

0.482467 (Hartree/Particle)

0.505273

0.533119

$-931.544810$

$-931.522004$

$-931.522004$

$-931.594159$

0.482618 (Hartree/Particle)

0.505380

0.506324

0.433280

$-931.543095$

$-931.520333$

$-931.519389$

0.482602 (Hartree/Particle)

0.50537

$-931.543278$

$-931.520509$

$-931.519565$

$-931.592434$

0.482590 (Hartree/Particle)

0.505277

0.506221

$-931.542430$

$-931.51974$

$-931.518799$ 
$5 \mathrm{e} \_1 R 2 R 7 S 8 S 10 S 11 R 12 S \_2$ DPP4+

5e_1R2R7S8S10S11R12S_3_DP4+

$5 \mathrm{e} \_1 R 2 R 758 S 10 S 11 R 12 S \_4$ DP44

5e_1R2R7S8S10S11R12S_5_DP4+

5e_1R2R7S8S10S11R12S_6_DP4+

5e_1R2R7S8S10S11R12S 7 DP4+

5e_1R2R7S8S10S11R12S_8_DP4

5e_1R2R7S8S10S11R12S_9_DP4+

$5 \mathrm{f} \_1 R 2 R 7 S 8 S 10 S 11 R 12 R \_1 \_\mathrm{DP} 4$

$5 f \_1 R 2 R 7 S 8 S 10 S 11 R 12 R \_2$ DP $4+$

$5 f \_1 R 2 R 7 S 8 S 10 S 11 R 12 R \_3$ DPP4+
Imaginary Freq $=0$

Zero-point

Thermal correction to Enthalp

Thermal correction to Gibbs Free Energy=

Sum of electronic and zero-point Energies=

Sum of electronic and thermal Free Energies=

Imaginary Freq $=0$

Zero-point correction=

Thermal correction to Energy=

Thermal correction to Gibbs Free Energy=

Sum of electronic and zero-point Energies-

Sum of ectronic and then Engas

Imaginary Freq $=0$

Zero-poin

ection to Energy=

Thermal correction to Enthalpy

Thermal correction to Gibbs Free Energy=

Sum of electronic and zero-point Energi

Sum of electronic and thermal Energies

Sum of electronic and thermal Free Energies=

Imaginary Freq $=0$

Zero-point correction

Thermal correction to Energy=

The

Thermal correction to Gibbs Free Energy=

Sum of electronic and thermes

Sum of electronic and thermal Free Energies

Imaginary Freq $=0$

Zero-point correction=

Thermal correction to Energy=

Thermal correction to Gibbs Free Energy=

Sum of electronic and zero-point Energies

Sum of electronic and thermal Energies

Sum of electronic and thermal Free Energies=

Imaginary Freq $=0$

Zero-point correctio

Thermal correction to Energy=

Thermal correction to Gibbs Free Energy=

Sum of electronic and zero-point Energies=

Sum of electronic and thermal Energie

Sum of electronic and thermal Enthalpies=

Sum of electronic and thermal Free Energies=

Imaginary Freq $=0$

Zero-point correction=

Thermal correction to Energy=

Thermal correction to Enthalpy=

Thermal correction to Gibbs Free Energy=

Sum of electronic and zero-point Energies

Sum of electronic and thermal Energies

Free Energies=

Imaginary Freq $=0$

Zero-point correction

Thermal correction to Energy=

Thermal correction to Gibbs Free Energy=

Sum of electronic and rero-point Energes=

Sum of electronic and thermal Energies=

Sum of electronic and thermal Enthalpies=

Sum of electronic and thermal Free Energies=

Imaginary Freq $=0$

Zero-point correction=

Thermal correction to Energy=

Thermal correction to Enthalpy

Thermal correction to Gibbs Free Energy=

Sum of electronic and zero-point Energies

Sum of electronic and thermal En

Sum of electronic and thermal Free Energies=

Imaginary Freq $=0$

Zero-point correctio

Thermal correction to Energy=

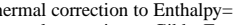

Free Energy=

zero-point Energies=

Sum of electronic and thermal Enthalpies=

Sum of electronic and thermal Free Energies=

Imaginary Freq $=0$

Zero-point correction $=$

Thermal correction to Energy=

Thermal correction

Thermal correction to Gibbs Free Energy=

Sum of electronic and zero-p

and zero-point Energies=

Sum of electronic and thermal Energies=
Sum of electronic and thermal Enthalpies=
.482356 (Hartree/Particle)

0.505153

0.506097

0.433141

$-931.541910$

$-931.519114$

$-931.518169$

$-931.591125$

0.482441 (Hartree/Particle)

0.505212

0.506156

-

$-931.541708$

$-931.517993$

$-931.590953$

0.482345 (Hartree/Particle)

0.505165

0.50610

0.433079

-931.541106
-931.518287

-931.517343
-931.590373

0.482420 (Hartree/Particle)

0.505225

0.506169

. $433110-931.541719$

-931.541719
-931.518914

$-931.518914$

$-931.591028$

.482330 (Hartree/Particle)

0.505181

0.506125

432991

$-931.541122$

$-931.51827$

$-931.517328$

$-931.590462$

0.482624 (Hartree/Particle)

0.50534

0.506285

$-931.53924$

$-931.539248$

$-931.515587$

$-931.589393$

0.482365 (Hartree/Particle)

0.505183

0.506127

0.431582

$-931.538975$

$-931.516158$

$-931.515214$

0.482358 (Hartree/Particle)

0.504267

0.434492

$-931.539340$

$-931.51743$

$-931.516487$

$-931.587206$

0.482225 (Hartree/Particle)

0.505077

0.50602

0.432871

$-931.544228$

-931.521376
-931.520432

-931.520432
-931.593582

0.482291 (Hartree/Particle)

0.505096

0.506040

-931.544142
-931.521337

$-931.520393$

$-931.593320$

0.482109 (Hartree/Particle)

0.505017

0.505961

$-931.543405$

$-931.52049$

$-931.519553$ 
$5 f \_1 R 2 R 7 S 8 S 10 S 11 R 12 R \_4 \_D P 4+$

5f_1R2R7S8S10S11R12R_5_DP4+

$5 f_{-} 1 R 2 R 7 S 8 S 10 S 11 R 12 R \_6$ DPP4+

5g_1R2R7S8S10S11S12S_1_DP4+

5g_1R2R7S8S10S11S12S_2_DP4+

5g_1R2R7S8S10S11S12S 3 DPP4+

5g_1R2R7S8S10S11S12S_4_DP4+

5g_1R2R7S8S10S11S12S_5_DP4+

5g_1R2R7S8S10S11S12S_6_DP4+

$5 \mathrm{~h} \_1 R 2 R 7 S 8 S 10 S 11 S 12 R \_1$ DP4+

$5 \mathrm{~h} \_1 R 2 R 7 S 8 S 10 S 11 S 12 R \_1 \_\mathrm{DP} 4$
Imaginary Freq $=0$

Zero-point

Therm correction to Engy=

Thermal correction to Gibbs Free Energy=

Sum of electronic and zero-point Energies=

Sum of electronic and thermal Free Energies=

Imaginary Freq $=0$

Zero-point correction-

Thermal correction to Energy=

Thermal correction to Gibbs Free Energy=

Sum of electronic and zero-point Energies=

Sum of eectric and thermal Energies=

Imaginary Freq $=0$

Zero-point co

Tero-point correction $=$

Thermal correction to Enthalpy

Thermal correction to Gibbs Free Energy=

Sum of electronic and zero-point En

Sum of electronic and thermal Energies

Sum of electronic and thermal Enthalpies=
Sum of electronic and thermal Free Energies=

Imaginary Freq $=0$

Zero-point correction=

Thermal correction to Energy=

Thermal correction to Gibbs Free Energy=

Sum of electronic and zero-point Energies-

Sum of electronic and thermal Energies-

Imaginary Freq $=0$

Zero-point correction

Thermal correction to Energy=

Thermal correction to Gibbs Free Energy=

Sum of electronic and thermal Energies=

Sum of electronic and thermal Free Energies=

Imaginary Freq $=0$

Zero-point correction =

Thermal correction to Energy=

Thermal correction to Gibbs Free Energy=

Sum of electronic and zero-point Energies

Sum of ecteric and

Imaginary Freq $=0$

Zero-poin co

to Energy=

Thermal correction to Enthalpy

Thermal correction to Gibbs Free Energy=

Sum of electronic and zero-point Energies=

Sum of electronic and thermal Energies=

Sum of electronic and thermal Enthalpies=
Sum of electronic and thermal Free Energies=

Imaginary Freq $=0$

Zero-point correction

Thermal correction to Energy=

Thermal correction to Gibbs Free Energy=

Sun

Sum of electronic and thermal Energies-

Sum of electronic and thermat Free Energies

Imaginary Freq $=0$

Zero-poin

Thermal correction $=$

Thermal correction to Enthalpy

Thermal correction to Gibbs Free Energy=

Sum of electronic and zero-point Energie

Sum of electronic and thermal Energies=

Sum of electronic and thermal Free Energies=

Imaginary Freq $=0$

Zero-point correction=

Thermal correction to Gibbs Free Energy=

Sum of electronic and zero-point Energies

Sum of electronic and thermal Energies=

Imaginary Freq $=0$

Zero-point correction

(t)

Thermal correction to Enthy $=$

Thermal correction to Gibbs Free Energy=

Sum of electronic and zero-point Energies=

Sum of electronic and thermal Energies=
Sum of electronic and thermal Enthalpies=
0.482322 (Hartree/Particle)

0.505120

$-931.542813$

$-931.520015$

$-931.519071$

$-931.592141$

0.482255 (Hartree/Particle)

0.505104

0.506048

0.532707

$-931.542883$

$-931.519090$

$-931.592431$

0.482161 (Hartree/Particle)

0.505085

0.506029

0.432592

$-931.541583$

$-931.518658$

$-931.517714$

$-931.591151$

0.483198 (Hartree/Particle)

0.505839

0.506783

434638

$-931.474682$

$-931.452042$

$-931.451097$

0.483398 (Hartree/Particle)

0.505980
0.506924

0.434924

$-931.474779$

$-931.45219$

$-931.451252$

$-931.523252$

0.483775 (Hartree/Particle)

0.506198

0.507142

435800

$-931.476426$

$-931.454003$

$-931.524401$

0.483724 (Hartree/Particle)

0.506152

0.507097

0.435731

$-931.476263$

$-931.453834$

$-931.452890$

$-931.524256$

0.483162 (Hartree/Particle)

0.505840

0.506784

. 434456

$-931.473800$

$-931.451123$

$-931.522507$

0.483655 (Hartree/Particle)

0.506107

0.50705

0.435624

$-931.475563$

$-931.453111$

$-931.452167$

$-931.523594$

0.483217 (Hartree/Particle)

0.505798

0.506742

.434916

-931.480427
-931.457846

$-931.457846$

$-931.456901$

0.483205 (Hartree/Particle)

0.505759

0.506704

0.434968

$-931.480202$

-931.457648
-931.456704 
5h_1R2R7S8S10S11S12R_1_DP4

5h_1R2R7S8S10S11S12R_1_DP4+

5i_1S2S7S8S10S11R12S_1_DP4+

5i_1S2S7S8S10S11R12S_2_DP4+

$5 \mathrm{j}_{-} 1 S 2 S 7 S 8 S 10 S 11 R 12 R \_1 \_\mathrm{DP} 4+$

5j_1S2S7S8S10S11R12R_2_DP4+

5j_1S2S7S8S10S11R12R_3_DP4+

$5 \mathrm{k} \_1 S 2 S 7 S 8 S 10 S 11 S 12 R \_1 \_\mathrm{DP} 4+$

$5 \mathrm{k} \_1 S 2 S 7 S 8 S 10 S 11 S 12 R \_2 \_\mathrm{DP} 4+$

5k_1S2S7S8S10S11S12R_3_DP4+

5k_1S2S7S8S10S11S12R_4_DP4+
Imaginary Freq $=0$

Zero-point correction

Them conergy=

Thermal correction to Gibbs Free Energy=

Sum of electronic and zero-point Energies=

Sum of electronic and thermal Free Energies=

Imaginary Freq $=0$

Zero-point correction

Thermal correction to Energy=

Thermal correction to Gibbs Free Energy=

Sum of electronic and zero-point Energies-

Sum of elctric and

Imaginary Freq $=0$

Zero-point correction

Thermal correction to Energy=

Thermal correction to Gibbs Free Energy=

Sum of electronic and zero-point Energies

Sum of electronic and thermal Energies=

Sum of electronic and thermal Enthalpies=

Zero-point correction $=$

Thermal correction to Energy=

Thermal correction to Gibbs Free Energy=

Sum of electronic and zero-point Energies-

Sum of electronic and thermal Energies=

Sum of electronic and thermal Free Energies

Imaginary Freq $=0$

Zero-point correction

Thermal correction to Energy=

Thermal correction to Gibbs Free Energy

Sum of electronic and zero-point Energies=

Sum of electronic and zero-point Enger

Sum of electronic and thermal Enthalpies=

Sum of electronic and thermal Free Energies=

Imaginary Freq $=0$

Zero-point correction=

Thermal correction to Energy=

Thermal correction to Enthalpy

Thermal correction to Gibbs Free Energy=

Sum of electronic and zero-point Energies-

Sum of electronic and thermal Energies=

Sum of electronic and thermal Enthalpies=
Sum of electronic and thermal Free Energie

Imaginary Freq $=$

Zero-point correction

ZThergy=

Thermal correction to Gibbs Free Energy=

Sum of electronic and zero-point Energies

Sum of electronic and thermal Energies=-

Sum of electronic and thermal Enthalpies=

Sum of electronic and thermal Free Energies=

Imaginary Freq $=0$

Zero-point correction=

Thermal correction to Energy=

Thermal correction to Enthalpy

Thermal correction to Gibbs Free Energy=

Sum of electronic and zero-point Energies

Sum of electronic and thermal E

Ipies=

Sum of electronic and thermal Free Energies=

Imaginary Freq $=0$

Zero-point correctio

Thermal correction to Energy=

Thermal correction to Enthalpy=
Thermal correction to Gibbs Free Energy=

Sum of electronic and zero-point Energies=

Sum of electronic and zero-point Energies

Sum of electronic and thermal Enthalpies=

Sum of electronic and thermal Free Energies=

Imaginary Freq $=0$

Thermal correction to Energy=

Thermal correction to Enthalpy

Thermal correction to Gibbs Free Energy=

Sum of electronic and zero-point Energies

Sum of electronic and thermal Energies=

Sum of electronic and thermal Enthalpies=

Imaginary Freq $=0$

Zero-point correction

Thermal correction to Energy=

Thermal correction to Gibbs Free Energy

Sum of electronic and zero-point Energies=

Sum of electronic and thermal Enthalpies=

S152
0.483516 (Hartree/Particle)

0.506000

0.435369

$-931.480644$

$-931.457217$

$-931.528791$

0.483325 (Hartree/Particle)

0.505881

0.506825

(0.53100

$-931.480521$

$-931.457021$

$-931.528746$

0.483025 (Hartree/Particle)

0.505563

0.506507

-931.492536
-931.469998

-931.469998
-931.469053

-931.469053
-931.540687

0.482964 (Hartree/Particle)

0.505512

0.506456

434831

$-931.492228$

$-931.469681$

$-931.468736$

0.483339 (Hartree/Particle)

0.50583

0.435266

- -931.48902

$-931.466538$

-931.466538
-931.465594

$-931.537102$

0.483436 (Hartree/Particle)

0.505866

0.435492

$-931.488856$

$-931.466426$

$-931.465482$

0.483250 (Hartree/Particle)

0.505765

0.435146

$-931.488140$

$-931.488140$

$-931.465625$

-931.464680
-931.536243

0.483283 (Hartree/Particle)

0.505711

0.50665

0.435237

$-931.531436$

$-931.509008$

$-931.508064$

0.483204 (Hartree/Particle)

0.50565

0.506599

-.435140 -931.530730

$-931.530730$

-931.508280
-931.507335

$-931.578794$

0.482922 (Hartree/Particle)

0.505474

0.506418
0.434482

0.434482

$-931.531604$

$-931.509052$

$-931.508108$

0.482904 (Hartree/Particle)

0.505452

0.434534

$-931.530862$

-931.508314
-931.507370 
5k_1S2S7S8S10S11S12R_5_DP4+

51_1S2S7S8S10S11S12S_1_DP4+

51_1S2S7S8S10S11S12S_2_DP4+

51_1S2S7S8S10S11S12S_3 DP4+

51_1S2S7S8S10S11S12S_4_DP4+

51_1S2S7S8S10S11S12S 5_DP4+

51_1S2S7S8S10S11S12S_6_DP4+

5m_1R2R7S8S10R11S12S_1_DP4+

$5 \mathrm{~m} \_1 R 2 R 7 S 8 S 10 R 11 S 12 S \_2$ DP $4+$

5m_1R2R7S8S10R11S12S_3_DP4+

5n_1R2R7S8S10R11S12R_1_DP4+
Imaginary Freq $=0$

Zero-point

Therm correction to Energy=

Thermal correction to Gibbs Free Energy=

Sum of electronic and zero-point Energies=

Sum of electronic and thermal Free Energies=

Imaginary Freq $=0$

Zero-point correction=

Thermal correction to Energy=

Thermal correction to Enthalpy

Thermal correction to Gibbs Free Energy=

Sum of electronic and zero-point Energies

Sum of electronic and thermal Energies=

Sum of electronic and thermal Enthalpies=

Imaginary Freq $=0$

Zero-point correction

Thermal correction to Energy=

Thermal correction to Gibbs Free Energy=

Sum of electronic and zero-point Energies

Sum of electronic and thermal Energies

Sum of electronic and thermal Enthalpies=

Zero-point correction=

Thermal correction to Energy=

Thermal correction to Gibbs Free Energy=

Sum of electronic and zero-point Energies

Sum of electronic and thermal Energies=

Sum of electronic and thermal Free Energies

Imaginary Freq $=0$

Zero-point correction

Thermal correction to Energy=

Thermal correction to Gibbs Free Energy=

Sum of electronic and thermal Energies=

Sum of electronic and thermal Enthalpies=
Sum of electronic and thermal Free Energies=

Imaginary Freq $=0$

Zero-point correction =

Thermal correction to Energy=

Thermal correction to Gibbs Free Energy=

Sum of electronic and zero-point Energies

Sum of ectros and

Imaginary Freq $=0$

Zero-poin

to

Thermal correction to Enthalpy

Thermal correction to Gibbs Free Energy=

Sum of electronic and zero-point Energies=

Sum of electronic and thermal Energies=

Sum of electronic and thermal Enthalpies=
Sum of electronic and thermal Free Energies=

Imaginary Freq $=0$

Zero-point correction=

Thermal correction to Energy

Thermal correction to Gibbs Free Energy=

Sum of electronic and zero-point Energies=

Sum of electronic and thermal Energies=

Sum of electronic and thermal Free Energies

Imaginary Freq $=0$

Zero-point correction

Thrmal correction to Energy=

Thermal correction to Gibbs Free Energy=

Sum of electronic and zero-point Energies-

Sum of electronic and thermal Energie

Sum of electronic and thermal Enthalpies=

Sum of electronic and thermal Free Energies=

Imaginary Freq $=0$

Zero-point correction=

Thermal correction to Energy=

Thermal correction to Gibbs Free Energy=

Sum of electronic and zero-point Energies

Sum of electronic and themal Energies=

Sum of electior

Imaginary Freq $=0$

Zero-point correction

Thermal correction to Energy=

Free Energy=

Sum of electronic and zero-point Energies=

Sum of electronc and tho-point Energes=

Sum of electronic and thermal Enthalpies=

S153
0.483120 (Hartree/Particle)

0.505630

0.506574

$-931.530366$

$-931.507856$

$-931.506912$

$-931.506912$

0.483266 (Hartree/Particle)

0.50573

0.506676

0.435144

$-931.531771$

$-931.509306$

$-931.508362$

0.

0.505655

0.506600

$-0.435034$

$-931.50902$

$-931.509022$

$-931.579643$

0.483397 (Hartree/Particle)

0.505808

0.506752

435455

$-931.530693$

$-931.508282$

$-931.578635$

0.483288 (Hartree/Particle)

0.505750

0.435113

$-931.531174$

$-931.508713$

$-931.507769$

$-931.579350$

0.483130 (Hartree/Particle)

0.505649

0.506593

434869

$-931.531024$

$-931.50850$

$-931.579286$

0.483014 (Hartree/Particle)

0.505620

0.506564

0.434637

$-931.529958$

$-931.50735$

$-931.506409$

$-931.578336$

0.483543 (Hartree/Particle)

0.505998

0.506942

0.435603

$-931.490030$

$-931.467576$

$-931.466631$

0.483540 (Hartree/Particle)

0.505971

0.435633

$-931.489885$

-931.489885
-931.467455

$-931.466510$

$-931.537792$

0.483507 (Hartree/Particle)

0.505954

0.506898

.435578

$-931.489215$

$-931.466767$

$-931.537143$

0.483378 (Hartree/Particle)

0.505832

0.435450

0.435450
-931.49354

$-931.471090$

-931.471090
-931.470146 
$5 \mathrm{n} \_1 R 2 R 7 S 8 S 10 R 11 S 12 R \_2$ DP4+

5o_1R2R7S8S10R11R12R_1_DP4+

5o_1R2R7S8S10R11R12R_2_DP4+

5o_1R2R7S8S10R11R12R_3_DP4+

5o_1R2R7S8S10R11R12R_4_DP4+

5o $1 R 2 R 7 S 8 S 10 R 11 R 12 R$ 5 DPP4+

5o_1R2R7S8S10R11R12R_6_DP4+

5p_1R2R7S8S10R11R12S_1_DP4+

5p_1R2R7S8S10R11R12S_2_DP4+

5p_1R2R7S8S10R11R12S_3_DP4+

$5 \mathrm{p} \_1 R 2 R 7 S 8 S 10 R 11 R 12 S \_4$ DP4
Imaginary Freq $=0$

Zero-point com

Thermal correction to Enthalpy

Thermal correction to Gibbs Free Energy=

Sum of electronic and zero-point Energies=

Sum of electronic and thermal Free Energies=

Imaginary Freq $=0$

Zero-point correction=

Thermal correction to Energy=

Thermal correction to Enthalpy

Thermal correction to Gibbs Free Energy=

Sum of electronic and zero-point Energies

Sum of electronic and thermal Energies=

Sum of electronic and thermal Enthalpies=

Imaginary Freq $=0$

Zero-point correction

Thermal correction to Energy=

Thermal correction to Gibbs Free Energy=

Sum of electronic and zero-point Energies

Sum of electronic and thermal Energies=

Sum of electronic and thermal Enthalpies=

Sum of electronic and thermal Free Energies=

Imaginary Freq $=0$

Zero-point correction $=$

Thermal correction to Energy=

Thermal correction to Gibbs Free Energy=

Sum of electronic and zero-point Energies-

Sum of electronic and thermal Energies=

Imaginary Freq $=0$

Zero-point correction

Thermal correction to Energy=

Thermal correction to Gibbs Free Energy=

Sum of electronic and zero-point Energies-

Sum of electronic and thermal Energies=

Sum of electronic and thermal Enthalpies=
Sum of electronic and thermal Free Energies=

Imaginary Freq $=0$

Zero-point correction =

Thermal correction to Energy=

Thermal correction to Gibbs Free Energy=

Sum of electronic and zero-point Energies

Sum of ectron and

Imaginary Freq $=0$

Zero-poin co

to Energy

Thermal correction to Enthalpy

Thermal correction to Gibbs Free Energy=

Sum of electronic and zero-point Energies=

Sum of electronic and thermal Energies=

Sum of electronic and thermal Enthalpies=

Imaginary Freq $=0$

Zero-point correction=

Thermal correction to Energy

Thermal correction to Gibbs Free Energy=

Sum of electronic and zero-point Energies=

Sum of electronic and thermal Energies=

Sum of electronic and thermal Free Energies=

Imaginary Freq $=0$

Zero-point correction

Thermal correction to Energy=

Thermal correction to Gibbs Free Energy=

Sum of electronic and zero-point Energies-

Sum of electronic and thermal Energies

Sum of electronic and thermal Enthalpies=

Sum of electronic and thermal Free Energies=

Imaginary Freq $=0$

Zero-point correction=

Thermal correction to Energy=

Thermal correction to Gibbs Free Energy=

Sum of electronic and zero-point Energies

Sum of electronic and thermal Energies=

Imaginary Freq $=0$

Zero-point correction

on to Energy=

Thermal correction to Enthalpy=

Thermal correction to Gibbs Free Energy=

Sum of electronic and zero-point Energies=

Sum of electronic and thermal Energies=
Sum of electronic and thermal Enthalpies=
0.483179 (Hartree/Particle)

0.505706

0.435163

$-931.493481$

$-931.47095$

$-931.470009$

$-931.541496$

0.483281 (Hartree/Particle)

0.505861

0.506805

434747

$-931.530170$

$-931.507591$

$-931.506647$

0.483484 (Hartree/Particle)

0.50595

0.50689

$-435299$

$-931.507303$

$-931.507303$

$-931.5779585$

0.483410 (Hartree/Particle)

0.505891

0.506835

0.435134

$-931.529297$

$-931.506816$

$-931.505872$

0.483397 (Hartree/Particle)

0.505881
0.506825

0.435119

$-931.529179$

$-931.50669$

$-931.505750$

$-931.577457$

0.483310 (Hartree/Particle)

0.505866

0.506810

0.434929

$-931.529052$

$-931.50649$

$-931.577432$

0.483288 (Hartree/Particle)

0.505845

0.50678

0.434888

$-931.528037$

$-931.505480$

$-931.504536$

$-931.576437$

0.483614 (Hartree/Particle)

0.505990

0.506934

0.435610

$-931.529761$

$-931.50738$

$-931.506441$

0.483392 (Hartree/Particle)

0.505870

0.435170

$-931.529193$

$-931.506715$

$-931.505771$

$-931.577415$

0.483403 (Hartree/Particle)

0.505853

0.506797

0.435253

$-931.529491$

$-931.507041$

$-931.506097$

0.483320 (Hartree/Particle)

0.505799

0.506744

0.435151

$-931.528852$

-931.506373
-931.505429 
$5 \mathrm{p} \_1 R 2 R 7 S 8 S 10 R 11 R 12 S \_5$ DPP4+

6a_1S2S7S8S10R11R12S_1_DP4+

6a_1S2S7S8S10R11R12S_2_DP4+

6a_1S2S7S8S10R11R12S_3 DP4+

6a_1S2S7S8S10R11R12S_4_DP4

6a_1S2S7S8S10R11R12S_5_DP4+

6a_1S2S7S8S10R11R12S_6_DP4

6a_1S2S7S8S10R11R12S_7_DP4+

6a_1S2S7S8S10R11R12S_8_DP4

6b_1S2S7S8S10R11R12R_1_DP4+

6b_1S2S7S8S10R11R12R_2_DP4
Imaginary Freq $=0$

Zero-point

Thermal correction to Enthalpy

Thermal correction to Gibbs Free Energy=

Sum of electronic and zero-point Energies=

Sum of electronic and thermal Free Energies=

Imaginary Freq $=0$

Zero-point correction=

Thermal correction to Energy=

Thermal correction to Enthalpy

Thermal correction to Gibbs Free Energy=

Sum of electronic and zero-point Energies

Sum of electronic and thermal Energies=

Sum of electronic and thermal Enthalpies=

Imaginary Freq $=0$

Zero-point correction

Thermal correction to Energy=

Thermal correction to Gibbs Free Energy=

Sum of electronic and zero-point Energies

Sum of electronic and thermal Energies

Sum of electronic and thermal Enthalpies=

Sum of electronic and thermal Free Energies=

Imaginary Freq $=0$

Zero-point correction $=$

Thermal correction to Energy=

Thermal correction to Gibbs Free Energy=

Sum of electronic and zero-point Energies-

Sum of electronic and thermal Energies=

Imaginary Freq $=0$

Zero-point correction

Thermal correction to Energy=

Thermal correction to Gibbs Free Energy=

Sum of electronic and zero-point Energies-

Sum of electronic and thermal Energies=

Sum of electronic and thermal Enthalpies=

Sum of electronic and

Zero-point correction

Thermal correction to Energy=

Thermal correction to Gibbs Free Energy=

Sum of electronic and zero-point Energies

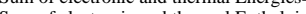

Imaginary Freq $=0$

Zero-poin co

to Energy=

Thermal correction to Enthalpy

Thermal correction to Gibbs Free Energy=

Sum of electronic and zero-point Energics

Sum of electronic and thermal Free Energies=

Imaginary Freq $=0$

Zero-point correction

Thermal correction to Energy=

Thermal correction to Gibbs Free Energy=

Sumergies

Sum electric an the

Sum of electronic and thermel Free Energies

Imaginary Freq $=0$

Zero-poin

Zero-point correction=

Thermal correction to Enthalpy

Thermal correction to Gibbs Free Energy=

Sum of electronic and zero-point Energie

Sum of electronic a

Energies=

Sum of electronic and thermal Free Energies=

Imaginary Freq $=0$

Zero-point correction=

Thermal conection to Energy=

Thermal correction to Gibbs Free Energy=

Sum of electronic and zero-point Energies-

Sum of electronic and thermal Energies=

Imaginary Freq $=0$

Zero-point co

to Energy=

Thermal correction to Entha $=$

Thermal correction to Gibbs Free Energy=

Sum of electronic and zero-point Energies=

Sum of electronic and thermal Energies=
Sum of electronic and thermal Enthalpies=
0.483138 (Hartree/Particle)

0.505664

0.435055

$-931.530134$

$-931.507609$

$-931.506664$

$-931.578218$

0.486412 (Hartree/Particle)

0.510335

0.511280

0.436311

$-1006.629149$

$-1006.60522$

$-1006.604281$

.486479 (Hartree/Particle)

0.510365

0.51130

$-1006.629532$

$-1006.629532$

$-1006.604702$

$-1006.679586$

0.486747 (Hartree/Particle)

0.510553

0.51149

$-1006.6302$

-1006.630260
-1006.606454

$-1006.606454$

$-1006.605510$

0.486240 (Hartree/Particle)

0.510416

0.511360

$-1006.629284$

$-1006.60510$

$-1006.604164$

$-1006.680244$

0.486430 (Hartree/Particle)

0.510383

0.511327

436023

006.626762

$-1006.602809$

$-1006.677168$

0.486398 (Hartree/Particle)

0.510384

0.511328

$-1006.626031$

$-1006.602046$

(106.60110

$-1006.676507$

0.486263 (Hartree/Particle)

0.51029

0.511236

$-1006.626825$

1006.626825

$-1006.602796$

$-1006.677348$

0.486526 (Hartree/Particle)

0.510418
0.511362

0.436346

$-1006.626947$

$-1006.603055$

$-1006.602111$

0.486849 (Hartree/Particle)

0.510759

0.511703

.436748

$-1006.626716$

$-1006.602807$

$-1006.676818$

0.486901 (Hartree/Particle)

0.510777

0.511721

0.436806

$-1006.626893$

-1006.603017
-1006.602073 
6b_1S2S7S8S10R11R12R_3_DP4+

6b_1S2S7S8S10R11R12R_4_DP4+

6b_1S2S7S8S10R11R12R_5_DP4+

6b_1S2S7S8S10R11R12R_6_DP4+

6b_1S2S7S8S10R11R12R_7_DP4+

6b_1S2S7S8S10R11R12R 8 DP4

6c_1S2S7S8S10R11S12S_1_DP4+

6c_1S2S7S8S10R11S12S_2_DP4+

6c_1S2S7S8S10R11S12S_3_DP4+

6c_1S2S7S8S10R11S12S_4_DP4

6c_1S2S7S8S10R11S12S 5 DP4
Imaginary Freq $=0$

Thermal correction to Enthalpy

Thermal correction to Gibbs Free Energy=

Sum of electronic and zero-point Energies=

Sum of electronic and thermal Energies=

Sum of electronic and thermal Enthalpies=

maginary Freq $=0$

Zero-point correction

Thermal correction to Energy=

Thermal correction to Gibbs Free Energy=

Sum of electronic and zero-point Energies=

Sum ofectric and hermal Energies=

Imaginary Freq $=0$

Tero-point correction=

Thermal correction to Enthalpy

Thermal correction to Gibbs Free Energy=

Sum of electronic and zero-point Energies

Sum of electronic and thermal Energies

Sum of electronic and thermal Free Energies=

Imaginary Freq $=0$

Zero-point correction

Thermal correction to Energy=

Thermal correction to Enthalpy

Thermal correction to Gibbs Free Energy=

Sum of electronic and thermes

Sum of electronic and thermal Free Energies=

Imaginary Freq $=0$

Zero-point correction

Thermal correction to Energy=

Thermal correct

Thermal correction to Gibbs Free Energy=

Sum of electronic and zero-point Energies

Sum of electronic and thermal Energies

Sum of electronic and thermal Free Energies=

Imaginary Freq $=0$

Zero-point correction

Thermal correction to Energy=

Thermal correction to Gibbs Free Energy=

Sum of electronic and zero-point Energies=

Sum of electronic and therme- Energies=

Sum of electronic and thermal Enthalpies=

Sum of electronic and thermal Free Energies=

Imaginary Freq $=0$

Zero-point correction=

to Energy

Thermal correction to Enthalpy

Thermal correction to Gibbs Free Energy=

Sum of electronic and zero-point Energies=

Sum of electronic and thermal Energies=

Sum of electronic and thermal Enthalpies=

Imaginary Freq $=0$

Zero-point correction

Thermal correction to Energy

Thermal correction to Gibbs Free Energy=

Therie

Sum of electronic and thermal Enthalpies

Sum of electronic and thermel Free Energies

Imaginary Freq =

Zero-poin

Thermal correction to Energy=

Thermal correction to Enthalpy

Thermal correction to Gibbs Free Energy=

Sum of electronic and zero-point Energies

Sum of electro

mal Energies=

Sum of electronic and thermal Free Energies=

Imaginary Freq $=0$

Zero-point correctio

Thermal correction to Energy=

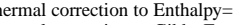

The Energy=

zero-point Energies=

Sum of election

Sum of electronic and thermal Energies=

Sum of electronic and thermal Free Energies=

Imaginary Freq $=0$

Zero-point correction $=$

Thermal correction to Energy=

Thermal correction to

Thermal correction to Gibbs Free Energy=

Sum of electronic and zero-po

d zero-point Energies=

Sum of electronic and thermal Energies=
Sum of electronic and thermal Enthalpies=
0.486839 (Hartree/Particle)

0.510692

0.436852

$-1006.626216$

$-1006.602363$

$-1006.601418$

$-1006.676203$

0.486700 (Hartree/Particle)

0.510623

0.511567

.436618

006.625759

$-1006.600893$

$-1006.675842$

0.486361 (Hartree/Particle)

0.510398

0.511342

0.435655

$-1006.622037$

$-1006.598000$

006.597056

$-1006.672743$

0.486142 (Hartree/Particle)

0.51029

0.511243

435218

$-1006.621594$

$-1006.596493$

$-1006.672518$

0.486789 (Hartree/Particle)

0.510646

0.436556

$-1006.622440$

$-1006.598583$

$-1006.597639$

- 006.672673

0.486611 (Hartree/Particle)

0.51054

0.436194

$-1006.622728$

-1006.622728
-1006.598795

$-1006.597851$

$-1006.673145$

0.485895 (Hartree/Particle)

0.509879

0.510823

0.435477

$-1006.697480$

$-1006.673496$

$-1006.672552$

0.485827 (Hartree/Particle)

0.509865

0.510809

0.435397

$-1006.696796$

-1006.672757
-1006.671813

$-1006.747225$

0.485616 (Hartree/Particle)

0.509724

0.51066

0.434808

$-1006.697237$

$-1006.672185$

-1006.672185
-1006.748044

0.485738 (Hartree/Particle)

0.509798

0.510742

$-1006.697284$

$-1006.697284$

$-1006.672280$

$-1006.747964$

0.486105 (Hartree/Particle)

0.510005

0.510949

0.435647

$-1006.696075$

$-1006.672175$ 
6c_1S2S7S8S10R11S12S_6_DP4+

6c_1S2S7S8S10R11S12S_7_DP4+

6c_1S2S7S8S10R11S12S_8_DP4+

6d_1S2S7S8S10R11S12R_1_DP4+

6d_1S2S7S8S10R11S12R_2_DP4

6d_1S2S7S8S10R11S12R_3_DP4+

6d_1S2S7S8S10R11S12R_4_DP4

6d_1S2S7S8S10R11S12R_5_DP4+

6d_1S2S7S8S10R11S12R_6_DP4+

6d_1S2S7S8S10R11S12R 7 DP4

6d_1S2S7S8S10R11S12R_8_DP4+
Imaginary Freq $=0$

Zero-point core

Thermal correction to Enthalpy

Thermal correction to Gibbs Free Energy=

Sum of electronic and zero-point Energies=

Sum of electronic and thermal Enthalpies=

maginary Freq $=0$

Zero-point correction

Thermal correction to Energy=

Thermal correction to Gibbs Free Energy=

Sum of electronic and zero-point Energies=

Sum ofectric and hermal Energies=

Imaginary Freq $=0$

Zero-pointc

Tero-point correction=

Thermal correction to Enthalpy

Thermal correction to Gibbs Free Energy=

Sum of electronic and zero-point Energie

Sum of electronic and thermal Energiese

Sum of electronic and thermal Free Energies=

Imaginary Freq $=0$

Zero-point correction=

Thermal correction to Energy=

Thermal correction to Gibbs Free Energy=

Sum of electronic and zero-point Energies=

Sum of electronic and thermal Energies=

Imaginary Freq $=0$

Zero-point correction

Thermal correction to Energy=

Thermal correction to Gibbs Free Energy=

Sum of electronic and zero-point Energies

Sum of electronic and thermal Energies=

Sum of electronic and thermal Enthalpies=
Sum of electronic and thermal Free Energies=

Imaginary Freq $=0$

Zero-point correction =

Thermal correction to Energy=

Thermal correction to Gibbs Free Energy=

Sum of electronic and zero-point Energies

Sum of electronic and thermal Enthalpies

Imaginary Freq $=0$

Zero-point

Thermal correction $=$

Thermal correction to Enthalpy

Thermal correction to Gibbs Free Energy=

Sum of electronic and zero-point Energics

Sum of electronic and thermal Free Energies=

Imaginary Freq $=0$

Zero-point correction

Thermal correction to Energy=

Thermal correction to Gibbs Free Energy=

S

Sum of electric and thermal Energies

Sum of electronic and thermel Free Energies

Imaginary Freq =

Zero-poin

Thermal correction to Energy

Thermal correction to Enthalpy

Thermal correction to Gibbs Free Energy=

Sum of electronic and zero-point Energie

Sum of electronic

Sum of electronic and thermal Free Energies=

Imaginary Freq $=0$

Zero-point correctio

Thermal correction to Energy=

Thermal correction to Enthalpy=

Thernal

nd zero-point Energies=

Sum of electronic and thermal Energies=

Sum of electronic and thermal Free Energies=

Imaginary Freq $=0$

Zero-point correction $=$

Thermal correction to Energy=

Thermal correction to

Thermal correction to Gibbs Free Energy=

Sum of electronic and zero-p

-

Sum of electronic and thermal Enthalpies=
0.485862 (Hartree/Particle)

0.509892

0.510836

0.435080

$-1006.696438$

$-1006.672407$

$-1006.671463$

$-1006.747220$

0.485880 (Hartree/Particle)

0.509904

0.510848

.435216

006.696328

$-1006.671360$

$-1006.746992$

0.485820 (Hartree/Particle)

0.509873

0.510818

0.435082

$-1006.696624$

$-1006.672570$

1006.671626

$-1006.747362$

0.485934 (Hartree/Particle)

0.509979

0.510923

.435220

$-1006.694948$

-1006.670903
-1006.669959

$-1006.745662$

0.486118 (Hartree/Particle)

0.510052
0.510996

0.435629

$-1006.695372$

$-1006.671438$

$-1006.670493$

$-1006.745860$

0.486246 (Hartree/Particle)

0.510126

0.511070

0.436137

$-1006.694081$

$-1006.67020$

$-1006.744190$

0.486231 (Hartree/Particle)

0.586231

0.511046

0.436144

$-1006.694204$

$-1006.67033$

$-1006.669389$

$-1006.744291$

0.485902 (Hartree/Particle)

0.509989

0.510933

$-1006.694931$

$-1006.694931$

$-1006.670844$

$-1006.745696$

0.486014 (Hartree/Particle)

0.510032

0.510976

0.435375

$-1006.695309$

$-1006.671291$

$-1006.670347$

0.486140 (Hartree/Particle)

0.510094

0.511038

$-1006.6941$

-1006.694113
-1006.670159

$-1006.669214$

$-1006.744562$

0.486096 (Hartree/Particle)

0.51006

0.511012

0.435574

$-1006.694241$

$-1006.670270$

$-1006.669326$ 
6d_1S2S7S8S10R11S12R_9_DP4-

6d_1S2S7S8S10R11S12R_10_DP4+

6d_1S2S7S8S10R11S12R_11_DP4+

6e $1 R 2 R 7 S 8 S 10 S 11 R 12 S \_1$ DP4+

6e_1R2R7S8S10S11R12S_2_DP4+

6e $1 R 2 R 7 S 8 S 10 S 11 R 12 S \_3$ DP4+

6e_1R2R7S8S10S11R12S_4_DP4+

6e_1R2R7S8S10S11R12S_5_DP4+

6e_1R2R7S8S10S11R12S_6_DP4+

6e_1R2R7S8S10S11R12S_7_DP4+

6e_1R2R7S8S10S11R12S_8_DP4
Imaginary Freq $=0$

Zero-point

Thermal correction to Enthalpy

Thermal correction to Gibbs Free Energy=

Sum of electronic and zero-point Energies=

Sum of electronic and thermal Free Energies=

Imaginary Freq $=0$

Zero-point correction=

Thermal correction to Energy $=$

Thermal correction to Gibbs Free Energy=

Sum of electronic and zero-point Energies=

Sum of electric and

Imaginary Freq $=0$

Tero-point correction=

Thermal correction to Enthalpy

Thermal correction to Gibbs Free Energy=

Sum of electronic and zero-point Energies=

Sum of electronic and thermal Energies=

Sum of electronic and thermal Enthalpies=
Sum of electronic and thermal Free Energies=

Imaginary Freq $=0$

Zero-point correction=

Thermal correction to Energy=

Thermal correction to Gibbs Free Energy=

Sum of electronic and zero-point Energies-

Sum of electronic and thermal Energies=

Imaginary Freq $=0$

Zero-point correction

Thermal correction to Energy=

Thermal correction to Gibbs Free Energy=

Sum of electronic and zero-point Energies

Sum of electronic and thermal Energies=

Sum of electronic and thermal Free Energies=

Imaginary Freq $=0$

Zero-point correction =

Thermal correction to Energy=

Thermal correction to Gibbs Free Energy=

Sum of electronic and zero-point Energies

Sum of electronic and thermal Enthalpies

Imaginary Freq $=0$

Zero-point correction=
Thermal correction to Energy

Thermal correction to Enthalpy=

Thermal correction to Gibbs Free Energy=

Sum of electronic and zero-point Energies

Sum of electronic and therm

Sum of electronic and thermal Free Energies=

Imaginary Freq $=0$

Zero-point correction

Thermal correction to Energy=

Thermal correction to Gibbs Free Energy=

Sic

Sum of electrocic and

Sum of electronic and thermel Free Energies

Imaginary Freq =

Zero-poin

Thermal correction to Energy

Thermal correction to Enthalpy

Thermal correction to Gibbs Free Energy=

Sum of electronic and zero-point Energies

Sum of electronis

thermal Energies=

Sum of electronic and thermal Free Energies=

Imaginary Freq $=0$

Zero-point correctio

Thermal correction to Energy=

Thermal correction to Enthalpy=

Thrnal corre Energy=

zero-point Energies=

Sum of electronic and thermal Energies=

Sum of electronic and thermal Free Energies=

Imaginary Freq $=0$

Zero-point correction=

Thermal correction to Energy=

Thermal correction to

Thermal correction to Gibbs Free Energy=

Sum of electronic and zero-p

and zero-point Energies=

Sum of electronic and thermal Energies=
Sum of electronic and thermal Enthalpies=
0.486239 (Hartree/Particle)

0.510053

0.436119

$-1006.693978$

006.67016

$-1006.669219$

$-1006.744097$

0.485954 (Hartree/Particle)

0.509931

0.510875

435407

$-1006.694282$

$-1006.669361$

$-1006.744830$

0.486228 (Hartree/Particle)

0.510078

0.511022

0.436231

$-1006.693120$

$-1006.669270$

$-1006.668326$

$-1006.743117$

0.486035 (Hartree/Particle)

0.510030

0.510975

0.435372

$-1006.690974$

$-1006.666978$

$-1006.741637$

0.486006 (Hartree/Particle)

0.509980

0.435385

$-1006.691232$

$-1006.691232$

$-1006.666313$

$-1006.741852$

0.486321 (Hartree/Particle)

0.510181

0.511125

. 435983

006.689619

$-1006.66575$

$-1006.739957$

486258 (Hartree/Particle)

0.510151

0.511095

0.435796

$-1006.689659$

$-1006.665767$

$-1006.664822$

$-1006.740121$

0.485865 (Hartree/Particle)

0.509973

0.510917

$-1006.690220$

006.690220

$-1006.666112$

$-1006.741263$

0.485801 (Hartree/Particle)

0.509890

0.510834

0.434618

$-1006.690446$

$-1006.666357$

$-1006.665413$

$-1006.741628$

0.485812 (Hartree/Particle

0.509895

0.510839

$-1006.689293$

-1006.689293
-1006.665210

$-1006.664266$

$-1006.740363$

0.485826 (Hartree/Particle)

0.509902

0.510846

0.434810

$-1006.689294$

$-1006.665218$

$-1006.664274$ 
$6 \mathrm{f} \_1 R 2 R 7 S 8 S 10 S 11 R 12 R \_1 \_\mathrm{DP} 4+$

6f_1R2R7S8S10S11R12R_2_DP4+

6f_1R2R7S8S10S11R12R_3_DP4+

6f $1 R 2 R 7 S 8 S 10 S 11 R 12 R \quad 4$ DP4+

6f_1R2R7S8S10S11R12R_5_DP4+

6f $1 R 2 R 7 S 8 S 10 S 11 R 12 R \_6$ DP4+

6f_1R2R7S8S10S11R12R_7_DP4+

6f_1R2R7S8S10S11R12R_8_DP4+

6g_1R2R7S8S10S11S12S_1_DP4+

6g_1R2R7S8S10S11S12S 2 DP4+

6g_1R2R7S8S10S11S12S_3_DP4
Imaginary Freq $=0$

Zero-point correction

Thermal correction to Energy=

Thermal correction to Enthalpy=
Thermal correction to Gibbs Free Energy=

Tum of erctoric

Sum of electronic and zero-point Energies-

Sum of electronic and thermal Enthalpies=

Sum of electronic and thermal Free Energies=

Imaginary Freq $=0$

Zero-point correction=

Thermal correction to Energy=

Thermal correction to Enthalpy

Thermal correction to Gibbs Free Energy=

Sum of electronic and zero-point Energies-

Sum of electronic and thermal Energies=

Sum of electronic and thermal Enthalpies=

Imaginary Freq =

Zero-point correction=

Thermal correction to Enthalpy

Thermal correction to Gibbs Free Energy

Sum of electronic and zero-poit Engy=

Sum of electronic and thermal Energies=

Sum of electronic and thermal Free Energies=

Imaginary Freq $=0$

Zero-point correction $=$

Thermal correction to Energy=

Thermal correction to Gibbs Free Energy=

Sum of electronic and zero-point Energies-

Sum of electronic and thermal Energies=

Sum of elctronic and themnal Enhalpies=

Imaginary Freq $=0$

Zero-point correction

Thermal correction to Energy=

Thermal correction to Gibbs Free Energy=

Sum of electronic and zero-point Energies

Sum of electronic and thermal Energies=

Sum of electronic and thermal Free Energies=

Imaginary Freq $=0$

Zero-point correction =

Thermal correction to Energy=

Thermal correction to Gibbs Free Energy=

Sum of electronic and zero-point Energies

Sum of ectroc and

Imaginary Freq $=0$

Zero-point

Thermal correction $=$

Thermal correction to Enthal

Thermal correction to Gibbs Free Energy=

Sum of electronic and zero-point Energies=

Sum of electronic and thermal Energies=

Sum of electronic and thermal Enthalpies=
Sum of electronic and thermal Free Energies=

Imaginary Freq $=0$

Zero-point correction

Thermal correction to Energy=

Thermal correction to Gibbs Free Energy=

Seric

Sum of electronic and thermal Energies=-

Sum of electronic and thermel Free Energies

Imaginary Freq $=0$

Zero-point correction

Thermal correction to Energy=

Thermal correction to Gibbs Free Energy=

Sum of electronic and zero-point Energies=

Sum of electronic and thermal Energies-

Sum of electronic and thermal Enthalpies=

Sum of electronic and thermal Free Energies=

Imaginary Freq $=0$

Zero-point correction-

Thermal correction to Energy=

Thermal correction to Gibbs Free Energy=

Sum of electronic and zero-point Energies

Sum of electronic and themal Energies=

Imaginary Freq =

Zero-point correc

Fnergy

Thermal correction to Energy=

Thermal correction to Gibbs Free Energy=

Sum of electronic and zero-point Energies=

Sum of electronic and thermal Energies=
Sum of electronic and thermal Enthalpies=
0.485737 (Hartree/Particle)

0.50979

0.434950

$-1006.693168$

$-1006.693168$

$-1006.66911$

$-1006.743955$

0.485675 (Hartree/Particle)

0.509770

0.510714

0.434834

$-1006.692561$

$-1006.668466$

$-1006.667521$

0.485575 (Hartree/Particle)

0.509700

0.434447

$-1006.692985$

$-1006.66886$

$-1006.667916$

$-1006.744112$

0.485546 (Hartree/Particle)

0.509706

0.510650

434340

$-1006.693177$

$-1006.66901$

$-1006.668073$

0.485968 (Hartree/Particle)

0.509977

0.510921

$-1006.691510$

$-1006.66750$

$-1006.666557$

$-1006.742250$

0.486078 (Hartree/Particle)

0.510026

0.510970

435538

$-1006.691221$

$-1006.667273$

$-1006.741761$

0.485666 (Hartree/Particle)

0.509784

0.510728

0.434378

-1006.691681
-1006.667563

$-1006.666619$

$-1006.742968$

0.485622 (Hartree/Particle)

0.509764

0.510708

0.434299
-1006.691974

$-1006.691974$

$-1006.667832$

$-1006.743297$

0.486697 (Hartree/Particle)

0.510544

0.436744

$-1006.62673$

-1006.626732
-1006.60288

$-1006.601940$

$-1006.676684$

0.486685 (Hartree/Particle)

0.510525

0.511469

.436700

$-1006.626768$

$-1006.602928$

$-1006.676753$

0.486590 (Hartree/Particle)

0.510462

0.511406

0.436461

$-1006.624371$

-1006.600498
-1006.599554 
6g_1R2R7S8S10S11S12S_4_DP4

6g_1R2R7S8S10S11S12S_5_DP4+

6g_1R2R7S8S10S11S12S_6_DP4

6g_1R2R7S8S10S11S12S_7_DP4+

6g_1R2R7S8S10S11S12S_8_DP4

6h_1 $1 R 2 R 7 S 8 S 10 S 11 S 12 R$ _ 1 DP4

6h_1R2R7S8S10S11S12R_2_DP4+

6h_1R2R7S8S10S11S12R_3 DP4+

6h_1R2R7S8S10S11S12R_4_DP4+

6h_1R2R7S8S10S11S12R 5 DPP4+

6h_1R2R7S8S10S11S12R_6_DP4+
Imaginary Freq $=0$

Zero-point

Thermal correction to Enthalpy

Thermal correction to Gibbs Free Energy=

Sum of electronic and zero-point Energies=

Sum of electronic and thermal Energies=

Sum of electronic and thermal Enthalpies=

maginary Freq $=0$

Zero-point correction=

Thermal correction to Energy=

Thermal correction to Gibbs Free Energy=

Sum of electronic and zero-point Energies=

Sum of ectric and thermal Energie

Imaginary Freq $=0$

Zero-pointc

Tero-point correction=

Thermal correction to Enthalpy

Thermal correction to Gibbs Free Energy=

Sum of electronic and zero-point Energies=

Sum of electronic and thermal Energies=

Sum of electronic and thermal Enthalpies=
Sum of electronic and thermal Free Energies=

maginary Freq =

Thermal correction to Energy=

Thermal correction to Enthalpy=

Thermal correction to Gibbs Free Energy=

Sum or electric and zero-point Energies=

Sum of ectronic and thermal Engres

Sum of electronic and thermal Free Energies

Imaginary Freq $=0$

Zero-point correction

Thermal correction to Energy=

Thermal correction to Enthalpy

Thermal correction to Gibbs Free Energy=

Sum of electronic and zero-point Energies

Sum of electronic and thermal Energies

Sum of electronic and thermal Free Energies=

Imaginary Freq $=0$

Zero-point correction-

Thermal correction to Energy=

Thermal correction to Gibbs Free Energy=

Sum of electronic and zero-point Energies

Sum of electronic and thermal Enthalpies

Imaginary Freq $=0$

Zero-point

to Energy

Thermal correction to Enthalpy

Thermal correction to Gibbs Free Energy=

Sum of electronic and zero-point Energics

Sum of electronic and thermal Free Energies=

Imaginary Freq $=0$

Zero-point correction

Thermal correction to Energy=

Thermal correction to Gibbs Free Energy=

Sure

Sum of electronic and thermal Energies

Sum of electronic and thermel Free Energies

Imaginary Freq =

Zero-point

Thermal correction to Energy=

Thermal correction to Enthalpy

Thermal correction to Gibbs Free Energy=

Sum of electronic and zero-point Energies

Sum of electro

-

Sum of electronic and thermal Free Energies=

Imaginary Freq $=0$

Zero-point correctio

Thermal correction to Energy

Thermal correction to Enthalpy=

The Energy=

zero-point Energies

Sum of electronic and thermal Energies=

Sum of electronic and thermal Free Energies=

Imaginary Freq $=0$

Zero-point correction=

Thermal correction to Energy=

Thermal correction to

Thermal correction to Gibbs Free Energy=

Sum of electronic and zero-point

and zero-point Energies=

Sum of electronic and thermal Enthalpies=
0.486305 (Hartree/Particle)

0.510315

0.435872

$-1006.623929$

006.59991

$-1006.598975$

$-1006.674362$

0.486589 (Hartree/Particle)

0.510496

0.511440

436426

$-006.625202$

$-1006.600351$

$-1006.675365$

0.486453 (Hartree/Particle)

0.510396

0.511340

0.436159

$-1006.625308$

$-1006.601365$

$-1006.600421$

$-1006.675602$

0.486384 (Hartree/Particle)

0.51028

0.511225

$-1006.626354$

$-1006.602458$

$-1006.602458$

$-1006.676302$

0.486350 (Hartree/Particle)

0.510274

0.436378

$-1006.625827$

$-1006.601903$

$-1006.600959$

$-1006.675799$

0.486327 (Hartree/Particle)

0.510213

0.511157

436328

006.629611

(1006.604781

$-1006.679610$

0.486308 (Hartree/Particle)

0.510183

0.511127

0.436432

$-1006.628780$

$-1006.60490$

$-1006.603961$

$-1006.678656$

0.486288 (Hartree/Particle)

0.510211

0.511155

0.436308

$-1006.629355$

$-1006.605432$

$-1006.679335$

0.486495 (Hartree/Particle)

0.510369

0.511313

0.436426

$-1006.629350$

$-1006.605476$

-1006.604532
-1006.679420

0.486334 (Hartree/Particle)

0.51023

0.511174

$-1006.629795$

-1006.629795
-1006.605899

$-1006.604955$

$-1006.679701$

0.486139 (Hartree/Particle)

0.510110

0.51105

0.436059

$-1006.630902$

$-1006.606931$ 
6h_1R2R7S8S10S11S12R_7_DP4+

6h_1R2R7S8S10S11S12R 8 DP4

6i_1S2S7S8S10S11R12S_1_DP4+

6i_1S2S7S8S10S11R12S_2_DP4+

6i_1S2S7S8S10S11R12S_3_DP4+

6i_1S2S7S8S10S11R12S_4_DP4+

6j_1S2S7S8S10S11R12R_1_DP4+

6j_1S2S7S8S10S11R12R_2_DP4+

6j_1S2S7S8S10S11R12R_3_DP4+

6j_1S2S7S8S10S11R12R_4_DP4+

6k_1S2S7S8S10S11S12R_1_DP4+
Imaginary Freq $=0$

Zero-point

Therm correction to Entalpy=

Thermal correction to Gibbs Free Energy=

Sum of electronic and zero-point Energies=

Sum of electronic and thermal Free Energies=

Imaginary Freq $=0$

Zero-point correction

Thermal correction to Energy $=$

Thermal correction to Gibbs Free Energy=

Sum of electronic and zero-point Energies-

Sum of ectronic and thermat Enthes

Imaginary Freq $=0$

Zero-point correction

Thergy=

Thermal correction to Gibbs Free Energy=

Sum of electronic and zero-point Energies

Sum of electronic and thermal Energies

Sum of electronic and thermal Free Energies=

Imaginary Freq $=0$

Zero-point correction

Thermal correction to Energy=

Thermal correction to Gibbs Free Energy=

Sum of electronic and zero-point Energies=

Sum of electronic and thermal Energies=

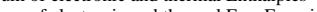

Imaginary Freq $=0$

Zero-point correction

Thermal correction to Energy=

Thermal correction to Gibbs Free Energy=

Sum of electronic and zero-point Energies-

Sum of electronic and thermal Energies=

Sum of electronic and thermal Enthalpies=

Sum of electronic and

Zero-point correction

Thermal correction to Energy $=$

Thermal correction to Gibbs Free Energy=

Sum of electronic and zero-point Energies

STm o ectric and

Imaginary Freq $=0$

Zero-point correction=

Thernal concetion to Energy=

correction to Gibbs Free Energy=

Sum of electronic and zero-point Energies

Sum of electronic and thermal Energies=

Sum of electronic and thermal Enthalpies=
Sum of electronic and thermal Free Energies=

Imaginary Freq $=0$

Zero-point correction

Thermal correction to Energy=

Thermal correction to Gibbs Free Energy=

Sum of electronic and zero-point Energies=

Sum of electronic and thermal Energies=

Sum of electronic and thermal Free Energies=

Imaginary Freq $=0$

Zero-point correction

Thrma correction to Energy=

Thermal correction to Gibbs Free Energy

Sum of electronic and thermal Enthalpies=

Sum of electronic and thermal Free Energies=

Imaginary Freq $=0$

Zero-point correction-

Thermal correction to Energy=

Thermal correction to Gibbs Free Energy=

Sum of electronic and zero-point Energies-

Sum of electronic and thermal Energies=

Imaginary Freq $=0$

Zero-point correction

Thermal correction to Energy=

Free Energy=

Sum of electronic and zero-point Energies-

Sum of electro

Sum of electronic and thermal Enthalpies=

S161
0.486613 (Hartree/Particle)

0.510447

0.436833

$-1006.629150$

$-1006.60531$

-1006.604372
-1006.678930

0.485891 (Hartree/Particle)

0.510024

0.510968

0.435520

006.629411

$-1006.604334$

$-1006.679782$

0.485940 (Hartree/Particle)

0.509877

0.510821

$-1006.640990$

$-1006.640990$

$-1006.691128$

0.486008 (Hartree/Particle)

0.509904

0.510848

435948

$-1006.641392$

$-1006.617496$

$-1006.616552$

0.486233 (Hartree/Particle)

0.510043

0.436523

$-1006.642048$

$-1006.61823$

$-1006.617295$

$-1006.691759$

0.485984 (Hartree/Particle)

0.509956

0.510900

435965

$-1006.640584$

$-1006.616612$

$-1006.690603$

0.486235 (Hartree/Particle)

0.51004

0.536426

$-1006.63969$

-1006.639694
-1006.615886

$-1006.614942$

$-1006.689504$

0.486087 (Hartree/Particle)

0.509948

0.510892

436065

$-1006.639816$

$-1006.61595$

$-1006.615012$

0.486461 (Hartree/Particle)

0.510233

0.436551

$-1006.63879$

$-1006.6381501$

$-1006.61407$

$-1006.688701$

0.486305 (Hartree/Particle)

0.510175

0.511120

.436232

$-1006.638359$

$-1006.614488$

$-1006.688431$

0.486469 (Hartree/Particle)

0.510180

0.436792

$-1006.680015$

$-1006.656303$

-1006.656303
-1006.655359 
6k_1S2S7S8S10S11S12R_2_DP4+

6k_1S2S7S8S10S11S12R_3_DP4+

6k_1S2S7S8S10S11S12R_4_DP4

6k_1S2S7S8S10S11S12R_5_DP4+

6k_1S2S7S8S10S11S12R_6_DP4

6k_1S2S7S8S10S11S12R_7_DP4+

6k_1S2S7S8S10S11S12R_8_DP4+

61_1S2S7S8S10S11S12S_1_DP4+

61_1S2S7S8S10S11S12S_2_DP4+

61_1S2S7S8S10S11S12S_3_DP4+

61_1S2S7S8S10S11S12S_4_DP4+
Imaginary Freq $=0$

Zero-point

Thermal correction to Enthalpy

Thermal correction to Gibbs Free Energy=

Sum of electronic and zero-point Energies=

Sum of electronic and thermal Energies-

Sum of electronic and thermal Enthalpies=

maginary Freq $=0$

Zero-point correction

Thermal correction to Energy=

Thermal correction to Gibbs Free Energy=

Sum of electronic and zero-point Energies=

Sum ofectric and hermal Energies=

Imaginary Freq $=0$

Zero-po

Tero-point correction=

Thermal correction to Enthalpy

Thermal correction to Gibbs Free Energy=

Sum of electronic and zero-point Energies

Sum of electronic and thermal Energies

Sum of electronic and thermal Free Energies=

Imaginary Freq $=0$

Zero-point correction

Thermal correction to Energy=

Thermal correction to Enthalpy

Thermal correction to Gibbs Free Energy=

Sum of ectronic and them Engles

Sum of electronic and thermal Free Energies

Imaginary Freq $=0$

Zero-point correction

Thermal correction to Energy=

Thermal correction to Enthalpy

Thermal correction to Gibbs Free Energy=

Sum of electronic and zero-point Energies

Sum of electronic and thermal Energies

Sum of electronic and thermal Free Energies=

Imaginary Freq $=0$

Zero-point correction

Thermal correction to Energy=

Thermal correction to Gibbs Free Energy=

Sum of electronic and zero-point Energies=

Sum of electronic and thermi Energes

Sum of electronic and thermal Enthalpies=

Sum of electronic and thermal Free Energies=

Imaginary Freq $=0$

Zero-point correction=

Thermal correction to Energy=

Thermal correction to Enthalpy

Thermal correction to Gibbs Free Energy=

Sum of electronic and zero-point Energies

Sum of electronic and thermal Energies

Free Energies=

Imaginary Freq $=0$

Zero-point correction

Thermal correction to Energy=

Thermal correction to Gibbs Free Energy=

Sum of electronic and Gero

Sum of electronic and thermal Energies-

Sum of electronic and thermel Free Energies

Imaginary Freq =

Zero-point co

Thermal correction to Energy

Thermal correction to Enthalpy

Thermal correction to Gibbs Free Energy=

Sum of electronic and zero-point Energie

Sum of electron

Sum of electronic and thermal Free Energies=

Imaginary Freq $=0$

Zero-point correctio

Thermal correction to Energy=

halpy $=$

The Energy=

zero-point Energies=

Sum of electronic and thermal Energies=

Sum of electronic and thermal Free Energies -

Imaginary Freq $=0$

Zero-point correction=

Thermal correction to Energy=

Thermal correction to

Thermal correction to Gibbs Free Energy=

Sum of electronic and zero-p

and zero-point Energies=

Sum of electronic and thermal Enthalpies=
0.486462 (Hartree/Particle)

0.510233

0.511177

0.436745

$-1006.678830$

$-1006.655059$

$-1006.654115$

$-1006.728547$

0.486377 (Hartree/Particle)

0.510175

0.511119

. 436551

006.679852

$-1006.6565110$

$-1006.729679$

0.486545 (Hartree/Particle)

0.510276

0.51122

0.436842

$-1006.678924$

$-1006.655193$

006.654248

$-1006.728627$

0.486319 (Hartree/Particle)

0.51021

0.511155

$-1006.678941$

$-1006.655049$

$-1006.655049$

$-1006.729172$

0.486210 (Hartree/Particle)

0.510080

0.511025

0.436134

$-1006.680211$

$-1006.656341$

$-1006.655397$

0.486397 (Hartree/Particle)

0.510240

0.511184

$-1006.6790$

-1006.679040
-1006.655197

$-1006.654253$

$-1006.729067$

0.486129 (Hartree/Particle)

0.510032

0.510976

0.435893

$-1006.680094$

$-1006.656192$

$-1006.655248$

.486596 (Hartree/Particle)

0.51026

0.51120

$-1006.680581$

$-1006.656916$

$-1006.730069$

0.486426 (Hartree/Particle)

0.510185

0.511130

0.436726

$-1006.680087$

$-1006.656328$

$-1006.655384$

$-1006.729787$

0.485973 (Hartree/Particle)

0.509950

0.510894

0.435679
-1006.680826

-1006.680826
-1006.656849

$-1006.655905$

$-1006.731120$

0.486006 (Hartree/Particle)

0.509986

0.510930

0.435820

$-1006.680918$

-1006.656938
-1006.655994 
61_1S2S7S8S10S11S12S_5_DP4+

61_1S2S7S8S10S11S12S_6_DP4+

61_1S2S7S8S10S11S12S_7_DP4+

61_1S2S7S8S10S11S12S_8_DP4+

$6 \mathrm{~m} \_1 R 2 R 7 S 8 S 10 R 11 S 12 S \_1 \_D P 4+$

$6 \mathrm{~m} \_1 R 2 R 7 S 8 S 10 R 11 S 12 S \_2$ DP44+

$6 \mathrm{~m} \_1 R 2 R 7 S 8 S 10 R 11 S 12 S \_3$ DPP4+

$6 \mathrm{~m} \_1 R 2 R 7 S 8 S 10 R 11 S 12 S \_4$ DP4+

6n_1R2R7S8S10R11S12R_1_DP4+

6n_1R2R7S8S10R11S12R_2_DP4+

$6 \mathrm{n} \_1 R 2 R 7 S 8 S 10 R 11 S 12 R \_3$ DPP4
Imaginary Freq $=0$

Zero-point corr

Thermatcosy =

Thermal correction to Gibbs Free Energy=

Sum of electronic and zero-point Energies=

Sum of electronic and thermal Free Energies=

Imaginary Freq $=0$

Zero-point correction=

Thermal correction to Energy $=$

Thermal correction to Gibbs Free Energy=

Sum of electronic and zero-point Energies=

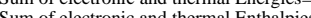

Imaginary Freq $=0$

Zero-pointc

Tero-point correction=

Thermal correction to Enthalpy

Thermal correction to Gibbs Free Energy=

Sum of electronic and zero-point Energie

Sum of electronic and thermal Energies

Sum of electronic and thermal Free Energies=

Imaginary Freq $=0$

Thermal correction to Energ

Thermal correction to Energy=

Thermal correction to Gibbs Free Energy=

Sum of electronic and zeropoint Energies

Sum of ectronic and thermal Enthasies

Sum of electronic and thermal Free Energies

Imaginary Freq $=0$

Zero-point correction

Thermal correction to Energy=

Thermal correction to Gibbs Free Energy=

Sum of electronic and zero-point Energies-

Sum of electronic and thermal Energies=

Sum of electronic and thermal Enthalpies=

Sum of electronic

Zero-point correction

Thermal correction to Energy=

Thermal correction to Gibbs Free Energy=

Sum of electronic and zero-point Energies

Sum of electronic and thermal Enthalpies

Imaginary Freq $=0$

Zero-point correction=

Thermal correction to Enthalpy

Thermal correction to Gibbs Free Energy=

Sum of electronic and zero-point Energies=

Sum of electronic and thermal Energies=

Sum of electronic and thermal Enthalpies=
Sum of electronic and thermal Free Energies=

Imaginary Freq $=0$

Zero-point correction=

Thermal correction to Energy=

Thermal correction to Gibbs Free Energy=

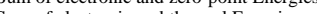

Sum electronic an the

Sum of electronic and thermel Free Energies

Imaginary Freq $=0$

Zero-point correction

Thermal correction to Energy=

Thermal correction to Gibbs Free Energy=

Sum of electronic and zero-point Energies=

Sum of electronic and thermal Energies

Sum of electronic and thermal Enthalpies=

Sum of electronic and thermal Free Energies=

Imaginary Freq $=0$

Zero-point correction-

Thermal correction to Energy=

Thermal correction to Gibbs Free Energy=

Sum of electronic and zero-point Energies

Sum of electronic and thermal Energies=

Imaginary Freq $=0$

Zero-point correction=

Thermal correction to Energy=

Thermal correction to Gibbs Free Energy=

Sum of electronic and zero-point Energies=

Sum of electronic and thermal Energies=
Sum of electronic and thermal Enthalpies=
0.486153 (Hartree/Particle)

0.510042

0.5359803

$-1006.680182$

$-1006.656292$

$-1006.655348$

$-1006.730432$

0.486175 (Hartree/Particle)

0.510051

0.510995

436065

$-1006.679941$

$-1006.655121$

$-1006.730052$

0.486419 (Hartree/Particle)

0.486419

0.511122

0.436656

$-1006.680176$

$-1006.656417$

006.655473

$-1006.729939$

0.486292 (Hartree/Particle)

0.51014

0.511084

$-1006.680480$

$-1006.656633$

$-1006.656633$

$-1006.730440$

0.486380 (Hartree/Particle)

0.510246

0.511190

$-1006.641048$

$-1006.61718$

$-1006.616237$

$-1006.691084$

0.486634 (Hartree/Particle)

0.510356

0.511300

437041

$-1006.640386$

$-1006.61666$

$-1006.689979$

0.486689 (Hartree/Particle)

0.510388

0.511332

0.437129

$-1006.639683$

$-1006.61598$

$-1006.615040$

$-1006.689244$

0.486434 (Hartree/Particle)

0.510273

0.511217

$-1006.639408$

$-1006.639408$

$-1006.615569$

$-1006.689194$

0.486338 (Hartree/Particle)

0.510235

0.436421

$-1006.642107$

$-1006.618210$

$-1006.617266$

$-1006.692024$

0.486470 (Hartree/Particle)

0.510306

0.511250

436642

$-1006.642454$

$-1006.618618$

$-1006.692283$

0.486378 (Hartree/Particle)

0.510147

0.511091

0.436691

$-1006.643354$

-1006.619585
-1006.618641 
6n_1R2R7S8S10R11S12R_4_DP4+

6o_ $1 R 2 R 7 S 8 S 10 R 11 R 12 R \_1$ DP4+

6o_1R2R7S8S10R11R12R_2_DP4+

6o $1 R 2 R 7 S 8 S 10 R 11 R 12 R 3$ _DP4+

6o_1R2R7S8S10R11R12R_4_DP4+

6o_ $1 R 2 R 7 S 8 S 10 R 11 R 12 R$ 5 DPP4+

6o_1R2R7S8S10R11R12R_6_DP4+

6o_1R2R7S8S10R11R12R_7_DP4+

6o_1R2R7S8S10R11R12R_8_DP4+

6p_1R2R7S8S10R11R12S_1_DP4+

6p_1R2R7S8S10R11R12S_2_DP4
Imaginary Freq $=0$

Zero-point

Thermal correction to Enthalp

Thermal correction to Gibbs Free Energy=

Sum of electronic and zero-point Energies=

Sum of electronic and thermal Free Energies=

Imaginary Freq $=0$

Zero-point correction=

Thermal correction to Energy=

Thermal correction to Enthalpy

Thermal correction to Gibbs Free Energy=

Sum of electronic and zero-point Energies

Sum of electronic and thermal Energies=

Sum of electronic and thermal Enthalpies=

Imaginary Freq =

Zero-point correction=

Thermal correction to Enthalpy

Thermal correction to Gibbs Free Energy

Sum of electronic and zero-pein

Sum of electronic and thermal Energies

Sum of electronic and thermal Free Energies=

Imaginary Freq $=0$

Zero-point correction=

Thermal correction to Energy=

Thermal correction to Gibbs Free Energy=

Sum of electronic and zero-point Energies-

Sum of electronic and thermal Energies=

Imaginary Freq $=0$

Zero-point correction

Thermal correction to Energy=

Thermal correction to Gibbs Free Energy

Sum of electronic and thermal Energies=

Sum of electronic and thermal Free Energies=

Imaginary Freq $=0$

Zero-point correction =

Thermal correction to Energy=

Thermal correction to Gibbs Free Energy=

Sum of electronic and zero-point Energies

Sum of electronic and thermal Enthalpies

Imaginary Freq $=0$

Zero-point co

to Energy=

Thermal correction to Enthalpy

Thermal correction to Gibbs Free Energy=

Sum of electronic and zero-point Energies

Sum of electronic and thermal Free Energies=

Imaginary Freq $=0$

Zero-point correction

Thermal correction to Energy=

Thermal correction to Gibbs Free Energy=

Sumergies

Sum of ectronic and thermal Enthalpies

Sum of electronic and thermel Free Energies

Imaginary Freq =

Zero-poin co

Tero-point correction $=$

Thermal correction to Enthalpy

Thermal correction to Gibbs Free Energy=

Sum of electronic and zero-point Energie

Sum of electronic and thermal Energies

Sum of electronic and thermal Free Energies=

Imaginary Freq $=0$

Thermal correction to Energy=

Thermal correction to Gibbs Free Energy=

Sum of electronic and zero-point Energies-

Sum of electronic and themal Energies=

Imaginary Freq =

Zero-point corre

to Energy=

Thermal correction to Enthay=

Thermal correction to Gibbs Free Energy=

Sum of electronic and zero-point Energies=

Sum of electronic and thermal Energies=
Sum of electronic and thermal Enthalpies=
0.486085 (Hartree/Particle)

0.510002

0.436201

$-1006.641796$

$-1006.61787$

$-1006.616934$

$-1006.691679$

0.486677 (Hartree/Particle)

0.51050

0.511450

436638

$-1006.679048$

$-1006.655219$

$-1006.654275$

0.486657 (Hartree/Particle)

0.510492

0.436690

$-1006.678503$

$-1006.678503$

$-1006.653723$

$-1006.728469$

0.486808 (Hartree/Particle)

0.510553

0.511497

437009

$-1006.678767$

$-1006.655022$

$-1006.728566$

0.486613 (Hartree/Particle)

0.510399

0.436625

$-1006.678134$

$-1006.654349$

$-1006.653405$

$-1006.728123$

0.486828 (Hartree/Particle)

0.510575

0.511519

436979

$-1006.678849$

$-1006.655101$

$-1006.728698$

0.486345 (Hartree/Particle)

0.510269

0.511213

0.436027

$-1006.678106$

$-1006.65418$

$-1006.653238$

$-1006.728424$

0.486746 (Hartree/Particle)

0.510463

0.511407

$-1006.678$

$-1006.678176$

$-1006.654459$

$-1006.728039$

0.486714 (Hartree/Particle)

0.510459

0.511403

0.436774

$-1006.678386$

$-1006.654641$

$-1006.653697$

$-1006.728326$

0.486531 (Hartree/Particle)

0.510376

0.511320

. 36540

$-1006.677431$

$-1006.653586$

$-1006.727422$

0.486470 (Hartree/Particle)

0.510327

0.511271

0.436469

$-1006.677408$

$-1006.65355$

$-1006.652607$ 
6p_1R2R7S8S10R11R12S_3_DP4+

6p_1R2R7S8S10R11R12S_4_DP4+

6p_1R2R7S8S10R11R12S_5_DP4+

6p_1R2R7S8S10R11R12S_6_DP4+

6p_1R2R7S8S10R11R12S_7_DP4+

6p_1R2R7S8S10R11R12S_8_DP4+

6p_1R2R7S8S10R11R12S_9_DP4+
Imaginary Freq $=0$

Zero-point correction

Thermal correction to Energy=

Thermal correction to Gibbs Free Energy=

Sum of electronic and zero-point Energies=

Sum of electronic and thermal Energies=

Sum of electronic and thermal Enthalpies=
Sum of electronic and thermal Free Energies=

Imaginary Freq =

Zero-point correction=

Thermal correction to Energy=

Thermal correction to Gibbs Free Energy=

Sum of electronic and zero-point Energies-

Sum of electronic and the

Sum of electronic and thermal Free Energies=

Imaginary Freq $=0$

Zero-point correction=

Thermal correction to Enthalpy

Thermal correction to Gibbs Free Energy=

Sum of electronic and zero-point Energies=

Sum of electronic and thermal Energies=

Sum of electronic and thermal Enthalpies=
Sum of electronic and thermal Free Energies=

maginary Freq $=0$

\section{Zero-point correctio}

Thermal correction to Energy=

Thermal correction to Enthalpy=

Thermal correction to Gibbs Free Energy=

Sum of electonic and tho-point Energies

Sum of electic

Sum of electronic and thermal Free Energies

Imaginary Freq $=0$

Zero-point correction

Thermal correction to Energy=

Thermal correction to Enthalpy

Thermal correction to Gibbs Free Energy=

Sum of electronic and zero-point Energies-

Sum of electronic and thermal Energies

m of electronic and thermal Free Energies=

Imaginary Freq $=0$

Zero-point correction=

Thermal correction to Energy=

Thermal correction to Gibbs Free Energy=

Sum of electronic and zero-point Energies=

Sum of electronic and thermal Energies

Sum of electronic and thermal Enthalpies-

Sum of electronic and thermal Free Energies=

Imaginary Freq $=0$

Zero-point correction=

Thermal correction to Energy=

Thermal correction to Enthalpy=

Thermal correction to Gibbs Free Energy=

Sum of electronic and zero-point Energies=

Sum of electronic and thermal Energies-

Sum of elect
0.487006 (Hartree/Particle)

0.510657

0.511601

$-1006.678069$

$-1006.654418$

$-1006.653473$

$-1006.727674$

0.486645 (Hartree/Particle)

0.510453

0.411397

$-1006.677038$

$-1006.677038$

$-1006.653230$

$-1006.726959$

0.486677 (Hartree/Particle)

0.486677
0.510456

0.511401

0.436829

$-1006.676915$

$-1006.653136$

$-1006.652192$

$-1006.726763$

0.486832 (Hartree/Particle)

0.510635

0.511579

$-1006.6779$

$-1006.677948$

$-1006.654145$

$-1006.727813$

0.486761 (Hartree/Particle)

0.510514

0.511459

0.436844

$-1006.677827$

$-1006.654073$

$-1006.653129$

$-1006.727744$

0.486768 (Hartree/Particle)

0.510603

0.511547

36788

-1006.677523
-1006.653688

$-1006.652744$

$-1006.727503$

0.486476 (Hartree/Particle)

0.510323
0.511267

0.436597

$-1006.677583$

$-1006.653736$

$-1006.652792$ 
5.1.5 Isotropic magnetic shielding constants of studied isomers of compounds 1-6

Table S6. Boltzmann averaged GIAO isotropic magnetic shielding constants $(\sigma)$ of isomers of compound $\mathbf{1}$ calculated at the

PCM/mPW1PW91/6-31G(d)//B3LYP/6-31G(d,p) level of theory

\begin{tabular}{|c|c|c|c|c|}
\hline \multicolumn{5}{|c|}{ Isotropic magnetic shielding constants } \\
\hline Nuclei & 1a & 1b & 1c & 1d \\
\hline C 1 & 47.32135 & 45.94483 & 46.40864 & 46.5174 \\
\hline $\mathrm{C} 2$ & 76.62917 & 77.27257 & 76.81049 & 76.95106 \\
\hline C 3 & 113.8858 & 113.0698 & 113.7681 & 113.2275 \\
\hline $\mathrm{C} 4$ & 125.7901 & 124.8425 & 125.6204 & 124.9841 \\
\hline C 5 & 157.1007 & 155.2446 & 156.5522 & 155.2683 \\
\hline C 6 & 171.7584 & 169.7525 & 171.025 & 168.9834 \\
\hline C 7 & 115.758 & 114.5345 & 111.9456 & 113.1505 \\
\hline C 8 & 120.3043 & 120.6543 & 120.598 & 120.7859 \\
\hline C 9 & 152.8843 & 153.029 & 151.5867 & 155.562 \\
\hline C 10 & 169.431 & 169.28 & 168.8832 & 169.9669 \\
\hline C 11 & 66.76789 & 66.98734 & 70.48356 & 68.16697 \\
\hline C 12 & 66.97403 & 66.04018 & 62.96168 & 63.64134 \\
\hline C 13 & 156.8681 & 156.0999 & 158.6662 & 156.2065 \\
\hline C 14 & 163.8215 & 163.2957 & 161.6129 & 161.5313 \\
\hline C 15 & 159.3316 & 158.8539 & 160.9366 & 159.2875 \\
\hline C 16 & 172.9928 & 172.5576 & 173.2232 & 172.7481 \\
\hline C 17 & 170.7715 & 171.0987 & 170.3174 & 170.5409 \\
\hline C 18 & 169.0315 & 173.0749 & 168.7702 & 172.9309 \\
\hline C 19 & 170.7462 & 170.8516 & 170.2293 & 168.5587 \\
\hline C 20 & 176.0644 & 176.0899 & 173.5374 & 175.5538 \\
\hline H 2 & 26.40938 & 26.57801 & 26.36039 & 26.54699 \\
\hline H 3 & 28.47253 & 28.46297 & 28.19792 & 28.33121 \\
\hline H $5 \mathrm{a}$ & 30.44806 & 30.41192 & 30.46167 & 30.45944 \\
\hline $\mathrm{H} 5 \mathrm{~b}$ & 30.67098 & 30.61295 & 30.63231 & 30.59419 \\
\hline H $6 \mathrm{a}$ & 30.07234 & 30.307 & 30.41774 & 30.68513 \\
\hline $\mathrm{H} 6 \mathrm{~b}$ & 30.88333 & 30.75745 & 30.71707 & 30.68879 \\
\hline H 7 & 28.83884 & 28.88673 & 28.69628 & 28.77081 \\
\hline H 9a & 30.21921 & 30.30644 & 30.28974 & 29.99849 \\
\hline $\mathrm{H} 9 \mathrm{~b}$ & 30.598 & 30.50613 & 30.53832 & 30.7824 \\
\hline H 10a & 30.08955 & 30.12137 & 29.86635 & 29.84698 \\
\hline $\mathrm{H} 10 \mathrm{~b}$ & 30.21579 & 30.15822 & 30.0443 & 30.1427 \\
\hline H 11 & 26.72662 & 26.73625 & 26.46621 & 26.60376 \\
\hline H 13a & 30.0495 & 30.06975 & 29.94202 & 30.03065 \\
\hline $\mathrm{H} 13 b$ & 30.27055 & 30.25826 & 30.14426 & 30.237 \\
\hline H 14a & 29.7519 & 29.68173 & 29.57754 & 29.53893 \\
\hline $\mathrm{H} 14 \mathrm{~b}$ & 30.18462 & 30.13209 & 30.05648 & 30.17311 \\
\hline H 15 & 29.77901 & 29.78504 & 29.65862 & 29.79229 \\
\hline H 16a & 31.06758 & 31.05621 & 31.05854 & 31.06914 \\
\hline H $16 b$ & 31.06821 & 31.04988 & 31.06722 & 31.07544 \\
\hline H 16c & 30.92352 & 31.00983 & 30.90536 & 30.91528 \\
\hline H 17a & 31.00186 & 31.0173 & 31.00053 & 31.46702 \\
\hline $\mathrm{H} 17 \mathrm{~b}$ & 31.4437 & 31.38314 & 31.49416 & 31.01775 \\
\hline $\mathrm{H} 17 \mathrm{c}$ & 30.90149 & 30.91534 & 30.88535 & 30.90583 \\
\hline H $18 \mathrm{a}$ & 31.17087 & 31.44576 & 31.22278 & 30.57901 \\
\hline $\mathrm{H} 18 \mathrm{~b}$ & 31.23298 & 31.03037 & 31.48737 & 31.48742 \\
\hline $\mathrm{H} 18 \mathrm{c}$ & 31.52272 & 30.57825 & 31.0748 & 31.00281 \\
\hline H 19a & 31.03816 & 31.24524 & 31.31064 & 31.13481 \\
\hline H 19b & 31.31624 & 31.19806 & 31.09311 & 31.14382 \\
\hline H 19c & 31.15064 & 31.10663 & 30.85689 & 31.09318 \\
\hline H 20a & 30.26592 & 30.45346 & 30.69968 & 30.66862 \\
\hline $\mathrm{H} 20 \mathrm{~b}$ & 30.85632 & 30.24551 & 30.93391 & 30.21333 \\
\hline $\mathrm{H} 20 \mathrm{c}$ & 30.59013 & 30.85771 & 30.33516 & 30.56227 \\
\hline
\end{tabular}


Table S7. Boltzmann averaged GIAO isotropic magnetic shielding constants $(\sigma)$ of isomers of compound 2 calculated at the PCM/mPW1PW91/6-31G(d)//B3LYP/6-31G(d,p) level of theory

\begin{tabular}{|c|c|c|}
\hline \multicolumn{3}{|c|}{ Isotropic magnetic shielding constants } \\
\hline Nuclei & 2a & $2 \mathbf{b}$ \\
\hline $\mathrm{C} 1$ & 145.7646 & 151.4351 \\
\hline $\mathrm{C} 2$ & 159.3912 & 164.732 \\
\hline C 3 & 71.68866 & 73.36417 \\
\hline $\mathrm{C} 4$ & 60.21921 & 62.68772 \\
\hline C 5 & 158.4597 & 158.2897 \\
\hline $\mathrm{C} 6$ & 162.951 & 165.9954 \\
\hline $\mathrm{C} 7$ & 123.1143 & 121.8524 \\
\hline $\mathrm{C} 8$ & 118.9491 & 119.3583 \\
\hline $\mathrm{C} 9$ & 155.0582 & 158.0003 \\
\hline C 10 & 168.8639 & 168.6332 \\
\hline C 11 & 72.28698 & 71.99823 \\
\hline C 12 & 59.86068 & 61.33913 \\
\hline C 13 & 159.011 & 156.7851 \\
\hline C 14 & 162.3014 & 162.5351 \\
\hline C 15 & 50.37401 & 48.80659 \\
\hline C 16 & 86.29371 & 86.37253 \\
\hline C 17 & 172.2357 & 170.798 \\
\hline C 18 & 177.0441 & 177.5783 \\
\hline C 19 & 170.3482 & 169.938 \\
\hline C 20 & 174.2055 & 177.7567 \\
\hline H 1 & 30.07474 & 30.04534 \\
\hline $\mathrm{H} 2 \mathrm{a}$ & 30.05464 & 29.59178 \\
\hline $\mathrm{H} 2 \mathrm{~b}$ & 30.37736 & 30.17438 \\
\hline H 3 & 26.45833 & 26.69065 \\
\hline H 5a & 29.87877 & 30.02229 \\
\hline $\mathrm{H} 5 \mathrm{~b}$ & 29.9789 & 30.12952 \\
\hline H $6 \mathrm{a}$ & 30.33343 & 30.28178 \\
\hline $\mathrm{H} 6 \mathrm{~b}$ & 30.54602 & 30.72595 \\
\hline H 7 & 28.31057 & 28.25105 \\
\hline H 9a & 30.28827 & 30.33529 \\
\hline $\mathrm{H} \mathrm{9b}$ & 30.61802 & 30.67079 \\
\hline H 10a & 29.78591 & 29.88474 \\
\hline H 10b & 30.02465 & 30.21008 \\
\hline H 11 & 26.64035 & 27.02964 \\
\hline H 13a & 30.10773 & 30.27356 \\
\hline $\mathrm{H} 13 \mathrm{~b}$ & 30.43741 & 30.27909 \\
\hline H 14a & 30.4357 & 30.51656 \\
\hline $\mathrm{H} 14 \mathrm{~b}$ & 30.50814 & 30.65033 \\
\hline H 16a & 27.24386 & 27.24294 \\
\hline H 16b & 27.2527 & 27.32313 \\
\hline H 17a & 30.55563 & 30.52078 \\
\hline H 17b & 30.2857 & 30.45956 \\
\hline $\mathrm{H} 17 \mathrm{c}$ & 30.50854 & 30.28915 \\
\hline H 18a & 30.74815 & 30.43092 \\
\hline $\mathrm{H} 18 \mathrm{~b}$ & 30.57616 & 30.85674 \\
\hline H $18 \mathrm{c}$ & 30.24266 & 30.20239 \\
\hline H 19a & 31.18226 & 31.28368 \\
\hline H 19b & 30.97265 & 31.06976 \\
\hline H 19c & 30.97916 & 30.53327 \\
\hline H 20a & 30.76252 & 30.5578 \\
\hline $\mathrm{H} 20 \mathrm{~b}$ & 30.24908 & 30.30254 \\
\hline $\mathrm{H} 20 \mathrm{c}$ & 30.72278 & 30.93551 \\
\hline
\end{tabular}


Table S8. Boltzmann averaged GIAO isotropic magnetic shielding constants $(\sigma)$ of isomers of compound $\mathbf{3}$ calculated at the PCM/mPW1PW91/6-31G(d)//B3LYP/6-31G(d,p) level of theory

\begin{tabular}{|c|c|c|}
\hline \multicolumn{3}{|c|}{ Isotropic magnetic shielding constants } \\
\hline Nuclei & 3a & $3 \mathbf{b}$ \\
\hline C 1 & 53.04976381 & 53.32367788 \\
\hline $\mathrm{C} 2$ & 77.03930204 & 76.73673631 \\
\hline C 3 & 73.80030094 & 74.74398761 \\
\hline $\mathrm{C} 4$ & 62.79800396 & 60.68407619 \\
\hline C 5 & 156.9160735 & 157.3225752 \\
\hline $\mathrm{C} 6$ & 166.5553303 & 165.5768786 \\
\hline C 7 & 133.8178207 & 129.74666 \\
\hline $\mathrm{C} 8$ & 134.323584 & 133.51496 \\
\hline C 9 & 156.7287792 & 154.8526498 \\
\hline C 10 & 169.6428819 & 168.6032232 \\
\hline C 11 & 69.63338732 & 72.88816249 \\
\hline C 12 & 61.90308107 & 62.55032661 \\
\hline C 13 & 156.798536 & 157.7931678 \\
\hline C 14 & 160.7475605 & 161.760889 \\
\hline C 15 & 153.2635403 & 154.1424482 \\
\hline C 16 & 125.5729014 & 125.34578 \\
\hline C 17 & 176.3961795 & 176.8332288 \\
\hline C 18 & 177.9190353 & 177.4084477 \\
\hline C 19 & 175.7382362 & 176.9954119 \\
\hline C 20 & 175.3989857 & 175.7381024 \\
\hline $\mathrm{H} 2$ & 25.98960453 & 25.98126174 \\
\hline H 3 & 25.98469083 & 25.87058454 \\
\hline H 5a & 29.97897473 & 29.88244934 \\
\hline $\mathrm{H} 5 \mathrm{~b}$ & 29.98710443 & 29.95706195 \\
\hline H $6 \mathrm{a}$ & 30.19632277 & 30.40462896 \\
\hline $\mathrm{H} 6 \mathrm{~b}$ & 30.8196604 & 30.53786383 \\
\hline H 7 & 29.38203439 & 29.32397795 \\
\hline H 9a & 30.27614655 & 30.17950906 \\
\hline $\mathrm{H} 9 \mathrm{~b}$ & 30.72285962 & 31.09388311 \\
\hline H 10a & 30.10513969 & 30.01742287 \\
\hline H 10b & 30.1112293 & 30.06629767 \\
\hline H 11 & 26.7430498 & 26.59150028 \\
\hline $\mathrm{H} 13 \mathrm{a}$ & 30.03046599 & 29.99525788 \\
\hline $\mathrm{H} 13 \mathrm{~b}$ & 30.15243328 & 30.00553382 \\
\hline $\mathrm{H} 14 \mathrm{a}$ & 29.61260674 & 29.47290667 \\
\hline $\mathrm{H} 14 \mathrm{~b}$ & 29.93718251 & 30.00941069 \\
\hline H 15 & 29.66280067 & 29.63621985 \\
\hline H 16a & 28.49798513 & 28.56273519 \\
\hline $\mathrm{H} 16 \mathrm{~b}$ & 28.53850407 & 28.5776531 \\
\hline H 17a & 30.98888534 & 30.99345036 \\
\hline $\mathrm{H} 17 \mathrm{~b}$ & 31.15448613 & 31.0957046 \\
\hline $\mathrm{H} 17 \mathrm{c}$ & 31.12529357 & 31.24956538 \\
\hline H 18a & 30.51809368 & 30.54449592 \\
\hline $\mathrm{H} 18 \mathrm{~b}$ & 30.29633091 & 30.21505823 \\
\hline $\mathrm{H} 18 \mathrm{c}$ & 30.61009664 & 30.79611906 \\
\hline H 19a & 30.94947328 & 30.96814917 \\
\hline H 19b & 30.83379558 & 30.7499225 \\
\hline H 19c & 31.17467906 & 31.38009432 \\
\hline H 20a & 30.85765906 & 30.81385791 \\
\hline $\mathrm{H} 20 \mathrm{~b}$ & 30.38408322 & 30.53181258 \\
\hline $\mathrm{H} 20 \mathrm{c}$ & 30.59658749 & 30.6822532 \\
\hline
\end{tabular}


Table S9. Boltzmann averaged GIAO isotropic magnetic shielding constants $(\sigma)$ of isomers of compound $\mathbf{4}$ calculated at the PCM/mPW1PW91/6-31G(d)//B3LYP/6-31G(d,p) level of theory

\begin{tabular}{|c|c|c|}
\hline \multicolumn{3}{|c|}{ Isotropic magnetic shielding constants } \\
\hline Nuclei & $4 \mathbf{a}$ & $4 \mathbf{b}$ \\
\hline C 1 & 49.64764 & 49.5116 \\
\hline $\mathrm{C} 2$ & 79.08571 & 79.45054 \\
\hline C 3 & 74.71043 & 74.688 \\
\hline $\mathrm{C} 4$ & 61.37001 & 61.87649 \\
\hline C 5 & 158.2818 & 158.0882 \\
\hline C 6 & 166.4454 & 166.851 \\
\hline $\mathrm{C} 7$ & 131.7459 & 133.2984 \\
\hline $\mathrm{C} 8$ & 132.8002 & 133.6267 \\
\hline $\mathrm{C} 9$ & 151.116 & 151.3123 \\
\hline C 10 & 73.2857 & 73.41952 \\
\hline C 11 & 58.49307 & 58.48996 \\
\hline $\mathrm{C} 12$ & 121.7064 & 121.3875 \\
\hline C 13 & 152.2016 & 153.341 \\
\hline C 14 & 167.9059 & 168.1494 \\
\hline C 15 & 159.2627 & 159.7394 \\
\hline C 16 & 171.9965 & 171.9164 \\
\hline C 17 & 172.7729 & 172.8938 \\
\hline C 18 & 176.5172 & 176.8268 \\
\hline C 19 & 176.6317 & 176.2293 \\
\hline C 20 & 166.0942 & 164.8107 \\
\hline $\mathrm{H} 2$ & 26.13855 & 26.12392 \\
\hline H 3 & 26.10893 & 26.0667 \\
\hline $\mathrm{H} 5 \mathrm{a}$ & 29.96765 & 29.98091 \\
\hline $\mathrm{H} 5 \mathrm{~b}$ & 30.03111 & 29.99072 \\
\hline H $6 \mathrm{a}$ & 30.3537 & 30.35446 \\
\hline $\mathrm{H} 6 \mathrm{~b}$ & 30.73162 & 30.70415 \\
\hline $\mathrm{H} 7$ & 29.35722 & 29.28766 \\
\hline H 9a & 29.51334 & 29.57445 \\
\hline $\mathrm{H} \mathrm{9b}$ & 30.37944 & 30.29789 \\
\hline H 10 & 26.15188 & 26.36104 \\
\hline H 11 & 26.19914 & 26.22879 \\
\hline $\mathrm{H} 13 \mathrm{a}$ & 30.4214 & 30.27199 \\
\hline $\mathrm{H} 13 \mathrm{~b}$ & 30.49367 & 30.57385 \\
\hline $\mathrm{H} 14 \mathrm{a}$ & 29.92057 & 29.81401 \\
\hline $\mathrm{H} 14 \mathrm{~b}$ & 30.04829 & 29.94975 \\
\hline H 15 & 29.67277 & 29.69412 \\
\hline H 16a & 31.05214 & 31.04255 \\
\hline H 16b & 30.96774 & 30.8849 \\
\hline $\mathrm{H} 16 \mathrm{c}$ & 31.30095 & 31.36523 \\
\hline $\mathrm{H} \mathrm{17a}$ & 31.07572 & 31.07784 \\
\hline $\mathrm{H} 17 \mathrm{~b}$ & 31.13483 & 31.07802 \\
\hline $\mathrm{H} 17 \mathrm{c}$ & 31.03841 & 31.08525 \\
\hline $\mathrm{H} 18 \mathrm{a}$ & 30.76334 & 30.70462 \\
\hline $\mathrm{H} 18 \mathrm{~b}$ & 30.68084 & 30.16947 \\
\hline $\mathrm{H} 18 \mathrm{c}$ & 30.16899 & 30.69702 \\
\hline H 19a & 30.83392 & 30.88975 \\
\hline H 19b & 30.76548 & 30.8283 \\
\hline $\mathrm{H} 19 \mathrm{c}$ & 31.36633 & 31.32923 \\
\hline H 20a & 30.98592 & 30.93146 \\
\hline $\mathrm{H} 20 \mathrm{~b}$ & 31.08835 & 30.92547 \\
\hline $\mathrm{H} 20 \mathrm{c}$ & 30.87815 & 31.053 \\
\hline
\end{tabular}


Table S10. Boltzmann averaged GIAO isotropic magnetic shielding constants $(\sigma)$ of isomers of compound $\mathbf{5}$ calculated at the PCM/mPW1PW91/6-31G(d)//B3LYP/6-31G(d,p) level of theory

\begin{tabular}{|c|c|c|c|c|c|c|c|c|c|c|c|c|c|c|c|c|}
\hline Nuclei & $5 a$ & $5 b$ & $5 c$ & $5 d$ & $5 e$ & $5 f$ & $5 \mathrm{~g}$ & $5 \mathrm{~h}$ & $5 i$ & $5 \mathbf{j}$ & $5 \mathrm{k}$ & 51 & $5 \mathrm{~m}$ & $5 n$ & 50 & $5 p$ \\
\hline C 1 & 138.4332 & 139.067 & 138.1938 & 139.5385 & 141.2977 & 139.6042 & 138.8334 & 138.3766 & 140.8233 & 141.4433 & 141.0465 & 139.4983 & 140.6858 & 140.1326 & 139.1683 & 140.383 \\
\hline C 2 & 151.2337 & 151.5526 & 150.0203 & 151.3799 & 152.6731 & 152.9349 & 147.1148 & 146.4309 & 151.2844 & 151.2506 & 151.4635 & 152.2291 & 153.3889 & 153.4564 & 154.4654 & 153.2746 \\
\hline C 3 & 68.6764 & 68.9402 & 67.93849 & 67.96716 & 69.15814 & 68.82891 & 69.88852 & 69.72511 & 72.0124 & 72.34361 & 70.65411 & 70.4957 & 71.4609 & 71.04911 & 69.63033 & 69.76792 \\
\hline $\mathrm{C} 4$ & 64.3613 & 64.25211 & 64.29678 & 64.50577 & 64.73746 & 64.72352 & 63.82684 & 63.88909 & 60.62036 & 60.36471 & 60.49084 & 60.47278 & 60.87829 & 61.1709 & 61.61331 & 61.8403 \\
\hline C 5 & 163.378 & 163.3444 & 164.4011 & 164.3218 & 163.8746 & 163.9384 & 163.9358 & 163.9565 & 163.9586 & 163.936 & 163.4071 & 163.3338 & 164.0054 & 164.0365 & 163.6933 & 163.682 \\
\hline C 6 & 168.9836 & 169.0019 & 168.815 & 168.783 & 170.1079 & 170.1804 & 169.4143 & 169.3642 & 167.952 & 167.956 & 168.8357 & 168.7818 & 172.1395 & 172.154 & 172.0879 & 171.8742 \\
\hline C 7 & 130.8805 & 130.8328 & 130.2804 & 130.258 & 133.6438 & 133.6877 & 134.4695 & 134.4407 & 131.5852 & 131.5898 & 131.5622 & 131.347 & 130.3803 & 130.3414 & 130.6165 & 130.9452 \\
\hline C 8 & 134.1815 & 134.1667 & 135.5564 & 135.3237 & 134.6569 & 134.7178 & 132.6471 & 132.5268 & 133.1331 & 133.0662 & 133.6895 & 134.0321 & 136.4813 & 136.3971 & 136.6582 & 136.5164 \\
\hline C 9 & 156.9152 & 156.836 & 152.1122 & 151.8881 & 154.4194 & 154.3874 & 160.4875 & 160.5199 & 155.3018 & 155.4387 & 161.9653 & 161.7239 & 152.6492 & 152.5797 & 155.6609 & 155.8637 \\
\hline C 10 & 146.3851 & 146.1563 & 155.5022 & 158.0007 & 157.8428 & 154.9264 & 144.4979 & 144.7014 & 148.9277 & 148.6779 & 155.882 & 157.101 & 147.8303 & 148.0745 & 155.9992 & 154.8299 \\
\hline C 11 & 136.5704 & 135.5188 & 137.2202 & 139.0749 & 138.0025 & 135.4913 & 135.2255 & 136.8244 & 130.4332 & 129.0275 & 143.2589 & 139.9341 & 131.3948 & 132.8864 & 138.5303 & 142.1361 \\
\hline C 12 & 118.1919 & 118.736 & 113.6457 & 115.7115 & 116.1794 & 113.7943 & 119.1 & 118.6269 & 118.7241 & 119.4951 & 114.3679 & 113.8966 & 119.7606 & 118.8491 & 113.9857 & 114.3016 \\
\hline C 13 & 148.5163 & 149.3555 & 154.0397 & 153.5968 & 154.5961 & 154.3789 & 148.5588 & 148.0511 & 148.5702 & 149.5446 & 153.609 & 153.3946 & 149.7067 & 148.6964 & 153.7112 & 153.6219 \\
\hline C 14 & 158.3793 & 158.91 & 167.5987 & 166.4792 & 166.3384 & 166.6615 & 161.4241 & 161.1489 & 159.1406 & 159.8306 & 165.8118 & 165.9153 & 159.689 & 158.8932 & 164.9115 & 165.1425 \\
\hline C 15 & 159.6461 & 161.1953 & 153.7897 & 154.5415 & 154.7926 & 154.5712 & 159.2025 & 157.7745 & 160.3487 & 161.6293 & 155.4943 & 155.2271 & 161.58 & 160.2466 & 156.1271 & 156.2361 \\
\hline C 16 & 171.5825 & 172.1836 & 176.2021 & 176.1613 & 176.9821 & 176.6588 & 173.3413 & 174.1399 & 172.7293 & 173.6232 & 176.5201 & 176.2881 & 174.4148 & 174.6093 & 176.2635 & 176.6979 \\
\hline C 17 & 175.1931 & 174.9704 & 176.3396 & 176.3599 & 176.373 & 176.2031 & 173.1256 & 173.2504 & 175.0172 & 174.8067 & 176.7635 & 176.2989 & 173.2477 & 172.3878 & 176.1962 & 176.5023 \\
\hline C 18 & 167.2802 & 167.298 & 167.5444 & 167.5275 & 168.655 & 168.7182 & 168.6551 & 168.6521 & 167.6522 & 167.6589 & 167.4345 & 167.4599 & 169.4166 & 169.4222 & 169.2557 & 169.1787 \\
\hline C 19 & 174.162 & 174.219 & 175.3232 & 175.2661 & 170.7754 & 170.8529 & 170.9287 & 170.9774 & 170.1202 & 170.185 & 170.2664 & 170.3126 & 175.7895 & 175.8384 & 175.732 & 175.826 \\
\hline C 20 & 165.662 & 166.7866 & 171.7098 & 165.774 & 165.6396 & 171.8475 & 167.2916 & 165.3517 & 165.8352 & 167.3014 & 163.3709 & 169.117 & 167.3454 & 165.7824 & 168.9648 & 162.9656 \\
\hline H 2 & 29.20434 & 29.29764 & 29.44996 & 29.45282 & 29.43122 & 29.44656 & 29.35381 & 29.25925 & 29.11534 & 29.19057 & 29.24896 & 29.27311 & 29.23507 & 29.16303 & 29.21107 & 29.186 \\
\hline H 3 & 26.30072 & 26.23863 & 26.40079 & 26.3461 & 26.27203 & 26.36673 & 26.20896 & 26.27881 & 26.19982 & 26.12975 & 26.06646 & 26.20725 & 26.32342 & 26.38839 & 26.26771 & 26.12033 \\
\hline H 5a & 29.6349 & 29.67157 & 29.65806 & 29.66538 & 29.67715 & 29.6786 & 29.62955 & 29.58996 & 29.61733 & 29.64373 & 29.74095 & 29.74347 & 29.69822 & 29.67419 & 29.74518 & 29.7477 \\
\hline H 5b & 30.17169 & 30.17198 & 30.20694 & 30.21267 & 30.27302 & 30.27972 & 30.26358 & 30.26118 & 30.17121 & 30.17015 & 30.18088 & 30.17358 & 30.20573 & 30.20842 & 30.21319 & 30.21637 \\
\hline H 6a & 30.35115 & 30.35873 & 30.34689 & 30.34795 & 30.23281 & 30.25113 & 30.19698 & 30.1967 & 30.31956 & 30.32599 & 30.38512 & 30.37363 & 30.152 & 30.1628 & 30.16779 & 30.15645 \\
\hline $\mathrm{H} 6 \mathrm{~b}$ & 30.93389 & 30.92935 & 31.01576 & 30.99677 & 31.05171 & 31.06114 & 30.98965 & 30.97784 & 30.77703 & 30.77394 & 30.79197 & 30.78601 & 31.06043 & 31.06093 & 31.04167 & 31.04515 \\
\hline H 7 & 29.19267 & 29.24972 & 29.20489 & 29.22082 & 29.33911 & 29.41661 & 29.26687 & 29.28545 & 29.23281 & 29.26525 & 29.31878 & 29.31145 & 29.51537 & 29.5338 & 29.53786 & 29.46193 \\
\hline $\mathrm{H} 9 \mathrm{a}$ & 30.10946 & 30.10818 & 30.08828 & 30.07409 & 30.29904 & 30.30897 & 30.13561 & 30.00948 & 30.05587 & 30.0905 & 29.59274 & 30.42961 & 30.07984 & 30.0583 & 30.3736 & 30.14806 \\
\hline H 9b & 30.52433 & 30.62027 & 31.07771 & 31.1106 & 30.56356 & 30.52492 & 30.37833 & 30.36711 & 30.69704 & 30.61764 & 30.43415 & 30.46181 & 31.14844 & 31.19915 & 30.91173 & 30.35607 \\
\hline H 10 & 29.62872 & 29.55953 & 30.40456 & 29.68566 & 29.91104 & 30.58307 & 29.77821 & 29.83909 & 29.33493 & 29.4308 & 29.52456 & 29.55293 & 29.27574 & 29.16936 & 29.18913 & 29.21377 \\
\hline H 11 & 29.62873 & 28.79707 & 30.28722 & 30.27921 & 30.40897 & 30.38349 & 29.03151 & 29.84427 & 30.27216 & 29.54148 & 30.00463 & 29.95709 & 29.65818 & 30.36155 & 29.91107 & 29.95841 \\
\hline H 13a & 30.1266 & 30.12597 & 30.12117 & 30.0621 & 30.11173 & 30.26821 & 30.07757 & 30.07852 & 30.07685 & 30.06361 & 29.8138 & 30.17024 & 30.07278 & 30.06775 & 30.2275 & 30.46764 \\
\hline H 13b & 30.26229 & 30.28383 & 30.48247 & 30.46449 & 30.52938 & 30.51852 & 30.25203 & 30.23547 & 30.2203 & 30.25153 & 30.42288 & 30.39347 & 30.23545 & 30.20949 & 30.43271 & 29.86936 \\
\hline H 14a & 30.53925 & 30.27423 & 30.35139 & 30.2693 & 30.40384 & 30.31164 & 30.33027 & 30.51346 & 30.52355 & 30.28269 & 30.41193 & 30.27382 & 30.29154 & 30.53374 & 30.24467 & 30.34794 \\
\hline H 14b & 30.54732 & 30.695 & 30.45656 & 30.66769 & 30.67049 & 30.46977 & 30.66007 & 30.60608 & 30.62291 & 30.76169 & 30.64412 & 30.45591 & 30.73328 & 30.58796 & 30.40336 & 30.6281 \\
\hline H 15 & 30.12516 & 30.44704 & 30.29391 & 30.39736 & 30.32356 & 30.24138 & 30.22427 & 30.05595 & 30.01386 & 30.37414 & 30.3306 & 30.2625 & 30.32847 & 29.97171 & 30.23483 & 30.30123 \\
\hline H 16a & 31.4201 & 31.16498 & 31.3959 & 31.42081 & 31.39426 & 31.39709 & 31.31228 & 30.16901 & 31.28503 & 31.25601 & 31.42926 & 31.3851 & 31.40295 & 31.39289 & 31.38438 & 31.38578 \\
\hline H $16 \mathrm{~b}$ & 30.67596 & 30.98623 & 31.16449 & 31.17871 & 31.16503 & 30.9913 & 31.00431 & 31.44198 & 30.54916 & 30.87672 & 31.23413 & 31.19809 & 31.2268 & 31.25385 & 31.06395 & 31.18856 \\
\hline H $16 \mathrm{c}$ & 31.19315 & 31.35336 & 31.56294 & 31.49358 & 31.47494 & 31.43517 & 31.32258 & 31.44247 & 31.3564 & 31.27245 & 31.51765 & 31.51656 & 31.3275 & 31.31545 & 31.43407 & 31.46872 \\
\hline H $17 \mathrm{a}$ & 31.05031 & 31.36263 & 31.43747 & 31.41624 & 31.39164 & 31.34936 & 30.99759 & 30.88173 & 31.32517 & 31.41138 & 31.41626 & 31.43339 & 31.21892 & 31.31128 & 31.32365 & 31.36977 \\
\hline H 17b & 31.3552 & 31.34728 & 31.45476 & 31.49384 & 31.49092 & 31.51455 & 31.29642 & 31.29264 & 31.40461 & 31.33852 & 31.49833 & 31.45586 & 31.22888 & 31.2423 & 31.44354 & 31.4655 \\
\hline $\mathrm{H} 17 \mathrm{c}$ & 31.38362 & 31.21288 & 30.97397 & 31.21435 & 31.15989 & 31.1256 & 31.29582 & 31.3243 & 31.28563 & 31.25903 & 31.20092 & 31.04658 & 30.78176 & 30.45932 & 31.14675 & 31.18364 \\
\hline H 18a & 30.66066 & 30.63086 & 30.68646 & 30.666 & 30.61964 & 30.64948 & 30.56942 & 30.59876 & 30.59586 & 30.55944 & 30.58821 & 30.62342 & 30.55074 & 30.58963 & 30.60712 & 30.56997 \\
\hline H 18b & 30.43778 & 30.43549 & 30.46782 & 30.47316 & 30.15523 & 30.1842 & 30.1831 & 30.19433 & 30.41334 & 30.4102 & 30.43144 & 30.43197 & 30.12592 & 30.14479 & 30.13013 & 30.08586 \\
\hline $\mathrm{H} 18 \mathrm{c}$ & 30.2742 & 30.26431 & 30.28363 & 30.26597 & 30.47278 & 30.47398 & 30.44352 & 30.44387 & 30.17865 & 30.16513 & 30.16153 & 30.19271 & 30.47513 & 30.47976 & 30.5152 & 30.50794 \\
\hline H 19a & 31.66422 & 31.66685 & 31.70795 & 31.70428 & 31.3765 & 31.37549 & 31.41353 & 31.40589 & 30.97736 & 30.94936 & 31.71725 & 31.70304 & 31.46049 & 31.46247 & 31.46478 & 31.48851 \\
\hline H 19b & 30.90893 & 30.90387 & 30.98413 & 30.93433 & 30.48725 & 30.48564 & 30.48102 & 30.46068 & 30.72302 & 30.71242 & 30.65906 & 30.68016 & 30.79063 & 30.78785 & 30.85202 & 30.87734 \\
\hline H 19c & 30.70248 & 30.68999 & 30.86249 & 30.77235 & 30.65284 & 30.64304 & 30.68269 & 30.63535 & 31.70474 & 31.70615 & 30.94624 & 30.99378 & 30.69421 & 30.66468 & 30.60146 & 30.61939 \\
\hline H 20a & 30.73893 & 30.84685 & 31.12231 & 31.10036 & 31.14338 & 31.16927 & 30.88346 & 30.7444 & 30.84154 & 30.81482 & 31.15576 & 30.98242 & 30.8505 & 30.84836 & 30.96966 & 31.10658 \\
\hline $\mathrm{H} 20 \mathrm{~b}$ & 30.69177 & 30.82717 & 30.9798 & 30.82518 & 31.0802 & 31.06163 & 30.81431 & 31.06838 & 30.75081 & 30.92539 & 30.76025 & 30.96921 & 30.81117 & 31.0715 & 30.95597 & 31.19454 \\
\hline H 20c & 31.03544 & 30.85399 & 31.00957 & 31.02294 & 30.79026 & 31.02353 & 30.66873 & 30.71183 & 31.0404 & 30.88753 & 31.2029 & 30.86685 & 30.90344 & 30.75646 & 30.97248 & 30.79296 \\
\hline
\end{tabular}


Table S11. Boltzmann averaged GIAO isotropic magnetic shielding constants $(\sigma)$ of isomers of compound 6 calculated at the PCM/mPW1PW91/6-31G(d)//B3LYP/6-31G(d,p) level of theory

\begin{tabular}{|c|c|c|c|c|c|c|c|c|c|c|c|c|c|c|c|c|}
\hline Nuclei & $6 a$ & $6 \mathbf{b}$ & $6 c$ & 6d & $6 e$ & 6f & $6 \mathrm{~g}$ & $6 \mathrm{~h}$ & $6 \mathrm{i}$ & $6 \mathrm{j}$ & $6 \mathrm{k}$ & 61 & $6 \mathrm{~m}$ & 6n & 60 & $6 p$ \\
\hline C 1 & 138.6301 & $\begin{array}{ll}138.888 \\
\end{array}$ & $\begin{array}{l}138.6663 \\
\end{array}$ & 139.9659 & 141.3391 & 139.9585 & 138.7535 & 138.7096 & 141.0522 & 141.0302 & 141.0879 & 139.7946 & 140.2505 & 140.1501 & 139.447 & 140.539 \\
\hline C 2 & 151.5706 & 151.4408 & 149.9602 & 150.7714 & 152.6748 & 152.5436 & 148.0021 & 147.1085 & 151.3319 & 150.9337 & 151.9937 & 151.8275 & 153.2543 & 153.4421 & 153.6481 & 153.5608 \\
\hline C 3 & 69.1378 & 69.12032 & 68.12664 & 68.5502 & 69.55072 & 69.07543 & 70.15183 & 70.1525 & 72.51229 & 72.65616 & 71.12911 & 70.81435 & 71.85351 & 71.65013 & 69.99818 & 70.33459 \\
\hline C 4 & 64.09431 & 64.11763 & 63.93645 & 63.90464 & 64.30776 & 64.42132 & 63.64887 & 63.50749 & 60.1713 & 60.02544 & 60.09677 & 60.20295 & 60.55923 & 60.7576 & 61.23454 & 61.29661 \\
\hline C 5 & 163.5183 & 163.3918 & 164.3219 & 164.3253 & 163.7483 & 163.8293 & 164.0718 & 163.983 & 163.9711 & 163.9827 & 163.4746 & 163.3898 & 163.9735 & 164.1002 & 163.7503 & 163.6713 \\
\hline C 6 & 169.2115 & 169.3558 & 168.7889 & 168.8418 & 170.1211 & 170.145 & 169.5268 & 169.3326 & 167.8867 & 167.8086 & 168.7271 & 168.6884 & 172.0441 & 172.1051 & 172.1789 & 172.0569 \\
\hline C 7 & 130.8005 & 130.701 & 130.2857 & 130.0938 & 133.6933 & 133.7979 & 134.525 & 134.4508 & 131.6996 & 131.7022 & 131.6049 & 131.3811 & 130.1536 & 130.328 & 130.5956 & 130.9128 \\
\hline C 8 & 134.1577 & 134.0418 & 135.6652 & 135.387 & 134.7828 & 134.8124 & 132.904 & 132.745 & 133.2467 & 133.3125 & 133.8136 & 134.1079 & 136.4515 & 136.3939 & 136.7691 & 136.7707 \\
\hline C 9 & 156.8851 & 157.1532 & 152.2447 & 152.2134 & 154.4605 & 154.4917 & 160.9733 & 160.1899 & 155.4779 & 155.1706 & 162.2104 & 161.4657 & 152.4266 & 152.6981 & 155.466 & 155.7441 \\
\hline C 10 & 145.8511 & 144.8348 & 155.7458 & 158.7495 & 158.5294 & 155.2273 & 143.3133 & 144.4045 & 148.1742 & 148.5997 & 156.519 & 157.2558 & 147.7055 & 147.1336 & 156.1214 & 155.5047 \\
\hline C 11 & 136.4692 & 135.9731 & 142.0966 & 141.325 & 139.3768 & 140.5037 & 136.5616 & 136.586 & 130.5835 & 129.433 & 144.2424 & 145.2305 & 131.5982 & 132.9868 & 144.1005 & 142.2017 \\
\hline C 12 & 105.6894 & 105.906 & 100.0112 & 103.5396 & 103.9961 & 100.1986 & 106.3296 & 106.0098 & 106.2025 & 106.6235 & 102.4418 & 100.4705 & 106.7155 & 106.1817 & 100.375 & 102.2161 \\
\hline C 13 & 153.3264 & 152.8532 & 157.8434 & 157.3278 & 157.6966 & 158.125 & 152.2842 & 152.6011 & 153.4291 & 152.9835 & 156.6491 & 156.911 & 153.0064 & 153.3939 & 156.8635 & 156.5935 \\
\hline C 14 & 158.4088 & 158.9312 & 167.5309 & 166.9221 & 166.6237 & 166.8642 & 160.9228 & 161.0552 & 159.3215 & 160.0373 & 165.9165 & 166.2053 & 159.7016 & 158.9546 & 165.2852 & 165.2249 \\
\hline C 15 & 159.8745 & 161.2972 & 153.8652 & 154.1937 & 154.6167 & 154.499 & 159.6769 & 157.862 & 160.5948 & 161.5788 & 155.385 & 155.1627 & 161.623 & 160.4074 & 156.1213 & 156.1779 \\
\hline C 16 & 172.2509 & 172.0861 & 176.2569 & 176.2564 & 176.947 & 176.7686 & 173.6276 & 174.2944 & 173.6524 & 173.7381 & 176.6103 & 176.361 & 174.379 & 174.5097 & 176.3129 & 176.7191 \\
\hline C 17 & 175.1244 & 175.1155 & 176.5456 & 176.6638 & 176.323 & 176.2479 & 172.97 & 173.4187 & 174.979 & 174.8165 & 176.7109 & 176.4424 & 173.3714 & 173.2963 & 176.3283 & 176.5269 \\
\hline C 18 & 167.3271 & 167.3931 & 167.5787 & 167.5806 & 168.702 & 168.7472 & 168.6311 & 168.6146 & 167.622 & 167.5066 & 167.4283 & 167.4341 & 169.4695 & 169.3699 & 169.2905 & 169.2101 \\
\hline C 19 & 174.3513 & 174.3957 & 175.2322 & 175.2302 & 170.8243 & 170.894 & 170.9664 & 171.0201 & 170.0712 & 170.0863 & 170.215 & 170.301 & 175.7936 & 175.9834 & 175.8564 & 175.9027 \\
\hline C 20 & 171.3695 & 171.8189 & 176.8592 & 171.17 & 170.9686 & 176.9911 & 172.2465 & 171.2038 & 171.381 & 172.3906 & 169.4007 & 174.2897 & 172.4057 & 171.3097 & 173.9407 & 169.0085 \\
\hline $\mathrm{H} 2$ & 29.23342 & 29.22414 & 29.41973 & 29.40719 & 29.39939 & 29.42957 & 29.33157 & 29.29029 & 29.11838 & 29.13241 & 29.25221 & 29.26628 & 29.19019 & 29.17315 & 29.21115 & 29.1973 \\
\hline H 3 & 26.31769 & 26.23829 & 26.41475 & 26.37061 & 26.31333 & 26.38543 & 26.21443 & 26.30137 & 26.23216 & 26.14754 & 26.1385 & 26.23728 & 26.32631 & 26.41908 & 26.3102 & 26.20808 \\
\hline H 5a & 29.66518 & 29.68051 & 29.65727 & 29.67208 & 29.69514 & 29.68459 & 29.67283 & 29.61756 & 29.63988 & 29.63967 & 29.75186 & 29.7469 & 29.70142 & 29.70285 & 29.73866 & 29.75794 \\
\hline $\mathrm{H} 5 \mathrm{~b}$ & 30.15389 & 30.17572 & 30.21605 & 30.21137 & 30.26739 & 30.27532 & 30.25684 & 30.27083 & 30.17035 & 30.16078 & 30.17421 & 30.1697 & 30.20959 & 30.21599 & 30.22859 & 30.21222 \\
\hline H 6a & 30.35759 & 30.34194 & 30.33635 & 30.32588 & 30.21012 & 30.23221 & 30.18835 & 30.20606 & 30.33031 & 30.33848 & 30.38899 & 30.37747 & 30.16089 & 30.17269 & 30.18995 & 30.17443 \\
\hline $\mathrm{H} 6 \mathrm{~b}$ & 30.94306 & 30.95185 & 31.01823 & 30.99133 & 31.04521 & 31.05538 & 30.98063 & 30.98074 & 30.78679 & 30.78011 & 30.81336 & 30.80273 & 31.01788 & 31.05929 & 31.04791 & 31.04918 \\
\hline H 7 & 29.22257 & 29.24946 & 29.2005 & 29.23643 & 29.37489 & 29.4435 & 29.32368 & 29.31833 & 29.26244 & 29.24368 & 29.32811 & 29.31621 & 29.52412 & 29.54483 & 29.53437 & 29.49059 \\
\hline н9а & 30.11973 & 30.07953 & 30.10846 & 30.04607 & 30.27474 & 30.33817 & 30.10803 & 30.09792 & 30.01461 & 30.05892 & 29.8175 & 30.48332 & 30.05776 & 30.0162 & 30.38048 & 30.27696 \\
\hline $\mathrm{H} 9 \mathrm{~b}$ & 30.56722 & 30.585 & 31.05206 & 31.07868 & 30.5285 & 30.5062 & 30.37768 & 30.38284 & 30.69578 & 30.65768 & 30.37602 & 30.48851 & 31.19222 & 31.19954 & 30.9505 & 30.41244 \\
\hline H 10 & 29.5939 & 29.51681 & 30.36252 & 29.80989 & 29.99482 & 30.54859 & 29.75593 & 29.7954 & 29.29998 & 29.38619 & 29.52533 & 29.49755 & 29.22445 & 29.1391 & 29.12036 & 29.24974 \\
\hline H 11 & 29.55237 & 28.81772 & 29.94363 & 30.05905 & 30.18907 & 30.05069 & 29.08356 & 29.75193 & 30.24165 & 29.5609 & 29.82785 & 29.54417 & 29.64444 & 30.30605 & 29.45938 & 29.80936 \\
\hline H 13a & 29.90766 & 30.3056 & 30.22741 & 30.08142 & 30.16129 & 30.26685 & 30.2399 & 29.85033 & 29.86219 & 30.24361 & 29.93815 & 30.22464 & 30.20627 & 29.8436 & 30.28238 & 29.92356 \\
\hline H 13b & 30.44558 & 30.35377 & 30.26866 & 30.47443 & 30.49694 & 30.40188 & 30.24978 & 30.42646 & 30.42941 & 30.33518 & 30.3252 & 30.29246 & 30.3445 & 30.40429 & 30.31051 & 30.27412 \\
\hline H 14a & 30.54166 & 30.32799 & 30.47513 & 30.33248 & 30.37988 & 30.44223 & 30.37929 & 30.54416 & 30.52881 & 30.36232 & 30.36631 & 30.45084 & 30.34703 & 30.5395 & 30.42295 & 30.32076 \\
\hline H 14b & 30.60649 & 30.67816 & 30.47578 & 30.64855 & 30.63724 & 30.51373 & 30.65696 & 30.58792 & 30.67075 & 30.74247 & 30.62772 & 30.51912 & 30.73549 & 30.64956 & 30.47555 & 30.60781 \\
\hline H 15 & 30.315 & 30.4568 & 30.298 & 30.3879 & 30.30698 & 30.24101 & 30.25031 & 30.15907 & 30.21684 & 30.39088 & 30.33267 & 30.25456 & 30.31925 & 30.15262 & 30.22785 & 30.30527 \\
\hline H 16a & 31.1887 & 31.14774 & 31.41202 & 31.41754 & 31.38572 & 31.41932 & 31.30357 & 31.38251 & 31.28277 & 31.23939 & 31.41643 & 31.39946 & 31.31578 & 31.37612 & 31.38064 & 31.38858 \\
\hline H 16b & 30.7233 & 30.9652 & 31.18481 & 31.18553 & 31.18255 & 31.07229 & 31.06678 & 30.53976 & 30.5715 & 30.86523 & 31.24817 & 31.24172 & 31.23459 & 31.27964 & 31.12528 & 31.19714 \\
\hline H 16c & 31.43109 & 31.3256 & 31.56814 & 31.52912 & 31.48151 & 31.41755 & 31.32484 & 31.40432 & 31.35736 & 31.23909 & 31.53297 & 31.54503 & 31.37876 & 31.32703 & 31.41001 & 31.47685 \\
\hline H 17a & 31.35416 & 31.32902 & 31.45968 & 31.41832 & 31.38175 & 31.37103 & 31.24042 & 31.28205 & 31.33288 & 31.39373 & 31.40109 & 31.42854 & 31.21871 & 31.32944 & 31.34848 & 31.38145 \\
\hline H 17b & 31.36145 & 31.35535 & 31.43603 & 31.50798 & 31.51313 & 31.52444 & 31.26271 & 31.32504 & 31.39218 & 31.31121 & 31.51069 & 31.42955 & 31.19901 & 31.22488 & 31.4852 & 31.4841 \\
\hline H $17 \mathrm{c}$ & 31.15464 & 31.2319 & 31.06575 & 31.21294 & 31.17175 & 31.16491 & 30.96748 & 30.89063 & 31.30187 & 31.25659 & 31.21253 & 31.10798 & 30.77901 & 30.48307 & 31.18283 & 31.19733 \\
\hline H 18a & 30.66828 & 30.63435 & 30.68739 & 30.66953 & 30.6255 & 30.65552 & 30.57183 & 30.60348 & 30.5946 & 30.54282 & 30.59872 & 30.63241 & 30.53833 & 30.6011 & 30.59607 & 30.5778 \\
\hline H 18b & 30.43994 & 30.43874 & 30.46918 & 30.47039 & 30.14912 & 30.1784 & 30.16745 & 30.19121 & 30.41705 & 30.39229 & 30.43897 & 30.4418 & 30.12246 & 30.14987 & 30.20554 & 30.09476 \\
\hline H 18c & 30.28684 & 30.27143 & 30.2804 & 30.26345 & 30.46544 & 30.47059 & 30.44 & 30.44772 & 30.18374 & 30.15923 & 30.17524 & 30.20116 & 30.47816 & 30.47933 & 30.46486 & 30.50528 \\
\hline H 19a & 31.68192 & 31.67515 & 31.70656 & 31.69479 & 31.36306 & 31.3624 & 31.41022 & 31.41819 & 30.98039 & 30.94267 & 31.72273 & 31.7126 & 31.45245 & 31.46809 & 31.47049 & 31.50235 \\
\hline H 19b & 30.89971 & 30.89517 & 30.98504 & 30.91106 & 30.48089 & 30.47825 & 30.48139 & 30.46599 & 30.72273 & 30.69354 & 30.64459 & 30.68412 & 30.78397 & 30.78472 & 30.84595 & 30.87157 \\
\hline H 19c & 30.74805 & 30.71055 & 30.85836 & 30.78086 & 30.6582 & 30.63624 & 30.66065 & 30.65534 & 31.71567 & 31.70465 & 30.96447 & 31.01045 & 30.70915 & 30.70393 & 30.61239 & 30.65183 \\
\hline H 20a & 30.55555 & 30.3548 & 30.87715 & 30.74414 & 30.75135 & 30.93261 & 30.50984 & 30.64765 & 30.63805 & 31.04853 & 30.86358 & 30.70986 & 30.37492 & 30.64295 & 30.69155 & 30.97858 \\
\hline $\mathrm{H} 20 \mathrm{~b}$ & 30.40735 & 31.05078 & 30.86122 & 31.00022 & 30.91599 & 31.29316 & 30.68526 & 31.32032 & 30.46585 & 30.41814 & 31.01941 & 30.86112 & 30.85411 & 31.30033 & 31.18733 & 30.72122 \\
\hline H 20c & 31.27716 & 30.84445 & 31.2371 & 30.90156 & 31.01241 & 30.91337 & 30.91915 & 30.37059 & 31.27889 & 30.91832 & 30.87174 & 31.09685 & 31.08677 & 30.47563 & 30.88929 & 31.03997 \\
\hline
\end{tabular}


Table S12. DP4+ results obtained using experimental data of compound 1 versus isomers 1a-1d

\begin{tabular}{|c|c|c|c|c|c|c|}
\hline Functional & \multicolumn{2}{|c|}{ Solvent? } & \multicolumn{2}{|c|}{ Basis Set } & \multicolumn{2}{|c|}{ Type of Data } \\
\hline mPW1PW91 & \multicolumn{2}{|c|}{ PCM } & \multicolumn{2}{|c|}{$6-31 G(d)$} & \multicolumn{2}{|c|}{ Shielding Tensors } \\
\hline & Isomer 1 & Isomer 2 & Isomer 3 & Isomer 4 & Isomer 5 & Isomer 6 \\
\hline sDP4+ (H data) & 메 $1.81 \%$ & $91.15 \%$ & $0.92 \%$ & If $6.12 \%$ & - & - \\
\hline sDP4+ (C data) & जी $0.11 \%$ & 에 $99.86 \%$ & $0.00 \%$ & $0.03 \%$ & - & - \\
\hline sDP4+ (a11 data) & $0.00 \%$ & $100.00 \%$ & $0.00 \%$ & $0.00 \%$ & - & - \\
\hline uDP4+ (H data) & ज्ञl $0.01 \%$ & - $99.92 \%$ & $0.00 \%$ & ज्ञी $0.07 \%$ & - & - \\
\hline uDP4+ (C data) & जी $0.02 \%$ & - $99.42 \%$ & जी $0.00 \%$ & 메 $0.55 \%$ & - & - \\
\hline uDP4+ (a11 data) & $0.00 \%$ & $100.00 \%$ & $0.00 \%$ & 메 $0.00 \%$ & - & - \\
\hline DP4+ (H data) & जी $0.00 \%$ & $100.00 \%$ & $0.00 \%$ & जी $0.00 \%$ & - & - \\
\hline DP4+ (C data) & जी $0.00 \%$ & $100.00 \%$ & $0.00 \%$ & 페 $0.00 \%$ & - & - \\
\hline DP4+ (a11 data) & जी $0.00 \%$ & $100.00 \%$ & $0.00 \%$ & जी $0.00 \%$ & - & - \\
\hline
\end{tabular}

Table S13. DP4+ results obtained using experimental data of compound 2 versus isomers $2 \mathrm{a}-2 \mathrm{~b}$

\begin{tabular}{|c|c|c|c|c|c|c|}
\hline Functional & \multicolumn{2}{|c|}{ Solvent? } & \multicolumn{2}{|c|}{ Basis Set } & \multicolumn{2}{|c|}{ Type of Data } \\
\hline mPW1PW91 & \multicolumn{2}{|c|}{ PCM } & \multicolumn{2}{|c|}{$6-31 G(d)$} & \multicolumn{2}{|c|}{ Shielding Tensors } \\
\hline & Isomer 1 & Isomer 2 & Isomer 3 & Isomer 4 & Isomer 5 & Isomer 6 \\
\hline sDP4+ (H data) & - $199.95 \%$ & 메 $0.05 \%$ & - & - & - & - \\
\hline sDP4+ (C data) & $86.39 \%$ & जी $13.61 \%$ & - & - & - & - \\
\hline sDP4+ (a11 data) & - $99.99 \%$ & 메 $0.01 \%$ & - & - & - & - \\
\hline uDP4+ (H data) & $-88.46 \%$ & 메 $11.54 \%$ & - & - & - & - \\
\hline uDP4+ (C data) & - $65.25 \%$ & 政34.75\% & - & - & - & - \\
\hline uDP4+ (a11 data) & $93.50 \%$ & 메 $6.50 \%$ & - & - & - & - \\
\hline DP4+ (H data) & \begin{tabular}{|l|l|}
$99.99 \%$ \\
\end{tabular} & जी $0.01 \%$ & - & - & - & - \\
\hline DP4+ (C data) & - $92.26 \%$ & 페 $7.74 \%$ & - & - & - & - \\
\hline DP4+ (a11 data) & N100. 00\% & - $0.00 \%$ & - & - & - & - \\
\hline
\end{tabular}

Table S14. DP4+ results obtained using experimental data of compound 3 versus isomers 3a-3b

\begin{tabular}{|c||c||c||c|}
\hline Functional & Solvent? & Basis Set & Type of Data \\
mPW1PW91 & PCM & $6-31 G(d)$ & Shielding Tensors \\
\hline
\end{tabular}

\begin{tabular}{|c|c|c|c|c|c|c|}
\hline & Isomer 1 & Isomer 2 & Isomer 3 & Isomer 4 & Isomer 5 & Isomer 6 \\
\hline sDP4+ (H data) & - $99.91 \%$ & 페 $0.09 \%$ & - & - & - & - \\
\hline sDP4+ (C data) & 에 $98.19 \%$ & 메 $1.81 \%$ & - & - & - & - \\
\hline sDP4+ (a11 data) & H $100.00 \%$ & 메 $0.00 \%$ & - & - & - & - \\
\hline uDP4+ (H data) & -n $99.92 \%$ & जी $0.08 \%$ & - & - & - & - \\
\hline uDP4+ (C data) & 메 $17.87 \%$ & - $82.13 \%$ & - & - & - & - \\
\hline uDP4+ (a11 data) & -1199.65\% & 페 $0.35 \%$ & - & - & - & - \\
\hline $\mathrm{DP}^{+}$(H data) & $100.00 \%$ & 武 $0.00 \%$ & - & - & - & - \\
\hline $\mathrm{DP}^{+}+(\mathrm{C}$ data $)$ & - $92.20 \%$ & 페 $7.80 \%$ & - & - & - & - \\
\hline DP4+ (a11 data) & N100.00\% & 페 $0.00 \%$ & - & - & - & - \\
\hline
\end{tabular}

Table S15. DP4+ results obtained using experimental data of compound 4 versus isomers $4 \mathrm{a}-4 \mathrm{~b}$

\begin{tabular}{|c||c||c||c|}
\hline Functiona1 & Solvent? & Basis Set & Type of Data \\
mPW1PW91 & PCM & $6-31 G(d)$ & Shielding Tensors \\
\hline
\end{tabular}

\begin{tabular}{|c|c|c|c|c|c|c|}
\hline & Isomer 1 & Isomer 2 & Isomer 3 & Isomer 4 & Isomer 5 & Isomer 6 \\
\hline sDP4+ (H data) & 焉 $0.04 \%$ & 에 99. 96\% & - & - & - & - \\
\hline sDP4+ (C data) & 메 $4.14 \%$ & -n $95.86 \%$ & - & - & - & - \\
\hline sDP4+ (a11 data) & 페 $0.00 \%$ & $100.00 \%$ & - & - & - & - \\
\hline uDP4+ (H data $)$ & 메 $0.12 \%$ & 99. 88\% & - & - & - & - \\
\hline uDP4+ (C data) & - $50.14 \%$ & 페 $49.86 \%$ & - & - & - & - \\
\hline uDP4+ (a11 data) & 페 $0.12 \%$ & - $99.88 \%$ & - & - & - & - \\
\hline DP4+ (H data) & जी $0.00 \%$ & $100.00 \%$ & - & - & - & - \\
\hline $\mathrm{DP}^{+}+(\mathrm{C}$ data $)$ & जी $4.17 \%$ & - $95.83 \%$ & - & - & - & - \\
\hline $\mathrm{DP}^{+}+(\mathrm{a} 11$ data $)$ & 馬 $0.00 \%$ & $100.00 \%$ & - & - & - & - \\
\hline
\end{tabular}


Table S16. DP4+ results obtained using experimental data of compound 5 versus isomers $5 \mathrm{a}-5 \mathrm{p}$

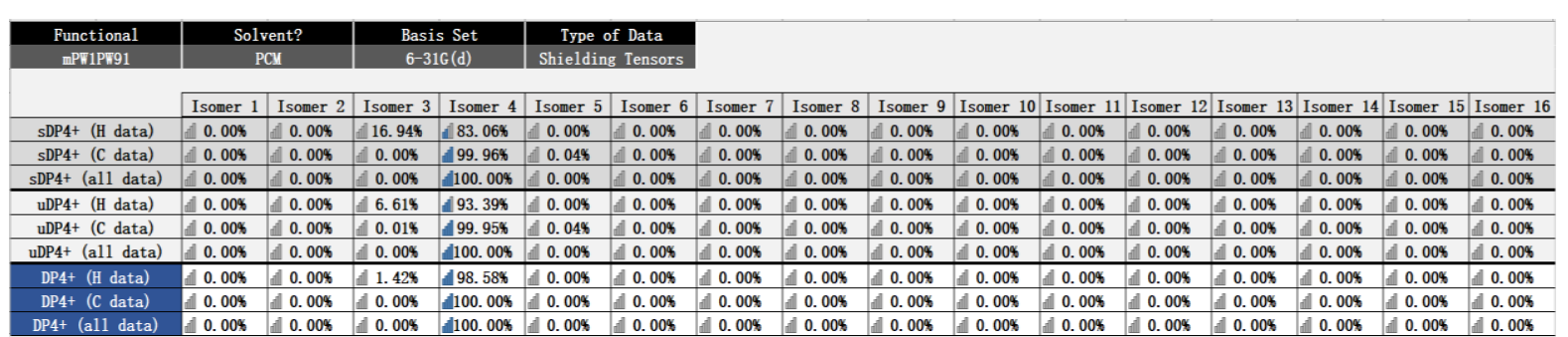

Table S17. DP4+ results obtained using experimental data of compound 6 versus isomers $6 \mathrm{a}-6 \mathrm{p}$

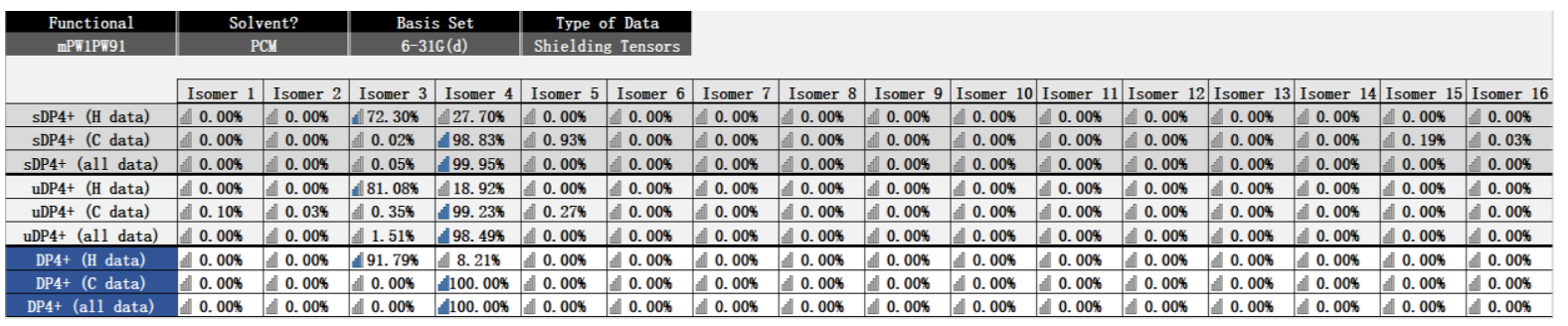

\subsection{TDDFT-ECD calculations of compounds 3,4}

\section{Computational Section.}

Conformational searches were carried out using the torsional sampling (MCMM) method and OPLS_2005 force field. Conformers above 1\% population were reoptimized at the B3LYP/6-311G(d,p) level with IEFPCM (Polarizable Continuum Model using the Integral Equation Formalism variant) solvent model for acetonitrile. For the resulting geometries, ECD spectra were obtained by TDDFT calculations performed with the same functional, basis set and solvent model as the energy optimization. Finally, the Boltzmann-averaged ECD spectra of $(7 S, 8 S, 15 R)-\mathbf{3}$, and (7S,8S, 12S)-4 were obtained with SpecDis1.62.

\section{Computational data of $(7 S, 8 S, 15 R)-3$}

Torsional sampling (MCMM) conformational searches using OPLS_2005 force field were carried out by means of the conformational search module in the Macromodel ${ }^{1}$ applying an energy window of $21 \mathrm{~kJ} / \mathrm{mol}$, which afforded 346 conformers for $(7 S, 8 S, 15 R)-3$. The Boltzmann populations of the conformers were obtained based on the potential energy provided by the OPLS_2005 force field, which afforded 24 conformers for $(7 S, 8 S, 15 R)-\mathbf{3}$ above $1 \%$ population for re-optimization. The reoptimization and the following TDDFT calculations of the re-optimized geometries (Fig. S68, Table S18) were all performed with Gaussian 09 at the B3LYP/6-311G(d,p) level with IEFPCM solvent model for acetonitrile. Frequency analysis was performed 
as well to confirm that the re-optimized geometries were at the energy minima. Finally, the SpecDis1.62 software was used to obtain the Boltzmann-averaged ECD spectra of $(7 S, 8 S, 15 R)-3$ and visualize the results.
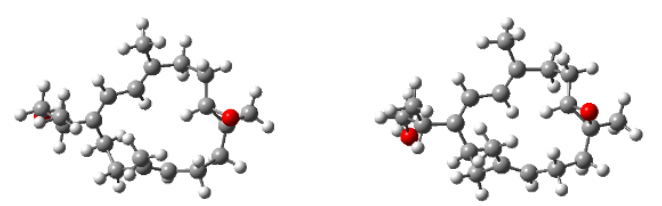

Conf. 1
$17.15 \%$

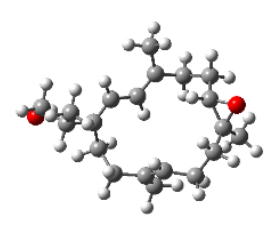

Conf. 5
$6.19 \%$

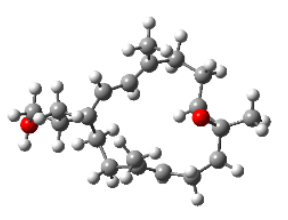

Conf. 9

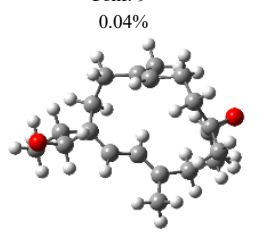

Conf. 13

$10.98 \%$

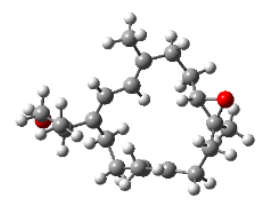

Conf. 17

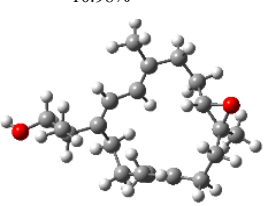

Conf. 21
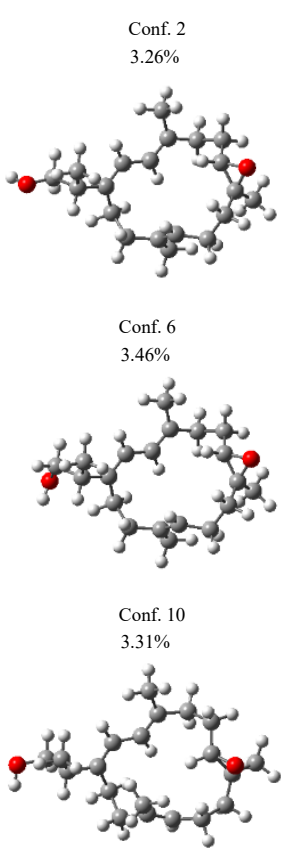

Conf. 14

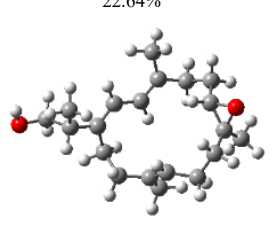

Conf. 18

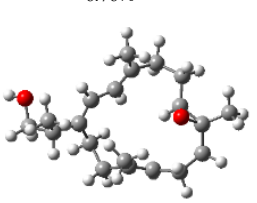

Conf. 22
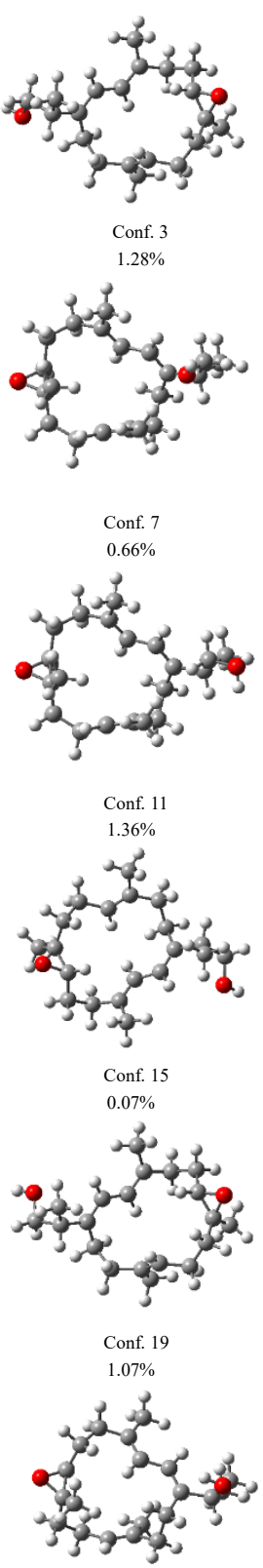

Conf. 23

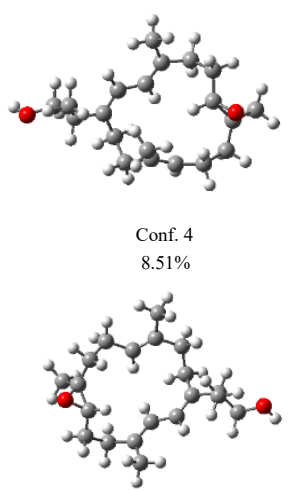

Conf. 8
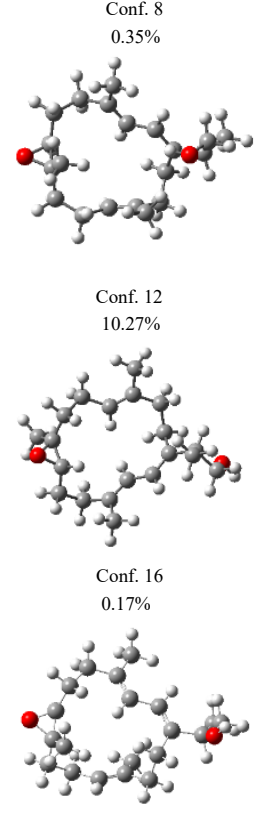

Conf. 20

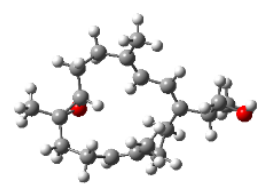

Conf. 24

$2.14 \%$

Figure S68. Re-optimized conformers above 1\% population (OPLS_2005) of (7S,8S,15R)-3 calculated at the B3LYP/6-311G(d,p) level with IEFPCM solvent model for acetonitrile.

Table S18. Cartesian coordinates for the re-optimized conformers of $(7 S, 8 S, 15 R)-3$ at the B3LYP/6-311G(d,p) level with IEFPCM solvent model for acetonitrile.

\begin{tabular}{|c|c|c|c|c|}
\hline \multicolumn{2}{|c|}{$\begin{array}{l}(7 S, 8 S, 15 R)-\mathbf{3} \\
\text { Conf. } 1 \\
\end{array}$} & \multicolumn{3}{|c|}{$\begin{array}{c}\text { Standard Orientation } \\
\text { (Ångstroms) }\end{array}$} \\
\hline I & atom & $\mathrm{X}$ & $\mathrm{Y}$ & $\mathrm{Z}$ \\
\hline 1 & $\mathrm{C}$ & 2.84398500 & 0.60497800 & 0.38015700 \\
\hline
\end{tabular}




\begin{tabular}{|c|c|c|c|c|}
\hline 2 & $\mathrm{C}$ & 2.80026400 & 2.11111400 & 0.24424600 \\
\hline 3 & $\mathrm{C}$ & 1.66404900 & 2.60573900 & -0.68452600 \\
\hline 4 & $\mathrm{C}$ & 3.80026000 & -0.29005800 & -0.30448100 \\
\hline 5 & $\mathrm{C}$ & 3.49365200 & -1.76363400 & -0.55725600 \\
\hline 6 & $\mathrm{C}$ & 2.43601500 & -2.44122900 & 0.34025000 \\
\hline 7 & $\mathrm{C}$ & 1.04073400 & -2.46799200 & -0.23195100 \\
\hline 8 & $\mathrm{C}$ & -0.13033500 & -2.24855000 & 0.38235500 \\
\hline 9 & $\mathrm{C}$ & -1.43247700 & -2.43425800 & -0.38220300 \\
\hline 10 & $\mathrm{C}$ & 4.87049300 & 0.25045000 & -1.23047200 \\
\hline 11 & $\mathrm{C}$ & 0.27676400 & 2.45225100 & -0.09557900 \\
\hline 12 & $\mathrm{C}$ & -0.49495600 & 1.40704000 & -0.45926300 \\
\hline 13 & $\mathrm{C}$ & -1.81988400 & 1.07085000 & 0.03362500 \\
\hline 14 & $\mathrm{C}$ & -1.98474600 & -1.17593500 & -1.11055100 \\
\hline 15 & $\mathrm{C}$ & -2.50153000 & -0.06783000 & -0.21897900 \\
\hline 16 & $\mathrm{C}$ & -3.90126200 & -0.29298200 & 0.35435800 \\
\hline 17 & $\mathrm{C}$ & -4.96373100 & 0.46150900 & -0.47262300 \\
\hline 18 & $\mathrm{C}$ & -4.05966900 & 0.07608500 & 1.83801100 \\
\hline 19 & $\mathrm{C}$ & -0.12150700 & 3.51147500 & 0.89914600 \\
\hline 20 & $\mathrm{O}$ & 3.97462800 & 0.05252800 & 1.09519300 \\
\hline 21 & $\mathrm{C}$ & -0.26799900 & -1.86737700 & 1.83529900 \\
\hline 22 & $\mathrm{H}$ & 1.89769200 & 0.16171800 & 0.68103000 \\
\hline 23 & $\mathrm{O}$ & -4.93386400 & 0.15892600 & -1.86802100 \\
\hline 24 & $\mathrm{H}$ & 2.67148700 & 2.53583000 & 1.24639600 \\
\hline 25 & $\mathrm{H}$ & 3.75563300 & 2.48621500 & -0.12614400 \\
\hline 26 & $\mathrm{H}$ & 1.84748300 & 3.66337300 & -0.90494800 \\
\hline 27 & $\mathrm{H}$ & 1.72586400 & 2.06942100 & -1.63642500 \\
\hline 28 & $\mathrm{H}$ & 4.44689300 & -2.29124600 & -0.43601300 \\
\hline 29 & $\mathrm{H}$ & 3.22067300 & -1.88268400 & -1.61194500 \\
\hline 30 & $\mathrm{H}$ & 2.75404600 & -3.48303400 & 0.47701200 \\
\hline 31 & $\mathrm{H}$ & 2.46895200 & -1.99223100 & 1.33497800 \\
\hline 32 & $\mathrm{H}$ & 1.00002400 & -2.77152900 & -1.27915600 \\
\hline 33 & $\mathrm{H}$ & -2.20037400 & -2.81912100 & 0.29860300 \\
\hline 34 & $\mathrm{H}$ & -1.28689700 & -3.20181200 & -1.14822600 \\
\hline 35 & $\mathrm{H}$ & 4.51740100 & 0.25017100 & -2.26581800 \\
\hline 36 & $\mathrm{H}$ & 5.16964400 & 1.26340800 & -0.96587400 \\
\hline 37 & $\mathrm{H}$ & 5.75889700 & -0.38632400 & -1.18064600 \\
\hline 38 & $\mathrm{H}$ & -0.06409700 & 0.72181100 & -1.18248800 \\
\hline 39 & $\mathrm{H}$ & -2.29197100 & 1.80202300 & 0.68291800 \\
\hline 40 & $\mathrm{H}$ & -1.21138100 & -0.81117300 & -1.78916600 \\
\hline 41 & $\mathrm{H}$ & -2.81795900 & -1.51009400 & -1.73878800 \\
\hline 42 & $\mathrm{H}$ & -4.12765600 & -1.36039000 & 0.25240100 \\
\hline 43 & $\mathrm{H}$ & -5.96129800 & 0.17638300 & -0.12855700 \\
\hline 44 & $\mathrm{H}$ & -4.84651400 & 1.54151700 & -0.31007000 \\
\hline 45 & $\mathrm{H}$ & -5.06485200 & -0.17704100 & 2.18808400 \\
\hline 46 & $\mathrm{H}$ & -3.34109200 & -0.46554000 & 2.45650200 \\
\hline 47 & $\mathrm{H}$ & -3.91241400 & 1.14536300 & 2.01026200 \\
\hline 48 & $\mathrm{H}$ & -0.18966200 & 4.48857200 & 0.40577800 \\
\hline 49 & $\mathrm{H}$ & -1.07596500 & 3.31209400 & 1.38477900 \\
\hline 50 & $\mathrm{H}$ & 0.63486400 & 3.61596900 & 1.68467000 \\
\hline 51 & $\mathrm{H}$ & -0.80057800 & -2.65335800 & 2.38407200 \\
\hline 52 & $\mathrm{H}$ & 0.69167400 & -1.71100400 & 2.32782900 \\
\hline 53 & $\mathrm{H}$ & -0.86114400 & -0.95445600 & 1.94024700 \\
\hline 54 & $\mathrm{H}$ & -4.12220300 & 0.53565000 & -2.22604100 \\
\hline
\end{tabular}

B3LYP/6-311G(d,p) Energy $=-931.85550049$ a.u.; Population $=17.15 \%$ 


\begin{tabular}{|c|c|c|c|c|}
\hline \multicolumn{2}{|c|}{$\begin{array}{c}(7 S, 8 S, 15 R)-\mathbf{3} \\
\text { Conf. } 2 \\
\end{array}$} & \multicolumn{3}{|c|}{$\begin{array}{c}\text { Standard Orientation } \\
\text { (Ångstroms) }\end{array}$} \\
\hline I & atom & $\mathrm{X}$ & $\mathrm{Y}$ & $\mathrm{Z}$ \\
\hline 1 & $\mathrm{C}$ & 2.8703 & 0.5873 & 0.35962 \\
\hline 2 & $\mathrm{C}$ & 2.85053 & 2.09047 & 0.18948 \\
\hline 3 & $\mathrm{C}$ & 1.71524 & 2.58341 & -0.74131 \\
\hline 4 & $\mathrm{C}$ & 3.80458 & -0.33923 & -0.31341 \\
\hline 5 & $\mathrm{C}$ & 3.47282 & -1.81333 & -0.52856 \\
\hline 6 & $\mathrm{C}$ & 2.40878 & -2.45244 & 0.38923 \\
\hline 7 & $\mathrm{C}$ & 1.01079 & -2.46812 & -0.1771 \\
\hline 8 & $\mathrm{C}$ & -0.1548 & -2.21855 & 0.43616 \\
\hline 9 & $\mathrm{C}$ & -1.4623 & -2.39541 & -0.3215 \\
\hline 10 & $\mathrm{C}$ & 4.8727 & 0.16282 & -1.26306 \\
\hline 11 & $\mathrm{C}$ & 0.3294 & 2.46272 & -0.14113 \\
\hline 12 & $\mathrm{C}$ & -0.4626 & 1.42484 & -0.48117 \\
\hline 13 & $\mathrm{C}$ & -1.79091 & 1.11909 & 0.02392 \\
\hline 14 & $\mathrm{C}$ & -1.99436 & -1.14437 & -1.07752 \\
\hline 15 & $\mathrm{C}$ & -2.49285 & -0.0104 & -0.21001 \\
\hline 16 & $\mathrm{C}$ & -3.89181 & -0.20598 & 0.37432 \\
\hline 17 & $\mathrm{C}$ & -4.97091 & 0.43856 & -0.50853 \\
\hline 18 & $\mathrm{C}$ & -4.06203 & 0.29129 & 1.81925 \\
\hline 19 & $\mathrm{C}$ & -0.04486 & 3.54588 & 0.83752 \\
\hline 20 & $\mathrm{O}$ & 3.99908 & 0.0323 & 1.07615 \\
\hline 21 & $\mathrm{C}$ & -0.28165 & -1.81009 & 1.88268 \\
\hline 22 & $\mathrm{H}$ & 1.91974 & 0.16746 & 0.67996 \\
\hline 23 & $\mathrm{O}$ & -4.95137 & -0.15946 & -1.80682 \\
\hline 24 & $\mathrm{H}$ & 2.7371 & 2.53979 & 1.18275 \\
\hline 25 & $\mathrm{H}$ & 3.80921 & 2.44096 & -0.1965 \\
\hline 26 & $\mathrm{H}$ & 1.91357 & 3.63357 & -0.98416 \\
\hline 27 & $\mathrm{H}$ & 1.76335 & 2.02775 & -1.68296 \\
\hline 28 & $\mathrm{H}$ & 4.41834 & -2.35289 & -0.39907 \\
\hline 29 & $\mathrm{H}$ & 3.19279 & -1.9536 & -1.57879 \\
\hline 30 & $\mathrm{H}$ & 2.71031 & -3.49596 & 0.54873 \\
\hline 31 & $\mathrm{H}$ & 2.45367 & -1.98151 & 1.3734 \\
\hline 32 & $\mathrm{H}$ & 0.96183 & -2.78976 & -1.21859 \\
\hline 33 & $\mathrm{H}$ & -2.23471 & -2.75116 & 0.37023 \\
\hline 34 & $\mathrm{H}$ & -1.33329 & -3.18348 & -1.06963 \\
\hline 35 & $\mathrm{H}$ & 5.75106 & -0.4875 & -1.20987 \\
\hline 36 & $\mathrm{H}$ & 4.50717 & 0.14631 & -2.29395 \\
\hline 37 & $\mathrm{H}$ & 5.19141 & 1.17611 & -1.02396 \\
\hline 38 & $\mathrm{H}$ & -0.04776 & 0.72116 & -1.1961 \\
\hline 39 & $\mathrm{H}$ & -2.24648 & 1.87033 & 0.66172 \\
\hline 40 & $\mathrm{H}$ & -1.21323 & -0.80571 & -1.76084 \\
\hline 41 & $\mathrm{H}$ & -2.833 & -1.47138 & -1.69932 \\
\hline 42 & $\mathrm{H}$ & -4.09982 & -1.28241 & 0.37199 \\
\hline 43 & $\mathrm{H}$ & -5.95215 & 0.29208 & -0.0368 \\
\hline 44 & $\mathrm{H}$ & -4.78152 & 1.51831 & -0.57599 \\
\hline 45 & $\mathrm{H}$ & -5.0434 & 0.00418 & 2.20695 \\
\hline 46 & $\mathrm{H}$ & -3.30069 & -0.13942 & 2.47253 \\
\hline 47 & $\mathrm{H}$ & -3.98821 & 1.37975 & 1.89043 \\
\hline 48 & $\mathrm{H}$ & -0.09273 & 4.51685 & 0.32969 \\
\hline 49 & $\mathrm{H}$ & -1.0033 & 3.37422 & 1.32606 \\
\hline 50 & $\mathrm{H}$ & 0.71351 & 3.64644 & 1.62183 \\
\hline 51 & $\mathrm{H}$ & -0.81629 & -2.58248 & 2.44862 \\
\hline 52 & $\mathrm{H}$ & 0.68182 & -1.65125 & 2.36716 \\
\hline 53 & $\mathrm{H}$ & -0.86847 & -0.89158 & 1.9741 \\
\hline 54 & $\mathrm{H}$ & -5.60788 & 0.29126 & -2.34749 \\
\hline
\end{tabular}

B3LYP/6-311G(d,p) Energy $=-931.85230200$ a.u.; Population $=3.26 \%$ 


\begin{tabular}{|c|c|c|c|c|}
\hline \multicolumn{2}{|c|}{$\begin{array}{c}(7 S, 8 S, 15 R)-\mathbf{3} \\
\text { Conf. } 3 \\
\end{array}$} & \multicolumn{3}{|c|}{$\begin{array}{c}\text { Standard Orientation } \\
\text { (Ångstroms) }\end{array}$} \\
\hline I & atom & $\mathrm{X}$ & $\mathrm{Y}$ & $\mathrm{Z}$ \\
\hline 1 & $\mathrm{C}$ & 2.96943 & 1.10967 & 0.52333 \\
\hline 2 & $\mathrm{C}$ & 2.97137 & 2.18653 & -0.53969 \\
\hline 3 & $\mathrm{C}$ & 1.71995 & 2.18201 & -1.44636 \\
\hline 4 & $\mathrm{C}$ & 3.59776 & -0.22517 & 0.41525 \\
\hline 5 & $\mathrm{C}$ & 3.16148 & -1.34854 & 1.34937 \\
\hline 6 & $\mathrm{C}$ & 2.28826 & -2.47929 & 0.76085 \\
\hline 7 & $\mathrm{C}$ & 0.80248 & -2.22302 & 0.733 \\
\hline 8 & $\mathrm{C}$ & -0.06714 & -2.46278 & -0.259 \\
\hline 9 & $\mathrm{C}$ & -1.56399 & -2.33824 & -0.03933 \\
\hline 10 & $\mathrm{C}$ & 4.33499 & -0.65772 & -0.83377 \\
\hline 11 & $\mathrm{C}$ & 0.40817 & 2.29404 & -0.70081 \\
\hline 12 & $\mathrm{C}$ & -0.45058 & 1.25362 & -0.7102 \\
\hline 13 & $\mathrm{C}$ & -1.70201 & 1.1306 & 0.01695 \\
\hline 14 & $\mathrm{C}$ & -2.27569 & -1.1863 & -0.81887 \\
\hline 15 & $\mathrm{C}$ & -2.51872 & 0.05617 & 0.01187 \\
\hline 16 & $\mathrm{C}$ & -3.78869 & 0.02161 & 0.86074 \\
\hline 17 & $\mathrm{C}$ & -4.99305 & 0.61557 & 0.1135 \\
\hline 18 & $\mathrm{C}$ & -3.66755 & 0.70305 & 2.23321 \\
\hline 19 & $\mathrm{C}$ & 0.17818 & 3.58965 & 0.03465 \\
\hline 20 & $\mathrm{O}$ & 4.23986 & 0.84767 & 1.1588 \\
\hline 21 & $\mathrm{C}$ & 0.32414 & -2.96269 & -1.62956 \\
\hline 22 & $\mathrm{H}$ & 2.14839 & 1.18698 & 1.23539 \\
\hline 23 & $\mathrm{O}$ & -5.23584 & -0.12519 & -1.0847 \\
\hline 24 & $\mathrm{H}$ & 3.05704 & 3.15229 & -0.02849 \\
\hline 25 & $\mathrm{H}$ & 3.86259 & 2.09417 & -1.16338 \\
\hline 26 & $\mathrm{H}$ & 1.71841 & 1.26694 & -2.04561 \\
\hline 27 & $\mathrm{H}$ & 1.81885 & 3.02114 & -2.14699 \\
\hline 28 & $\mathrm{H}$ & 2.66034 & -0.90558 & 2.21572 \\
\hline 29 & $\mathrm{H}$ & 4.08848 & -1.79709 & 1.72687 \\
\hline 30 & $\mathrm{H}$ & 2.66327 & -2.77047 & -0.22171 \\
\hline 31 & $\mathrm{H}$ & 2.44586 & $\begin{array}{r}-3.35639 \\
\end{array}$ & 1.40295 \\
\hline 32 & $\mathrm{H}$ & 0.39076 & -1.88571 & 1.68441 \\
\hline 33 & $\mathrm{H}$ & -1.77098 & -2.23412 & 1.02928 \\
\hline 34 & $\mathrm{H}$ & -2.01871 & -3.287 & -0.35044 \\
\hline 35 & $\mathrm{H}$ & 5.13153 & -1.36146 & -0.57322 \\
\hline 36 & $\mathrm{H}$ & 3.66256 & -1.15712 & -1.53579 \\
\hline 37 & $\mathrm{H}$ & 4.78923 & 0.19153 & -1.34242 \\
\hline 38 & $\mathrm{H}$ & -0.1483 & 0.38661 & -1.28878 \\
\hline 39 & $\mathrm{H}$ & -1.97797 & 1.96988 & 0.64738 \\
\hline 40 & $\mathrm{H}$ & -1.70973 & -0.94695 & -1.72139 \\
\hline 41 & $\mathrm{H}$ & -3.24953 & -1.54223 & -1.15973 \\
\hline 42 & $\mathrm{H}$ & -4.02935 & -1.03362 & 1.03933 \\
\hline 43 & $\mathrm{H}$ & -5.87318 & 0.57636 & 0.76955 \\
\hline 44 & $\mathrm{H}$ & -4.78587 & 1.6692 & -0.11774 \\
\hline 45 & $\mathrm{H}$ & -4.56366 & 0.51544 & 2.83108 \\
\hline 46 & $\mathrm{H}$ & -2.80574 & 0.31947 & 2.78329 \\
\hline 47 & $\mathrm{H}$ & -3.55471 & 1.78702 & 2.14533 \\
\hline 48 & $\mathrm{H}$ & -0.83191 & 3.68073 & 0.43258 \\
\hline 49 & $\mathrm{H}$ & 0.87551 & 3.70465 & 0.87264 \\
\hline 50 & $\mathrm{H}$ & 0.3542 & 4.44095 & -0.63283 \\
\hline 51 & $\mathrm{H}$ & -0.03117 & -3.98993 & -1.77591 \\
\hline 52 & $\mathrm{H}$ & -0.14223 & -2.36054 & -2.41605 \\
\hline 53 & $\mathrm{H}$ & 1.39999 & -2.95371 & -1.80103 \\
\hline 54 & $\mathrm{H}$ & -5.97887 & 0.28615 & -1.53782 \\
\hline
\end{tabular}

B3LYP/6-311G(d,p) Energy = -931.85042122 a.u.; Population $=1.28 \%$ 


\begin{tabular}{|c|c|c|c|c|}
\hline \multicolumn{2}{|c|}{$\begin{array}{c}(7 S, 8 S, 15 R)-\mathbf{3} \\
\text { Conf. } 4 \\
\end{array}$} & \multicolumn{3}{|c|}{$\begin{array}{c}\text { Standard Orientation } \\
\text { (Ångstroms) }\end{array}$} \\
\hline I & atom & $\mathrm{X}$ & $\mathrm{Y}$ & $\mathrm{Z}$ \\
\hline 1 & $\mathrm{C}$ & 2.92082 & 0.5841 & 0.40067 \\
\hline 2 & $\mathrm{C}$ & 2.90827 & 2.08736 & 0.23063 \\
\hline 3 & $\mathrm{C}$ & 1.80963 & 2.57989 & -0.74343 \\
\hline 4 & $\mathrm{C}$ & 3.87997 & -0.34188 & -0.23715 \\
\hline 5 & $\mathrm{C}$ & 3.55543 & -1.81512 & -0.46753 \\
\hline 6 & $\mathrm{C}$ & 2.45633 & -2.45415 & 0.40794 \\
\hline 7 & $\mathrm{C}$ & 1.08093 & -2.46624 & -0.21087 \\
\hline 8 & $\mathrm{C}$ & -0.1067 & -2.21488 & 0.35764 \\
\hline 9 & $\mathrm{C}$ & -1.3843 & -2.39468 & -0.44853 \\
\hline 10 & $\mathrm{C}$ & 4.98446 & 0.16166 & -1.14327 \\
\hline 11 & $\mathrm{C}$ & 0.40252 & 2.45831 & -0.19554 \\
\hline 12 & $\mathrm{C}$ & -0.37584 & 1.42059 & -0.56634 \\
\hline 13 & $\mathrm{C}$ & -1.72128 & 1.11664 & -0.10815 \\
\hline 14 & $\mathrm{C}$ & -1.89358 & -1.14385 & -1.22114 \\
\hline 15 & $\mathrm{C}$ & -2.41787 & -0.01045 & -0.36724 \\
\hline 16 & $\mathrm{C}$ & -3.83727 & -0.20899 & 0.15831 \\
\hline 17 & $\mathrm{C}$ & -4.84019 & 0.34674 & -0.86351 \\
\hline 18 & $\mathrm{C}$ & -4.11075 & 0.35694 & 1.5581 \\
\hline 19 & $\mathrm{C}$ & -0.00726 & 3.54012 & 0.76992 \\
\hline 20 & $\mathrm{O}$ & 4.02031 & 0.02739 & 1.15966 \\
\hline 21 & $\mathrm{C}$ & -0.28966 & -1.80644 & 1.79823 \\
\hline 22 & $\mathrm{H}$ & 1.958 & 0.16505 & 0.68311 \\
\hline 23 & $\mathrm{O}$ & -6.1528 & -0.09269 & -0.49969 \\
\hline 24 & $\mathrm{H}$ & 2.75653 & 2.53649 & 1.21881 \\
\hline 25 & $\mathrm{H}$ & 3.88085 & 2.43809 & -0.11833 \\
\hline 26 & $\mathrm{H}$ & 2.01617 & 3.63013 & -0.9786 \\
\hline 27 & $\mathrm{H}$ & 1.8934 & 2.02381 & -1.68223 \\
\hline 28 & $\mathrm{H}$ & 4.49457 & -2.35621 & -0.303 \\
\hline 29 & $\mathrm{H}$ & 3.31534 & -1.95317 & -1.52789 \\
\hline 30 & $\mathrm{H}$ & 2.74922 & -3.49876 & 0.57597 \\
\hline 31 & $\mathrm{H}$ & 2.46517 & -1.98585 & 1.39433 \\
\hline 32 & $\mathrm{H}$ & 1.0708 & -2.78803 & -1.25338 \\
\hline 33 & $\mathrm{H}$ & -2.18081 & -2.75395 & 0.21306 \\
\hline 34 & $\mathrm{H}$ & -1.22529 & -3.18045 & -1.19313 \\
\hline 35 & $\mathrm{H}$ & 4.65865 & 0.15003 & -2.18748 \\
\hline 36 & $\mathrm{H}$ & 5.29544 & 1.17337 & -0.8879 \\
\hline 37 & $\mathrm{H}$ & 5.85902 & -0.49047 & -1.05899 \\
\hline 38 & $\mathrm{H}$ & 0.06457 & 0.71796 & -1.26691 \\
\hline 39 & $\mathrm{H}$ & -2.19531 & 1.86434 & 0.51904 \\
\hline 40 & $\mathrm{H}$ & -1.09484 & -0.8062 & -1.8837 \\
\hline 41 & $\mathrm{H}$ & -2.70695 & -1.48605 & -1.87279 \\
\hline 42 & $\mathrm{H}$ & -4.02159 & -1.2897 & 0.19779 \\
\hline 43 & $\mathrm{H}$ & -4.78187 & 1.44378 & -0.86593 \\
\hline 44 & $\mathrm{H}$ & -4.58464 & -0.00795 & -1.8699 \\
\hline 45 & $\mathrm{H}$ & -5.12869 & 0.10896 & 1.86404 \\
\hline 46 & $\mathrm{H}$ & -3.4172 & -0.05833 & 2.29311 \\
\hline 47 & $\mathrm{H}$ & -4.01871 & 1.44637 & 1.58173 \\
\hline 48 & $\mathrm{H}$ & -0.03897 & 4.5108 & 0.26043 \\
\hline 49 & $\mathrm{H}$ & -0.98137 & 3.36711 & 1.22563 \\
\hline 50 & $\mathrm{H}$ & 0.72429 & 3.64146 & 1.57899 \\
\hline 51 & $\mathrm{H}$ & -0.84146 & -2.58139 & 2.34388 \\
\hline 52 & $\mathrm{H}$ & 0.6542 & -1.64294 & 2.31849 \\
\hline 53 & $\mathrm{H}$ & -0.88386 & -0.89072 & 1.86782 \\
\hline 54 & $\mathrm{H}$ & -6.77665 & 0.30069 & -1.11829 \\
\hline
\end{tabular}

B3LYP/6-311G(d,p) Energy = -931.85259060 a.u.; Population $=8.51 \%$ 


\begin{tabular}{|c|c|c|c|c|}
\hline \multicolumn{2}{|c|}{$\begin{array}{c}(7 S, 8 S, 15 R)-\mathbf{3} \\
\text { Conf. } 5 \\
\end{array}$} & \multicolumn{3}{|c|}{$\begin{array}{c}\text { Standard Orientation } \\
\text { (Ångstroms) }\end{array}$} \\
\hline I & atom & $\mathrm{X}$ & $\mathrm{Y}$ & $\mathrm{Z}$ \\
\hline 1 & $\mathrm{C}$ & 2.91912 & 1.13851 & 0.54942 \\
\hline 2 & $\mathrm{C}$ & 2.91659 & 2.23185 & -0.4969 \\
\hline 3 & $\mathrm{C}$ & 1.67451 & 2.22414 & -1.41661 \\
\hline 4 & $\mathrm{C}$ & 3.56988 & -0.18457 & 0.42935 \\
\hline 5 & $\mathrm{C}$ & 3.14106 & -1.32816 & 1.34246 \\
\hline 6 & $\mathrm{C}$ & 2.29968 & -2.46914 & 0.72726 \\
\hline 7 & $\mathrm{C}$ & 0.80872 & -2.24712 & 0.68593 \\
\hline 8 & $\mathrm{C}$ & -0.04298 & -2.48758 & -0.32126 \\
\hline 9 & $\mathrm{C}$ & -1.54484 & -2.40196 & -0.11745 \\
\hline 10 & $\mathrm{C}$ & 4.32949 & -0.5863 & -0.81637 \\
\hline 11 & $\mathrm{C}$ & 0.35571 & 2.29843 & -0.67932 \\
\hline 12 & $\mathrm{C}$ & -0.47965 & 1.23946 & -0.70836 \\
\hline 13 & $\mathrm{C}$ & -1.72512 & 1.07615 & 0.01973 \\
\hline 14 & $\mathrm{C}$ & -2.26458 & -1.23328 & -0.86306 \\
\hline 15 & $\mathrm{C}$ & -2.51727 & -0.01692 & 0.00312 \\
\hline 16 & $\mathrm{C}$ & -3.77854 & -0.09114 & 0.86397 \\
\hline 17 & $\mathrm{C}$ & -4.95295 & 0.65508 & 0.19672 \\
\hline 18 & $\mathrm{C}$ & -3.60619 & 0.41691 & 2.30421 \\
\hline 19 & $\mathrm{C}$ & 0.09461 & 3.57707 & 0.07467 \\
\hline 20 & $\mathrm{O}$ & 4.18564 & 0.88738 & 1.19631 \\
\hline 21 & $\mathrm{C}$ & 0.37493 & -2.94988 & -1.69707 \\
\hline 22 & $\mathrm{H}$ & 2.08851 & 1.19172 & 1.25254 \\
\hline 23 & $\mathrm{O}$ & -5.23126 & 0.22416 & -1.13632 \\
\hline 24 & $\mathrm{H}$ & 2.98288 & 3.19046 & 0.0303 \\
\hline 25 & $\mathrm{H}$ & 3.81528 & 2.16244 & -1.11273 \\
\hline 26 & $\mathrm{H}$ & 1.69393 & 1.32119 & -2.03353 \\
\hline 27 & $\mathrm{H}$ & 1.76477 & 3.07883 & -2.0991 \\
\hline 28 & $\mathrm{H}$ & 2.61855 & -0.90612 & 2.20653 \\
\hline 29 & $\mathrm{H}$ & 4.07108 & -1.76309 & 1.72831 \\
\hline 30 & $\mathrm{H}$ & 2.69237 & -2.73786 & -0.25474 \\
\hline 31 & $\mathrm{H}$ & 2.46928 & -3.35165 & 1.35872 \\
\hline 32 & $\mathrm{H}$ & 0.37755 & -1.93951 & 1.63874 \\
\hline 33 & $\mathrm{H}$ & -1.76944 & -2.34127 & 0.95078 \\
\hline 34 & $\mathrm{H}$ & -1.97822 & -3.3454 & -0.47133 \\
\hline 35 & $\mathrm{H}$ & 5.13498 & -1.27992 & -0.55615 \\
\hline 36 & $\mathrm{H}$ & 3.67457 & -1.08675 & -1.53395 \\
\hline 37 & $\mathrm{H}$ & 4.77526 & 0.27789 & -1.30704 \\
\hline 38 & $\mathrm{H}$ & -0.1575 & 0.38792 & -1.29891 \\
\hline 39 & $\mathrm{H}$ & -2.01563 & 1.89531 & 0.67032 \\
\hline 40 & $\mathrm{H}$ & -1.70259 & -0.96694 & -1.76041 \\
\hline 41 & $\mathrm{H}$ & -3.23672 & -1.59302 & -1.21138 \\
\hline 42 & $\mathrm{H}$ & -4.07073 & -1.14619 & 0.91894 \\
\hline 43 & $\mathrm{H}$ & -5.86882 & 0.47214 & 0.7646 \\
\hline 44 & $\mathrm{H}$ & -4.75245 & 1.73479 & 0.21836 \\
\hline 45 & $\mathrm{H}$ & -4.52344 & 0.25427 & 2.8779 \\
\hline 46 & $\mathrm{H}$ & -2.79303 & -0.10924 & 2.80908 \\
\hline 47 & $\mathrm{H}$ & -3.38477 & 1.48687 & 2.33704 \\
\hline 48 & $\mathrm{H}$ & -0.91793 & 3.63998 & 0.47164 \\
\hline 49 & $\mathrm{H}$ & 0.78817 & 3.69505 & 0.9152 \\
\hline 50 & $\mathrm{H}$ & 0.25292 & 4.44132 & -0.58032 \\
\hline 51 & $\mathrm{H}$ & -0.09359 & -2.34022 & -2.47656 \\
\hline 52 & $\mathrm{H}$ & 1.45237 & -2.91625 & -1.85485 \\
\hline 53 & $\mathrm{H}$ & 0.04176 & -3.98037 & -1.86956 \\
\hline 54 & $\mathrm{H}$ & -4.49754 & 0.51201 & -1.69096 \\
\hline
\end{tabular}

B3LYP/6-311G(d,p) Energy = -931.85363151 a.u.; Population $=6.19 \%$ 


\begin{tabular}{|c|c|c|c|c|}
\hline \multicolumn{2}{|c|}{$\begin{array}{c}(7 S, 8 S, 15 R)-3 \\
\text { Conf. } 6\end{array}$} & \multicolumn{3}{|c|}{$\begin{array}{c}\text { Standard Orientation } \\
\text { (Ångstroms) }\end{array}$} \\
\hline $\mathrm{I}$ & atom & $\mathrm{X}$ & $\mathrm{Y}$ & $\mathrm{Z}$ \\
\hline 1 & $\mathrm{C}$ & 2.96376 & 1.12751 & 0.60607 \\
\hline 2 & $\mathrm{C}$ & 3.02135 & 2.20011 & -0.45947 \\
\hline 3 & $\mathrm{C}$ & 1.82475 & 2.17974 & -1.43765 \\
\hline 4 & $\mathrm{C}$ & 3.6265 & -0.19377 & 0.55136 \\
\hline 5 & $\mathrm{C}$ & 3.14249 & -1.32461 & 1.45192 \\
\hline 6 & $\mathrm{C}$ & 2.32435 & -2.46306 & 0.80118 \\
\hline 7 & $\mathrm{C}$ & 0.83911 & -2.22776 & 0.68858 \\
\hline 8 & $\mathrm{C}$ & 0.03205 & -2.46279 & -0.35597 \\
\hline 9 & $\mathrm{C}$ & -1.47661 & -2.36813 & -0.21676 \\
\hline 10 & $\mathrm{C}$ & 4.46752 & -0.61234 & -0.63554 \\
\hline 11 & $\mathrm{C}$ & 0.47252 & 2.27929 & -0.76622 \\
\hline 12 & $\mathrm{C}$ & -0.37185 & 1.2284 & -0.81656 \\
\hline 13 & $\mathrm{C}$ & -1.6565 & 1.09408 & -0.15228 \\
\hline 14 & $\mathrm{C}$ & -2.17113 & -1.22407 & -1.02245 \\
\hline 15 & $\mathrm{C}$ & -2.46307 & 0.01357 & -0.19908 \\
\hline 16 & $\mathrm{C}$ & -3.77537 & -0.0406 & 0.57777 \\
\hline 17 & $\mathrm{C}$ & -4.92672 & 0.42437 & -0.32606 \\
\hline 18 & $\mathrm{C}$ & -3.78838 & 0.71585 & 1.91219 \\
\hline 19 & $\mathrm{C}$ & 0.18809 & 3.57494 & -0.05031 \\
\hline 20 & $\mathrm{O}$ & 4.18758 & 0.89473 & 1.33668 \\
\hline 21 & $\mathrm{C}$ & 0.5088 & -2.9363 & -1.70863 \\
\hline 22 & $\mathrm{H}$ & 2.08999 & 1.18958 & 1.25367 \\
\hline 23 & $\mathrm{O}$ & -6.1664 & 0.10421 & 0.31369 \\
\hline 24 & $\mathrm{H}$ & 3.06742 & 3.1686 & 0.05152 \\
\hline 25 & $\mathrm{H}$ & 3.94851 & 2.1136 & -1.02911 \\
\hline 26 & $\mathrm{H}$ & 1.86701 & 1.26299 & -2.03268 \\
\hline 27 & $\mathrm{H}$ & 1.95376 & 3.01816 & -2.13404 \\
\hline 28 & $\mathrm{H}$ & 2.57753 & -0.8908 & 2.28284 \\
\hline 29 & $\mathrm{H}$ & 4.04676 & -1.76304 & 1.89117 \\
\hline 30 & $\mathrm{H}$ & 2.76167 & -2.73806 & -0.16 \\
\hline 31 & $\mathrm{H}$ & 2.45628 & -3.34443 & 1.44308 \\
\hline 32 & $\mathrm{H}$ & 0.36733 & -1.91189 & 1.6192 \\
\hline 33 & $\mathrm{H}$ & -1.74395 & -2.2773 & 0.8395 \\
\hline 34 & $\mathrm{H}$ & -1.89533 & -3.32266 & -0.55907 \\
\hline 35 & $\mathrm{H}$ & 5.25344 & -1.30175 & -0.31207 \\
\hline 36 & $\mathrm{H}$ & 3.86251 & -1.12295 & -1.38893 \\
\hline 37 & $\mathrm{H}$ & 4.94524 & 0.24574 & -1.1063 \\
\hline 38 & $\mathrm{H}$ & -0.03079 & 0.36278 & -1.37516 \\
\hline 39 & $\mathrm{H}$ & -1.96884 & 1.92644 & 0.46903 \\
\hline 40 & $\mathrm{H}$ & -1.57721 & -0.97867 & -1.9048 \\
\hline 41 & $\mathrm{H}$ & -3.12242 & -1.60818 & -1.40355 \\
\hline 42 & $\mathrm{H}$ & -3.97561 & -1.09781 & 0.79594 \\
\hline 43 & $\mathrm{H}$ & -4.83966 & 1.50713 & -0.49081 \\
\hline 44 & $\mathrm{H}$ & -4.86321 & -0.0719 & -1.30244 \\
\hline 45 & $\mathrm{H}$ & -4.7423 & 0.5552 & 2.41757 \\
\hline 46 & $\mathrm{H}$ & -2.98482 & 0.37082 & 2.56741 \\
\hline 47 & $\mathrm{H}$ & -3.67159 & 1.7941 & 1.77073 \\
\hline 48 & $\mathrm{H}$ & -0.84079 & 3.65289 & 0.29907 \\
\hline 49 & $\mathrm{H}$ & 0.84411 & 3.70492 & 0.81803 \\
\hline 50 & $\mathrm{H}$ & 0.38274 & 4.42466 & -0.71455 \\
\hline 51 & $\mathrm{H}$ & 0.0894 & -2.32286 & -2.51274 \\
\hline 52 & $\mathrm{H}$ & 1.59311 & -2.91968 & -1.81258 \\
\hline 53 & $\mathrm{H}$ & 0.16864 & -3.96226 & -1.894 \\
\hline 54 & $\mathrm{H}$ & -6.87832 & 0.43844 & -0.24136 \\
\hline
\end{tabular}

B3LYP/6-311G(d,p) Energy $=-931.85058847$ a.u.; Population $=3.46 \%$ 


\begin{tabular}{|c|c|c|c|c|}
\hline \multicolumn{2}{|c|}{$\begin{array}{c}(7 S, 8 S, 15 R)-\mathbf{3} \\
\text { Conf. } 7 \\
\end{array}$} & \multicolumn{3}{|c|}{$\begin{array}{c}\text { Standard Orientation } \\
\text { (Ångstroms) }\end{array}$} \\
\hline I & atom & $\mathrm{X}$ & $\mathrm{Y}$ & $\mathrm{Z}$ \\
\hline 1 & $\mathrm{C}$ & -3.3894 & 0.58647 & -0.65472 \\
\hline 2 & $\mathrm{C}$ & -3.19971 & 2.06501 & -0.384 \\
\hline 3 & $\mathrm{C}$ & -1.92436 & 2.67443 & -1.00577 \\
\hline 4 & $\mathrm{C}$ & -3.36206 & -0.52235 & 0.32877 \\
\hline 5 & $\mathrm{C}$ & -3.21239 & -1.96398 & -0.15104 \\
\hline 6 & $\mathrm{C}$ & -1.93957 & -2.74238 & 0.23818 \\
\hline 7 & $\mathrm{C}$ & -0.71034 & -2.46429 & -0.58817 \\
\hline 8 & $\mathrm{C}$ & 0.55636 & -2.3303 & -0.17038 \\
\hline 9 & $\mathrm{C}$ & 1.69053 & -2.2124 & -1.17848 \\
\hline 10 & $\mathrm{C}$ & -3.06992 & -0.27531 & 1.79144 \\
\hline 11 & $\mathrm{C}$ & -0.63437 & 2.40006 & -0.26216 \\
\hline 12 & $\mathrm{C}$ & 0.26158 & 1.52595 & -0.76436 \\
\hline 13 & $\mathrm{C}$ & 1.58181 & 1.21465 & -0.2373 \\
\hline 14 & $\mathrm{C}$ & 2.00648 & -0.78371 & -1.70575 \\
\hline 15 & $\mathrm{C}$ & 2.40482 & 0.23061 & -0.65609 \\
\hline 16 & $\mathrm{C}$ & 3.83037 & 0.08498 & -0.12845 \\
\hline 17 & $\mathrm{C}$ & 4.10881 & 0.72028 & 1.23239 \\
\hline 18 & $\mathrm{C}$ & 4.84781 & 0.64695 & -1.14727 \\
\hline 19 & $\mathrm{C}$ & -0.44211 & 3.18552 & 1.00982 \\
\hline 20 & $\mathrm{O}$ & -4.6198 & 0.03211 & -0.14327 \\
\hline 21 & $\mathrm{C}$ & 0.98477 & -2.35677 & 1.27632 \\
\hline 22 & $\mathrm{H}$ & -3.19599 & 0.30516 & -1.69154 \\
\hline 23 & $\mathrm{O}$ & 3.28082 & 0.12127 & 2.23118 \\
\hline 24 & $\mathrm{H}$ & -4.06843 & 2.56662 & -0.82713 \\
\hline 25 & $\mathrm{H}$ & -3.24507 & 2.27299 & 0.68682 \\
\hline 26 & $\mathrm{H}$ & -1.83478 & 2.32514 & -2.03942 \\
\hline 27 & $\mathrm{H}$ & -2.07033 & 3.76028 & -1.05774 \\
\hline 28 & $\mathrm{H}$ & -3.34489 & -1.98836 & -1.23758 \\
\hline 29 & $\mathrm{H}$ & -4.07145 & -2.49827 & 0.27299 \\
\hline 30 & $\mathrm{H}$ & -1.7403 & -2.62016 & 1.30421 \\
\hline 31 & $\mathrm{H}$ & -2.1841 & -3.80595 & 0.10909 \\
\hline 32 & $\mathrm{H}$ & -0.88573 & -2.46126 & -1.66499 \\
\hline 33 & $\mathrm{H}$ & 1.45866 & -2.82435 & -2.05574 \\
\hline 34 & $\mathrm{H}$ & 2.59798 & -2.64036 & -0.73933 \\
\hline 35 & $\mathrm{H}$ & -3.57271 & -1.02663 & 2.40821 \\
\hline 36 & $\mathrm{H}$ & -1.99738 & -0.33583 & 1.99167 \\
\hline 37 & $\mathrm{H}$ & -3.42274 & 0.70665 & 2.10433 \\
\hline 38 & $\mathrm{H}$ & -0.02525 & 1.02462 & -1.68401 \\
\hline 39 & $\mathrm{H}$ & 1.93695 & 1.8606 & 0.55786 \\
\hline 40 & $\mathrm{H}$ & 2.81804 & -0.89072 & -2.43503 \\
\hline 41 & $\mathrm{H}$ & 1.13807 & -0.43713 & -2.26659 \\
\hline 42 & $\mathrm{H}$ & 4.03676 & -0.98706 & -0.01809 \\
\hline 43 & $\mathrm{H}$ & 5.16753 & 0.56069 & 1.47305 \\
\hline 44 & $\mathrm{H}$ & 3.94494 & 1.80545 & 1.18781 \\
\hline 45 & $\mathrm{H}$ & 5.87305 & 0.44426 & -0.82407 \\
\hline 46 & $\mathrm{H}$ & 4.71731 & 0.1995 & -2.13401 \\
\hline 47 & $\mathrm{H}$ & 4.72914 & 1.72947 & -1.25157 \\
\hline 48 & $\mathrm{H}$ & 0.44875 & 2.89329 & 1.56478 \\
\hline 49 & $\mathrm{H}$ & -0.37301 & 4.25847 & 0.79238 \\
\hline 50 & $\mathrm{H}$ & -1.30058 & 3.06184 & 1.67871 \\
\hline 51 & $\mathrm{H}$ & 1.56091 & -3.2687 & 1.47987 \\
\hline 52 & $\mathrm{H}$ & 1.64253 & -1.5142 & 1.50568 \\
\hline 53 & $\mathrm{H}$ & 0.14602 & -2.33537 & 1.97271 \\
\hline 54 & $\mathrm{H}$ & 3.49331 & 0.53201 & 3.07551 \\
\hline
\end{tabular}

B3LYP/6-311G(d,p) Energy = -931.84819192 a.u.; Population $=0.66 \%$ 


\begin{tabular}{|c|c|c|c|c|}
\hline \multicolumn{2}{|c|}{$\begin{array}{c}(7 S, 8 S, 15 R)-\mathbf{3} \\
\text { Conf. } 8 \\
\end{array}$} & \multicolumn{3}{|c|}{$\begin{array}{c}\text { Standard Orientation } \\
\text { (Ångstroms) }\end{array}$} \\
\hline I & atom & $\mathrm{X}$ & $\mathrm{Y}$ & $\mathrm{Z}$ \\
\hline 1 & $\mathrm{C}$ & 3.03131 & 0.94813 & 0.67633 \\
\hline 2 & $\mathrm{C}$ & 3.19322 & 2.25541 & -0.06789 \\
\hline 3 & $\mathrm{C}$ & 2.02454 & 2.58012 & -1.02747 \\
\hline 4 & $\mathrm{C}$ & 3.55591 & -0.37203 & 0.26181 \\
\hline 5 & $\mathrm{C}$ & 2.95599 & -1.64048 & 0.861 \\
\hline 6 & $\mathrm{C}$ & 2.14338 & -2.57516 & -0.06423 \\
\hline 7 & $\mathrm{C}$ & 0.75895 & -2.11713 & -0.45256 \\
\hline 8 & $\mathrm{C}$ & -0.40071 & -2.73957 & -0.19663 \\
\hline 9 & $\mathrm{C}$ & -1.74742 & -2.3217 & -0.77274 \\
\hline 10 & $\mathrm{C}$ & 4.34749 & -0.54816 & -1.0152 \\
\hline 11 & $\mathrm{C}$ & 0.66067 & 2.53022 & -0.37411 \\
\hline 12 & $\mathrm{C}$ & -0.18442 & 1.5282 & -0.69263 \\
\hline 13 & $\mathrm{C}$ & -1.48443 & 1.24415 & -0.11274 \\
\hline 14 & $\mathrm{C}$ & -1.94174 & -0.91122 & -1.37473 \\
\hline 15 & $\mathrm{C}$ & -2.26842 & 0.17596 & -0.37101 \\
\hline 16 & $\mathrm{C}$ & -3.63811 & 0.05034 & 0.29612 \\
\hline 17 & $\mathrm{C}$ & -4.61786 & 1.03603 & -0.35488 \\
\hline 18 & $\mathrm{C}$ & -3.62203 & 0.20396 & 1.82482 \\
\hline 19 & $\mathrm{C}$ & 0.375 & 3.6097 & 0.63719 \\
\hline 20 & $\mathrm{O}$ & 4.22473 & 0.41362 & 1.28764 \\
\hline 21 & $\mathrm{C}$ & -0.52279 & -4.00464 & 0.62321 \\
\hline 22 & $\mathrm{H}$ & 2.16825 & 0.91895 & 1.34026 \\
\hline 23 & $\mathrm{O}$ & -5.93983 & 0.72758 & 0.09856 \\
\hline 24 & $\mathrm{H}$ & 3.29196 & 3.04888 & 0.68171 \\
\hline 25 & $\mathrm{H}$ & 4.1278 & 2.2526 & -0.63223 \\
\hline 26 & $\mathrm{H}$ & 2.20297 & 3.57923 & -1.44391 \\
\hline 27 & $\mathrm{H}$ & 2.04943 & 1.87703 & -1.8649 \\
\hline 28 & $\mathrm{H}$ & 2.35227 & -1.36596 & 1.73109 \\
\hline 29 & $\mathrm{H}$ & 3.80744 & -2.21784 & 1.24276 \\
\hline 30 & $\mathrm{H}$ & 2.71996 & -2.74604 & -0.98182 \\
\hline 31 & $\mathrm{H}$ & 2.09386 & -3.54576 & 0.43057 \\
\hline 32 & $\mathrm{H}$ & 0.73084 & -1.21299 & -1.05283 \\
\hline 33 & $\mathrm{H}$ & -2.51023 & -2.4855 & -0.00296 \\
\hline 34 & $\mathrm{H}$ & -1.98768 & -3.05758 & -1.5527 \\
\hline 35 & $\mathrm{H}$ & 5.07704 & -1.35537 & -0.89636 \\
\hline 36 & $\mathrm{H}$ & 3.69366 & -0.80831 & -1.85169 \\
\hline 37 & $\mathrm{H}$ & 4.88943 & 0.36045 & -1.27449 \\
\hline 38 & $\mathrm{H}$ & 0.16503 & 0.83769 & -1.45273 \\
\hline 39 & $\mathrm{H}$ & -1.84733 & 1.95941 & 0.61913 \\
\hline 40 & $\mathrm{H}$ & -1.08686 & -0.64531 & -1.99707 \\
\hline 41 & $\mathrm{H}$ & -2.79416 & -0.98076 & -2.06265 \\
\hline 42 & $\mathrm{H}$ & -4.03165 & -0.94653 & 0.07055 \\
\hline 43 & $\mathrm{H}$ & -4.3427 & 2.06373 & -0.08177 \\
\hline 44 & $\mathrm{H}$ & -4.55683 & 0.94878 & -1.44746 \\
\hline 45 & $\mathrm{H}$ & -4.63037 & 0.07678 & 2.22371 \\
\hline 46 & $\mathrm{H}$ & -2.96982 & -0.54234 & 2.2853 \\
\hline 47 & $\mathrm{H}$ & -3.26726 & 1.19325 & 2.12632 \\
\hline 48 & $\mathrm{H}$ & 0.5604 & 4.59695 & 0.19899 \\
\hline 49 & $\mathrm{H}$ & -0.65044 & 3.59237 & 1.00447 \\
\hline 50 & $\mathrm{H}$ & 1.03883 & 3.52743 & 1.50556 \\
\hline 51 & $\mathrm{H}$ & -1.01099 & -4.79388 & 0.03944 \\
\hline 52 & $\mathrm{H}$ & 0.42962 & -4.39313 & 0.97966 \\
\hline 53 & $\mathrm{H}$ & -1.16069 & -3.82765 & 1.49671 \\
\hline 54 & $\mathrm{H}$ & -6.54202 & 1.36895 & -0.29215 \\
\hline
\end{tabular}

B3LYP/6-311G(d,p) Energy = -931.84288311 a.u.; Population $=0.35 \%$ 


\begin{tabular}{|c|c|c|c|c|}
\hline \multicolumn{2}{|c|}{$\begin{array}{c}(7 S, 8 S, 15 R)-\mathbf{3} \\
\text { Conf. } 9 \\
\end{array}$} & \multicolumn{3}{|c|}{$\begin{array}{c}\text { Standard Orientation } \\
\text { (Ångstroms) }\end{array}$} \\
\hline I & atom & $\mathrm{X}$ & $\mathrm{Y}$ & $\mathrm{Z}$ \\
\hline 1 & $\mathrm{C}$ & 2.67425 & 0.5486 & -0.34359 \\
\hline 2 & $\mathrm{C}$ & 2.89859 & 2.03355 & -0.57594 \\
\hline 3 & $\mathrm{C}$ & 1.64116 & 2.76493 & -1.11025 \\
\hline 4 & $\mathrm{C}$ & 3.72819 & -0.41601 & 0.01 \\
\hline 5 & $\mathrm{C}$ & 3.59312 & -1.89065 & -0.38882 \\
\hline 6 & $\mathrm{C}$ & 2.39438 & -2.66213 & 0.20449 \\
\hline 7 & $\mathrm{C}$ & 1.04697 & -2.47807 & -0.44902 \\
\hline 8 & $\mathrm{C}$ & -0.1272 & -2.18216 & 0.14357 \\
\hline 9 & $\mathrm{C}$ & -1.4296 & -2.24752 & -0.63796 \\
\hline 10 & $\mathrm{C}$ & 5.15871 & 0.04191 & 0.19805 \\
\hline 11 & $\mathrm{C}$ & 0.40625 & 2.57116 & -0.25652 \\
\hline 12 & $\mathrm{C}$ & -0.51581 & 1.66378 & -0.63988 \\
\hline 13 & $\mathrm{C}$ & -1.72833 & 1.25892 & 0.05613 \\
\hline 14 & $\mathrm{C}$ & -2.00983 & -0.91217 & -1.19142 \\
\hline 15 & $\mathrm{C}$ & -2.42873 & 0.12607 & -0.1716 \\
\hline 16 & $\mathrm{C}$ & -3.72529 & -0.17206 & 0.57711 \\
\hline 17 & $\mathrm{C}$ & -4.96865 & 0.32338 & -0.19871 \\
\hline 18 & $\mathrm{C}$ & -3.79563 & 0.39063 & 2.00638 \\
\hline 19 & $\mathrm{C}$ & 0.34884 & 3.37172 & 1.01745 \\
\hline 20 & $\mathrm{O}$ & 2.80019 & 0.06044 & 1.01675 \\
\hline 21 & $\mathrm{C}$ & -0.2641 & -1.86739 & 1.61495 \\
\hline 22 & $\mathrm{H}$ & 1.807 & 0.13062 & -0.8481 \\
\hline 23 & $\mathrm{O}$ & -5.15232 & -0.27174 & -1.4841 \\
\hline 24 & $\mathrm{H}$ & 3.22964 & 2.48465 & 0.36303 \\
\hline 25 & $\mathrm{H}$ & 3.70966 & 2.1822 & -1.29739 \\
\hline 26 & $\mathrm{H}$ & 1.87989 & 3.83153 & -1.19491 \\
\hline 27 & $\mathrm{H}$ & 1.43824 & 2.40646 & -2.12394 \\
\hline 28 & $\mathrm{H}$ & 4.50267 & -2.40534 & -0.06181 \\
\hline 29 & $\mathrm{H}$ & 3.5864 & -1.96007 & -1.48316 \\
\hline 30 & $\mathrm{H}$ & 2.64512 & -3.72778 & 0.1109 \\
\hline 31 & $\mathrm{H}$ & 2.34226 & -2.45752 & 1.27379 \\
\hline 32 & $\mathrm{H}$ & 1.02656 & -2.71336 & -1.51439 \\
\hline 33 & $\mathrm{H}$ & -2.18688 & -2.72972 & -0.00748 \\
\hline 34 & $\mathrm{H}$ & -1.29129 & -2.90367 & -1.50249 \\
\hline 35 & $\mathrm{H}$ & 5.63245 & -0.53262 & 0.99993 \\
\hline 36 & $\mathrm{H}$ & 5.73417 & -0.12852 & -0.71732 \\
\hline 37 & $\mathrm{H}$ & 5.21966 & 1.10029 & 0.45086 \\
\hline 38 & $\mathrm{H}$ & -0.31315 & 1.15413 & -1.57671 \\
\hline 39 & $\mathrm{H}$ & -2.0828 & 1.9288 & 0.83341 \\
\hline 40 & $\mathrm{H}$ & -1.27973 & -0.50022 & -1.88937 \\
\hline 41 & $\mathrm{H}$ & -2.89276 & -1.17222 & -1.78295 \\
\hline 42 & $\mathrm{H}$ & -3.82034 & -1.26328 & 0.65265 \\
\hline 43 & $\mathrm{H}$ & -5.85901 & 0.16232 & 0.42316 \\
\hline 44 & $\mathrm{H}$ & -4.87515 & 1.39717 & -0.37985 \\
\hline 45 & $\mathrm{H}$ & -4.68136 & 0.00778 & 2.52016 \\
\hline 46 & $\mathrm{H}$ & -2.91722 & 0.10577 & 2.58877 \\
\hline 47 & $\mathrm{H}$ & -3.86252 & 1.48214 & 2.01214 \\
\hline 48 & $\mathrm{H}$ & 0.40344 & 4.4449 & 0.80078 \\
\hline 49 & $\mathrm{H}$ & -0.55509 & 3.18735 & 1.59757 \\
\hline 50 & $\mathrm{H}$ & 1.20649 & 3.14087 & 1.65991 \\
\hline 51 & $\mathrm{H}$ & -0.66467 & -2.73187 & 2.15936 \\
\hline 52 & $\mathrm{H}$ & 0.68335 & -1.58217 & 2.06993 \\
\hline 53 & $\mathrm{H}$ & -0.96728 & -1.04529 & 1.76506 \\
\hline 54 & $\mathrm{H}$ & -5.36442 & -1.20192 & -1.34926 \\
\hline
\end{tabular}

B3LYP/6-311G(d,p) Energy = -931.84829149 a.u.; Population $=0.04 \%$ 


\begin{tabular}{|c|c|c|c|c|}
\hline \multicolumn{2}{|c|}{$\begin{array}{c}(7 S, 8 S, 15 R)-\mathbf{3} \\
\text { Conf. } 10 \\
\end{array}$} & \multicolumn{3}{|c|}{$\begin{array}{c}\text { Standard Orientation } \\
\text { (Ångstroms) }\end{array}$} \\
\hline I & atom & $\mathrm{X}$ & $\mathrm{Y}$ & $\mathrm{Z}$ \\
\hline 1 & $\mathrm{C}$ & 2.98123 & 1.09455 & 0.51949 \\
\hline 2 & $\mathrm{C}$ & 2.99411 & 2.16606 & -0.5489 \\
\hline 3 & $\mathrm{C}$ & 1.74305 & 2.17016 & -1.45609 \\
\hline 4 & $\mathrm{C}$ & 3.59784 & -0.24644 & 0.41902 \\
\hline 5 & $\mathrm{C}$ & 3.15142 & -1.36104 & 1.35893 \\
\hline 6 & $\mathrm{C}$ & 2.26995 & -2.48821 & 0.77589 \\
\hline 7 & $\mathrm{C}$ & 0.78645 & -2.2197 & 0.74509 \\
\hline 8 & $\mathrm{C}$ & -0.08426 & -2.45849 & -0.24614 \\
\hline 9 & $\mathrm{C}$ & -1.5799 & -2.31639 & -0.02925 \\
\hline 10 & $\mathrm{C}$ & 4.33222 & -0.6921 & -0.82714 \\
\hline 11 & $\mathrm{C}$ & 0.43178 & 2.29837 & -0.71215 \\
\hline 12 & $\mathrm{C}$ & -0.43579 & 1.26527 & -0.7168 \\
\hline 13 & $\mathrm{C}$ & -1.68866 & 1.15626 & 0.01015 \\
\hline 14 & $\mathrm{C}$ & -2.27408 & -1.15864 & -0.81577 \\
\hline 15 & $\mathrm{C}$ & -2.51336 & 0.08756 & 0.01084 \\
\hline 16 & $\mathrm{C}$ & -3.78309 & 0.06341 & 0.85768 \\
\hline 17 & $\mathrm{C}$ & -5.00425 & 0.61212 & 0.085 \\
\hline 18 & $\mathrm{C}$ & -3.68044 & 0.80078 & 2.20252 \\
\hline 19 & $\mathrm{C}$ & 0.2123 & 3.60017 & 0.01535 \\
\hline 20 & $\mathrm{O}$ & 4.24874 & 0.82457 & 1.15743 \\
\hline 21 & $\mathrm{C}$ & 0.3035 & -2.97145 & -1.61283 \\
\hline 22 & $\mathrm{H}$ & 2.16036 & 1.18313 & 1.23043 \\
\hline 23 & $\mathrm{O}$ & -5.31371 & -0.09324 & -1.11795 \\
\hline 24 & $\mathrm{H}$ & 3.08971 & 3.13333 & -0.04237 \\
\hline 25 & $\mathrm{H}$ & 3.88438 & 2.06135 & -1.17196 \\
\hline 26 & $\mathrm{H}$ & 1.73279 & 1.25256 & -2.05137 \\
\hline 27 & $\mathrm{H}$ & 1.85066 & 3.00514 & -2.16035 \\
\hline 28 & $\mathrm{H}$ & 2.65283 & -0.90934 & 2.22224 \\
\hline 29 & $\mathrm{H}$ & 4.07441 & -1.81474 & 1.74004 \\
\hline 30 & $\mathrm{H}$ & 2.64353 & -2.788 & -0.2046 \\
\hline 31 & $\mathrm{H}$ & 2.41974 & -3.36285 & 1.42318 \\
\hline 32 & $\mathrm{H}$ & 0.37694 & -1.87181 & 1.69363 \\
\hline 33 & $\mathrm{H}$ & -1.78719 & -2.20469 & 1.03845 \\
\hline 34 & $\mathrm{H}$ & -2.0456 & -3.26078 & -0.33705 \\
\hline 35 & $\mathrm{H}$ & 5.12131 & -1.40258 & -0.56231 \\
\hline 36 & $\mathrm{H}$ & 3.6557 & -1.18796 & -1.52774 \\
\hline 37 & $\mathrm{H}$ & 4.7955 & 0.15031 & -1.33899 \\
\hline 38 & $\mathrm{H}$ & -0.13946 & 0.39293 & -1.29029 \\
\hline 39 & $\mathrm{H}$ & -1.95734 & 2.00097 & 0.6361 \\
\hline 40 & $\mathrm{H}$ & -1.69793 & -0.9256 & -1.71326 \\
\hline 41 & $\mathrm{H}$ & -3.2461 & -1.50686 & -1.16977 \\
\hline 42 & $\mathrm{H}$ & -4.00189 & -0.98961 & 1.08184 \\
\hline 43 & $\mathrm{H}$ & -5.87431 & 0.62206 & 0.75456 \\
\hline 44 & $\mathrm{H}$ & -4.80291 & 1.64261 & -0.21902 \\
\hline 45 & $\mathrm{H}$ & -4.57295 & 0.61497 & 2.80627 \\
\hline 46 & $\mathrm{H}$ & -2.81028 & 0.4629 & 2.76928 \\
\hline 47 & $\mathrm{H}$ & -3.59619 & 1.88309 & 2.07093 \\
\hline 48 & $\mathrm{H}$ & -0.79634 & 3.70094 & 0.41459 \\
\hline 49 & $\mathrm{H}$ & 0.91212 & 3.71563 & 0.85118 \\
\hline 50 & $\mathrm{H}$ & 0.393 & 4.44583 & -0.65801 \\
\hline 51 & $\mathrm{H}$ & -0.05892 & -3.99727 & -1.75152 \\
\hline 52 & $\mathrm{H}$ & -0.15845 & -2.37195 & -2.40395 \\
\hline 53 & $\mathrm{H}$ & 1.3794 & -2.97125 & -1.78402 \\
\hline 54 & $\mathrm{H}$ & -5.63692 & -0.96659 & -0.87147 \\
\hline
\end{tabular}

B3LYP/6-311G(d,p) Energy = -931.85203184 a.u.; Population $=3.31 \%$ 


\begin{tabular}{|c|c|c|c|c|}
\hline \multicolumn{2}{|c|}{$\begin{array}{c}(7 S, 8 S, 15 R)-\mathbf{3} \\
\text { Conf. } 11 \\
\end{array}$} & \multicolumn{3}{|c|}{$\begin{array}{c}\text { Standard Orientation } \\
\text { (Ångstroms) }\end{array}$} \\
\hline I & atom & $\mathrm{X}$ & $\mathrm{Y}$ & $\mathrm{Z}$ \\
\hline 1 & $\mathrm{C}$ & -3.49663 & 0.60177 & -0.54288 \\
\hline 2 & $\mathrm{C}$ & -3.28127 & 2.07618 & -0.26844 \\
\hline 3 & $\mathrm{C}$ & -2.03443 & 2.68168 & -0.95009 \\
\hline 4 & $\mathrm{C}$ & -3.42756 & -0.51985 & 0.42431 \\
\hline 5 & $\mathrm{C}$ & -3.3187 & -1.95628 & -0.08325 \\
\hline 6 & $\mathrm{C}$ & -2.04819 & -2.7631 & 0.25251 \\
\hline 7 & $\mathrm{C}$ & -0.83463 & -2.48151 & -0.59478 \\
\hline 8 & $\mathrm{C}$ & 0.43758 & -2.33036 & -0.20071 \\
\hline 9 & $\mathrm{C}$ & 1.55486 & -2.20989 & -1.2266 \\
\hline 10 & $\mathrm{C}$ & -3.05475 & -0.2962 & 1.87234 \\
\hline 11 & $\mathrm{C}$ & -0.71778 & 2.42895 & -0.24656 \\
\hline 12 & $\mathrm{C}$ & 0.15081 & 1.52517 & -0.74392 \\
\hline 13 & $\mathrm{C}$ & 1.48405 & 1.21592 & -0.24924 \\
\hline 14 & $\mathrm{C}$ & 1.87868 & -0.77745 & -1.73831 \\
\hline 15 & $\mathrm{C}$ & 2.29152 & 0.22264 & -0.68154 \\
\hline 16 & $\mathrm{C}$ & 3.7167 & 0.06489 & -0.16449 \\
\hline 17 & $\mathrm{C}$ & 3.92597 & 0.54099 & 1.2818 \\
\hline 18 & $\mathrm{C}$ & 4.73013 & 0.74574 & -1.1076 \\
\hline 19 & $\mathrm{C}$ & -0.47285 & 3.26899 & 0.98043 \\
\hline 20 & $\mathrm{O}$ & -4.70286 & 0.05228 & 0.02748 \\
\hline 21 & $\mathrm{C}$ & 0.88767 & -2.33216 & 1.23959 \\
\hline 22 & $\mathrm{H}$ & -3.36209 & 0.33113 & -1.59174 \\
\hline 23 & $\mathrm{O}$ & 5.23372 & 0.23278 & 1.77239 \\
\hline 24 & $\mathrm{H}$ & -4.16849 & 2.58692 & -0.66149 \\
\hline 25 & $\mathrm{H}$ & -3.2694 & 2.27443 & 0.80513 \\
\hline 26 & $\mathrm{H}$ & -1.97996 & 2.312 & -1.97909 \\
\hline 27 & $\mathrm{H}$ & -2.18819 & 3.76521 & -1.01819 \\
\hline 28 & $\mathrm{H}$ & -3.48729 & -1.96143 & -1.16496 \\
\hline 29 & $\mathrm{H}$ & -4.17191 & -2.4834 & 0.36092 \\
\hline 30 & $\mathrm{H}$ & -1.82302 & -2.67415 & 1.31649 \\
\hline 31 & $\mathrm{H}$ & -2.31132 & -3.8187 & 0.09865 \\
\hline 32 & $\mathrm{H}$ & -1.02731 & -2.48962 & -1.6685 \\
\hline 33 & $\mathrm{H}$ & 1.30141 & -2.80696 & -2.1078 \\
\hline 34 & $\mathrm{H}$ & 2.46498 & -2.65396 & -0.80892 \\
\hline 35 & $\mathrm{H}$ & -3.54771 & -1.03909 & 2.50704 \\
\hline 36 & $\mathrm{H}$ & -1.97569 & -0.391 & 2.01708 \\
\hline 37 & $\mathrm{H}$ & -3.36127 & 0.69244 & 2.21195 \\
\hline 38 & $\mathrm{H}$ & -0.17347 & 0.98848 & -1.63024 \\
\hline 39 & $\mathrm{H}$ & 1.86622 & 1.87885 & 0.51994 \\
\hline 40 & $\mathrm{H}$ & 2.69218 & -0.87919 & -2.46683 \\
\hline 41 & $\mathrm{H}$ & 1.01363 & -0.41771 & -2.29599 \\
\hline 42 & $\mathrm{H}$ & 3.9454 & -1.01039 & -0.16452 \\
\hline 43 & $\mathrm{H}$ & 3.84753 & 1.62844 & 1.34988 \\
\hline 44 & $\mathrm{H}$ & 3.15946 & 0.10836 & 1.93603 \\
\hline 45 & $\mathrm{H}$ & 5.74624 & 0.59153 & -0.73849 \\
\hline 46 & $\mathrm{H}$ & 4.67045 & 0.34459 & -2.12191 \\
\hline 47 & $\mathrm{H}$ & 4.53966 & 1.82208 & -1.15615 \\
\hline 48 & $\mathrm{H}$ & 0.43291 & 2.99288 & 1.51917 \\
\hline 49 & $\mathrm{H}$ & -0.39803 & 4.32916 & 0.70919 \\
\hline 50 & $\mathrm{H}$ & -1.31054 & 3.18965 & 1.68165 \\
\hline 51 & $\mathrm{H}$ & 1.52988 & -3.19892 & 1.43683 \\
\hline 52 & $\mathrm{H}$ & 1.48707 & -1.44262 & 1.45339 \\
\hline 53 & $\mathrm{H}$ & 0.06293 & -2.35961 & 1.95125 \\
\hline 54 & $\mathrm{H}$ & 5.32177 & -0.72668 & 1.78593 \\
\hline
\end{tabular}

B3LYP/6-311G(d,p) Energy = -931.84895533 a.u.; Population $=1.13 \%$ 


\begin{tabular}{|c|c|c|c|c|}
\hline \multicolumn{2}{|c|}{$\begin{array}{c}(7 S, 8 S, 15 R)-\mathbf{3} \\
\text { Conf. } 12 \\
\end{array}$} & \multicolumn{3}{|c|}{$\begin{array}{c}\text { Standard Orientation } \\
\text { (Ångstroms) }\end{array}$} \\
\hline I & atom & $\mathrm{X}$ & $\mathrm{Y}$ & $\mathrm{Z}$ \\
\hline 1 & $\mathrm{C}$ & -3.40596 & 0.56787 & -0.60619 \\
\hline 2 & $\mathrm{C}$ & -3.22424 & 2.04345 & -0.31695 \\
\hline 3 & $\mathrm{C}$ & -1.98413 & 2.67667 & -0.98582 \\
\hline 4 & $\mathrm{C}$ & -3.29705 & -0.56345 & 0.34553 \\
\hline 5 & $\mathrm{C}$ & -3.15063 & -1.98783 & -0.1857 \\
\hline 6 & $\mathrm{C}$ & -1.86304 & -2.76754 & 0.1416 \\
\hline 7 & $\mathrm{C}$ & -0.63958 & -2.41151 & -0.66452 \\
\hline 8 & $\mathrm{C}$ & 0.63499 & -2.38644 & -0.251 \\
\hline 9 & $\mathrm{C}$ & 1.77151 & -2.17379 & -1.24336 \\
\hline 10 & $\mathrm{C}$ & -2.91682 & -0.34992 & 1.79297 \\
\hline 11 & $\mathrm{C}$ & -0.67224 & 2.44743 & -0.2659 \\
\hline 12 & $\mathrm{C}$ & 0.20826 & 1.54151 & -0.73743 \\
\hline 13 & $\mathrm{C}$ & 1.53771 & 1.25522 & -0.21911 \\
\hline 14 & $\mathrm{C}$ & 2.01848 & -0.71465 & -1.71554 \\
\hline 15 & $\mathrm{C}$ & 2.37916 & 0.28347 & -0.63722 \\
\hline 16 & $\mathrm{C}$ & 3.80163 & 0.16522 & -0.09423 \\
\hline 17 & $\mathrm{C}$ & 3.99624 & 0.68503 & 1.3362 \\
\hline 18 & $\mathrm{C}$ & 4.80706 & 0.87197 & -1.02833 \\
\hline 19 & $\mathrm{C}$ & -0.44983 & 3.31116 & 0.94878 \\
\hline 20 & $\mathrm{O}$ & -4.59121 & -0.02106 & -0.0322 \\
\hline 21 & $\mathrm{C}$ & 1.07027 & -2.64607 & 1.17096 \\
\hline 22 & $\mathrm{H}$ & -3.27348 & 0.31346 & -1.65944 \\
\hline 23 & $\mathrm{O}$ & 3.15187 & 0.05888 & 2.30437 \\
\hline 24 & $\mathrm{H}$ & -4.11888 & 2.54029 & -0.71081 \\
\hline 25 & $\mathrm{H}$ & -3.22195 & 2.23151 & 0.75852 \\
\hline 26 & $\mathrm{H}$ & -1.91127 & 2.30934 & -2.01445 \\
\hline 27 & $\mathrm{H}$ & -2.15791 & 3.75686 & -1.05397 \\
\hline 28 & $\mathrm{H}$ & -3.31426 & -1.97814 & -1.26825 \\
\hline 29 & $\mathrm{H}$ & -3.99189 & -2.54466 & 0.24473 \\
\hline 30 & $\mathrm{H}$ & -1.66142 & -2.71589 & 1.21317 \\
\hline 31 & $\mathrm{H}$ & -2.09065 & -3.82408 & -0.05806 \\
\hline 32 & $\mathrm{H}$ & -0.82769 & -2.24749 & -1.72642 \\
\hline 33 & $\mathrm{H}$ & 1.57908 & -2.76461 & -2.14449 \\
\hline 34 & $\mathrm{H}$ & 2.6952 & -2.57261 & -0.81264 \\
\hline 35 & $\mathrm{H}$ & -3.39083 & -1.10928 & 2.42262 \\
\hline 36 & $\mathrm{H}$ & -1.83498 & -0.42726 & 1.92728 \\
\hline 37 & $\mathrm{H}$ & -3.23828 & 0.62892 & 2.14692 \\
\hline 38 & $\mathrm{H}$ & -0.10026 & 0.9853 & -1.61709 \\
\hline 39 & $\mathrm{H}$ & 1.89535 & 1.93677 & 0.54735 \\
\hline 40 & $\mathrm{H}$ & 2.83748 & -0.75316 & -2.44425 \\
\hline 41 & $\mathrm{H}$ & 1.1381 & -0.38474 & -2.26732 \\
\hline 42 & $\mathrm{H}$ & 4.06035 & -0.9003 & -0.07772 \\
\hline 43 & $\mathrm{H}$ & 5.01857 & 0.46707 & 1.65248 \\
\hline 44 & $\mathrm{H}$ & 3.87588 & 1.77616 & 1.36935 \\
\hline 45 & $\mathrm{H}$ & 5.83351 & 0.71194 & -0.68478 \\
\hline 46 & $\mathrm{H}$ & 4.73694 & 0.49511 & -2.05067 \\
\hline 47 & $\mathrm{H}$ & 4.61764 & 1.94896 & -1.05331 \\
\hline 48 & $\mathrm{H}$ & 0.44566 & 3.04877 & 1.51106 \\
\hline 49 & $\mathrm{H}$ & -0.37161 & 4.36575 & 0.6578 \\
\hline 50 & $\mathrm{H}$ & -1.30101 & 3.24414 & 1.63484 \\
\hline 51 & $\mathrm{H}$ & 1.56102 & -3.62516 & 1.2427 \\
\hline 52 & $\mathrm{H}$ & 1.80958 & -1.90835 & 1.49377 \\
\hline 53 & $\mathrm{H}$ & 0.24582 & -2.63812 & 1.88424 \\
\hline 54 & $\mathrm{H}$ & 2.24001 & 0.2441 & 2.0511 \\
\hline
\end{tabular}

B3LYP/6-311G(d,p) Energy = -931.85065151 a.u.; Population $=10.27 \%$ 


\begin{tabular}{|c|c|c|c|c|}
\hline \multicolumn{2}{|c|}{$\begin{array}{c}(7 S, 8 S, 15 R)-3 \\
\text { Conf. } 13\end{array}$} & \multicolumn{3}{|c|}{$\begin{array}{c}\text { Standard Orientation } \\
\text { (Ångstroms) }\end{array}$} \\
\hline $\mathrm{I}$ & atom & $\mathrm{X}$ & $\mathrm{Y}$ & $\mathrm{Z}$ \\
\hline 1 & $\mathrm{C}$ & 3.00111 & -0.14171 & -0.26096 \\
\hline 2 & $\mathrm{C}$ & 3.26924 & -1.45131 & -0.97754 \\
\hline 3 & $\mathrm{C}$ & 2.08245 & -1.90597 & -1.85901 \\
\hline 4 & $\mathrm{C}$ & 3.05628 & 0.07924 & 1.19992 \\
\hline 5 & $\mathrm{C}$ & 2.3043 & 1.21289 & 1.89087 \\
\hline 6 & $\mathrm{C}$ & 1.79363 & 2.38085 & 1.01827 \\
\hline 7 & $\mathrm{C}$ & 0.35117 & 2.25525 & 0.59711 \\
\hline 8 & $\mathrm{C}$ & -0.20489 & 2.43834 & -0.60791 \\
\hline 9 & $\mathrm{C}$ & -1.70947 & 2.35672 & -0.78504 \\
\hline 10 & $\mathrm{C}$ & 3.423 & -1.04292 & 2.14887 \\
\hline 11 & $\mathrm{C}$ & 0.78661 & -2.09194 & -1.09949 \\
\hline 12 & $\mathrm{C}$ & -0.18916 & -1.16767 & -1.21992 \\
\hline 13 & $\mathrm{C}$ & -1.45724 & -1.11505 & -0.51333 \\
\hline 14 & $\mathrm{C}$ & -2.23646 & 1.07925 & -1.50418 \\
\hline 15 & $\mathrm{C}$ & -2.37444 & -0.12768 & -0.6004 \\
\hline 16 & $\mathrm{C}$ & -3.6674 & -0.17129 & 0.20548 \\
\hline 17 & $\mathrm{C}$ & -3.49762 & -0.73785 & 1.62461 \\
\hline 18 & $\mathrm{C}$ & -4.78256 & -0.91338 & -0.55652 \\
\hline 19 & $\mathrm{C}$ & 0.71263 & -3.31556 & -0.22388 \\
\hline 20 & $\mathrm{O}$ & 4.13981 & 0.51655 & 0.33993 \\
\hline 21 & $\mathrm{C}$ & 0.56473 & 2.79374 & -1.85689 \\
\hline 22 & $\mathrm{H}$ & 2.3765 & 0.54291 & -0.83071 \\
\hline 23 & $\mathrm{O}$ & -4.69141 & -0.62506 & 2.40482 \\
\hline 24 & $\mathrm{H}$ & 4.14137 & -1.30269 & -1.62426 \\
\hline 25 & $\mathrm{H}$ & 3.54183 & -2.2384 & -0.27211 \\
\hline 26 & $\mathrm{H}$ & 1.93502 & -1.16742 & -2.65279 \\
\hline 27 & $\mathrm{H}$ & 2.3674 & -2.84488 & -2.34848 \\
\hline 28 & $\mathrm{H}$ & 2.99545 & 1.60767 & 2.64486 \\
\hline 29 & $\mathrm{H}$ & 1.46905 & 0.7791 & 2.45178 \\
\hline 30 & $\mathrm{H}$ & 1.87978 & 3.29435 & 1.62043 \\
\hline 31 & $\mathrm{H}$ & 2.46727 & 2.52617 & 0.17128 \\
\hline 32 & $\mathrm{H}$ & -0.32643 & 2.02934 & 1.4207 \\
\hline 33 & $\mathrm{H}$ & -2.03292 & 3.22391 & -1.37373 \\
\hline 34 & $\mathrm{H}$ & -2.20054 & 2.44358 & 0.18861 \\
\hline 35 & $\mathrm{H}$ & 3.92432 & -0.63321 & 3.03092 \\
\hline 36 & $\mathrm{H}$ & 2.52684 & -1.57022 & 2.48841 \\
\hline 37 & $\mathrm{H}$ & 4.09681 & -1.76248 & 1.68519 \\
\hline 38 & $\mathrm{H}$ & 0.01237 & -0.34469 & -1.89799 \\
\hline 39 & $\mathrm{H}$ & -1.66687 & -1.94312 & 0.15636 \\
\hline 40 & $\mathrm{H}$ & -3.22783 & 1.31454 & -1.907 \\
\hline 41 & $\mathrm{H}$ & -1.60768 & 0.86093 & -2.36959 \\
\hline 42 & $\mathrm{H}$ & -3.99888 & 0.86872 & 0.33547 \\
\hline 43 & $\mathrm{H}$ & -3.27933 & -1.80758 & 1.59537 \\
\hline 44 & $\mathrm{H}$ & -2.65917 & -0.23718 & 2.12413 \\
\hline 45 & $\mathrm{H}$ & -5.71109 & -0.89263 & 0.01829 \\
\hline 46 & $\mathrm{H}$ & -4.97191 & -0.45663 & -1.53122 \\
\hline 47 & $\mathrm{H}$ & -4.50158 & -1.95794 & -0.72107 \\
\hline 48 & $\mathrm{H}$ & -0.22241 & -3.39438 & 0.32945 \\
\hline 49 & $\mathrm{H}$ & 0.822 & -4.22172 & -0.83164 \\
\hline 50 & $\mathrm{H}$ & 1.53179 & -3.3321 & 0.50325 \\
\hline 51 & $\mathrm{H}$ & 0.33424 & 2.10469 & -2.67681 \\
\hline 52 & $\mathrm{H}$ & 0.28023 & 3.79338 & -2.20605 \\
\hline 53 & $\mathrm{H}$ & 1.64452 & 2.78895 & -1.71045 \\
\hline 54 & $\mathrm{H}$ & -4.88268 & 0.31334 & 2.51105 \\
\hline
\end{tabular}

B3LYP/6-311G(d,p) Energy = -931.84996435 a.u.; Population $=10.98 \%$ 


\begin{tabular}{|c|c|c|c|c|}
\hline \multicolumn{2}{|c|}{$\begin{array}{c}(7 S, 8 S, 15 R)-3 \\
\text { Conf. } 14\end{array}$} & \multicolumn{3}{|c|}{$\begin{array}{c}\text { Standard Orientation } \\
\text { (Ångstroms) }\end{array}$} \\
\hline I & atom & $X$ & $\mathrm{Y}$ & $\mathrm{Z}$ \\
\hline 1 & $\mathrm{C}$ & 2.92045 & 0.58593 & 0.40175 \\
\hline 2 & $\mathrm{C}$ & 2.90595 & 2.08912 & 0.2316 \\
\hline 3 & $\mathrm{C}$ & 1.8066 & 2.58015 & -0.74245 \\
\hline 4 & $\mathrm{C}$ & 3.88093 & -0.33882 & -0.23584 \\
\hline 5 & $\mathrm{C}$ & 3.55812 & -1.81243 & -0.46646 \\
\hline 6 & $\mathrm{C}$ & 2.45943 & -2.4527 & 0.40862 \\
\hline 7 & $\mathrm{C}$ & 1.08441 & -2.46662 & -0.211 \\
\hline 8 & $\mathrm{C}$ & -0.10388 & -2.21716 & 0.35694 \\
\hline 9 & $\mathrm{C}$ & -1.38067 & -2.39847 & -0.45018 \\
\hline 10 & $\mathrm{C}$ & 4.9851 & 0.16602 & -1.14163 \\
\hline 11 & $\mathrm{C}$ & 0.39966 & 2.45705 & -0.19454 \\
\hline 12 & $\mathrm{C}$ & -0.37757 & 1.41838 & -0.56533 \\
\hline 13 & $\mathrm{C}$ & -1.72254 & 1.11288 & -0.10727 \\
\hline 14 & $\mathrm{C}$ & -1.89192 & -1.14743 & -1.22116 \\
\hline 15 & $\mathrm{C}$ & -2.41771 & -0.01549 & -0.36609 \\
\hline 16 & $\mathrm{C}$ & -3.83869 & -0.21201 & 0.15424 \\
\hline 17 & $\mathrm{C}$ & -4.84075 & 0.36117 & -0.87207 \\
\hline 18 & $\mathrm{C}$ & -4.11876 & 0.34396 & 1.55579 \\
\hline 19 & $\mathrm{C}$ & -0.01133 & 3.53847 & 0.77083 \\
\hline 20 & $\mathrm{O}$ & 4.02042 & 0.03059 & 1.16104 \\
\hline 21 & $\mathrm{C}$ & -0.2884 & -1.80945 & 1.79751 \\
\hline 22 & $\mathrm{H}$ & 1.95813 & 0.16557 & 0.68397 \\
\hline 23 & $\mathrm{O}$ & -6.20341 & 0.06726 & -0.55534 \\
\hline 24 & $\mathrm{H}$ & 2.75374 & 2.53826 & 1.21971 \\
\hline 25 & $\mathrm{H}$ & 3.87804 & 2.44103 & -0.11756 \\
\hline 26 & $\mathrm{H}$ & 2.01191 & 3.63059 & -0.97778 \\
\hline 27 & $\mathrm{H}$ & 1.89097 & 2.02405 & -1.68119 \\
\hline 28 & $\mathrm{H}$ & 4.49778 & -2.35254 & -0.3018 \\
\hline 29 & $\mathrm{H}$ & 3.31843 & -1.95051 & -1.52691 \\
\hline 30 & $\mathrm{H}$ & 2.7535 & -3.49691 & 0.57707 \\
\hline 31 & $\mathrm{H}$ & 2.46711 & -1.98419 & 1.39492 \\
\hline 32 & $\mathrm{H}$ & 1.07534 & -2.78798 & -1.25363 \\
\hline 33 & $\mathrm{H}$ & -2.17666 & -2.76062 & 0.21059 \\
\hline 34 & $\mathrm{H}$ & -1.21964 & -3.18272 & -1.19593 \\
\hline 35 & $\mathrm{H}$ & 5.86027 & -0.48525 & -1.0572 \\
\hline 36 & $\mathrm{H}$ & 4.65958 & 0.15425 & -2.18592 \\
\hline 37 & $\mathrm{H}$ & 5.295 & 1.17799 & -0.88597 \\
\hline 38 & $\mathrm{H}$ & 0.06377 & 0.71621 & -1.26576 \\
\hline 39 & $\mathrm{H}$ & -2.19731 & 1.86013 & 0.51996 \\
\hline 40 & $\mathrm{H}$ & -1.09379 & -0.80783 & -1.88341 \\
\hline 41 & $\mathrm{H}$ & -2.70467 & -1.49012 & -1.87341 \\
\hline 42 & $\mathrm{H}$ & -4.02121 & -1.29482 & 0.18923 \\
\hline 43 & $\mathrm{H}$ & -4.76585 & 1.45182 & -0.87994 \\
\hline 44 & $\mathrm{H}$ & -4.59512 & 0.00175 & -1.87877 \\
\hline 45 & $\mathrm{H}$ & -5.14684 & 0.11507 & 1.84325 \\
\hline 46 & $\mathrm{H}$ & -3.44646 & -0.0949 & 2.29673 \\
\hline 47 & $\mathrm{H}$ & -4.00417 & 1.43071 & 1.59402 \\
\hline 48 & $\mathrm{H}$ & -0.0437 & 4.50913 & 0.26137 \\
\hline 49 & $\mathrm{H}$ & -0.98544 & 3.36467 & 1.22625 \\
\hline 50 & $\mathrm{H}$ & 0.71989 & 3.64037 & 1.58013 \\
\hline 51 & $\mathrm{H}$ & -0.83885 & -2.58567 & 2.34274 \\
\hline 52 & $\mathrm{H}$ & 0.65488 & -1.6442 & 2.31828 \\
\hline 53 & $\mathrm{H}$ & -0.88444 & -0.89493 & 1.86698 \\
\hline 54 & $\mathrm{H}$ & -6.32084 & -0.88647 & -0.62535 \\
\hline
\end{tabular}

B3LYP/6-311G(d,p) Energy = -931.85432186 a.u.; Population $=22.64 \%$ 


\begin{tabular}{|c|c|c|c|c|}
\hline \multicolumn{2}{|c|}{$\begin{array}{c}(7 S, 8 S, 15 R)-3 \\
\text { Conf. } 15\end{array}$} & \multicolumn{3}{|c|}{$\begin{array}{c}\text { Standard Orientation } \\
\text { (Ångstroms) }\end{array}$} \\
\hline I & atom & $X$ & $\mathrm{Y}$ & $\mathrm{Z}$ \\
\hline 1 & $\mathrm{C}$ & 2.91824 & 1.07297 & 0.65687 \\
\hline 2 & $\mathrm{C}$ & 2.92109 & 2.42104 & -0.02885 \\
\hline 3 & $\mathrm{C}$ & 1.70369 & 2.65394 & -0.95349 \\
\hline 4 & $\mathrm{C}$ & 3.57897 & -0.15782 & 0.17014 \\
\hline 5 & $\mathrm{C}$ & 3.1323 & -1.51391 & 0.70512 \\
\hline 6 & $\mathrm{C}$ & 2.36239 & -2.45754 & -0.24841 \\
\hline 7 & $\mathrm{C}$ & 0.91746 & -2.11992 & -0.52882 \\
\hline 8 & $\mathrm{C}$ & -0.16276 & -2.7948 & -0.11079 \\
\hline 9 & $\mathrm{C}$ & -1.5866 & -2.52244 & -0.57954 \\
\hline 10 & $\mathrm{C}$ & 4.36501 & -0.18099 & -1.12284 \\
\hline 11 & $\mathrm{C}$ & 0.36373 & 2.47833 & -0.27196 \\
\hline 12 & $\mathrm{C}$ & -0.4003 & 1.4096 & -0.57929 \\
\hline 13 & $\mathrm{C}$ & -1.67544 & 1.03421 & 0.00447 \\
\hline 14 & $\mathrm{C}$ & -1.95961 & -1.16724 & -1.22707 \\
\hline 15 & $\mathrm{C}$ & -2.38104 & -0.08751 & -0.24826 \\
\hline 16 & $\mathrm{C}$ & -3.74699 & -0.31973 & 0.39624 \\
\hline 17 & $\mathrm{C}$ & -4.88108 & 0.265 & -0.46451 \\
\hline 18 & $\mathrm{C}$ & -3.87102 & 0.14612 & 1.8549 \\
\hline 19 & $\mathrm{C}$ & 0.00358 & 3.52981 & 0.74524 \\
\hline 20 & $\mathrm{O}$ & 4.1739 & 0.64555 & 1.22737 \\
\hline 21 & $\mathrm{C}$ & -0.10487 & -3.99054 & 0.8131 \\
\hline 22 & $\mathrm{H}$ & 2.07488 & 0.91763 & 1.32824 \\
\hline 23 & $\mathrm{O}$ & -4.82746 & 1.69187 & -0.42469 \\
\hline 24 & $\mathrm{H}$ & 2.94924 & 3.18896 & 0.75258 \\
\hline 25 & $\mathrm{H}$ & 3.83765 & 2.54446 & -0.60901 \\
\hline 26 & $\mathrm{H}$ & 1.77097 & 1.96864 & -1.80328 \\
\hline 27 & $\mathrm{H}$ & 1.7832 & 3.67077 & -1.35773 \\
\hline 28 & $\mathrm{H}$ & 2.54909 & -1.35565 & 1.61695 \\
\hline 29 & $\mathrm{H}$ & 4.05135 & -2.03095 & 1.00879 \\
\hline 30 & $\mathrm{H}$ & 2.89637 & -2.50376 & -1.20484 \\
\hline 31 & $\mathrm{H}$ & 2.43614 & -3.46147 & 0.17219 \\
\hline 32 & $\mathrm{H}$ & 0.76752 & -1.26857 & -1.18546 \\
\hline 33 & $\mathrm{H}$ & -2.25983 & -2.70694 & 0.26506 \\
\hline 34 & $\mathrm{H}$ & -1.82656 & -3.32041 & -1.29607 \\
\hline 35 & $\mathrm{H}$ & 4.81112 & 0.79003 & -1.33375 \\
\hline 36 & $\mathrm{H}$ & 5.17232 & -0.91705 & -1.05773 \\
\hline 37 & $\mathrm{H}$ & 3.72784 & -0.45647 & -1.96717 \\
\hline 38 & $\mathrm{H}$ & -0.00422 & 0.74696 & -1.34148 \\
\hline 39 & $\mathrm{H}$ & -2.09974 & 1.73388 & 0.71541 \\
\hline 40 & $\mathrm{H}$ & -1.15882 & -0.82786 & -1.88464 \\
\hline 41 & $\mathrm{H}$ & -2.81409 & -1.361 & -1.88725 \\
\hline 42 & $\mathrm{H}$ & -3.92954 & -1.40066 & 0.38897 \\
\hline 43 & $\mathrm{H}$ & -4.78801 & -0.0959 & -1.49694 \\
\hline 44 & $\mathrm{H}$ & -5.84144 & -0.09279 & -0.06839 \\
\hline 45 & $\mathrm{H}$ & -4.83285 & -0.17207 & 2.26824 \\
\hline 46 & $\mathrm{H}$ & -3.07696 & -0.28212 & 2.47099 \\
\hline 47 & $\mathrm{H}$ & -3.82381 & 1.23251 & 1.93839 \\
\hline 48 & $\mathrm{H}$ & 0.0308 & 4.52558 & 0.28747 \\
\hline 49 & $\mathrm{H}$ & -0.98487 & 3.38598 & 1.17958 \\
\hline 50 & $\mathrm{H}$ & 0.72646 & 3.54938 & 1.56871 \\
\hline 51 & $\mathrm{H}$ & -0.58929 & -4.85855 & 0.3506 \\
\hline 52 & $\mathrm{H}$ & 0.90617 & -4.27942 & 1.09537 \\
\hline 53 & $\mathrm{H}$ & -0.66116 & -3.78039 & 1.73373 \\
\hline 54 & $\mathrm{H}$ & -5.55182 & 2.02638 & -0.96258 \\
\hline
\end{tabular}

B3LYP/6-311G(d,p) Energy $=-931.84073100$ a.u.; Population $=0.07 \%$ 


\begin{tabular}{|c|c|c|c|c|}
\hline \multicolumn{2}{|c|}{$\begin{array}{l}(7 S, 8 S, 15 R)-\mathbf{3} \\
\text { Conf. } 16 \\
\end{array}$} & \multicolumn{3}{|c|}{$\begin{array}{c}\text { Standard Orientation } \\
\text { (Ångstroms) }\end{array}$} \\
\hline I & atom & $\mathrm{X}$ & $\mathrm{Y}$ & $\mathrm{Z}$ \\
\hline 1 & $\mathrm{C}$ & 3.03141 & 0.89383 & 0.5998 \\
\hline 2 & $\mathrm{C}$ & 3.18178 & 2.20377 & -0.14166 \\
\hline 3 & $\mathrm{C}$ & 1.966 & 2.56255 & -1.02819 \\
\hline 4 & $\mathrm{C}$ & 3.50791 & -0.43309 & 0.15073 \\
\hline 5 & $\mathrm{C}$ & 2.90902 & -1.69386 & 0.76693 \\
\hline 6 & $\mathrm{C}$ & 2.03114 & -2.59998 & -0.12685 \\
\hline 7 & $\mathrm{C}$ & 0.63644 & -2.11147 & -0.43325 \\
\hline 8 & $\mathrm{C}$ & -0.51841 & -2.72886 & -0.14533 \\
\hline 9 & $\mathrm{C}$ & -1.88453 & -2.2708 & -0.63836 \\
\hline 10 & $\mathrm{C}$ & 4.23666 & -0.61495 & -1.1624 \\
\hline 11 & $\mathrm{C}$ & 0.64283 & 2.53147 & -0.29405 \\
\hline 12 & $\mathrm{C}$ & -0.24214 & 1.5531 & -0.5758 \\
\hline 13 & $\mathrm{C}$ & -1.50801 & 1.28052 & 0.08031 \\
\hline 14 & $\mathrm{C}$ & -2.08486 & -0.84091 & -1.18881 \\
\hline 15 & $\mathrm{C}$ & -2.32573 & 0.23072 & -0.14518 \\
\hline 16 & $\mathrm{C}$ & -3.64638 & 0.10971 & 0.6198 \\
\hline 17 & $\mathrm{C}$ & -4.71124 & 1.06251 & 0.06188 \\
\hline 18 & $\mathrm{C}$ & -3.51326 & 0.30751 & 2.13908 \\
\hline 19 & $\mathrm{C}$ & 0.44497 & 3.59863 & 0.75099 \\
\hline 20 & $\mathrm{O}$ & 4.24099 & 0.32982 & 1.14965 \\
\hline 21 & $\mathrm{C}$ & -0.61994 & -4.02182 & 0.63296 \\
\hline 22 & $\mathrm{H}$ & 2.20054 & 0.87626 & 1.30378 \\
\hline 23 & $\mathrm{O}$ & -4.96177 & 0.73093 & -1.30657 \\
\hline 24 & $\mathrm{H}$ & 3.34105 & 2.98777 & 0.60746 \\
\hline 25 & $\mathrm{H}$ & 4.08193 & 2.18609 & -0.75909 \\
\hline 26 & $\mathrm{H}$ & 2.14052 & 3.56226 & -1.4451 \\
\hline 27 & $\mathrm{H}$ & 1.92636 & 1.86748 & -1.87177 \\
\hline 28 & $\mathrm{H}$ & 2.35472 & -1.41472 & 1.66787 \\
\hline 29 & $\mathrm{H}$ & 3.76436 & -2.2942 & 1.1017 \\
\hline 30 & $\mathrm{H}$ & 2.55542 & -2.76732 & -1.07605 \\
\hline 31 & $\mathrm{H}$ & 1.99026 & -3.57713 & 0.3558 \\
\hline 32 & $\mathrm{H}$ & 0.59168 & -1.18564 & -0.99832 \\
\hline 33 & $\mathrm{H}$ & -2.60865 & -2.44751 & 0.16523 \\
\hline 34 & $\mathrm{H}$ & -2.17839 & -2.97829 & -1.42646 \\
\hline 35 & $\mathrm{H}$ & 4.95593 & -1.43598 & -1.08111 \\
\hline 36 & $\mathrm{H}$ & 3.54113 & -0.85814 & -1.96983 \\
\hline 37 & $\mathrm{H}$ & 4.78328 & 0.28515 & -1.44087 \\
\hline 38 & $\mathrm{H}$ & 0.04455 & 0.87095 & -1.36907 \\
\hline 39 & $\mathrm{H}$ & -1.81308 & 1.9912 & 0.84268 \\
\hline 40 & $\mathrm{H}$ & -1.26338 & -0.57745 & -1.85594 \\
\hline 41 & $\mathrm{H}$ & -2.98345 & -0.86414 & -1.81491 \\
\hline 42 & $\mathrm{H}$ & -4.03689 & -0.90007 & 0.45627 \\
\hline 43 & $\mathrm{H}$ & -5.63111 & 0.95968 & 0.65369 \\
\hline 44 & $\mathrm{H}$ & -4.3604 & 2.09907 & 0.15328 \\
\hline 45 & $\mathrm{H}$ & -4.46417 & 0.10038 & 2.63821 \\
\hline 46 & $\mathrm{H}$ & -2.75921 & -0.36628 & 2.55164 \\
\hline 47 & $\mathrm{H}$ & -3.22257 & 1.32998 & 2.39452 \\
\hline 48 & $\mathrm{H}$ & 0.60419 & 4.59097 & 0.31354 \\
\hline 49 & $\mathrm{H}$ & -0.54926 & 3.58354 & 1.19609 \\
\hline 50 & $\mathrm{H}$ & 1.17321 & 3.49931 & 1.56408 \\
\hline 51 & $\mathrm{H}$ & -1.14057 & -4.7846 & 0.04203 \\
\hline 52 & $\mathrm{H}$ & 0.34186 & -4.43248 & 0.93531 \\
\hline 53 & $\mathrm{H}$ & -1.21947 & -3.87057 & 1.53791 \\
\hline 54 & $\mathrm{H}$ & -5.59608 & 1.36676 & -1.65277 \\
\hline
\end{tabular}

B3LYP/6-311G(d,p) Energy = -931.84284379 a.u.; Population $=0.17 \%$ 


\begin{tabular}{|c|c|c|c|c|}
\hline \multicolumn{2}{|c|}{$\begin{array}{c}(7 S, 8 S, 15 R)-\mathbf{3} \\
\text { Conf. } 17 \\
\end{array}$} & \multicolumn{3}{|c|}{$\begin{array}{c}\text { Standard Orientation } \\
\text { (Ångstroms) }\end{array}$} \\
\hline I & atom & $\mathrm{X}$ & $\mathrm{Y}$ & $\mathrm{Z}$ \\
\hline 1 & $\mathrm{C}$ & 2.72097 & 0.95456 & 0.16089 \\
\hline 2 & $\mathrm{C}$ & 2.39268 & 2.00906 & -0.87975 \\
\hline 3 & $\mathrm{C}$ & 1.52349 & 3.14033 & -0.30938 \\
\hline 4 & $\mathrm{C}$ & 3.55807 & -0.23947 & -0.05314 \\
\hline 5 & $\mathrm{C}$ & 3.34399 & -1.44126 & 0.85423 \\
\hline 6 & $\mathrm{C}$ & 2.64887 & -2.67499 & 0.2327 \\
\hline 7 & $\mathrm{C}$ & 1.30242 & -2.4847 & -0.43779 \\
\hline 8 & $\mathrm{C}$ & 0.09607 & -2.40087 & 0.14201 \\
\hline 9 & $\mathrm{C}$ & -1.16443 & -2.38066 & -0.71057 \\
\hline 10 & $\mathrm{C}$ & 4.23642 & -0.49909 & -1.37937 \\
\hline 11 & $\mathrm{C}$ & 0.12193 & 2.77368 & 0.14709 \\
\hline 12 & $\mathrm{C}$ & -0.44021 & 1.58635 & -0.15828 \\
\hline 13 & $\mathrm{C}$ & -1.74027 & 1.07927 & 0.2516 \\
\hline 14 & $\mathrm{C}$ & -1.68414 & -0.99604 & -1.18758 \\
\hline 15 & $\mathrm{C}$ & -2.29743 & -0.0848 & -0.14728 \\
\hline 16 & $\mathrm{C}$ & -3.67704 & -0.50741 & 0.35959 \\
\hline 17 & $\mathrm{C}$ & -4.80374 & 0.21988 & -0.38805 \\
\hline 18 & $\mathrm{C}$ & -3.87718 & -0.33556 & 1.87447 \\
\hline 19 & $\mathrm{C}$ & -0.55271 & 3.85215 & 0.95497 \\
\hline 20 & $\mathrm{O}$ & 4.07286 & 0.90805 & 0.67675 \\
\hline 21 & $\mathrm{C}$ & -0.11139 & -2.38345 & 1.6354 \\
\hline 22 & $\mathrm{H}$ & 1.9774 & 0.86503 & 0.94964 \\
\hline 23 & $\mathrm{O}$ & -4.72539 & -0.08646 & -1.78238 \\
\hline 24 & $\mathrm{H}$ & 3.32613 & 2.43454 & -1.2554 \\
\hline 25 & $\mathrm{H}$ & 1.89591 & 1.54799 & -1.74011 \\
\hline 26 & $\mathrm{H}$ & 2.05017 & 3.59231 & 0.54279 \\
\hline 27 & $\mathrm{H}$ & 1.44924 & 3.94624 & -1.05208 \\
\hline 28 & $\mathrm{H}$ & 2.7862 & -1.10471 & 1.73241 \\
\hline 29 & $\mathrm{H}$ & 4.32961 & -1.76161 & 1.21538 \\
\hline 30 & $\mathrm{H}$ & 3.32659 & -3.12116 & -0.50139 \\
\hline 31 & $\mathrm{H}$ & 2.5555 & -3.41638 & 1.03359 \\
\hline 32 & $\mathrm{H}$ & 1.3246 & -2.48627 & -1.52673 \\
\hline 33 & $\mathrm{H}$ & -1.96497 & -2.89779 & -0.1697 \\
\hline 34 & $\mathrm{H}$ & -0.97967 & -2.96843 & -1.6146 \\
\hline 35 & $\mathrm{H}$ & 5.1751 & -1.03963 & -1.22298 \\
\hline 36 & $\mathrm{H}$ & 3.60381 & -1.10799 & -2.03058 \\
\hline 37 & $\mathrm{H}$ & 4.46214 & 0.43337 & -1.89668 \\
\hline 38 & $\mathrm{H}$ & 0.1498 & 0.90223 & -0.75472 \\
\hline 39 & $\mathrm{H}$ & -2.29969 & 1.68981 & 0.95408 \\
\hline 40 & $\mathrm{H}$ & -0.8762 & -0.49498 & -1.72318 \\
\hline 41 & $\mathrm{H}$ & -2.46818 & -1.19108 & -1.92735 \\
\hline 42 & $\mathrm{H}$ & -3.80054 & -1.57213 & 0.13155 \\
\hline 43 & $\mathrm{H}$ & -5.77104 & -0.10447 & 0.0193 \\
\hline 44 & $\mathrm{H}$ & -4.70896 & 1.30141 & -0.22216 \\
\hline 45 & $\mathrm{H}$ & -4.8404 & -0.75151 & 2.18338 \\
\hline 46 & $\mathrm{H}$ & -3.09212 & -0.85118 & 2.43107 \\
\hline 47 & $\mathrm{H}$ & -3.8625 & 0.71631 & 2.17205 \\
\hline 48 & $\mathrm{H}$ & -0.5249 & 4.80582 & 0.415 \\
\hline 49 & $\mathrm{H}$ & -1.59409 & 3.63131 & 1.18645 \\
\hline 50 & $\mathrm{H}$ & -0.02126 & 4.01695 & 1.90002 \\
\hline 51 & $\mathrm{H}$ & -0.7736 & -3.20093 & 1.94305 \\
\hline 52 & $\mathrm{H}$ & 0.82111 & -2.471 & 2.19392 \\
\hline 53 & $\mathrm{H}$ & -0.60156 & -1.45283 & 1.94123 \\
\hline 54 & $\mathrm{H}$ & -5.41174 & 0.41611 & -2.23274 \\
\hline
\end{tabular}

B3LYP/6-311G(d,p) Energy $=-931.84616470$ a.u.; Population $=0.08 \%$ 


\begin{tabular}{|c|c|c|c|c|}
\hline \multicolumn{2}{|c|}{$\begin{array}{l}(7 S, 8 S, 15 R)-\mathbf{3} \\
\text { Conf. } 18 \\
\end{array}$} & \multicolumn{3}{|c|}{$\begin{array}{c}\text { Standard Orientation } \\
\text { (Ångstroms) }\end{array}$} \\
\hline I & atom & $\mathrm{X}$ & $\mathrm{Y}$ & $\mathrm{Z}$ \\
\hline 1 & $\mathrm{C}$ & 2.97399 & 1.13466 & 0.60017 \\
\hline 2 & $\mathrm{C}$ & 3.01498 & 2.20694 & -0.46645 \\
\hline 3 & $\mathrm{C}$ & 1.81253 & 2.17613 & -1.43675 \\
\hline 4 & $\mathrm{C}$ & 3.64259 & -0.1833 & 0.53829 \\
\hline 5 & $\mathrm{C}$ & 3.17398 & -1.31612 & 1.4443 \\
\hline 6 & $\mathrm{C}$ & 2.34962 & -2.45536 & 0.80359 \\
\hline 7 & $\mathrm{C}$ & 0.86367 & -2.21906 & 0.70414 \\
\hline 8 & $\mathrm{C}$ & 0.04574 & -2.46439 & -0.32951 \\
\hline 9 & $\mathrm{C}$ & -1.46127 & -2.36803 & -0.17487 \\
\hline 10 & $\mathrm{C}$ & 4.47167 & -0.59881 & -0.65801 \\
\hline 11 & $\mathrm{C}$ & 0.4629 & 2.27301 & -0.75969 \\
\hline 12 & $\mathrm{C}$ & -0.38061 & 1.22124 & -0.80813 \\
\hline 13 & $\mathrm{C}$ & -1.66678 & 1.08844 & -0.14673 \\
\hline 14 & $\mathrm{C}$ & -2.16688 & -1.24093 & -0.99538 \\
\hline 15 & $\mathrm{C}$ & -2.47031 & 0.00484 & -0.18776 \\
\hline 16 & $\mathrm{C}$ & -3.78949 & -0.04584 & 0.57395 \\
\hline 17 & $\mathrm{C}$ & -4.94454 & 0.3597 & -0.36939 \\
\hline 18 & $\mathrm{C}$ & -3.83373 & 0.76903 & 1.87277 \\
\hline 19 & $\mathrm{C}$ & 0.17866 & 3.56869 & -0.04376 \\
\hline 20 & $\mathrm{O}$ & 4.20707 & 0.90814 & 1.31704 \\
\hline 21 & $\mathrm{C}$ & 0.50804 & -2.95302 & -1.6818 \\
\hline 22 & $\mathrm{H}$ & 2.10706 & 1.19245 & 1.25742 \\
\hline 23 & $\mathrm{O}$ & -6.23811 & 0.08091 & 0.17106 \\
\hline 24 & $\mathrm{H}$ & 3.05703 & 3.17625 & 0.04331 \\
\hline 25 & $\mathrm{H}$ & 3.93896 & 2.12718 & -1.04224 \\
\hline 26 & $\mathrm{H}$ & 1.85579 & 1.25715 & -2.02827 \\
\hline 27 & $\mathrm{H}$ & 1.93346 & 3.0121 & -2.13759 \\
\hline 28 & $\mathrm{H}$ & 2.61936 & -0.88428 & 2.28318 \\
\hline 29 & $\mathrm{H}$ & 4.08507 & -1.75309 & 1.87078 \\
\hline 30 & $\mathrm{H}$ & 2.77786 & -2.73256 & -0.16105 \\
\hline 31 & $\mathrm{H}$ & 2.4871 & -3.33554 & 1.44604 \\
\hline 32 & $\mathrm{H}$ & 0.40185 & -1.89298 & 1.63623 \\
\hline 33 & $\mathrm{H}$ & -1.71628 & -2.25653 & 0.88242 \\
\hline 34 & $\mathrm{H}$ & -1.88246 & -3.32973 & -0.49326 \\
\hline 35 & $\mathrm{H}$ & 5.26603 & -1.2823 & -0.34271 \\
\hline 36 & $\mathrm{H}$ & 3.86061 & -1.11533 & -1.40246 \\
\hline 37 & $\mathrm{H}$ & 4.93794 & 0.26107 & -1.13695 \\
\hline 38 & $\mathrm{H}$ & -0.03889 & 0.35518 & -1.36567 \\
\hline 39 & $\mathrm{H}$ & -1.98422 & 1.92587 & 0.46509 \\
\hline 40 & $\mathrm{H}$ & -1.57519 & -1.00059 & -1.8806 \\
\hline 41 & $\mathrm{H}$ & -3.11334 & -1.64018 & -1.37225 \\
\hline 42 & $\mathrm{H}$ & -3.9719 & -1.09594 & 0.83665 \\
\hline 43 & $\mathrm{H}$ & -4.84699 & 1.42375 & -0.62239 \\
\hline 44 & $\mathrm{H}$ & -4.88766 & -0.20965 & -1.29918 \\
\hline 45 & $\mathrm{H}$ & -4.76366 & 0.57391 & 2.41402 \\
\hline 46 & $\mathrm{H}$ & -3.00657 & 0.50123 & 2.53403 \\
\hline 47 & $\mathrm{H}$ & -3.78213 & 1.84544 & 1.68423 \\
\hline 48 & $\mathrm{H}$ & -0.84974 & 3.64628 & 0.30714 \\
\hline 49 & $\mathrm{H}$ & 0.83564 & 3.69873 & 0.82386 \\
\hline 50 & $\mathrm{H}$ & 0.37225 & 4.41857 & -0.70808 \\
\hline 51 & $\mathrm{H}$ & 0.07776 & -2.35035 & -2.48826 \\
\hline 52 & $\mathrm{H}$ & 1.59103 & -2.93486 & -1.79857 \\
\hline 53 & $\mathrm{H}$ & 0.16849 & -3.982 & -1.85095 \\
\hline 54 & $\mathrm{H}$ & -6.41449 & 0.72133 & 0.86732 \\
\hline
\end{tabular}

B3LYP/6-311G(d,p) Energy $=-931.85204400$ a.u.; Population $=6.76 \%$ 


\begin{tabular}{|c|c|c|c|c|}
\hline \multicolumn{2}{|c|}{$\begin{array}{c}(7 S, 8 S, 15 R)-\mathbf{3} \\
\text { Conf. } 19\end{array}$} & \multicolumn{3}{|c|}{$\begin{array}{c}\text { Standard Orientation } \\
\text { (Ångstroms) }\end{array}$} \\
\hline $\mathrm{I}$ & atom & $\mathrm{X}$ & $\mathrm{Y}$ & $\mathrm{Z}$ \\
\hline 1 & $\mathrm{C}$ & 2.88233 & 1.2333 & 0.56735 \\
\hline 2 & $\mathrm{C}$ & 2.80265 & 2.33051 & -0.47123 \\
\hline 3 & $\mathrm{C}$ & 1.56615 & 2.2392 & -1.3935 \\
\hline 4 & $\mathrm{C}$ & 3.63499 & -0.0336 & 0.44063 \\
\hline 5 & $\mathrm{C}$ & 3.28641 & -1.21495 & 1.33859 \\
\hline 6 & $\mathrm{C}$ & 2.49417 & -2.38471 & 0.7139 \\
\hline 7 & $\mathrm{C}$ & 0.9948 & -2.22587 & 0.68861 \\
\hline 8 & $\mathrm{C}$ & 0.14103 & -2.52314 & -0.30149 \\
\hline 9 & $\mathrm{C}$ & -1.35936 & -2.50978 & -0.07224 \\
\hline 10 & $\mathrm{C}$ & 4.43075 & -0.36559 & -0.80302 \\
\hline 11 & $\mathrm{C}$ & 0.24041 & 2.23697 & -0.66414 \\
\hline 12 & $\mathrm{C}$ & -0.53821 & 1.13583 & -0.70442 \\
\hline 13 & $\mathrm{C}$ & -1.79457 & 0.91549 & -0.00984 \\
\hline 14 & $\mathrm{C}$ & -2.16722 & -1.43244 & -0.86622 \\
\hline 15 & $\mathrm{C}$ & -2.53222 & -0.21291 & -0.04427 \\
\hline 16 & $\mathrm{C}$ & -3.82132 & -0.35886 & 0.75955 \\
\hline 17 & $\mathrm{C}$ & -5.06576 & -0.16358 & -0.12525 \\
\hline 18 & $\mathrm{C}$ & -3.91527 & 0.51352 & 2.01892 \\
\hline 19 & $\mathrm{C}$ & -0.09736 & 3.49922 & 0.08773 \\
\hline 20 & $\mathrm{O}$ & 4.16095 & 1.07591 & 1.22071 \\
\hline 21 & $\mathrm{C}$ & 0.56296 & -2.99728 & -1.67202 \\
\hline 22 & $\mathrm{H}$ & 2.04515 & 1.21521 & 1.26436 \\
\hline 23 & $\mathrm{O}$ & -5.1406 & 1.20198 & -0.54021 \\
\hline 24 & $\mathrm{H}$ & 2.79887 & 3.28803 & 0.0619 \\
\hline 25 & $\mathrm{H}$ & 3.70543 & 2.32975 & -1.08487 \\
\hline 26 & $\mathrm{H}$ & 1.64379 & 1.33618 & -2.00582 \\
\hline 27 & $\mathrm{H}$ & 1.60577 & 3.09403 & -2.0809 \\
\hline 28 & $\mathrm{H}$ & 2.75555 & -0.83652 & 2.21751 \\
\hline 29 & $\mathrm{H}$ & 4.24366 & -1.60732 & 1.70276 \\
\hline 30 & $\mathrm{H}$ & 2.89044 & -2.62314 & -0.2747 \\
\hline 31 & $\mathrm{H}$ & 2.70817 & -3.2674 & 1.33181 \\
\hline 32 & $\mathrm{H}$ & 0.56379 & -1.91797 & 1.64138 \\
\hline 33 & $\mathrm{H}$ & -1.56594 & -2.40051 & 0.99577 \\
\hline 34 & $\mathrm{H}$ & -1.73989 & -3.49787 & -0.35987 \\
\hline 35 & $\mathrm{H}$ & 4.80449 & 0.53411 & -1.28983 \\
\hline 36 & $\mathrm{H}$ & 5.29043 & -0.99022 & -0.54117 \\
\hline 37 & $\mathrm{H}$ & 3.82286 & -0.91719 & -1.52468 \\
\hline 38 & $\mathrm{H}$ & -0.16266 & 0.30268 & -1.29014 \\
\hline 39 & $\mathrm{H}$ & -2.1514 & 1.72673 & 0.61424 \\
\hline 40 & $\mathrm{H}$ & -1.61979 & -1.14771 & -1.76648 \\
\hline 41 & $\mathrm{H}$ & -3.09351 & -1.89536 & -1.2192 \\
\hline 42 & $\mathrm{H}$ & -3.87118 & -1.40747 & 1.08399 \\
\hline 43 & $\mathrm{H}$ & -5.01671 & -0.82746 & -0.9973 \\
\hline 44 & $\mathrm{H}$ & -5.95651 & -0.43857 & 0.45556 \\
\hline 45 & $\mathrm{H}$ & -4.80649 & 0.24459 & 2.59346 \\
\hline 46 & $\mathrm{H}$ & -3.04215 & 0.37466 & 2.66051 \\
\hline 47 & $\mathrm{H}$ & -3.99521 & 1.57233 & 1.76833 \\
\hline 48 & $\mathrm{H}$ & 0.00468 & 4.37081 & -0.56904 \\
\hline 49 & $\mathrm{H}$ & -1.1103 & 3.49895 & 0.48851 \\
\hline 50 & $\mathrm{H}$ & 0.59003 & 3.66181 & 0.92584 \\
\hline 51 & $\mathrm{H}$ & 0.03181 & -2.45235 & -2.45887 \\
\hline 52 & $\mathrm{H}$ & 1.63101 & -2.88502 & -1.85587 \\
\hline 53 & $\mathrm{H}$ & 0.30872 & -4.056 & -1.80388 \\
\hline 54 & $\mathrm{H}$ & -5.94789 & 1.30715 & -1.05319 \\
\hline
\end{tabular}

B3LYP/6-311G(d,p) Energy $=-931.84901618$ a.u.; Population $=1.07 \%$ 


\begin{tabular}{|c|c|c|c|c|}
\hline \multicolumn{2}{|c|}{$\begin{array}{l}(7 S, 8 S, 15 R)-\mathbf{3} \\
\text { Conf. } 20 \\
\end{array}$} & \multicolumn{3}{|c|}{$\begin{array}{c}\text { Standard Orientation } \\
\text { (Ångstroms) }\end{array}$} \\
\hline I & atom & $\mathrm{X}$ & $\mathrm{Y}$ & $\mathrm{Z}$ \\
\hline 1 & $\mathrm{C}$ & -3.27543 & 0.86356 & 0.11087 \\
\hline 2 & $\mathrm{C}$ & -2.60525 & 2.05334 & 0.78499 \\
\hline 3 & $\mathrm{C}$ & -1.74941 & 2.9318 & -0.13883 \\
\hline 4 & $\mathrm{C}$ & -3.41383 & -0.50045 & 0.6709 \\
\hline 5 & $\mathrm{C}$ & -3.64599 & -1.6792 & -0.27658 \\
\hline 6 & $\mathrm{C}$ & -2.48501 & -2.0576 & -1.21931 \\
\hline 7 & $\mathrm{C}$ & -1.1967 & -2.39222 & -0.51327 \\
\hline 8 & $\mathrm{C}$ & 0.05393 & -2.15103 & -0.92969 \\
\hline 9 & $\mathrm{C}$ & 1.21986 & -2.43724 & -0.00194 \\
\hline 10 & $\mathrm{C}$ & -2.88079 & -0.838 & 2.04633 \\
\hline 11 & $\mathrm{C}$ & -0.32073 & 2.53677 & -0.45703 \\
\hline 12 & $\mathrm{C}$ & 0.28711 & 1.44154 & 0.04664 \\
\hline 13 & $\mathrm{C}$ & 1.6801 & 1.06504 & -0.16051 \\
\hline 14 & $\mathrm{C}$ & 1.60896 & -1.23268 & 0.90699 \\
\hline 15 & $\mathrm{C}$ & 2.29119 & -0.08313 & 0.20055 \\
\hline 16 & $\mathrm{C}$ & 3.78178 & -0.29455 & -0.07281 \\
\hline 17 & $\mathrm{C}$ & 4.65277 & 0.29078 & 1.04877 \\
\hline 18 & $\mathrm{C}$ & 4.27394 & 0.24658 & -1.42524 \\
\hline 19 & $\mathrm{C}$ & 0.35161 & 3.53329 & -1.37089 \\
\hline 20 & $\mathrm{O}$ & -4.52388 & 0.43612 & 0.69875 \\
\hline 21 & $\mathrm{C}$ & 0.39971 & -1.59307 & -2.28755 \\
\hline 22 & $\mathrm{H}$ & -3.33407 & 0.94562 & -0.97542 \\
\hline 23 & $\mathrm{O}$ & 4.3291 & -0.34036 & 2.29002 \\
\hline 24 & $\mathrm{H}$ & -3.4195 & 2.67839 & 1.16572 \\
\hline 25 & $\mathrm{H}$ & -2.02945 & 1.74649 & 1.66118 \\
\hline 26 & $\mathrm{H}$ & -2.28718 & 3.07802 & -1.08647 \\
\hline 27 & $\mathrm{H}$ & -1.70467 & 3.93664 & 0.30296 \\
\hline 28 & $\mathrm{H}$ & -4.51637 & -1.42823 & -0.88887 \\
\hline 29 & $\mathrm{H}$ & -3.9264 & -2.55361 & 0.32202 \\
\hline 30 & $\mathrm{H}$ & -2.82572 & -2.91736 & -1.81269 \\
\hline 31 & $\mathrm{H}$ & -2.32804 & -1.24463 & -1.93271 \\
\hline 32 & $\mathrm{H}$ & -1.31232 & -2.8743 & 0.45672 \\
\hline 33 & $\mathrm{H}$ & 2.09599 & -2.75724 & -0.57713 \\
\hline 34 & $\mathrm{H}$ & 0.95853 & -3.26861 & 0.65986 \\
\hline 35 & $\mathrm{H}$ & -3.53783 & -1.57219 & 2.52229 \\
\hline 36 & $\mathrm{H}$ & -1.88126 & -1.2733 & 1.98782 \\
\hline 37 & $\mathrm{H}$ & -2.84005 & 0.04281 & 2.68688 \\
\hline 38 & $\mathrm{H}$ & -0.30479 & 0.77721 & 0.66672 \\
\hline 39 & $\mathrm{H}$ & 2.29378 & 1.80265 & -0.66664 \\
\hline 40 & $\mathrm{H}$ & 0.70831 & -0.89775 & 1.42599 \\
\hline 41 & $\mathrm{H}$ & 2.29778 & -1.60062 & 1.67273 \\
\hline 42 & $\mathrm{H}$ & 3.96384 & -1.37582 & -0.06745 \\
\hline 43 & $\mathrm{H}$ & 5.71054 & 0.12592 & 0.80224 \\
\hline 44 & $\mathrm{H}$ & 4.48032 & 1.37391 & 1.10846 \\
\hline 45 & $\mathrm{H}$ & 5.3106 & -0.05405 & -1.60071 \\
\hline 46 & $\mathrm{H}$ & 3.66541 & -0.14144 & -2.24452 \\
\hline 47 & $\mathrm{H}$ & 4.23839 & 1.33853 & -1.46905 \\
\hline 48 & $\mathrm{H}$ & 0.38774 & 4.52368 & -0.90145 \\
\hline 49 & $\mathrm{H}$ & 1.36598 & 3.25674 & -1.65212 \\
\hline 50 & $\mathrm{H}$ & -0.22838 & 3.651 & -2.29351 \\
\hline 51 & $\mathrm{H}$ & 0.97289 & -2.33682 & -2.85476 \\
\hline 52 & $\mathrm{H}$ & -0.47888 & -1.33404 & -2.87867 \\
\hline 53 & $\mathrm{H}$ & 1.03411 & -0.70774 & -2.20066 \\
\hline 54 & $\mathrm{H}$ & 4.86198 & 0.07284 & 2.9769 \\
\hline
\end{tabular}

B3LYP/6-311G(d,p) Energy = -931.84563066 a.u.; Population $=0.01 \%$ 


\begin{tabular}{|c|c|c|c|c|}
\hline \multicolumn{2}{|c|}{$\begin{array}{c}(7 S, 8 S, 15 R)-3 \\
\text { Conf. } 21\end{array}$} & \multicolumn{3}{|c|}{$\begin{array}{c}\text { Standard Orientation } \\
\text { (Ångstroms) }\end{array}$} \\
\hline I & atom & $X$ & $\mathrm{Y}$ & $\mathrm{Z}$ \\
\hline 1 & $\mathrm{C}$ & 2.80199 & 0.91648 & 0.20008 \\
\hline 2 & $\mathrm{C}$ & 2.53076 & 1.97184 & -0.8563 \\
\hline 3 & $\mathrm{C}$ & 1.66047 & 3.12035 & -0.32389 \\
\hline 4 & $\mathrm{C}$ & 3.62399 & -0.29364 & 0.02018 \\
\hline 5 & $\mathrm{C}$ & 3.35338 & -1.48743 & 0.92304 \\
\hline 6 & $\mathrm{C}$ & 2.6513 & -2.7067 & 0.28112 \\
\hline 7 & $\mathrm{C}$ & 1.33701 & -2.48748 & -0.44215 \\
\hline 8 & $\mathrm{C}$ & 0.11013 & -2.3823 & 0.08899 \\
\hline 9 & $\mathrm{C}$ & -1.11478 & -2.34486 & -0.81351 \\
\hline 10 & $\mathrm{C}$ & 4.34422 & -0.571 & -1.28002 \\
\hline 11 & $\mathrm{C}$ & 0.23551 & 2.78175 & 0.07756 \\
\hline 12 & $\mathrm{C}$ & -0.3333 & 1.60077 & -0.23945 \\
\hline 13 & $\mathrm{C}$ & -1.65931 & 1.12343 & 0.12002 \\
\hline 14 & $\mathrm{C}$ & -1.59262 & -0.95406 & -1.31561 \\
\hline 15 & $\mathrm{C}$ & -2.22576 & -0.02935 & -0.29827 \\
\hline 16 & $\mathrm{C}$ & -3.63491 & -0.42116 & 0.13978 \\
\hline 17 & $\mathrm{C}$ & -4.66175 & 0.29217 & -0.75174 \\
\hline 18 & $\mathrm{C}$ & -3.94409 & -0.19601 & 1.62644 \\
\hline 19 & $\mathrm{C}$ & -0.45423 & 3.88082 & 0.84351 \\
\hline 20 & $\mathrm{O}$ & 4.13335 & 0.84726 & 0.76386 \\
\hline 21 & $\mathrm{C}$ & -0.15798 & -2.36185 & 1.57262 \\
\hline 22 & $\mathrm{H}$ & 2.02929 & 0.84368 & 0.96209 \\
\hline 23 & $\mathrm{O}$ & -5.94998 & -0.28422 & -0.5137 \\
\hline 24 & $\mathrm{H}$ & 3.48488 & 2.38015 & -1.19742 \\
\hline 25 & $\mathrm{H}$ & 2.05922 & 1.51537 & -1.73317 \\
\hline 26 & $\mathrm{H}$ & 2.16072 & 3.56619 & 0.54715 \\
\hline 27 & $\mathrm{H}$ & 1.62947 & 3.92467 & -1.0712 \\
\hline 28 & $\mathrm{H}$ & 2.77482 & -1.13511 & 1.78128 \\
\hline 29 & $\mathrm{H}$ & 4.31876 & -1.82928 & 1.31759 \\
\hline 30 & $\mathrm{H}$ & 3.34512 & -3.17347 & -0.42458 \\
\hline 31 & $\mathrm{H}$ & 2.50854 & -3.44099 & 1.0812 \\
\hline 32 & $\mathrm{H}$ & 1.40272 & -2.49005 & -1.52931 \\
\hline 33 & $\mathrm{H}$ & -1.94528 & -2.84443 & -0.30253 \\
\hline 34 & $\mathrm{H}$ & -0.90522 & -2.94025 & -1.70701 \\
\hline 35 & $\mathrm{H}$ & 4.59638 & 0.35483 & -1.79684 \\
\hline 36 & $\mathrm{H}$ & 5.27146 & -1.11953 & -1.08725 \\
\hline 37 & $\mathrm{H}$ & 3.72787 & -1.17906 & -1.94738 \\
\hline 38 & $\mathrm{H}$ & 0.26922 & 0.89944 & -0.80241 \\
\hline 39 & $\mathrm{H}$ & -2.23081 & 1.74475 & 0.80215 \\
\hline 40 & $\mathrm{H}$ & -0.76029 & -0.46866 & -1.82701 \\
\hline 41 & $\mathrm{H}$ & -2.34573 & -1.14999 & -2.09038 \\
\hline 42 & $\mathrm{H}$ & -3.7579 & -1.49127 & -0.06432 \\
\hline 43 & $\mathrm{H}$ & -4.66428 & 1.36502 & -0.51557 \\
\hline 44 & $\mathrm{H}$ & -4.38143 & 0.17858 & -1.80671 \\
\hline 45 & $\mathrm{H}$ & -4.95756 & -0.53479 & 1.84921 \\
\hline 46 & $\mathrm{H}$ & -3.24663 & -0.74842 & 2.26056 \\
\hline 47 & $\mathrm{H}$ & -3.88312 & 0.86148 & 1.89801 \\
\hline 48 & $\mathrm{H}$ & -0.39701 & 4.82435 & 0.2883 \\
\hline 49 & $\mathrm{H}$ & -1.50529 & 3.6756 & 1.04306 \\
\hline 50 & $\mathrm{H}$ & 0.04721 & 4.05627 & 1.80274 \\
\hline 51 & $\mathrm{H}$ & -0.83643 & -3.17564 & 1.85367 \\
\hline 52 & $\mathrm{H}$ & 0.75064 & -2.45377 & 2.16828 \\
\hline 53 & $\mathrm{H}$ & -0.65551 & -1.42863 & 1.8578 \\
\hline 54 & $\mathrm{H}$ & -6.59101 & 0.19809 & -1.04575 \\
\hline
\end{tabular}

B3LYP/6-311G(d,p) Energy $=-931.84634756$ a.u.; Population $=0.18 \%$ 


\begin{tabular}{|c|c|c|c|c|}
\hline \multicolumn{2}{|c|}{$\begin{array}{c}(7 S, 8 S, 15 R)-\mathbf{3} \\
\text { Conf. } 22 \\
\end{array}$} & \multicolumn{3}{|c|}{$\begin{array}{c}\text { Standard Orientation } \\
\text { (Ångstroms) }\end{array}$} \\
\hline I & atom & $\mathrm{X}$ & $\mathrm{Y}$ & $\mathrm{Z}$ \\
\hline 1 & $\mathrm{C}$ & 2.63696 & 0.70032 & -0.32665 \\
\hline 2 & $\mathrm{C}$ & 2.74157 & 2.20759 & -0.47749 \\
\hline 3 & $\mathrm{C}$ & 1.43963 & 2.84965 & -1.01976 \\
\hline 4 & $\mathrm{C}$ & 3.74098 & -0.19131 & 0.06287 \\
\hline 5 & $\mathrm{C}$ & 3.75214 & -1.6513 & -0.40946 \\
\hline 6 & $\mathrm{C}$ & 2.62051 & -2.55531 & 0.12777 \\
\hline 7 & $\mathrm{C}$ & 1.27274 & -2.46594 & -0.54369 \\
\hline 8 & $\mathrm{C}$ & 0.07432 & -2.28723 & 0.03308 \\
\hline 9 & $\mathrm{C}$ & -1.20418 & -2.43555 & -0.77541 \\
\hline 10 & $\mathrm{C}$ & 5.1106 & 0.36954 & 0.37924 \\
\hline 11 & $\mathrm{C}$ & 0.20651 & 2.51794 & -0.20666 \\
\hline 12 & $\mathrm{C}$ & -0.61059 & 1.5323 & -0.63118 \\
\hline 13 & $\mathrm{C}$ & -1.80465 & 1.00865 & 0.01471 \\
\hline 14 & $\mathrm{C}$ & -1.87969 & -1.13616 & -1.30792 \\
\hline 15 & $\mathrm{C}$ & -2.40618 & -0.16533 & -0.27112 \\
\hline 16 & $\mathrm{C}$ & -3.69908 & -0.59686 & 0.41578 \\
\hline 17 & $\mathrm{C}$ & -4.92595 & -0.31853 & -0.47258 \\
\hline 18 & $\mathrm{C}$ & -3.92073 & -0.02737 & 1.82441 \\
\hline 19 & $\mathrm{C}$ & 0.03445 & 3.28436 & 1.07793 \\
\hline 20 & $\mathrm{O}$ & 2.70553 & 0.15839 & 1.01565 \\
\hline 21 & $\mathrm{C}$ & -0.11295 & -2.02643 & 1.50904 \\
\hline 22 & $\mathrm{H}$ & 1.8499 & 0.23712 & -0.91669 \\
\hline 23 & $\mathrm{O}$ & -5.11769 & 1.09285 & -0.58748 \\
\hline 24 & $\mathrm{H}$ & 3.00178 & 2.637 & 0.49326 \\
\hline 25 & $\mathrm{H}$ & 3.55875 & 2.46046 & -1.16236 \\
\hline 26 & $\mathrm{H}$ & 1.58565 & 3.93522 & -1.06044 \\
\hline 27 & $\mathrm{H}$ & 1.29357 & 2.51236 & -2.05038 \\
\hline 28 & $\mathrm{H}$ & 4.70061 & -2.09558 & -0.09077 \\
\hline 29 & $\mathrm{H}$ & 3.76483 & -1.66992 & -1.50562 \\
\hline 30 & $\mathrm{H}$ & 2.96952 & -3.58855 & -0.00545 \\
\hline 31 & $\mathrm{H}$ & 2.53218 & -2.40196 & 1.20337 \\
\hline 32 & $\mathrm{H}$ & 1.28866 & -2.66927 & -1.61562 \\
\hline 33 & $\mathrm{H}$ & -1.93264 & -2.99075 & -0.17194 \\
\hline 34 & $\mathrm{H}$ & -0.9992 & -3.0572 & -1.6521 \\
\hline 35 & $\mathrm{H}$ & 5.76292 & 0.29214 & -0.49634 \\
\hline 36 & $\mathrm{H}$ & 5.06383 & 1.41535 & 0.68265 \\
\hline 37 & $\mathrm{H}$ & 5.572 & -0.20471 & 1.18858 \\
\hline 38 & $\mathrm{H}$ & -0.33262 & 1.05927 & -1.56801 \\
\hline 39 & $\mathrm{H}$ & -2.24116 & 1.62117 & 0.79602 \\
\hline 40 & $\mathrm{H}$ & -1.17404 & -0.64657 & -1.97973 \\
\hline 41 & $\mathrm{H}$ & -2.71783 & -1.46448 & -1.935 \\
\hline 42 & $\mathrm{H}$ & -3.66602 & -1.69015 & 0.50788 \\
\hline 43 & $\mathrm{H}$ & -4.78481 & -0.76901 & -1.46287 \\
\hline 44 & $\mathrm{H}$ & -5.80481 & -0.7897 & -0.01198 \\
\hline 45 & $\mathrm{H}$ & -4.80606 & -0.48535 & 2.27504 \\
\hline 46 & $\mathrm{H}$ & -3.06656 & -0.23112 & 2.47406 \\
\hline 47 & $\mathrm{H}$ & -4.0869 & 1.05054 & 1.80003 \\
\hline 48 & $\mathrm{H}$ & -0.01486 & 4.36153 & 0.88071 \\
\hline 49 & $\mathrm{H}$ & -0.86063 & 2.99822 & 1.6299 \\
\hline 50 & $\mathrm{H}$ & 0.89447 & 3.12909 & 1.73983 \\
\hline 51 & $\mathrm{H}$ & -0.46904 & -2.93094 & 2.01829 \\
\hline 52 & $\mathrm{H}$ & 0.8034 & -1.69405 & 1.99487 \\
\hline 53 & $\mathrm{H}$ & -0.87175 & -1.25623 & 1.66539 \\
\hline 54 & $\mathrm{H}$ & -5.91421 & 1.23778 & -1.10755 \\
\hline
\end{tabular}

B3LYP/6-311G(d,p) Energy = -931.84480306 a.u.; Population $=0.01 \%$ 


\begin{tabular}{|c|c|c|c|c|}
\hline \multicolumn{2}{|c|}{$\begin{array}{c}(7 S, 8 S, 15 R)-\mathbf{3} \\
\text { Conf. } 23 \\
\end{array}$} & \multicolumn{3}{|c|}{$\begin{array}{c}\text { Standard Orientation } \\
\text { (Ångstroms) }\end{array}$} \\
\hline I & atom & $\mathrm{X}$ & $\mathrm{Y}$ & $\mathrm{Z}$ \\
\hline 1 & $\mathrm{C}$ & 3.25035 & 0.91648 & -0.04974 \\
\hline 2 & $\mathrm{C}$ & 2.5599 & 2.12738 & -0.66225 \\
\hline 3 & $\mathrm{C}$ & 1.67419 & 2.93331 & 0.29913 \\
\hline 4 & $\mathrm{C}$ & 3.4068 & -0.41667 & -0.67547 \\
\hline 5 & $\mathrm{C}$ & 3.66565 & -1.63531 & 0.21247 \\
\hline 6 & $\mathrm{C}$ & 2.51363 & -2.08752 & 1.13378 \\
\hline 7 & $\mathrm{C}$ & 1.23541 & -2.41929 & 0.40859 \\
\hline 8 & $\mathrm{C}$ & -0.02193 & -2.21986 & 0.82682 \\
\hline 9 & $\mathrm{C}$ & -1.17578 & -2.49154 & -0.12072 \\
\hline 10 & $\mathrm{C}$ & 2.87017 & -0.69643 & -2.06255 \\
\hline 11 & $\mathrm{C}$ & 0.24833 & 2.49588 & 0.56961 \\
\hline 12 & $\mathrm{C}$ & -0.32411 & 1.41031 & 0.00705 \\
\hline 13 & $\mathrm{C}$ & -1.71133 & 0.99543 & 0.17294 \\
\hline 14 & $\mathrm{C}$ & -1.57438 & -1.25677 & -0.98386 \\
\hline 15 & $\mathrm{C}$ & -2.29091 & -0.15297 & -0.23876 \\
\hline 16 & $\mathrm{C}$ & -3.78202 & -0.40194 & 0.00402 \\
\hline 17 & $\mathrm{C}$ & -4.64302 & 0.39323 & -0.99807 \\
\hline 18 & $\mathrm{C}$ & -4.2592 & -0.11039 & 1.43541 \\
\hline 19 & $\mathrm{C}$ & -0.46347 & 3.4366 & 1.51188 \\
\hline 20 & $\mathrm{O}$ & 4.50168 & 0.53777 & -0.66419 \\
\hline 21 & $\mathrm{C}$ & -0.38671 & -1.72307 & 2.20332 \\
\hline 22 & $\mathrm{H}$ & 3.31363 & 0.94711 & 1.03891 \\
\hline 23 & $\mathrm{O}$ & -4.30233 & 0.15285 & -2.36408 \\
\hline 24 & $\mathrm{H}$ & 3.36388 & 2.79124 & -0.99644 \\
\hline 25 & $\mathrm{H}$ & 2.00171 & 1.85852 & -1.56219 \\
\hline 26 & $\mathrm{H}$ & 2.19386 & 3.0313 & 1.26286 \\
\hline 27 & $\mathrm{H}$ & 1.61714 & 3.96196 & -0.08181 \\
\hline 28 & $\mathrm{H}$ & 4.52995 & -1.3953 & 0.83756 \\
\hline 29 & $\mathrm{H}$ & 3.96592 & -2.47196 & -0.42887 \\
\hline 30 & $\mathrm{H}$ & 2.87475 & -2.96714 & 1.68432 \\
\hline 31 & $\mathrm{H}$ & 2.33657 & -1.3148 & 1.88603 \\
\hline 32 & $\mathrm{H}$ & 1.36614 & -2.85811 & -0.57989 \\
\hline 33 & $\mathrm{H}$ & -2.05195 & -2.84688 & 0.43279 \\
\hline 34 & $\mathrm{H}$ & -0.8948 & -3.29135 & -0.81235 \\
\hline 35 & $\mathrm{H}$ & 3.52834 & -1.40633 & -2.5725 \\
\hline 36 & $\mathrm{H}$ & 1.8726 & -1.13818 & -2.0199 \\
\hline 37 & $\mathrm{H}$ & 2.82388 & 0.2113 & -2.66386 \\
\hline 38 & $\mathrm{H}$ & 0.29508 & 0.78646 & -0.62824 \\
\hline 39 & $\mathrm{H}$ & -2.35018 & 1.69899 & 0.6976 \\
\hline 40 & $\mathrm{H}$ & -0.6733 & -0.88353 & -1.47493 \\
\hline 41 & $\mathrm{H}$ & -2.24176 & -1.61125 & -1.77725 \\
\hline 42 & $\mathrm{H}$ & -3.97115 & -1.46221 & -0.19725 \\
\hline 43 & $\mathrm{H}$ & -5.68997 & 0.09604 & -0.89638 \\
\hline 44 & $\mathrm{H}$ & -4.57245 & 1.46463 & -0.76574 \\
\hline 45 & $\mathrm{H}$ & -5.31458 & -0.37656 & 1.54762 \\
\hline 46 & $\mathrm{H}$ & -3.68647 & -0.68803 & 2.16391 \\
\hline 47 & $\mathrm{H}$ & -4.1586 & 0.94747 & 1.69192 \\
\hline 48 & $\mathrm{H}$ & -0.52647 & 4.44154 & 1.0777 \\
\hline 49 & $\mathrm{H}$ & -1.47092 & 3.11865 & 1.77338 \\
\hline 50 & $\mathrm{H}$ & 0.10489 & 3.53853 & 2.44337 \\
\hline 51 & $\mathrm{H}$ & -0.9644 & -2.49242 & 2.73018 \\
\hline 52 & $\mathrm{H}$ & 0.48393 & -1.48782 & 2.81559 \\
\hline 53 & $\mathrm{H}$ & -1.0228 & -0.83633 & 2.14857 \\
\hline 54 & $\mathrm{H}$ & -3.42661 & 0.52841 & -2.51013 \\
\hline
\end{tabular}

B3LYP/6-311G(d,p) Energy $=-931.84882835$ a.u.; Population $=0.06 \%$ 


\begin{tabular}{|c|c|c|c|c|}
\hline \multicolumn{2}{|c|}{$\begin{array}{c}(7 S, 8 S, 15 R)-\mathbf{3} \\
\text { Conf. } 24 \\
\end{array}$} & \multicolumn{3}{|c|}{$\begin{array}{c}\text { Standard Orientation } \\
\text { (Ångstroms) }\end{array}$} \\
\hline I & atom & $\mathrm{X}$ & $\mathrm{Y}$ & $\mathrm{Z}$ \\
\hline 1 & $\mathrm{C}$ & -2.7163 & 0.56262 & 0.2437 \\
\hline 2 & $\mathrm{C}$ & -2.87847 & 2.05825 & 0.39692 \\
\hline 3 & $\mathrm{C}$ & -1.81847 & 2.83886 & -0.42206 \\
\hline 4 & $\mathrm{C}$ & -3.77843 & -0.40755 & -0.09442 \\
\hline 5 & $\mathrm{C}$ & -3.67742 & -1.8742 & 0.31282 \\
\hline 6 & $\mathrm{C}$ & -2.36265 & -2.39494 & 0.92274 \\
\hline 7 & $\mathrm{C}$ & -1.17472 & -2.42758 & -0.00684 \\
\hline 8 & $\mathrm{C}$ & 0.11288 & -2.20244 & 0.29072 \\
\hline 9 & $\mathrm{C}$ & 1.18074 & -2.3365 & -0.78159 \\
\hline 10 & $\mathrm{C}$ & -5.20288 & 0.03561 & -0.35887 \\
\hline 11 & $\mathrm{C}$ & -0.38632 & 2.58435 & 0.0061 \\
\hline 12 & $\mathrm{C}$ & 0.31437 & 1.58942 & -0.57672 \\
\hline 13 & $\mathrm{C}$ & 1.6793 & 1.17557 & -0.28807 \\
\hline 14 & $\mathrm{C}$ & 1.58115 & -1.02606 & -1.5243 \\
\hline 15 & $\mathrm{C}$ & 2.27546 & 0.03278 & -0.69451 \\
\hline 16 & $\mathrm{C}$ & 3.73913 & -0.25843 & -0.38558 \\
\hline 17 & $\mathrm{C}$ & 4.22642 & 0.31138 & 0.94818 \\
\hline 18 & $\mathrm{C}$ & 4.65186 & 0.20109 & -1.54211 \\
\hline 19 & $\mathrm{C}$ & 0.12686 & 3.46467 & 1.11563 \\
\hline 20 & $\mathrm{O}$ & -2.82354 & 0.02544 & -1.09675 \\
\hline 21 & $\mathrm{C}$ & 0.61692 & -1.86248 & 1.67242 \\
\hline 22 & $\mathrm{H}$ & -1.8539 & 0.16459 & 0.77045 \\
\hline 23 & $\mathrm{O}$ & 5.51986 & -0.24432 & 1.21248 \\
\hline 24 & $\mathrm{H}$ & -3.86987 & 2.38344 & 0.07468 \\
\hline 25 & $\mathrm{H}$ & -2.79281 & 2.30459 & 1.46134 \\
\hline 26 & $\mathrm{H}$ & -1.94541 & 2.56261 & -1.47228 \\
\hline 27 & $\mathrm{H}$ & -2.04324 & 3.90793 & -0.34256 \\
\hline 28 & $\mathrm{H}$ & -3.92798 & -2.46982 & -0.57471 \\
\hline 29 & $\mathrm{H}$ & -4.47902 & -2.06548 & 1.0346 \\
\hline 30 & $\mathrm{H}$ & -2.13899 & -1.83819 & 1.83584 \\
\hline 31 & $\mathrm{H}$ & -2.56986 & -3.42302 & 1.25173 \\
\hline 32 & $\mathrm{H}$ & -1.4103 & -2.70694 & -1.03317 \\
\hline 33 & $\mathrm{H}$ & 0.83042 & -3.03384 & -1.54849 \\
\hline 34 & $\mathrm{H}$ & 2.07891 & -2.78688 & -0.34324 \\
\hline 35 & $\mathrm{H}$ & -5.68706 & -0.66395 & -1.04734 \\
\hline 36 & $\mathrm{H}$ & -5.78371 & 0.0485 & 0.56798 \\
\hline 37 & $\mathrm{H}$ & -5.2385 & 1.02725 & -0.80807 \\
\hline 38 & $\mathrm{H}$ & -0.21075 & 1.02164 & -1.33875 \\
\hline 39 & $\mathrm{H}$ & 2.26683 & 1.86336 & 0.31204 \\
\hline 40 & $\mathrm{H}$ & 2.25539 & -1.32373 & -2.33681 \\
\hline 41 & $\mathrm{H}$ & 0.68572 & -0.62598 & -2.00154 \\
\hline 42 & $\mathrm{H}$ & 3.84849 & -1.34653 & -0.29616 \\
\hline 43 & $\mathrm{H}$ & 4.28994 & 1.406 & 0.90366 \\
\hline 44 & $\mathrm{H}$ & 3.52432 & 0.04286 & 1.74707 \\
\hline 45 & $\mathrm{H}$ & 5.68895 & -0.06911 & -1.33417 \\
\hline 46 & $\mathrm{H}$ & 4.36141 & -0.26035 & -2.48894 \\
\hline 47 & $\mathrm{H}$ & 4.59427 & 1.28704 & -1.66331 \\
\hline 48 & $\mathrm{H}$ & 1.12134 & 3.18631 & 1.46339 \\
\hline 49 & $\mathrm{H}$ & 0.1592 & 4.51192 & 0.79188 \\
\hline 50 & $\mathrm{H}$ & -0.54834 & 3.43057 & 1.97856 \\
\hline 51 & $\mathrm{H}$ & 1.24567 & -2.67647 & 2.05375 \\
\hline 52 & $\mathrm{H}$ & 1.24405 & -0.96747 & 1.6473 \\
\hline 53 & $\mathrm{H}$ & -0.1833 & -1.69864 & 2.39433 \\
\hline 54 & $\mathrm{H}$ & 5.86098 & 0.1723 & 2.01015 \\
\hline
\end{tabular}

B3LYP/6-311G(d,p) Energy = -931.85147231 a.u.; Population $=2.14 \%$ 


\section{Computational data of $(7 R, 8 S, 12 S)-4$}

Torsional sampling (MCMM) conformational searches using OPLS_2005 force field were carried out by means of the conformational search module in the Macromodel applying an energy window of $21 \mathrm{~kJ} / \mathrm{mol}$, which afforded 200 conformers for (7R,8S,12S)-4. The Boltzmann populations of the conformers were obtained based on the potential energy provided by the OPLS_2005 force field, which afforded 26 conformers for $(7 R, 8 S, 12 S)-\mathbf{4}$ above $1 \%$ population for re-optimization. The reoptimization and the following TDDFT calculations of the re-optimized geometries (Fig. S69, Table S19) were all performed with Gaussian 09 at the B3LYP/6-311G(d,p) level with IEFPCM solvent model for acetonitrile. Frequency analysis was performed as well to confirm that the re-optimized geometries were at the energy minima. Finally, the SpecDis1.62 software was used to obtain the Boltzmann-averaged ECD spectra of $(7 R, 8 S, 12 S)-\mathbf{4}$ and visualize the results. 

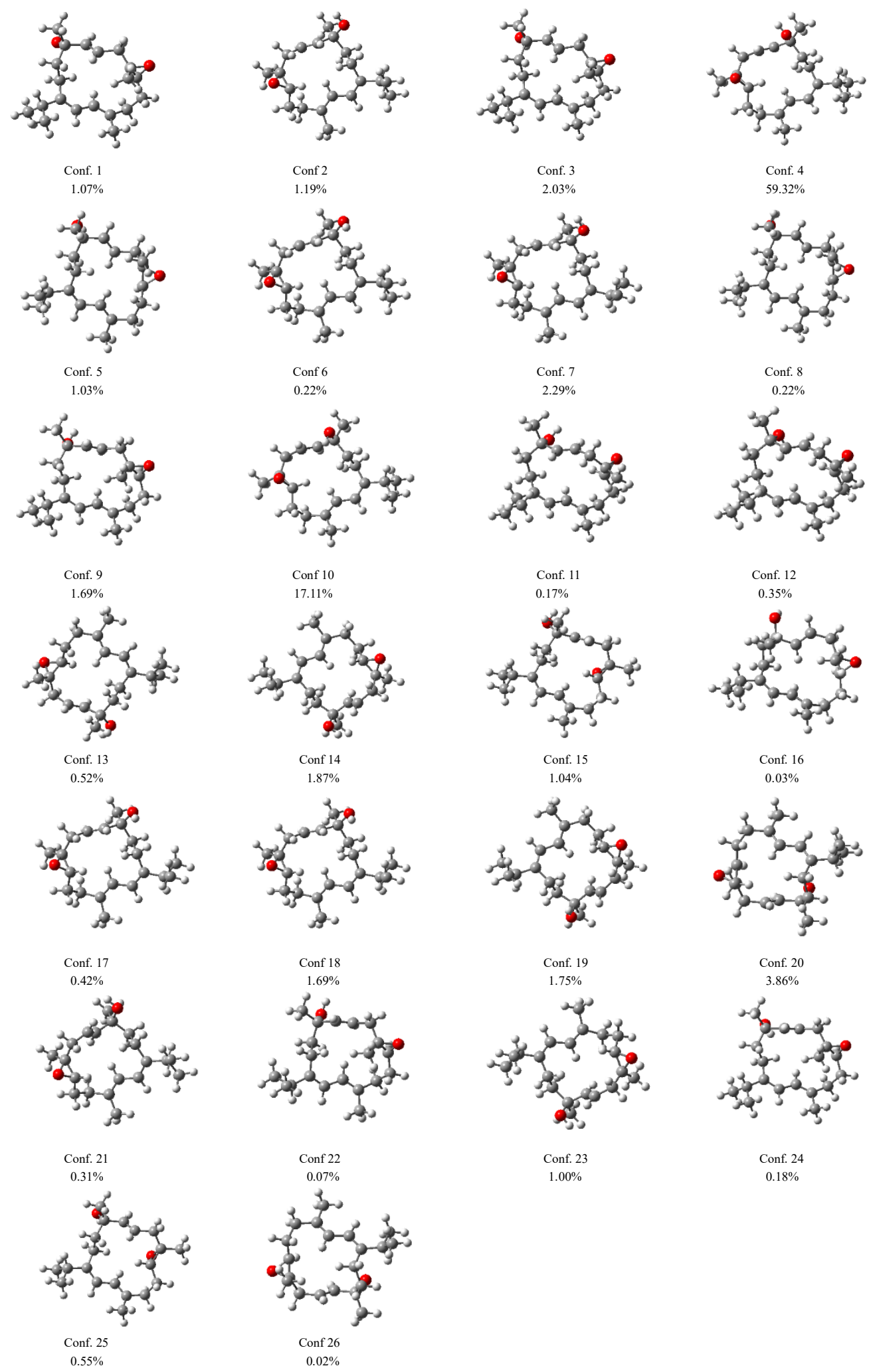

$$
\begin{aligned}
& \text { Conf. } 23 \\
& 1.00 \%
\end{aligned}
$$

$$
\text { Conf. } 24
$$

$0.18 \%$

Figure S69. Re-optimized conformers above 1\% population (OPLS_2005) of (7S,8S,12S)-4 calculated at the B3LYP/6-311G(d,p) level with IEFPCM solvent model for acetonitrile.

Table S19. Cartesian coordinates for the re-optimized conformers of $(7 S, 8 S, 12 S)-4$ at the B3LYP/6-311G(d,p) level with IEFPCM solvent model for acetonitrile.

\begin{tabular}{|c|c|}
\hline $\begin{array}{c}(7 S, 8 S, 12 S)-4 \\
\text { Conf. 1 }\end{array}$ & $\begin{array}{c}\text { Standard Orientation } \\
\text { (Ångstroms) }\end{array}$ \\
\hline
\end{tabular}




\begin{tabular}{|c|c|c|c|c|}
\hline I & atom & $X$ & $\mathrm{Y}$ & $\mathrm{Z}$ \\
\hline 1 & $\mathrm{C}$ & 3.37258 & 0.33155 & -0.56893 \\
\hline 2 & $\mathrm{C}$ & 3.75688 & -1.12302 & -0.72088 \\
\hline 3 & $\mathrm{C}$ & 2.68935 & -1.96575 & -1.45738 \\
\hline 4 & $\mathrm{C}$ & 2.90901 & 1.00829 & 0.65863 \\
\hline 5 & $\mathrm{C}$ & 2.10879 & 2.30253 & 0.51782 \\
\hline 6 & $\mathrm{C}$ & 0.61262 & 2.14317 & 0.56942 \\
\hline 7 & $\mathrm{C}$ & -0.23614 & 2.67094 & -0.3114 \\
\hline 8 & $\mathrm{C}$ & -1.76018 & 2.64195 & -0.24786 \\
\hline 9 & $\mathrm{C}$ & -2.31835 & 1.29355 & 0.23838 \\
\hline 10 & $\mathrm{C}$ & 2.75434 & 0.28075 & 1.97459 \\
\hline 11 & $\mathrm{C}$ & 1.48813 & -2.35644 & -0.62073 \\
\hline 12 & $\mathrm{C}$ & 0.32022 & -1.69676 & -0.76006 \\
\hline 13 & $\mathrm{C}$ & -0.94149 & -1.98179 & -0.08956 \\
\hline 14 & $\mathrm{C}$ & -2.11547 & 0.13616 & -0.77117 \\
\hline 15 & $\mathrm{C}$ & -2.0605 & -1.22528 & -0.11081 \\
\hline 16 & $\mathrm{C}$ & -3.36175 & -1.69314 & 0.53525 \\
\hline 17 & $\mathrm{C}$ & -4.37075 & -2.14527 & -0.54443 \\
\hline 18 & $\mathrm{C}$ & -3.20907 & -2.78879 & 1.59842 \\
\hline 19 & $\mathrm{C}$ & 1.71374 & -3.51081 & 0.32176 \\
\hline 20 & $\mathrm{O}$ & -2.29352 & 2.82323 & -1.57647 \\
\hline 21 & $\mathrm{C}$ & -2.258 & 3.78635 & 0.65235 \\
\hline 22 & $\mathrm{O}$ & 4.27356 & 1.15982 & 0.19908 \\
\hline 23 & $\mathrm{H}$ & 3.06778 & 0.79782 & -1.50776 \\
\hline 24 & $\mathrm{H}$ & 4.68423 & -1.14654 & -1.30538 \\
\hline 25 & $\mathrm{H}$ & 3.99673 & -1.56257 & 0.24947 \\
\hline 26 & $\mathrm{H}$ & 2.35841 & -1.41617 & -2.34452 \\
\hline 27 & $\mathrm{H}$ & 3.17588 & -2.87795 & -1.8223 \\
\hline 28 & $\mathrm{H}$ & 2.42697 & 2.9612 & 1.33884 \\
\hline 29 & $\mathrm{H}$ & 2.40374 & 2.79474 & -0.41243 \\
\hline 30 & $\mathrm{H}$ & 0.22166 & 1.58436 & 1.41654 \\
\hline 31 & $\mathrm{H}$ & 0.16375 & 3.2434 & -1.14862 \\
\hline 32 & $\mathrm{H}$ & -1.84188 & 1.04817 & 1.19104 \\
\hline 33 & $\mathrm{H}$ & -3.38331 & 1.42609 & 0.44909 \\
\hline 34 & $\mathrm{H}$ & 2.9492 & 0.96787 & 2.80388 \\
\hline 35 & $\mathrm{H}$ & 1.74174 & -0.1137 & 2.08916 \\
\hline 36 & $\mathrm{H}$ & 3.4559 & -0.54851 & 2.05471 \\
\hline 37 & $\mathrm{H}$ & 0.3176 & -0.87951 & -1.47466 \\
\hline 38 & $\mathrm{H}$ & -0.98279 & -2.91855 & 0.45526 \\
\hline 39 & $\mathrm{H}$ & -2.92859 & 0.17357 & -1.50196 \\
\hline 40 & $\mathrm{H}$ & -1.20122 & 0.32414 & -1.33062 \\
\hline 41 & $\mathrm{H}$ & -3.80323 & -0.82222 & 1.03606 \\
\hline 42 & $\mathrm{H}$ & -5.3351 & -2.39121 & -0.08984 \\
\hline 43 & $\mathrm{H}$ & -4.54476 & -1.36968 & -1.29349 \\
\hline 44 & $\mathrm{H}$ & -4.00068 & -3.03603 & -1.06102 \\
\hline 45 & $\mathrm{H}$ & -4.17287 & -2.97583 & 2.07994 \\
\hline 46 & $\mathrm{H}$ & -2.87636 & -3.73512 & 1.16177 \\
\hline 47 & $\mathrm{H}$ & -2.49351 & -2.50247 & 2.37363 \\
\hline 48 & $\mathrm{H}$ & 2.60404 & -3.34187 & 0.93733 \\
\hline 49 & $\mathrm{H}$ & 0.87654 & -3.68667 & 0.99635 \\
\hline 50 & $\mathrm{H}$ & 1.89813 & -4.4348 & -0.24004 \\
\hline 51 & $\mathrm{H}$ & -2.03986 & 3.70191 & -1.88046 \\
\hline 52 & $\mathrm{H}$ & -3.34926 & 3.83982 & 0.61745 \\
\hline 53 & $\mathrm{H}$ & -1.94019 & 3.63738 & 1.68716 \\
\hline 54 & $\mathrm{H}$ & -1.85272 & 4.7454 & 0.31408 \\
\hline
\end{tabular}

B3LYP/6-311G(d,p) Energy = -931.84872215 a.u.; Population $=1.07 \%$ 


\begin{tabular}{|c|c|c|c|c|}
\hline \multicolumn{2}{|c|}{$\begin{array}{c}(7 S, 8 S, 12 S)-\mathbf{4} \\
\text { Conf. } 2 \\
\end{array}$} & \multicolumn{3}{|c|}{$\begin{array}{c}\text { Standard Orientation } \\
\text { (Ångstroms) }\end{array}$} \\
\hline $\mathrm{I}$ & atom & $X$ & $\mathrm{Y}$ & $\mathrm{Z}$ \\
\hline 1 & $\mathrm{C}$ & 2.72768 & -1.03595 & -0.88284 \\
\hline 2 & $\mathrm{C}$ & 2.76902 & -2.3812 & -0.1896 \\
\hline 3 & $\mathrm{C}$ & 1.79259 & -2.49619 & 1.006 \\
\hline 4 & $\mathrm{C}$ & 3.47095 & 0.1633 & -0.44392 \\
\hline 5 & $\mathrm{C}$ & 2.94031 & 1.54098 & -0.84978 \\
\hline 6 & $\mathrm{C}$ & 1.85035 & 2.07373 & 0.0446 \\
\hline 7 & $\mathrm{C}$ & 0.63668 & 2.40386 & -0.39768 \\
\hline 8 & $\mathrm{C}$ & -0.56127 & 2.88299 & 0.40483 \\
\hline 9 & $\mathrm{C}$ & -1.49519 & 1.69926 & 0.74619 \\
\hline 10 & $\mathrm{C}$ & 4.38978 & 0.15849 & 0.75802 \\
\hline 11 & $\mathrm{C}$ & 0.32559 & -2.66495 & 0.65102 \\
\hline 12 & $\mathrm{C}$ & -0.4672 & -1.58356 & 0.51353 \\
\hline 13 & $\mathrm{C}$ & -1.90865 & -1.54799 & 0.28832 \\
\hline 14 & $\mathrm{C}$ & -1.9004 & 0.83598 & -0.46738 \\
\hline 15 & $\mathrm{C}$ & -2.60333 & -0.45934 & -0.10366 \\
\hline 16 & $\mathrm{C}$ & -4.11739 & -0.45567 & -0.2615 \\
\hline 17 & $\mathrm{C}$ & -4.51435 & -0.5297 & -1.75258 \\
\hline 18 & $\mathrm{C}$ & -4.85692 & -1.53699 & 0.53625 \\
\hline 19 & $\mathrm{C}$ & -0.14008 & -4.08785 & 0.48667 \\
\hline 20 & $\mathrm{O}$ & -1.34928 & 3.75886 & -0.4324 \\
\hline 21 & $\mathrm{C}$ & -0.17343 & 3.6282 & 1.68746 \\
\hline 22 & $\mathrm{O}$ & 3.9306 & -0.62106 & -1.57062 \\
\hline 23 & $\mathrm{H}$ & 1.82362 & -0.84903 & -1.46074 \\
\hline 24 & $\mathrm{H}$ & 2.55397 & -3.16113 & -0.92872 \\
\hline 25 & $\mathrm{H}$ & 3.78763 & -2.56334 & 0.15961 \\
\hline 26 & $\mathrm{H}$ & 1.91685 & -1.61317 & 1.6399 \\
\hline 27 & $\mathrm{H}$ & 2.10437 & -3.35531 & 1.60984 \\
\hline 28 & $\mathrm{H}$ & 3.79118 & 2.23565 & -0.85739 \\
\hline 29 & $\mathrm{H}$ & 2.57421 & 1.47199 & -1.87685 \\
\hline 30 & $\mathrm{H}$ & 2.09131 & 2.17504 & 1.10046 \\
\hline 31 & $\mathrm{H}$ & 0.4274 & 2.29791 & -1.46025 \\
\hline 32 & $\mathrm{H}$ & -0.98899 & 1.0814 & 1.49151 \\
\hline 33 & $\mathrm{H}$ & -2.3905 & 2.10864 & 1.22589 \\
\hline 34 & $\mathrm{H}$ & 5.26901 & 0.77512 & 0.54779 \\
\hline 35 & $\mathrm{H}$ & 3.88867 & 0.58003 & 1.63399 \\
\hline 36 & $\mathrm{H}$ & 4.73351 & -0.84389 & 1.00955 \\
\hline 37 & $\mathrm{H}$ & 0.02182 & -0.62015 & 0.62071 \\
\hline 38 & $\mathrm{H}$ & -2.45483 & -2.46239 & 0.49484 \\
\hline 39 & $\mathrm{H}$ & -2.5389 & 1.43904 & -1.11698 \\
\hline 40 & $\mathrm{H}$ & -1.00808 & 0.59913 & -1.05073 \\
\hline 41 & $\mathrm{H}$ & -4.46163 & 0.5192 & 0.11229 \\
\hline 42 & $\mathrm{H}$ & -5.59595 & -0.41408 & -1.86999 \\
\hline 43 & $\mathrm{H}$ & -4.02918 & 0.25084 & -2.34325 \\
\hline 44 & $\mathrm{H}$ & -4.2269 & -1.49817 & -2.17312 \\
\hline 45 & $\mathrm{H}$ & -5.93754 & -1.39127 & 0.45209 \\
\hline 46 & $\mathrm{H}$ & -4.63552 & -2.54013 & 0.15966 \\
\hline 47 & $\mathrm{H}$ & -4.59139 & -1.50689 & 1.59601 \\
\hline 48 & $\mathrm{H}$ & -0.07012 & -4.632 & 1.43646 \\
\hline 49 & $\mathrm{H}$ & -1.16501 & -4.16279 & 0.124 \\
\hline 50 & $\mathrm{H}$ & 0.50326 & -4.62191 & -0.22233 \\
\hline 51 & $\mathrm{H}$ & -0.78615 & 4.49422 & -0.69962 \\
\hline 52 & $\mathrm{H}$ & -1.07638 & 3.97879 & 2.19178 \\
\hline 53 & $\mathrm{H}$ & 0.37911 & 2.98711 & 2.37857 \\
\hline 54 & $\mathrm{H}$ & 0.4522 & 4.49475 & 1.4555 \\
\hline
\end{tabular}

B3LYP/6-311G(d,p) Energy = -931.85594709 a.u.; Population $=1.19 \%$ 


\begin{tabular}{|c|c|c|c|c|}
\hline \multicolumn{2}{|c|}{$\begin{array}{c}(7 S, 8 S, 12 S)-\mathbf{4} \\
\text { Conf. } 3 \\
\end{array}$} & \multicolumn{3}{|c|}{$\begin{array}{c}\text { Standard Orientation } \\
\text { (Ångstroms) }\end{array}$} \\
\hline I & atom & $\mathrm{X}$ & $\mathrm{Y}$ & $\mathrm{Z}$ \\
\hline 1 & $\mathrm{C}$ & 3.35034 & 0.45091 & -0.5549 \\
\hline 2 & $\mathrm{C}$ & 3.79772 & -0.97816 & -0.76514 \\
\hline 3 & $\mathrm{C}$ & 2.75171 & -1.84803 & -1.50099 \\
\hline 4 & $\mathrm{C}$ & 2.86269 & 1.05364 & 0.70132 \\
\hline 5 & $\mathrm{C}$ & 1.99471 & 2.30764 & 0.62103 \\
\hline 6 & $\mathrm{C}$ & 0.50996 & 2.05693 & 0.56622 \\
\hline 7 & $\mathrm{C}$ & -0.3359 & 2.71421 & -0.22736 \\
\hline 8 & $\mathrm{C}$ & -1.8531 & 2.6092 & -0.2559 \\
\hline 9 & $\mathrm{C}$ & -2.39052 & 1.24262 & 0.21877 \\
\hline 10 & $\mathrm{C}$ & 2.75366 & 0.26704 & 1.98794 \\
\hline 11 & $\mathrm{C}$ & 1.573 & -2.28823 & -0.65706 \\
\hline 12 & $\mathrm{C}$ & 0.38358 & -1.66451 & -0.77859 \\
\hline 13 & $\mathrm{C}$ & -0.86167 & -1.99085 & -0.09682 \\
\hline 14 & $\mathrm{C}$ & -2.11122 & 0.08417 & -0.77245 \\
\hline 15 & $\mathrm{C}$ & -2.00531 & -1.27171 & -0.10525 \\
\hline 16 & $\mathrm{C}$ & -3.28326 & -1.77803 & 0.55747 \\
\hline 17 & $\mathrm{C}$ & -4.29917 & -2.24831 & -0.50792 \\
\hline 18 & $\mathrm{C}$ & -3.08196 & -2.8771 & 1.60902 \\
\hline 19 & $\mathrm{C}$ & 1.8447 & -3.44397 & 0.27103 \\
\hline 20 & $\mathrm{O}$ & -2.31356 & 2.87903 & -1.60006 \\
\hline 21 & $\mathrm{C}$ & -2.45438 & 3.74057 & 0.58778 \\
\hline 22 & $\mathrm{O}$ & 4.21598 & 1.28788 & 0.24289 \\
\hline 23 & $\mathrm{H}$ & 3.01909 & 0.93977 & -1.47319 \\
\hline 24 & $\mathrm{H}$ & 4.70906 & -0.94108 & -1.37352 \\
\hline 25 & $\mathrm{H}$ & 4.0841 & -1.43583 & 0.18405 \\
\hline 26 & $\mathrm{H}$ & 3.26553 & -2.7385 & -1.88159 \\
\hline 27 & $\mathrm{H}$ & 2.39313 & -1.29938 & -2.37795 \\
\hline 28 & $\mathrm{H}$ & 2.22287 & 2.91071 & 1.51167 \\
\hline 29 & $\mathrm{H}$ & 2.30986 & 2.89719 & -0.24364 \\
\hline 30 & $\mathrm{H}$ & 0.12438 & 1.31518 & 1.26061 \\
\hline 31 & $\mathrm{H}$ & 0.0526 & 3.472 & -0.90745 \\
\hline 32 & $\mathrm{H}$ & -1.95756 & 1.01216 & 1.19616 \\
\hline 33 & $\mathrm{H}$ & -3.46768 & 1.34516 & 0.37507 \\
\hline 34 & $\mathrm{H}$ & 2.95598 & 0.9239 & 2.8396 \\
\hline 35 & $\mathrm{H}$ & 1.75121 & -0.15035 & 2.11138 \\
\hline 36 & $\mathrm{H}$ & 3.47081 & -0.55205 & 2.01835 \\
\hline 37 & $\mathrm{H}$ & 0.35103 & -0.84254 & -1.4867 \\
\hline 38 & $\mathrm{H}$ & -0.86693 & -2.92742 & 0.44932 \\
\hline 39 & $\mathrm{H}$ & -2.90894 & 0.07192 & -1.52279 \\
\hline 40 & $\mathrm{H}$ & -1.18673 & 0.29676 & -1.30949 \\
\hline 41 & $\mathrm{H}$ & -3.73818 & -0.92307 & 1.07325 \\
\hline 42 & $\mathrm{H}$ & -5.24708 & -2.52559 & -0.0374 \\
\hline 43 & $\mathrm{H}$ & -4.51071 & -1.47103 & -1.24562 \\
\hline 44 & $\mathrm{H}$ & -3.91453 & -3.12338 & -1.04036 \\
\hline 45 & $\mathrm{H}$ & -4.03255 & -3.09599 & 2.10292 \\
\hline 46 & $\mathrm{H}$ & -2.72779 & -3.80959 & 1.15973 \\
\hline 47 & $\mathrm{H}$ & -2.36405 & -2.57524 & 2.37602 \\
\hline 48 & $\mathrm{H}$ & 2.73389 & -3.25176 & 0.88114 \\
\hline 49 & $\mathrm{H}$ & 1.01954 & -3.65532 & 0.95025 \\
\hline 50 & $\mathrm{H}$ & 2.0552 & -4.3549 & -0.3026 \\
\hline 51 & $\mathrm{H}$ & -1.87248 & 2.26327 & -2.19511 \\
\hline 52 & $\mathrm{H}$ & -3.53926 & 3.76279 & 0.45496 \\
\hline 53 & $\mathrm{H}$ & -2.22777 & 3.59324 & 1.6457 \\
\hline 54 & $\mathrm{H}$ & -2.0488 & 4.70549 & 0.27533 \\
\hline
\end{tabular}

B3LYP/6-311G(d,p) Energy $=-931.56507782$ a.u.; Population $=2.03 \%$ 


\begin{tabular}{|c|c|c|c|c|}
\hline \multicolumn{2}{|c|}{$\begin{array}{c}(7 S, 8 S, 12 S)-4 \\
\text { Conf. } 4\end{array}$} & \multicolumn{3}{|c|}{$\begin{array}{c}\text { Standard Orientation } \\
\text { (Ångstroms) }\end{array}$} \\
\hline $\mathrm{I}$ & atom & $\mathrm{X}$ & $\mathrm{Y}$ & $\mathrm{Z}$ \\
\hline 1 & $\mathrm{C}$ & -2.67634 & -0.74251 & 0.4606 \\
\hline 2 & $\mathrm{C}$ & -2.76017 & -2.24802 & 0.3777 \\
\hline 3 & $\mathrm{C}$ & -1.73665 & -2.82337 & -0.6361 \\
\hline 4 & $\mathrm{C}$ & -3.59169 & 0.20823 & -0.20265 \\
\hline 5 & $\mathrm{C}$ & -3.10079 & 1.60538 & -0.59526 \\
\hline 6 & $\mathrm{C}$ & -1.87823 & 2.08706 & 0.13185 \\
\hline 7 & $\mathrm{C}$ & -0.71654 & 2.37432 & -0.45401 \\
\hline 8 & $\mathrm{C}$ & 0.54321 & 2.81325 & 0.27432 \\
\hline 9 & $\mathrm{C}$ & 1.44935 & 1.59474 & 0.56703 \\
\hline 10 & $\mathrm{C}$ & -4.78933 & -0.25105 & -1.00553 \\
\hline 11 & $\mathrm{C}$ & -0.29657 & -2.79795 & -0.15972 \\
\hline 12 & $\mathrm{C}$ & 0.52383 & -1.7883 & -0.51544 \\
\hline 13 & $\mathrm{C}$ & 1.92876 & -1.61908 & -0.16328 \\
\hline 14 & $\mathrm{C}$ & 2.00043 & 0.84108 & -0.66304 \\
\hline 15 & $\mathrm{C}$ & 2.63868 & -0.47568 & -0.26164 \\
\hline 16 & $\mathrm{C}$ & 4.1246 & -0.39993 & 0.06633 \\
\hline 17 & $\mathrm{C}$ & 4.6429 & -1.49686 & 1.00482 \\
\hline 18 & $\mathrm{C}$ & 4.96316 & -0.37041 & -1.23105 \\
\hline 19 & $\mathrm{C}$ & 0.10456 & -3.94751 & 0.72807 \\
\hline 20 & $\mathrm{O}$ & 0.23106 & 3.31518 & 1.58606 \\
\hline 21 & $\mathrm{C}$ & 1.27523 & 3.90133 & -0.52529 \\
\hline 22 & $\mathrm{O}$ & -3.68311 & -0.03489 & 1.22066 \\
\hline 23 & $\mathrm{H}$ & -1.67378 & -0.37313 & 0.66102 \\
\hline 24 & $\mathrm{H}$ & -2.57325 & -2.66232 & 1.3748 \\
\hline 25 & $\mathrm{H}$ & -3.76679 & -2.56218 & 0.09516 \\
\hline 26 & $\mathrm{H}$ & -2.02062 & -3.85881 & -0.85403 \\
\hline 27 & $\mathrm{H}$ & -1.82692 & -2.27062 & -1.5766 \\
\hline 28 & $\mathrm{H}$ & -2.92069 & 1.61035 & -1.67564 \\
\hline 29 & $\mathrm{H}$ & -3.93467 & 2.2973 & -0.41359 \\
\hline 30 & $\mathrm{H}$ & -1.96291 & 2.18006 & 1.21125 \\
\hline 31 & $\mathrm{H}$ & -0.62565 & 2.26955 & -1.53388 \\
\hline 32 & $\mathrm{H}$ & 2.27813 & 1.94578 & 1.19073 \\
\hline 33 & $\mathrm{H}$ & 0.86049 & 0.90573 & 1.17745 \\
\hline 34 & $\mathrm{H}$ & -5.58864 & 0.49324 & -0.93754 \\
\hline 35 & $\mathrm{H}$ & -4.52796 & -0.3664 & -2.0616 \\
\hline 36 & $\mathrm{H}$ & -5.18272 & -1.19774 & -0.63792 \\
\hline 37 & $\mathrm{H}$ & 0.08857 & -1.01331 & -1.14078 \\
\hline 38 & $\mathrm{H}$ & 2.4388 & -2.50162 & 0.20744 \\
\hline 39 & $\mathrm{H}$ & 1.19366 & 0.67134 & -1.37916 \\
\hline 40 & $\mathrm{H}$ & 2.73843 & 1.4678 & -1.17245 \\
\hline 41 & $\mathrm{H}$ & 4.28477 & 0.56148 & 0.57279 \\
\hline 42 & $\mathrm{H}$ & 5.68613 & -1.30101 & 1.26772 \\
\hline 43 & $\mathrm{H}$ & 4.06248 & -1.54088 & 1.9298 \\
\hline 44 & $\mathrm{H}$ & 4.60776 & -2.48355 & 0.5336 \\
\hline 45 & $\mathrm{H}$ & 6.01985 & -0.20082 & -1.00343 \\
\hline 46 & $\mathrm{H}$ & 4.87666 & -1.32439 & -1.75975 \\
\hline 47 & $\mathrm{H}$ & 4.63814 & 0.42086 & -1.91109 \\
\hline 48 & $\mathrm{H}$ & 0.07332 & -4.89212 & 0.17149 \\
\hline 49 & $\mathrm{H}$ & 1.10166 & -3.83434 & 1.15201 \\
\hline 50 & $\mathrm{H}$ & -0.59855 & -4.05691 & 1.56137 \\
\hline 51 & $\mathrm{H}$ & -0.38694 & 4.04772 & 1.4771 \\
\hline 52 & $\mathrm{H}$ & 2.18193 & 4.20597 & 0.00282 \\
\hline 53 & $\mathrm{H}$ & 1.5513 & 3.55265 & -1.52362 \\
\hline 54 & $\mathrm{H}$ & 0.63403 & 4.7799 & -0.64554 \\
\hline
\end{tabular}

B3LYP/6-311G(d,p) Energy = -931.56869290 a.u.; Population $=59.32 \%$ 


\begin{tabular}{|c|c|c|c|c|}
\hline \multicolumn{2}{|c|}{$\begin{array}{c}(7 S, 8 S, 12 S)-\mathbf{4} \\
\text { Conf. } 5 \\
\end{array}$} & \multicolumn{3}{|c|}{$\begin{array}{c}\text { Standard Orientation } \\
\text { (Ångstroms) }\end{array}$} \\
\hline I & atom & $\mathrm{X}$ & $\mathrm{Y}$ & $\mathrm{Z}$ \\
\hline 1 & $\mathrm{C}$ & 3.15435 & -0.50923 & -0.25272 \\
\hline 2 & $\mathrm{C}$ & 3.07815 & -1.7274 & 0.65674 \\
\hline 3 & $\mathrm{C}$ & 2.44015 & -2.95629 & -0.00315 \\
\hline 4 & $\mathrm{C}$ & 3.1659 & 0.8947 & 0.20599 \\
\hline 5 & $\mathrm{C}$ & 2.6046 & 1.96208 & -0.73353 \\
\hline 6 & $\mathrm{C}$ & 1.10088 & 1.94463 & -0.73205 \\
\hline 7 & $\mathrm{C}$ & 0.3077 & 2.91949 & -0.28981 \\
\hline 8 & $\mathrm{C}$ & -1.21054 & 2.91897 & -0.28664 \\
\hline 9 & $\mathrm{C}$ & -1.84736 & 1.53394 & -0.52784 \\
\hline 10 & $\mathrm{C}$ & 3.14476 & 1.24778 & 1.67533 \\
\hline 11 & $\mathrm{C}$ & 0.94321 & -2.96369 & -0.2476 \\
\hline 12 & $\mathrm{C}$ & 0.12928 & -1.94133 & 0.09207 \\
\hline 13 & $\mathrm{C}$ & -1.32292 & -1.91363 & -0.03778 \\
\hline 14 & $\mathrm{C}$ & -1.69453 & 0.50094 & 0.6149 \\
\hline 15 & $\mathrm{C}$ & -2.15959 & -0.88412 & 0.21368 \\
\hline 16 & $\mathrm{C}$ & -3.67614 & -1.05165 & 0.13211 \\
\hline 17 & $\mathrm{C}$ & -4.16344 & -2.13179 & -0.84378 \\
\hline 18 & $\mathrm{C}$ & -4.26869 & -1.29786 & 1.5373 \\
\hline 19 & $\mathrm{C}$ & 0.47114 & -4.24624 & -0.88717 \\
\hline 20 & $\mathrm{O}$ & -1.65214 & 3.80941 & -1.34493 \\
\hline 21 & $\mathrm{C}$ & -1.73407 & 3.57077 & 0.99567 \\
\hline 22 & $\mathrm{O}$ & 4.37997 & 0.259 & -0.24612 \\
\hline 23 & $\mathrm{H}$ & 2.78153 & -0.67987 & -1.26314 \\
\hline 24 & $\mathrm{H}$ & 4.10191 & -1.98632 & 0.94189 \\
\hline 25 & $\mathrm{H}$ & 2.55168 & -1.4917 & 1.58655 \\
\hline 26 & $\mathrm{H}$ & 2.67311 & -3.835 & 0.61334 \\
\hline 27 & $\mathrm{H}$ & 2.94681 & -3.1491 & -0.9599 \\
\hline 28 & $\mathrm{H}$ & 2.98428 & 2.94814 & -0.44708 \\
\hline 29 & $\mathrm{H}$ & 2.98077 & 1.74286 & -1.73853 \\
\hline 30 & $\mathrm{H}$ & 0.66057 & 1.02259 & -1.10229 \\
\hline 31 & $\mathrm{H}$ & 0.75586 & 3.84453 & 0.07089 \\
\hline 32 & $\mathrm{H}$ & -2.90695 & 1.71887 & -0.72313 \\
\hline 33 & $\mathrm{H}$ & -1.43843 & 1.1145 & -1.45329 \\
\hline 34 & $\mathrm{H}$ & 3.75375 & 2.14063 & 1.84626 \\
\hline 35 & $\mathrm{H}$ & 2.12696 & 1.46761 & 2.008 \\
\hline 36 & $\mathrm{H}$ & 3.54735 & 0.44142 & 2.28776 \\
\hline 37 & $\mathrm{H}$ & 0.59033 & -1.06282 & 0.52959 \\
\hline 38 & $\mathrm{H}$ & -1.78075 & -2.84547 & -0.34861 \\
\hline 39 & $\mathrm{H}$ & -0.65651 & 0.47988 & 0.94727 \\
\hline 40 & $\mathrm{H}$ & -2.2842 & 0.84109 & 1.47307 \\
\hline 41 & $\mathrm{H}$ & -4.08405 & -0.0969 & -0.22137 \\
\hline 42 & $\mathrm{H}$ & -5.25379 & -2.09861 & -0.92164 \\
\hline 43 & $\mathrm{H}$ & -3.74706 & -1.9865 & -1.84388 \\
\hline 44 & $\mathrm{H}$ & -3.89513 & -3.13741 & -0.50722 \\
\hline 45 & $\mathrm{H}$ & -5.36221 & -1.30251 & 1.49865 \\
\hline 46 & $\mathrm{H}$ & -3.93724 & -2.26517 & 1.92662 \\
\hline 47 & $\mathrm{H}$ & -3.96424 & -0.52696 & 2.24953 \\
\hline 48 & $\mathrm{H}$ & 0.69866 & -5.10405 & -0.24316 \\
\hline 49 & $\mathrm{H}$ & -0.59552 & -4.26134 & -1.10322 \\
\hline 50 & $\mathrm{H}$ & 1.00349 & -4.41821 & -1.82985 \\
\hline 51 & $\mathrm{H}$ & -1.25371 & 3.49351 & -2.1642 \\
\hline 52 & $\mathrm{H}$ & -2.82654 & 3.60115 & 0.98377 \\
\hline 53 & $\mathrm{H}$ & -1.40705 & 3.02723 & 1.8838 \\
\hline 54 & $\mathrm{H}$ & -1.36343 & 4.59615 & 1.0616 \\
\hline
\end{tabular}

B3LYP/6-311G(d,p) Energy $=-931.56522261$ a.u.; Population $=1.03 \%$ 


\begin{tabular}{|c|c|c|c|c|}
\hline \multicolumn{2}{|c|}{$\begin{array}{c}(7 S, 8 S, 12 S)-\mathbf{4} \\
\text { Conf. } 6 \\
\end{array}$} & \multicolumn{3}{|c|}{$\begin{array}{c}\text { Standard Orientation } \\
\text { (Ångstroms) }\end{array}$} \\
\hline $\mathrm{I}$ & atom & $\mathrm{X}$ & $\mathrm{Y}$ & $\mathrm{Z}$ \\
\hline 1 & $\mathrm{C}$ & 2.74358 & -1.0171 & -0.88434 \\
\hline 2 & $\mathrm{C}$ & 2.7895 & -2.36895 & -0.20441 \\
\hline 3 & $\mathrm{C}$ & 1.81336 & -2.49884 & 0.98975 \\
\hline 4 & $\mathrm{C}$ & 3.47353 & 0.18281 & -0.42564 \\
\hline 5 & $\mathrm{C}$ & 2.93672 & 1.56086 & -0.82071 \\
\hline 6 & $\mathrm{C}$ & 1.82774 & 2.07389 & 0.06182 \\
\hline 7 & $\mathrm{C}$ & 0.62797 & 2.42585 & -0.39869 \\
\hline 8 & $\mathrm{C}$ & -0.5844 & 2.89736 & 0.38972 \\
\hline 9 & $\mathrm{C}$ & -1.49886 & 1.69555 & 0.74494 \\
\hline 10 & $\mathrm{C}$ & 4.38149 & 0.17131 & 0.78451 \\
\hline 11 & $\mathrm{C}$ & 0.34697 & -2.66904 & 0.63363 \\
\hline 12 & $\mathrm{C}$ & -0.4492 & -1.58924 & 0.50287 \\
\hline 13 & $\mathrm{C}$ & -1.89168 & -1.56002 & 0.28467 \\
\hline 14 & $\mathrm{C}$ & -1.9056 & 0.82603 & -0.46426 \\
\hline 15 & $\mathrm{C}$ & -2.59703 & -0.47558 & -0.09851 \\
\hline 16 & $\mathrm{C}$ & -4.1125 & -0.48086 & -0.24334 \\
\hline 17 & $\mathrm{C}$ & -4.52285 & -0.56512 & -1.73031 \\
\hline 18 & $\mathrm{C}$ & -4.8378 & -1.56265 & 0.56662 \\
\hline 19 & $\mathrm{C}$ & -0.11477 & -4.09226 & 0.4618 \\
\hline 20 & $\mathrm{O}$ & -1.31511 & 3.85174 & -0.4136 \\
\hline 21 & $\mathrm{C}$ & -0.21591 & 3.66405 & 1.65925 \\
\hline 22 & $\mathrm{O}$ & 3.94894 & -0.58585 & -1.5569 \\
\hline 23 & $\mathrm{H}$ & 1.84308 & -0.83093 & -1.46814 \\
\hline 24 & $\mathrm{H}$ & 2.57843 & -3.14295 & -0.95083 \\
\hline 25 & $\mathrm{H}$ & 3.80853 & -2.54981 & 0.14406 \\
\hline 26 & $\mathrm{H}$ & 1.93482 & -1.62179 & 1.63235 \\
\hline 27 & $\mathrm{H}$ & 2.12753 & -3.36288 & 1.58513 \\
\hline 28 & $\mathrm{H}$ & 3.78066 & 2.26368 & -0.80466 \\
\hline 29 & $\mathrm{H}$ & 2.58917 & 1.50336 & -1.85498 \\
\hline 30 & $\mathrm{H}$ & 2.04473 & 2.1505 & 1.12493 \\
\hline 31 & $\mathrm{H}$ & 0.45427 & 2.34329 & -1.47146 \\
\hline 32 & $\mathrm{H}$ & -0.97519 & 1.07821 & 1.47935 \\
\hline 33 & $\mathrm{H}$ & -2.39408 & 2.08952 & 1.23715 \\
\hline 34 & $\mathrm{H}$ & 5.25726 & 0.79764 & 0.58938 \\
\hline 35 & $\mathrm{H}$ & 3.86902 & 0.57881 & 1.66059 \\
\hline 36 & $\mathrm{H}$ & 4.73128 & -0.83102 & 1.02781 \\
\hline 37 & $\mathrm{H}$ & 0.03617 & -0.6244 & 0.61418 \\
\hline 38 & $\mathrm{H}$ & -2.43193 & -2.47744 & 0.49307 \\
\hline 39 & $\mathrm{H}$ & -2.5667 & 1.41127 & -1.11156 \\
\hline 40 & $\mathrm{H}$ & -1.01591 & 0.59711 & -1.05596 \\
\hline 41 & $\mathrm{H}$ & -4.45933 & 0.49339 & 0.12971 \\
\hline 42 & $\mathrm{H}$ & -5.60588 & -0.45471 & -1.83854 \\
\hline 43 & $\mathrm{H}$ & -4.04694 & 0.21357 & -2.33127 \\
\hline 44 & $\mathrm{H}$ & -4.23508 & -1.53471 & -2.14781 \\
\hline 45 & $\mathrm{H}$ & -5.91993 & -1.42312 & 0.49282 \\
\hline 46 & $\mathrm{H}$ & -4.61485 & -2.56619 & 0.19222 \\
\hline 47 & $\mathrm{H}$ & -4.56154 & -1.52611 & 1.62335 \\
\hline 48 & $\mathrm{H}$ & -0.0431 & -4.64096 & 1.40876 \\
\hline 49 & $\mathrm{H}$ & -1.13924 & -4.16892 & 0.09826 \\
\hline 50 & $\mathrm{H}$ & 0.5308 & -4.62027 & -0.24964 \\
\hline 51 & $\mathrm{H}$ & -1.51368 & 3.44382 & -1.26331 \\
\hline 52 & $\mathrm{H}$ & -1.12601 & 4.01453 & 2.151 \\
\hline 53 & $\mathrm{H}$ & 0.33121 & 3.03215 & 2.36123 \\
\hline 54 & $\mathrm{H}$ & 0.40045 & 4.52996 & 1.41053 \\
\hline
\end{tabular}

B3LYP/6-311G(d,p) Energy $=-931.85376556$ a.u.; Population $=0.22 \%$ 


\begin{tabular}{|c|c|c|c|c|}
\hline \multicolumn{2}{|c|}{$\begin{array}{c}(7 S, 8 S, 12 S)-4 \\
\text { Conf. } 7\end{array}$} & \multicolumn{3}{|c|}{$\begin{array}{c}\text { Standard Orientation } \\
\text { (Ångstroms) }\end{array}$} \\
\hline $\mathrm{I}$ & atom & $\mathrm{X}$ & $\mathrm{Y}$ & $\mathrm{Z}$ \\
\hline 1 & $\mathrm{C}$ & -2.88874 & -0.70075 & 0.86749 \\
\hline 2 & $\mathrm{C}$ & -3.1441 & -2.00291 & 0.14039 \\
\hline 3 & $\mathrm{C}$ & -2.18877 & -2.24463 & -1.05399 \\
\hline 4 & $\mathrm{C}$ & -3.42449 & 0.61336 & 0.45618 \\
\hline 5 & $\mathrm{C}$ & -2.67611 & 1.87486 & 0.89486 \\
\hline 6 & $\mathrm{C}$ & -1.51827 & 2.24625 & 0.00476 \\
\hline 7 & $\mathrm{C}$ & -0.26097 & 2.33998 & 0.43855 \\
\hline 8 & $\mathrm{C}$ & 0.99123 & 2.64407 & -0.36603 \\
\hline 9 & $\mathrm{C}$ & 1.73672 & 1.34037 & -0.73376 \\
\hline 10 & $\mathrm{C}$ & -4.32236 & 0.78491 & -0.749 \\
\hline 11 & $\mathrm{C}$ & -0.77127 & -2.65496 & -0.69558 \\
\hline 12 & $\mathrm{C}$ & 0.18541 & -1.71966 & -0.52613 \\
\hline 13 & $\mathrm{C}$ & 1.60876 & -1.92894 & -0.28975 \\
\hline 14 & $\mathrm{C}$ & 2.04318 & 0.42088 & 0.4685 \\
\hline 15 & $\mathrm{C}$ & 2.48972 & -0.98548 & 0.10711 \\
\hline 16 & $\mathrm{C}$ & 3.9602 & -1.33784 & 0.2671 \\
\hline 17 & $\mathrm{C}$ & 4.87668 & -0.42999 & -0.57465 \\
\hline 18 & $\mathrm{C}$ & 4.39803 & -1.32925 & 1.74574 \\
\hline 19 & $\mathrm{C}$ & -0.54406 & -4.13833 & -0.56597 \\
\hline 20 & $\mathrm{O}$ & 1.90556 & 3.37914 & 0.47913 \\
\hline 21 & $\mathrm{C}$ & 0.71363 & 3.45967 & -1.63435 \\
\hline 22 & $\mathrm{O}$ & -4.01252 & -0.11164 & 1.56233 \\
\hline 23 & $\mathrm{H}$ & -1.96988 & -0.67818 & 1.45154 \\
\hline 24 & $\mathrm{H}$ & -3.06514 & -2.82637 & 0.85905 \\
\hline 25 & $\mathrm{H}$ & -4.17565 & -2.00753 & -0.21839 \\
\hline 26 & $\mathrm{H}$ & -2.16377 & -1.33879 & -1.66718 \\
\hline 27 & $\mathrm{H}$ & -2.62891 & -3.02852 & -1.67967 \\
\hline 28 & $\mathrm{H}$ & -3.40217 & 2.69834 & 0.92785 \\
\hline 29 & $\mathrm{H}$ & -2.32182 & 1.71754 & 1.91625 \\
\hline 30 & $\mathrm{H}$ & -1.74762 & 2.43254 & -1.04198 \\
\hline 31 & $\mathrm{H}$ & -0.06274 & 2.15708 & 1.49267 \\
\hline 32 & $\mathrm{H}$ & 1.13089 & 0.80681 & -1.46963 \\
\hline 33 & $\mathrm{H}$ & 2.66907 & 1.62019 & -1.23386 \\
\hline 34 & $\mathrm{H}$ & -5.09879 & 1.52271 & -0.52488 \\
\hline 35 & $\mathrm{H}$ & -3.75452 & 1.14901 & -1.60984 \\
\hline 36 & $\mathrm{H}$ & -4.81251 & -0.14557 & -1.03188 \\
\hline 37 & $\mathrm{H}$ & -0.13817 & -0.68655 & -0.60859 \\
\hline 38 & $\mathrm{H}$ & 1.99711 & -2.92641 & -0.48063 \\
\hline 39 & $\mathrm{H}$ & 2.79531 & 0.91043 & 1.08995 \\
\hline 40 & $\mathrm{H}$ & 1.14753 & 0.34149 & 1.08866 \\
\hline 41 & $\mathrm{H}$ & 4.0848 & -2.3624 & -0.10139 \\
\hline 42 & $\mathrm{H}$ & 5.91782 & -0.75456 & -0.48658 \\
\hline 43 & $\mathrm{H}$ & 4.60111 & -0.45994 & -1.63207 \\
\hline 44 & $\mathrm{H}$ & 4.82788 & 0.61083 & -0.24119 \\
\hline 45 & $\mathrm{H}$ & 5.44223 & -1.64378 & 1.83587 \\
\hline 46 & $\mathrm{H}$ & 4.31603 & -0.33068 & 2.18509 \\
\hline 47 & $\mathrm{H}$ & 3.78482 & -2.01117 & 2.34055 \\
\hline 48 & $\mathrm{H}$ & -0.69613 & -4.64064 & -1.52911 \\
\hline 49 & $\mathrm{H}$ & 0.45234 & -4.38949 & -0.2034 \\
\hline 50 & $\mathrm{H}$ & -1.27048 & -4.57716 & 0.12804 \\
\hline 51 & $\mathrm{H}$ & 1.45898 & 4.18588 & 0.76023 \\
\hline 52 & $\mathrm{H}$ & 1.65777 & 3.68716 & -2.13372 \\
\hline 53 & $\mathrm{H}$ & 0.07664 & 2.91598 & -2.33614 \\
\hline 54 & $\mathrm{H}$ & 0.21716 & 4.40197 & -1.3861 \\
\hline
\end{tabular}

B3LYP/6-311G(d,p) Energy $=-931.85774948$ a.u.; Population $=2.29 \%$ 


\begin{tabular}{|c|c|c|c|c|}
\hline \multicolumn{2}{|c|}{$\begin{array}{c}(7 S, 8 S, 12 S)-\mathbf{4} \\
\text { Conf. } 8 \\
\end{array}$} & \multicolumn{3}{|c|}{$\begin{array}{c}\text { Standard Orientation } \\
\text { (Ångstroms) }\end{array}$} \\
\hline I & atom & $\mathrm{X}$ & $\mathrm{Y}$ & $\mathrm{Z}$ \\
\hline 1 & $\mathrm{C}$ & 3.16794 & -0.50246 & -0.24873 \\
\hline 2 & $\mathrm{C}$ & 3.08517 & -1.73568 & 0.63959 \\
\hline 3 & $\mathrm{C}$ & 2.44217 & -2.95137 & -0.0397 \\
\hline 4 & $\mathrm{C}$ & 3.16098 & 0.89449 & 0.23154 \\
\hline 5 & $\mathrm{C}$ & 2.61548 & 1.97482 & -0.70271 \\
\hline 6 & $\mathrm{C}$ & 1.11262 & 1.95274 & -0.74037 \\
\hline 7 & $\mathrm{C}$ & 0.30608 & 2.91009 & -0.28684 \\
\hline 8 & $\mathrm{C}$ & -1.21411 & 2.90482 & -0.31279 \\
\hline 9 & $\mathrm{C}$ & -1.83632 & 1.51796 & -0.5484 \\
\hline 10 & $\mathrm{C}$ & 3.10871 & 1.22558 & 1.70534 \\
\hline 11 & $\mathrm{C}$ & 0.94364 & -2.95594 & -0.27321 \\
\hline 12 & $\mathrm{C}$ & 0.13189 & -1.93706 & 0.08137 \\
\hline 13 & $\mathrm{C}$ & -1.32166 & -1.91207 & -0.03421 \\
\hline 14 & $\mathrm{C}$ & -1.69046 & 0.5052 & 0.60974 \\
\hline 15 & $\mathrm{C}$ & -2.1573 & -0.88324 & 0.22191 \\
\hline 16 & $\mathrm{C}$ & -3.67427 & -1.05289 & 0.15583 \\
\hline 17 & $\mathrm{C}$ & -4.16994 & -2.13416 & -0.81455 \\
\hline 18 & $\mathrm{C}$ & -4.25205 & -1.2987 & 1.56717 \\
\hline 19 & $\mathrm{C}$ & 0.46661 & -4.23251 & -0.92123 \\
\hline 20 & $\mathrm{O}$ & -1.66226 & 3.67679 & -1.45813 \\
\hline 21 & $\mathrm{C}$ & -1.75561 & 3.56809 & 0.96211 \\
\hline 22 & $\mathrm{O}$ & 4.38809 & 0.27311 & -0.20499 \\
\hline 23 & $\mathrm{H}$ & 2.81676 & -0.66017 & -1.26895 \\
\hline 24 & $\mathrm{H}$ & 4.1082 & -2.00369 & 0.91917 \\
\hline 25 & $\mathrm{H}$ & 2.56084 & -1.51338 & 1.57377 \\
\hline 26 & $\mathrm{H}$ & 2.67962 & -3.84139 & 0.55861 \\
\hline 27 & $\mathrm{H}$ & 2.94249 & -3.12628 & -1.00321 \\
\hline 28 & $\mathrm{H}$ & 2.98416 & 2.95702 & -0.38942 \\
\hline 29 & $\mathrm{H}$ & 3.01635 & 1.77521 & -1.70214 \\
\hline 30 & $\mathrm{H}$ & 0.68352 & 1.04436 & -1.15473 \\
\hline 31 & $\mathrm{H}$ & 0.75083 & 3.81674 & 0.12581 \\
\hline 32 & $\mathrm{H}$ & -2.89472 & 1.69094 & -0.76152 \\
\hline 33 & $\mathrm{H}$ & -1.40954 & 1.09961 & -1.46365 \\
\hline 34 & $\mathrm{H}$ & 3.70938 & 2.11899 & 1.90115 \\
\hline 35 & $\mathrm{H}$ & 2.08342 & 1.43502 & 2.02147 \\
\hline 36 & $\mathrm{H}$ & 3.50386 & 0.4127 & 2.314 \\
\hline 37 & $\mathrm{H}$ & 0.59531 & -1.06065 & 0.52074 \\
\hline 38 & $\mathrm{H}$ & -1.78092 & -2.84581 & -0.33727 \\
\hline 39 & $\mathrm{H}$ & -0.65327 & 0.48583 & 0.94561 \\
\hline 40 & $\mathrm{H}$ & -2.28259 & 0.85578 & 1.46215 \\
\hline 41 & $\mathrm{H}$ & -4.08671 & -0.09884 & -0.19438 \\
\hline 42 & $\mathrm{H}$ & -5.26117 & -2.10333 & -0.88056 \\
\hline 43 & $\mathrm{H}$ & -3.76468 & -1.98764 & -1.81896 \\
\hline 44 & $\mathrm{H}$ & -3.89575 & -3.1392 & -0.48095 \\
\hline 45 & $\mathrm{H}$ & -5.34595 & -1.30379 & 1.54016 \\
\hline 46 & $\mathrm{H}$ & -3.91617 & -2.26568 & 1.95358 \\
\hline 47 & $\mathrm{H}$ & -3.94025 & -0.52732 & 2.27578 \\
\hline 48 & $\mathrm{H}$ & 0.68765 & -5.09557 & -0.28189 \\
\hline 49 & $\mathrm{H}$ & -0.59941 & -4.24008 & -1.1408 \\
\hline 50 & $\mathrm{H}$ & 1.00057 & -4.40142 & -1.86349 \\
\hline 51 & $\mathrm{H}$ & -1.24153 & 4.54301 & -1.41056 \\
\hline 52 & $\mathrm{H}$ & -2.84799 & 3.58641 & 0.94212 \\
\hline 53 & $\mathrm{H}$ & -1.42814 & 3.04678 & 1.86509 \\
\hline 54 & $\mathrm{H}$ & -1.39817 & 4.60063 & 1.0271 \\
\hline
\end{tabular}

B3LYP/6-311G(d,p) Energy $=-931.84491223$ a.u.; Population $=0.22 \%$ 


\begin{tabular}{|c|c|c|c|c|}
\hline \multicolumn{2}{|c|}{$\begin{array}{c}(7 S, 8 S, 12 S)-4 \\
\text { Conf. } 9\end{array}$} & \multicolumn{3}{|c|}{$\begin{array}{c}\text { Standard Orientation } \\
\text { (Ångstroms) }\end{array}$} \\
\hline $\mathrm{I}$ & atom & $\mathrm{X}$ & $\mathrm{Y}$ & $\mathrm{Z}$ \\
\hline 1 & $\mathrm{C}$ & 3.49565 & 0.381 & -0.42284 \\
\hline 2 & $\mathrm{C}$ & 3.8119 & -1.09504 & -0.52311 \\
\hline 3 & $\mathrm{C}$ & 2.79446 & -1.90078 & -1.36888 \\
\hline 4 & $\mathrm{C}$ & 2.76388 & 1.06609 & 0.66236 \\
\hline 5 & $\mathrm{C}$ & 2.12025 & 2.42499 & 0.3693 \\
\hline 6 & $\mathrm{C}$ & 0.74271 & 2.37793 & -0.24272 \\
\hline 7 & $\mathrm{C}$ & -0.39035 & 2.58845 & 0.42601 \\
\hline 8 & $\mathrm{C}$ & -1.7941 & 2.60224 & -0.15513 \\
\hline 9 & $\mathrm{C}$ & -2.51305 & 1.2611 & 0.13339 \\
\hline 10 & $\mathrm{C}$ & 2.20621 & 0.33702 & 1.86137 \\
\hline 11 & $\mathrm{C}$ & 1.56603 & -2.35517 & -0.60735 \\
\hline 12 & $\mathrm{C}$ & 0.40362 & -1.68266 & -0.72599 \\
\hline 13 & $\mathrm{C}$ & -0.86768 & -1.99681 & -0.08831 \\
\hline 14 & $\mathrm{C}$ & -2.05531 & 0.1033 & -0.78818 \\
\hline 15 & $\mathrm{C}$ & -1.99506 & -1.25203 & -0.1145 \\
\hline 16 & $\mathrm{C}$ & -3.29951 & -1.74342 & 0.50591 \\
\hline 17 & $\mathrm{C}$ & -4.308 & -2.1478 & -0.59289 \\
\hline 18 & $\mathrm{C}$ & -3.15258 & -2.88155 & 1.52419 \\
\hline 19 & $\mathrm{C}$ & 1.76681 & -3.57773 & 0.25122 \\
\hline 20 & $\mathrm{O}$ & -1.77427 & 2.74991 & -1.5834 \\
\hline 21 & $\mathrm{C}$ & -2.58618 & 3.76422 & 0.4677 \\
\hline 22 & $\mathrm{O}$ & 4.21088 & 1.1184 & 0.59036 \\
\hline 23 & $\mathrm{H}$ & 3.48815 & 0.88675 & -1.39079 \\
\hline 24 & $\mathrm{H}$ & 4.80138 & -1.17292 & -0.98838 \\
\hline 25 & $\mathrm{H}$ & 3.91155 & -1.52558 & 0.47539 \\
\hline 26 & $\mathrm{H}$ & 3.3089 & -2.78334 & -1.76603 \\
\hline 27 & $\mathrm{H}$ & 2.49608 & -1.30179 & -2.23543 \\
\hline 28 & $\mathrm{H}$ & 2.09006 & 2.98778 & 1.30881 \\
\hline 29 & $\mathrm{H}$ & 2.79836 & 2.96139 & -0.30156 \\
\hline 30 & $\mathrm{H}$ & 0.6911 & 2.17614 & -1.30995 \\
\hline 31 & $\mathrm{H}$ & -0.34288 & 2.78278 & 1.49695 \\
\hline 32 & $\mathrm{H}$ & -2.33201 & 1.01124 & 1.18312 \\
\hline 33 & $\mathrm{H}$ & -3.59112 & 1.41979 & 0.03264 \\
\hline 34 & $\mathrm{H}$ & 2.33959 & 0.95248 & 2.75681 \\
\hline 35 & $\mathrm{H}$ & 1.13872 & 0.14853 & 1.73084 \\
\hline 36 & $\mathrm{H}$ & 2.70655 & -0.61593 & 2.02824 \\
\hline 37 & $\mathrm{H}$ & 0.42029 & -0.82055 & -1.38475 \\
\hline 38 & $\mathrm{H}$ & -0.90694 & -2.94284 & 0.43982 \\
\hline 39 & $\mathrm{H}$ & -2.73153 & 0.06276 & -1.64857 \\
\hline 40 & $\mathrm{H}$ & -1.08152 & 0.35756 & -1.19697 \\
\hline 41 & $\mathrm{H}$ & -3.74075 & -0.89311 & 1.04117 \\
\hline 42 & $\mathrm{H}$ & -5.26924 & -2.42208 & -0.14821 \\
\hline 43 & $\mathrm{H}$ & -4.48975 & -1.33706 & -1.30192 \\
\hline 44 & $\mathrm{H}$ & -3.93472 & -3.00971 & -1.15432 \\
\hline 45 & $\mathrm{H}$ & -4.11897 & -3.0875 & 1.99259 \\
\hline 46 & $\mathrm{H}$ & -2.81731 & -3.80934 & 1.0511 \\
\hline 47 & $\mathrm{H}$ & -2.44164 & -2.6273 & 2.31468 \\
\hline 48 & $\mathrm{H}$ & 2.6547 & -3.46923 & 0.88373 \\
\hline 49 & $\mathrm{H}$ & 0.92154 & -3.7907 & 0.90464 \\
\hline 50 & $\mathrm{H}$ & 1.94208 & -4.46088 & -0.37554 \\
\hline 51 & $\mathrm{H}$ & -1.30881 & 3.5704 & -1.78297 \\
\hline 52 & $\mathrm{H}$ & -3.57939 & 3.81608 & 0.01643 \\
\hline 53 & $\mathrm{H}$ & -2.6985 & 3.63319 & 1.54767 \\
\hline 54 & $\mathrm{H}$ & -2.07505 & 4.71651 & 0.29569 \\
\hline
\end{tabular}

B3LYP/6-311G(d,p) Energy $=-931.84909914$ a.u.; Population $=1.69 \%$ 


\begin{tabular}{|c|c|c|c|c|}
\hline \multicolumn{2}{|c|}{$\begin{array}{l}(7 S, 8 S, 12 S)-\mathbf{4} \\
\text { Conf. } 10 \\
\end{array}$} & \multicolumn{3}{|c|}{$\begin{array}{c}\text { Standard Orientation } \\
\text { (Ångstroms) }\end{array}$} \\
\hline $\mathrm{I}$ & atom & $X$ & $\mathrm{Y}$ & $\mathrm{Z}$ \\
\hline 1 & $\mathrm{C}$ & -2.64936 & -0.76521 & 0.43313 \\
\hline 2 & $\mathrm{C}$ & -2.68596 & -2.27446 & 0.39083 \\
\hline 3 & $\mathrm{C}$ & -1.64929 & -2.84392 & -0.61348 \\
\hline 4 & $\mathrm{C}$ & -3.61116 & 0.14061 & -0.22715 \\
\hline 5 & $\mathrm{C}$ & -3.17081 & 1.53884 & -0.67641 \\
\hline 6 & $\mathrm{C}$ & -2.00588 & 2.1224 & 0.07304 \\
\hline 7 & $\mathrm{C}$ & -0.78944 & 2.28491 & -0.44333 \\
\hline 8 & $\mathrm{C}$ & 0.43567 & 2.78167 & 0.3032 \\
\hline 9 & $\mathrm{C}$ & 1.40902 & 1.60038 & 0.56166 \\
\hline 10 & $\mathrm{C}$ & -4.81324 & -0.37752 & -0.98636 \\
\hline 11 & $\mathrm{C}$ & -0.21034 & -2.78336 & -0.13682 \\
\hline 12 & $\mathrm{C}$ & 0.59483 & -1.76941 & -0.51446 \\
\hline 13 & $\mathrm{C}$ & 1.99844 & -1.57214 & -0.16865 \\
\hline 14 & $\mathrm{C}$ & 2.00844 & 0.88609 & -0.67168 \\
\hline 15 & $\mathrm{C}$ & 2.68352 & -0.41416 & -0.27421 \\
\hline 16 & $\mathrm{C}$ & 4.16844 & -0.30204 & 0.0454 \\
\hline 17 & $\mathrm{C}$ & 4.72259 & -1.39564 & 0.96687 \\
\hline 18 & $\mathrm{C}$ & 4.99725 & -0.234 & -1.25686 \\
\hline 19 & $\mathrm{C}$ & 0.2101 & -3.90704 & 0.77493 \\
\hline 20 & $\mathrm{O}$ & 0.08132 & 3.33753 & 1.58015 \\
\hline 21 & $\mathrm{C}$ & 1.10483 & 3.92861 & -0.45842 \\
\hline 22 & $\mathrm{O}$ & -3.65749 & -0.06958 & 1.20368 \\
\hline 23 & $\mathrm{H}$ & -1.65431 & -0.36001 & 0.59757 \\
\hline 24 & $\mathrm{H}$ & -2.48019 & -2.65561 & 1.39748 \\
\hline 25 & $\mathrm{H}$ & -3.68301 & -2.62966 & 0.12391 \\
\hline 26 & $\mathrm{H}$ & -1.74953 & -2.30774 & -1.56247 \\
\hline 27 & $\mathrm{H}$ & -1.91153 & -3.88815 & -0.81605 \\
\hline 28 & $\mathrm{H}$ & -2.93953 & 1.4866 & -1.74598 \\
\hline 29 & $\mathrm{H}$ & -4.0415 & 2.19996 & -0.57588 \\
\hline 30 & $\mathrm{H}$ & -2.19135 & 2.40451 & 1.10528 \\
\hline 31 & $\mathrm{H}$ & -0.61893 & 2.00615 & -1.48156 \\
\hline 32 & $\mathrm{H}$ & 2.21724 & 1.98168 & 1.1945 \\
\hline 33 & $\mathrm{H}$ & 0.8611 & 0.86063 & 1.15565 \\
\hline 34 & $\mathrm{H}$ & -4.58076 & -0.49156 & -2.04936 \\
\hline 35 & $\mathrm{H}$ & -5.15389 & -1.33677 & -0.59911 \\
\hline 36 & $\mathrm{H}$ & -5.64084 & 0.3329 & -0.89893 \\
\hline 37 & $\mathrm{H}$ & 0.14804 & -1.01519 & -1.15695 \\
\hline 38 & $\mathrm{H}$ & 2.52761 & -2.4433 & 0.20215 \\
\hline 39 & $\mathrm{H}$ & 1.22467 & 0.69572 & -1.40714 \\
\hline 40 & $\mathrm{H}$ & 2.73251 & 1.54764 & -1.15566 \\
\hline 41 & $\mathrm{H}$ & 4.30569 & 0.6578 & 0.56193 \\
\hline 42 & $\mathrm{H}$ & 5.76273 & -1.17629 & 1.2231 \\
\hline 43 & $\mathrm{H}$ & 4.15207 & -1.46509 & 1.89652 \\
\hline 44 & $\mathrm{H}$ & 4.70798 & -2.37745 & 0.48454 \\
\hline 45 & $\mathrm{H}$ & 6.05029 & -0.0387 & -1.03332 \\
\hline 46 & $\mathrm{H}$ & 4.93315 & -1.18348 & -1.79667 \\
\hline 47 & $\mathrm{H}$ & 4.64667 & 0.55645 & -1.92508 \\
\hline 48 & $\mathrm{H}$ & 0.2005 & -4.86268 & 0.23676 \\
\hline 49 & $\mathrm{H}$ & 1.203 & -3.76523 & 1.20029 \\
\hline 50 & $\mathrm{H}$ & -0.49436 & -4.0149 & 1.60723 \\
\hline 51 & $\mathrm{H}$ & -0.21264 & 2.61618 & 2.14811 \\
\hline 52 & $\mathrm{H}$ & 2.01111 & 4.24686 & 0.06264 \\
\hline 53 & $\mathrm{H}$ & 1.37045 & 3.62954 & -1.47441 \\
\hline 54 & $\mathrm{H}$ & 0.42101 & 4.7781 & -0.51718 \\
\hline
\end{tabular}

B3LYP/6-311G(d,p) Energy = -931.85344872 a.u.; Population $=17.11 \%$ 


\begin{tabular}{|c|c|c|c|c|}
\hline \multicolumn{2}{|c|}{$\begin{array}{c}(7 S, 8 S, 12 S)-4 \\
\text { Conf. } 11\end{array}$} & \multicolumn{3}{|c|}{$\begin{array}{c}\text { Standard Orientation } \\
\text { (Ångstroms) }\end{array}$} \\
\hline $\mathrm{I}$ & atom & $X$ & $\mathrm{Y}$ & $\mathrm{Z}$ \\
\hline 1 & $\mathrm{C}$ & 2.91106 & 0.27055 & -0.51426 \\
\hline 2 & $\mathrm{C}$ & 3.54707 & -1.00271 & -1.03002 \\
\hline 3 & $\mathrm{C}$ & 2.48938 & -1.92329 & -1.68856 \\
\hline 4 & $\mathrm{C}$ & 2.95445 & 0.76977 & 0.87377 \\
\hline 5 & $\mathrm{C}$ & 1.83131 & 1.64781 & 1.42818 \\
\hline 6 & $\mathrm{C}$ & 0.79846 & 2.10324 & 0.43677 \\
\hline 7 & $\mathrm{C}$ & -0.51605 & 1.98772 & 0.61435 \\
\hline 8 & $\mathrm{C}$ & -1.59033 & 2.49117 & -0.33259 \\
\hline 9 & $\mathrm{C}$ & -2.74334 & 1.48018 & -0.50647 \\
\hline 10 & $\mathrm{C}$ & 3.75476 & 0.06692 & 1.9482 \\
\hline 11 & $\mathrm{C}$ & 1.33151 & -2.27404 & -0.77616 \\
\hline 12 & $\mathrm{C}$ & 0.16165 & -1.61216 & -0.90282 \\
\hline 13 & $\mathrm{C}$ & -1.0407 & -1.77358 & -0.10399 \\
\hline 14 & $\mathrm{C}$ & -2.39091 & 0.10816 & -1.14049 \\
\hline 15 & $\mathrm{C}$ & -2.1733 & -1.04155 & -0.17535 \\
\hline 16 & $\mathrm{C}$ & -3.4013 & -1.4329 & 0.64981 \\
\hline 17 & $\mathrm{C}$ & -4.23063 & -2.5001 & -0.09669 \\
\hline 18 & $\mathrm{C}$ & -3.09596 & -1.89393 & 2.0834 \\
\hline 19 & $\mathrm{C}$ & 1.61403 & -3.34282 & 0.24701 \\
\hline 20 & $\mathrm{O}$ & -1.07435 & 2.72703 & -1.65276 \\
\hline 21 & $\mathrm{C}$ & -2.16945 & 3.80659 & 0.2271 \\
\hline 22 & $\mathrm{O}$ & 3.75987 & 1.38525 & -0.16128 \\
\hline 23 & $\mathrm{H}$ & 2.05083 & 0.58473 & -1.10101 \\
\hline 24 & $\mathrm{H}$ & 4.29786 & -0.73613 & -1.782 \\
\hline 25 & $\mathrm{H}$ & 4.07706 & -1.53317 & -0.23583 \\
\hline 26 & $\mathrm{H}$ & 2.99032 & -2.8367 & -2.02902 \\
\hline 27 & $\mathrm{H}$ & 2.10511 & -1.42131 & -2.58169 \\
\hline 28 & $\mathrm{H}$ & 1.3405 & 1.10702 & 2.24359 \\
\hline 29 & $\mathrm{H}$ & 2.31931 & 2.52098 & 1.88447 \\
\hline 30 & $\mathrm{H}$ & 1.18088 & 2.5558 & -0.47481 \\
\hline 31 & $\mathrm{H}$ & -0.88996 & 1.54255 & 1.53494 \\
\hline 32 & $\mathrm{H}$ & -3.2196 & 1.34484 & 0.46827 \\
\hline 33 & $\mathrm{H}$ & -3.48179 & 1.97611 & -1.14289 \\
\hline 34 & $\mathrm{H}$ & 3.14608 & -0.68413 & 2.46007 \\
\hline 35 & $\mathrm{H}$ & 4.63833 & -0.41803 & 1.53421 \\
\hline 36 & $\mathrm{H}$ & 4.08975 & 0.79325 & 2.69519 \\
\hline 37 & $\mathrm{H}$ & 0.11514 & -0.87111 & -1.69467 \\
\hline 38 & $\mathrm{H}$ & -1.0255 & -2.58624 & 0.61534 \\
\hline 39 & $\mathrm{H}$ & -3.23204 & -0.17035 & -1.78841 \\
\hline 40 & $\mathrm{H}$ & -1.53776 & 0.24595 & -1.80337 \\
\hline 41 & $\mathrm{H}$ & -4.03677 & -0.54469 & 0.73379 \\
\hline 42 & $\mathrm{H}$ & -5.16994 & -2.6994 & 0.42876 \\
\hline 43 & $\mathrm{H}$ & -4.47649 & -2.18032 & -1.11274 \\
\hline 44 & $\mathrm{H}$ & -3.67258 & -3.43838 & -0.16654 \\
\hline 45 & $\mathrm{H}$ & -4.02782 & -2.04916 & 2.63512 \\
\hline 46 & $\mathrm{H}$ & -2.54907 & -2.84069 & 2.10143 \\
\hline 47 & $\mathrm{H}$ & -2.50124 & -1.152 & 2.6226 \\
\hline 48 & $\mathrm{H}$ & 2.49239 & -3.08581 & 0.85 \\
\hline 49 & $\mathrm{H}$ & 0.78419 & -3.51729 & 0.93099 \\
\hline 50 & $\mathrm{H}$ & 1.84836 & -4.29243 & -0.24915 \\
\hline 51 & $\mathrm{H}$ & -0.46233 & 3.46938 & -1.6075 \\
\hline 52 & $\mathrm{H}$ & -2.96636 & 4.17448 & -0.42441 \\
\hline 53 & $\mathrm{H}$ & -2.57565 & 3.66653 & 1.23238 \\
\hline 54 & $\mathrm{H}$ & -1.38558 & 4.56735 & 0.28796 \\
\hline
\end{tabular}

B3LYP/6-311G(d,p) Energy $=-931.85051537$ a.u.; Population $=0.17 \%$ 


\begin{tabular}{|c|c|c|c|c|}
\hline \multicolumn{2}{|c|}{$\begin{array}{c}(7 S, 8 S, 12 S)-4 \\
\text { Conf. } 12\end{array}$} & \multicolumn{3}{|c|}{$\begin{array}{c}\text { Standard Orientation } \\
\text { (Ångstroms) }\end{array}$} \\
\hline $\mathrm{I}$ & atom & $\mathrm{X}$ & $\mathrm{Y}$ & $\mathrm{Z}$ \\
\hline 1 & $\mathrm{C}$ & 2.90648 & 0.27307 & -0.49657 \\
\hline 2 & $\mathrm{C}$ & 3.51945 & -0.98545 & -1.07219 \\
\hline 3 & $\mathrm{C}$ & 2.44168 & -1.86877 & -1.75 \\
\hline 4 & $\mathrm{C}$ & 2.94276 & 0.69713 & 0.91647 \\
\hline 5 & $\mathrm{C}$ & 1.82507 & 1.56236 & 1.50338 \\
\hline 6 & $\mathrm{C}$ & 0.82525 & 2.10272 & 0.52212 \\
\hline 7 & $\mathrm{C}$ & -0.49177 & 1.91923 & 0.61362 \\
\hline 8 & $\mathrm{C}$ & -1.52017 & 2.48128 & -0.34914 \\
\hline 9 & $\mathrm{C}$ & -2.72766 & 1.52945 & -0.54995 \\
\hline 10 & $\mathrm{C}$ & 3.7154 & -0.07818 & 1.96109 \\
\hline 11 & $\mathrm{C}$ & 1.2893 & -2.23313 & -0.83662 \\
\hline 12 & $\mathrm{C}$ & 0.11816 & -1.57013 & -0.94523 \\
\hline 13 & $\mathrm{C}$ & -1.07167 & -1.73083 & -0.12791 \\
\hline 14 & $\mathrm{C}$ & -2.46147 & 0.1279 & -1.15959 \\
\hline 15 & $\mathrm{C}$ & -2.20832 & -1.00394 & -0.18163 \\
\hline 16 & $\mathrm{C}$ & -3.4113 & -1.37488 & 0.6878 \\
\hline 17 & $\mathrm{C}$ & -4.28753 & -2.42587 & -0.02815 \\
\hline 18 & $\mathrm{C}$ & -3.06273 & -1.84459 & 2.10823 \\
\hline 19 & $\mathrm{C}$ & 1.57814 & -3.31702 & 0.16857 \\
\hline 20 & $\mathrm{O}$ & -0.92546 & 2.80261 & -1.61942 \\
\hline 21 & $\mathrm{C}$ & -2.04483 & 3.82364 & 0.18646 \\
\hline 22 & $\mathrm{O}$ & 3.77331 & 1.34788 & -0.07578 \\
\hline 23 & $\mathrm{H}$ & 2.05908 & 0.63661 & -1.07398 \\
\hline 24 & $\mathrm{H}$ & 4.26187 & -0.6985 & -1.82495 \\
\hline 25 & $\mathrm{H}$ & 4.05531 & -1.55162 & -0.30735 \\
\hline 26 & $\mathrm{H}$ & 2.92653 & -2.77706 & -2.12555 \\
\hline 27 & $\mathrm{H}$ & 2.05521 & -1.33244 & -2.62205 \\
\hline 28 & $\mathrm{H}$ & 1.30667 & 0.97714 & 2.2696 \\
\hline 29 & $\mathrm{H}$ & 2.31716 & 2.39429 & 2.0267 \\
\hline 30 & $\mathrm{H}$ & 1.22142 & 2.68797 & -0.30418 \\
\hline 31 & $\mathrm{H}$ & -0.89646 & 1.35317 & 1.45011 \\
\hline 32 & $\mathrm{H}$ & -3.24431 & 1.42786 & 0.40929 \\
\hline 33 & $\mathrm{H}$ & -3.41514 & 2.06195 & -1.21337 \\
\hline 34 & $\mathrm{H}$ & 3.08331 & -0.83695 & 2.43145 \\
\hline 35 & $\mathrm{H}$ & 4.58941 & -0.5658 & 1.53017 \\
\hline 36 & $\mathrm{H}$ & 4.06307 & 0.60187 & 2.74491 \\
\hline 37 & $\mathrm{H}$ & 0.06578 & -0.82323 & -1.73155 \\
\hline 38 & $\mathrm{H}$ & -1.03632 & -2.5312 & 0.60389 \\
\hline 39 & $\mathrm{H}$ & -3.35732 & -0.139 & -1.73425 \\
\hline 40 & $\mathrm{H}$ & -1.66322 & 0.19868 & -1.90082 \\
\hline 41 & $\mathrm{H}$ & -4.02581 & -0.47433 & 0.79553 \\
\hline 42 & $\mathrm{H}$ & -5.2105 & -2.60708 & 0.53143 \\
\hline 43 & $\mathrm{H}$ & -4.56517 & -2.1024 & -1.03475 \\
\hline 44 & $\mathrm{H}$ & -3.75032 & -3.37467 & -0.11704 \\
\hline 45 & $\mathrm{H}$ & -3.97685 & -1.97921 & 2.69369 \\
\hline 46 & $\mathrm{H}$ & -2.5381 & -2.80403 & 2.10528 \\
\hline 47 & $\mathrm{H}$ & -2.43193 & -1.11738 & 2.62589 \\
\hline 48 & $\mathrm{H}$ & 2.45712 & -3.06767 & 0.77339 \\
\hline 49 & $\mathrm{H}$ & 0.75065 & -3.50685 & 0.85108 \\
\hline 50 & $\mathrm{H}$ & 1.81416 & -4.25674 & -0.34504 \\
\hline 51 & $\mathrm{H}$ & -0.4291 & 2.03268 & -1.91737 \\
\hline 52 & $\mathrm{H}$ & -2.78982 & 4.23651 & -0.49896 \\
\hline 53 & $\mathrm{H}$ & -2.50584 & 3.69822 & 1.16883 \\
\hline 54 & $\mathrm{H}$ & -1.21887 & 4.53125 & 0.27695 \\
\hline
\end{tabular}

B3LYP/6-311G(d,p) Energy $=-931.85090626$ a.u.; Population $=0.35 \%$ 


\begin{tabular}{|c|c|c|c|c|}
\hline \multicolumn{2}{|c|}{$\begin{array}{l}(7 S, 8 S, 12 S)-\mathbf{4} \\
\text { Conf. } 13\end{array}$} & \multicolumn{3}{|c|}{$\begin{array}{c}\text { Standard Orientation } \\
\text { (Ångstroms) }\end{array}$} \\
\hline I & atom & $\mathrm{X}$ & $\mathrm{Y}$ & $\mathrm{Z}$ \\
\hline 1 & $\mathrm{C}$ & 2.60162 & -1.13784 & -0.41015 \\
\hline 2 & $\mathrm{C}$ & 2.31731 & -2.24149 & 0.5916 \\
\hline 3 & $\mathrm{C}$ & 1.36157 & -3.34135 & 0.10366 \\
\hline 4 & $\mathrm{C}$ & 3.54972 & -0.0371 & -0.17161 \\
\hline 5 & $\mathrm{C}$ & 3.27118 & 1.30583 & -0.85243 \\
\hline 6 & $\mathrm{C}$ & 2.21814 & 2.08413 & -0.10592 \\
\hline 7 & $\mathrm{C}$ & 0.98861 & 2.30182 & -0.57229 \\
\hline 8 & $\mathrm{C}$ & -0.18506 & 2.92104 & 0.16257 \\
\hline 9 & $\mathrm{C}$ & -1.16343 & 1.81348 & 0.62479 \\
\hline 10 & $\mathrm{C}$ & 4.38736 & 0.03788 & 1.08636 \\
\hline 11 & $\mathrm{C}$ & -0.12755 & -3.04568 & 0.0701 \\
\hline 12 & $\mathrm{C}$ & -0.64415 & -1.80839 & 0.20711 \\
\hline 13 & $\mathrm{C}$ & -2.06209 & -1.44639 & 0.24965 \\
\hline 14 & $\mathrm{C}$ & -1.69841 & 0.91506 & -0.50829 \\
\hline 15 & $\mathrm{C}$ & -2.56929 & -0.2266 & -0.02141 \\
\hline 16 & $\mathrm{C}$ & -4.05663 & 0.08845 & 0.08433 \\
\hline 17 & $\mathrm{C}$ & -4.72337 & 0.06007 & -1.30847 \\
\hline 18 & $\mathrm{C}$ & -4.839 & -0.79428 & 1.06524 \\
\hline 19 & $\mathrm{C}$ & -0.96957 & -4.27807 & -0.14923 \\
\hline 20 & $\mathrm{O}$ & -0.93723 & 3.73501 & -0.76543 \\
\hline 21 & $\mathrm{C}$ & 0.22799 & 3.78048 & 1.36285 \\
\hline 22 & $\mathrm{O}$ & 3.89423 & -1.11841 & -1.06774 \\
\hline 23 & $\mathrm{H}$ & 1.79003 & -0.92442 & -1.10317 \\
\hline 24 & $\mathrm{H}$ & 3.27008 & -2.70609 & 0.85576 \\
\hline 25 & $\mathrm{H}$ & 1.91759 & -1.80168 & 1.51257 \\
\hline 26 & $\mathrm{H}$ & 1.50128 & -4.21785 & 0.74953 \\
\hline 27 & $\mathrm{H}$ & 1.67446 & -3.68168 & -0.89415 \\
\hline 28 & $\mathrm{H}$ & 4.20784 & 1.87406 & -0.91129 \\
\hline 29 & $\mathrm{H}$ & 2.94047 & 1.10846 & -1.87485 \\
\hline 30 & $\mathrm{H}$ & 2.48466 & 2.41753 & 0.89397 \\
\hline 31 & $\mathrm{H}$ & 0.74709 & 1.96514 & -1.57829 \\
\hline 32 & $\mathrm{H}$ & -0.6471 & 1.20185 & 1.37012 \\
\hline 33 & $\mathrm{H}$ & -2.00211 & 2.30107 & 1.13376 \\
\hline 34 & $\mathrm{H}$ & 5.36742 & 0.46293 & 0.84951 \\
\hline 35 & $\mathrm{H}$ & 3.91559 & 0.68188 & 1.83394 \\
\hline 36 & $\mathrm{H}$ & 4.54274 & -0.94474 & 1.53002 \\
\hline 37 & $\mathrm{H}$ & 0.05043 & -0.98345 & 0.32022 \\
\hline 38 & $\mathrm{H}$ & -2.75004 & -2.23039 & 0.54838 \\
\hline 39 & $\mathrm{H}$ & -2.267 & 1.54315 & -1.19894 \\
\hline 40 & $\mathrm{H}$ & -0.86034 & 0.51386 & -1.07974 \\
\hline 41 & $\mathrm{H}$ & -4.12823 & 1.12197 & 0.45026 \\
\hline 42 & $\mathrm{H}$ & -5.76182 & 0.39917 & -1.24668 \\
\hline 43 & $\mathrm{H}$ & -4.20391 & 0.70451 & -2.0216 \\
\hline 44 & $\mathrm{H}$ & -4.72028 & -0.95779 & -1.71012 \\
\hline 45 & $\mathrm{H}$ & -5.86441 & -0.42701 & 1.16444 \\
\hline 46 & $\mathrm{H}$ & -4.89904 & -1.83027 & 0.71906 \\
\hline 47 & $\mathrm{H}$ & -4.38035 & -0.79519 & 2.05731 \\
\hline 48 & $\mathrm{H}$ & -0.87461 & -4.97132 & 0.69523 \\
\hline 49 & $\mathrm{H}$ & -2.02608 & -4.05502 & -0.2917 \\
\hline 50 & $\mathrm{H}$ & -0.62182 & -4.82111 & -1.03566 \\
\hline 51 & $\mathrm{H}$ & -0.34099 & 4.40866 & -1.1117 \\
\hline 52 & $\mathrm{H}$ & -0.66057 & 4.24663 & 1.79316 \\
\hline 53 & $\mathrm{H}$ & 0.715 & 3.18757 & 2.14073 \\
\hline 54 & $\mathrm{H}$ & 0.91832 & 4.57057 & 1.05444 \\
\hline
\end{tabular}

B3LYP/6-311G(d,p) Energy $=-931.84927931$ a.u.; Population $=0.52 \%$ 


\begin{tabular}{|c|c|c|c|c|}
\hline \multicolumn{2}{|c|}{$\begin{array}{l}(7 S, 8 S, 12 S)-\mathbf{4} \\
\text { Conf. } 14\end{array}$} & \multicolumn{3}{|c|}{$\begin{array}{c}\text { Standard Orientation } \\
\text { (Ångstroms) }\end{array}$} \\
\hline $\mathrm{I}$ & atom & $\mathrm{X}$ & $\mathrm{Y}$ & $\mathrm{Z}$ \\
\hline 1 & $\mathrm{C}$ & -2.46433 & 1.27632 & -0.44373 \\
\hline 2 & $\mathrm{C}$ & -2.18064 & 2.17663 & 0.74514 \\
\hline 3 & $\mathrm{C}$ & -1.19739 & 3.32196 & 0.45943 \\
\hline 4 & $\mathrm{C}$ & -3.40321 & 0.13828 & -0.42704 \\
\hline 5 & $\mathrm{C}$ & -3.10849 & -1.01962 & -1.37066 \\
\hline 6 & $\mathrm{C}$ & -1.97221 & -1.92697 & -0.96098 \\
\hline 7 & $\mathrm{C}$ & -1.30017 & -1.89941 & 0.18794 \\
\hline 8 & $\mathrm{C}$ & -0.09968 & -2.758 & 0.54454 \\
\hline 9 & $\mathrm{C}$ & 1.12303 & -1.84543 & 0.79536 \\
\hline 10 & $\mathrm{C}$ & -4.26619 & -0.18352 & 0.77388 \\
\hline 11 & $\mathrm{C}$ & 0.27727 & 2.99206 & 0.30872 \\
\hline 12 & $\mathrm{C}$ & 0.75232 & 1.73019 & 0.27907 \\
\hline 13 & $\mathrm{C}$ & 2.14609 & 1.30682 & 0.17474 \\
\hline 14 & $\mathrm{C}$ & 1.59171 & -1.0608 & -0.44751 \\
\hline 15 & $\mathrm{C}$ & 2.56369 & 0.05833 & -0.12365 \\
\hline 16 & $\mathrm{C}$ & 4.03865 & -0.31963 & -0.18742 \\
\hline 17 & $\mathrm{C}$ & 4.52467 & -0.38831 & -1.65199 \\
\hline 18 & $\mathrm{C}$ & 4.97525 & 0.57082 & 0.63948 \\
\hline 19 & $\mathrm{C}$ & 1.14637 & 4.21848 & 0.1853 \\
\hline 20 & $\mathrm{O}$ & 0.26819 & -3.64144 & -0.52358 \\
\hline 21 & $\mathrm{C}$ & -0.40388 & -3.57924 & 1.80958 \\
\hline 22 & $\mathrm{O}$ & -3.75299 & 1.37722 & -1.09206 \\
\hline 23 & $\mathrm{H}$ & -1.65141 & 1.20198 & -1.16369 \\
\hline 24 & $\mathrm{H}$ & -3.129 & 2.6083 & 1.07364 \\
\hline 25 & $\mathrm{H}$ & -1.8046 & 1.57741 & 1.58245 \\
\hline 26 & $\mathrm{H}$ & -1.28711 & 4.0565 & 1.27072 \\
\hline 27 & $\mathrm{H}$ & -1.52526 & 3.86283 & -0.44023 \\
\hline 28 & $\mathrm{H}$ & -4.01919 & -1.61402 & -1.52552 \\
\hline 29 & $\mathrm{H}$ & -2.86906 & -0.59166 & -2.35062 \\
\hline 30 & $\mathrm{H}$ & -1.65998 & -2.63815 & -1.72227 \\
\hline 31 & $\mathrm{H}$ & -1.57766 & -1.19374 & 0.96686 \\
\hline 32 & $\mathrm{H}$ & 0.85889 & -1.14708 & 1.59508 \\
\hline 33 & $\mathrm{H}$ & 1.94109 & -2.46582 & 1.17564 \\
\hline 34 & $\mathrm{H}$ & -5.27406 & -0.44097 & 0.43408 \\
\hline 35 & $\mathrm{H}$ & -3.87238 & -1.04263 & 1.32216 \\
\hline 36 & $\mathrm{H}$ & -4.34417 & 0.6607 & 1.45837 \\
\hline 37 & $\mathrm{H}$ & 0.0303 & 0.92583 & 0.35058 \\
\hline 38 & $\mathrm{H}$ & 2.89925 & 2.0617 & 0.37161 \\
\hline 39 & $\mathrm{H}$ & 2.05525 & -1.76613 & -1.14153 \\
\hline 40 & $\mathrm{H}$ & 0.71861 & -0.66062 & -0.9655 \\
\hline 41 & $\mathrm{H}$ & 4.11419 & -1.33719 & 0.22067 \\
\hline 42 & $\mathrm{H}$ & 5.54792 & -0.77268 & -1.70141 \\
\hline 43 & $\mathrm{H}$ & 3.89342 & -1.04014 & -2.26045 \\
\hline 44 & $\mathrm{H}$ & 4.5128 & 0.60853 & -2.10318 \\
\hline 45 & $\mathrm{H}$ & 5.99034 & 0.16409 & 0.6234 \\
\hline 46 & $\mathrm{H}$ & 5.02772 & 1.58717 & 0.23792 \\
\hline 47 & $\mathrm{H}$ & 4.65143 & 0.63554 & 1.6814 \\
\hline 48 & $\mathrm{H}$ & 1.08178 & 4.83284 & 1.09132 \\
\hline 49 & $\mathrm{H}$ & 2.19531 & 3.98637 & 0.00684 \\
\hline 50 & $\mathrm{H}$ & 0.79976 & 4.84924 & -0.64162 \\
\hline 51 & $\mathrm{H}$ & -0.43946 & -4.28692 & -0.63165 \\
\hline 52 & $\mathrm{H}$ & 0.46513 & -4.18391 & 2.08017 \\
\hline 53 & $\mathrm{H}$ & -0.65498 & -2.93103 & 2.65336 \\
\hline 54 & $\mathrm{H}$ & -1.25376 & -4.24632 & 1.63521 \\
\hline
\end{tabular}

B3LYP/6-311G(d,p) Energy $=-931.84934974$ a.u.; Population $=1.87 \%$ 


\begin{tabular}{|c|c|c|c|c|}
\hline \multicolumn{2}{|c|}{$\begin{array}{l}(7 S, 8 S, 12 S)-\mathbf{4} \\
\text { Conf. } 15\end{array}$} & \multicolumn{3}{|c|}{$\begin{array}{c}\text { Standard Orientation } \\
\text { (Ångstroms) }\end{array}$} \\
\hline $\mathrm{I}$ & atom & $\mathrm{X}$ & $\mathrm{Y}$ & $\mathrm{Z}$ \\
\hline 1 & $\mathrm{C}$ & 2.49183 & -0.762 & 0.21583 \\
\hline 2 & $\mathrm{C}$ & 2.72593 & -2.23051 & 0.49333 \\
\hline 3 & $\mathrm{C}$ & 1.7106 & -3.12541 & -0.26384 \\
\hline 4 & $\mathrm{C}$ & 3.48347 & 0.21582 & -0.28051 \\
\hline 5 & $\mathrm{C}$ & 3.28979 & 1.72097 & -0.046 \\
\hline 6 & $\mathrm{C}$ & 1.96304 & 2.14071 & 0.52883 \\
\hline 7 & $\mathrm{C}$ & 0.88858 & 2.45741 & -0.19384 \\
\hline 8 & $\mathrm{C}$ & -0.48141 & 2.84595 & 0.34287 \\
\hline 9 & $\mathrm{C}$ & -1.36857 & 1.60336 & 0.57558 \\
\hline 10 & $\mathrm{C}$ & 4.91808 & -0.16592 & -0.57152 \\
\hline 11 & $\mathrm{C}$ & 0.26318 & -2.95404 & 0.16261 \\
\hline 12 & $\mathrm{C}$ & -0.4795 & -1.96089 & -0.36531 \\
\hline 13 & $\mathrm{C}$ & -1.88464 & -1.66055 & -0.10556 \\
\hline 14 & $\mathrm{C}$ & -1.71736 & 0.7794 & -0.68303 \\
\hline 15 & $\mathrm{C}$ & -2.48859 & -0.47077 & -0.3072 \\
\hline 16 & $\mathrm{C}$ & -3.98934 & -0.27352 & -0.12543 \\
\hline 17 & $\mathrm{C}$ & -4.69523 & -0.24613 & -1.49927 \\
\hline 18 & $\mathrm{C}$ & -4.6741 & -1.2866 & 0.80121 \\
\hline 19 & $\mathrm{C}$ & -0.22909 & -3.92318 & 1.20588 \\
\hline 20 & $\mathrm{O}$ & -1.16532 & 3.63574 & -0.65329 \\
\hline 21 & $\mathrm{C}$ & -0.39154 & 3.65834 & 1.64365 \\
\hline 22 & $\mathrm{O}$ & 2.50569 & -0.35871 & -1.17296 \\
\hline 23 & $\mathrm{H}$ & 1.6445 & -0.34212 & 0.75153 \\
\hline 24 & $\mathrm{H}$ & 3.73376 & -2.53099 & 0.19725 \\
\hline 25 & $\mathrm{H}$ & 2.64745 & -2.39498 & 1.57401 \\
\hline 26 & $\mathrm{H}$ & 2.00925 & -4.17006 & -0.12863 \\
\hline 27 & $\mathrm{H}$ & 1.81185 & -2.9016 & -1.32905 \\
\hline 28 & $\mathrm{H}$ & 4.09641 & 2.06686 & 0.60918 \\
\hline 29 & $\mathrm{H}$ & 3.44705 & 2.20321 & -1.01771 \\
\hline 30 & $\mathrm{H}$ & 1.90084 & 2.15402 & 1.61471 \\
\hline 31 & $\mathrm{H}$ & 0.95034 & 2.42276 & -1.27962 \\
\hline 32 & $\mathrm{H}$ & -0.85496 & 0.961 & 1.29628 \\
\hline 33 & $\mathrm{H}$ & -2.29471 & 1.94305 & 1.05156 \\
\hline 34 & $\mathrm{H}$ & 5.31553 & 0.46521 & -1.37233 \\
\hline 35 & $\mathrm{H}$ & 5.54457 & -0.01971 & 0.31327 \\
\hline 36 & $\mathrm{H}$ & 4.99987 & -1.20404 & -0.89114 \\
\hline 37 & $\mathrm{H}$ & 0.02412 & -1.3133 & -1.07779 \\
\hline 38 & $\mathrm{H}$ & -2.49141 & -2.48209 & 0.26161 \\
\hline 39 & $\mathrm{H}$ & -2.30763 & 1.40715 & -1.35528 \\
\hline 40 & $\mathrm{H}$ & -0.79727 & 0.52755 & -1.21295 \\
\hline 41 & $\mathrm{H}$ & -4.12792 & 0.71933 & 0.32233 \\
\hline 42 & $\mathrm{H}$ & -5.75358 & 0.00712 & -1.38437 \\
\hline 43 & $\mathrm{H}$ & -4.24688 & 0.48918 & -2.1717 \\
\hline 44 & $\mathrm{H}$ & -4.62873 & -1.22676 & -1.98 \\
\hline 45 & $\mathrm{H}$ & -5.72152 & -1.00945 & 0.94992 \\
\hline 46 & $\mathrm{H}$ & -4.66265 & -2.29553 & 0.37816 \\
\hline 47 & $\mathrm{H}$ & -4.19091 & -1.32491 & 1.78102 \\
\hline 48 & $\mathrm{H}$ & 0.43866 & -3.92318 & 2.07584 \\
\hline 49 & $\mathrm{H}$ & -1.23415 & -3.69511 & 1.56066 \\
\hline 50 & $\mathrm{H}$ & -0.22641 & -4.94859 & 0.81644 \\
\hline 51 & $\mathrm{H}$ & -0.63722 & 4.42607 & -0.81309 \\
\hline 52 & $\mathrm{H}$ & -1.39217 & 3.97984 & 1.94015 \\
\hline 53 & $\mathrm{H}$ & 0.03848 & 3.07399 & 2.46054 \\
\hline 54 & $\mathrm{H}$ & 0.23176 & 4.54524 & 1.49958 \\
\hline
\end{tabular}

B3LYP/6-311G(d,p) Energy $=-931.85172773$ a.u.; Population $=1.04 \%$ 


\begin{tabular}{|c|c|c|c|c|}
\hline \multicolumn{2}{|c|}{$\begin{array}{c}(7 S, 8 S, 12 S)-4 \\
\text { Conf. } 16\end{array}$} & \multicolumn{3}{|c|}{$\begin{array}{c}\text { Standard Orientation } \\
\text { (Ångstroms) }\end{array}$} \\
\hline $\mathrm{I}$ & atom & $\mathrm{X}$ & $\mathrm{Y}$ & $\mathrm{Z}$ \\
\hline 1 & $\mathrm{C}$ & 3.33606 & -0.41864 & -0.71004 \\
\hline 2 & $\mathrm{C}$ & 3.3651 & -1.89 & -0.35015 \\
\hline 3 & $\mathrm{C}$ & 2.16465 & -2.70494 & -0.88149 \\
\hline 4 & $\mathrm{C}$ & 3.20179 & 0.73438 & 0.21245 \\
\hline 5 & $\mathrm{C}$ & 2.79467 & 2.0949 & -0.34478 \\
\hline 6 & $\mathrm{C}$ & 1.36488 & 2.55296 & -0.18273 \\
\hline 7 & $\mathrm{C}$ & 0.28163 & 1.79112 & -0.04652 \\
\hline 8 & $\mathrm{C}$ & -1.1304 & 2.31646 & 0.14827 \\
\hline 9 & $\mathrm{C}$ & -2.09809 & 1.84514 & -0.97381 \\
\hline 10 & $\mathrm{C}$ & 3.03862 & 0.55985 & 1.70559 \\
\hline 11 & $\mathrm{C}$ & 0.87178 & -2.54865 & -0.10914 \\
\hline 12 & $\mathrm{C}$ & -0.14038 & -1.82179 & -0.62352 \\
\hline 13 & $\mathrm{C}$ & -1.46997 & -1.62936 & -0.05563 \\
\hline 14 & $\mathrm{C}$ & -2.07576 & 0.37148 & -1.45078 \\
\hline 15 & $\mathrm{C}$ & -2.37696 & -0.69728 & -0.41905 \\
\hline 16 & $\mathrm{C}$ & -3.79244 & -0.68426 & 0.1512 \\
\hline 17 & $\mathrm{C}$ & -4.80117 & -1.23117 & -0.88453 \\
\hline 18 & $\mathrm{C}$ & -3.96558 & -1.42456 & 1.48408 \\
\hline 19 & $\mathrm{C}$ & 0.81602 & -3.2714 & 1.21169 \\
\hline 20 & $\mathrm{O}$ & -1.16362 & 3.75519 & 0.15501 \\
\hline 21 & $\mathrm{C}$ & -1.62317 & 1.92527 & 1.54808 \\
\hline 22 & $\mathrm{O}$ & 4.4956 & 0.33417 & -0.30337 \\
\hline 23 & $\mathrm{H}$ & 3.0512 & -0.23092 & -1.74743 \\
\hline 24 & $\mathrm{H}$ & 4.27848 & -2.29453 & -0.80218 \\
\hline 25 & $\mathrm{H}$ & 3.47852 & -2.02385 & 0.72741 \\
\hline 26 & $\mathrm{H}$ & 2.45244 & -3.76313 & -0.86691 \\
\hline 27 & $\mathrm{H}$ & 1.99938 & -2.44506 & -1.93213 \\
\hline 28 & $\mathrm{H}$ & 3.44673 & 2.83519 & 0.13608 \\
\hline 29 & $\mathrm{H}$ & 3.06865 & 2.12136 & -1.40672 \\
\hline 30 & $\mathrm{H}$ & 1.23358 & 3.63215 & -0.18056 \\
\hline 31 & $\mathrm{H}$ & 0.37813 & 0.70949 & -0.02138 \\
\hline 32 & $\mathrm{H}$ & -3.10816 & 2.13415 & -0.66792 \\
\hline 33 & $\mathrm{H}$ & -1.86593 & 2.44954 & -1.85926 \\
\hline 34 & $\mathrm{H}$ & 3.55338 & 1.37307 & 2.2265 \\
\hline 35 & $\mathrm{H}$ & 1.98616 & 0.59116 & 1.99372 \\
\hline 36 & $\mathrm{H}$ & 3.46851 & -0.38127 & 2.04656 \\
\hline 37 & $\mathrm{H}$ & 0.05023 & -1.35581 & -1.58599 \\
\hline 38 & $\mathrm{H}$ & -1.75611 & -2.33171 & 0.71947 \\
\hline 39 & $\mathrm{H}$ & -2.81757 & 0.30672 & -2.25585 \\
\hline 40 & $\mathrm{H}$ & -1.11281 & 0.18133 & -1.92351 \\
\hline 41 & $\mathrm{H}$ & -4.05984 & 0.36424 & 0.32928 \\
\hline 42 & $\mathrm{H}$ & -5.82344 & -1.14079 & -0.50568 \\
\hline 43 & $\mathrm{H}$ & -4.75134 & -0.69214 & -1.83316 \\
\hline 44 & $\mathrm{H}$ & -4.60526 & -2.28856 & -1.08611 \\
\hline 45 & $\mathrm{H}$ & -4.97911 & -1.27112 & 1.8643 \\
\hline 46 & $\mathrm{H}$ & -3.82161 & -2.5031 & 1.37057 \\
\hline 47 & $\mathrm{H}$ & -3.26412 & -1.06673 & 2.24182 \\
\hline 48 & $\mathrm{H}$ & 1.68049 & -3.01551 & 1.83345 \\
\hline 49 & $\mathrm{H}$ & -0.08071 & -3.04472 & 1.78731 \\
\hline 50 & $\mathrm{H}$ & 0.85783 & -4.35647 & 1.05673 \\
\hline 51 & $\mathrm{H}$ & -0.93788 & 4.06003 & -0.73135 \\
\hline 52 & $\mathrm{H}$ & -2.64688 & 2.27747 & 1.69784 \\
\hline 53 & $\mathrm{H}$ & -1.59459 & 0.84472 & 1.68826 \\
\hline 54 & $\mathrm{H}$ & -0.98199 & 2.39297 & 2.29848 \\
\hline
\end{tabular}

B3LYP/6-311G(d,p) Energy $=-931.84550091$ a.u.; Population $=0.03 \%$ 


\begin{tabular}{|c|c|c|c|c|}
\hline \multicolumn{2}{|c|}{$\begin{array}{c}(7 S, 8 S, 12 S)-4 \\
\text { Conf. } 17\end{array}$} & \multicolumn{3}{|c|}{$\begin{array}{c}\text { Standard Orientation } \\
\text { (Ångstroms) }\end{array}$} \\
\hline $\mathrm{I}$ & atom & $X$ & $\mathrm{Y}$ & $\mathrm{Z}$ \\
\hline 1 & $\mathrm{C}$ & -2.89904 & -0.67868 & 0.8692 \\
\hline 2 & $\mathrm{C}$ & -3.16481 & -1.985 & 0.15339 \\
\hline 3 & $\mathrm{C}$ & -2.21561 & -2.24135 & -1.04273 \\
\hline 4 & $\mathrm{C}$ & -3.42088 & 0.6362 & 0.44296 \\
\hline 5 & $\mathrm{C}$ & -2.66262 & 1.8951 & 0.8703 \\
\hline 6 & $\mathrm{C}$ & -1.4899 & 2.2409 & -0.01097 \\
\hline 7 & $\mathrm{C}$ & -0.24324 & 2.36798 & 0.44202 \\
\hline 8 & $\mathrm{C}$ & 1.02125 & 2.65621 & -0.35275 \\
\hline 9 & $\mathrm{C}$ & 1.73728 & 1.33405 & -0.73624 \\
\hline 10 & $\mathrm{C}$ & -4.31415 & 0.80344 & -0.76627 \\
\hline 11 & $\mathrm{C}$ & -0.79884 & -2.6547 & -0.68555 \\
\hline 12 & $\mathrm{C}$ & 0.16151 & -1.72211 & -0.52164 \\
\hline 13 & $\mathrm{C}$ & 1.58423 & -1.93893 & -0.28981 \\
\hline 14 & $\mathrm{C}$ & 2.04152 & 0.40815 & 0.4625 \\
\hline 15 & $\mathrm{C}$ & 2.47501 & -1.0027 & 0.10106 \\
\hline 16 & $\mathrm{C}$ & 3.94383 & -1.36609 & 0.25242 \\
\hline 17 & $\mathrm{C}$ & 4.86335 & -0.46627 & -0.59457 \\
\hline 18 & $\mathrm{C}$ & 4.39122 & -1.36417 & 1.72824 \\
\hline 19 & $\mathrm{C}$ & -0.57676 & -4.13827 & -0.55038 \\
\hline 20 & $\mathrm{O}$ & 1.89875 & 3.47287 & 0.45599 \\
\hline 21 & $\mathrm{C}$ & 0.76512 & 3.49041 & -1.60729 \\
\hline 22 & $\mathrm{O}$ & -4.01875 & -0.07234 & 1.55493 \\
\hline 23 & $\mathrm{H}$ & -1.98149 & -0.65919 & 1.45552 \\
\hline 24 & $\mathrm{H}$ & -3.08839 & -2.80372 & 0.87768 \\
\hline 25 & $\mathrm{H}$ & -4.19754 & -1.98576 & -0.20192 \\
\hline 26 & $\mathrm{H}$ & -2.18889 & -1.34111 & -1.66394 \\
\hline 27 & $\mathrm{H}$ & -2.6613 & -3.02893 & -1.65961 \\
\hline 28 & $\mathrm{H}$ & -3.37868 & 2.72785 & 0.88186 \\
\hline 29 & $\mathrm{H}$ & -2.32292 & 1.75052 & 1.8986 \\
\hline 30 & $\mathrm{H}$ & -1.69968 & 2.38748 & -1.06809 \\
\hline 31 & $\mathrm{H}$ & -0.07541 & 2.22476 & 1.50909 \\
\hline 32 & $\mathrm{H}$ & 1.11057 & 0.80607 & -1.45921 \\
\hline 33 & $\mathrm{H}$ & 2.66745 & 1.5948 & -1.25005 \\
\hline 34 & $\mathrm{H}$ & -5.08595 & 1.54848 & -0.55043 \\
\hline 35 & $\mathrm{H}$ & -3.74156 & 1.15675 & -1.62847 \\
\hline 36 & $\mathrm{H}$ & -4.80989 & -0.12596 & -1.04282 \\
\hline 37 & $\mathrm{H}$ & -0.15741 & -0.68779 & -0.60772 \\
\hline 38 & $\mathrm{H}$ & 1.96569 & -2.93876 & -0.48173 \\
\hline 39 & $\mathrm{H}$ & 2.81187 & 0.87698 & 1.08217 \\
\hline 40 & $\mathrm{H}$ & 1.14815 & 0.33752 & 1.08856 \\
\hline 41 & $\mathrm{H}$ & 4.05705 & -2.39114 & -0.11783 \\
\hline 42 & $\mathrm{H}$ & 5.90153 & -0.80185 & -0.51431 \\
\hline 43 & $\mathrm{H}$ & 4.57987 & -0.49168 & -1.64988 \\
\hline 44 & $\mathrm{H}$ & 4.82891 & 0.57488 & -0.26001 \\
\hline 45 & $\mathrm{H}$ & 5.43265 & -1.68934 & 1.81094 \\
\hline 46 & $\mathrm{H}$ & 4.32358 & -0.36562 & 2.17064 \\
\hline 47 & $\mathrm{H}$ & 3.77509 & -2.04065 & 2.32614 \\
\hline 48 & $\mathrm{H}$ & -0.73278 & -4.64343 & -1.51131 \\
\hline 49 & $\mathrm{H}$ & 0.41909 & -4.39237 & -0.18845 \\
\hline 50 & $\mathrm{H}$ & -1.30403 & -4.5711 & 0.14643 \\
\hline 51 & $\mathrm{H}$ & 2.04545 & 3.02062 & 1.29367 \\
\hline 52 & $\mathrm{H}$ & 1.71573 & 3.71357 & -2.09667 \\
\hline 53 & $\mathrm{H}$ & 0.13133 & 2.95686 & -2.31795 \\
\hline 54 & $\mathrm{H}$ & 0.28105 & 4.432 & -1.34168 \\
\hline
\end{tabular}

B3LYP/6-311G(d,p) Energy $=-931.85549875$ a.u.; Population $=0.42 \%$ 


\begin{tabular}{|c|c|c|c|c|}
\hline \multicolumn{2}{|c|}{$\begin{array}{c}(7 S, 8 S, 12 S)-4 \\
\text { Conf. } 18\end{array}$} & \multicolumn{3}{|c|}{$\begin{array}{c}\text { Standard Orientation } \\
\text { (Ångstroms) }\end{array}$} \\
\hline $\mathrm{I}$ & atom & $\mathrm{X}$ & $\mathrm{Y}$ & $\mathrm{Z}$ \\
\hline 1 & $\mathrm{C}$ & 3.49587 & 0.38076 & -0.42278 \\
\hline 2 & $\mathrm{C}$ & 3.81195 & -1.09533 & -0.52285 \\
\hline 3 & $\mathrm{C}$ & 2.79433 & -1.90075 & -1.36881 \\
\hline 4 & $\mathrm{C}$ & 2.76387 & 1.06595 & 0.66223 \\
\hline 5 & $\mathrm{C}$ & 2.12045 & 2.4249 & 0.36886 \\
\hline 6 & $\mathrm{C}$ & 0.74284 & 2.378 & -0.24297 \\
\hline 7 & $\mathrm{C}$ & -0.39014 & 2.58846 & 0.42592 \\
\hline 8 & $\mathrm{C}$ & -1.79395 & 2.60232 & -0.15504 \\
\hline 9 & $\mathrm{C}$ & -2.51289 & 1.26118 & 0.13357 \\
\hline 10 & $\mathrm{C}$ & 2.20604 & 0.33711 & 1.86128 \\
\hline 11 & $\mathrm{C}$ & 1.56596 & -2.35521 & -0.60724 \\
\hline 12 & $\mathrm{C}$ & 0.40358 & -1.68258 & -0.72568 \\
\hline 13 & $\mathrm{C}$ & -0.86775 & -1.99671 & -0.08814 \\
\hline 14 & $\mathrm{C}$ & -2.05539 & 0.10341 & -0.78812 \\
\hline 15 & $\mathrm{C}$ & -1.99515 & -1.25195 & -0.11447 \\
\hline 16 & $\mathrm{C}$ & -3.29967 & -1.74331 & 0.50574 \\
\hline 17 & $\mathrm{C}$ & -4.308 & -2.1478 & -0.59317 \\
\hline 18 & $\mathrm{C}$ & -3.15291 & -2.88138 & 1.52413 \\
\hline 19 & $\mathrm{C}$ & 1.76672 & -3.57792 & 0.2511 \\
\hline 20 & $\mathrm{O}$ & -1.77431 & 2.74997 & -1.5833 \\
\hline 21 & $\mathrm{C}$ & -2.58594 & 3.76431 & 0.46788 \\
\hline 22 & $\mathrm{O}$ & 4.2109 & 1.1182 & 0.59045 \\
\hline 23 & $\mathrm{H}$ & 3.48853 & 0.88641 & -1.39077 \\
\hline 24 & $\mathrm{H}$ & 4.80151 & -1.17349 & -0.98788 \\
\hline 25 & $\mathrm{H}$ & 3.91123 & -1.52586 & 0.47568 \\
\hline 26 & $\mathrm{H}$ & 3.30858 & -2.78323 & -1.76637 \\
\hline 27 & $\mathrm{H}$ & 2.49586 & -1.3014 & -2.23508 \\
\hline 28 & $\mathrm{H}$ & 2.09053 & 2.98793 & 1.30824 \\
\hline 29 & $\mathrm{H}$ & 2.7986 & 2.96096 & -0.30222 \\
\hline 30 & $\mathrm{H}$ & 0.69106 & 2.17633 & -1.31021 \\
\hline 31 & $\mathrm{H}$ & -0.34255 & 2.7827 & 1.49687 \\
\hline 32 & $\mathrm{H}$ & -2.33168 & 1.01129 & 1.18326 \\
\hline 33 & $\mathrm{H}$ & -3.59097 & 1.41995 & 0.03302 \\
\hline 34 & $\mathrm{H}$ & 2.33961 & 0.95261 & 2.75666 \\
\hline 35 & $\mathrm{H}$ & 1.1385 & 0.14887 & 1.7308 \\
\hline 36 & $\mathrm{H}$ & 2.70608 & -0.61599 & 2.02821 \\
\hline 37 & $\mathrm{H}$ & 0.42038 & -0.82036 & -1.38431 \\
\hline 38 & $\mathrm{H}$ & -0.90709 & -2.94273 & 0.44003 \\
\hline 39 & $\mathrm{H}$ & -2.73178 & 0.06292 & -1.64838 \\
\hline 40 & $\mathrm{H}$ & -1.08166 & 0.35759 & -1.19712 \\
\hline 41 & $\mathrm{H}$ & -3.74103 & -0.89298 & 1.04088 \\
\hline 42 & $\mathrm{H}$ & -5.26927 & -2.42206 & -0.14857 \\
\hline 43 & $\mathrm{H}$ & -4.48967 & -1.33709 & -1.30226 \\
\hline 44 & $\mathrm{H}$ & -3.93462 & -3.00972 & -1.1545 \\
\hline 45 & $\mathrm{H}$ & -4.11937 & -3.08729 & 1.9924 \\
\hline 46 & $\mathrm{H}$ & -2.81757 & -3.80922 & 1.05119 \\
\hline 47 & $\mathrm{H}$ & -2.44212 & -2.62708 & 2.31474 \\
\hline 48 & $\mathrm{H}$ & 2.65394 & -3.46912 & 0.88451 \\
\hline 49 & $\mathrm{H}$ & 0.92097 & -3.79164 & 0.90367 \\
\hline 50 & $\mathrm{H}$ & 1.94311 & -4.46074 & -0.37582 \\
\hline 51 & $\mathrm{H}$ & -1.30852 & 3.57026 & -1.78293 \\
\hline 52 & $\mathrm{H}$ & -3.57921 & 3.81617 & 0.01671 \\
\hline 53 & $\mathrm{H}$ & -2.69817 & 3.63333 & 1.54786 \\
\hline 54 & $\mathrm{H}$ & -2.07484 & 4.7166 & 0.29578 \\
\hline
\end{tabular}

B3LYP/6-311G(d,p) Energy = -931.84909993 a.u.; Population $=0.1 .69 \%$ 


\begin{tabular}{|c|c|c|c|c|}
\hline \multicolumn{2}{|c|}{$\begin{array}{c}(7 S, 8 S, 12 S)-\mathbf{4} \\
\text { Conf. } 19 \\
\end{array}$} & \multicolumn{3}{|c|}{$\begin{array}{c}\text { Standard Orientation } \\
\text { (Ångstroms) }\end{array}$} \\
\hline I & atom & $\mathrm{X}$ & $\mathrm{Y}$ & $\mathrm{Z}$ \\
\hline 1 & $\mathrm{C}$ & -2.47613 & 1.28655 & -0.43858 \\
\hline 2 & $\mathrm{C}$ & -2.14817 & 2.20742 & 0.72357 \\
\hline 3 & $\mathrm{C}$ & -1.16085 & 3.33686 & 0.39186 \\
\hline 4 & $\mathrm{C}$ & -3.42803 & 0.16074 & -0.36396 \\
\hline 5 & $\mathrm{C}$ & -3.20489 & -1.02284 & -1.29478 \\
\hline 6 & $\mathrm{C}$ & -2.09278 & -1.96806 & -0.90655 \\
\hline 7 & $\mathrm{C}$ & -1.29958 & -1.86535 & 0.15813 \\
\hline 8 & $\mathrm{C}$ & -0.11993 & -2.7607 & 0.49251 \\
\hline 9 & $\mathrm{C}$ & 1.12023 & -1.87158 & 0.77946 \\
\hline 10 & $\mathrm{C}$ & -4.23865 & -0.12778 & 0.88113 \\
\hline 11 & $\mathrm{C}$ & 0.31121 & 2.99414 & 0.2493 \\
\hline 12 & $\mathrm{C}$ & 0.77634 & 1.72846 & 0.24619 \\
\hline 13 & $\mathrm{C}$ & 2.1685 & 1.29465 & 0.16825 \\
\hline 14 & $\mathrm{C}$ & 1.61169 & -1.07252 & -0.44727 \\
\hline 15 & $\mathrm{C}$ & 2.5848 & 0.04137 & -0.10854 \\
\hline 16 & $\mathrm{C}$ & 4.05782 & -0.34861 & -0.13662 \\
\hline 17 & $\mathrm{C}$ & 4.58223 & -0.41184 & -1.58813 \\
\hline 18 & $\mathrm{C}$ & 4.97787 & 0.53039 & 0.72064 \\
\hline 19 & $\mathrm{C}$ & 1.19087 & 4.21068 & 0.10653 \\
\hline 20 & $\mathrm{O}$ & 0.16012 & -3.69525 & -0.55994 \\
\hline 21 & $\mathrm{C}$ & -0.44089 & -3.62265 & 1.71916 \\
\hline 22 & $\mathrm{O}$ & -3.78656 & 1.39066 & -1.03998 \\
\hline 23 & $\mathrm{H}$ & -1.68928 & 1.19156 & -1.18515 \\
\hline 24 & $\mathrm{H}$ & -3.08338 & 2.6565 & 1.06562 \\
\hline 25 & $\mathrm{H}$ & -1.75902 & 1.62209 & 1.56463 \\
\hline 26 & $\mathrm{H}$ & -1.49005 & 3.84827 & -0.52429 \\
\hline 27 & $\mathrm{H}$ & -1.24221 & 4.09943 & 1.17754 \\
\hline 28 & $\mathrm{H}$ & -4.1413 & -1.58673 & -1.40087 \\
\hline 29 & $\mathrm{H}$ & -2.98996 & -0.62543 & -2.29372 \\
\hline 30 & $\mathrm{H}$ & -1.92898 & -2.79152 & -1.59816 \\
\hline 31 & $\mathrm{H}$ & -1.45588 & -1.06145 & 0.87276 \\
\hline 32 & $\mathrm{H}$ & 0.86382 & -1.17913 & 1.58735 \\
\hline 33 & $\mathrm{H}$ & 1.92429 & -2.51268 & 1.15378 \\
\hline 34 & $\mathrm{H}$ & -5.26125 & -0.38989 & 0.5932 \\
\hline 35 & $\mathrm{H}$ & -3.82093 & -0.97542 & 1.42982 \\
\hline 36 & $\mathrm{H}$ & -4.28431 & 0.73164 & 1.54941 \\
\hline 37 & $\mathrm{H}$ & 0.04738 & 0.93137 & 0.32864 \\
\hline 38 & $\mathrm{H}$ & 2.9231 & 2.04567 & 0.37406 \\
\hline 39 & $\mathrm{H}$ & 2.09631 & -1.76535 & -1.14317 \\
\hline 40 & $\mathrm{H}$ & 0.74846 & -0.66124 & -0.976 \\
\hline 41 & $\mathrm{H}$ & 4.11529 & -1.36857 & 0.26798 \\
\hline 42 & $\mathrm{H}$ & 5.60341 & -0.80369 & -1.61259 \\
\hline 43 & $\mathrm{H}$ & 3.96358 & -1.05509 & -2.21867 \\
\hline 44 & $\mathrm{H}$ & 4.58962 & 0.58776 & -2.03301 \\
\hline 45 & $\mathrm{H}$ & 5.98978 & 0.11579 & 0.73013 \\
\hline 46 & $\mathrm{H}$ & 5.0492 & 1.54836 & 0.32635 \\
\hline 47 & $\mathrm{H}$ & 4.62571 & 0.59159 & 1.75346 \\
\hline 48 & $\mathrm{H}$ & 1.13917 & 4.83498 & 1.00653 \\
\hline 49 & $\mathrm{H}$ & 2.23605 & 3.96682 & -0.07819 \\
\hline 50 & $\mathrm{H}$ & 0.84318 & 4.83586 & -0.72404 \\
\hline 51 & $\mathrm{H}$ & 0.32944 & -3.19589 & -1.36663 \\
\hline 52 & $\mathrm{H}$ & 0.41685 & -4.25223 & 1.96891 \\
\hline 53 & $\mathrm{H}$ & -0.67861 & -2.99749 & 2.58284 \\
\hline 54 & $\mathrm{H}$ & -1.29786 & -4.26518 & 1.5071 \\
\hline
\end{tabular}

B3LYP/6-311G(d,p) Energy $=-931.84975925$ a.u.; Population $=1.75 \%$ 


\begin{tabular}{|c|c|c|c|c|}
\hline \multicolumn{2}{|c|}{$\begin{array}{l}(7 S, 8 S, 12 S)-\mathbf{4} \\
\text { Conf. } 20 \\
\end{array}$} & \multicolumn{3}{|c|}{$\begin{array}{c}\text { Standard Orientation } \\
\text { (Ångstroms) }\end{array}$} \\
\hline $\mathrm{I}$ & atom & $\mathrm{X}$ & $\mathrm{Y}$ & $\mathrm{Z}$ \\
\hline 1 & $\mathrm{C}$ & 3.1322 & -0.42638 & -0.28778 \\
\hline 2 & $\mathrm{C}$ & 3.05685 & -1.81898 & 0.32183 \\
\hline 3 & $\mathrm{C}$ & 2.26503 & -2.82673 & -0.52181 \\
\hline 4 & $\mathrm{C}$ & 3.23799 & 0.83439 & 0.47171 \\
\hline 5 & $\mathrm{C}$ & 2.69895 & 2.10918 & -0.17709 \\
\hline 6 & $\mathrm{C}$ & 1.22671 & 2.29908 & 0.07792 \\
\hline 7 & $\mathrm{C}$ & 0.28787 & 2.16205 & -0.85703 \\
\hline 8 & $\mathrm{C}$ & -1.21622 & 2.29949 & -0.7029 \\
\hline 9 & $\mathrm{C}$ & -1.74476 & 2.03112 & 0.72469 \\
\hline 10 & $\mathrm{C}$ & 3.32378 & 0.84511 & 1.98126 \\
\hline 11 & $\mathrm{C}$ & 0.75721 & -2.6889 & -0.60303 \\
\hline 12 & $\mathrm{C}$ & 0.07406 & -1.70304 & 0.01614 \\
\hline 13 & $\mathrm{C}$ & -1.37409 & -1.54102 & 0.04609 \\
\hline 14 & $\mathrm{C}$ & -1.47265 & 0.6359 & 1.34185 \\
\hline 15 & $\mathrm{C}$ & -2.08935 & -0.54679 & 0.62126 \\
\hline 16 & $\mathrm{C}$ & -3.61746 & -0.61605 & 0.67584 \\
\hline 17 & $\mathrm{C}$ & -4.28792 & -1.02187 & -0.64548 \\
\hline 18 & $\mathrm{C}$ & -4.06683 & -1.53639 & 1.83003 \\
\hline 19 & $\mathrm{C}$ & 0.11893 & -3.77824 & -1.42862 \\
\hline 20 & $\mathrm{O}$ & -1.84989 & 1.40605 & -1.64479 \\
\hline 21 & $\mathrm{C}$ & -1.64469 & 3.7018 & -1.15694 \\
\hline 22 & $\mathrm{O}$ & 4.39362 & 0.27787 & -0.19078 \\
\hline 23 & $\mathrm{H}$ & 2.68983 & -0.34763 & -1.28077 \\
\hline 24 & $\mathrm{H}$ & 4.08193 & -2.18896 & 0.41705 \\
\hline 25 & $\mathrm{H}$ & 2.64842 & -1.78402 & 1.3363 \\
\hline 26 & $\mathrm{H}$ & 2.48104 & -3.83447 & -0.1423 \\
\hline 27 & $\mathrm{H}$ & 2.66588 & -2.82612 & -1.54578 \\
\hline 28 & $\mathrm{H}$ & 3.26854 & 2.96371 & 0.20966 \\
\hline 29 & $\mathrm{H}$ & 2.88968 & 2.04905 & -1.25126 \\
\hline 30 & $\mathrm{H}$ & 0.941 & 2.52862 & 1.10181 \\
\hline 31 & $\mathrm{H}$ & 0.58883 & 1.94574 & -1.88117 \\
\hline 32 & $\mathrm{H}$ & -1.32505 & 2.78276 & 1.40148 \\
\hline 33 & $\mathrm{H}$ & -2.82238 & 2.21759 & 0.69969 \\
\hline 34 & $\mathrm{H}$ & 3.9489 & 1.68125 & 2.30889 \\
\hline 35 & $\mathrm{H}$ & 2.33614 & 0.96696 & 2.43487 \\
\hline 36 & $\mathrm{H}$ & 3.76601 & -0.076 & 2.36019 \\
\hline 37 & $\mathrm{H}$ & 0.65121 & -0.96665 & 0.56218 \\
\hline 38 & $\mathrm{H}$ & -1.94503 & -2.3373 & -0.42032 \\
\hline 39 & $\mathrm{H}$ & -0.39863 & 0.49814 & 1.45846 \\
\hline 40 & $\mathrm{H}$ & -1.88881 & 0.66115 & 2.35774 \\
\hline 41 & $\mathrm{H}$ & -3.97682 & 0.39043 & 0.91386 \\
\hline 42 & $\mathrm{H}$ & -5.3763 & -0.98127 & -0.54284 \\
\hline 43 & $\mathrm{H}$ & -3.99735 & -0.34456 & -1.45141 \\
\hline 44 & $\mathrm{H}$ & -4.02803 & -2.04188 & -0.94212 \\
\hline 45 & $\mathrm{H}$ & -5.15328 & -1.49762 & 1.95527 \\
\hline 46 & $\mathrm{H}$ & -3.78343 & -2.57348 & 1.62835 \\
\hline 47 & $\mathrm{H}$ & -3.60852 & -1.24273 & 2.77847 \\
\hline 48 & $\mathrm{H}$ & 0.56194 & -3.80262 & -2.43074 \\
\hline 49 & $\mathrm{H}$ & 0.31022 & -4.76116 & -0.98192 \\
\hline 50 & $\mathrm{H}$ & -0.95742 & -3.66606 & -1.54594 \\
\hline 51 & $\mathrm{H}$ & -1.65401 & 0.5004 & -1.36824 \\
\hline 52 & $\mathrm{H}$ & -2.73543 & 3.77529 & -1.15286 \\
\hline 53 & $\mathrm{H}$ & -1.23141 & 4.46679 & -0.49658 \\
\hline 54 & $\mathrm{H}$ & -1.29112 & 3.8909 & -2.17309 \\
\hline
\end{tabular}

B3LYP/6-311G(d,p) Energy $=-931.85028172$ a.u.; Population $=3.86 \%$ 


\begin{tabular}{|c|c|c|c|c|}
\hline \multicolumn{2}{|c|}{$\begin{array}{l}(7 S, 8 S, 12 S)-\mathbf{4} \\
\text { Conf. } 21\end{array}$} & \multicolumn{3}{|c|}{$\begin{array}{c}\text { Standard Orientation } \\
\text { (Ångstroms) }\end{array}$} \\
\hline I & atom & $\mathrm{X}$ & $\mathrm{Y}$ & $\mathrm{Z}$ \\
\hline 1 & $\mathrm{C}$ & -2.60616 & -1.25521 & 0.82408 \\
\hline 2 & $\mathrm{C}$ & -2.69666 & -2.41111 & -0.14831 \\
\hline 3 & $\mathrm{C}$ & -1.63589 & -2.39261 & -1.27326 \\
\hline 4 & $\mathrm{C}$ & -3.27324 & 0.06038 & 0.68287 \\
\hline 5 & $\mathrm{C}$ & -2.71037 & 1.23807 & 1.47112 \\
\hline 6 & $\mathrm{C}$ & -1.55284 & 2.02375 & 0.90772 \\
\hline 7 & $\mathrm{C}$ & -0.99043 & 1.94713 & -0.29664 \\
\hline 8 & $\mathrm{C}$ & 0.24835 & 2.71782 & -0.73042 \\
\hline 9 & $\mathrm{C}$ & 1.44083 & 1.74758 & -0.91171 \\
\hline 10 & $\mathrm{C}$ & -4.17002 & 0.4093 & -0.48446 \\
\hline 11 & $\mathrm{C}$ & -0.19486 & -2.58109 & -0.8317 \\
\hline 12 & $\mathrm{C}$ & 0.56798 & -1.49664 & -0.58909 \\
\hline 13 & $\mathrm{C}$ & 1.9822 & -1.42336 & -0.24899 \\
\hline 14 & $\mathrm{C}$ & 1.84539 & 0.99873 & 0.37957 \\
\hline 15 & $\mathrm{C}$ & 2.60992 & -0.29651 & 0.15217 \\
\hline 16 & $\mathrm{C}$ & 4.10078 & -0.24495 & 0.45428 \\
\hline 17 & $\mathrm{C}$ & 4.34972 & -0.207 & 1.97868 \\
\hline 18 & $\mathrm{C}$ & 4.93464 & -1.35957 & -0.18943 \\
\hline 19 & $\mathrm{C}$ & 0.27664 & -4.0056 & -0.70938 \\
\hline 20 & $\mathrm{O}$ & 0.66431 & 3.66321 & 0.26603 \\
\hline 21 & $\mathrm{C}$ & -0.02999 & 3.45374 & -2.0518 \\
\hline 22 & $\mathrm{O}$ & -3.80866 & -0.95933 & 1.56503 \\
\hline 23 & $\mathrm{H}$ & -1.71284 & -1.263 & 1.44739 \\
\hline 24 & $\mathrm{H}$ & -2.61412 & -3.33934 & 0.42913 \\
\hline 25 & $\mathrm{H}$ & -3.69188 & -2.42119 & -0.59876 \\
\hline 26 & $\mathrm{H}$ & -1.72759 & -1.44856 & -1.81868 \\
\hline 27 & $\mathrm{H}$ & -1.89478 & -3.18533 & -1.98421 \\
\hline 28 & $\mathrm{H}$ & -3.53578 & 1.92903 & 1.69502 \\
\hline 29 & $\mathrm{H}$ & -2.3993 & 0.84661 & 2.44602 \\
\hline 30 & $\mathrm{H}$ & -1.10826 & 2.71366 & 1.62188 \\
\hline 31 & $\mathrm{H}$ & -1.38542 & 1.27038 & -1.05001 \\
\hline 32 & $\mathrm{H}$ & 1.17665 & 1.03522 & -1.69666 \\
\hline 33 & $\mathrm{H}$ & 2.28955 & 2.32682 & -1.28884 \\
\hline 34 & $\mathrm{H}$ & -5.05322 & 0.9389 & -0.1141 \\
\hline 35 & $\mathrm{H}$ & -3.66071 & 1.07028 & -1.18959 \\
\hline 36 & $\mathrm{H}$ & -4.50969 & -0.47601 & -1.02118 \\
\hline 37 & $\mathrm{H}$ & 0.06341 & -0.5431 & -0.6877 \\
\hline 38 & $\mathrm{H}$ & 2.56508 & -2.33085 & -0.36539 \\
\hline 39 & $\mathrm{H}$ & 2.43981 & 1.676 & 0.99594 \\
\hline 40 & $\mathrm{H}$ & 0.94239 & 0.78533 & 0.95581 \\
\hline 41 & $\mathrm{H}$ & 4.46262 & 0.71055 & 0.04836 \\
\hline 42 & $\mathrm{H}$ & 5.41262 & -0.0603 & 2.19265 \\
\hline 43 & $\mathrm{H}$ & 3.7969 & 0.60163 & 2.46243 \\
\hline 44 & $\mathrm{H}$ & 4.03612 & -1.14989 & 2.43712 \\
\hline 45 & $\mathrm{H}$ & 5.99874 & -1.18326 & -0.00909 \\
\hline 46 & $\mathrm{H}$ & 4.69284 & -2.34019 & 0.23126 \\
\hline 47 & $\mathrm{H}$ & 4.77697 & -1.40659 & -1.26994 \\
\hline 48 & $\mathrm{H}$ & 0.2667 & -4.50362 & -1.6866 \\
\hline 49 & $\mathrm{H}$ & 1.28204 & -4.08591 & -0.29607 \\
\hline 50 & $\mathrm{H}$ & -0.39557 & -4.58147 & -0.06276 \\
\hline 51 & $\mathrm{H}$ & -0.03254 & 4.32345 & 0.35592 \\
\hline 52 & $\mathrm{H}$ & 0.86318 & 3.99417 & -2.37423 \\
\hline 53 & $\mathrm{H}$ & -0.31997 & 2.75526 & -2.84135 \\
\hline 54 & $\mathrm{H}$ & -0.84498 & 4.17303 & -1.92411 \\
\hline
\end{tabular}

B3LYP/6-311G(d,p) Energy $=-931.85260637$ a.u.; Population $=0.31 \%$ 


\begin{tabular}{|c|c|c|c|c|}
\hline \multicolumn{2}{|c|}{$\begin{array}{l}(7 S, 8 S, 12 S)-\mathbf{4} \\
\text { Conf. } 22\end{array}$} & \multicolumn{3}{|c|}{$\begin{array}{c}\text { Standard Orientation } \\
\text { (Ångstroms) }\end{array}$} \\
\hline $\mathrm{I}$ & atom & $\mathrm{X}$ & $\mathrm{Y}$ & $\mathrm{Z}$ \\
\hline 1 & $\mathrm{C}$ & 3.52422 & 0.07018 & -0.14955 \\
\hline 2 & $\mathrm{C}$ & 3.5649 & -1.43113 & -0.33298 \\
\hline 3 & $\mathrm{C}$ & 2.55825 & -1.92355 & -1.41059 \\
\hline 4 & $\mathrm{C}$ & 2.86486 & 0.8239 & 0.9359 \\
\hline 5 & $\mathrm{C}$ & 2.41965 & 2.26298 & 0.64661 \\
\hline 6 & $\mathrm{C}$ & 1.17102 & 2.33391 & -0.1948 \\
\hline 7 & $\mathrm{C}$ & -0.05633 & 2.5631 & 0.27056 \\
\hline 8 & $\mathrm{C}$ & -1.3224 & 2.57263 & -0.57816 \\
\hline 9 & $\mathrm{C}$ & -1.83451 & 1.13497 & -0.83886 \\
\hline 10 & $\mathrm{C}$ & 2.15631 & 0.15021 & 2.08689 \\
\hline 11 & $\mathrm{C}$ & 1.24239 & -2.46661 & -0.88234 \\
\hline 12 & $\mathrm{C}$ & 0.18318 & -1.65399 & -0.6908 \\
\hline 13 & $\mathrm{C}$ & -1.169 & -2.04683 & -0.30788 \\
\hline 14 & $\mathrm{C}$ & -1.9341 & 0.24043 & 0.41191 \\
\hline 15 & $\mathrm{C}$ & -2.15618 & -1.23785 & 0.13272 \\
\hline 16 & $\mathrm{C}$ & -3.52998 & -1.82086 & 0.4319 \\
\hline 17 & $\mathrm{C}$ & -3.84622 & -1.81835 & 1.94116 \\
\hline 18 & $\mathrm{C}$ & -4.65052 & -1.11908 & -0.35828 \\
\hline 19 & $\mathrm{C}$ & 1.2341 & -3.94897 & -0.61164 \\
\hline 20 & $\mathrm{O}$ & -1.04767 & 3.07251 & -1.90207 \\
\hline 21 & $\mathrm{C}$ & -2.39306 & 3.45042 & 0.08463 \\
\hline 22 & $\mathrm{O}$ & 4.30119 & 0.63559 & 0.9248 \\
\hline 23 & $\mathrm{H}$ & 3.65345 & 0.6122 & -1.08877 \\
\hline 24 & $\mathrm{H}$ & 4.58399 & -1.68038 & -0.64905 \\
\hline 25 & $\mathrm{H}$ & 3.40261 & -1.94506 & 0.61669 \\
\hline 26 & $\mathrm{H}$ & 3.03986 & -2.71094 & -1.99831 \\
\hline 27 & $\mathrm{H}$ & 2.36172 & -1.10417 & -2.10951 \\
\hline 28 & $\mathrm{H}$ & 2.26738 & 2.78271 & 1.59825 \\
\hline 29 & $\mathrm{H}$ & 3.24659 & 2.76102 & 0.13177 \\
\hline 30 & $\mathrm{H}$ & 1.29559 & 2.15646 & -1.26089 \\
\hline 31 & $\mathrm{H}$ & -0.19506 & 2.73725 & 1.3363 \\
\hline 32 & $\mathrm{H}$ & -2.80473 & 1.20065 & -1.34061 \\
\hline 33 & $\mathrm{H}$ & -1.14221 & 0.69237 & -1.55696 \\
\hline 34 & $\mathrm{H}$ & 2.39282 & 0.67898 & 3.01557 \\
\hline 35 & $\mathrm{H}$ & 1.07416 & 0.17938 & 1.94656 \\
\hline 36 & $\mathrm{H}$ & 2.45972 & -0.88949 & 2.20077 \\
\hline 37 & $\mathrm{H}$ & 0.34554 & -0.59781 & -0.88165 \\
\hline 38 & $\mathrm{H}$ & -1.41462 & -3.09958 & -0.42426 \\
\hline 39 & $\mathrm{H}$ & -1.01035 & 0.34558 & 0.98655 \\
\hline 40 & $\mathrm{H}$ & -2.7338 & 0.61271 & 1.05798 \\
\hline 41 & $\mathrm{H}$ & -3.5083 & -2.86761 & 0.10902 \\
\hline 42 & $\mathrm{H}$ & -4.80937 & $\begin{array}{r}-2.30259 \\
\end{array}$ & 2.12873 \\
\hline 43 & $\mathrm{H}$ & -3.0797 & -2.35701 & 2.50426 \\
\hline 44 & $\mathrm{H}$ & -3.9073 & -0.8017 & 2.34105 \\
\hline 45 & $\mathrm{H}$ & -5.61202 & -1.60536 & -0.16837 \\
\hline 46 & $\mathrm{H}$ & -4.75119 & -0.06896 & -0.06786 \\
\hline 47 & $\mathrm{H}$ & -4.45902 & -1.15514 & -1.43374 \\
\hline 48 & $\mathrm{H}$ & 2.07584 & -4.22098 & 0.03622 \\
\hline 49 & $\mathrm{H}$ & 0.32059 & -4.29425 & -0.12863 \\
\hline 50 & $\mathrm{H}$ & 1.36679 & -4.51437 & -1.54201 \\
\hline 51 & $\mathrm{H}$ & -0.66558 & 3.95265 & -1.8045 \\
\hline 52 & $\mathrm{H}$ & -3.2847 & 3.48843 & -0.54476 \\
\hline 53 & $\mathrm{H}$ & -2.67423 & 3.0661 & 1.06905 \\
\hline 54 & $\mathrm{H}$ & -2.02195 & 4.47111 & 0.22091 \\
\hline
\end{tabular}

B3LYP/6-311G(d,p) Energy $=-931.85222374$ a.u.; Population $=0.07 \%$ 


\begin{tabular}{|c|c|c|c|c|}
\hline \multicolumn{2}{|c|}{$\begin{array}{c}(7 S, 8 S, 12 S)-4 \\
\text { Conf. } 23\end{array}$} & \multicolumn{3}{|c|}{$\begin{array}{c}\text { Standard Orientation } \\
\text { (Ångstroms) }\end{array}$} \\
\hline $\mathrm{I}$ & atom & $\mathrm{X}$ & $\mathrm{Y}$ & $\mathrm{Z}$ \\
\hline 1 & $\mathrm{C}$ & 2.83011 & 0.87165 & 0.81011 \\
\hline 2 & $\mathrm{C}$ & 3.11172 & 1.98392 & -0.17694 \\
\hline 3 & $\mathrm{C}$ & 2.05027 & 2.13734 & -1.29014 \\
\hline 4 & $\mathrm{C}$ & 3.24201 & -0.54435 & 0.66781 \\
\hline 5 & $\mathrm{C}$ & 2.48297 & -1.59536 & 1.47017 \\
\hline 6 & $\mathrm{C}$ & 1.19173 & -2.1528 & 0.92465 \\
\hline 7 & $\mathrm{C}$ & 0.63643 & -1.9714 & -0.27186 \\
\hline 8 & $\mathrm{C}$ & -0.72082 & -2.51407 & -0.6966 \\
\hline 9 & $\mathrm{C}$ & -1.72887 & -1.35368 & -0.88079 \\
\hline 10 & $\mathrm{C}$ & 4.04042 & -1.05503 & -0.51147 \\
\hline 11 & $\mathrm{C}$ & 0.67415 & 2.59201 & -0.83625 \\
\hline 12 & $\mathrm{C}$ & -0.27177 & 1.66928 & -0.56997 \\
\hline 13 & $\mathrm{C}$ & -1.6695 & 1.86081 & -0.21377 \\
\hline 14 & $\mathrm{C}$ & -2.00807 & -0.54711 & 0.40901 \\
\hline 15 & $\mathrm{C}$ & -2.50176 & 0.87602 & 0.19089 \\
\hline 16 & $\mathrm{C}$ & -3.95912 & 1.18623 & 0.49276 \\
\hline 17 & $\mathrm{C}$ & -4.92342 & 0.32425 & -0.3439 \\
\hline 18 & $\mathrm{C}$ & -4.27778 & 1.05635 & 1.99584 \\
\hline 19 & $\mathrm{C}$ & 0.47421 & 4.08038 & -0.73122 \\
\hline 20 & $\mathrm{O}$ & -1.29062 & -3.36862 & 0.30543 \\
\hline 21 & $\mathrm{C}$ & -0.57908 & -3.29351 & -2.01497 \\
\hline 22 & $\mathrm{O}$ & 3.97022 & 0.36344 & 1.5341 \\
\hline 23 & $\mathrm{H}$ & 1.96443 & 1.04522 & 1.448 \\
\hline 24 & $\mathrm{H}$ & 3.19923 & 2.91914 & 0.38821 \\
\hline 25 & $\mathrm{H}$ & 4.08792 & 1.81334 & -0.63675 \\
\hline 26 & $\mathrm{H}$ & 1.96138 & 1.18319 & -1.81819 \\
\hline 27 & $\mathrm{H}$ & 2.43746 & 2.85795 & -2.01942 \\
\hline 28 & $\mathrm{H}$ & 3.16829 & -2.42811 & 1.68331 \\
\hline 29 & $\mathrm{H}$ & 2.26523 & -1.15209 & 2.4483 \\
\hline 30 & $\mathrm{H}$ & 0.6405 & -2.75421 & 1.64438 \\
\hline 31 & $\mathrm{H}$ & 1.13751 & -1.37471 & -1.02961 \\
\hline 32 & $\mathrm{H}$ & -1.3447 & -0.69575 & -1.66387 \\
\hline 33 & $\mathrm{H}$ & -2.66106 & -1.78022 & -1.26317 \\
\hline 34 & $\mathrm{H}$ & 4.82284 & -1.73016 & -0.15121 \\
\hline 35 & $\mathrm{H}$ & 3.40875 & -1.61984 & -1.20097 \\
\hline 36 & $\mathrm{H}$ & 4.5202 & -0.24701 & -1.06275 \\
\hline 37 & $\mathrm{H}$ & 0.04647 & 0.63758 & -0.65729 \\
\hline 38 & $\mathrm{H}$ & -2.07992 & 2.8628 & -0.31208 \\
\hline 39 & $\mathrm{H}$ & -2.72333 & -1.10489 & 1.01555 \\
\hline 40 & $\mathrm{H}$ & -1.08846 & -0.50888 & 0.99798 \\
\hline 41 & $\mathrm{H}$ & -4.12745 & 2.23266 & 0.21428 \\
\hline 42 & $\mathrm{H}$ & -5.96078 & 0.6071 & -0.14175 \\
\hline 43 & $\mathrm{H}$ & -4.74028 & 0.45112 & -1.41417 \\
\hline 44 & $\mathrm{H}$ & -4.82002 & -0.73882 & -0.10684 \\
\hline 45 & $\mathrm{H}$ & -5.31703 & 1.3378 & 2.19098 \\
\hline 46 & $\mathrm{H}$ & -4.14194 & 0.02999 & 2.34848 \\
\hline 47 & $\mathrm{H}$ & -3.63148 & 1.70624 & 2.59142 \\
\hline 48 & $\mathrm{H}$ & 0.56661 & 4.55556 & -1.71546 \\
\hline 49 & $\mathrm{H}$ & -0.49512 & 4.35099 & -0.31261 \\
\hline 50 & $\mathrm{H}$ & 1.2474 & 4.53032 & -0.09759 \\
\hline 51 & $\mathrm{H}$ & -0.71333 & -4.13472 & 0.4023 \\
\hline 52 & $\mathrm{H}$ & -1.55368 & -3.672 & -2.33232 \\
\hline 53 & $\mathrm{H}$ & -0.17398 & -2.66083 & -2.80924 \\
\hline 54 & $\mathrm{H}$ & 0.09851 & -4.1429 & -1.88438 \\
\hline
\end{tabular}

B3LYP/6-311G(d,p) Energy $=-931.85423011$ a.u.; Population $=1.00 \%$ 


\begin{tabular}{|c|c|c|c|c|}
\hline \multicolumn{2}{|c|}{$\begin{array}{c}(7 S, 8 S, 12 S)-4 \\
\text { Conf. } 24\end{array}$} & \multicolumn{3}{|c|}{$\begin{array}{c}\text { Standard Orientation } \\
\text { (Ångstroms) }\end{array}$} \\
\hline $\mathrm{I}$ & atom & $X$ & $\mathrm{Y}$ & $\mathrm{Z}$ \\
\hline 1 & $\mathrm{C}$ & 3.50595 & 0.30018 & -0.43062 \\
\hline 2 & $\mathrm{C}$ & 3.77479 & -1.18704 & -0.51068 \\
\hline 3 & $\mathrm{C}$ & 2.74057 & -1.97746 & -1.35055 \\
\hline 4 & $\mathrm{C}$ & 2.79176 & 1.02304 & 0.64223 \\
\hline 5 & $\mathrm{C}$ & 2.21073 & 2.40909 & 0.34042 \\
\hline 6 & $\mathrm{C}$ & 0.83188 & 2.43902 & -0.27572 \\
\hline 7 & $\mathrm{C}$ & -0.30129 & 2.56332 & 0.41224 \\
\hline 8 & $\mathrm{C}$ & -1.71243 & 2.63848 & -0.14578 \\
\hline 9 & $\mathrm{C}$ & -2.46397 & 1.31261 & 0.16095 \\
\hline 10 & $\mathrm{C}$ & 2.1968 & 0.32246 & 1.84057 \\
\hline 11 & $\mathrm{C}$ & 1.5021 & -2.40153 & -0.5875 \\
\hline 12 & $\mathrm{C}$ & 0.35209 & -1.71123 & -0.72135 \\
\hline 13 & $\mathrm{C}$ & -0.92942 & -1.9947 & -0.08881 \\
\hline 14 & $\mathrm{C}$ & -2.0475 & 0.14621 & -0.76953 \\
\hline 15 & $\mathrm{C}$ & -2.03562 & -1.21915 & -0.11184 \\
\hline 16 & $\mathrm{C}$ & -3.35756 & -1.67087 & 0.49997 \\
\hline 17 & $\mathrm{C}$ & -4.3883 & -1.99909 & -0.60327 \\
\hline 18 & $\mathrm{C}$ & -3.2529 & -2.84315 & 1.48387 \\
\hline 19 & $\mathrm{C}$ & 1.67731 & -3.61531 & 0.28832 \\
\hline 20 & $\mathrm{O}$ & -1.72974 & 2.91684 & -1.55373 \\
\hline 21 & $\mathrm{C}$ & -2.44559 & 3.82036 & 0.49834 \\
\hline 22 & $\mathrm{O}$ & 4.24022 & 1.01889 & 0.58236 \\
\hline 23 & $\mathrm{H}$ & 3.52657 & 0.79588 & -1.40351 \\
\hline 24 & $\mathrm{H}$ & 4.76402 & -1.30055 & -0.96894 \\
\hline 25 & $\mathrm{H}$ & 3.85755 & -1.60622 & 0.49412 \\
\hline 26 & $\mathrm{H}$ & 3.23642 & -2.87388 & -1.74006 \\
\hline 27 & $\mathrm{H}$ & 2.45517 & -1.37985 & -2.22239 \\
\hline 28 & $\mathrm{H}$ & 2.20561 & 2.97103 & 1.28096 \\
\hline 29 & $\mathrm{H}$ & 2.91633 & 2.9137 & -0.32528 \\
\hline 30 & $\mathrm{H}$ & 0.79139 & 2.39068 & -1.36148 \\
\hline 31 & $\mathrm{H}$ & -0.25179 & 2.62035 & 1.49924 \\
\hline 32 & $\mathrm{H}$ & -2.2707 & 1.04919 & 1.20541 \\
\hline 33 & $\mathrm{H}$ & -3.53876 & 1.49688 & 0.07467 \\
\hline 34 & $\mathrm{H}$ & 2.33538 & 0.94206 & 2.73223 \\
\hline 35 & $\mathrm{H}$ & 1.12632 & 0.16182 & 1.69741 \\
\hline 36 & $\mathrm{H}$ & 2.66801 & -0.64247 & 2.02265 \\
\hline 37 & $\mathrm{H}$ & 0.39073 & -0.85982 & -1.3931 \\
\hline 38 & $\mathrm{H}$ & -0.99623 & -2.94257 & 0.43294 \\
\hline 39 & $\mathrm{H}$ & -2.71675 & 0.13512 & -1.63719 \\
\hline 40 & $\mathrm{H}$ & -1.0487 & 0.34919 & -1.15666 \\
\hline 41 & $\mathrm{H}$ & -3.75867 & -0.81832 & 1.06273 \\
\hline 42 & $\mathrm{H}$ & -5.35529 & -2.25175 & -0.15878 \\
\hline 43 & $\mathrm{H}$ & -4.54611 & -1.15803 & -1.28222 \\
\hline 44 & $\mathrm{H}$ & -4.05323 & -2.85466 & -1.19754 \\
\hline 45 & $\mathrm{H}$ & -4.22586 & -3.02521 & 1.94821 \\
\hline 46 & $\mathrm{H}$ & -2.95386 & -3.76865 & 0.98281 \\
\hline 47 & $\mathrm{H}$ & -2.53244 & -2.63975 & 2.2804 \\
\hline 48 & $\mathrm{H}$ & 2.56101 & -3.51141 & 0.92723 \\
\hline 49 & $\mathrm{H}$ & 0.82323 & -3.80712 & 0.93679 \\
\hline 50 & $\mathrm{H}$ & 1.84535 & -4.50855 & -0.32581 \\
\hline 51 & $\mathrm{H}$ & -1.35053 & 2.16639 & -2.02209 \\
\hline 52 & $\mathrm{H}$ & -3.45319 & 3.89927 & 0.08413 \\
\hline 53 & $\mathrm{H}$ & -2.52035 & 3.68891 & 1.58039 \\
\hline 54 & $\mathrm{H}$ & -1.91089 & 4.75106 & 0.29613 \\
\hline
\end{tabular}

B3LYP/6-311G(d,p) Energy $=-931.84656797$ a.u.; Population $=0.18 \%$ 


\begin{tabular}{|c|c|c|c|c|}
\hline \multicolumn{2}{|c|}{$\begin{array}{l}(7 S, 8 S, 12 S)-\mathbf{4} \\
\text { Conf. } 25\end{array}$} & \multicolumn{3}{|c|}{$\begin{array}{c}\text { Standard Orientation } \\
\text { (Ångstroms) }\end{array}$} \\
\hline $\mathrm{I}$ & atom & $\mathrm{X}$ & $\mathrm{Y}$ & $\mathrm{Z}$ \\
\hline 1 & $\mathrm{C}$ & 2.57235 & -0.67075 & 0.18556 \\
\hline 2 & $\mathrm{C}$ & 2.97581 & -2.12328 & 0.24607 \\
\hline 3 & $\mathrm{C}$ & 2.00778 & -3.00178 & -0.59215 \\
\hline 4 & $\mathrm{C}$ & 3.44295 & 0.50602 & 0.00479 \\
\hline 5 & $\mathrm{C}$ & 2.9712 & 1.88514 & 0.48324 \\
\hline 6 & $\mathrm{C}$ & 1.48953 & 2.0278 & 0.70113 \\
\hline 7 & $\mathrm{C}$ & 0.67309 & 2.71549 & -0.09549 \\
\hline 8 & $\mathrm{C}$ & -0.82415 & 2.93512 & 0.09225 \\
\hline 9 & $\mathrm{C}$ & -1.58903 & 1.64679 & 0.4872 \\
\hline 10 & $\mathrm{C}$ & 4.94452 & 0.39048 & -0.13046 \\
\hline 11 & $\mathrm{C}$ & 0.57621 & -2.99645 & -0.08716 \\
\hline 12 & $\mathrm{C}$ & -0.26358 & -2.01542 & -0.47626 \\
\hline 13 & $\mathrm{C}$ & -1.65409 & -1.82239 & -0.08343 \\
\hline 14 & $\mathrm{C}$ & -1.76841 & 0.62898 & -0.66331 \\
\hline 15 & $\mathrm{C}$ & -2.37007 & -0.68329 & -0.19752 \\
\hline 16 & $\mathrm{C}$ & -3.85988 & -0.63166 & 0.13115 \\
\hline 17 & $\mathrm{C}$ & -4.69781 & -0.71853 & -1.1639 \\
\hline 18 & $\mathrm{C}$ & -4.34095 & -1.68014 & 1.1433 \\
\hline 19 & $\mathrm{C}$ & 0.22266 & -4.0907 & 0.88551 \\
\hline 20 & $\mathrm{O}$ & -1.37384 & 3.48194 & -1.12497 \\
\hline 21 & $\mathrm{C}$ & -1.0573 & 4.02894 & 1.14301 \\
\hline 22 & $\mathrm{O}$ & 2.68187 & -0.02201 & -1.104 \\
\hline 23 & $\mathrm{H}$ & 1.61562 & -0.47838 & 0.66189 \\
\hline 24 & $\mathrm{H}$ & 3.99128 & -2.26708 & -0.12947 \\
\hline 25 & $\mathrm{H}$ & 2.96812 & -2.44613 & 1.29373 \\
\hline 26 & $\mathrm{H}$ & 2.39337 & -4.02635 & -0.60465 \\
\hline 27 & $\mathrm{H}$ & 2.04129 & -2.6363 & -1.6222 \\
\hline 28 & $\mathrm{H}$ & 3.50431 & 2.11425 & 1.41439 \\
\hline 29 & $\mathrm{H}$ & 3.30729 & 2.61782 & -0.25907 \\
\hline 30 & $\mathrm{H}$ & 1.08514 & 1.52586 & 1.57747 \\
\hline 31 & $\mathrm{H}$ & 1.091 & 3.2423 & -0.95227 \\
\hline 32 & $\mathrm{H}$ & -1.06955 & 1.16678 & 1.32156 \\
\hline 33 & $\mathrm{H}$ & -2.57208 & 1.94717 & 0.86101 \\
\hline 34 & $\mathrm{H}$ & 5.32372 & 1.18834 & -0.77622 \\
\hline 35 & $\mathrm{H}$ & 5.42929 & 0.48968 & 0.84522 \\
\hline 36 & $\mathrm{H}$ & 5.23531 & -0.56345 & -0.56875 \\
\hline 37 & $\mathrm{H}$ & 0.14844 & -1.28048 & -1.16169 \\
\hline 38 & $\mathrm{H}$ & -2.15792 & -2.69229 & 0.32483 \\
\hline 39 & $\mathrm{H}$ & -2.42466 & 1.07898 & -1.4167 \\
\hline 40 & $\mathrm{H}$ & -0.80156 & 0.46186 & -1.14207 \\
\hline 41 & $\mathrm{H}$ & -4.05961 & 0.3523 & 0.57243 \\
\hline 42 & $\mathrm{H}$ & -5.76006 & -0.57157 & -0.94641 \\
\hline 43 & $\mathrm{H}$ & -4.39982 & 0.03858 & -1.89317 \\
\hline 44 & $\mathrm{H}$ & -4.57713 & -1.70091 & -1.6302 \\
\hline 45 & $\mathrm{H}$ & -5.38753 & -1.49589 & 1.40147 \\
\hline 46 & $\mathrm{H}$ & -4.28224 & -2.69435 & 0.73781 \\
\hline 47 & $\mathrm{H}$ & -3.75352 & -1.64803 & 2.06458 \\
\hline 48 & $\mathrm{H}$ & 0.93605 & -4.11263 & 1.71798 \\
\hline 49 & $\mathrm{H}$ & -0.7757 & -3.98295 & 1.30896 \\
\hline 50 & $\mathrm{H}$ & 0.28521 & -5.0727 & 0.40124 \\
\hline 51 & $\mathrm{H}$ & -1.15503 & 2.88401 & -1.84794 \\
\hline 52 & $\mathrm{H}$ & -2.12005 & 4.2814 & 1.18545 \\
\hline 53 & $\mathrm{H}$ & -0.73226 & 3.68955 & 2.12868 \\
\hline 54 & $\mathrm{H}$ & -0.49607 & 4.92898 & 0.8827 \\
\hline
\end{tabular}

B3LYP/6-311G(d,p) Energy $=-931.85126297$ a.u.; Population $=0.55 \%$ 


\begin{tabular}{|c|c|c|c|c|}
\hline \multicolumn{2}{|c|}{$\begin{array}{c}(7 S, 8 S, 12 S)-4 \\
\text { Conf. } 26\end{array}$} & \multicolumn{3}{|c|}{$\begin{array}{c}\text { Standard Orientation } \\
\text { (Ångstroms) }\end{array}$} \\
\hline I & atom & $\mathrm{X}$ & $\mathrm{Y}$ & $\mathrm{Z}$ \\
\hline 1 & $\mathrm{C}$ & 3.13254 & -0.26735 & -0.28284 \\
\hline 2 & $\mathrm{C}$ & 3.21223 & -1.58077 & 0.48296 \\
\hline 3 & $\mathrm{C}$ & 2.56429 & -2.76151 & -0.25138 \\
\hline 4 & $\mathrm{C}$ & 3.14987 & 1.07594 & 0.32751 \\
\hline 5 & $\mathrm{C}$ & 2.47971 & 2.22206 & -0.42931 \\
\hline 6 & $\mathrm{C}$ & 1.02614 & 2.39915 & -0.07512 \\
\hline 7 & $\mathrm{C}$ & 0.01633 & 2.1185 & -0.89678 \\
\hline 8 & $\mathrm{C}$ & -1.47016 & 2.28833 & -0.61552 \\
\hline 9 & $\mathrm{C}$ & -1.89738 & 1.83785 & 0.7955 \\
\hline 10 & $\mathrm{C}$ & 3.29479 & 1.26181 & 1.82131 \\
\hline 11 & $\mathrm{C}$ & 1.0556 & -2.77371 & -0.40763 \\
\hline 12 & $\mathrm{C}$ & 0.26009 & -1.80915 & 0.10036 \\
\hline 13 & $\mathrm{C}$ & -1.1923 & -1.7388 & 0.0165 \\
\hline 14 & $\mathrm{C}$ & -1.47783 & 0.42773 & 1.26872 \\
\hline 15 & $\mathrm{C}$ & -2.00176 & -0.7703 & 0.4983 \\
\hline 16 & $\mathrm{C}$ & -3.51937 & -0.85825 & 0.36206 \\
\hline 17 & $\mathrm{C}$ & -4.02347 & -1.89442 & -0.65033 \\
\hline 18 & $\mathrm{C}$ & -4.19316 & -1.09542 & 1.73198 \\
\hline 19 & $\mathrm{C}$ & 0.55802 & -3.97228 & -1.17674 \\
\hline 20 & $\mathrm{O}$ & -2.22226 & 1.47067 & -1.53434 \\
\hline 21 & $\mathrm{C}$ & -1.87337 & 3.76031 & -0.8287 \\
\hline 22 & $\mathrm{O}$ & 4.32447 & 0.55437 & -0.33049 \\
\hline 23 & $\mathrm{H}$ & 2.64231 & -0.3411 & -1.25302 \\
\hline 24 & $\mathrm{H}$ & 4.27097 & -1.80962 & 0.63513 \\
\hline 25 & $\mathrm{H}$ & 2.7743 & -1.47994 & 1.4809 \\
\hline 26 & $\mathrm{H}$ & 2.85665 & -3.68868 & 0.26017 \\
\hline 27 & $\mathrm{H}$ & 3.01365 & -2.84406 & -1.25197 \\
\hline 28 & $\mathrm{H}$ & 3.03449 & 3.14397 & -0.21128 \\
\hline 29 & $\mathrm{H}$ & 2.58411 & 2.0276 & -1.49961 \\
\hline 30 & $\mathrm{H}$ & 0.81493 & 2.76426 & 0.92831 \\
\hline 31 & $\mathrm{H}$ & 0.24291 & 1.75583 & -1.8991 \\
\hline 32 & $\mathrm{H}$ & -1.48702 & 2.55552 & 1.51288 \\
\hline 33 & $\mathrm{H}$ & -2.98399 & 1.95157 & 0.84651 \\
\hline 34 & $\mathrm{H}$ & 2.31876 & 1.32172 & 2.31095 \\
\hline 35 & $\mathrm{H}$ & 3.85431 & 0.44069 & 2.26879 \\
\hline 36 & $\mathrm{H}$ & 3.83264 & 2.19186 & 2.02895 \\
\hline 37 & $\mathrm{H}$ & 0.74915 & -0.9967 & 0.62349 \\
\hline 38 & $\mathrm{H}$ & -1.66966 & -2.56657 & -0.49316 \\
\hline 39 & $\mathrm{H}$ & -0.39133 & 0.3922 & 1.31739 \\
\hline 40 & $\mathrm{H}$ & -1.81895 & 0.34353 & 2.30866 \\
\hline 41 & $\mathrm{H}$ & -3.85255 & 0.11886 & -0.00259 \\
\hline 42 & $\mathrm{H}$ & -5.10854 & -1.80864 & -0.75687 \\
\hline 43 & $\mathrm{H}$ & -3.57556 & -1.74233 & -1.63517 \\
\hline 44 & $\mathrm{H}$ & -3.80843 & -2.91887 & -0.33058 \\
\hline 45 & $\mathrm{H}$ & -5.28197 & -1.10298 & 1.62501 \\
\hline 46 & $\mathrm{H}$ & -3.88756 & -2.0603 & 2.14903 \\
\hline 47 & $\mathrm{H}$ & -3.93973 & -0.31993 & 2.45841 \\
\hline 48 & $\mathrm{H}$ & 1.0023 & -3.99536 & -2.17894 \\
\hline 49 & $\mathrm{H}$ & 0.86455 & -4.90142 & -0.68142 \\
\hline 50 & $\mathrm{H}$ & -0.52415 & -3.99706 & -1.2929 \\
\hline 51 & $\mathrm{H}$ & -2.0254 & 1.77229 & -2.42835 \\
\hline 52 & $\mathrm{H}$ & -2.95104 & 3.8754 & -0.68435 \\
\hline 53 & $\mathrm{H}$ & -1.34672 & 4.42029 & -0.13544 \\
\hline 54 & $\mathrm{H}$ & -1.6261 & 4.07924 & -1.84623 \\
\hline
\end{tabular}

B3LYP/6-311G(d,p) Energy $=-931.84333700$ a.u.; Population $=0.02 \%$ 


\subsection{Optical Rotatory Dispersion (ORD) Experiments of compound 1.}

\section{Computational Section.}

The specific optical rotation calculations for compounds were performed using Information Gaussian 09. Conformers above 1\% population were re-optimized were further optimized at the B3LYP/6-311G(d,p) level with the IEFPCM solvent model for chloroform, all of which were subjected to specific optical rotation calculations at the B3LYP/6-311+G(d) level in chloroform with SMD model. The calculated specific optical rotation data of these conformers were averaged according to the Boltzmann distribution theory and their relative Gibbs free energy. The predicted ORD curves were generated from specific rotations calculated at four different wavelengths.

Table S20. Measured specific rotation of (+)-1 and computed (Boltzmann-averaged and relative free energies computed at B3LYP/6-

$311 \mathrm{G}(\mathrm{d}, \mathrm{p})$ level over 19 conformers, 1-1 to 1-19) specific rotation of $(3 S, 4 R, 7 S, 8 S)$-1 at different wavelengths at mPW1PW91/6-31G(d)

level. The values are used to generate Figure S70.

\begin{tabular}{lcccc}
\hline & $589 \mathrm{~nm}$ & $546 \mathrm{~nm}$ & $436 \mathrm{~nm}$ & $405 \mathrm{~nm}$ \\
\hline Experiment $\left(c 0.28, \mathrm{CHCl}_{3}\right)$ & 50.33 & 59.00 & 114.67 & 143.67 \\
mPW1PW91/6-31G* & 70.35 & 86.63 & 171.74 & 221.40 \\
\hline
\end{tabular}

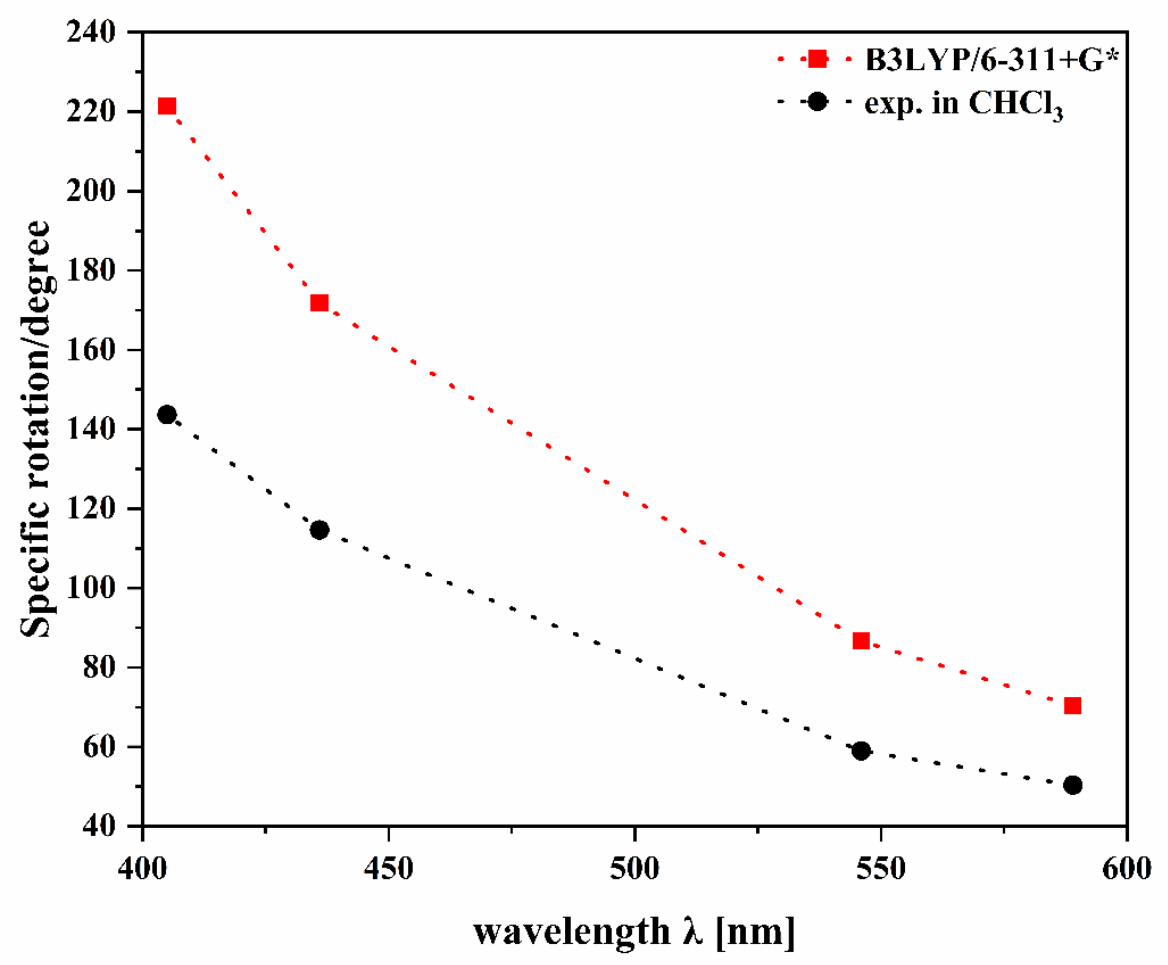

Figure S70. Measured specific rotation of (+)-1 and computed (Boltzmann-averaged and relative free energies computed at B3LYP/6-311G(d,p) level over 19 conformers, 1-1 to 1-19) specific rotation of $(3 S, 4 R, 7 S, 8 S)-1$ at different wavelengths at mPW1PW91/6-31G(d) level. 


\subsection{Optical Rotatory calculations of compounds 4-6, 8 .}

\section{Computational Section.}

The specific optical rotation calculations for compounds were performed using Information Gaussian 09. Conformers above 1\% population were re-optimized were further optimized at the B3LYP/6-311G(d,p) level with the IEFPCM solvent model for chloroform, all of which were subjected to specific optical rotation calculations at the B3LYP/6-311+G(d) level in chloroform with SMD model. The calculated specific optical rotation data of these conformers were averaged according to the Boltzmann distribution theory and their relative Gibbs free energy.
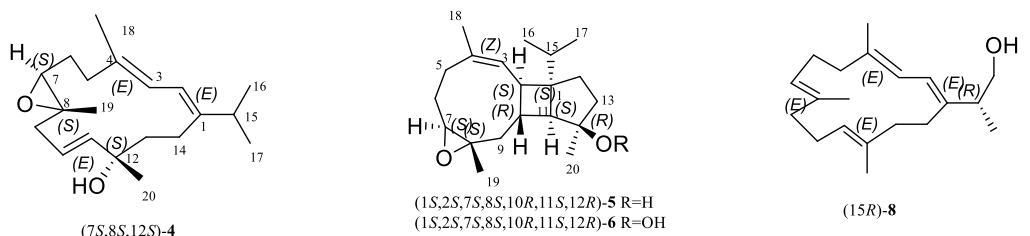

Figure S71. Structures of isomers of compounds 4-6,8

Table S21. Measured specific rotation of compounds 4-6, 8 and computed (Boltzmann-averaged and relative free energies computed at B3LYP/6-311G(d,p) level) specific rotation at 589nm.

\begin{tabular}{|c|c|c|c|c|}
\hline & $(7 S, 8 S, 12 S)-\mathbf{4}$ & $(1 S, 2 S, 7 S, 8 S, 10 R, 11 S, 12 R)-\mathbf{5}$ & $(1 S, 2 S, 7 S, 8 S, 10 R, 11 S, 12 R)-6$ & $(15 R)-8$ \\
\hline Conformer 1 & 136.35 & 119 & 150.92 & -183.98 \\
\hline Conformer 2 & -336.19 & 103.97 & 227.86 & -162.92 \\
\hline Conformer 3 & 160.72 & 131.56 & 58.55 & 267.08 \\
\hline Conformer 4 & -89.95 & 116.99 & 3.71 & 59.35 \\
\hline Conformer 5 & -4.2 & 157.12 & 149.14 & -108.13 \\
\hline Conformer 6 & -322.68 & 102.89 & 227.31 & -550.06 \\
\hline Conformer 7 & -322 & 141.28 & 59.26 & -533.61 \\
\hline Conformer 8 & -51.55 & 109.43 & 7.84 & -767.1 \\
\hline Conformer 9 & 311.98 & 145.55 & 213.93 & -50.39 \\
\hline Conformer 10 & -90.45 & 129.41 & 207.89 & 309.76 \\
\hline Conformer 11 & 165.59 & 150.81 & 160.07 & 95.02 \\
\hline Conformer 12 & 118.17 & 138.24 & & 34.4 \\
\hline Conformer 13 & -603.12 & & & 103.22 \\
\hline Conformer 14 & -269.41 & & & 121.03 \\
\hline Conformer 15 & 262.03 & & & 169 \\
\hline Conformer 16 & 535.5 & & & -5.63 \\
\hline Conformer 17 & -304.5 & & & 163.9 \\
\hline Conformer 18 & 311.66 & & & -68.06 \\
\hline Conformer 19 & -258.81 & & & 944.24 \\
\hline Conformer 20 & -140.76 & & & -62.83 \\
\hline Conformer 21 & -158.27 & & & -483.36 \\
\hline Conformer 22 & 572.33 & & & \\
\hline Conformer 23 & -135.01 & & & \\
\hline Conformer 24 & 375.3 & & & \\
\hline Conformer 25 & 166.11 & & & \\
\hline Conformer 26 & -37.96 & & & \\
\hline $\begin{array}{l}\text { Boltzmann-averaged } \\
\text { specific rotation }\end{array}$ & -11.49406064 & +121.3473579 & +136.1772 & -61.63502979 \\
\hline $\begin{array}{lr}\text { Mirrored } & \text { Boltzmann- } \\
\text { averaged } & \text { specific } \\
\text { rotation } & \end{array}$ & +11.49406064 & -121.3473579 & -136.1772 & +61.63502979 \\
\hline $\begin{array}{l}\text { Measured specific } \\
\text { rotation }\end{array}$ & $\begin{array}{c}\mathbf{- 1 2 . 7} \\
\left(c 0.13, \mathrm{CHCl}_{3}\right)\end{array}$ & $\begin{array}{c}+\mathbf{1 9 . 5} \\
\left(c 0.22, \mathrm{CHCl}_{3}\right)\end{array}$ & $\begin{array}{c}+\mathbf{2 6 . 3} \\
\left(c 0.28, \mathrm{CHCl}_{3}\right)\end{array}$ & $\begin{array}{c}\mathbf{- 1 5 . 1} \\
\left(c 0.37, \mathrm{CHCl}_{3}\right) \\
\end{array}$ \\
\hline
\end{tabular}




\section{Anti-inflammatory activity assay}

BV-2 microglial cells $(2.0 \times 105$ cells $)$ were cultured in 96-well plates with DMEM high-glucose medium containing $10 \%$ fetal bovine serum in a humidified, $37{ }^{\circ} \mathrm{C}, 5 \%$ $\mathrm{CO} 2$-containing incubator for $24 \mathrm{~h}$. To assess the in vitro anti-inflammatory effect of test compounds, BV-2 cells were then pretreated with $10 \mu \mathrm{M}$ or $20 \mu \mathrm{M}$ of test compounds for $2 \mathrm{~h}$, followed by $100 \mathrm{ng} / \mathrm{ml}$ of LPS exposure for $24 \mathrm{~h}$. The culture medium of each well ( $50 \mu \mathrm{L})$ was collected, and then incubated with $50 \mu \mathrm{L}$ of Greiss buffer (Sigma-Aldrich, St.Louis, MO, USA) for $15 \mathrm{~min}$ at room temperature. The absorbance of mixture was measured at $540 \mathrm{~nm}$ using a microplate reader, and the level of nitrite was calculated from a standard curve of sodium nitrite. The anti-inflammatory effect of compound 6 was from results of three independent experiments.

\section{Cell viability determination}

BV-2 microglial cells $(1.25 \times 104$ cells $)$ were cultured in 96 -well plates in triplicate with DMEM high-glucose medium containing $10 \%$ fetal bovine serum in a humidified, $37{ }^{\circ} \mathrm{C}, 5 \% \mathrm{CO} 2$-containing incubator for $24 \mathrm{~h}$. BV-2 cells were then pretreated with DMEM high-glucose medium containing $10 \%$ fetal bovine serum for $24 \mathrm{~h}$ in the presence or absence of $20 \mu \mathrm{M}$ of compound 6 . A total of $5 \mathrm{mg} / \mathrm{mL}$ MTT (10 $\mu \mathrm{L} /$ well) was added to each well and incubated for $3 \mathrm{~h}$, the absorbance value at $490 \mathrm{~nm}$ was then collected by a microplate reader (PerkinElmer Envision). The cell viability was calculated from results of three independent experiments.

In bioassay, humilisins A-F (1-6) were evaluated for anti-inflammatory effect in lipopolysaccharide (LPS)-stimulated BV-2 microglial cells. Compound 6 displayed statistically significant inhibitory effect on LPS-induced inflammatory response (NO production) in BV-2 microglial cells, and the level of NO decreased to $83.96 \pm 2.02 \%$ at $10 \mu \mathrm{M}$ and $65.70 \pm 2.76 \%$ at $20 \mu \mathrm{M}$, respectively, comparable to that of the positive control resveratrol $(63.42 \pm 4.21 \%)$ at $20 \mu \mathrm{M}$ (NO data were normalized by average of the LPS alone group). In addition, compound 6 at $20 \mu \mathrm{M}$ did not show noticeable influence on the cell viability of BV-2 cells $(95.98 \pm 0.81 \%$ of the control group), indicating low cytotoxicity of compound $\mathbf{6}$ on microglial cells.

Table S22. Anti-inflammatory Effects of Compounds 6.

\begin{tabular}{lc} 
Compounds & $\mathrm{IR}^{\mathrm{a}}$ \\
$\mathbf{6}$ & $65.70 \pm 2.76 \% * * *$ \\
Control & $3.141 \pm 0.69$ \\
Model - LPS $(100 \mathrm{ng} / \mathrm{ml})$ & $100.0 \pm 0.0 \# \# \#$ \\
Positive control- Resveratrol $(20 \mu \mathrm{M})$ & $73.10 \pm 3.71 * * *$ \\
\hline
\end{tabular}

aIR is inhibitory ratio (IR\%) of the compounds tested at $20 \mu \mathrm{M} ;{ }^{b \# \# \#} P<0.001$ vs control group, ${ }^{\star} P<0.05,{ }^{* \star} P<0.01,{ }^{\star \star \star *} P<0.001$ vs model group. 